\title{
One dose of Architecture, taken daily: Building for Mental Health in New Zealand.
}

by

Rebecca McLaughlan

\begin{abstract}
A thesis
submitted to the Victoria University of Wellington in fulfilment of the requirements for the degree of Doctor of Philosophy.
\end{abstract}

Victoria University of Wellington 2014 the permission of the copyright owner. 



\section{ABSTRACT}

Thousands of New Zealanders were treated in the nation's mental hospitals in the late nineteenth and twentieth centuries. Existing research has examined this history of institutionalisation from the perspectives of policy, psychiatric medicine and nursing culture, but to date little has been written about the built fabric of this type of institutional care. This dissertation asks what does the architectural approach taken to Seacliff Asylum (1878-84), Kingseat Hospital (1927-40) and Cherry Farm Hospital (1943-71) indicate about official attitudes to mental illness in New Zealand. Architecture was thought to be capable of performing a curative role in the treatment of mental illness; the administrators of New Zealand's mental hospitals stated this belief publically in various press releases and reports to the government between 1878 and 1957. This dissertation examines Seacliff, Kingseat and Cherry Farm against current thought regarding the treatment of mental illness and against best architectural practice in mental hospital design.

While these three institutions were the jewels in the crown of New Zealand's mental hospital network, only Kingseat could be considered an exemplary hospital of its time. The compromises that occurred in the construction of Seacliff, Kingseat and Cherry Farm hospitals indicate that meeting the needs of the mentally ill was only one of a number of agendas that were addressed by the officials involved in the design of these institutions. Many of these agendas were peripheral to the delivery of mental health care, such as the political desire for colonial propaganda and professional concerns of marginalisation, and conflicted with the attainment of ideal environments for the treatment of mental illness. The needs of the mentally ill were a low priority for successive New Zealand governments who exhibited a reluctance to spend taxpayer funds on patients who were not considered curable. The architects and medical advisors involved in the design of these facilities did attempt to meet the needs of these patients; however, they were limited by a design and procurement process that elevated political and operational concerns over the curative potential of these hospitals.

This dissertation also examines the role of individuals in the design of these institutions. Architect Robert Lawson was reproached for deficiencies in the curative potential of Seacliff Asylum. Similarly, medical administrator Theodore Gray has received criticism for limiting the development of New Zealand's wider network of mental hospital care. This dissertation establishes that Lawson and Gray deserve greater recognition for their relative contributions to the architecture created, within New Zealand, for the treatment of mental illness. 

This dissertation is dedicated to the memory of

Christine McLaughlan (1952 - 2013)

whose excitement regarding its completion would have outshone all others. 



\section{ACKNOWLEDGEMENTS}

When I embarked on this research programme I was unaware that returning to study as an adult would bring a raft of challenges that were not present as an undergraduate. I owe my sincere gratitude to Professor Diane Brand who, during the course of supervising this research, has supported me through a number of unexpected hurdles. Her guidance on all matters has been invaluable. Dr Robin Skinner also deserves my sincere graditude for his meticulous and enthusiastic supervision. One could not hope for a more committed, knowledgable and supportive supervisory team.

I must thank Warwick Brunton (Otago University), firstly for preparing such a thorough doctoral thesis which facilited my ability to tackle such a wide scope of research within a three year doctoral programme. Secondly, for the time he took to meet with me and elaborate on many of the ideas contained within his thesis. This research could not have been completed without the support of the many people who allowed me to visit these former hospital sites, the majority of which are now in private ownership and have become family homes. I am humbled by the openness with which my requests to visit were met and thankful for the many coffees and conversations I was offered along the way that enriched this dissertation. The library staff at Victoria, Auckland and Otago deserve greater thanks than I can offer here for the spectacular job that they carry out everyday, as do the staff of Archives New Zealand, the Alexander Turnbull Library and the Television New Zealand Archive. These people are the unsung heros of academic research. Thank-you to Dan Thompson and Jared Green for their efforts in proof-reading this dissertation. Thank-you also to my fellow post-graduate students for struggling through this process of discovery with me and for all the support that was given along the way.

This reseach was made possible by several, generous financial grants. Thank-you to Victoria University and the Faculty of Architecure, the Postgraduate Students Association and the Stewart Charitable Trust. Lastly, thank-you to three people without whose support I would never have made it this far; to Mum, Dad and Jared, thank-you for continuing to recognise the value in what I was doing even when I lost sight of it. 



\section{TABLE OF CONTENTS}

Abstract 1

Dedication 3

Acknowledgments $\quad 5$

$\begin{array}{ll}\text { Contents } & 7\end{array}$

List of Figures 9

List of Tables $\quad 12$

List of Medical Terms 13

1. INTRODUCTION

Introduction 15

1.1 Research Aim and Questions 18

1.2 Research Design 20

1.3 Development of Research Methodology 20

1.4 Selection of Case Studies 24

1.5 Chapter Overview 26

1.6 Statement of Limitations 26

1.7 A Note Regarding Terminology 27

2. LITERATURE REVIEW

Introduction 31

2.1 Contemporary Understandings of New Zealand's Mental Hospitals 27

2.2 The Origins of the Asylum Typology 29

2.3 So How Exactly was Architecture Curative? 32

2.4 Early Indications of the Failure of Curative Environments 35

2.5 Existing Hypotheses for the Failure of the Asylum as a

Curative Environment $\quad 37$

2.6 Research in the Colonial Context 43

Conclusion $\quad 47$

3. ESTABLISHING A SET OF CURATIVE CRITERIA

Introduction $\quad 57$

3.1 Tuke, Brown \& Conolly: Pattern-makers for the Ideal
Nineteenth Century Asylum

3.2 The Villa Hospital: Solving the Problems of Traditional Asylum Design $\quad 64$

3.3 Waiting for a Breakthrough: Persevering with Moral Treatment 66

3.4 The Villa versus the Psychopathic Hospital: New Options for the 1920s 68

3.5 New Perspectives on Mental Illness 75

3.6 The 1953 WHO Report and Emergent Research 78

3.7 Expectations for a New Architectural Response 81 
4. SEACLIFF ASYLUM:

COLONIAL ASPIRATION AND THE CURATIVE INTENT

Introduction 95

4.1 Seacliff: one of the Finest Buildings of its kind in the Southern $\begin{array}{ll}\text { Hemisphere } & 97\end{array}$

4.2 Seacliff in an International Context 125

4.3 Obstacles in the Design of Seacliff: Resourcing Issues in Colonial New Zealand 131

4.4 Colonial Desire and Expectation in the Design of Seacliff 138

4.5 Against Asylum Care: Early Warnings \& Alternative Design Responses $\quad 145$

Conclusion 153

5. KINGSEAT MENTAL HOSPITAL:

\section{A VISION IN GRAY}

Introduction

5.1 Out with the Mental Hospital: Public Dissatisfaction in the 1920s 165

5.2 Kingseat: the "Showpiece" Mental Hospital 169

5.3 Kingseat in an International Context 184

5.4 Public Relations and the Influence of Theodore Gray 190

5.5 Delays, Funding Shortages and Communication Issues:

Obstacles in the Construction of Kingseat 199

5.6 Spending Priorities and the Question of the Queen Mary Hospital 203 Conclusion

6. CHERRY FARM:

THE CHANGING FACE OF MENTAL HEALTH CARE Introduction $\quad 219$

6.1 Cherry Farm: An Outstanding Hospital of its Kind 221

6.2 The Cherry Farm Villas: a New Design for the Nation 226

6.3 International Responses to Emergent Research 238

6.4 Obstacles to Innovation in the Design of Cherry Farm 251

6.5 Public Expectation in the Design of Cherry Farm 257 $\begin{array}{ll}\text { Conclusion } & 269\end{array}$

7. DISCUSSION

Introduction

7.1 Faith and Compromise in the Construction of Seacliff Asylum, Kingseat and Cherry Farm Hospitals 280

7.2 Political Agendas: Public Expectation and Funding 282

7.3 Professional Agendas: Architectural 284

7.4 Professional Agendas: Medical 287

8. CONCLUSION 293

$\begin{array}{ll}\text { BIBLIOGRAPHY } & 297\end{array}$ 


\section{LIST OF FIGURES}

Image sources are indicated within each chapter.

\section{INTRODUCTION}

Figure 1.1 Lake Alice Hospital under demolition, 2010.

Figure 1.2 Location map of New Zealand Mental Hospitals 1854-1971. 17

Figure 1.3 Diagram showing research aim relative to thesis questions $\begin{array}{ll}\text { and existing research. } & 19\end{array}$

Figure 1.3 Diagram showing sources employed and their relationship to each other. 20

Figure 1.4 Case study hospitals relative to medical development. 24

\section{ESTABLISHING A SET OF CURATIVE CRITERIA}

Figure 3.1 Illinois Eastern State Hospital for the Insane, Kankakee. 68

Figure 3.2 Illinois Eastern State Hospital for the Insane. 69

Figure 3.3 Illinois Eastern State Hospital for the Insane, Villa. 69

Figure 3.4 Aerial photograph of Kingseat Hospital, date unknown. $\quad 70$

Figure 3.5 A villa at Kingseat Hospital, Aberdeen. July 22, 2013.

Figure 3.6 Phipps Psychiatric Clinic, Johns Hopkins Hospital, 1913. 72

Figure 3.7 Maudsley Hospital, Denmark Hill, London. Sept. 12, 2013.

\section{SEACLIFF ASYLUM:}

\section{COLONIAL ASPIRATION AND THE CURATIVE INTENT}

Figure 4.1 Dunedin Lunatic Asylum, 187499

Figure 4.2 Plan of the temporary Dunedin Asylum, 1877.

Figure 4.3 Norwich Asylum Ground Floor Plan. 104

Figure 4.4 Seacliff Lunatic Asylum, Plan of First Floor, 1881.

Figure 4.5 Seacliff Lunatic Asylum, Plan of Ground Floor, 1881.106

$\begin{array}{ll}\text { Figure } 4.6 \quad \text { Norwich Asylum Perspective. } & 107\end{array}$

$\begin{array}{lll}\text { Figure } 4.7 & \text { Seacliff Asylum pre } 1917 . & 107\end{array}$

$\begin{array}{lll}\text { Figure 4.8 } & \text { Aerial view of Seacliff Asylum, 1947. } & 108\end{array}$

$\begin{array}{lll}\text { Figure } 4.9 \text { Seacliff Asylum Site Plan, undated. } & 109\end{array}$

$\begin{array}{lll}\text { Figure 4.10 Seacliff Asylum Site Plan, 1885. } & 110\end{array}$

Figure 4.11 Placement of Airing Courts on Seacliff site. 110

Figure 4.12 Plan showing access to Seacliff Airing Courts, 1881.

Figure 4.13 Seacliff "Block Plan," undated. 111

Figure 4.14 Seacliff from the air, undated. 112

Figure 4.15 Plan of Open Ambulatory, Ground Floor, Seacliff, 1881. 
Figure 4.16

Figure 4.17

Figure 4.18

Figure 4.19

Figure 4.20

Figure 4.21

Figure 4.22

Figure 4.23

Figure 4.24

Figure 4.25

Figure 4.26

Figure 4.27

Figure 4.28

Figure 4.29

Figure 4.30

Figure 4.31

Figure 4.32

Figure 4.33

Figure 4.34

Figure 4.35

Figure 4.36

Figure 4.37

Figure 4.38

Figure 4.39

Figure 4.40

Figure 4.41

Figure 4.42

Figure 4.43

Figure 4.44

Figure 4.45

Figure 4.46

Figure 4.47

Figure 4.48

Figure 4.49

Figure 4.50

Figure 4.51
Seacliff, ca 1926. 113

Section through Day Room Corridor, Seacliff, 1881.

Drawing for New Fire Escapes, Seacliff, 1906.

Aerial view of Seacliff relative to north, railway and coastline. 115

Seacliff Asylum Site Plan, undated. 115

Partial plan (first floor) showing Seacliff's northern most wing. 116

Plan of typical single room indicating door swings. 118

Seacliff Asylum etching, 1884, by Samuel Calvert. 119

Diagram of Day Rooms on all floors of Seacliff. 120

Seacliff Lunatic Asylum, Plan of First Floor, 1881.

Dayroom, Buffalo State Hospital, ca. 1900.

Dayroom, Bethlem Hospital. 121

Plan of Sunnyside Hospital, Christchurch, 1877.

Plan of Whau Lunatic Asylum, Auckland, 1877.

West Riding Pauper Asylum, opened 1888.

Seacliff, Front Elevation showing Proposed Future Extensions. 126

$\begin{array}{ll}\text { Seacliff (photograph) undated. } & 126\end{array}$

Sunnyside, Additions, $1888 . \quad 128$

Whau Asylum, Additions, 1895.

Day Room Configurations, Seacliff and Norwich. 129

Otago Benevolent Institution. 133

Dunedin Town Hall, ca 1885.

Otago Boys High School. 135

Seacliff Asylum, ca 1912.

“Designs of R.A. Lawson” by George O’Brien (1821-88). 139

Halloway Sanatorium, 1884 . 140

Royal Edinburgh Infirmary. $\quad 141$

Design for the Otago Benevolent Institution 1863.

Seacliff, Recreation Hall under demolition (photograph), 1959. 143

Seacliff, Section drawings through Recreation Hall, 1881.

Seaview Asylum, Hokitika, 1879.

Porirua Asylum, ca 1910 (photograph) D. Squires. 148

Porirua Asylum, early 1900s. 149

Porirua Asylum, Ground Floor Plan, 1891.

Dormitory layout, Porirua Asylum, 1891.

Tokanui Hospital 50-bed villa, 1912.

\section{KINGSEAT MENTAL HOSPITAL: A VISION IN GRAY}

$\begin{array}{ll}\text { Figure 5.1 Hornby Lodge, Christchurch. } & 167\end{array}$

Figure 5.2 Aerial photograph of Kingseat Hospital, 1972, Whites Aviation. 169 
Figure 5.3 Kingseat Hospital, 1937 (photograph) Whites Aviation.

Figure 5.4 Sunnyside villa type, Templeton Farm School. 170

Figure 5.5 Dunoon Villa, Ngawhatu (opened 1929). 171

Figure 5.6 Kingseat Hospital Villa, October 10, 2010.

Figure 5.7 Kingseat Hospital Villa Plans, Ground and First Floor. 172

$\begin{array}{lll}\text { Figure 5.8 Sunnyside 50-Bed Villa Type, } 1929 . & 173\end{array}$

$\begin{array}{lll}\text { Figure 5.9 Dormitory photographs: Kingseat, Porirua and Seaview. } & 174\end{array}$

$\begin{array}{lll}\text { Figure 5.10 Aerial view of Kingseat villa layouts. } & 175\end{array}$

$\begin{array}{lll}\text { Figure 5.11 Kingseat Villa Orientation Analysis. } & 176\end{array}$

Figure 5.12 Sun Diagram for Kingseat Villas oriented South-West. 176

$\begin{array}{lll}\text { Figure 5.13 Sun diagram for Porirua Villas as oriented at Lake Alice. } & 177\end{array}$

$\begin{array}{lll}\text { Figure 5.14 Aerial view highlighting villa orientation at Kingseat. } & 178\end{array}$

Figure 5.15 Orientation diagram highlighting axis between entry $\begin{array}{ll}\text { and treatment unit. } & 179\end{array}$

Figure 5.16 Entrance to Kingseat Hospital in the 1940s. 180

Figure 5.17 Kingseat still from 1967 stock footage of mental hospitals. 181

Figure 5.18 The Entrance Building at Bethlem Hospital. 184

Figure 5.19 Perspective drawing of Bethlem Hospital, 1930.

Figure 5.20 Partial site plans, Bethlem Hospital, 1928 -1929. 186

Figure 5.21 Aerial photograph of Barrow Mental Hospital, Somerset. 187

Figure 5.22 A villa at Barrow Mental Hospital, May 07, 2012.

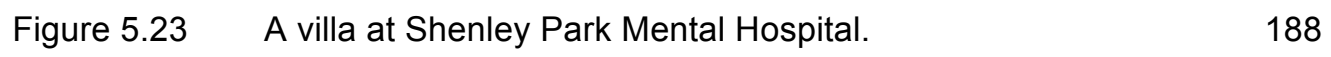

Figure 5.24 Lake Alice 11-bed villas, Lake Alice Hospital, ca. 1948.

Figure 5.25 Lake Alice Hospital, aerial perspective of grounds, ca 1943. 197

Figure 5.26 The Women's Ward, Queen Mary Hospital. March 28, 2010.203

Figure 5.27 Plan of Chisholm Ward, Queen Mary Hospital, 1950.

Figure 5.28 Images of the Chisholm Ward, March 28, 2010.

Figure 5.29 The Women's Lounge Room at Queen Mary Hospital, c. 1950. 205

Figure 5.30 A Day Room at Porirua Hospital, c. 1950.

Figure 5.31 Interior, Chisholm Ward, March 28, 2010.

Figure 5.32 Wellington Fever Hospital, 1972. 206

Figure 5.33 Interior, Bethlem Hospital. 207

\section{CHERRY FARM THERAPEUTIC COMMUNITY: THE CHANGING FACE OF MENTAL HEALTH CARE}

Figure 6.1 The Cherry Farm Hospital, ca. 1970222

Figure 6.2 Cherry Farm Hospital Villa ca 1980.226

$\begin{array}{lll}\text { Figure 6.3 Cherry Farm villas: location and distribution map. } & 227\end{array}$ 
Figure 6.4 Cherry Farm Mental Hospital, 50-Bed Villa, 1949.

Figure 6.5 Cherry Farm Mental Hospital, 1953.229

Figure 6.6 Location and treatment of external door. 230

Figure 6.7 Villa entrance, Cherry Farm, July 6, 2012 and entrance plan. 231

$\begin{array}{lll}\text { Figure } 6.8 & \text { Sun diagram for Cherry Farm Villas. } & 232\end{array}$

Figure 6.9 New house by Watkin \& Stemson Architects.

Home and Building, December 1949.

Figure 6.10 Selected pages from Home and Building Oct/Nov Issue 1948 and June/July Issue 1949.

Figure 6.11 Interior, Cherry Farm villa. 234

Figure 6.12 Interior, Cherry Farm villa at Lake Alice Hospital. 234

Figure 6.13 Development of bathing and dressing spaces. 236

Figure 6.14 Lake Alice 11-Bed Villa, 1947.

Figure 6.15 Relationship Diagram, lines of communication for Design and Procurement Process of New Zealand Mental Hospitals. 244

Figure 6.16 Development of the Cherry Farm Reception Unit, 1964 - 1970. 246

Figure 6.17 Proposed Acute Care Unit at Central State Hospital, Indiana. 247

Figure 6.18 Plan of a 160-bed villa, Manteno State Hospital, Illinios. 248

Figure 6.19 Satellite photograph of Manteno State Hospital, 1998.

Figure 6.20 H-Shape Villas, Levin Farm Colony, June 3, 2010.

Figure 6.21 Levin Farm Colony, H-shape Villa Plan. 253

Figure 6.22 Lineage of modernist styles employed for Mental Hospital use. 265

Figure 6.23 Glazing advertisement, Home and Building, April/May 1949. 266

Figure 6.24 Cover image, Home and Building Magazine, Dec. 1946. 267

Figure 6.25 State Fire Insurance Building, October 24, 2013.

Table 1.1 Relevance of Case Study Selection 25

Table 3.1 Architectural Criteria for an Ideal Curative Environment: Seacliff Asylum, $19^{\text {th }}$ Century

Table 3.2 Architectural Criteria for an Ideal Curative Environment: Kingseat Hospital, 1929

Table 3.3 Architectural Criteria for an Ideal Curative Environment: Cherry Farm Hospital, 1943-52 86

Table 3.4 Overview of Curative Criteria, All Hospital Models 87 


\section{LIST OF MEDICAL TERMS}

The terms below have been defined by the author relative to the context in which each term is most commonly employed within this dissertation and as they were understood and used during the period this study is concerned with.

Acute

Cardiazol shock

treatment

Chronic

Classification

Convalescent

Electroconvulsive therapy

Hydrotherapy

Incipient

Insulin-coma therapy

Moral treatment an illness of recent onset or short duration.

a forerunner to electroconvulsive therapy, seizures were induced by an injection of the drug known as cardiazol, or metrazol.

First used in New Zealand in 1939.

an illness of six months duration or more; following six months of no discernable improvement mentally ill patients were not expected to recover.

the separation of groups of patients by behavior or severity of illness. Classification was used in the nineteenth and early twentieth century care of mental illness to separate patients from those whose behavior was considered harmful to their recovery.

a patient who is in a stage of recovery.

known as E.C.T., or electroshock treatment, seizures are induced through the use of electricity. First used in New Zealand in 1943.

various therapies that involved the use of water, often delivered in a bath. Hydrotherapy was little used within the New Zealand context.

the stage that precedes the onset of mental illness, when an illness is beginning to develop.

a forerunner to electroconvulsive therapy, recurrent doses of insulin were injected in order to produce daily comas over a course of days or weeks. First used in New Zealand in 1938.

a nineteenth century approach to the treatment of mental illness based on humane care. 
Neuropathic

Neuroses, also psycho-neuroses

Psychopathic

Psychopharmaceuticals

Psychotherapy, also psychotherapeutic

Refractory

Somatic a disease related to the nervous system. IIInesses related to anxiety and depression, including shellshock, were considered to be neuropathic illnesses during the period of this research $(1910$ - 1957).

a mild form of mental illness that arises as a symptom of stress, not caused by organic disease. Can include depression and anxiety.

a term used to define a new type of hospital in the early twentieth century. Psychopathic hospitals were created to study acute cases of mental illness during treatment and were run in association with medical schools and general hospitals.

medicinal drugs for the chemical treatment of mental illnesses.

colloquially termed "the talking cure," psychotherapy is the treatment of mental disorder by psychological means.

while the term denotes an illness that is resistant to treatment, within the mental hospital environment, a patient was often classified as refractory if their behavior was difficult to control and/or likely to disturb other patients.

relates to the body instead of the mind. Within the early twentieth century some physicians believed that mental illness was caused by physical symptoms such as in infection. 


\section{CHAPTER ONE}

\section{Introduction}

The asylum, as it was understood within the nineteenth century, was a constructed environment in which architecture and landscape were carefully articulated to aid the restoration of sanity. ${ }^{1}$ Architecture was thus considered a therapeutic tool; one of the few remedies available for the treatment of an affliction that carried devastating consequences. At that time, psychiatrists believed that six months was the crucial period in which a patient would either recover from mental illness or lapse into an incurable state of madness. ${ }^{2}$ With the wellbeing of patients at stake, compromise in the construction of asylums should not have occurred but, for a variety of reasons, it did. The mental hospital is retrospectively understood as a space in which harmful institutional cultures developed and where patients tended to be stripped of their autonomy, dignity and self-esteem. ${ }^{3}$ The discrepancy between worthy intention and flawed execution in the design of these institutions is the starting point for this research.

In the mid-nineteenth century, when the asylum typology rose to prominence in Britain, the risks associated with this new architectural typology were understood. John Conolly, a leading advisor on asylum design and management, recognized, in 1830, that even the best conducted asylums would fail to benefit more than one third of the patients they treated. For the remaining two-thirds of any asylum population the experience of confinement with other lunatics would "fix and render permanent" mental afflictions that might otherwise have been transitory. ${ }^{4}$ Factors such as inadequate funding, difficulties in obtaining staff and the necessity of accommodating more patients than each hospital had been constructed for exacerbated the risk of harm. An official visitor to the Gloucester Asylum in 1839 stated:

There must be a point at which we should say, to admit to be crowded on floors, to admit to be disturbed by unseparated noisy cases, is not to admit to cure. $^{5}$ 
The fact that these institutions continued to be constructed despite their shortcomings suggests that the asylum was fulfilling more than just a curative role. Leonard Smith, Andrew Scull and Thomas Markus have all highlighted the public desire to control lunacy in the nineteenth century. ${ }^{6}$ Scull and Leslie Topp have observed the contribution of professional concerns, of legitimization and public relations, to the development of this typology and within various approaches taken to the design of these institutions. ${ }^{7}$ This dissertation does not seek to answer the question of whether architecture could perform a curative role. It accepts that this was believed to be the case and examines whether, in accordance with this belief, the facilities created for mental health care in New Zealand were constructed taking full account of the most current medical knowledge and leading architectural developments in this field.

Thousands of New Zealanders were treated in the nation's mental hospitals in the late nineteenth and twentieth centuries; this history deserves academic attention from a wide array of disciplines (figure 1.2). Existing research has examined this history of institutionalisation for mental illness from the perspectives of policy, psychiatric medicine and nursing culture ${ }^{8}$, as chapter two will detail, but to date little has been written about the built fabric of this type of institutional care. That fabric, now in decay and disrepair, demands historical evaluation before its inevitable disappearance from local landscapes (figure 1.1). This dissertation aims to expand our existing understanding of official attitudes to mental illness in New Zealand through a close examination of the architecture created for its treatment and containment.

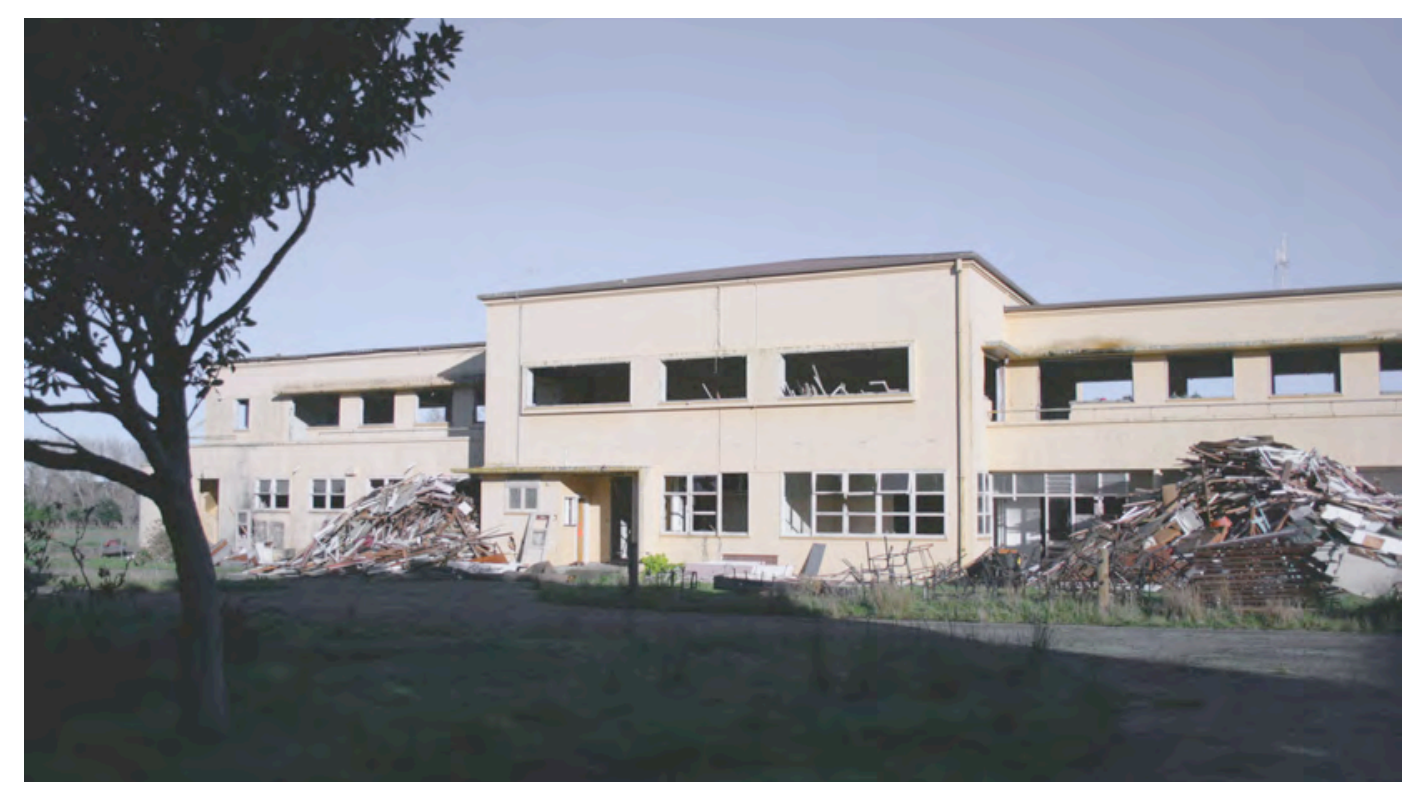

Figure 1.1: Lake Alice Hospital under demolition, June 6, 2010.

Photograph by author. 


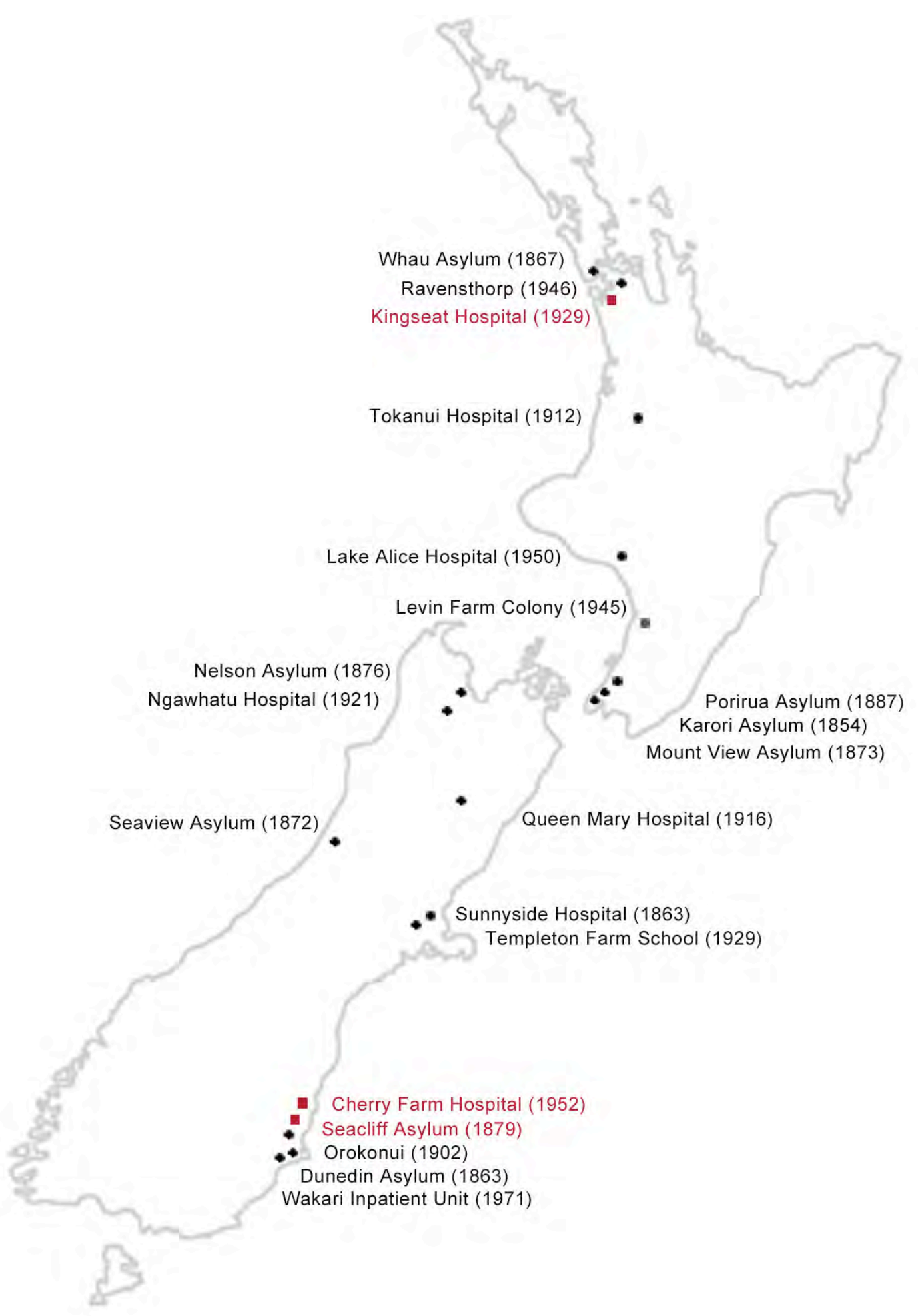

Figure 1.2: Location map of New Zealand Mental Hospitals 1854-1971.

Dates indicate first year of patient occupation. Image by author. 


\subsection{RESEARCH AIM AND QUESTIONS}

This dissertation asks:

What does the architectural approach taken to Seacliff Asylum (1878-84), Kingseat Hospital (1927-40) and Cherry Farm Hospital (1943-71) indicate about official attitudes to mental illness in New Zealand?

In order to address this research question, three lines of inquiry will be pursued relative to the three case study hospitals named above (selection of case studies discussed under section 1.4). Firstly, questions will be addressed regarding the relationship between treatment theory and architecture to establish whether best architectural practice was followed in the construction of these facilities. Secondly, issues that arose regarding the public perception and expectations of these institutions will be examined to understand the extent to which this factor influenced the design responses to the three case study hospitals. Thirdly, the peripheral factors that impacted on the decisions made in the design of these institutions will be accounted for (figure 1.3).

This dissertation will examine the attitudes of the governments who commissioned and paid for these facilities, the architects who designed them and the medical men who briefed the architects, and consulted with them throughout the design process, regarding the requirements of these institutions. As chapter two will detail, existing research in this field suggests that the asylum typology was susceptible to compromise from individual agendas. The approach taken to this research problem will examine the relative influences of architect Robert Lawson and medical administrator Theodore Gray in the development of New Zealand's architecture for mental health care. An understanding of how and why compromises were allowed to occur in the creation of environments for the treatment of mental illness will contribute to our existing understanding of official attitudes to mental illness. 


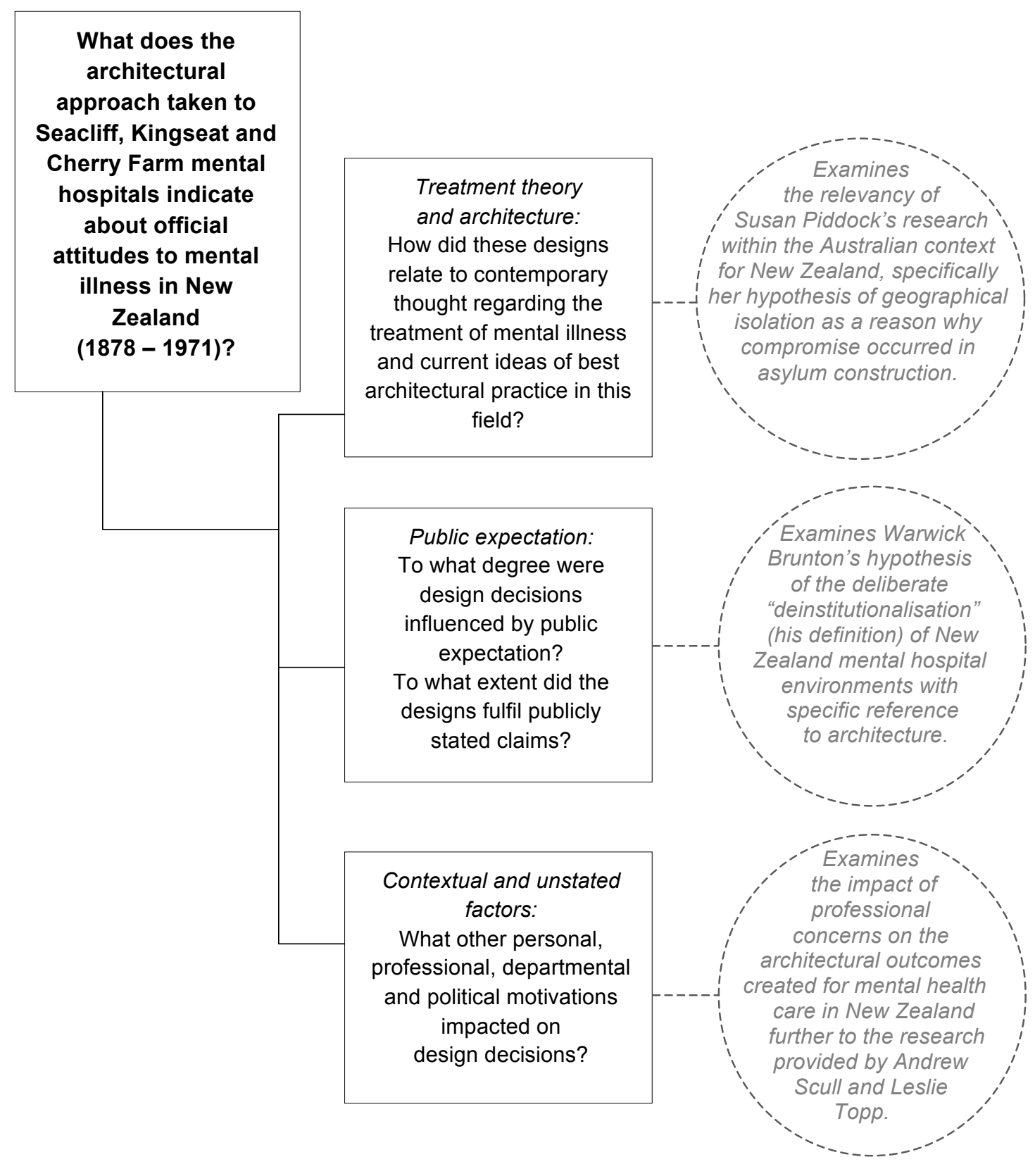

Figure 1.3: Diagram showing research aim (left) relative to thesis questions (middle) and existing research (right). 


\subsection{RESEARCH DESIGN}

Each case study hospital will be examined against a set of criteria that will translate contemporary thought regarding mental illness into architectural terms. A thorough examination of medical literature for each period will be used to formulate these criteria (outlined in chapter three). In order to gain a full understanding of the context within which these hospitals were constructed, each will be positioned relative to geographical, cultural and economic conditions. The following diagram lists the sources employed and their relationship to each other (figure 1.4):

\begin{tabular}{|c|c|c|}
\hline SITE / ARCHITECTURE & $\mathrm{T}$ & DISCOURSE / STATEMENTS \\
\hline $\begin{array}{l}\text { Physical remains (buildings) } \\
\text { Plans and project records } \\
\text { Archival photographs } \\
\text { Patient accounts (published) } \\
\text { Hospital histories (by staff) }\end{array}$ & $\begin{array}{c}\mathrm{T} \\
\\
\mathrm{A} \\
\mathrm{G} \\
\mathrm{A} \\
\mathrm{I} \\
\mathrm{N} \\
\mathrm{S} \\
\mathrm{T}\end{array}$ & $\begin{array}{l}\text { Professional books and journals } \\
\text { (medicine and architecture) } \\
\text { Government / departmental records } \\
\text { Media releases and centenary } \\
\text { publications (hospitals) } \\
\text { Public criticism (media) }\end{array}$ \\
\hline
\end{tabular}

Figure 1.4: Diagram showing sources employed and their relationship to each other.

* Between 2010 and 2011 site visits were carried out to the following former mental hospital sites: Seacliff, Cherry Farm, Orokonui, Wakari (acute unit on general hospital grounds), Sunnyside, Templeton, Seaview, Ngawhatu, Porirua, Kimberley Centre, Lake Alice, Auckland and Kingseat. The only hospital not visited was Tokanui as permission to visit this hospital was not granted by the custodians of this site. ${ }^{9}$

\subsection{DEVELOPMENT OF RESEARCH METHODOLOGY}

This research follows an interdisciplinary approach as defined by Andrew Leach. It will employ the tools available to architectural historians in order to contribute "new perspectives on issues beyond architecture." 10 This research is both thematic and analogical, in accordance with Leach's definitions. It "engages in the realm of architectural ideas and themes"11 through an examination of patterns of inhabitation and representational choices. It understands architecture to be "evidence of the world of phenomena exceeding architecture and a player in that world" 12 by acknowledging that the mental hospital was a product of social and political preconceptions towards mental illness but also, a representational tool in the perpetuation of positive ideologies around mental health care.

The historical nature of this research, coupled with the limitations of the archival material that has been retained, does not allow the attainment of design intents from any person directly involved in the design of the three case study hospitals. The exception to this is Dr Theodore Gray who left an autobiography discussing various aspects of the approach taken in the design of Ngawhatu and Kingseat hospitals. ${ }^{13}$ This section will examine the methodologies commonly employed for dealing with this 
issue, it will evaluate the strengths and weaknesses of various approaches in order to validate the methodological approach that has been adopted for this research. The work of Michel Foucault, Thomas Markus, Leslie Topp, Leonard Smith and Susan Piddock was influential in the development of a methodological approach for this research. While the literature review chapter will provide a critical survey of current research in this field, including the work undertaken by these scholars, a brief introduction will be given here.

Thomas Markus completed some of the earliest work in the field of asylum architecture. His 1982 publication, Order in Space and Society: Architectural Form and its Context in the Scottish Enlightenment, examined the early development of institutional typologies including prisons, bridewells, general hospitals and asylums. ${ }^{14}$ Leslie Topp has examined aesthetic responses in asylum design relative to the development of the villa hospital model in Germany and Austria in the late nineteenth century. In her publications "Otto Wagner and the Steinhof Psychiatric Hospital: Architecture as Misunderstanding" and "The Modern Mental Hospital in Late Nineteenth-Century Germany and Austria: Psychiatric Space and Images of Freedom and Control," she posits the villa typology as a vehicle for advancing the professional standing of psychiatrists. ${ }^{15}$ Two publications by Leonard Smith, Cure, Comfort and Safe Custody: Public Lunatic Asylums in Early Nineteenth-Century England and "The Architecture of Confinement: Urban Public Asylums in England, 1750 - 1820," explore the early development of the asylum typology. Of specific interest to this study is Smith's examination of the evolution of architectural styles relative to changes in the administration of these institutions, including the shift from custodial to curative models and between various funding models (state versus philanthropic). ${ }^{16}$ Susan Piddock's publication, A Space of their Own: the Archaeology of Nineteenth Century Lunatic Asylums in Britain, South Australia, and Tasmania, is similar to the research undertaken within this dissertation because it too utilises the discrepancies occurring between architectural expectation and built form to comment on wider cultural phenomena. However, Piddock employed an archaeological methodology that resulted in the exclusion of significant sources which could have better informed her findings. ${ }^{17}$ For this reason, Piddock's research offered a number of lessons for the development of a methodology for this research. Michel Foucault's The History of Madness, first translated in English (in a condensed format) in 1961 under the title Madness and Civilisation has significantly influenced historians working in the field of psychiatry. ${ }^{18}$ While this aspect of his work will be discussed within chapter two, it is Foucault's publication, The Archaeology of Knowledge and the Discourse on Language, that is most valuable for this work. When conducting archival architectural research the designer's intentions are seldom directly accessible, Foucault provides a justification for reading these intentions from the architecture itself. 
Paul Hirst credits Foucault's Archaeology of Knowledge with broadening the discourse of architecture by allowing for buildings to be read as part of the conversation, thereby removing reliance on the opinion of the first person in historical research. Hirst explains:

we find a way of superseding the problem of the "gap" between intellectual "influences" on architects and the practice of construction - that is, a way which avoids the problem of declared "intentions," and their absence, and sidesteps the cul-de-sac of trying to enter the mind of the architect-author. ${ }^{19}$

Topp's research methodology draws on the work of Foucault as it assumes that buildings can be read as "cultural and social document[s]" through the utilisation of resources around the design process. ${ }^{20}$ Topp's methodology provides an appropriate model for this research because it "concentrates on the gaps between the intentions and discourses of the various players - including the architect." The building is understood as being:

the result of a complex and fraught interaction between the intentions and discourses of interaction between groups, or disciplines, with distinct cultures, worldviews, and assumptions about how a building mediates meaning and what meanings it should mediate. ${ }^{21}$

With regard to New Zealand's history of asylum architecture this research will examine the medical, architectural and colonial discourses surrounding these institutions as well as examining the individuals who partook of these discourses: the architects, medical superintendents and policy makers.

Markus' work on the architectural forms of the Scottish Enlightenment also takes into account Foucault's ideas and explains how links may be drawn between the philosophy and the architecture of an era, through the ideas that permeate them. Markus distils three kinds of "discourses of intentions in architecture": form, space and function. Markus believes that the discourse of space is the most pertinent for institutional research because an analysis of topological relationships can allow spatial structures to be related to social structures; it takes account of the physical structure, sequencing and permeability of spaces. ${ }^{22}$ In the work of Smith and Topp, however, Markus' discourse of form is more prominent. ${ }^{23}$ The discourse of form, as defined by Markus, deals with "the formal properties of space and the boundaries which define it." ${ }^{24}$ Since the surfaces of these boundaries call aesthetics into consideration, issues of style occur within the discourse of form. Within this research discourses of space and form will be utilised.

Piddock examined the physical remains of asylum architecture against a checklist for the ideal construction of these environments created from nineteenth century documents on asylum design. Using an archaeological methodology, asylums were treated as "artifacts" and site excavation was substituted for the scrutiny of plans and photographs. ${ }^{25}$ To borrow from Topp's classification of various research methodologies in this field, Piddock's archeological approach separated the building from both the architect and the discipline of "academic architectural training." 26 This approach highlights a number of issues, most of which were attributable to this 
separation of an architectural study from the discipline of architecture, which will need to be addressed within the research methodology employed for this study.

Piddock's decision to read architecture in relative isolation, divorced from the theories of medical treatment that informed these architectural approaches, and without attempting to understand how this architecture was inhabited following construction, highlights the risk of misinterpretation. For example, Piddock draws the conclusion that the female patients who worked in the laundry led lives characterised by constraint. ${ }^{27}$ While this was a logical deduction given the spatial information available to Piddock, non-architectural records suggest a different reality. Useful employment was regarded as an essential element of moral treatment and Conolly observed, in 1847, that female patients who were employed in asylum laundries and kitchens were more likely to recover than patients employed elsewhere. ${ }^{28}$ At New Zealand's Levin Farm Colony, although a twentieth century example, former staff member Anne Hunt recalled that patients who held jobs in the laundry had a sense of purpose and took pride in their work. Although the laundry did not open until nine a.m., patients often arrived an hour early for work and waited at the door. ${ }^{29} \mathrm{~A}$ critical consideration for securing recoveries was that a tranquil environment would be secured around all patients, yet, no clear set of principles was provided for the architectural realisation of tranquillity. While specific recommendations were available regarding planning configuration, surface finishes, lock types and window heights, they did not distil the relationship of these elements to the treatment delivered. Nonetheless, a number of architectural elements were relevant to the provision of tranquillity, such as asylum size, the provision of private versus public space and, the size and location of dormitories and wards. Piddock's reliance on specified architectural elements does not allow for aspects such as the provision of a tranquil environment to be tested. Furthermore, the reliance of this methodological approach on a set of narrow specifications limited the extent to which an alternative architectural solution could be qualified. Since architecture is a practice of compromise and recompense, altering a day room configuration, for example, may provide spatial benefits elsewhere. The skill of the architect is an ability to balance the various requirements necessary in any given project.

Piddock acknowledged the limitations imposed by her methodological approach in attempting to read a history that was far more complex than could be understood from its architectural remnants, plans and government documents. ${ }^{30}$ In response, this research will cast a wider net, drawing on all available sources of information to understand how these spaces were planned, inhabited and managed. This research will engage with medical literature and philosophies of treatment in order to allow alternative solutions to be qualified through an understanding of the theories that underpinned the specifications for asylum construction. A translation of contemporary thought regarding mental health treatment into architectural terms will be provided for each era under examination. Hospital histories and accounts by former staff members, wherever available, will be utilised in order to move beyond the static understanding that can be obtained from drawings and empty buildings. 
The methodological approach for this research draws on Topp's understanding that buildings are the result of the negotiations between different personalities and professional disciplines, government policies and public expectations and the limitations that these create. A full understanding of the discipline of architecture will be employed, including discourses of form and space as defined by Markus. In addition information on the medical treatment of mental illness and issues of institutional operation, such as staffing and management, will be incorporated further to the lessons learnt from Piddock's research.

\subsection{SELECTION OF CASE STUDIES}

Since it was claimed that the architecture of the asylum played a part in the therapeutic process, the selection of case studies for this dissertation was decided relative to medical developments in the field of mental illness. For over a century, moral treatment was the therapeutic approach taken to mental illness, Seacliff Asylum (1878-84) was designed to respond to moral treatment. The first successful somatic treatments for mental illness, such as insulin coma and electroconvulsive therapies were not available until the late 1930s, with effective psychopharmaceuticals arriving a decade later in 1947. The design and construction of Cherry Farm Hospital (1943-71) occurred within the midst of these relatively late therapeutic changes. Kingseat Hospital (1927-40) was chosen as a counter point to Seacliff and Cherry Farm because it was designed during a period of relative stagnation in the development of treatments for mental illness (figure 1.5).

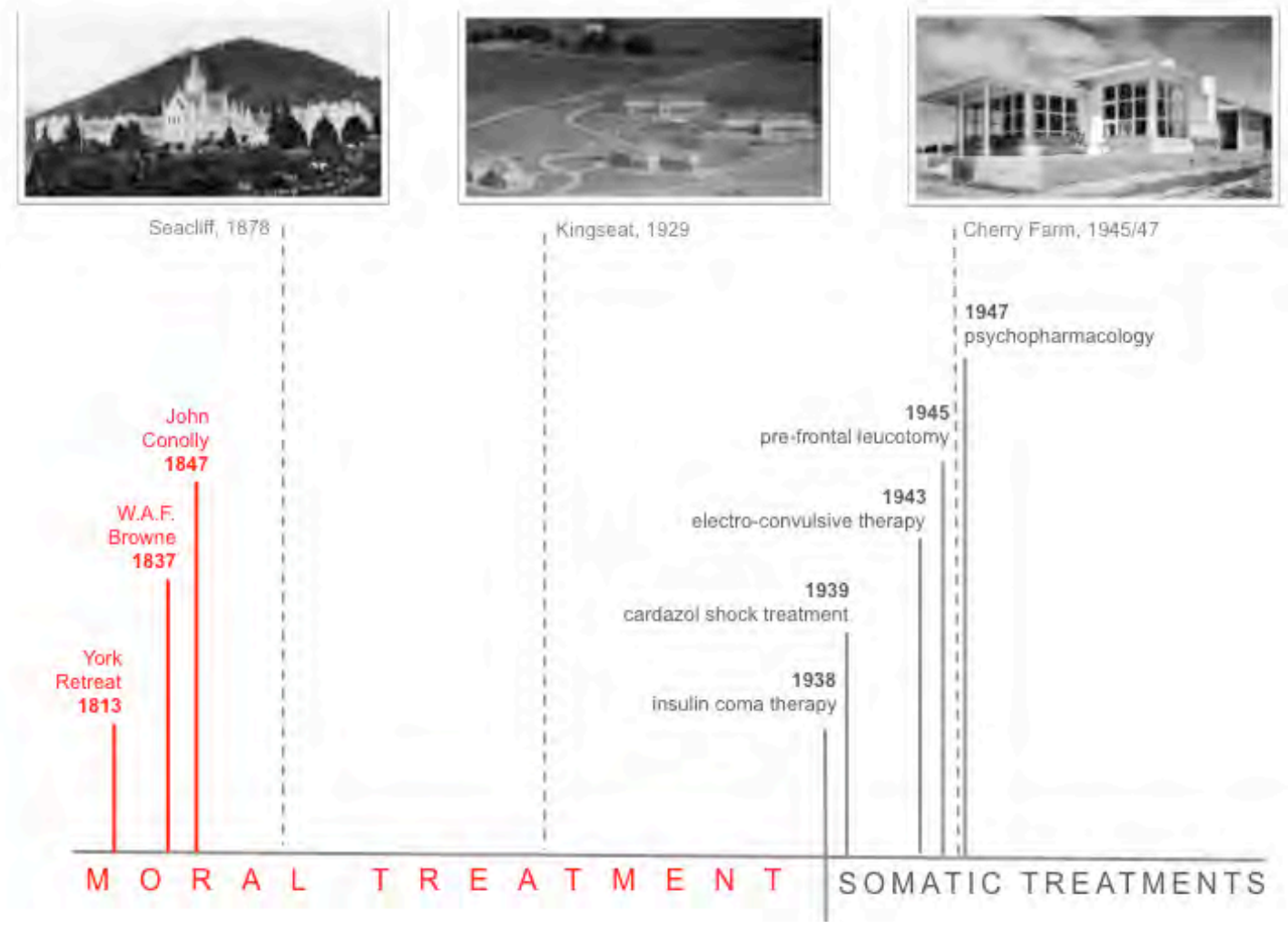

Figure 1.5: Case study hospitals relative to medical development.

Images (left to right): Seacliff, Hocken Collections: S09-038d. Kingseat, Alexander

Turnbull Library: WA-55912-G. Cherry Farm, Archives New Zealand: AAQT 6401, A29455. 
This dissertation acknowledges that the effects of insufficient funding on any construction project can be detrimental and thus obscure a proper understanding of the full raft of factors that can compromise an architectural outcome. In order to mitigate the effects of insufficient funding on the outcomes of this research, the three case study hospitals selected were the most expensive hospitals to be constructed within each era. ${ }^{31}$ The three hospitals selected further support the aims of this thesis by offering significant points of difference as outlined by Table 1.1 .

TABLE 1.1: RELEVANCE OF CASE STUDY SELECTION

\begin{tabular}{|c|c|c|c|c|}
\hline & $\begin{array}{l}\text { New } \\
\text { architectural } \\
\text { approach } \\
\text { adopted. }\end{array}$ & $\begin{array}{l}\text { New therapeutic } \\
\text { developments to } \\
\text { consider. }\end{array}$ & $\begin{array}{l}\text { Unique opportunity for } \\
\text { innovation present. }\end{array}$ & $\begin{array}{l}\text { Dominant } \\
\text { professional } \\
\text { personality } \\
\text { involved. }\end{array}$ \\
\hline $\begin{array}{l}\text { Seacliff } \\
\text { Asylum }\end{array}$ & $\begin{array}{l}\text { First "corridor- } \\
\text { pavilion" asylum } \\
\text { constructed in } \\
\text { New Zealand. }\end{array}$ & $\begin{array}{l}\text { One of the earliest } \\
\text { permanent asylums } \\
\text { constructed with the } \\
\text { intent of supporting } \\
\text { moral treatment. }\end{array}$ & $\begin{array}{l}\text { Constructed three } \\
\text { decades after Britain's } \\
\text { adoption of the asylum } \\
\text { typology, the timing of } \\
\text { Seacliff offered the } \\
\text { opportunity to evaluate } \\
\text { British responses. }\end{array}$ & $\begin{array}{l}\text { Architect Robert } \\
\text { Lawson displayed } \\
\text { significant } \\
\text { professional } \\
\text { ambition and } \\
\text { Seacliff was the } \\
\text { largest commission } \\
\text { of his career. }\end{array}$ \\
\hline $\begin{array}{l}\text { Kingseat } \\
\text { Mental } \\
\text { Hospital }\end{array}$ & $\begin{array}{l}\text { One of the } \\
\text { earliest "villa } \\
\text { hospitals" } \\
\text { constructed in } \\
\text { New Zealand. }\end{array}$ & N/A & $\begin{array}{l}\text { Prior to the construction } \\
\text { of this hospital, Theodore } \\
\text { Gray, Director-General of } \\
\text { the Mental Hospitals } \\
\text { Department, conducted } \\
\text { an international tour of } \\
\text { the worlds most "up to } \\
\text { date" mental hospitals } \\
\text { that included viewing the } \\
\text { new psychopathic } \\
\text { hospital model. }\end{array}$ & $\begin{array}{l}\text { Gray left various } \\
\text { records confirming } \\
\text { a desire to leave an } \\
\text { architectural } \\
\text { legacy. }\end{array}$ \\
\hline $\begin{array}{l}\text { Cherry } \\
\text { Farm } \\
\text { Hospital }\end{array}$ & $\begin{array}{l}\text { New Zealand's } \\
\text { only purpose-built } \\
\text { "therapeutic } \\
\text { community" (it } \\
\text { was possible to } \\
\text { alter an existing } \\
\text { hospital to follow } \\
\text { this model). }\end{array}$ & $\begin{array}{l}\text { Constructed during } \\
\text { the same period as } \\
\text { the World Health } \\
\text { Organisation } \\
\text { released its ground } \\
\text { breaking report on } \\
\text { the future of mental } \\
\text { health care. }\end{array}$ & $\begin{array}{l}\text { The WHO report offered } \\
\text { new ideas for innovation } \\
\text { in the treatment of } \\
\text { mental illness while } \\
\text { developments in } \\
\text { psychopharmacology } \\
\text { offered new options for } \\
\text { patient care. }\end{array}$ & N/A \\
\hline
\end{tabular}




\subsection{CHAPTER OVERVIEW}

Chapter two will provide the background to this research problem and outline how this dissertation will contribute to existing research in the field. Chapter three will provide an overview of the medical context in which each case study hospital was constructed. This will include an overview of the relevant developments within the asylum typology. Within this chapter the evaluative criteria for each case study hospital will be established. Chapters four to six will contain the case studies and each will follow a similar format: the hospital in question will be positioned relative to the geographical, cultural, and economic context within which it was constructed. It will be examined relative to the evaluative criteria set up within chapter three and against leading international precedents in mental hospital design. This process will establish where ideal curative strategies were successfully translated into built form and where discrepancies occurred; an explanation for these discrepancies will then be sought. Finally, where local precedents from within New Zealand's network of mental hospitals, or on the periphery of this network, can enhance our understanding of official attitudes to mental illness then these too will be examined. Chapter seven will discuss the patterns of compromise that occurred across these three hospitals and the relative contribution of the politicians, architects and medical professionals involved. Chapter eight will summarise the major findings of this dissertation.

\subsection{STATEMENT OF LIMITATIONS}

1971 is the end date of this study; this was the year the inpatient unit at Wakari General Hospital was opened as an extension, and thus completion, of the Cherry Farm Hospital complex. This study period ends prior to the shift of administration of New Zealand's mental hospitals, from central (Division of Mental Hygiene) to local. In 1972 the administrative control of these institutions was vested with local District Health Boards. This dissertation does not examine the issues around the changes to the administration of these facilities.

This dissertation will not address issues specific to Maori as this research spans from 1878 to 1971 and Maori rates of admission to mental hospitals remained low during this period. In 1949, for example, Maori patients accounted for only 232 of the 9,034 patients resident in New Zealand's mental hospitals. ${ }^{32}$ Consequently, the specific needs of Maori were given little attention in the design and construction of new mental hospitals for the period examined by this dissertation.

Non-architectural improvements to the hospital environment, such as the provision of pocket money to patients in the 1940s, will not be evaluated within this research. However, their relevance to the changing therapeutic milieu of mental hospital care in the mid-twentieth century will be acknowledged and discussed where this is beneficial to understanding changing approaches to care.

Between six and ten nineteenth century sources cited within the work of other historians could not be located. Many records seem not to have survived the transfer from hospitals and departmental offices (including the Ministry of Works) to Archives New Zealand. ${ }^{33}$ In instances where the secondary source has been relied upon acknowledgement is given within the relevant endnote. 
From 1891 onward the Public Works Department (later the Ministry of Works) were engaged to design New Zealand's mental health care facilities. Owing to the structure of the Public Works Department and the sparse archival evidence that has survived, the architect has been rendered relatively anonymous within this process. During Kingseat's construction, John Thomas Mair was government architect and during the design of the Cherry Farm Hospital R.A. Patterson held this position. While the influence of these individuals should fairly be assumed within the design responses created for these hospitals, within the archival record only R.A. Patterson's name appears and, even then, this is in relation to correspondence regarding work flow issues and communication between the Mental Hospitals Department and the Public Works Department. Harry Burt can be identified as the architect of the Cherry Farm villas because his name appears on the drawings, but little else could be discovered regarding his involvement. Owing to the lack of information regarding these architects within the archival record, and because archival documentation suggests that, for various hospitals, the administrators of these institutions may have limited the potential influence of the architect, ${ }^{34}$ assumptions and hypotheses regarding the relative influence of the individual architects involved has been avoided.

\subsection{A NOTE REGARDING TERMINOLOGY}

Terms such as "inmates," "lunatic" and "asylum" were gradually eliminated from official use in New Zealand between 1905 and 1911 when "patient," "mental" and "hospital" were deemed to be more appropriate. ${ }^{35}$ The convention among medical historians, and by extension historians of asylum architecture, is to use historically grounded language as appropriate to the period of time under discussion. Carla Yanni follows this convention in her research in order to "re-create the cultural context for the reader." ${ }^{36}$ While terms like "inmate" were employed in official literature they nonetheless contributed to the stigma that surrounded mental illness. This researcher takes the view that studies which engage with discriminating practices should not necessarily be bound to adopt the language of discrimination. ${ }^{37}$ Furthermore, official terms did not always reflect the terms preferred by the medical practitioners who resided on a daily basis with these patients. Official reports for the period 1881 - 1887 referred to the Christchurch facility as "Sunnyside Asylum" or "Christchurch Asylum," yet, the asylums own stationery during this time was printed with the title "Sunnyside Hospital for the Insane." "38

In the hopes of making this research accessible to a wide audience, medical jargon has been minimised where possible and specialist historic terms, such as "alienist" (the nineteenth century term for a doctor specializing in the treatment of mental illness) have been deliberately avoided.

The government department responsible for the administration of mental hospitals was known by various names. When the government took over the administration of provincial asylums in 1876 the Asylums Department was formed. This was renamed the Mental Hospitals Department in 1908 (abbreviated MHD) and, in 1947, became known as the Division of Mental Hygiene (abbreviated DMH) when it was placed under the administrative umbrella of the Ministry of Health. Throughout this 
dissertation these various bodies will be referred to as the "department" or "division" as appropriate to the era under discussion, and abbreviated within endnotes as indicated above.

\footnotetext{
${ }^{1}$ Yanni 2007, 1, 8. Treadwell 1998, 390. Also refer Browne, 1837, and Conolly, 1847.

${ }^{2}$ Thompson 1992, 98.

${ }^{3}$ Belknap 1956, Goffman 1961, Frame 2005.

${ }^{4}$ Conolly $1830,12,17$.

${ }^{5}$ Smith 1999,71 . Smith cites an archival source but the origin is not clearly stated.

${ }^{6}$ Smith 1999, 38. Scull 1979, 25-35. Markus 1982, 25-6.

${ }^{7}$ Scull 1979, 44, 93-4, 165. Topp 2007, 242-6.

${ }^{8}$ Brunton 2001, Prebble 2007, Thompson 1992.
}

9 The current administrator of Tokanui Hospital, the Office of Treaty Settlements, was unwilling to grant permission to this site for this research; the author would like to acknowledge the helpful, though ultimately unsuccessful, efforts of the Waikato District Health Board to procure a site visit.

${ }^{10}$ Leach 2010, 71.

${ }^{11}$ Ibid.

12 Ibid, 72.

${ }^{13}$ Gray 1959.

${ }^{14}$ Markus 1982.

${ }^{15}$ Topp 2005, 2007.

${ }^{16}$ Smith 1999, 2007.

${ }^{17}$ Piddock 2007, 22-6, 216.

${ }^{18}$ Foucault, 1961, 2006.

${ }^{19}$ Hirst 2005, 158.

${ }^{20}$ Topp 2005, 130.

${ }^{21}$ Ibid, 131.

${ }^{22}$ Markus 1982, 4.

${ }^{23}$ Both Topp and Smith examined the relationship of architectural style to the narrative of medical progress. Smith 2007, 54-5. Topp 2007, 255-9.

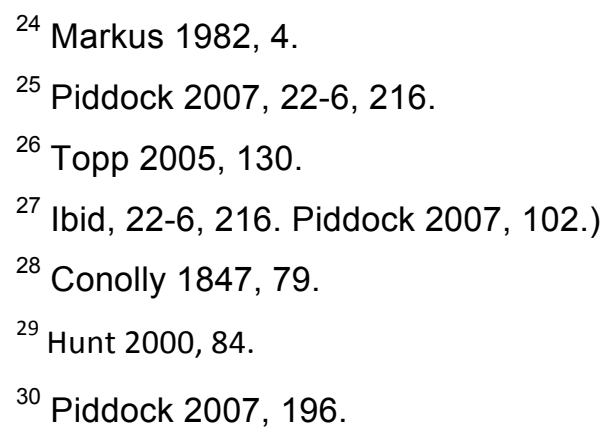


${ }^{31}$ The expense of each hospital relative to other hospitals constructed during each period is detailed within the relevant case study.

${ }^{32}$ New Zealand Department of Statistics 1950.

${ }^{33}$ Brunton's doctoral dissertation lists a number of Mental Hospitals Department Files as "whereabouts unknown," he explains that while these files were originally cited at the Department of Health Record Storage Room, Stout Street, Wellington, he was unable to locate them at the time of writing up his thesis. Brunton 2001, 483-4.

${ }^{34}$ Refer correspondence between Gray and the government architect, relative to Lake Alice Hospital, between 1940 and 1943 (held in ANZ file: R22502230): In 1940 Gray forwards the plan he wishes the Lake Alice 11-bed villas to be based upon with specific instruction as to which rooms to remove. In 1943 he advises on the appearance of these villas, suggesting alternate window and entrance designs. With regard to the 50-bed villas he specifies that the Kingseat plan will be followed but asks for a more homely appearance, while three separate letters infer an intention by Gray to have the final say on the master planning of this hospital. In 1945 Gray asks for the design of the sun porches to be adjusted and provides his own sketches regarding changes to the hospital block. While these may appear like reasonable requests I suggest it more likely indicates a tendency toward micro-management on Grays part - few design decisions are left untouched by him.

${ }^{35}$ Prebble 2007, 187.

${ }^{36}$ Yanni 2007, 9.

${ }^{37}$ This decision emerged from conversations with my partner, Jared Green, who is a medical practitioner who holds an arts degree in Spanish, with a specific focus on post-colonial literature.

${ }^{38}$ See AJHR 1886, H-6B, 2 and Brunton 2001, 269. Brunton cites a letter found within a patient casebook (Sunnyside Hospital files) during this period. Original source not cited by author. 


\section{CHAPTER TWO \\ Literature Review}

This chapter aims to satisfy two objectives. Firstly, it aims to provide the reader with sufficient background to understand the research problem. The first three sections will address this objective. Section one will acknowledge the patient experience of these institutions, section two will summarise the origins of the asylum typology and section three will detail how this architecture was expected to facilitate the restoration of a patient's sanity. The second objective of this chapter is to identify gaps in the existing field of research. Section four will look at the various reasons why the asylum environment, and the treatment regime it supported, was not able to deliver the curative outcomes that were anticipated. Section five will examine the work of various historians who question the sincerity of institutional psychiatrists in the development of the asylum typology. It will also acknowledge the difficulties of asylum administration. Section six will review the transposition of British ideas around lunacy care to new British colonies in the nineteenth century, including New Zealand. 


\subsection{CONTEMPORARY UNDERSTANDINGS OF NEW ZEALAND'S MENTAL HOSPITALS}

Growing up in New Zealand through the 1980s and 1990s, it was difficult to miss the furore surrounding the proposed closure of New Zealand's mental hospitals, or the stories of mistreatment by former patients that surfaced within the media following the closure of these institutions. This chapter begins by acknowledging the pain that was experienced by thousands of patients who were accommodated within New Zealand's mental hospitals.

Janet Frame's autobiographical novel Faces in the Water, published in 1961, provides the most detailed account of patient life within a New Zealand mental hospital. Originally posited as fiction, Frame would later explain that only the characters were invented, the events were drawn from her own experiences at three of New Zealand's largest mental hospitals, Auckland, Sunnyside and Seacliff, between 1945 and 1953. In 1984 Frame confirmed that Faces in the Water resided much closer to reality than initially suggested. In her autobiography she wrote:

The squalor and inhumanity were almost indescribable ... were I to rewrite Faces in the Water I would include much that I had omitted because I did not want a record by a former patient to appear to be over-dramatic. $^{1}$

The veracity of Frame's account is evident in the fact that it so closely echoed the observations made by Erving Goffman in Asylums: Essays on the Social Situation of Mental Patients and Other Inmates, published in the United States the same year. Goffman was a sociologist and spent twelve months as a passive observer at St Elizabeth's Psychiatric Hospital in Washington, D.C. The resulting publication has been labelled "a devastating critique of the realities of mental hospital life" and a clear illustration that "little that could be described as therapeutic was found in the asylum." Goffman's book revealed the detrimental effects to a patient's self-esteem that resulted from the strict daily routines, the forced use of collective space and the social hierarchies that accompanied asylum life. Frame's description of bathing procedures at the Auckland Asylum provides a clear illustration of how hospital routines were able to cause damage to a patient's self-esteem:

crowded into the tiny washroom to be dressed. There was little hope of washing, and as one entered the room one was bulldozed ... by the smell of stale bodies. We stood there naked, packed tightly like cattle at the sale yards, and awaiting the random distribution of our clothes... ${ }^{3}$

Various New Zealand accounts, by former patients and staff, reveal a commonality of experience. Frame's personal experience, as described in Faces in the Water, was by no means unusual. ${ }^{4}$ 
In 2005, New Zealand's Labour Government established a confidential forum for former in-patients of New Zealand's psychiatric hospitals. 493 former patients responded. While the earliest experiences dated from the 1940s, most participants spoke of their experiences between 1970 and the late 1990s. The summary document that was prepared following this forum stated that few patients recalled their experience as positive. For most patients the time they spent within these institutions was "humiliating and demeaning" and, for some, this experience had taken a lifelong toll. ${ }^{5}$ Former patients described:

having to sleep in large dormitories with beds very close together... days spent locked in dirty, noisy, smoke-filled day rooms... poor sanitation and the presence of cockroaches and rats. Many gave an account of a lack of privacy and routines being carried out in ways that they found degrading and humiliating. ...the absence of doors on toilets and having to use toilets in front of staff; communal showering with patients being lined up naked and hosed down before showering; or baths in cold water already used by others. ${ }^{6}$

Staff treatment was described as ranging from indifferent to "callous, threatening [and] abusive." Many accounts were coloured by fear. Patients described the hospital as having an atmosphere of violence created by certain patients and members of staff:

Former patients spoke graphically of witnessing and hearing frightening situations such as crying and wailing from the seclusion units, episodes of physical or sexual violence, patients who had selfharmed or suicided, and people screaming while having ECT... Some spoke of their abiding regret or shame at not intervening or not having been able to do more to assist [their fellow patients]. ${ }^{8}$

The report acknowledged that, "although psychiatric hospitals were supposed to be safe for patients, the experience of many participants was that they were not." Family members who spoke to the forum expressed a feeling of betrayal by "a system that had been entrusted to look after their relative but had failed to do so." 9

To engage with the history of New Zealand's mental hospitals is a humbling experience. What must be kept in view are the thousands of New Zealanders whose lives were affected owing to their engagement with these institutions. For all of the 493 patients whose stories were told to the government's Confidential Forum there are thousands more that will never be heard. This history deserves academic attention. Warwick Brunton completed his doctoral dissertation on the history of lunacy policy in New Zealand, while Kate Prebble examined the history of psychiatric nursing, and Shayleen Thompson the history of psychiatry. ${ }^{10}$ This thesis will contribute an architectural perspective to an important aspect of New Zealand's history that remains relatively understudied. 


\subsection{THE ORIGINS OF THE ASYLUM TYPOLOGY}

Warwick Brunton has suggested that New Zealand drew heavily from nineteenth century British models in the formation of lunacy policy and asylum construction. ${ }^{11}$ In order to gain an appreciation of Britain's influence on the construction of New Zealand's asylums it is necessary to understand the origins and subsequent development of this architectural typology.

Andrew Scull and Thomas Markus both link the rise of the asylum to nineteenth century industrialisation. ${ }^{12}$ Scull suggests that asylums arose as a solution to an increasing discontent, among Britain's middle class, with non-institutional responses to the poor, idle and mad. Urbanisation and increased pressure for family members to be productive within the industrial era made family and parish-based models of care difficult to sustain. An institutional response was demanded by Britain's middle-class, who were increasingly driven by self-interest. ${ }^{13}$ Markus gives more credit to the influence of fear in the proliferation of asylums within Scotland. Pauperism, deviancy and madness provided a threat to social instability which he suggests was feared by the public following the upheavals caused by the French Revolution and industrialisation in the late eighteenth century. Scotland responded by seeking greater control through the employment of law, religion, science and reason. Asylums, workhouses, prisons and general hospitals were the physical manifestations of this social control. ${ }^{14}$ Michel Foucault had previously suggested that the fear of madness increased within the second half of the eighteenth century and that madness itself was believed to be on the rise. However, he observed that archival records are insufficient to answer the question of whether an increase in the number of persons who suffered from madness actually occurred. ${ }^{15}$ Scull, Markus and Foucault all agree that the societal response towards madness altered during the eighteenth century.

The insane were originally accommodated within workhouses but their presence disrupted the order and discipline of these institutions. The asylum provided a space for segregation and achieved a dual purpose; it removed threats to the workhouse while rescuing the madman from the harsh treatment he received in this environment. ${ }^{16}$ Like prisons, and later asylums, the workhouse performed the functions of deterrence, segregation, punishment and reform. Through the workhouse a pauper could be transformed into a productive member of capitalist society. ${ }^{17}$ The similarity of purpose between these three institutional types is evident in their architectural responses. Leonard Smith points out that a number of architects experienced in prison design completed asylums. ${ }^{18}$ Yet the curative ideology of the mid-nineteenth century asylum, which Brunton asserts New Zealand borrowed, was far removed from the principles these institutions were originally founded upon. How did a typology created from a desire for social control come to be understood as an ideal curative environment? 
Early asylums segregated lunatics from workhouses but the harsh treatment and foul living conditions that characterised these institutions were replicated. The fact that early asylum architecture was based on prison design presented a dilemma. Markus suggests that, while lunatics, criminals and paupers had a number of characteristics in common, namely idleness and poverty, lunatics exhibited these defects while labouring under an illness. Idleness and poverty were clear moral defects, but the line between madness and criminality was difficult to draw. Should lunatics be treated as criminals, whose behaviour they mimicked, or as patients suffering from an illness over which they had little control? ${ }^{19}$ Lunacy reformers believed the latter. Their efforts within Britain had secured a significant collection of charitable, private and country asylums by $1825 .{ }^{20}$ In 1845 , their struggle culminated in the establishment of the Lunatics Act. This set out the requirements for the creation of a compulsory network of pauper asylums and the establishment of a national inspectorate to maintain appropriate standards of care. ${ }^{21}$

The idea that asylums should be curative environments was central to the reform movement and, as a consequence, the approach to asylum design changed. According to Barry Edginton, from 1848 onward asylum architecture began to align more closely with the principles developed at the York Retreat and shifted away from the custodial solutions that had hitherto informed this typology. ${ }^{22}$ The York Retreat was founded by Quakers, in 1792, for the treatment of patients from their own Society of Friends. The establishment of the Retreat was motivated by the observation that:

the general treatment of insane persons was too frequently calculated to depress and degrade, rather than to awaken the slumbering reason, or correct its wild hallucinations. ${ }^{23}$

According to Scull, Samuel Tuke's Description of the York Retreat, published in 1813, was a constant guide for reformers. The Retreat, therefore, was instrumental in the promotion of moral treatment in Britain. ${ }^{24}$ In France, a similar approach to care was advanced by Philippe Pinel at La Salpêtrière. However, Pinel featured little in British medical literature of the nineteenth century and Carla Yanni suggests that Tuke and Pinel were unaware of each other's efforts. ${ }^{25}$

Moral treatment employed kindness, social and occupational distraction in a bid to restore sanity. Ruth Caplan explains that the goal was to distract a patient from their delusions and that treatment took place within "a closely knit social system" that provided "examples of correct behaviour." ${ }^{26}$ For those patients deemed curable the goal was to restore healthy functioning. But for those patients deemed incurable, moral treatment was delivered in the hopes that further deterioration of the mind might be starved off. ${ }^{27}$ Smith observed that many historians have tried to present the shift to moral treatment as a clear break with the past. He refutes this view, arguing that, while posterity has misleadingly attributed the creation of moral treatment to 
William Tuke (Samuel's father) and Philippe Pinel, there is clear evidence to confirm that a more humane approach was occurring in a handful of eighteenth-century asylums. ${ }^{28}$ Foucault disputes the view that moral treatment was a more humane approach to the treatment of madness. He suggests that this simply replaced physical restraint with the expectation of self-restraint, which, although visibly imperceptible, was a more oppressive form of control because it exerted control over the mind of the lunatic in ways that straightforward confinement did not. Moral treatment forced the patient to recognise his own madness and utilised fear as a tool for encouraging him to behave in a manner consistent with societal norms. Moral treatment caused the patient to feel guilt and responsibility for the aspects of his own character that could "trouble morality and good society." 29 This would result in a state of perpetual anxiety where, if a patient failed to conform to social expectation, they remained fully aware that they were at odds with the reasoned world. ${ }^{30}$ Nonetheless, within the nineteenth century, the Retreat was viewed as a model of asylum design and administration that was worthy of replication.

In the late nineteenth century, when New Zealand referenced the British system of asylum care, the design philosophy behind these institutions had changed. What emerged as a derivative of the prison, a typology intended to punish, underwent a significant transformation to become what was considered to be an ideal space for the treatment of mental illness along humane lines. 


\subsection{SO HOW EXACTLY WAS ARCHITECTURE CURATIVE?}

The asylum ideal was that the appropriate articulation of architecture and landscape would aid the restoration of reason over madness. Advice regarding the ideal construction of asylums was plentiful in the nineteenth century but exactly how architecture and landscape were understood to facilitate a return to sanity was not defined. This section will draw upon contemporary interpretations in order to make sense of how this architecture was understood to function as a curative tool.

In addition to the curative practices of physical exercise and social and occupational distractions, moral treatment was dependent on an appropriately designed environment to support it. Edginton defines moral treatment as "an attempt to create an environment that encouraged the patient to conform to the ideals and expectations of the outside world," ${ }^{31}$ or, as Brunton more poetically phrases it, "the domestic routines of a middleclass Victorian household." ${ }^{32}$ According to Edginton, the expectation that human behaviour could be manipulated via changes to the physical environment was simply part of a wider set of nineteenth century spatial beliefs. ${ }^{33}$ The faith vested within the prison typology, to reform and redeem criminals, was also a product of these spatial beliefs. Edginton suggests that the asylum, its goals and functions, are inseparable from its architecture because moral management and moral architecture are synonymous. ${ }^{34}$

The York Retreat was the first asylum purpose built with moral treatment in mind and many contemporary scholars have examined this institution in their efforts to understand how architecture was expected to function as a curative tool. Leslie Topp uses the terms "deliberately domestic" and "parallel universe" in her discussion of the Retreat. It was a replica of the sane, external world. ${ }^{35}$ Anne Digby echoes this interpretation, suggesting that within the retreat the rituals of everyday life were preserved as closely as possible. ${ }^{36}$ The architecture reflected this with spaces organised to encourage patients to maintain civil habits; dining rooms increasingly mimicked the appearance of domestic settings. Pictures adorned the walls and mantelpieces, while tables were set with flower vases, napkins, cutlery and water glasses. ${ }^{37}$ Scull adds that:

From its architecture to its domestic arrangements, the Retreat was designed to encourage the individual's own efforts to reassert his powers of self-control. ${ }^{38}$

Edginton suggests that moral treatment required an environment that was "instilled with order, discipline and clarity"; an environment that would promote sanity because it was encoded with rational, sensible, sensations, behaviours and ideas. ${ }^{39}$ Put more simply, if an insane patient was placed in an environment characterised by sanity and tranquillity, then they were more likely to reconnect with a prior state of reason. As Topp has 
interpreted Edginton's hypothesis, a patient's sanity would be restored "through a kind of osmosis." 40

An important aspect of treating mental illness was to remove the patient from the stresses of daily life and from the environment in which madness had developed. Rural locations were favoured for asylum construction owing to their ability to "neutralise the moral poisons of congestion and disorder" that were prevalent in cities. ${ }^{41}$ Richard Sennett observed that, in the nineteenth century, cities were viewed as both morally and physically unhealthy. ${ }^{42}$ While rural locations enabled an array of outdoor recreations and employments, a necessary aspect of moral treatment, pastoral views, made an equally important contribution. A pleasant and tranquil outlook was believed to have a calming influence on the mind. Clare Hickman posits a direct link between eighteenth century writers on landscape, such as Joseph Addison, and the beliefs of nineteenth century asylum superintendents. Addison wrote in 1712:

Delightful scenes, whether in nature, painting, or poetry, have a kindly influence on ... the mind, and not only serve to clear and brighten the imagination, but are able to disperse grief and melancholy... ${ }^{43}$

Francis Kowsky identifies a similar belief on the part of American landscape architect Frederick Law Olmsted, who completed designs for New York's Central Park (1858) and the Buffalo State Asylum (1872-80). Olmsted believed that pastoral scenery "subconsciously exerted a calming and rejuvenating influence on the psyche." ${ }^{44}$ Sera Cedar Millar posits a religious basis for Olmsted's belief in rejuvenation through nature. Olmsted "craved the soothing pastoral landscape of the $23^{\text {rd }}$ Psalm" which reads: "He maketh me lie down in green pastures and leadeth me beside the still waters, he restoreth my soul." 45 Drawing on Richard Brantley's study of the poet William Wordsworth, Hickman agrees that the aesthetic experience of landscape had a spiritual dimension. Wordsworth believed that a close relationship with the natural world developed one's moral character and could heal the adult mind. ${ }^{46}$ Brantley's reading of Wordsworth's poem The Excursion (1814) is that from wandering through nature, "the wanderer acquires... a reverent sense of magnitude and infinity ... moral wisdom and spiritual insight." ${ }^{\prime 47}$ The ideas contained within Wordsworth's poem echo through a passage written by leading critic and advisor on nineteenth century asylum design, W.A.F. Browne, in 1837:

To many... [the] country affords delight; to some the beauty of the wood and water, hill and dale, convey grateful impressions... the inanimate objects, the changes of season... the living and moving things which pass across the scene, form a strong and imperishable tie with the world and the friends to which the heart still clings... to all a succession of new and varied and healthy impressions must be imparted [emphasis added]. ${ }^{48}$ 
Edginton suggests that the creation of an environment that allowed a patient to develop an "attachment to site" was more valuable than a well-designed asylum because through this attachment a patient could experience sanity once more. $^{49}$

Moral treatment relied upon the maintenance of a daily routine that incorporated social outings, work and exercise, preferably outdoor. It also relied on the appropriate articulation of architecture and landscape to support the delivery of this treatment through its encouragement of compliance with social expectation and civil habits. Within this environment landscape was valued for its perceived ability to calm a troubled mind. During the nineteenth century the architectural requirements for the achievement of an "ideal" curative environment were precisely specified and will be summarised within chapter three. 


\subsection{EARLY INDICATIONS OF THE FAILURE OF CURATIVE ENVIRONMENTS}

Scull concedes that, while the wider adoption of moral treatment bought a new optimism to the profession in the early nineteenth century this was short-lived. ${ }^{50}$ As early as 1830 , experts such as John Conolly were willing to acknowledge that, at best, only one-third of lunatics could be benefited by treatment within an asylum. ${ }^{51}$ It did not take long for the medical men who superintended asylums to realise that this environment would fail to deliver the curative outcomes that were anticipated. Various obstacles commonly prevented the attainment of what was then considered an ideal curative environment for the treatment of mental illness, as this section will outline.

The size of an asylum and the extent to which it was overcrowded were major hurdles in the delivery of moral treatment. According to Scull, reformers hoped that in the construction of new asylums the patient population would be limited to 200 . Yet, as early as 1844 , the year before the Lunatics Act was enforced, asylums were being constructed for populations between 300 and 1000. The decision regarding asylum size was made at the discretion of local magistrates who favoured economies of scale. ${ }^{52}$ Given that asylums could not be constructed fast enough to keep up with demand, magistrates no doubt felt this was a reasonable compromise. Smith advises that by 1848 the population of most British asylums had doubled from that for which they were originally designed. In some cases asylums were extended with lower-budget additions, heavily debased versions of the original construction. Often, however, patients were simply crammed into spaces intended for half their number. ${ }^{53}$ Large asylums and overcrowding can be reduced to a single factor: finance. The waning public support for these institutions within the nineteenth century can be gauged by the financial commitment to the construction of new asylums. Asylums constructed immediately after the Lunatics Act of 1845 were erected at costs of between $£ 160$ and $£ 245$ per head. This expenditure was rapidly reduced to $£ 80$ per head for those patients considered "curable" and even less for patients considered "chronically insane." Scull maintains that this resulted in asylums that were dreary and prison-like, not unlike the architecture of the prisons and workhouses they were intended to replace. ${ }^{54}$

Smith and Scull agree that, in light of these hurdles, asylum goals were redefined and the institutional focus shifted to matters of management: the organisation and control of large groups of "incapacitated and highly dependent people." 55 Success was rated in terms of "comfort, cleanliness and freedom from more obvious forms of maltreatment." ${ }^{56}$ Digby reveals that even the York Retreat struggled to retain its early practices in the face of increased numbers of patients. She cites hospital records in suggesting that approaches to patient care had altered markedly by 1878 , patients were no longer regarded as "subjects to be treated but objects to be 
managed." ${ }^{57}$ A custodial approach to patient management remained the status quo in Britain, and throughout the western world, for nearly a century until developments such as insulin-coma, electroconvulsive and chemical (pharmaceutical) therapies became available. This period of time, spanning roughly from 1845 to 1938 , has come to be regarded as the custodial era. ${ }^{58}$

Despite the known shortcomings of asylum care in the nineteenth century, few alternatives were sought and these institutions continued to be constructed for more than a century. While there is evidence to suggest that the psychiatric profession in Britain was aware of the failings of this system, we do not know whether this awareness existed within New Zealand. The Lunatics Act of 1845, the result of a thirty year struggle by asylum reformers, was passed just five years after the first settlers departed for the Southern Hemisphere, but well in advance of the great waves of migration that continued to arrive in New Zealand until 1881. Susan Piddock has identified the role of Australia's geographical isolation in limiting access to the lunacy "knowledge pool" which existed in Britain. ${ }^{59}$ Geographical isolation was likely to have similarly affected New Zealand, though this requires further research. The reason why such a compromised architectural typology continued to be constructed in Britain is a problem many historians have tried to address, as the following section will discuss. 


\subsection{EXISTING HYPOTHESES FOR THE FAILURE OF THE ASYLUM}

AS A CURATIVE TYPOLOGY

In J. Sheridan Le Fanu's nineteenth century novel The Rose and the Key (1871), institutional psychiatrists were portrayed as instruments of the wealthy, forsaking the physicians' oath to do no harm in return for their own financial gain. ${ }^{60}$ While The Rose and the Key was fictional, this section reviews the work of various historians who suggest that institutional psychiatrists were not motivated by a sincere concern for the mentally ill but by various professional agendas. These theories offer a possible explanation for why new asylums continued to be constructed despite their known shortcomings. This section will also acknowledge those historians who take a more sympathetic stance, recognising the difficult circumstances faced by asylum superintendents. In the hopes of maintaining a balanced view, only limited attention has been directed toward material that falls within the category of "anti-psychiatry" such as the writings of David Cooper, R.D. Laing and Thomas Szasz (who does not identify himself as a proponent of anti-psychiatry but was, nonetheless, influential within this movement). The opposing view, as described (but not believed) by Scull, of psychiatrists as "benevolent and disinterested purveyors of humanity and science" whose "well-intentioned actions" resulted in "accidental" consequences, is an equally limiting outlook with which to approach this history. ${ }^{61}$ The examination of all individuals and groups of officials within this dissertation has been approached, therefore, from an initial position of scepticism but with a conscisous effort to mitigate any preconceptions that might limit the outcomes of this research.

Andrew Scull, in his early research, asserted that the expansion of Britain's asylum network was necessary for the legitimisation of the profession we now know as psychiatry. Asylums created a self-reinforcing system. Their presence required a specialised profession to manage them who, in turn, encouraged the ongoing necessity of asylums. Scull suggests that from 1828 onward asylum superintendents were actively engaged in a discourse that would consolidate their position as medical specialists of lunacy: a discourse that framed asylum doctors as instrumental in securing cures and the asylum as the preeminent healing environment. Scull claims neither idea had any defensible scientific basis. ${ }^{62} \mathrm{He}$ explains that, while the home had been the traditional space for the treatment of illnesses, the presence of the asylum allowed superintendents to undermine this space. The public was led to believe that the home environment was noxious for the mentally afflicted because this was the space in which insanity had been allowed to germinate. In this promotion of the asylum, glaring institutional failures were overlooked while impressive rates of recovery were claimed without substantiation. Scull posits that this "sustained illusion" of asylums as medical institutions was motivated by the fear that medical practitioners would lose their professional standing. Superintending an asylum was considered lucrative and medically trained practitioners needed to 
distinguish themselves from lay superintendents who could also perform this role. As a professional ideology upon which to monopolise the treatment of lunacy, moral treatment was weak. "Warm baths and kindness" hardly seemed to require medical knowledge. ${ }^{63}$ Scull's early research suggests, therefore, that the asylum typology was exploited for the personal gain of those engaged in the profession of psychiatry.

Leslie Topp has also suggested that the psychiatric profession utilised the typology of the asylum as a vehicle to advance their own professional standing with the development of the "villa hospital" in the late nineteenth century. ${ }^{64}$ Villa hospitals accommodated patients in detached pavilions of between 24 and 50 beds. This allowed for the greater classification (separation) of patients so that those deemed trustworthy were no longer subjected to the strict security concerns of those who were not. It was considered a more humane approach to institutional care because patients who demonstrated consistent behaviour were no longer confined to a room, or a building, but given relative freedom within the wider boundaries of the hospital. Topp asserts, however, that the villa hospital model was created primarily as a public relations exercise, a response to early anti-psychiatry sentiments exhibited by the German public. The priority was for the architecture to simply "look free" [emphasis original] and thereby present an image of greater humanity in asylum care without necessarily delivering an improved patient experience. ${ }^{65}$

Smith also suggests a degree of insincerity and misrepresentation on the part of institutional psychiatrists in his research. He states that at the York Retreat, the very institution that reformers hoped to replicate, a review of the hospital's archives revealed that mechanical restraint continued to be used long after Tuke's publication of 1813 that encouraged other institutions not to employ it. ${ }^{66}$ Smith also revealed that the utilisation of imposing facades (1790-1820) communicated ideas too controversial to be openly acknowledged, ideas at odds with the "public benevolence and compassion" claimed in the construction of asylums: that madness "was to be controlled and managed as a prelude to bringing about a cure [emphasis added]."

Scull's early research was heavily influenced by the work of Foucault and his scepticism of moral treatment as the product of a curative agenda (as discussed earlier in section 2.2). Foucault argues that Tuke and Pinel should not be credited with freeing lunatics from the shackles of physical maltreatment because moral treatment replaced this with a more oppressive and pervasive form of control. His view infers that the general public was misled regarding the actions of these men:

It was thought that... [Tuke and Pinel] opened the asylum to medical knowledge. They did not introduce science, but a personality, whose powers borrowed from science only their disguise, or at most their justification.... [the physicians'] medical practice being for a long time 
no more than a complement to the old rites of Order, Authority and Punishment. $^{68}$

In more recent work, Scull has played down Foucault's influence on his own research and the subsequent field of scholarship. In 2007, in a review of the recent English translation of Foucault's History of Madness, the full version of his thesis previously translated only in part as Madness and Civilization, Scull went so far as to assert that Foucault's research "rest[ed] on the shakiest of scholarly foundations" with some of his theories entirely unable to withstand scrutiny. ${ }^{69}$ However, Colin Gordon observed that Scull's Museums of Madness, published in 1979, is "a work whose very language is in places steeped in Foucault's influence." ${ }^{70}$ In 1997 Scull wrote that:

one must acknowledge that heuristically, at least, the intellectual challenges he [Foucault] threw down three decades ago have directly or indirectly been the stimulus for much of the best recent work in the history of psychiatry. ${ }^{71}$

In 2006, however, Scull claimed the influence of Foucault's Madness and Civilization on the subsequent field of scholarship is commonly over-rated and that the scholarship emerging from the 1970s and 1980s would have drawn the same conclusions with or without Foucault's contribution. ${ }^{72} \mathrm{~A}$ number of contemporary historians, including Scull, have rejected Foucault's early scholarship on madness owing to its simplicity. Topp criticised Foucault's generalisation of the examples of La Salpêtrière and the York Retreat as universal responses. ${ }^{73}$ While Markus felt his theory on the imposition of reason over madness lacked "concrete evidence"; it failed to account for the "actual regimes, the laws and the buildings which were the social instruments through which intentions were achieved." ${ }^{74}$ Markus and Topp both agree, however, that Foucault's reduction of moral treatment to an invisible, oppressive, form of control has merit. ${ }^{75}$ Foucault's research on madness is of limited relevance to this particular study since, as Horrocks and Jevtic point out, although it deals with the origins of psychiatry and its scientific status, the wider focus of Foucault's thesis is the way that madness was "experienced, imagined and dispersed." ${ }^{76}$ Foucault's Archeology of Knowledge has greater relevancy for this study in terms of understanding the architecture created for the treatment of madness and will be discussed within the following section.

Scull's influence on the architectural history of asylum architecture, however, has been significant. The legacy of his research can be traced through more recent scholarship by Topp, Smith and Paul Hirst, which is also underpinned by a degree of mistrust of the psychiatric profession. The legacy of Scull's research (inclusive of its Foucauldian influence) raises the possibility that researchers in this field may be primed to mistrust those who were involved with the design and administration of mental hospitals, namely the psychiatric profession. Paul Hirst and Penny Woolly are critical of the weight Scull places on the professional struggle by asylum 
superintendents. They see this emphasis as "misplaced" because "the asylum develops like the hospital - as a site of investigation, observation, and classifying the symptoms of its population." 77 Yet subtle echoes of Foucault can be found in Hirst's research, for example, when he makes the suggestion that the York Retreat was constructed with a domestic ambience in order to mask the unpalatable necessity that the insane must be detained. ${ }^{78}$

That asylum doctors sought to deliberately mislead the public is an extreme position to take. As discussed in the previous section, asylums were compromised by factors well beyond the control of the doctors who administered them; these compromises led to a redefinition of asylum goals, from curing patients to maintaining environments that were clean, comfortable and free from mistreatment. Yet even these redefined goals often failed to be met. Living conditions were frequently dirty and overcrowded and patient abuse occurred. Even in asylums where these indicators of success were attained, the social conditions that developed within these institutions caused harm. In 1830, Conolly observed that a number of patients tended to be reduced to dependent, child-like states owing to their exposure to the unvaried routines of asylum care that rendered them incapable of returning to a normal life. ${ }^{79}$ Part of the Hippocratic Oath, sworn by doctors since around 400 AD, promises to do no harm. ${ }^{80}$ This presents a significant dilemma for historians; how did these men of medicine allow a situation to persist where the patients under their care were subjected to harm?

Underpinning Scull's scholarship is the idea that financial gain motivated asylum superintendents to engage in deception in order to consolidate their professional position. Ruth Caplan is less cynical. She suggests that the men attracted to early psychiatry embarked on this profession with the earnest intent of curing madness. They were "idealistic, active and confident of their eventual mastery of insanity." ${ }^{\prime 1}$ Scull admits that, while asylums attracted men with only a slight claim to the title of doctor, they also attracted their share of graduates from the best medical schools. ${ }^{82}$ Caplan argues that the custodial era (1845-1939), where institutions were known not to be working yet were still constructed despite this fact, is not representative of "lowered concern for the unfortunate" but illustrates a loss of faith in moral treatment at a time when there was little else to replace it. ${ }^{83}$ An address given by W.W. Godding, former president of the American Association of Medical Superintendents, highlights the difficult position these men found themselves in. He urged the association's members in 1890 to "leave nothing undone" in the bid to restore sanity:

Will hypnotism aid us in our treatment of mind? I do not know; try it. It probably belongs to the mere driftwood of science, but to throw a drowning man anything is better than nothing. ${ }^{84}$ 
The fact that little useful therapeutic relief was available for mental illness during the custodial era was only part of the challenge faced by asylum doctors. These institutions were underfunded and understaffed. Ivan Belknap completed a study of one of America's Southern public mental hospitals (the name and exact location was withheld) between 1952 and 1956. He identified that doctors were expected to handle impossibly large caseloads that diminished the degree of patient contact that was possible. Doctors were found to be responsible for anywhere between 300 and 1,000 patients. ${ }^{85}$ Within Faces in the Water, Frame made a perceptive and compassionate observation regarding the doctors who worked within New Zealand's mental hospitals (1945 - 1953):

the doctor enquiring as if his life depended on it... "Do you trust me, will you trust me"... when you knew privately, that he scarcely had time to trust himself in the confusion and tiredness that accompanied the day-and-night attempt to solve the human division sum that had been omitted from his medical training: if one thousand women depended on one-and-a-half doctors how much time must be devoted to each patient in one year... ${ }^{86}$

It must be acknowledged that Scull's own perception of the psychiatric profession seems to have changed markedly over the course of his career. His contemporary view is far more moderate than that illustrated by his early work. In 1993 he wrote:

I am profoundly sceptical of psychiatry's self-proclaimed rationality and disinterested benevolence... But I cannot accept... [Thomas Szasz'] vision of psychiatry as merely a malevolent or cynical enterprise, with the psychiatrists themselves no more than concentration camp guards or manufacturers of madness... ${ }^{87}$

Szasz' work falls within the category of anti-psychiatry literature that has been deliberately avoided by this researcher. It is worth acknowledging, however, that Scull's early work (1979), where he asserts that superintendents were willing to overlook the failings of the asylum in order to secure their financial and professional standing, resides a lot closer to the view that psychiatry was a "cynical enterprise, with the psychiatrists themselves no more than... manufacturers of madness." ${ }^{88}$ Smith suggests that Scull, in his later work, has come to see asylum superintendents as "unwitting participants" caught, by virtue of their sincere humanitarian concern, in a political system that required the control of deviancy. ${ }^{89}$

Discussing the influence of Foucault's Archaeology of Knowledge on the field of historical research, Amanda Hyde de Krester remarks that there is a need for any inquirer to "see the rules and conditions that cause existing definitions and practices to have emerged in the way they have and to question them." Within academic discourse, certain ideas and practices can become so ingrained that the need to question the validity of these assumptions can be overlooked. This research takes account of the 
possibility that the influence of Foucault and Scull, through the existing body of research, may prime researchers in this field to look for instances of insincerity and deception on the part of the psychiatric profession. It is not unwise, however, to approach the study of any professional group with a degree of scepticism. The same is true of individuals. For example, the myth that has built up around Robert Lawson, the architect of Seacliff Asylum, is that he was driven by a desire to shape the entire cityscape of Dunedin. ${ }^{91}$ Because this view is reinforced by his position as a colonial architect and the discourses surrounding colonial architecture then the temptation may be to accept this assumption when undertaking research. The intimation present within the work of Scull and Topp is that the asylum typology was susceptible to compromise from professional agendas that were potentially in conflict with the stated curative intent of these institutions. This dissertation will examine whether this was the case in New Zealand. 


\subsection{RESEARCH IN THE COLONIAL CONTEXT}

As architectural solutions worthy of academic attention and professional pride, New Zealand's mental hospitals have been largely overlooked. Rosslyn Noonan's history of the New Zealand Government's Public Works Department (later the Ministry of Works) makes no mention of the dozens of mental hospital facilities designed by this department between 1891 and $1970 .^{92}$ Lewis Martin's history of New Zealand's government and colonial architects also fails to mention these projects. ${ }^{93}$ Peter Richardson, in his doctoral dissertation on Government Architecture in New Zealand between 1840 and 1922, provided an extended discussion of the New Zealand Asylum Project of 1858, this was a national asylum designed for Nelson but never constructed. While Richardson also examined the design of the Porirua Asylum (1891) by Government Architect John Campbell he does not review this in medical terms or in relation to the development of the asylum typology. ${ }^{94}$ While the architect of Seacliff Asylum, Robert Lawson, has been the topic of academic research by Norman Ledgerwood, William Prior and Peter Entwisle, the asylum has not been examined in relation to the curative aspirations of the architectural typology to which it belongs. Seacliff Asylum is reviewed within these works as part of a larger body of colonial commissions completed by Lawson in Otago. ${ }^{95} \mathrm{~A}$ conference paper by Jeremy Treadwell, promisingly titled "Therapeutic Landscapes," discusses early asylums at Seacliff and Seaview (Hokitika). While Treadwell provides an interesting overview of the relationship between the asylum typology and its surrounding landscape, the focus of this paper is on the colonisation of landscape through the construction of English-styled asylums. ${ }^{96}$ Warwick Brunton's doctoral dissertation, regarding New Zealand's mental health policy from 1840-1947, offers the most substantial survey available of the architecture created for the Mental Hospitals Department. It discusses these buildings as the physical manifestation of mental health policies. ${ }^{97}$ Brunton is a social historian, unfamiliar with the discipline of architecture so his work provides only a cursory view of this architectural history. It is, however, valuable in providing a solid platform for further research to which this dissertation owes a great debt. This section will examine the transposition of British ideas regarding lunacy into New Zealand and other colonial contexts.

Brunton has established clear links between British ideals and New Zealand's approach to policy, asylum architecture and governance..$^{98}$ Susan Piddock's choice to examine South Australian asylums against British asylum models intimates that it was a cultural norm for Australia to look to Britain for guidance within the nineteenth century. ${ }^{99}$ James Belich has written extensively on the social and political history of New Zealand; he offers a number of ideas that are worthy of consideration in a study that deals with the transposition of British ideals to new colonial contexts. Belich's work highlights the extent to which the outlook of colonial New Zealand was informed by ideas of home, not just in the mid-nineteenth century settlement of this new land but also in the efforts made between 
1880 and 1930 to tighten New Zealand's links with Britain, which he terms "recolonisation." 100 Conservatism is a recurrent theme within Belich's work on the history of New Zealand from colonisation until the 1950s. He suggests that traditional values surrounding loyalty to Britain, and to British ideals and values, were retained in New Zealand well into the 1950s, far longer than in other British colonies such as Australia and Canada. ${ }^{101}$ Conservatism was reflected in the repression of difference, both racial and social, and vices such as alcoholism and immorality. ${ }^{102}$ Belich's work raises the question, to what extent did a conservative, British outlook influence the development of mental health care in New Zealand and the architectural solutions created for it?

Carla Yanni's research suggests a very different cultural approach within the United States where new architectural forms were deliberately sought. The first asylum to be constructed in America was the Friends Asylum, in Philadelphia, in 1817. This was the direct result of a letter of encouragement sent by Samuel Tuke to the Quaker community resident in Philadelphia. ${ }^{103}$ Since this asylum was constructed three decades prior to the York Retreat becoming influential in the design of British asylums (1848 according to the date given by Edginton ${ }^{104}$ ) it is perhaps best regarded as a parallel movement, not a transposition of a wider British movement into a colonial context. In 1851, an American version of the asylum was beginning to emerge. Physician Thomas Storey Kirkbride (who was also a Quaker) believed that establishing a new building type was "essential" for improving rates of cure. Kirkbride collaborated on many projects with architect Samuel Sloan and created a plan known as the "linear" or "Kirkbride" plan which influenced the construction of thirty American asylums prior to 1866 and a further forty by $1890 .^{105}$ The asylum was not the only architectural typology that was adjusted to better suit the ethos of this new world. Yanni, citing Paul Turner, points out that American universities rejected Britain's closed quadrangle typology in favour of "more open and domestic forms" that symbolised a desire to connect to the wider community. ${ }^{106}$

Piddock tested four Australian asylums against mid-nineteenth century British literature regarding the "ideal" design and construction of these institutions and found that they lacked some "necessary features" in the provision of an "appropriate [curative] environment."107 Piddock suggests that the economic realities of Australia's colonial setting and its geographical isolation were significant factors that contributed to this discrepancy. Australia's distance from the design expertise and ongoing development of this field, what Piddock terms the "lunacy knowledge pool," was another limitation identified. ${ }^{108}$ While Piddock identified key texts that "would have been available" in the design of Australian asylums, ${ }^{109}$ 
Brunton confirmed the purchase of three publications on this subject by agents of the New Zealand Government between 1872 and 1897:

John Conolly's The Construction and Government of Lunatic Asylums and Hospitals for the Insane (1847),

Charles Mercier's Lunatic Asylums: Their Organization and Management (1894),

Albrecht Paetz's Die Kolonisirung der Geisteskranken (1893). ${ }^{110}$

Brunton also identifies several attempts by New Zealand's Provincial Governments and the Lunatic Asylums Department to engage with the lunacy community beyond Britain: the ideas of Thomas Storey Kirkbride were cited regarding the design of Auckland's Whau Asylum (1864), the Nelson Province sought advice from the Yarra Bend Asylum in Melbourne (1872) and the Asylums Department obtained information on the Illinois Eastern State Hospital (1897). ${ }^{111}$ This suggests New Zealand may have suffered less of a disconnection from the knowledge pool than Australia. This dissertation will examine the consequences of New Zealand's isolation and trace the influence of British influence, especially the three publications identified by Brunton, through New Zealand's architectural responses to lunacy.

Brunton views the efforts of the medical men who directed the shape of New Zealand's mental hospital network as admirable in light of the difficulties of administering these institutions. He suggests that New Zealand's entire history of asylum care, and its architecture, can be understood in terms of an ongoing desire to "deinstitutionalise" it. Brunton's unique definition of "deinstitutionalisation" varies from the accepted definition of this term, which is typically understood to refer to the mass closure of asylums throughout the western world in the 1980s and 1990s. The Merriam-Webster Medical Dictionary defines "deinstitutionalisation" as "the release of institutionalised individuals from institutional care (as in a psychiatric hospital) to care in the community." 112 Brunton suggests, however, that this term should instead describe the incremental improvements, carried out under strained circumstances, to make hospital environments "less institutional" for the greater benefit of patients: "to prevent or to mitigate the undesirable psychosocial effects of long-term residential care."113 Brunton suggests that New Zealand superintendents recognised that these institutions were dehumanising for patients and were dissatisfied with this. They responded with a series of incremental improvements - the most that could be achieved given the funding restrictions, staffing shortages, public prejudice and overcrowding these hospitals were subject to. ${ }^{114}$ While Brunton's hypothesis extends to policy measures, such as boarding out programmes and the department's provision of outpatient services in addition to architecture, this dissertation will examine this hypothesis with specific reference to the architectural improvements made. 
Brunton's research also identified what he felt was an organically occurring version of the villa hospital model. From 1878 onward Seaview Hospital began to construct their own small accommodation units as a response to delays in the delivery of hospital buildings by the government's Public Works Department. ${ }^{115}$ Unfortunately, as Brunton points out, this costeffective solution, which also offered therapeutic benefits, was largely overlooked in the planning of New Zealand asylums for nearly twenty years. This approach was not adopted on a nationwide scale until Albrecht Paetz made these therapeutic benefits clear in his 1897 publication Die Kolonisirung der Geisteskranken (translation: The Colonization of the Insane in Connection with the Open-door System). ${ }^{116}$ Brunton suggests that ministerial preference provides the explanation for why such a fitting solution was not adopted earlier, or more widely, given that InspectorGeneral F.W.A. Skae recognised in 1879 that patients seemed to be happier in these small, simple dwellings. ${ }^{117}$ This dissertation will more closely examine the issues around the adoption of this new accommodation type.

The existing research regarding asylum design in the colonial context highlights a number of research gaps. Firstly, there is no dedicated study of New Zealand's history of architecture for the treatment of mental illness. Secondly, the research that currently exists for both Australia and the United States is limited to a few examples in each case. The main body of research in this field is currently centred on Britain within the eighteenth and nineteenth centuries. With regards to embarking on the first dedicated study of New Zealand's architectural history of mental health care facilities, the research completed by Piddock and Brunton highlights that some necessary groundwork needs to be completed in this area. It must first be ascertained whether these hospitals followed best architectural practice in their design and construction. Issues of geographical and professional isolation will need to be addressed. 


\section{CONCLUSION}

Much of the existing research in this field is focused on British responses to lunacy and concerned with the period spanning 1815-1910. Little research exists for the mid-twentieth century or for responses occurring within colonial contexts. This dissertation will test the relevance of nineteenth century causes of compromise in asylum construction against Seacliff Asylum (1878-84) and extend this research into the twentieth century by examining whether the same concerns persisted in the design of Kingseat and Cherry Farm hospitals (1930-70).

Scull has illustrated the role that cost cutting in the construction of British asylums played in compromising the curative ability of these institutions, while Piddock has observed the role that isolation from professional networks can play in limiting the currency and quality of the architectural responses constructed. ${ }^{118}$ This dissertation will explore how the designs of Seacliff, Kingseat and Cherry Farm related to contemporary thought regarding the treatment of mental illness and current ideas of best architectural practice in this field. As Brunton has already established, New Zealand borrowed heavily from British philosophy and design precedents in the construction of nineteenth century asylums. ${ }^{119}$ What remains to be established is whether the shortcomings of Britain's institutional approach to lunacy care were understood in New Zealand's adoption of this model. Smith has indicated architecture's ability to convey ideas too controversial to be openly acknowledged within their own time, such as the priority of controlling madness over curing it. ${ }^{120}$ This dissertation will examine to what degree the decisions made in the design of Seacliff, Kingseat and Cherry Farm were influenced by public perception and how consistent these architectural responses were with the public statements made about them. Piddock, Belich and Brunton have highlighted the potential for geographical isolation and a conservative British outlook to limit currency and innovation in colonial settings. ${ }^{121}$ Finally, Scull and Topp have illustrated the ease with which this architectural typology can be manipulated to satisfy professional agendas such as public relations and the defence of professional territories. ${ }^{122}$ This dissertation will examine the personal, professional and political motivations that impacted on the architectural solutions created for mental health care in New Zealand. Between these three research questions, Brunton's hypothesis of "deinstitutionalisation" (his definition) will be also tested.

Thousands of New Zealanders were involved with this country's mental hospitals over the century and a half they were in operation; this history deserves academic attention from a wide array of disciplines. A close examination of how this architecture responded to contemporary thought regarding mental health care, and the extent to which it may have been compromised by agendas that were peripheral to the restorative task this 
architecture was charged with, will enhance our existing understandings of official attitudes to mental illness in New Zealand between 1878 and 1971.

${ }^{1}$ Frame 2000, 99.

${ }^{2}$ Suibhne 2011, 1-2.

${ }^{3}$ Frame 2005, 104.

${ }^{4}$ Refer, for example: Goodwin 2004, 16. Williams 1987, 177. Department of Internal Affairs 2007.

${ }^{5}$ Department of Internal Affairs 2007, 1,3, 5-6, 18.

${ }^{6}$ Ibid, 18-9.

${ }^{7}$ Ibid, 20.

${ }^{8}$ Ibid, 21.

9 Ibid, 22, 29.

${ }^{10}$ Brunton 2001, Prebble 2007, Thompson 1992.

${ }^{11}$ Brunton 2003, 81-9.

${ }^{12}$ Scull 1979, 25, 30-5. Markus 1982, 25-6, 85.

${ }^{13}$ Scull 1979, 25, 30-5.

${ }^{14}$ Markus 1982, 25-6, 85.

${ }^{15}$ Foucault 2006, 362, 381

${ }^{16}$ Scull, 1979, 41.

${ }^{17}$ Ibid, 36.

${ }^{18}$ Smith 2007, 43.

${ }^{19}$ Markus 1982, 43.

${ }^{20}$ Smith 1999, 284.

${ }^{21}$ Scull 1979, 55.

22 Edginton 1994, 379.

${ }^{23}$ Tuke 1813, 23.

${ }^{24}$ Scull 1979, 104.

${ }^{25}$ Yanni 2007, 42-6.

${ }^{26}$ Caplan 1969, 31.

${ }^{27}$ Ibid.

${ }^{28}$ Smith 1999, 3.

${ }^{29}$ Foucault 2006, 483, 484.

${ }^{30}$ Foucault 1964, 247-50.

${ }^{31}$ Edginton 2007, 87.

${ }^{32}$ Brunton elaborated on many of the ideas occuring in his thesis in a private conversation on November 19, 2010. Quote confirmed via email, January 28, 2013. 
${ }^{33}$ Edginton 2007, 85.

${ }^{34}$ Ibid, 88.

${ }^{35}$ Topp 2005, 136.

${ }^{36}$ Digby 1985, 50.

${ }^{37}$ Digby 1985, 41. Refer the illustration titled "Plate 4. New dining-room for ladies, 1899."

${ }^{38}$ Scull 1993, 99.

${ }^{39}$ Edginton 2007, 85-6.

40 Topp 2005, 136.

${ }^{41}$ Kowsky 1992, 59.

42 Sennett 1990, 89-90.

${ }^{43}$ Addison 1824, 191-2, quoted in Hickman 2009, 426.

${ }^{44}$ Kowsky 1992, 58-9.

${ }^{45}$ Miller 2003, 19.

${ }^{46}$ Hickman 2009, 428-9, 431.

${ }^{47}$ Brantley 1975, 140, quoted in Hickman 2009, 432.

${ }^{48}$ Browne 1837, 182.

${ }^{49}$ Edginton 1994, 381.

${ }^{50}$ Scull 1979, 189-90.

${ }^{51}$ See, for example, Conolly 1830, 31.

52 Scull 1979, 117.

${ }^{53}$ Smith 1999, 81-2.

54 Scull 1979, 117.

${ }^{55}$ Smith 1999, 81-2.

${ }^{56}$ Scull 1979, 189-90.

${ }^{57}$ Digby 1985, 56.

${ }^{58}$ Caplan 1969, 49.

${ }^{59}$ Piddock 2007, 191.

${ }^{60}$ Le Fanu 1982.

${ }^{61}$ Scull 1993, 5.

${ }^{62}$ Scull 1979, 44, 93-4, 165.

${ }^{63}$ Ibid, 41-2, 91, 117, 129, 135-7, 141-2.

${ }^{64}$ Topp 2007, 242-6.

${ }^{65}$ Ibid.

${ }^{66}$ Smith 1999, 260.

${ }^{67}$ Ibid, 38.

${ }^{68}$ Foucault 1964, 258.

${ }^{69}$ Scull 2007, "Fictions of Focault's Scholarship". 
70 Gordon 2010, "Extreme Prejudice... [Scull's] review of Foucault's History of Madness." Colin Gordon was a former research assistant to Foucault and, accepting that biases are likely present in Gordon's assessment, I nonetheless found this particular comment to mirror my own experience of reading Scull shortly after reading Foucault.

71 Scull 1993, 5.

72 Scull 2006, 5.

73 Topp 2007, 245.

${ }^{74}$ Markus 1982, 105.

75 Ibid, 105. Refer also: Topp 2007, 245.

${ }^{76}$ Horrocks and Jevtic 2004, 47.

77 Hirst and Woolly 1982, 106. Refer footnote 7.

${ }^{78}$ Hirst 2005, 177.

${ }^{79}$ Conolly 1830,21

80 The full oath reads: "I will prescribe regimens for the good of my patients according to my ability and my judgement and never do harm to anyone." http://en.wikipedia.org/wiki/Hypocratic_oath Accessed December 28, 2010.

81 Caplan 1969, 89-90.

82 Scull 1979, 125-8.

${ }^{83}$ Caplan 1969, 49.

84 "Proceedings of the Association of Medical Superintendents" 1890, 166-239, quoted in Caplan 1969, 264.

${ }^{85}$ Belknap 1956, 67.

${ }^{86}$ Frame 2005, 225.

87 Scull 1993, 5 .

88 Ibid, 5.

${ }^{89}$ Smith 1999, 64.

${ }^{90}$ Hyde de Krester 2003, 3-4.

${ }^{91}$ Barsby and Tyler 2006.

92 Noonan 1975.

${ }^{93}$ Martin 2004.

${ }^{94}$ Richardson 1997, 177-184, 283-306.

${ }^{95}$ Prior 1990. Entwisle 1986. Ledgerwood 2013.

96 Treadwell 1998.

97 Brunton 2001.

${ }^{98}$ Brunton 2003, 81-9.

${ }^{99}$ Piddock 2007.

100 Belich 2001, 11.

101 Ibid, 12.

102 Ibid, 122-3, 307.

103 Yanni 2007, 27, 33. 
${ }^{104}$ Edginton 1994, 379.

${ }^{105}$ Yanni 2007, 38, 76-8.

${ }^{106}$ Turner 1984, 37, quoted in Yanni 2007, 95-6.

107 Piddock 2007, 81, 88, 214.

${ }^{108}$ Ibid, 191.

${ }^{109}$ Ibid, 18.

${ }^{110}$ Brunton 2003, 81-9.

${ }^{111}$ Brunton 2001, 78, 92.

${ }^{112}$ Merriam-Webster's Medical Dictionary. http://dictionary.reference.com/browse/ deinstitutionalization Accessed December 14, 2010.

${ }^{113}$ Brunton 2003, 75, 98.

${ }^{114}$ Ibid, 80, 98.

${ }^{115}$ AJHR 1880, H-06, 4.

${ }^{116}$ Brunton 2003, 81-9.

${ }^{117}$ Brunton 2003, 88.

${ }^{118}$ Piddock 2007, 191. Scull 1979, 117.

${ }^{119}$ Brunton 2003, 81-9.

${ }^{120}$ Smith 1999, 38.

${ }^{121}$ Piddock 2007, 191. Belich 2001, 11, 122-3, 307.

122 Topp 2007, 242-6. Scull 1979, 44, 93-4, 165. 


\section{CHAPTER THREE Establishing a Set of Curative Criteria}

This chapter aims to establish a set of curative criteria relative to the era in which each case study hospital was constructed. Section one will give an overview of the three leading advisors on asylum design in the nineteenth century: Samuel Tuke, W.A.F. Browne and John Conolly. Section two will outline the emergence of the villa hospital model near the end of the nineteenth century which was seen as a model capable of solving many of the problems of traditional asylum design while still responding to moral treatment. When Kingseat Hospital was designed in 1929, the field of psychiatry was divided with regard to the best treatment of mental illness and, correspondingly, the best architectural approach. Section three will discuss the various approaches to the treatment of mental illness in 1929, when Kingseat Hospital was planned. Section four will outline the choice of hospital models available in the late 1920s: the villa hospital versus the new psychopathic hospital model that emerged in the early twentieth century as a response to the search for a biological basis for mental illness. When Cherry Farm Hospital was designed, between 1943 and 1952, approaches to the treatment of mental illness were changing rapidly; section five will outline the reasons why this change occurred and how it altered the medical response. Section six examines the emergence of this research prior to the release of the 1953 World Health Organisation report (hereafter WHO) that suggested a new approach to the construction and administration of mental hospitals. Section seven will detail the expectations of this new architectural response, known as the therapeutic community. Within this chapter a set of curative criteria for the evaluation of each hospital will be established and the availability, to New Zealand psychiatrists, of the sources used in the formulation of these curative criteria will be confirmed. Since the purpose of this chapter is to give an overview of the medical and architectural evolution of the asylum typology and to establish a set of curative criteria for each case study hospital, no conclusion will be given. However, an overview table will be provided in order to illustrate how the key ideas in mental hospital design related to each other over the research period $(1878-1971)$. 


\subsection{TUKE, BROWN \& CONOLLY: PATTERN - MAKERS FOR THE IDEAL NINETEENTH CENTURY ASYLUM}

This section sets up the criteria by which individual asylum designs were judged as successful at the time of Seacliff's design and construction. Samuel Tuke, W.A.F. Browne and John Conolly were the three most influential men in nineteenth century asylum design. Tuke's Description of the Retreat (1813) was a key text in the spread of moral treatment and its corresponding architectural approach. According to Scull, this text became a constant guide for asylum reformers in Britain between 1813 and 1845. ${ }^{1}$ Browne's What Asylums Were, Are and Ought to Be $(1837)^{2}$ and Conolly's The Construction and Governance of Asylums (1847) ${ }^{3}$ followed as significant, if not equally influential, guides to asylum administration and design. Within these three sources five main themes develop: proximity to society, the role of nature, disguising confinement, concerns of safety and issues related to privacy and dignity for patients. These themes can be translated architecturally to provide a set of architectural criteria considered vital to support the delivery of moral treatment (table 3.1).

The Retreat continued to influence asylum administrators, including Brown and Conolly, long after Tuke's publication. However, the Retreat was a very different institution to those Brown and Conolly were familiar with. This early blueprint for asylum construction had private funding, the ability to refuse admissions and catered, initially, to only thirty patients. Browne's text, in 1837, offered a candid discussion on the inherent conflicts within large, public asylums. It acknowledged the difficulties of achieving an optimal curative environment when faced with financial restriction, staffing shortages and patients' intent on suicide. When Conolly wrote a decade later, it had become routine to construct asylums for upwards of six hundred patients. Conolly himself was the superintendent of the Hanwell Asylum which had a patient population of one thousand. ${ }^{4}$

The New Zealand Parliamentary Library obtained a copy of Conolly's book between 1872 and 1876, two years prior to Lawson's appointment as the architect for Seacliff Asylum. ${ }^{5}$ No record has been found confirming whether the other two titles were held in New Zealand. However, there is clear evidence to suggest that the medical professionals who would have consulted with Lawson during the design process would have been familiar with this literature. Browne was a dominant figure in Scotland where Skae and MacGregor both gained their professional experience. ${ }^{6}$ Furthermore, asylum reports published in the AJHR attest that the men in charge of New Zealand's asylums were familiar with the ideals of moral treatment as advanced by Tuke, Browne and Conolly. Grabham's discussion of the considerations necessary in choosing a site for the Porirua Asylum in 1886, for example, reiterated the requirements set out by Tuke, Browne and Conolly. He stipulated that the site chosen must be close to a railway line, but not overlooked by public roads, it should offer extensive landscape views and 
enough space to construct adequate airing courts (secure, outdoor recreational areas for patient use). ${ }^{7}$

\section{Criteria one: Proximity to Society (location).}

Elevated, rural sites were favoured for their ability to provide landscape views and pure air, while aiding drainage of rain and foul water. ${ }^{8}$ The Retreat at York occupied a rural location, only half a mile distant from the city of York since maintaining a close proximity to society helped patients to practise appropriate behaviour in social settings. Excursions to the city were frequent and external visitors were appointed to "take tea" with the patients. ${ }^{9}$ Browne also supported the need for "intercourse with healthy minds." His ideal site was similar to that occupied by the Retreat; rural but not too distant from a town of reasonable size. ${ }^{10}$ Conolly also favoured maintaining a close proximity to town in order to enable easy visitation by families. ${ }^{11}$ Furthermore, since an important part of moral treatment was outdoor occupation, rural sites provided the space for farm work and more leisurely outdoor pursuits to be undertaken by patients. Rural sites fulfilled another important function by protecting patients from the prying eyes of the public. This is revealed in the language chosen by Tuke: the front garden was "defended from the road," walking paths were "sheltered from the intrusive eye of the passenger" and patients were "never to be exhibited to gratify the curiosity of visitors" [emphases added]. ${ }^{12}$

\section{Criteria two: The Importance of Nature (landscape).}

The curative offerings of a natural landscape were particularly important to Browne. A varied and picturesque landscape would encourage patients to take exercise, remind them of their connection to loved ones and impart healthy impressions. ${ }^{13}$ While Tuke did not discuss landscape directly, it permeated his text. An important aspect of the moral treatment regime was outdoor recreation and employment. The Retreat strove to provide a variety of outdoor pursuits, such as farming and gentle walks. ${ }^{14}$ Conolly suggested that for a patient to be out of doors provided a kind of freedom and gave specific architectural instruction on the optimal relationship between building and landscape. Windows were to be "low and large" to ensure extensive landscape views while rooms occupied by patients were to be located no higher than two stories above ground to allow easy access to the outdoors. ${ }^{15}$ Sunshine and natural light were important and Tuke regretted that the Retreat had double-loaded corridors (a term that indicates a central corridor with rooms opening off both sides) as natural light could only enter at the ends of the corridor making this space "rather gloomy." ${ }^{16}$ Browne and Conolly agreed that "light and air should pervade every part of the asylum.."17 


\section{Criteria three: Concerns of Safety}

Patient suicide and self-harm presented a very real concern for asylum administrators. Browne felt that severity and restraint were preferable to suicide; it was dangerous to be "too extravagant of enlightened humanity." 18 Tuke opposed Browne on this point, warning that the real danger arose from "excessive attention to safety" [emphasis original]. In the case of window placement, for example, high window sills might prevent injury but they also denied patients the curative effects of a landscape view. He urged that "cure and comfort... be as much considered as security." 19 It is worth remembering, however, that Tuke's experience was gained in a small, private establishment with higher levels of staffing. Conolly sits somewhere between Browne and Tuke although many of his recommendations suggest that his views aligned more closely with Tuke's. He made the argument, for example, that suitable patients should have access to their bedrooms during the day. He felt that female patients especially "can be found to employ themselves most comfortably in their own rooms." ${ }^{20}$ The advice Conolly gave regarding safety was more often procedural than architectural. He advised, for example, that patient clothing should be left in corridors overnight, outside the patient's room and beyond their reach, to prevent this from being employed for suicidal means. ${ }^{21}$

\section{Criteria four: Disguising Signs of Confinement}

Browne believed that the architectural acknowledgement of confinement would adversely affect a patient's dignity and impede the curative process. He was critical of high walled airing courts and safety bars in stairwells which gave the "gloomy and painful" impression of iron cages. He went so far as to recommend the erection of single storied asylums to remove the need for stairwells entirely. ${ }^{22}$ At the Retreat much effort was directed toward "prevent[ing], entirely, the aspect of... confinement." ${ }^{23}$ Cast iron window bars were encased within timber window sashes, the "objectionable" sound of grating locks was muffled and the perceptible scale of perimeter fencing diminished by the choice of an elevated site ${ }^{24}$ John Beavans, the architect of the Retreat, sought to deliberately avoid a gloomy air, "if the outside appears heavy and prison-like it has considerable effect on the imagination." ${ }^{25} \mathrm{~A}$ Georgian domestic style was employed that, according to Anne Digby, evoked a sense of "everyday accessibility" in stark contrast to the imposing appearance of the neighbouring York Asylum. ${ }^{26}$ Conolly also drew links between dignity and the recognition of confinement. Instead of a domestic appearance he recommended that of a general hospital, "more cheerful than imposing" and set within the landscape.$^{27}$ Conolly's text was clearly inspired by practices carried out at the Retreat. Among his suggestions were the fashioning of locks to close without noise and the sinking of perimeter walls to allow more expansive landscape views. ${ }^{28}$ 


\section{Criteria five: Individual Treatment \& Tranquility}

Securing a tranquil environment around each patient was considered fundamental to an asylum's ability to heal lunacy, as was the degree to which an asylum could tailor to the individual needs of its patients. Classification made easier the achievement of tranquility through the separation of chronic and noisy patients from the melancholic, and sensitive patients from the involuntary outbursts of epileptics. Ward and dormitory divisions became increasingly accepted as the best means of keeping these types of patients apart. Edginton suggests that, at the Retreat, the question of how tranquil spaces could be created and maintained was a topic of constant conversation. ${ }^{29}$ Private sleeping spaces were favoured and attention was directed toward mitigating sound transmission between bedrooms. ${ }^{30}$ Tuke stipulated a maximum ward size of ten patients since he felt that familial relationships tended to develop in a ward of such limited size. Patients formed attachments and maintained an interest in their fellow ward mates when accommodated in groups of ten, whereas, in ward sizes of thirty patients they tended to keep to themselves. ${ }^{31}$ Conolly believed that two-thirds of the asylum population should be accommodated within private rooms, while dormitories should be employed sparingly and limited to five beds. ${ }^{32}$ Conolly did not believe in separating the curable from the incurable patients but he did argue for separation of convalescent patients from the "more agitated and turbulent." ${ }^{33}$ Although Conolly was experienced in managing an asylum of one-thousand patients, he advised that an upper limit of four hundred beds was a preferable size. ${ }^{34}$ Browne conceded that dormitory sleeping, while not ideal, provided a practical solution to spatial, staffing and budgetary constraints. Nonetheless, he specified that dormitories should be spacious, well ventilated and cheerful. ${ }^{35}$ Conolly was perhaps the most perceptive regarding the patient experience. In the case of chronic patients, for example, he urged the provision of personal, domestic fixtures such as wash-stands, looking glasses and drawers to store personal belongings: "most necessary for incurable patients, for whom the asylum is the only home."

It is in relation to the concerns of safely, individual treatment and tranquillity, that the inappropriateness of the Retreat as a model for large scale asylum design becomes most apparent. While Tuke perhaps had the opportunity to put his idealism into practice, Brown and Conolly could only offer insightful suggestions for the improvement of a system found wanting. Though both remained inspired by the blueprint set down by the York Retreat they recognised the shortcomings of asylum care. Constructing an ideal asylum was merely the first step, the challenge was to maintain the delicate balance between an institution that was curative and one that was harmful. In 1830 Conolly cautioned that an asylum could possess an intelligent, humane superintendent, spacious grounds, varied amusements and excellent accommodation, yet still: 
the association of lunatics with each other, and the infrequency of any communication between the patient and persons of sound mind mars the whole design [emphasis added]. ${ }^{37}$

He acknowledged that, even where patients are treated identically, "many of them will never be benefited by [asylum care]." A number of patients will become "so accustomed to the routine of the house" that they will assume a dependant, child-like state, rendering them incapable of returning to a normal life. Conolly further acknowledged that, for two-thirds of the asylum population, "confinement... fixes and renders permanent" mental afflictions that might otherwise have passed away. ${ }^{38}$ Browne made the point that even when an asylum looked "tranquil, orderly and humane" patients could still suffer from severe neglect. ${ }^{39}$

Table 3.1 sets up the curative criteria by which the architectural response created for Seacliff Asylum will be evaluated. 
TABLE 3.1: ARCHITECTURAL CRITERIA FOR AN IDEAL

CURATIVE ENVIRONMENT: SEACLIFF ASYLUM, $19^{\text {TH }}$ CENTURY

(SHOWING DIFFERENCES OF OPINION BETWEEN THE LEADING ADVISORS)

\begin{tabular}{|c|c|c|c|}
\hline Tuke, 1813 & Browne, 1837 & Conolly, 1847 & $\begin{array}{l}\text { Corresponding } \\
\text { architectural theme } \\
\text { \& components: }\end{array}$ \\
\hline $\begin{array}{l}\text { Proximity to } \\
\text { society to } \\
\text { maintain social } \\
\text { ties. }\end{array}$ & $\begin{array}{l}\text { Browne's view } \\
\text { echoes Tuke's }\end{array}$ & $\begin{array}{l}\text { Close proximity } \\
\text { to town to enable } \\
\text { easy visitation. }\end{array}$ & $\begin{array}{l}\text { Theme: Location } \\
\text { Components: decisions on } \\
\text { site. }\end{array}$ \\
\hline $\begin{array}{l}\text { Importance of } \\
\text { nature for } \\
\text { recreation/ } \\
\text { occupation. Rural } \\
\text { out-looks and } \\
\text { sunshine, privacy } \\
\text { from the public. }\end{array}$ & $\begin{array}{l}\text { Browne's view } \\
\text { echoes Tuke's } \\
\text { but states the } \\
\text { importance of } \\
\text { landscape more } \\
\text { strongly. }\end{array}$ & $\begin{array}{l}\text { Echoes Tuke but } \\
\text { also gives } \\
\text { specific } \\
\text { instruction on } \\
\text { window size and } \\
\text { outdoor access. }\end{array}$ & $\begin{array}{l}\text { Theme: Landscape } \\
\text { Components: windows, } \\
\text { orientation (outlook \& } \\
\text { sunshine), exterior/ interior } \\
\text { thresholds (access to } \\
\text { landscape), airing courts, } \\
\text { surveillance opportunities. }\end{array}$ \\
\hline $\begin{array}{l}\text { On safety; } \\
\text { too much } \\
\text { emphasis on this } \\
\text { aspect to the } \\
\text { detriment of cure } \\
\text { and comfort. }\end{array}$ & $\begin{array}{l}\text { Browne opposes } \\
\text { Tuke's view; } \\
\text { Severity and } \\
\text { restraint are } \\
\text { preferable to } \\
\text { patient suicide. }\end{array}$ & $\begin{array}{l}\text { Conolly sits } \\
\text { between Tuke \& } \\
\text { Browne on the } \\
\text { matter of safety. }\end{array}$ & $\begin{array}{l}\text { Theme: Safety } \\
\text { Components: locks, } \\
\text { viewing panes, windows, } \\
\text { doors, bathrooms, } \\
\text { surveillance opportunities } \\
\text { within the architecture etc. }\end{array}$ \\
\hline $\begin{array}{l}\text { Disguising } \\
\text { confinement - } \\
\text { Tuke } \\
\text { recommended } \\
\text { the adoption of } \\
\text { domestic motifs } \\
\text { to mitigate a } \\
\text { patient's } \\
\text { awareness of } \\
\text { their own } \\
\text { confinement. }\end{array}$ & $\begin{array}{l}\text { Brown also } \\
\text { advised that } \\
\text { signs of } \\
\text { confinement be } \\
\text { disguised but not } \\
\text { through motifs of } \\
\text { domesticity. }\end{array}$ & $\begin{array}{l}\text { Conolly also } \\
\text { advised that } \\
\text { signs of } \\
\text { confinement be } \\
\text { disguised but } \\
\text { through the } \\
\text { employment of a } \\
\text { general hospital } \\
\text { aesthetic. }\end{array}$ & $\begin{array}{l}\text { Theme: Disguising } \\
\text { Confinement } \\
\text { Components: architectural } \\
\text { style and scale, materials, } \\
\text { interior treatments. } \\
\text { Including the disguise of } \\
\text { locks, viewing panes, } \\
\text { heavy doors etc. }\end{array}$ \\
\hline $\begin{array}{l}\text { Asylum size: } \\
30 \text { patients }\end{array}$ & $\begin{array}{l}\text { Preferred size } \\
\text { not disclosed. }\end{array}$ & $\begin{array}{l}\text { Maximum asylum } \\
\text { size: } 400 \text { beds. }\end{array}$ & \multirow{3}{*}{$\begin{array}{l}\text { Theme: Individual } \\
\text { Treatment \& Tranquillity } \\
\text { Components: asylum size, } \\
\text { the provision of private } \\
\text { versus public space } \\
\text { (dormitories, bathrooms } \\
\text { etc.), dormitory and ward } \\
\text { size, dormitory quality, the } \\
\text { provision of personal, } \\
\text { domestic items (storage, } \\
\text { wash-stands, mirrors etc.). }\end{array}$} \\
\hline $\begin{array}{l}\text { Provision of } \\
\text { privacy and } \\
\text { tranquillity was } \\
\text { of the upmost } \\
\text { importance } \\
\text { (private rooms). }\end{array}$ & $\begin{array}{l}\text { Economy over } \\
\text { privacy } \\
\text { (dormitories have } \\
\text { their place). }\end{array}$ & $\begin{array}{l}\text { Preference for } \\
\text { private rooms (at } \\
\text { least } 2 / 3^{\text {rd, }} \text { ) of } \\
\text { asylum accom. } \\
\text { Dormitories of } 4- \\
6 \text { or single } \\
\text { rooms. }\end{array}$ & \\
\hline $\begin{array}{l}\text { The delivery } \\
\text { of individual } \\
\text { treatment } \\
\text { important. }\end{array}$ & $\begin{array}{l}\text { Browne echoes } \\
\text { Tuke. }\end{array}$ & $\begin{array}{l}\text { Conolly echoes } \\
\text { Tuke and also } \\
\text { notes the } \\
\text { provision of } \\
\text { personal fixtures, } \\
\text { e.g. wash- } \\
\text { stands, mirrors, } \\
\text { storage. }\end{array}$ & \\
\hline
\end{tabular}




\subsection{THE VILLA HOSPITAL: SOLVING THE PROBLEMS OF TRADITIONAL ASYLUM CARE}

In 1878 construction began on the Alt-Sherbitz Asylum, 150 kilometres south of Berlin, and the Illinois Eastern State Hospital for the Insane at Kankakee, 100 kilometres outside Chicago. In lieu of a monolithic asylum, patients of these new hospitals would be accommodated within detached cottages placed throughout the landscape. This was known as the villa system in Germany and New Zealand, and the cottage or colony system elsewhere. Cottages at Alt Sherbitz accommodated patients in groups of twenty-four or fifty, while the American hospital featured cottages of fifty and one hundred beds. ${ }^{40}$ In 1894 , Conolly Norman stated that the villa hospital presented a departure from traditional asylum design that was so successful that "one cannot doubt... it will be the model asylum of the future." ${ }^{41}$ This section will outline the ideology behind the development of the villa hospital.

Dr Theodore Gray, Director-General of New Zealand's mental hospitals (1927-1947), undertook his medical training at the Kingseat Hospital in Aberdeen, one of the first villa hospitals to have been constructed in the United Kingdom. Gray gave the following description of the villa hospital model in his autobiography:

each ward with its day rooms, dining rooms, sleeping accommodation, kitchen and other offices, is self-contained in a separate house or villa, which accommodates about fifty or less patients, and these villas are so arranged as to constitute a village. ${ }^{42}$

The key difference between this new hospital type and traditional asylums was that it could, if managed correctly, offer "maximum liberty to those best able to appreciate it." ${ }^{33}$ The villa hospital was intended to be run on an "opendoor system" where traditional, physical means of control such as high fences, locked doors and barred windows would be replaced with "humane but stringent supervision" by nurses and attendants. ${ }^{44}$ The physical configuration of the villa hospital facilitated open-door practices because patients with similar behaviour could be grouped together and the security measures for each villa specifically tailored in response. In traditional asylum design, extreme security measures were dictated by the worst behaved (or unpredictable) patients subjecting those who were trustworthy to unnecessary restrictions. ${ }^{45}$ This model responded to parallels that had been drawn between patient discontent and the degree to which their liberty was restricted. ${ }^{46}$ Advocates of the villa hospital claimed it was "an essential vital development of the principles of non-restraint." 47

Part of the success of the villa hospital was that it was able to mimic the semiformal arrangements of the lunatic colony at Gheel, $70 \mathrm{~km}$ outside Brussels, where lunatics had been "boarded" with the villagers since the sixteenth century. Villagers (not related to the patients) were paid to house and feed lunatics who sometimes helped with farm work. An admission unit evaluated 
patients and coordinated medical supervision through a system of visitation. ${ }^{48}$ Following a visit to Gheel, American physician John Galt wrote that the patients experienced "nearly the same freedom as the citizens of the commune, going everywhere at large." ${ }^{49}$ The villa hospital aspired to approximate normal life as far as possible so as to reduce the "monotony" of institutional life, which asylum superintendents recognised, tended to "cripple the intelligence and depress the spirits. ${ }^{" 50}$ Daily occupation remained at the core of treatment regimes, thus, in an ideal conception of the villa hospital, male patients would go to work during the day, on the farm or in the garden, and return to their own villas at night. While the female patients were more likely to cook, clean, sew and do laundry. This was a daily routine that was not dissimilar to the lifestyles of unmarried working class citizens in the late nineteenth century. Inspired by the villa hospital model, D. Hack Tuke wrote in 1891 that "the nearer an asylum can be made to approach the village household, and still serve the purpose of a useful institution, the better it will become." 51

Early villa hospitals, following the example set by the hospital at Alt-Scherbitz, borrowed the aesthetic of neighbouring rural dwellings. From a public relations standpoint this innocuous replication of domesticity presented a significant advance on the traditional asylum. Gray recounted that villa hospitals were characterised by "a welcome absence of that gloom which... pervade[s] large institutional buildings." ${ }^{52}$ According to Leslie Topp, Paetz and Gustav Kolb, the two most influential advocates in the development of the villa hospital, "envisioned an institution that visibly distanced itself from anything prison-like." 53 They deliberately sought a new hospital model able to break ties with traditional asylums. ${ }^{54}$ This was a consideration not lost on British psychiatrist R.H. Steen who questioned whether this new hospital model made a difference for the patients themselves or merely to the perceptions of visitors. ${ }^{55}$ Topp's research highlights a tension between the image presented by the villa hospital, of greater freedom for patients, and the fact that these institutions were not always managed in a manner consistent with the image they conveyed. ${ }^{56}$ Unless the approach to patient management was consistent with the ideology of the villa hospital, architectural reincarnation could be achieved without providing any real advances regarding patient care.

The villa hospital took the York Retreat's premise of replicating the sane outside world and increased its accessibility for use in large, public asylums. To hospital superintendents this must have seemed as though the curative ideals of moral treatment and non-restraint had, at last, been extended into physical form. Topp has made clear, however, that we should not assume all villa hospitals were created with the maintenance of open-door policies in mind. Each hospital must be carefully examined to ascertain whether a better environment for patient care actually resulted. 


\subsection{WAITING FOR A BREAKTHROUGH: PERSEVERING WITH MORAL TREATMENT}

In the period leading up to the construction of Kingseat Hospital, 1910-1929, three disparate approaches to the treatment of mental illness had emerged. The field of psychiatry was divided between those who sought biological explanations for mental illness, those who placed their faith in psychotherapy and those who believed that prevention would prove more effective than cure. This section will give a brief outline of these three approaches to mental illness and the architectural implications for the design of new hospitals.

The first new approach to treatment was psychotherapy, colloquially termed the "talking cure," this was the treatment of mental disorder by psychological means. According to Dr Bernard Hart, World War I resulted in a greater appreciation of the contribution of environmental factors in the development of mental illness and a corresponding interest in the various procedures associated with psychotherapy. ${ }^{57}$ Shellshock, for example, was thought to originate from the conflict soldiers' felt between their sense of duty and their desire for self-preservation. ${ }^{58}$ Truby King did not believe that these methods were suited to the types of illness that were prevalent within New Zealand's mental hospitals. ${ }^{59}$ Even if King had seen value in this approach, however, the various methods of psychotherapy were time consuming and required a one on one approach that New Zealand's mental hospitals did not have the staffing levels to offer. These methods were used in the treatment of returned soldiers but seldom for civilian patients. ${ }^{60}$ The architectural implication of psychotherapy was the simple provision of clinical rooms for private consultation.

The second approach to mental illness at the time of Kingseat's design was that of prevention. In 1908, the Mental Hygiene movement was initiated in America as a reform campaign aimed at the "humane and scientific institutional care of mental disease [emphasis added]." ${ }^{61}$ By 1929, the movement had gained significant international support and had also changed its focus toward the prevention of mental illness. Supporters of this movement believed that if the public could be taught to look after their mental health, akin to the way that physical health is attended to through sensible diet and exercise, then the progression of mental illness could be arrested. ${ }^{62}$ America set the example for movements in other nations; they encouraged a greater commitment to scientific research, they lobbied for a stronger relationship between mental hospitals and universities and the addition of psychiatry to medical school curricula. They provided child guidance clinics, services for the redirection and rehabilitation of returned service men and civilian guidance through wartime to maintain public morale. ${ }^{63}$ Perhaps the most important idea to come from the Mental Hygiene movement, however, was the recognition that specialist knowledge from all quarters - psychiatrists, psychologists, social workers, occupational therapists, educators and sociologists - would be required to make any real progress in the field of mental illness. ${ }^{64}$ It was an idea that would not gain significant traction until the 
1950s. In terms of architectural directives, the focus on prevention meant that no concrete suggestions for the architectural development of mental hospitals were offered.

While these first two approaches to the treatment of mental illness did not result in a new architectural approach, the third approach did. The search for a biological basis for all mental disease resulted in the development of the psychopathic hospital model which will be discussed within the following section. The idea that a biologial basis could be found for all mental disease was inspired by the discovery that penicillin could be used to treat syphilis (1910). Between 1880 and 1930 "immense progress" had been made in nearly every branch of medicine except psychiatry. ${ }^{65}$ The discovery of a biological basis for mental illness was desirable because it would "imbue psychiatry with the legitimacy of general medicine." ${ }^{66}$ The strength of this desire is visible in the welcome reception, and seeming lack of criticality, of the work of American doctor Henry Cotton (New Jersey State Hospital). Cotton advocated the surgical removal of tonsils, stomachs, testicles, colons, spleens, gall bladders, cervixes and ovaries, owing to his belief that these organs harboured bacteria. Despite a stated death rate of around 30 per cent, owing to the "very poor physical condition" of his patients, Cotton claimed cure rates of 85 per cent (presumably of his surviving patients). ${ }^{67}$ Contemporary estimates place his fatality rate at closer to 45 per cent. ${ }^{68}$ In 1922, the New York Times credited Cotton with being responsible for "the most searching, aggressive, and profound scientific investigation that has yet been made of the whole field of mental and nervous disorders." ${ }^{69}$ Cotton's "Doctrine of Focal Sepsis" lost its appeal following the success of later somatic treatments such as insulin coma, cardiozal shock and electroconvulsive therapies between 1933 and 1938. While Cotton's methods were not adopted for use within New Zealand's mental hospitals these later and more successful treatments were.

Disparate medical developments characterised the era preceding Kingseat's construction (1910-1929). As no proven alternative was offered for the treatment of mental illness, moral treatment continued to form the basis of mental hospital care. Correspondingly, the villa hospital model - an architectural response developed in the late nineteenth century to support the delivery of this therapeutic approach - was still considered a modern approach to hospital design in the late 1920s. 


\subsection{THE VILLA VERSUS THE PSYCHOPATHIC HOSPITAL: NEW OPTIONS FOR THE 1920s}

Within the era Kingseat Hospital was designed, the relationship between treatment and architecture became more ambiguous. Emergent treatments, such as somatic therapies and psychotherapy, suggested a future where the treatment of mental illness would be less dependent on the curative offerings of an appropriately designed environment. Reflecting the disparity that characterised medical developments over this period, psychiatrists were divided with regard to the "ideal" approach to mental hospital construction. Those who remained convinced of the benefits of moral treatment continued to believe that cures could only be obtained in a suitable environment such as the villa hospital provided. While those focused on finding new treatments developed a new architectural response to suit: the psychopathic hospital. This section will establish the architectural criteria for evaluating the relative success of both villa and psychopathic hospitals (table 3.2).

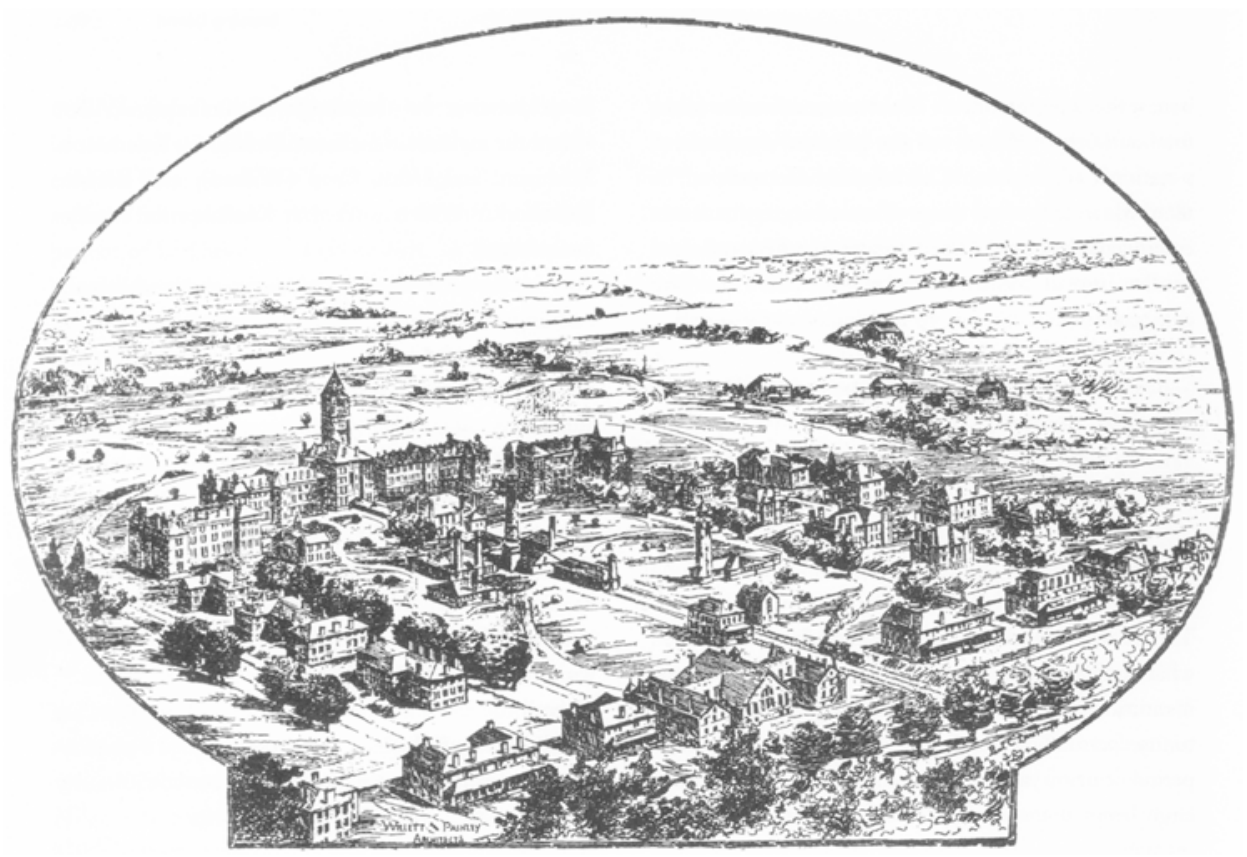

Figure 3.1: Illinois Eastern State Hospital for the Insane, Kankakee, Illinois, bird's-eye drawing signed "Willet and Pashley, Architects," as illustrated in Fifth Biennial Report, 1886. Published in Yanni 2007, 92.

Unlike the prescriptive recommendations available during the design of Seacliff Asylum, architectural discussion around the construction of villa hospitals occurred on far more general terms. The internal spatial arrangement of new facilities and their exact relationship to landscape was open to individual preference. With regard to psychopathic hospitals even less advice was given since the assumption was that these buildings would vary little from the construction of general hospitals. In order to establish a set of architectural criteria for both types, the design of early, influential hospitals will be examined. The two most important precedents for the construction of villa hospitals in New Zealand were the Aberdeen City District Mental Hospital (otherwise known as "Kingseat") designed by Marshall Mackenzie in 1901 
and the Illinois Eastern Hospital for the Insane in Kankakee, Illinois, designed by J.R. Willett in 1878 (figure 3.1). In 1910, while planning was underway for the Tokanui Mental Hospital (constructed near Te Awamutu in 1912), Dr A.H. Crosby, medical superintendent of the Mt View Asylum (Wellington), was sent to visit both the Kingseat Mental Hospital and the hospital at Kankakee. ${ }^{70}$ Theodore Gray himself had intimate knowledge of the Aberdeen Hospital having completed his training there. ${ }^{71}$ The first psychopathic hospital to be constructed was the Maudsley Hospital in London which Gray visited in 1927 as part of an international study tour of the "most modern" institutions for mental health care within Great Britain, the United States, Canada and the Continent. ${ }^{72}$ The Maudsley will be used as the basis for establishing the ideal construction criteria for psychopathic hospitals.

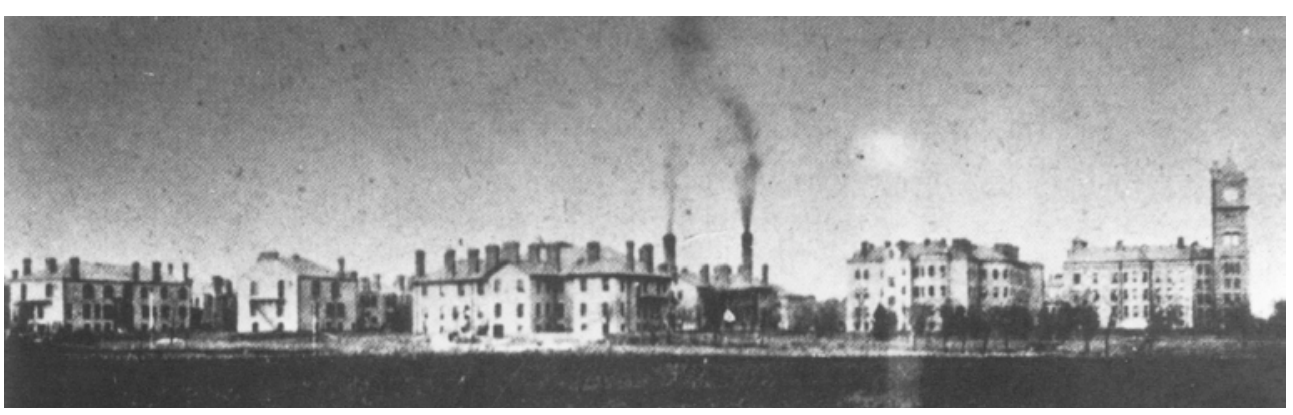

Figure 3.2: Illinois Eastern State Hospital for the Insane, undated. The main building is visible at the far right. Published in Yanni 2007, 93.

In his 1891 review of Kankakee, Henry Burdett talked of its rows of wards (or "villas" as was the preferred term in New Zealand) as being like "village streets." The wards were placed along wide avenues that were "boarded by walks and shaded with trees." ${ }^{73}$ Each housed between 50 and 100 patients (figure 3.3). ${ }^{74}$ While Yanni described the aesthetic of these villas as "modest," she acknowledged that this scale could not be mistaken for a domestic scale. ${ }^{75}$ The main hospital building, for the treatment of acute cases, followed the principles of Kirkbride's linear asylum plan on a smaller scale. Even at this smaller scale, however, it dominated the hospital complex. The bulk and arrangement of these buildings, placed close together in a formal grid pattern, gave the impression of a small industrial town (figure 3.2).

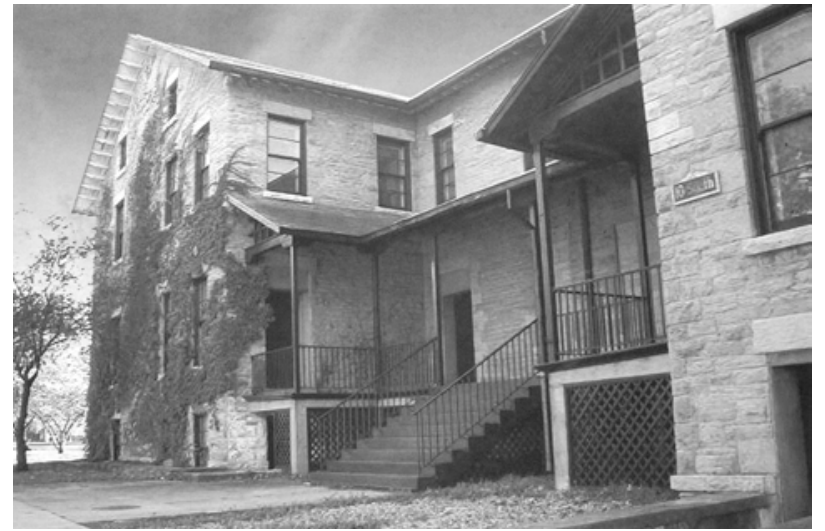

Figure 3.3: Illinois Eastern State Hospital for the Insane, Cottage No. 10. Photograph by Mark Yanni. Published in Yanni 2007, 93. 


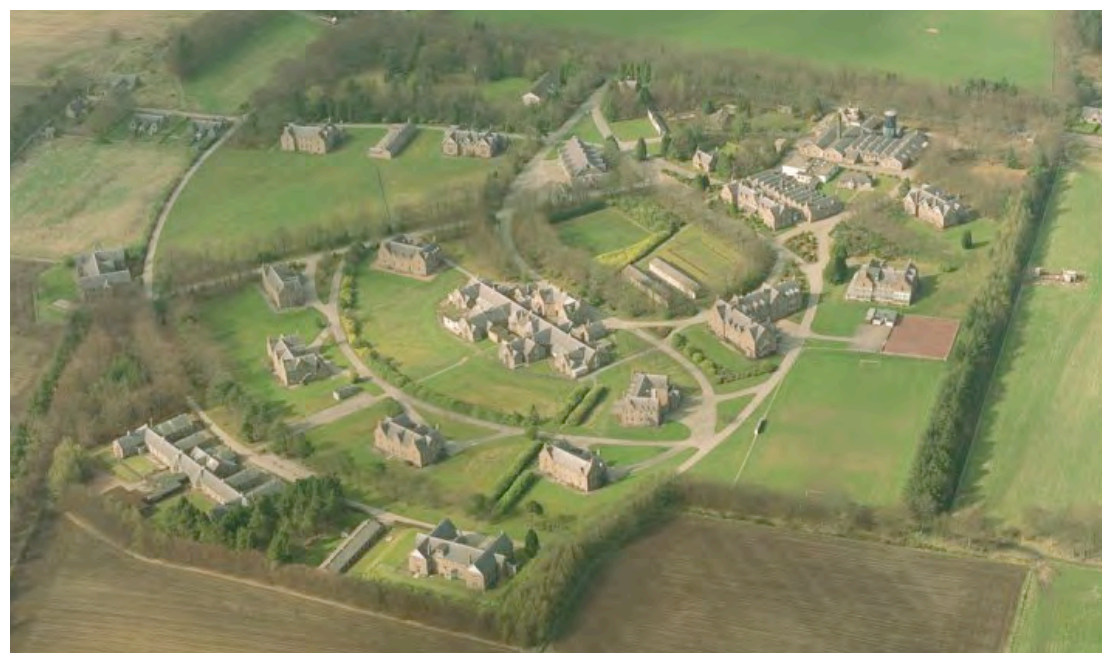

Figure 3.4: Aerial photograph of Kingseat Hospital, date unknown.

(c) Crown Copyright: RCAHMS (SC755772) Licensor www.rcahms.gov.uk

Gray visited a number of villa hospitals during his 1927 study tour. Yet, despite viewing more recently constructed hospitals, ${ }^{76}$ it was the Kingseat Hospital in Aberdeen (1901) that Gray considered to be "undoubtedly the best" he had seen (figure 3.4). ${ }^{77}$ Brunton has suggested that Gray's time as a junior doctor at Kingseat had a "profound influence" on him; he "never forgot the conceptual debt he owed to his training ground" and named the Papakura hospital after it. ${ }^{78}$ Kingseat was far more convincing as a collection of domestic dwellings in a rural landscape than the suburban, orthogonal planning of Kankakee. With just 500 beds, it was below half of the size of the hospital at Kankakee which housed close to 1200 patients. ${ }^{79}$ At Aberdeen patients were housed in villas that were significantly smaller and more domestic in character, each villa accommodated only 34 or 44 patients (figure $3.5){ }^{80}$

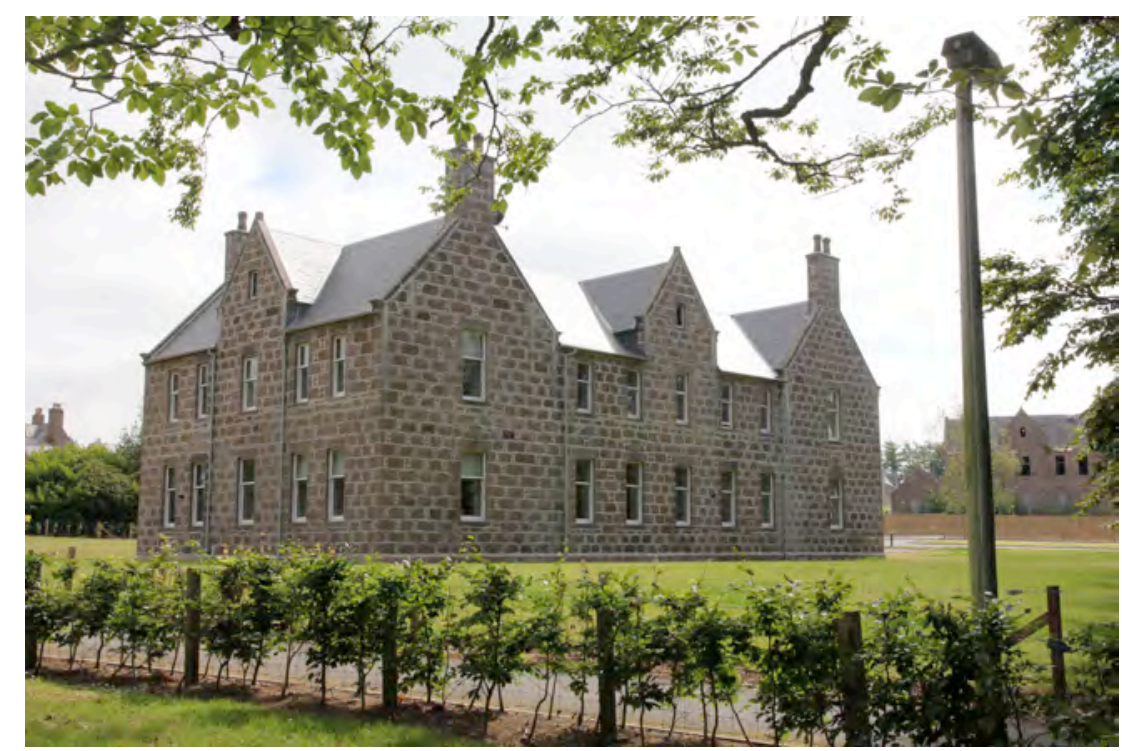

Figure 3.5: A villa at Kingseat Hospital, Aberdeen. July 22, 2013.

(These villas have been adapted for residential use). Photograph by author. 
At both Kankakee and Aberdeen additional buildings were provided to house administrative offices, nurses' accommodation, laundries, kitchens and workshops. Recreation halls for patients were also provided. The inclusion of an observation ward for new admissions at Alt-Scherbitz set the pattern for other villa hospitals - Kankakee and Kingseat both featured "hospital" buildings.

Many of the recommendations made by Tuke, Browne and Conolly remained relevant in the construction of villa hospitals, though the physical shape of this model resolved many of the issues encountered with traditional asylum design. Buildings of only two stories, distant from each other within the landscape, allowed easier access to sunshine, natural light and the outdoors, while the smaller scale and domestic aesthetic mitigated the "perceptible confinement" present in traditional asylums. Securing a tranquil environment around each patient was also easier since dormitories were generally smaller superintendents had more options for classification. Like their predecessors, villa hospitals were sited rurally and outdoor employment remained an important feature of the institutional routine. Some of the requirements set out by Tuke, Browne and Conolly either lost their relevance to mental hospital design or had become so ingrained in the planning process that they were no longer discussed. The need for elevated sites disappeared. Flat sites (facilitated by technological advances in drainage) allowed a single villa design to be replicated multiple times with minimal changes to documentation, cost or construction method and thus enabled the easy extension of these hospitals. Maintaining a close proximity to society and issues of safety were no longer discussion points in the design of new mental hospitals. Proximity to society was made difficult by the fact that even the relatives of hospital patients were loath to visit. An attendant at Seacliff estimated the number of patients who received visitors at only thirty per cent in $1893 .{ }^{81}$ More contemporary accounts indicate that low visitation rates remained a constant. Marion Kennedy's novel The Wrong Side of the Door was based on her experiences as a nurse at Porirua Hospital in the 1940s. She recalled that many patients could go years between visits. ${ }^{82}$ While the comparative silence, within the medical literature, on matters of safety could suggest that this had simply become second nature in mental hospital design. Andrews, Briggs, Porter et al. confirm that safety was carefully considered in the design of new premises for the Bethlem Hospital (1923 - 1930). Within the prolonged planning process for this hospital attention was paid to such things as avoiding sharp corners in wards so that patients would not injure themselves. ${ }^{83}$ 


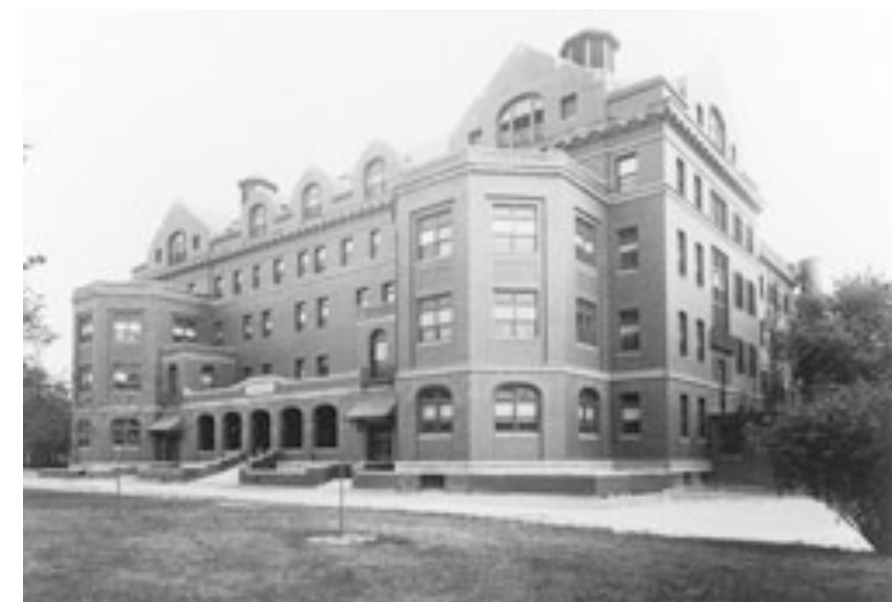

Figure 3.6: The Phipps Psychiatric Clinic at Johns Hopkins Hospital, 1913.

Image source: Johns Hopkins University, http://www.hopkinsmedicine.org.

In 1903, British doctors Henry Maudsley and Frederick Mott envisioned an entirely different hospital model based on their desire to bring psychiatry "into line with the other branches of medical science." ${ }^{\prime 4}$ Around the same time in America, a parallel development occurred which stemmed, instead, from the Mental Hygiene movement. Clifford Beers, the founder of this movement, published a book based on his experiences as a patient in $1908 .{ }^{85} \mathrm{His}$ book and subsequent campaign, to advance the scientific understanding of mental disease through increased collaboration between medical schools and general hospitals, inspired the addition of the Phipps Psychiatric Clinic to the Johns Hopkins University Hospital (Baltimore) in 1913 (figure 3.6). Since the Maudsley Hospital received a lengthy discussion in The Lancet, a British medical journal to which New Zealand professionals had access; it was the more accessible model for New Zealand and will be discussed here.

Just two years after the foundation stone was laid for the Kingseat Hospital near Aberdeen, Henry Maudsley donated $£ 30,000$ for the construction of his ideal hospital for the treatment of one hundred recent, curable cases of insanity. He wanted to advance the medical understanding of mental illness and to offer early treatment independent of public mental hospitals and the stigma that was associated with them. Maudsley and Mott believed that "the rapid advancement of knowledge of any disease" could only occur in close proximity to a medical school and located their new hospital across the road from the King's College (teaching) Hospital. The provision of outpatient clinics and voluntary admission ensured that the public could more easily access the services offered by this hospital. A separate institution would mitigate the risk of acute patients coming into contact with chronic patients who might retard their recovery, while sparing patients the distress and associated stigma of attending a county asylum. Important to this new hospital's ethos was that no patient would ever be committed; all admissions would be voluntary. ${ }^{86}$ 


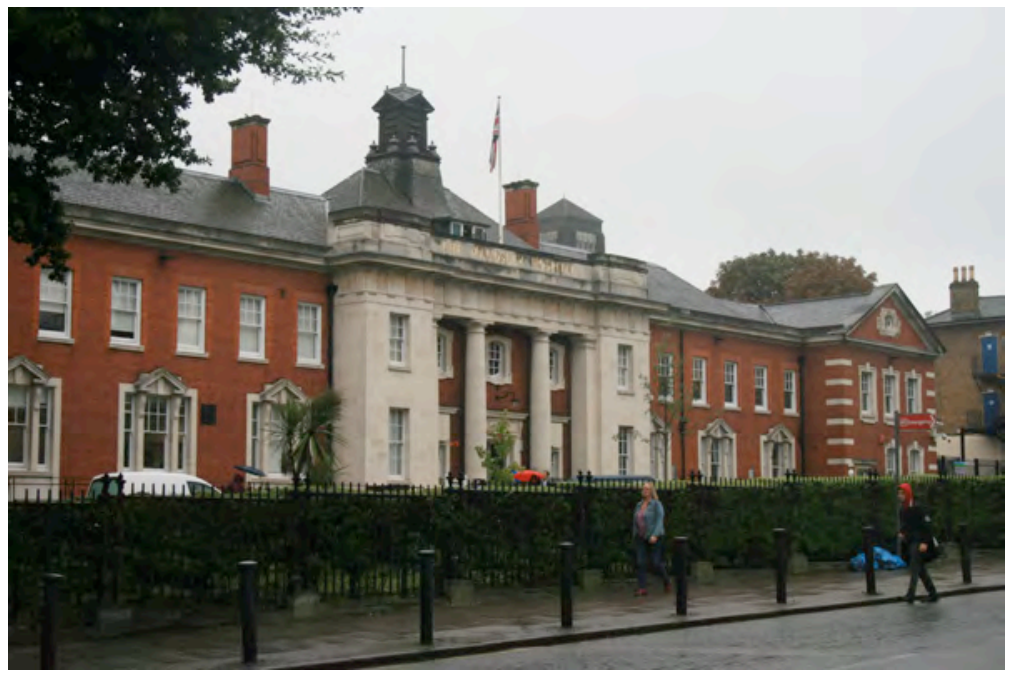

Figure 3.7: Maudsley Hospital, Denmark Hill, London. September 12, 2013. Photograph by author.

At the Maudsley Hospital, public spaces, such as the library, offices, outpatient services and laboratories for clinical, bacterial and microbiological research, were located in a building that faced the street (figure 3.7). Inpatient accommodation was located in two pavilions (male and female) directly behind the main building where they could benefit from greater privacy. A number of private rooms were provided for patients along with six wards each containing six or eight beds. ${ }^{87}$ The Maudsley may not have offered much of an architectural advance regarding patient accommodation but it proposed an idea that was far more challenging; that faith in the curative role of architecture and landscape was mislaid. The best employment of financial resources was in the direction of research and teaching. The Maudsley Hospital boasted the best medical equipment available, such as hydrotherapy baths, and much higher levels of staffing than were traditionally provided at public mental hospitals. Within time, it secured its place as London's foremost teaching hospital for mental disease. The most pertinent architectural message sent by the Maudsley, however, was that mental hospitals should no longer be isolated in rural areas. New mental hospitals should be easily accessible by the inhabitants of the city they serve, close to general hospitals, researchers and medical students.

Table 3.2 sets up the curative criteria by which the architectural response created for Kingseat Hospital (Papakura) will be evaluated. 
TABLE 3.2: ARCHITECTURAL CRITERIA FOR AN IDEAL

CURATIVE ENVIRONMENT: KINGSEAT HOSPITAL, 1929

(THE VILLA VERSUS THE PSYCHOPATHIC HOSPITAL)

\begin{tabular}{|c|c|c|}
\hline $\begin{array}{l}\text { Themes carried } \\
\text { over from } \\
\text { Moral Treatment: }\end{array}$ & $\begin{array}{l}\text { Villa Hospital model: } \\
\text { requirements \& corresponding } \\
\text { architectural considerations. }\end{array}$ & $\begin{array}{l}\text { Psychopathic Hospital model: } \\
\text { requirements \& corresponding } \\
\text { architectural considerations. }\end{array}$ \\
\hline Location & $\begin{array}{l}\text { Requires rural site, flat or gently } \\
\text { undulating. } \\
\text { Considerations: room for future } \\
\text { expansion, accommodation of } \\
\text { staff (given remote locations). }\end{array}$ & $\begin{array}{l}\text { Rejects rural site in favour of } \\
\text { urban site. } \\
\text { Considerations: proximity to } \\
\text { public transport, general hospitals } \\
\text { and medical schools. }\end{array}$ \\
\hline Landscape & $\begin{array}{l}\text { Access to landscape (nature) } \\
\text { remains important. } \\
\text { Considerations: relationship of } \\
\text { landscape to, and between, villas, } \\
\text { including exterior/interior } \\
\text { thresholds, orientation (outlook } \\
\text { and sunshine). }\end{array}$ & $\begin{array}{l}\text { Maintaining a relationship to } \\
\text { landscape was not stated or } \\
\text { inferred in this model. }\end{array}$ \\
\hline Appearance & $\begin{array}{l}\text { Domestic aesthetic and scale } \\
\text { favoured. } \\
\text { Considerations: scale, materials, } \\
\text { architectural style. } \\
\text { Relationship of service buildings, } \\
\text { staff accommodation and hospital } \\
\text { buildings to patient villas. } \\
\text { Differentiation of reception (acute) } \\
\text { wards from other villas. }\end{array}$ & $\begin{array}{l}\text { Favours general hospital } \\
\text { aesthetic over domestic (village) } \\
\text { aesthetic.* } \\
\text { Considerations: scale, materials, } \\
\text { architectural style. } \\
\text { *This is consistent with Conolly's } \\
\text { aesthetic preference (1847). }\end{array}$ \\
\hline $\begin{array}{l}\text { Individual } \\
\text { treatment and } \\
\text { tranquillity }\end{array}$ & $\begin{array}{l}\text { Individual treatment remains } \\
\text { important. The following } \\
\text { architectural elements effected } \\
\text { individual treatment and } \\
\text { tranquillity: hospital and villa size, } \\
\text { private versus public space } \\
\text { (dormitories, bathrooms, and } \\
\text { dayrooms), dormitory size and } \\
\text { quality. }\end{array}$ & $\begin{array}{l}\text { Individual treatment depended } \\
\text { upon high staffing levels and } \\
\text { small hospital populations in lieu } \\
\text { of architectural considerations. } \\
\text { The size of wards (referred to as } \\
\text { "dormitories" within the villa } \\
\text { hospital model) and the } \\
\text { proportion of single rooms to ward } \\
\text { accommodation impacted on the } \\
\text { provision of tranquillity. }\end{array}$ \\
\hline $\begin{array}{l}\text { NEW spatial } \\
\text { requirements }\end{array}$ & $\begin{array}{l}\text { Occupational therapy spaces. } \\
\text { Gymnasiums and swimming } \\
\text { pools (in addition to traditional } \\
\text { recreational facilities such as } \\
\text { halls, chapels, libraries). }\end{array}$ & $\begin{array}{l}\text { Teaching and research facilities. } \\
\text { Interview spaces for outpatient } \\
\text { care. }\end{array}$ \\
\hline
\end{tabular}




\subsection{NEW PERSPECTIVES ON MENTAL ILLNESS}

At the beginning of the twenty first century the landscape of mental health had changed radically from an institutional model of care that had persisted for nearly two centuries to a community-based model of care. When the Cherry Farm Hospital was designed this transformation was just beginning to take shape. In 1949 it was evident that change was afoot but the direction mental health care would take was unclear. This section discusses the context in which the Cherry Farm Hospital was designed.

In the decade prior to Cherry Farm's design, new treatments for mental illness became available with a rapidity formerly unwitnessed within this field. In 1938 insulin coma therapy was employed in New Zealand's mental hospitals, just five years after it had first become available overseas, a year later cardiazol shock treatment was in use. In 1943 these methods were replaced by electroconvulsive therapy (E.C.T.) which was faster and more cost effective to administer as it required less intensive staffing. In 1945 the country's first pre-frontal leucotomy (or "lobotomy" as it is contemporarily termed) was performed at Seacliff Asylum. By 1947 new and more effective psychopharmaceuticals had become available for the treatment of mental illness that, according to Kate Prebble, would transform the work carried out by nurses and attendants within a decade. ${ }^{88}$ The availability of effective psychopharmaceuticals produced remarkable transformations in the behaviour of patients and, as a result, hospital environments became less volatile. ${ }^{89}$ The construction programme of the Cherry Farm Hospital and the subsequent replication of villas, spanning 1949 and 1959, occurred in parallel with the transformation of New Zealand's mental hospital population to an increasingly more responsive, and thus more manageable, group of patients.

It was not just the science that was changing; the experiences of World War II advanced the understanding of the role of causal relationships in mental illness that had been gained during World War I. ${ }^{90}$ Martin James explained that medical teams lived under similar conditions to their patients. This allowed them the benefit of "full rapport with their background[s]" [emphasis original]:

The quality of the men, their fighting records, and the overwhelming stress to which they had succumbed were so obvious that it was impossible to think of them as degenerates ... War experiences laid bare psychodynamics in a way rarely attained in civil practice, where it is harder to have empathy with a schizophrenic because he responds to stresses which are less understandable to a normal person. ${ }^{91}$

Psychiatrists recognised that within the military individuals became hypersensitive to group influences. According to James, their standards of behaviour were "dependent upon their group life and morale." ${ }^{2}$ These observations resulted in a number of experiments with patient-led group and occupational therapies at the Northfield and Mill Hill Military Hospitals (1940 1948). Changes were also made to the social and physical environment of 
these hospitals and the corresponding psychological effects on patients were observed. ${ }^{93}$ Over the same period, similar experiments were being carried out with chronic patients within three British mental hospitals. This work was led by T.P. Rees at Warlingham Park Hospital (Surrey), by Duncan MacMillian at Mapperley Hospital (Nottingham) and by George McDonald Bell at Dingleton Hospital (Melrose, Scotland). These experiments included the accordance of greater trust to patients through the unlocking of hospital doors and the employment of various vocational and group therapies. ${ }^{94}$ Discussing his own motivations for the experiments conducted at Warlingham Park, T.P. Rees wrote that:

Those of us who have worked for a time in mental hospitals... often ponder... the extent to which the patient's symptoms are the result of the conditions under which he is treated. A schizophrenic whose relatives are prepared to look after him in his own home does not deteriorate or regress to the same extent as the schizophrenic in the mental hospital. ${ }^{95}$

Dr Robert Hunt reflected, in 1958, that the work of these men "shattered" the "smugness" with which state hospital doctors regarded their work. He credited these men with having shown:

beyond question that much of the aggressive, disturbed, suicidal, and regressive behaviour of the mentally ill is not necessarily or inherently part of the illness... but is very largely an artificial by product of the way of life imposed upon them. ${ }^{96}$

In 1953 the World Health Organisation released a report on the future of Mental Health Care. They titled it The Community Mental Hospital. It was a response to the new opportunities offered by effective pyschopharmaceuticals and a general public who were more willing to engage with non-institutional responses to mental illness. ${ }^{97}$ David Clark, a British psychiatrist who would go on to become regarded as a "pioneer ... in the development of therapeutic communities" wrote, in 1965, that the collision of these developments opened the door for a return to the nineteenth century ambitions of moral treatment: occupational therapy, patience, respect and kindness. ${ }^{98}$ While these developments marked the beginning of a sea change in the field of mental health, it must be acknowledged that in 1949, when the design of Cherry Farm Hospital was decided upon, this research was uncomfortably new. In his introduction to Modern Trends in Pscyhological Medicine 1948 Noel Harris wrote that although signifcant progress had been made in the field, the "confirmatory data, which would enable a real movement forward... is still sadly lacking." 99

Even the idea of unlocking hospital doors, which was certainly not new in 1949, continued to provoke fierce debate. In 1962 the Lancet ran an article titled "The Open Door: Ten Years' Experience in Dingleton." 100 The corresponding letters to the editor evidenced a deep scepticism regarding this practice. It was suggested, by more than one writer, that the only reason 
Dingleton Hospital was able to successfully implement the open door system was because their rural location shielded this hospital from the same proportion of "difficult" patients that urban hospitals had to contend with. ${ }^{101}$

What was clear in 1949 was that the landscape of mental health care was shifting but there was nothing clear about the long-term implications of this shift. The WHO report offered a number of recommendations for the design of new hospitals. However, this was not released until 1953, four years after plans for the Cherry Farm Hospital had been prepared but in the early stages of this hospital's construction programme, which had begun in 1951. The following section will examine whether there was an opportunity for the ideas contained within the WHO report to have been incorporated into the design of the Cherry Farm Hospital. It will detail the emergence of this research within medical literature and the accessibility of these sources for New Zealand decision makers. 


\subsection{THE 1953 WHO REPORT AND EMERGENT RESEARCH}

Clark regarded the publication of the WHO report in 1953 as "revolutionary." 102 It questioned how mental health services were provided, the curative objectives of the mental hospital and how patients were treated during hospitalization. The report also offered a number of suggestions for how mental hospitals should be constructed and administered. While it is these suggestions that are of most concern for the construction of the Cherry Farm Hospital, this section will provide some background regarding the philosophy of the Community Mental Hospital. Its primary aim, however, is to examine the timing and emergence of the ideas that informed this report. This is necessary in order to ascertain whether the decision makers involved in the design of the Cherry Farm Hospital could have been aware of this research and when, relative to this hospitals development.

The therapeutic community envisioned a return to many of the principles of moral treatment that the villa hospital had also been created as a response to. But there was one fundamental difference: while the villa hospital sought to replicate a home-like environment for the greater comfort of incurable patients, the therapeutic community model recognised that many of these same patients could lead normal lives beyond the hospital. A partial restoration to mental health alongside continued outpatient support could enable this to occur. Since cures were no longer considered imperative the job of the mental hospital was recast. In their 1953 report, the World Health Organisation stated that:

The most important social value of a mental hospital is its function of transforming a dissocialized individual into one who can adapt himself either to normal society, or to some kind of extramural care. ${ }^{103}$

The report stated that "atmosphere" was "the most important single factor in the efficacy of the treatment given in a mental hospital":

the more a psychiatric hospital imitates the general hospital... the less successful it will be in creating the atmosphere it needs. Too many psychiatric hospitals give the impression of being an uneasy compromise between a general hospital and a prison... the role they have to play is different from either: it is that of a therapeutic community. ${ }^{104}$

In the report's definition of atmosphere, the following considerations were given in italics: activity, the capacity for a considerable degree of responsibility and initiative, the assumption that patients are trustworthy, the preservation of a patient's individuality and [that] good behaviour must be encouraged. ${ }^{105}$ The WHO's expert committee recognised that even short mental hospital stays could cause debilitating effects for patients and advised mitigating this via the encouragement of self-direction, initiative and responsibility. The hospital was to "gradually impose upon recovering patients the responsibility which citizenship of the community implies." 
Hospital routines were traditionally regulated by the fear of suicide and staff tended to regard patients as "unreliable and unpredictable." ${ }^{107}$ The committee called, instead, for all patients to be assumed to be trustworthy until proven otherwise. A patient's "self-respect and sense of identity" was to be safeguarded and the isolation imposed by treatment was to be mitigated. Patients should be kept in touch with their social networks through the use of outpatient clinics, day-hospitals, work-programmes and after-care services. This would also be achieved through the encouragement of public participation within the daily life of the hospital. ${ }^{108}$ It was hoped that the dual benefits of these actions would alleviate the stigma associated with mental hospital admission and prepare the wider community to accept patients back following treatment.

Clark claimed that the arrival of the WHO report in 1953 was "an important point in the spread of the general therapeutic community approach." ${ }^{109}$ It was, however, the culmination of research occurring prior to 1953. This raises the question, how much of this research could have been accessed by those involved in the design of the Cherry Farm Hospital? A review of the Lancet over the period 1936 to 1953 turned up only a few articles with themes that corresponded with those put forward by the WHO report. ${ }^{110}$ Within the Menninger Clinic Bulletin, a journal produced by a small private clinic in Topeka, Kansas, sixteen articles with corresponding themes appeared between 1936 (the date of its first issue) and 1952. It was this journal where the work of $\mathrm{H}$. Bridger, S.H. Foulkes and T.F. Main, the men who were responsible for the experiments at Northfield and Mill Hill Military Hospitals, was first published in 1946. Over this same period, the Journal of Mental Science published eighteen articles with corresponding themes. ${ }^{111}$ Only one of these discussed the planning of modern psychiatric units. ${ }^{112}$ While the Journal of Mental Science had been delivered to the superintendents of New Zealand's mental hospitals since $1897,{ }^{113}$ it is unlikely that they had access to the Menninger Clinic Bulletin since the University of Otago (medical library) did not subscribe until 1954. ${ }^{114}$ Perhaps the most significant resource available at the time of Cherry Farm's design, however, was the publication Modern Trends in Psychological Medicine 1948. Dr Harold Palmer (University of Otago) contributed a chapter to this British publication which suggests that it was likely known to New Zealand readers. It was the chapter by T. F. Main, however, that discussed many of the same ideas that later appeared within the WHO report. ${ }^{115}$

Another potential source of ideas for improving the hospital environment was the publication of three patient accounts between 1946 and 1947. The first was Mary Jane Ward's The Snake Pit, a semi-autobiographical novel based on her experience as a patient at the Rockland State Hospital (New York) in 1939. The following year H.G. Woodley's Certified and J.A. Howard Ogdon's The Kingdom of the Lost were published. Woodley and Odgon were both committed to British mental hospitals (names undisclosed) between 1939 and 1942. These three accounts could have provided deeper insight into the 
dehumanising effects of mental hospital care from the perspective of the patient. In 1948, W. Rees-Thomas used his presidential address to the members of Britain's Royal Medico-Psychological Association to implore doctors to try and see mental hospitals "in a new light": "as the patients (and his friends) must do."116

While the WHO report was not published until 1953, many of the ideas it contained were available earlier to anyone willing to undertake a thorough survey of the available literature. While chapter six will look more closely at whether New Zealand decision makers were cognisant of this emergent research, this chapter will examine the direct architectural implications of these new ideas around treatment. 


\subsection{EXPECTATIONS FOR A NEW ARCHITECTURAL RESPONSE}

With regard to the architectural design of new mental hospitals the WHO report offered a number of specific architectural guidelines and a set of inferred principles. The latter were spatial considerations that would have been necessary for the successful delivery of the report's core values of trust, self-esteem, initiative and community engagement. This section will translate the recommendations of the 1953 report into a set of architectural criteria against which the Cherry Farm Hospital can be evaluated. These criteria will draw also on the research that was available prior to 1949, within medical journals and published patient accounts.

The architectural implications contained within the WHO report can be grouped into the five themes:

- the preservation of a patient's self-esteem.

- treatment regimes focused on the individual.

- the accordance of trust to patients.

- the creation of a group-based, Therapeutic Community.

- removing the barriers to community engagement.

Two additional themes arise within the report that are not directly related to the treatment of individual patients but carry ramifications for the design and location of new hospitals and these will also be discussed here:

- miscellaneous architectural specifications.

- education and research.

While some considerations were relevant to the wider hospital, others related specifically to patient accommodation (the individual villas). As this section will illustrate, the commonalities between the three patient accounts available in 1949 provided strong support for the five themes set forth within the WHO report.

\section{Criteria one: the Preservation of Self-esteem}

The importance of preserving a patients self-esteem was emphasised within the WHO report which stipulated that "every step... that can encourage the patient's self-respect and sense of identity should be taken, even at the cost of considerable inconvenience [emphasis added]." 117 Yet this report did not offer any discussion as to how a space might be designed to support this aim. It did specify, however, that "giant monoblock" buildings were to be avoided so that patients would not be "dwarfed" by their surroundings and that single bedrooms were the clear preference for sleeping. Six to eight beds were considered the optimum capacity for dormitories but 15 to 20 beds was deemed acceptable where economic conditions would not permit otherwise. ${ }^{118}$

Had the WHO report been read in conjunction with the three available patient accounts, the centrality of bathing and dressing spaces in relation to a patient dignity would have been apparent. All three patient accounts confirmed that 
privacy, with direct reference to dressing and bathing, was compromised. Ward recalled being herded like cattle through bathrooms and feeling like little more than a number, while Odgon complained about going "to the lavatory under escort... [and washing] under the vigilant eye of the ward-nurse."119

Main's writings and the articles contained within Menninger Clinic Bulletin strongly advocated the need to respect and preserve a patient's sense of identity and dignity throughout the treatment process. However, these publications did not make any suggestion regarding the handling of space to support this. Despite the availability of patient accounts, the Lancet and the Journal of Mental Science barely acknowledged this issue. The exception was an article written by J.J. O'Reilly (1948) who recommended to readers a ward design he had seen in America. Partitions three and a half feet high had been installed between beds providing "a measure of privacy... [without] interfer[ing] with nursing observation." 120

\section{Criteria two: Treatment Regimes focused on the Individual}

The WHO report encouraged the provision of varying types and levels of care which implied that a permeable network of facilities was required. Patients could be cared for in a variety of spaces, both within and beyond hospital confines such as day hospitals, ex-patient clubs and transitional hostels. With the adequate provision of outpatient services it was recognised that some patients could be cared for within their own homes. ${ }^{121}$

In 1948 Main urged that hospitals begin to differentiate between those patients who require the safety of a closed community, those who are chronic but can partake in life beyond the hospital and those who require only a temporary stay. He suggested that each group be provided with opportunities specifically tailored to their needs. ${ }^{122}$ This was an idea that Odgon had put forward in 1947. He suggested that "two or three different kinds of institutions were required... under separate skilled direction, housed in separate buildings, remote from one another" to cater to the diverse and specific needs of various types of patients. ${ }^{123}$

Both Main (1948) and the Journal of Mental Science (1939) suggested that, where beneficial, patients should be offered vocational training with extramural providers, such as polytechnics. ${ }^{124}$ The Journal of Mental Science supported the idea that the mental hospital should become a coordination hub for community mental health services and provide education to the wider community. Five articles discussed this idea. ${ }^{125}$

\section{Criteria three: the Accordance of Trust to Patients}

In stating that patients must be assumed to be trustworthy, the report stipulated that unlocked doors were to be prevalent throughout the hospital. ${ }^{126}$ While it recommended various other practices, such as allowing patients to eat with knives (traditionally absent within a hospital environment) and 
allowing patients to take employment in the community, the unlocking of doors was the only architectural implication stipulated. ${ }^{127}$

While the open-door hospital philosophy had been around since the late nineteenth century, this was still not widely employed in an international context. In the period which led up to the 1953 WHO report, there was little discussion of open-door practices within medical journals.

\section{Criteria four: the Creation of a Group-based, Therapeutic Community}

While resident at the Rockland State Hospital, Ward observed that mental hospital patients tended to lose their capacity for decision making. ${ }^{128}$ The WHO report was cognisant of this issue and responded by encouraging the use of group therapy and group living arrangements. ${ }^{129}$ Main advised that, for the whole hospital to function as a "therapeutic institution" group principles had to extend into the hospital's daily routines, offering group therapy in isolation was not enough. ${ }^{130}$ The WHO report recommended that patients should be responsible for running many hospital activities such as occupational therapy, social events, workshops and music groups. They could also form representative bodies to offer feedback on certain aspects of the hospitals organisation, such as the quality of food for example. ${ }^{131}$ Main explained that group participation required patients to employ initiative, responsibility and self-direction. This helped to mitigate the debilitating effects of dependency and isolation. ${ }^{132}$

The WHO report recommended that more space be devoted to "common activities" than was typically provided within mental hospitals. Male and female patients were to be desegregated in order to mimic the ordinary community beyond the hospital. While patients were to be housed in groups of twenty-five to thirty but "sleep, eat and work" in groups of ten. ${ }^{133}$

\section{Criteria five: Removing the Barriers to Community Engagement}

Ogdon observed that few of his fellow patients experienced a successful discharge from the mental hospital and soon returned. He described the conditions patients faced on discharge:

[they] go back to the same conditions as produced their first mental breakdown - the strain is renewed... Sometimes they are not really wanted - other associations have been formed, and the returned patient is a nuisance... the "herd" outside the institution is not kind. It senses the lorn stranger and seeks to be rid of him. ${ }^{134}$

In recognition of this reality the WHO report suggested that isolation between a patient and their family should be mitigated during hospitalization and support offered after discharge. In addition, steps should be taken to alleviate public misunderstandings around mental illness. New hospitals were to be situated "in the immediate vicinity" of the wider community they were to serve, close to existing medical and civic centres. Hospital boundaries were to be 
made increasingly permeable in both directions. Patients, where suitable, were to be encouraged to accept jobs beyond the hospital, while visitors were to be welcomed throughout hospital grounds; no longer restricted to "specially prepared and segregated visiting rooms." ${ }^{135}$ The 1953 report echoed Main's words from 1948:

Social traffic with the extra-hospital community should... be two-way, for rehabilitation concerns the environment as well as the patient. The community should have access to the hospital, to entertainments and social events, and workaday projects should be so arranged that hospital functions are also community functions... ${ }^{136}$

Main also believed that continued engagement with one's social network was critical to the re-adaptation of a patient to society. He advocated "free access of the patient to the community, to his family and friends, to cinemas, clubs, work-places and social events." ${ }^{37}$ The WHO report also recognised that day hospitals were useful in keeping a patient "in daily contact with the members of his home and... general social setting."138

\section{Criteria six: Miscellaneous Architectural Specifications}

While the WHO report included a sub-section on architecture, many of these spatial recommendations have been discussed already under the treatment theme to which they were most relevant. The report itself related a number of these spatial recommendations back to the values that the therapeutic community hoped to achieve. It stated, for example, that:

If the hospital is to become a therapeutic community... it must model its architecture and its plan on that of a community. If it is to support and recreate the sense of individuality in patients, it must not dwarf them by its size and by herding them together in thousands of giant monoblock buildings. ${ }^{139}$

Although a full section of the report was devoted to architecture, half of this section was taken up with a discussion on hospital size. This included a lengthy justification for the reports recommendation that the maximum size of any new hospital should be one thousand beds. ${ }^{140}$ The remainder of this section discussed the use of a village aesthetic (with regards to architectural treatment the arrangement of buildings), the ideal size of dormitories, the provision of common areas, hospital location and landscape treatment. With regard to the design of hospitals, little that could have been considered new was contained within the WHO report. Instead of an architectural advance this was a restatement of the principles of the villa hospital under a new guise. An inability to see beyond this model is evident in the contradiction that arose between the recommendations on landscape. Despite calling for hospitals to be constructed close to existing medical and civic centres, implying an urban or at least suburban context, the report went on to specify that new hospitals should be situated "within a natural area of woods, gardens and farm land."141 


\section{Criteria seven: Education and Research}

The WHO report stated that mental hospitals should take a more prominent role in education and research. All mental hospitals should be "training institutions" engaged in both postgraduate education and the on-going professional development of their own staff. Collaborative research was to be regarded not as "a luxury but a need." ${ }^{142}$ Institutional psychiatrists were encouraged to contribute to their own professional development and to the needs of the community through outpatient consultations and the provision of a liaison service to family physicians (GPs). ${ }^{143}$ The report also advised that mental hospital psychiatrists should be active participants in the provision of group and individual psychotherapy within the community as well as the hospital. ${ }^{144}$ The report's suggestion that general hospitals were "the most favourable setting" for outpatient clinics, along with the suggestions regarding professional liaison, implied that links with these institutions should be strengthened.

The approach recommended by the WHO report was not dissimilar to that of the psychopathic hospital. As discussed within the previous chapter, the existing institutions such as the Maudsley and Bethlem Hospitals, and the Phipps Clinic (Johns Hopkins University) had taken this approach for many years. This idea was supported within the Journal of Mental Science which advised that, in the planning of modern psychiatric units:

there should be the closest possible relation between psychiatry and general medicine... the psychiatric unit should be situated in close proximity to the large general hospital. ${ }^{145}$

The value of the WHO report, and the research leading up to it, was not in the directives it gave for new hospital construction but in the questions that this report raised. This report offered a number of new ideas that had the potential to make significant improvements to the mental hospital environment. Just how architecture could be articulated to support these new approaches to care, however, was not well understood or stated. This shortcoming, and the uncertainty around it, was acknowledged within the report:

There is room for much experimentation in the planning of the therapeutic community and for closer collaboration than has so far taken place between psychiatrists and architects. If the committee is correct in its view that the community mental hospital should model itself on the village, rather than on the general hospital, it may well prove that the domestic architect and the town planner have more to offer in such collaboration than has the hospital architect. ${ }^{146}$ 
TABLE 3.3: ARCHITECTURAL CRITERIA FOR AN IDEAL CURATIVE ENVIRONMENT: CHERRY FARM HOSPITAL, 1943-52

(SHOWING THE AVAILABILITY OF NEW RESEARCH PRIOR TO THE RELEASE OF THE 1953 WHO REPORT)

\begin{tabular}{|c|c|c|c|}
\hline $\begin{array}{c}\text { Treatment } \\
\text { values } \\
\text { (thematic). }\end{array}$ & $\begin{array}{c}\text { WHO Report, } \\
1953 .\end{array}$ & $\begin{array}{c}\text { Emergent research } \\
\text { (relative to the themes } \\
\text { of the WHO report) } \\
1932-\mathbf{5 2} \text {. }\end{array}$ & $\begin{array}{l}\text { Architectural } \\
\text { components \& } \\
\text { considerations. }\end{array}$ \\
\hline $\begin{array}{l}\text { The } \\
\text { preservation } \\
\text { of self- } \\
\text { esteem. }\end{array}$ & $\begin{array}{l}\text { Specified: } \\
\text { building scale, } \\
\text { sleeping spaces. }\end{array}$ & $\begin{array}{l}\text { The importance of } \\
\text { privacy in bathing and } \\
\text { dressing spaces was } \\
\text { highlighted within ex- } \\
\text { patient accounts } \\
(1946 \text { - 1947). }\end{array}$ & $\begin{array}{l}\text { Building scale, } \\
\text { sleeping spaces, } \\
\text { bathing and } \\
\text { dressing spaces. }\end{array}$ \\
\hline $\begin{array}{l}\text { Treatment } \\
\text { regimes } \\
\text { focused on } \\
\text { the individual. }\end{array}$ & $\begin{array}{l}\text { Specified: } \\
\text { the provision of } \\
\text { varying facilities for } \\
\text { care, including } \\
\text { some beyond } \\
\text { hospital } \\
\text { boundaries. }\end{array}$ & $\begin{array}{l}\text { Main urges different } \\
\text { facilities for different } \\
\text { patient groups (1948). } \\
\text { The Journal of Mental } \\
\text { Science supports a } \\
\text { variety of services co- } \\
\text { ordinated by the } \\
\text { hospital (1938 -1949). }\end{array}$ & $\begin{array}{l}\text { Varying facilities } \\
\text { to suit individual } \\
\text { patients including } \\
\text { those beyond } \\
\text { hospital grounds } \\
\text { (situated within the } \\
\text { community) } \\
\text { permeable } \\
\text { boundaries. }\end{array}$ \\
\hline $\begin{array}{l}\text { The } \\
\text { accordance of } \\
\text { trust to } \\
\text { patients. }\end{array}$ & $\begin{array}{l}\text { Specified: } \\
\text { unlocked doors }\end{array}$ & $\begin{array}{l}\text { Main urges trust for } \\
\text { patients but indicates } \\
\text { no architectural } \\
\text { response (1948). }\end{array}$ & $\begin{array}{l}\text { Unlocked doors, } \\
\text { relaxing hospital } \\
\text { boundaries. }\end{array}$ \\
\hline $\begin{array}{l}\text { The creation } \\
\text { of a group- } \\
\text { based, } \\
\text { therapeutic } \\
\text { community. }\end{array}$ & $\begin{array}{l}\text { Specified: } \\
\text { patient living } \\
\text { arrangements, the } \\
\text { physical shape and } \\
\text { appearance of the } \\
\text { hospital. }\end{array}$ & $\begin{array}{l}\text { Acknowledged by Main } \\
\text { but no architectural } \\
\text { response detailed } \\
(1948) .\end{array}$ & $\begin{array}{l}\text { Patient living } \\
\text { arrangements, } \\
\text { physical shape } \\
\text { and appearance } \\
\text { of the hospital. }\end{array}$ \\
\hline $\begin{array}{l}\text { Removing } \\
\text { barriers to } \\
\text { community } \\
\text { engagement. }\end{array}$ & $\begin{array}{l}\text { Specified: location } \\
\text { (close to the } \\
\text { community it served } \\
\text { and general } \\
\text { hospital services) } \\
\text { and the increased } \\
\text { permeability of } \\
\text { hospital } \\
\text { boundaries. }\end{array}$ & $\begin{array}{l}\text { Main advocates "two- } \\
\text { way" traffic between } \\
\text { community and } \\
\text { hospital (1948). }\end{array}$ & $\begin{array}{l}\text { Hospital location, } \\
\text { boundaries, visitor } \\
\text { spaces. }\end{array}$ \\
\hline $\begin{array}{l}\text { Miscellaneous } \\
\text { architectural } \\
\text { specifications. }\end{array}$ & $\begin{array}{l}\text { Specified: } \\
\text { landscape, } \\
\text { experimentation, } \\
\text { aesthetics (village } \\
\text { as model) }\end{array}$ & N/A. & $\begin{array}{l}\text { Landscape, design } \\
\text { experimentation, } \\
\text { aesthetics. }\end{array}$ \\
\hline $\begin{array}{l}\text { Education and } \\
\text { research. }\end{array}$ & $\begin{array}{l}\text { Specified: } \\
\text { outpatient and } \\
\text { research facilities. }\end{array}$ & $\begin{array}{l}\text { Existing psychopathic } \\
\text { hospital model (refer } \\
\text { chapter four) suggests } \\
\text { outpatient, research } \\
\text { and teaching facilities } \\
(1910-1930) \text {. }\end{array}$ & $\begin{array}{l}\text { Hospital location, } \\
\text { proximity to } \\
\text { general hospitals, } \\
\text { outpatient, } \\
\text { research and } \\
\text { teaching facilities. }\end{array}$ \\
\hline
\end{tabular}




\section{SUMMARY TABLE}

The villa hospital was designed to respond to moral treatment while the therapeutic community approach was viewed as a return, of sorts, to the aspirations of moral treatment. The criteria for both the villa hospital and the therapeutic community can be related back to the key architectural criteria of nineteenth century asylum construction. The summary table below provides an overview of the relationship between the four hospital models (table 3.4).

\section{TABLE 3.4: OVERVIEW OF CURATIVE CRITERIA,} ALL HOSPITAL MODELS

\begin{tabular}{|c|c|c|c|c|}
\hline $\begin{array}{l}\text { Architectural } \\
\text { components }\end{array}$ & $\begin{array}{l}\text { Moral Treatment } \\
\text { (Tuke, Brown } \\
\text { and Conolly) }\end{array}$ & $\begin{array}{l}\text { Villa Hospital } \\
\text { model }\end{array}$ & $\begin{array}{l}\text { Psychopathic } \\
\text { Hospital model }\end{array}$ & $\begin{array}{c}\text { Therapeutic } \\
\text { Community } \\
\text { model }\end{array}$ \\
\hline $\begin{array}{l}\text { Location } \\
\text { decisions on } \\
\text { site. Hospital } \\
\text { access } \\
\text { (proximity to } \\
\text { town) and } \\
\text { spaces for } \\
\text { visitation. }\end{array}$ & $\begin{array}{l}\text { All three } \\
\text { favoured keeping } \\
\text { a close proximity } \\
\text { to society; Tuke } \\
\text { and Browne in } \\
\text { order for social } \\
\text { ties to be } \\
\text { maintained, } \\
\text { Conolly in order } \\
\text { to enable easy } \\
\text { visitation by } \\
\text { friends and } \\
\text { family. }\end{array}$ & $\begin{array}{l}\text { Requires rural } \\
\text { site, flat or } \\
\text { gently } \\
\text { undulating. } \\
\text { NEW consid- } \\
\text { erations: room } \\
\text { for future } \\
\text { expansion, } \\
\text { accommodation } \\
\text { of staff (given } \\
\text { remote } \\
\text { locations). }\end{array}$ & $\begin{array}{l}\text { Rejects rural } \\
\text { site in favour of } \\
\text { urban site. } \\
\text { NEW consid- } \\
\text { erations: } \\
\text { proximity to } \\
\text { public transport, } \\
\text { general } \\
\text { hospitals and } \\
\text { medical } \\
\text { schools. }\end{array}$ & $\begin{array}{l}\text { NEW consid- } \\
\text { erations: } \\
\text { Removing } \\
\text { barriers to } \\
\text { community } \\
\text { engagement. } \\
\text { The WHO } \\
\text { report } \\
\text { suggested a } \\
\text { mix of facilities } \\
\text { (both rural and } \\
\text { urban based, } \\
\text { tailored to } \\
\text { different stages } \\
\text { and types of } \\
\text { illnesses) and } \\
\text { that hospital } \\
\text { boundaries } \\
\text { become more } \\
\text { permeable. }\end{array}$ \\
\hline $\begin{array}{l}\text { Appearance } \\
\text { (Disguising } \\
\text { Confinement) } \\
\text { architectural } \\
\text { style and } \\
\text { scale, } \\
\text { materials, } \\
\text { interior } \\
\text { treatments. } \\
\text { Including the } \\
\text { disguise of } \\
\text { locks, viewing } \\
\text { panes, heavy } \\
\text { doors etc. }\end{array}$ & $\begin{array}{l}\text { Tuke feared an } \\
\text { over emphasis on } \\
\text { safety to the } \\
\text { detriment of cure } \\
\text { and comfort. } \\
\text { Browne favoured } \\
\text { severity and } \\
\text { restraint to } \\
\text { mitigate suicide } \\
\text { risks. } \\
\text { Tuke favoured } \\
\text { the adoption of } \\
\text { domestic motifs, } \\
\text { Conolly favoured } \\
\text { a general hospital } \\
\text { aesthetic. }\end{array}$ & $\begin{array}{l}\text { Domestic } \\
\text { aesthetic and } \\
\text { scale favoured. } \\
\text { NEW consid- } \\
\text { erations: } \\
\text { Relationship of } \\
\text { service, staff } \\
\text { and hospital } \\
\text { buildings } \\
\text { relative to } \\
\text { patient villas. } \\
\text { Differentiation } \\
\text { of reception } \\
\text { (acute) wards } \\
\text { from other } \\
\text { villas. }\end{array}$ & $\begin{array}{l}\text { Favoured a } \\
\text { general hospital } \\
\text { aesthetic over a } \\
\text { village } \\
\text { aesthetic. } \\
\text { (this was } \\
\text { consistent with } \\
\text { Conolly's } \\
\text { preference). }\end{array}$ & $\begin{array}{l}\text { NEW consid- } \\
\text { erations: } \\
\text { The need to } \\
\text { preserve a } \\
\text { patients' self- } \\
\text { esteem was } \\
\text { identified. } \\
\text { The importance } \\
\text { of scale and } \\
\text { appearance } \\
\text { was specified. } \\
\text { Collaborations } \\
\text { with domestic } \\
\text { architects } \\
\text { encouraged. }\end{array}$ \\
\hline
\end{tabular}




\begin{tabular}{|c|c|c|c|c|}
\hline \multicolumn{5}{|c|}{ TABLE 3.4 continued. } \\
\hline $\begin{array}{l}\text { Architectural } \\
\text { components }\end{array}$ & $\begin{array}{l}\text { Moral Treatment } \\
\text { (Tuke, Brown } \\
\text { and Conolly) }\end{array}$ & $\begin{array}{l}\text { Villa Hospital } \\
\text { model }\end{array}$ & $\begin{array}{l}\text { Psychopathic } \\
\text { Hospital model }\end{array}$ & $\begin{array}{c}\text { Therapeutic } \\
\text { Community } \\
\text { model }\end{array}$ \\
\hline $\begin{array}{l}\text { Landscape } \\
\text { windows, } \\
\text { orientation } \\
\text { (outlook \& } \\
\text { sunshine), } \\
\text { exterior/ } \\
\text { interior } \\
\text { thresholds } \\
\text { (access to } \\
\text { landscape). }\end{array}$ & $\begin{array}{l}\text { All three agreed } \\
\text { on the importance } \\
\text { of nature for } \\
\text { recreation and } \\
\text { occupation; rural } \\
\text { outlooks, } \\
\text { sunshine and } \\
\text { privacy from the } \\
\text { public. }\end{array}$ & $\begin{array}{l}\text { NEW consid- } \\
\text { erations: Open } \\
\text { door practices } \\
\text { meant relative } \\
\text { freedom of } \\
\text { movement } \\
\text { within hospital } \\
\text { grounds. }\end{array}$ & N/a. & $\begin{array}{l}\text { NEW consid- } \\
\text { erations: } \\
\text { The need to } \\
\text { accord trust to } \\
\text { patients was } \\
\text { identified. } \\
\text { Unlocked doors } \\
\text { and further } \\
\text { relaxation of } \\
\text { hospital } \\
\text { boundaries. }\end{array}$ \\
\hline $\begin{array}{l}\text { Individual } \\
\text { treatment } \\
\text { and } \\
\text { tranquility } \\
\text { asylum size, } \\
\text { the provision } \\
\text { of private } \\
\text { versus public } \\
\text { space } \\
\text { (dormitories, } \\
\text { bathrooms } \\
\text { etc.), } \\
\text { dormitory and } \\
\text { ward size, } \\
\text { dormitory } \\
\text { quality, the } \\
\text { provision of } \\
\text { personal, } \\
\text { domestic } \\
\text { items } \\
\text { (storage, } \\
\text { wash-stands, } \\
\text { mirrors etc.). }\end{array}$ & $\begin{array}{l}\text { Tuke } \\
\text { recommended a } \\
\text { maximum asylum } \\
\text { size of } 30 \\
\text { patients and } \\
\text { Conolly } 400 \text {. } \\
\text { Tuke stated that } \\
\text { the provision of } \\
\text { privacy and } \\
\text { tranquility was of } \\
\text { the upmost } \\
\text { importance and } \\
\text { argued for private } \\
\text { rooms. Conolly's } \\
\text { preference was } \\
\text { two-thirds private } \\
\text { rooms and for } \\
\text { dormitory's to be } \\
\text { limited to } 6 \text { beds. } \\
\text { Browne valued } \\
\text { economy over } \\
\text { privacy } \\
\text { (dormitories had } \\
\text { their place). } \\
\text { All three stated } \\
\text { the importance of } \\
\text { individual } \\
\text { treatment. }\end{array}$ & $\begin{array}{l}\text { Individual } \\
\text { treatment } \\
\text { remains } \\
\text { important. } \\
\text { NEW consid- } \\
\text { erations: } \\
\text { Occupational } \\
\text { therapy spaces. } \\
\text { Gymnasiums } \\
\text { and swimming } \\
\text { pools (in } \\
\text { addition to } \\
\text { traditional } \\
\text { recreational } \\
\text { facilities). }\end{array}$ & $\begin{array}{l}\text { Individual } \\
\text { treatment } \\
\text { depended upon } \\
\text { high staffing } \\
\text { levels and small } \\
\text { hospital } \\
\text { populations in } \\
\text { lieu of } \\
\text { architectural } \\
\text { considerations. }\end{array}$ & $\begin{array}{l}\text { The WHO report } \\
\text { specified the } \\
\text { provision of } \\
\text { varying facilities } \\
\text { for care, } \\
\text { including some } \\
\text { beyond hospital } \\
\text { boundaries. } \\
\text { NEW consid- } \\
\text { erations: } \\
\text { The need to } \\
\text { preserve } \\
\text { patients self- } \\
\text { esteem was } \\
\text { identified. } \\
\text { Threw decisions } \\
\text { around } \\
\text { sleeping, } \\
\text { bathing and } \\
\text { dressing spaces } \\
\text { into question. } \\
\text { The creation of } \\
\text { a group based } \\
\text { therapeutic } \\
\text { community. } \\
\text { Threw decisions } \\
\text { around the } \\
\text { living } \\
\text { arrangements } \\
\text { of patients into } \\
\text { question. }\end{array}$ \\
\hline & & & $\begin{array}{l}\text { NEW consid- } \\
\text { erations: } \\
\text { Teaching, } \\
\text { research and } \\
\text { outpatient } \\
\text { facilities. }\end{array}$ & $\begin{array}{l}\text { The WHO } \\
\text { report recog- } \\
\text { nised the value } \\
\text { of teaching, } \\
\text { research and } \\
\text { outpatient } \\
\text { facilities. }\end{array}$ \\
\hline
\end{tabular}


${ }^{1}$ Scull 1979, 104.

${ }^{2}$ Browne 1837.

${ }^{3}$ Conolly 1847.

${ }^{4}$ Ibid, 11-2.

${ }^{5}$ Brunton 2003, 81-4.

${ }^{6}$ Scull 1991, vii.

${ }^{7}$ AJHR 1886, H-09, 2.

${ }^{8}$ Refer, for example, Conolly $1847,8$.

${ }^{9}$ Tuke 1813, 23.

${ }^{10}$ Browne 1837, 153, 181.

${ }^{11}$ Conolly $1847,8$.

${ }^{12}$ Tuke 1813, xii, 94-5.

${ }^{13}$ Browne 1837, 182.

${ }^{14}$ Tuke 1813, 40-1, 94-5.

${ }^{15}$ Conolly $1847,10,15,50-1$.

${ }^{16}$ Tuke 1813, 106.

${ }^{17}$ Conolly 1847,10 . Browne similarly stated that light and air should be "allowed to enter at every window." Browne 1837, 229.

${ }^{18}$ Browne 1837, 204.

${ }^{19}$ Tuke $1813,105-7$.

${ }^{20}$ Conolly $1847,16$.

${ }^{21}$ Ibid, 98.

${ }^{22}$ Browne 1837, 149, 183-4, 187-9.

${ }^{23}$ Tuke 1813, 94.

${ }^{24}$ Digby 1985, 39. Tuke 1813, 40-1, 94-5.

${ }^{25}$ Correspondence from John Beavans, Architect, to the Samuel Tuke (held by the York Retreat Archives) as quoted in Digby 1985, 37.

${ }^{26}$ Digby 1985, 37.

${ }^{27}$ Conolly $1847,14$.

${ }^{28}$ Ibid, 29, 53.

${ }^{29}$ Edginton 2007, 86.

${ }^{30}$ Tuke 1813, 144. Also refer correspondance from Samuel Tuke to John Beavans, 1793 (held by the York Retreat Archives) as quoted in Edginton 1997, 94.

${ }^{31}$ Samuel Tuke, A Letter on Pauper Lunatic Asylums (New York, 1815) as quoted in Scull 1979, 104.

${ }^{32}$ Conolly $1847,10-5,24-5$.

${ }^{33}$ Ibid, 19.

${ }^{34}$ Ibid, 10, 15.

${ }^{35}$ Browne 1837, 186-7.

${ }^{36}$ Conolly 1847, 22. 
${ }^{37}$ Conolly $1830,31$.

${ }^{38}$ Ibid, 11-2, 17, 21.

${ }^{39}$ Browne 1837, 144.

${ }^{40}$ Yanni 2007, 91-92. Hack-Tuke 1891, 471.

${ }^{41}$ Norman 1894, 494.

${ }^{42}$ Gray 1958, 64.

${ }^{43}$ Ibid.

${ }^{44}$ Topp 2007, 244.

${ }^{45}$ Gray 1958, 64.

${ }^{46}$ Knowles Stansfield 1914, 31. Lomax 1921, 247.

47 "Book Review: The Colonization of the Insane in Connection with the Open-Door System," 1895, 698.

${ }^{48}$ Yanni 2007, 84-8.

${ }^{49}$ Galt 1854-55, 352.

${ }^{50} \mathrm{Ibid}, 699$.

51 Tuke 1891, 471.

${ }^{52}$ Gray 1958, 64.

${ }^{53}$ Topp 2007, 242-6.

${ }^{54}$ Topp 2007, 246.

${ }^{55}$ Steen 1900, 99-100.

${ }^{56}$ Topp 2007, 242-6.

${ }^{57}$ Hart 1927, 64, 125.

${ }^{58}$ Ibid, 56, 64.

${ }^{59}$ AJHR 1925, H-07,4.

${ }^{60}$ Thompson 1992, 59.

${ }^{61}$ Winslow 1933 (reprinted in Beers 1944, 308).

${ }^{62}$ First International Congress on Mental Hygiene 1929, 21.

${ }^{63}$ Winslow 1933 and the United States National Committee for Mental Hygiene 1942 (both reprinted in Beers 1944, 308, 319-330, 333-4).

${ }^{64}$ First International Congress on Mental Hygiene 1929, 21.

${ }^{65}$ Hollander 1931, 39.

${ }^{66}$ Thompson 1992, 67.

${ }^{67}$ Scull 2006, 170-81.

${ }^{68}$ Scull 2006, 170-81.

${ }^{69}$ Review of Cotton's published lectures as printed in the New York Times, June 1922. Cited from http://en.wikipedia.org/wiki/Henry_Cotton_(doctor). Date accessed: March 14, 2013. For further examples of praise for Cotton's work refer Scull 2006, 181.

${ }^{70}$ Brunton 2001, 253, 256.

${ }^{71}$ Brunton 2001, 253, 256. Gray 1958. 
${ }^{72}$ Gray 1929.

${ }^{73}$ Burdett 1891, vol. 1, 127.

${ }^{74}$ Yanni 2007, 91-92.

${ }^{75}$ Ibid.

${ }^{76}$ Dunning (Chicago State) Hospital, 1910, and Whitby Hospital, Toronto, 1919. Gray 1929, 11.

${ }^{77}$ Gray 1929, 11.

${ }^{78}$ Brunton 2001, 256.

${ }^{79}$ The author has deduced the approximate size of the hospital building from an annotated plan (drawn by Richard Dewey 1878) reproduced in Yanni 2007, 91-92.

80 "The First British Village Asylum," 1906, 1500-01.

${ }^{81}$ Refer the Globe, April 18, 1893 and Seacliff Outwards Correspondence Book, Vol. 1, September 19, 1885, held by ANZ (as quoted in Hubbard 1977, 61, 64. The author was unable to locate these original sources).

${ }^{82}$ Kennedy 1963, 186-7.

${ }^{83}$ Andrews et al. 1997, 550.

84 "Proposed New Hospital for Mental Diseases," 1908, 728-729.

${ }^{85}$ Beers 1944.

86 "Proposed New Hospital for Mental Diseases," 1908, 728-729.

${ }^{87}$ Plans of Maudsley Hospital, 1912- 1913. Bethlem Hospital Archive: YDP-01 M1/14

${ }^{88}$ Prebble 2007, 125.

${ }^{89}$ Williams 1987, 204.

${ }^{90}$ James 1948, 146.

${ }^{91}$ Ibid, 144-5.

${ }^{92}$ Ibid, 144-5.

${ }^{93}$ Ibid, 128.

${ }^{94}$ Clark 1988, 32-5.

${ }^{95}$ Rees 1957, 312-3.

${ }^{96}$ United States National Institute of Health 1961, 46. The text cites a 1958 report by Dr Robert C. Hunt, Superintendent of the Hudson River State Hospital (New York).

97 Jones, Barker and Freeman 1952, xiii.

${ }^{98}$ Clark 1965, 948. "David Clark Obituary," The Guardian (London), May 11, 2010.

${ }^{99}$ Harris 1948.

${ }^{100}$ Racliff 1962, 188-90.

${ }^{101}$ Atkin 1962, 350. Crawford 1962, 351. Cook, 1962, 299. Todd and Mackie 1963, 952.

102 Clark 1988, 34.

${ }^{103}$ WHO 1953, 17.

104 Ibid, 17-8.

105 Ibid, 18.

${ }^{106}$ Ibid, 18, 20. 
${ }^{107}$ Clark 1965, 34.

${ }^{108}$ WHO 1953, 8, 18, 34.

${ }^{109}$ Clark 1965, 948.

110 "On Leaving the Mental Hospital" 1940, 654. "Mental Hospitals in the New Service" 1946, 94. Wilde 1952, 387.

111 Pentreath and Cunningham Dax 1937. McRae 1937. Stone and Evans 1938 Flind 1939. Fox 1939. Kimber 1939a. Kimber 1939b. Harris 1939. Bierer and Haldane 1941. Petrie 1944. Petrie 1945. Brock 1946. Goldschmidt 1946. MacKeith 1946. Webster 1948. O’Reilly 1948. Rees-Thomas 1949. Ivison Russell 1949.

112 O'Reilly 1948.

${ }^{113}$ Brunton 2003, 81-89. Brunton cites references by the Seacliff Superintendent to this journal as early as 1897 although it is likely the journal was subscribed to prior to this date.

${ }^{114}$ Personal correspondence, Richard German, Faculty Librarian, Health Sciences Library, University of Otago, July 02, 2012.

${ }^{115}$ Main did not contribute to this report, nor was his research acknowledged within it; however, his ideas closely matched those put forward by the WHO report. The similarities which will be discussed in Section 5.3.

${ }^{116}$ Rees-Thomas 1949, 1.

${ }^{117}$ WHO 1953, 18.

118 Ibid, 29, 31.

${ }^{119}$ Ward 1946, 34, 67. Ogdon 1947, 126. Also refer Woodley 1947, 13.

${ }^{120}$ O'Reilly $1948,110$.

${ }^{121}$ WHO 1953, 22-23, 27- 28, 34.

${ }^{122}$ Main 1948, 405-7.

${ }^{123}$ Ogdon 1947, 238.

${ }^{124}$ Main 1948, 405-7. Kimber 1939a, 29-44.

${ }^{125}$ Brock 1946, 287-304. Ivison Russell 1949, 785-794. Kimber 1939a, 29-44. Stone and Evans 1938, 381-399.

${ }^{126}$ WHO 1953, 18.

${ }^{127}$ Ibid, 18, 22.

${ }^{128}$ Ward 1946, 275.

${ }^{129}$ WHO 1953, 19.

${ }^{130}$ Main 1946, 66.

${ }^{131}$ WHO 1953, 13, 18, 20, 23.

132 Main 1948, 396, 399, 404.

${ }^{133}$ WHO 1953, 19, 20, 22, 31.

134 Ogdon 1947, 121, 145.

${ }^{135}$ WHO 1953, 18-9, 22, 32.

${ }^{136}$ Main 1948, 405.

${ }^{137}$ Ibid. 
${ }^{138}$ WHO 1953, 14.

139 Ibid, 29.

140 Ibid, 29-30.

141 lbid, 32.

142 Ibid, 24-5.

${ }^{143}$ Ibid, 9-10.

${ }^{144}$ Ibid, 12.

${ }^{145}$ O'Reilly 1948, 107.

${ }^{146}$ WHO 1953, 31. 


\section{CHAPTER FOUR \\ Seacliff Asylum: Colonial Aspiration and the Curative Intent}

Seacliff Asylum was constructed between 1878 and 1884, three decades on from Britain's establishment of the Lunatics Act (1845). It thus presented New Zealand with the opportunity to critically evaluate the success of the British system of asylum care and the architectural solutions created for it. As the previous two chapters have discussed, two significant changes occurred in the approach to asylum design between 1845 and 1877, when Seacliff was designed. The first was the wider integration of the architectural principles developed at the York Retreat which, according to Barry Edginton, became increasingly regarded as essential after the 1845 Lunatics Act was passed into law. ${ }^{1}$ The second shift to occur by 1877 , according to Andrew Scull and Ruth Caplan, was that the custodial role of asylums came to be regarded, once again, as acceptable owing to the failure of the asylum typology to deliver the cure rates initially hoped for. ${ }^{2}$ Warwick Brunton has suggested, however, that since colonists viewed British models of lunacy care as "progressive, humane and fashionable," they adopted them without reservation. ${ }^{3}$ This case study will evaluate Seacliff relative to contemporary thought regarding best architectural practice in lunacy care. It will also look at the opportunities that were available for advancing existing British models of practice architecturally.

This case study will also examine issues of colonial ambition and propaganda in the design of Seacliff Asylum, both from a political and professional standpoint. This dissertation aside, little investigation has so far been expended on the subject of architect Robert Lawson's achievement in the design of Seacliff Asylum and whether it was consistent with best architectural practice in the care of lunacy. Existing work by Frank Tod and William Prior has cited the criticisms made by G.W. Grabham and D. MacGregor who were subsequent Inspectors-General of New Zealand's asylums during the course of Seacliff's construction, without critical examination. Tod and Prior have assumed that, by virtue of their medical knowledge, these criticisms could be taken at their word. ${ }^{4}$ While little is known of Lawson's character or private life, the myth surrounding him is that of a man who wished to shape Dunedin's "entire cityscape." ${ }^{5}$ The repetition of the criticisms made by Grabham and MacGregor perpetuates the myth of Lawson as a man driven by ambition and raises the possibly that he was 
willing to place the consolidation of his own architectural reputation above the needs of the patients he was appointed to design for. This case study will test the role that Lawson's personal ambition may have played in limiting the curative potential of Seacliff Asylum. Furthermore, it will account for the context within which Lawson was employed and the expectations of colonial fear (of lunacy) and aspiration that his design was expected to address. This has yet to be examined by historians.

It wasn't simply medical criticism that plagued Lawson in the design of this institution, however, construction difficulties led to a Commission of Inquiry (1888) into the design of this building that saw Lawson accused of inadequate documentation and inadequate supervision of the construction works. ${ }^{6}$ The view has long been held that the fallout from this Inquiry damaged Lawson's career irreparably and motivated his departure from Otago. ${ }^{7}$ However, Norman Ledgerwood, in his recent publication on Lawson's career, has overturned this "popular misconception." He suggests that a shortage of available work, owing to the depression, motivated Lawson's departure from this province, in 1890, and that he left Otago "with his reputation intact and with the respect of his peers." 8 Since this dissertation is primarily concerned with the curative potential of the environment created at Seacliff, the issues raised in the 1888 Inquiry will be discussed only where they can heighten the understanding of the context in which this asylum was constructed.

This case study aims to understand how personal and political aspiration within colonial New Zealand was able to impact on the design of Seacliff Asylum. This understanding will contribute to our existing knowledge of official attitudes to mental illness in late nineteenth century New Zealand.

This chapter will first offer a background to colonial Dunedin and the decision to replace the original asylum. Section two and three will evaluate Seacliff relative to the curative criteria set up within chapter three (table 3.1) and against leading developments in asylum design. Section four will look at issues of colonial resourcing in the design of Seacliff, namely access to funding and professional knowledge. Section five will examine issues of colonial aspiration and expectation, including Lawson's. Finally, section six will examine the warnings against asylum care that were available at the time of Seacliff's design and the various alternatives for the design of environments for lunacy care. 


\subsection{SEACLIFF IN CONTEXT: THE SETTLEMENT OF DUNEDIN AND MYTHS OF COLONISATION}

Like any architectural undertaking in New Zealand during the nineteenth century, Seacliff was subject to the competing pressures that arose out of the country's colonial condition. This section will offer a brief background to Dunedin's settlement, the economic situation and the problem of lunacy relative to the great colonial dream.

Dunedin was situated at the farthest reaches of the British Empire and intended, originally, for Scottish migrants. The city, whose plan was arranged to reflect that of the Scottish capital, was founded in 1848 under a settlement scheme titled "New Edinburgh." From 1865 to 1900 Dunedin was the country's largest and most prosperous city. ${ }^{9}$ Within ten years of settlement, Dunedin had a population of 1,700. By 1874 this had grown to $18,500 .^{10}$ By 1881 , the population had more than doubled again, reaching $42,802 .{ }^{11}$ While Otago remained relatively stable until 1900, it existed within a wider context of instability. Historian James Belich explains that early New Zealand towns were "produced by war, gold and progress" and fought hard to retain a future. According to one source found by Belich (which he does not name) 240 New Zealand towns simply faded into history, while more than 180 newspapers were started up between 1860 and 1879. Each of these "trumpeted" its own infant town as "the London of the South." 12 According to Belich, settlers brought with them from Britain a "deep fear of economic insecurity and social disharmony." They longed for permanence and respectability: "even consumer credit was more accessible to those who looked like they would be in the same place next week." The resulting architectural response was the construction of provincial buildings in Otago and Canterbury that communicated stability. ${ }^{13}$

With regard to the priorities and outlooks of colonial settlers, Belich suggests that they bought into a collective identity, and a collective struggle, in the pursuit of a "Better Britain" - the idea that New Zealand would eventually equal or surpass Old Britain in wealth and population. ${ }^{14}$ William Pember Reeves, who wrote about New Zealand in 1898, explained that colonists saw this new land as "almost free from extremes of wealth and poverty, from class hatreds and fears and the barriers these create." They hoped to prevent the intrusion of the "social evils and miseries which afflict great nations." ${ }^{15}$ Lunacy was a thorn in the side of the colonial dream. According to Miles Fairburn, immigrants were sold a myth of New Zealand as a tranquil, "orderly society," free from crime and conflict. ${ }^{16}$ In 1878 , the same year the architectural commission for Seacliff was awarded, Inspector General Skae wrote that the ratio of asylum admissions per head of population was considerably higher than that found in Victoria and New South Wales (two years earlier) and larger than that found in Britain. ${ }^{17}$ In 1872, Dr W.L. Lindsay observed that the "wholesale transhipment... of certain classes of the insane" to New Zealand contributed to the high incidence of insanity. ${ }^{18}$ Lindsay was a Scottish Physician from the Murray 
Royal Institution for the Insane (Perth, Scotland) who had toured New Zealand for five months during 1861. He published his findings on lunacy within this new colony in the Edinburgh Medical Journal in 1872 and the Journal of Mental Science in 1873. Warwick Brunton has more recently disputed Lindsay's observation; he claims that there is little archival evidence to support the "mass shipments of lunatics to the antipodes." ${ }^{19} \mathrm{Dr}$ M.S. Grace, a medically qualified Legislative Councillor, gave the following opinion as to why insanity was more common in New Zealand in 1871:

[it is] chiefly on account of the limited range of sympathy which the isolation of individuals and families in the country gives rise to, and... the oppressive loneliness which many new comers experience... Many immigrants too, form the most extravagant anticipations of their new home, and are proportionately depressed by the result of actual experience. ${ }^{20}$

Asylum reports from 1874 observed that the suitability of migrants for the difficulties of this new country and the number of unmarried men who travelled to New Zealand in search of gold contributed to the incidence of insanity. ${ }^{21}$ In 1878, 46 per cent of New Zealand's asylum population were unmarried men, while unmarried women, by comparison, represented only 16 per cent. ${ }^{22}$ Fairburn observed that the consequences of social isolation and a shortage of family and close community ties within colonial New Zealand resulted in asylums resembling "dumping grounds." The elderly, alcoholics and those suffering from temporary or minor afflictions that would normally be cared for within the family ended up in institutions because they had no friends or relations to undertake this care. ${ }^{23}$

In colonial New Zealand, according to Brunton, insanity became a problem only when lives or property were threatened (either that of the lunatic himself or those in his vicinity). ${ }^{24}$ The Lunatics Ordinance of 1846 exhibited a clear concern toward upholding law and order. It was created:

to make provision for the safe custody and prevention of offences by persons dangerously insane, and for the care and maintenance of persons of unsound mind. ${ }^{25}$

The act assumed that a level of state funded care would be required and provided for lunatics to be temporarily held in gaols or hospitals, followed by transferral to an asylum if necessary. ${ }^{26}$ Despite this act, discussions regarding the Government provision of a central lunatic asylum did not begin until 1855, over a decade later. The provinces which, at that time, were self-governing found this progress inadequate and sought their own solutions to the lunacy problem. Wellington renovated an existing dwelling for asylum use in 1854, while Christchurch and Dunedin both opened small, purpose built asylums in 1863 (figures 4.1 and 4.2). Auckland was the first to commit to plans on a larger scale; the Whau Asylum was designed for one hundred patients but opened with only half that capacity in 1867 . Brunton advises that "fluctuating finances, diverse fortunes and uneven 
development of public works" throughout the provinces had consequences for the delivery of lunacy care..$^{27}$ In 1871 the Parliamentary Joint Committee decided that a national inspector was the best option for ensuring a uniform standard of care. ${ }^{28}$

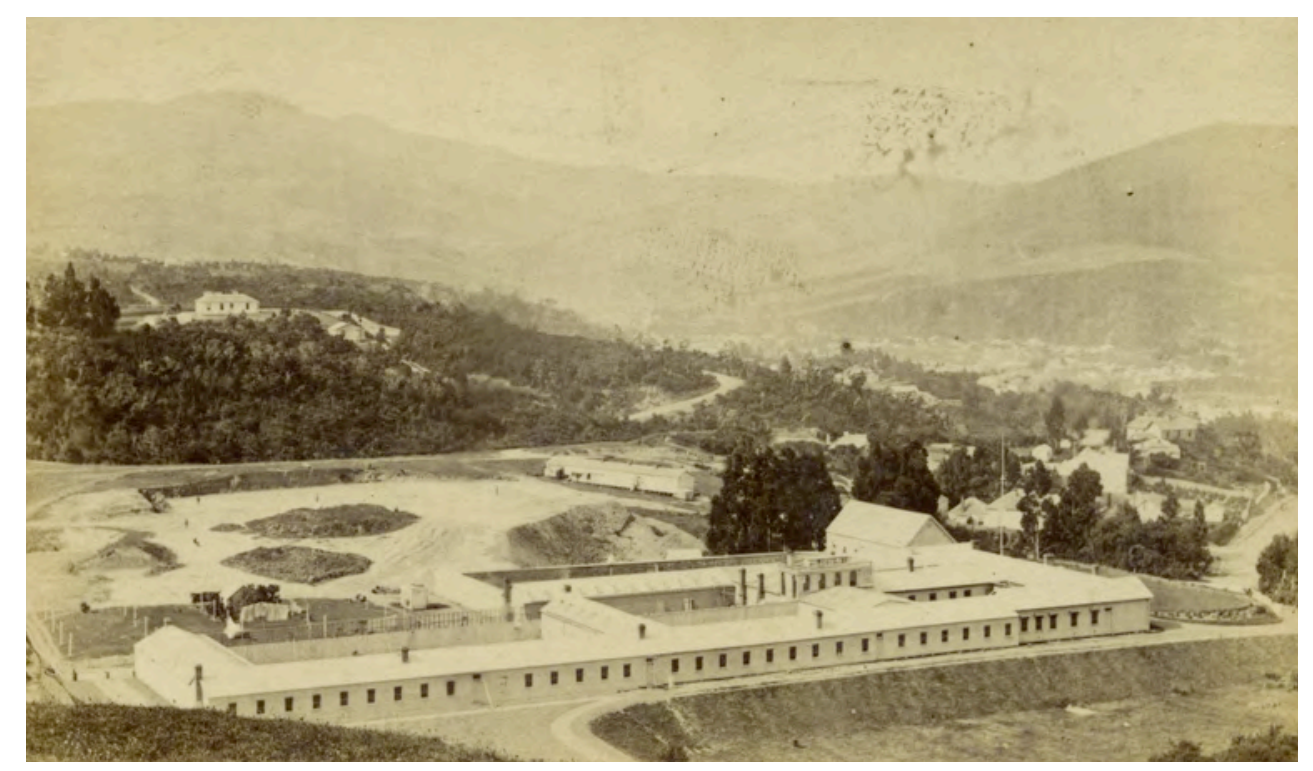

Figure 4.1: Dunedin Lunatic Asylum, 1874. Photograph by J.W. Allen. Alexander Turnbull Library: PA2-0005.

In 1872, a decade after his study tour, Lindsay reported on his observations regarding lunacy in New Zealand in the Edinburgh Medical Journal. Lindsay made a number of suggestions within this report including that "a dulyqualified medical officer from the United Kingdom" be appointed to supervise all of the colony's lunatic asylums. ${ }^{29}$ His recommendation was consistent with the decision made by the Parliamentary Joint Committee 1871. Four years later, F.W.A. Skae was appointed as New Zealand's first Inspector-General of Asylums (1876-81); he was followed by G.W. Grabham (1882-86) and D. MacGregor (1886-1906). Skae and Grabham were appointed directly to New Zealand from positions as asylum superintendents in the United Kingdom, Skae from the Stirling District Asylum in Scotland and Grabham from the Earlswood Idiot Asylum in Surrey, England. ${ }^{30}$ MacGregor was appointed from New Zealand but was born and educated in Scotland. He studied mental philosophy and medicine at the University of Edinburgh and arrived in New Zealand in 1871 to take up the post of Professor of Mental and Moral Philosophy at the University of Otago. MacGregor acted as an Inspector for the Dunedin Asylum prior to his appointment as national inspector in $1886 .^{31}$ 


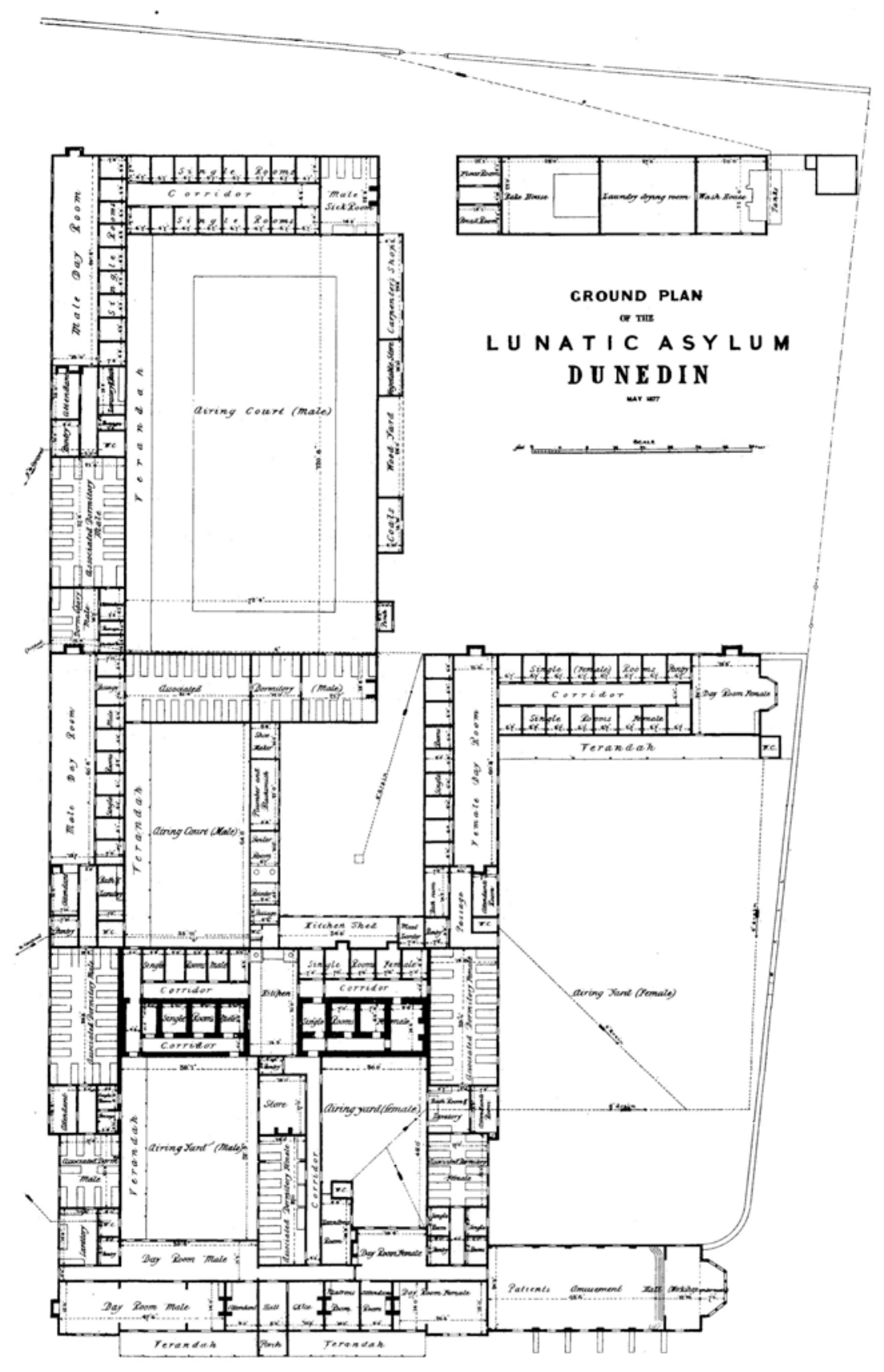

Figure 4.2: Plan of the temporary Dunedin Asylum, Arthur Street, 1877. As published in AJHR 1877, H-08, 41.

Between 1872 and 1874 New Zealand experienced an economic boom with "full employment and rising incomes" but export prices fell in 1876 and by 1879 New Zealand was heading into the Long Depression. ${ }^{32}$ The financial burden of maintaining lunatics in New Zealand was significant. In 1887 it cost $£ 34,757$ to maintain an average patient population of 818 . Only $£ 3,288$ of this expenditure was recoverable from the families of private patients. ${ }^{33}$ To put this expenditure in perspective, the budget for constructing a town hall for Dunedin in 1876, then the country's most populated and prosperous city, was set at $£ 30,000$. Only half of that budget, however, was available to be spent when construction began. ${ }^{34}$ At the same time the government was 
committed to constructing a national rail network that cost $£ 850,000$ annually. ${ }^{35}$ According to the Encyclopedia of New Zealand, sources of government revenue were so limited during the period in which Seacliff was built that "only the bare essentials could be paid for." ${ }^{36}$ In $1873 \mathrm{Dr}$ Buchannan of Dunedin wrote to Lindsay in Scotland that:

Whilst the colony is spending some $£ 40,000$ a-year on postal subsidies and several millions on public works and immigration... the Government refused a paltry $£ 1200$ or $£ 1500$ to provide... [a] medical officer... of course, the care of the Insane costs money and does not "pay." 37

Grabham's report to the Appendix to the Journals to the House of Representatives (hereafter $A J H R$ ) in 1888 reflected the serious effects of insufficient government revenue on the delivery of asylum care. Facilities at Auckland, Christchurch and Porirua were seriously overcrowded and plans for additional accommodation had been completed. Despite the funds being voted by the Legislature for additions to be made, Grabham could not get the government to carry out these works. Grabham's frustration at this state of affairs was palpable; at the Whau Asylum (Auckland), for example, he described the state of overcrowding as "positively disgraceful." ${ }^{38}$ Seacliff, however, did not appear to have suffered as severely from the effects of the Long Depression as the other New Zealand asylums. In 1878 Skae recommended a budget for the construction of Seacliff at $£ 200$ per patient. This was $£ 50$ per patient higher than the cost of construction at "more modern English Asylums" during the same period. ${ }^{39}$ This discrepancy is likely attributable to the distance of New Zealand from suppliers and the need to import specialist items such as lock fittings. Skae's estimate of 1878 was consistent with the expenditure incurred on additional accommodation for the Sunnyside Asylum in 1879 and 1880 which was constructed for around $£ 200$ per patient. ${ }^{40}$ The final construction cost of Seacliff, however, was close to $£ 600$ per patient. ${ }^{41}$ This expenditure raises the question of parity - was accommodation at Seacliff constructed to a much higher standard than that provided at Sunnyside?

Despite the financial constraints of being a small, young and remote colony, colonists sought to shape this new country according to egalitarian ideals. Lunacy, however, was an expensive and largely unanticipated problem. This led to early, piecemeal approaches to lunacy care that were exacerbated by the fact that there was no ready supply of men with sufficient experience to direct the development New Zealand's asylum system. Despite the effects of the Long Depression, however, a considerable amount of funding was contributed towards the construction of Seacliff, well in excess of the funds committed to the construction of other New Zealand asylums. This case study will examine how closely Seacliff adhered to best ideas around the treatment of lunacy and why such a variant response was taken to this one institution. 


\subsection{SEACLIFF: ONE OF THE FINEST BUILDINGS OF ITS KIND IN THE SOUTHERN HEMISPHERE}

In 1881, when Seacliff was under construction, $\mathrm{Dr}$ Neil, the medical superintendent of the (temporary) Dunedin Asylum, wrote that, once completed, Seacliff Asylum would be "one of the finest buildings of its kind in the Southern Hemisphere." ${ }^{42}$ The accumulated texts of Tuke, Browne and Conolly set up the architectural strategies for the successful creation of a curative environment and, as the previous section outlined, Brunton has established that Conolly's text was held by the Parliamentary Library when the planning of Seacliff was undertaken. ${ }^{43}$ It is not unreasonable, therefore, to expect this asylum to have followed the advice contained in Conolly's book, if not also the collective advice of Tuke and Browne. This section will outline the decision to build Seacliff in 1878 before examining how closely this asylum adhered to the curative criteria set out by Tuke, Brown and Conolly.

When the Otago Association prepared plans for the city of Dunedin it indicated a cemetery reserve in Arthur Street. The temporary asylum was erected within this reserve in 1863. According to local historian Frank Tod, this resulted in public outcry. Sixteen property owners petitioned the Provincial Government on the grounds that the Otago Association had acted in bad faith; the asylum's location was contrary to their terms of purchase and resulted in the depreciation of their property values. Land owners were also concerned by the possibility of patient escapes and demanded "immediate redress of their grievances." ${ }^{44}$ Just a year after the temporary asylum was opened the Provincial Government began considering alternative sites beyond city limits. ${ }^{45}$ Fourteen years passed before any action was taken to procure a replacement.

In Skae's first report as Inspector-General he recommended the replacement of the temporary asylum; it was badly constructed, "exceedingly gloomy and prison-like," and accommodated 236 patients in a space designed for $36 .{ }^{46}$ Skae's report did not acknowledge, however, that substantial additions were made to this asylum in 1864 that had effectively doubled its size. ${ }^{47}$ Nonetheless, best medical practice could not be delivered at the Dunedin site owing to its heavily overcrowded state, the "extreme publicity of the situation" and the lack of space available for patients to take outdoor exercise. ${ }^{48}$ Skae lamented that, owing to a "fear of fights and serious accidents," mechanical restraint and seclusion were being used "to an extent... which no one would think of justifying in a properly constructed Asylum." ${ }^{49}$ A year after Skae's report was published a site was chosen, at Brinns Point, Seacliff, for a new asylum and Robert Lawson was appointed as architect. ${ }^{50}$ 
In 1887, Grabham recorded in the AJHR that he believed Lawson had based the floor plans for Seacliff upon the Norwich Lunatic Asylum by R.M. Phipson, drawings of which had been published in The Builder a year prior (figures $4.3-4.5$ ). ${ }^{51}$ While Lawson left no record confirming this, there is a strong resemblance between these two plans. Norwich was composed of a number of two storied pavilions, joined by single storied corridors. The pavilions contained a mix of dayrooms, bathrooms and staff accommodation on the ground floor, with patient dormitories located above. Single-loaded corridors were used, leaving one side free for external windows that allowed maximum light and ventilation.

Seacliff was also composed of a number of pavilions which, like Phipson's design, accommodated day rooms on the ground floor and dormitories on the two floors above. On the second floor of the asylum Lawson placed a centralised service core that contained kitchens and stores. The recreation hall occurred directly ahead of these spaces on the same level; if this space was intended to double as a dining hall it would have been an efficient arrangement for the delivery of meals. In later years the recreation hall was used for dining, however, we have no documentation to confirm if that was the architect's intention or if patients were merely expected to dine within their day rooms. Below the recreation hall the doctor's office and four private visiting rooms were positioned. The corridors connecting the central core with the individual pavilions contained single rooms, for both patients and staff, as well as additional day room space. The asylum was divided, either side of its central core, into female and male sections. Female accommodation occurred to the north and male accommodation to the south. 


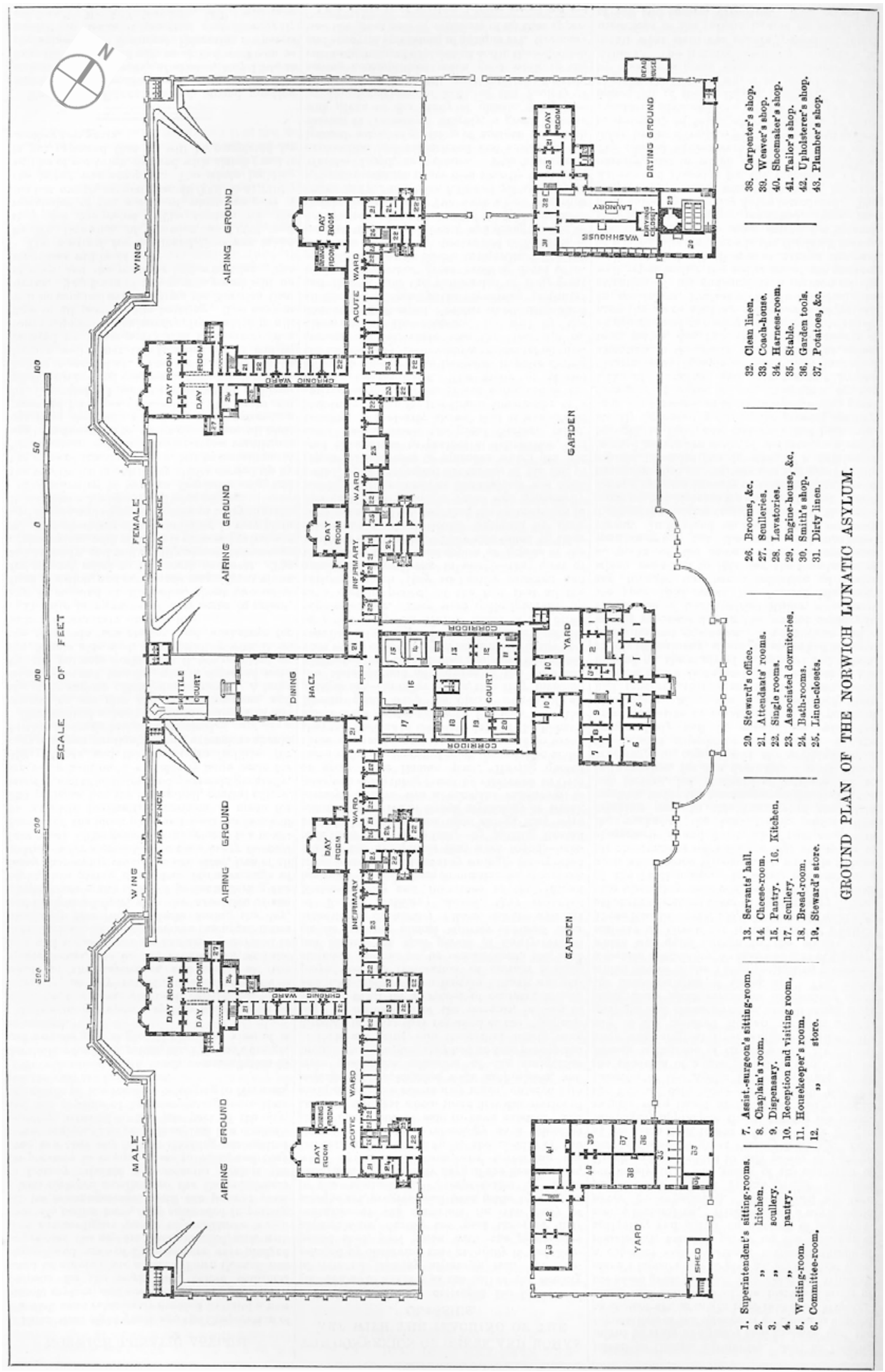

Figure 4.3: Norwich Asylum Ground Floor Plan, by R.M Phipson (north sign added by author). As published in The Builder, vol. 35, May 12 (1877): 481. 


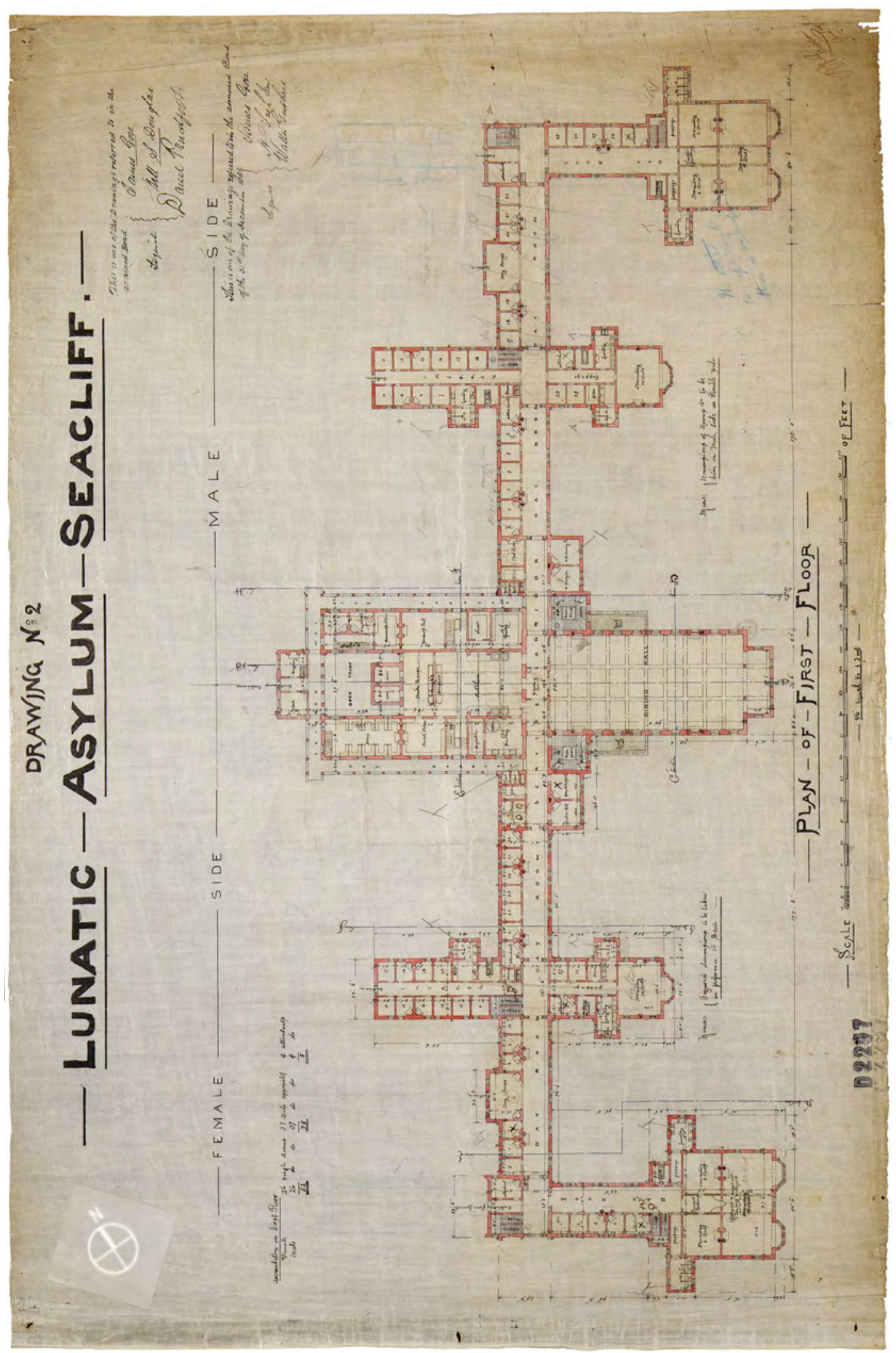

Figure 4.4: Seacliff Lunatic Asylum, Plan of first floor. Drawing No. 2. 1881. Alexander Turnbull Library: Plans-84-1186 (north sign added by author). 


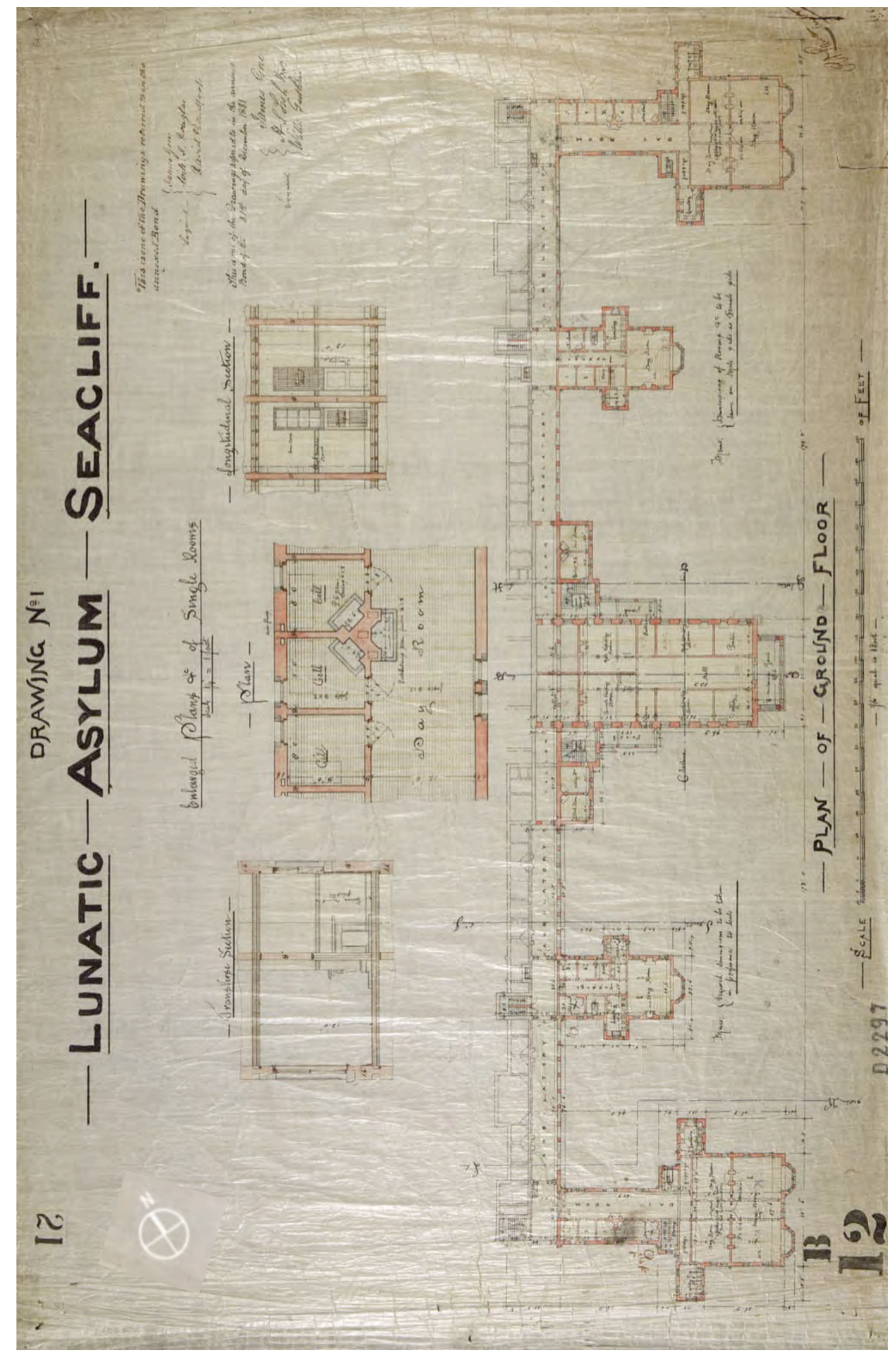

Figure 4.5: Seacliff Lunatic Asylum, Plan of ground floor. Drawing No. 1. 1881. Alexander Turnbull Library: Plans-84-1185 (north sign added by author). 


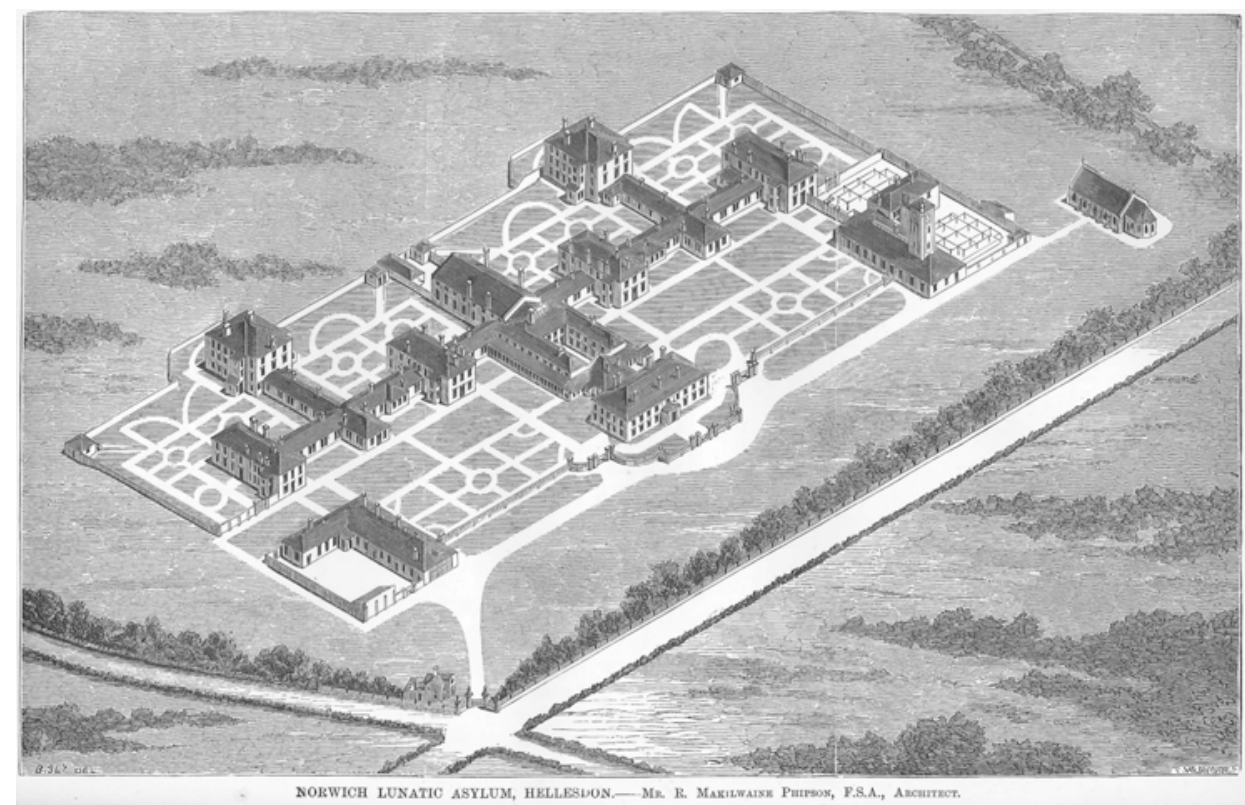

Figure 4.6: Norwich Asylum Perspective Drawing, by R.M Phipson As published in The Builder, vol. 35, May 12 (1877): 479.

The similarities between these two asylums, however, did not go beyond the floor plans; the aesthetic approach of these two architects' could not have been further apart. The Builder reported that Phipson's design was "very plain and simple [in character], and there is no attempt to try to make it look like a Medieval or Tudor edifice" (figure 4.6). ${ }^{52}$ Seacliff, designed in a style Lawson described as "Scottish Baronial," stood majestically on the Otago hillside at almost four and a half stories tall (figure 4.7).$^{53}$ In 1972 , when Seacliff Asylum was closed, Dr Charles Moore regretted having to leave such "stature and beauty." ${ }^{24}$ But how did all this stature and beauty meet the requirements of an ideal curative environment?

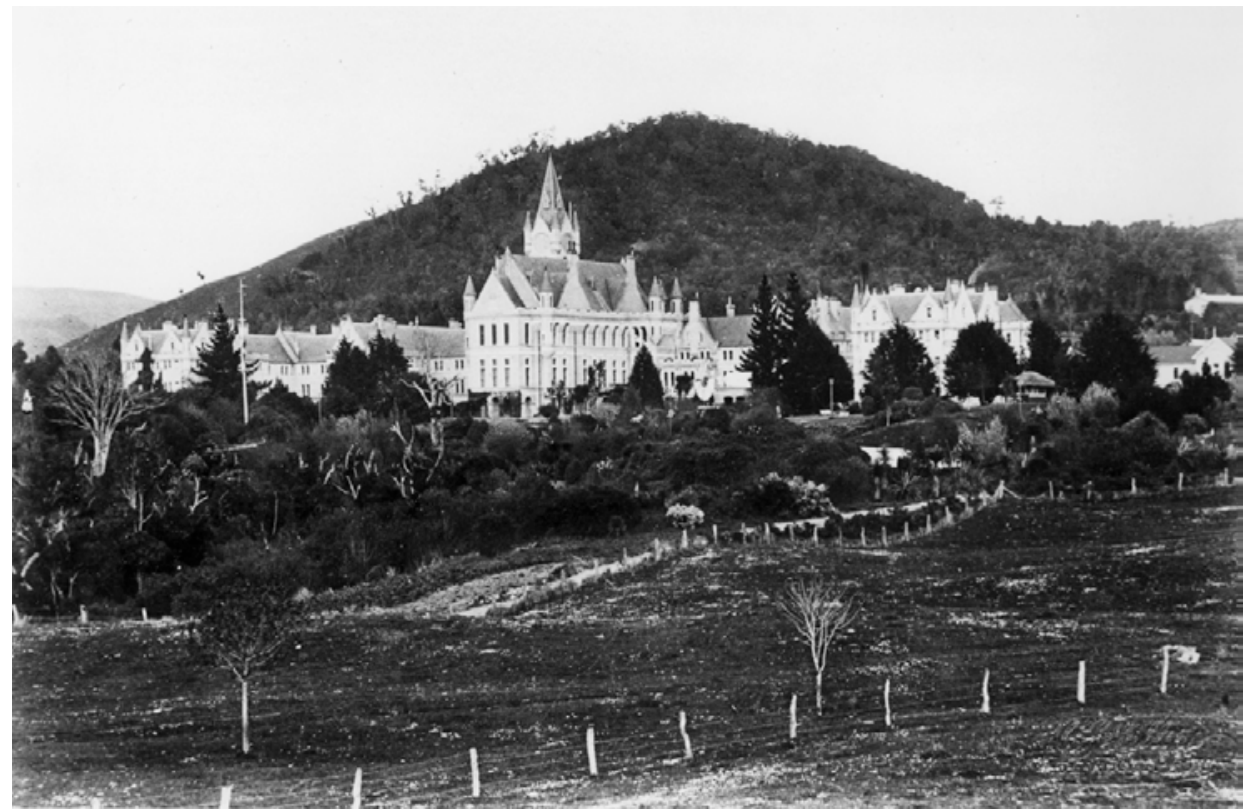

Figure 4.7: Seacliff Asylum pre 1917. Photograph by E. A. Phillips. Hocken Collections, University of Otago, S09-038d. 
Despite the government's allocation of an adequate budget, in line with "more modern English Asylums," ${ }^{55}$ and Lawson's selection of an appropriately progressive architectural precedent, Seacliff Asylum attracted harsh criticism. Grabham arrived from England just two years prior to Seacliff's opening and stated that it was "badly designed and [already] out of date. ${ }^{56}$ All but one of the five main areas of concern in successful asylum design (as recommended by Tuke, Brown and Conolly) were found wanting by Grabham. Only that of location escaped his reproach. He found the asylum interiors to be "by no means in accordance with modern notions, the day rooms... merely corridors in some parts of the building... seldom admitting any sunshine." The windows, he stated, were "absolutely dangerous" and the surrounding landscape "disheartening." 57 However, no thorough examination of Lawson's design relative to the key curative concerns of nineteenth century asylum design has, to date, been undertaken.

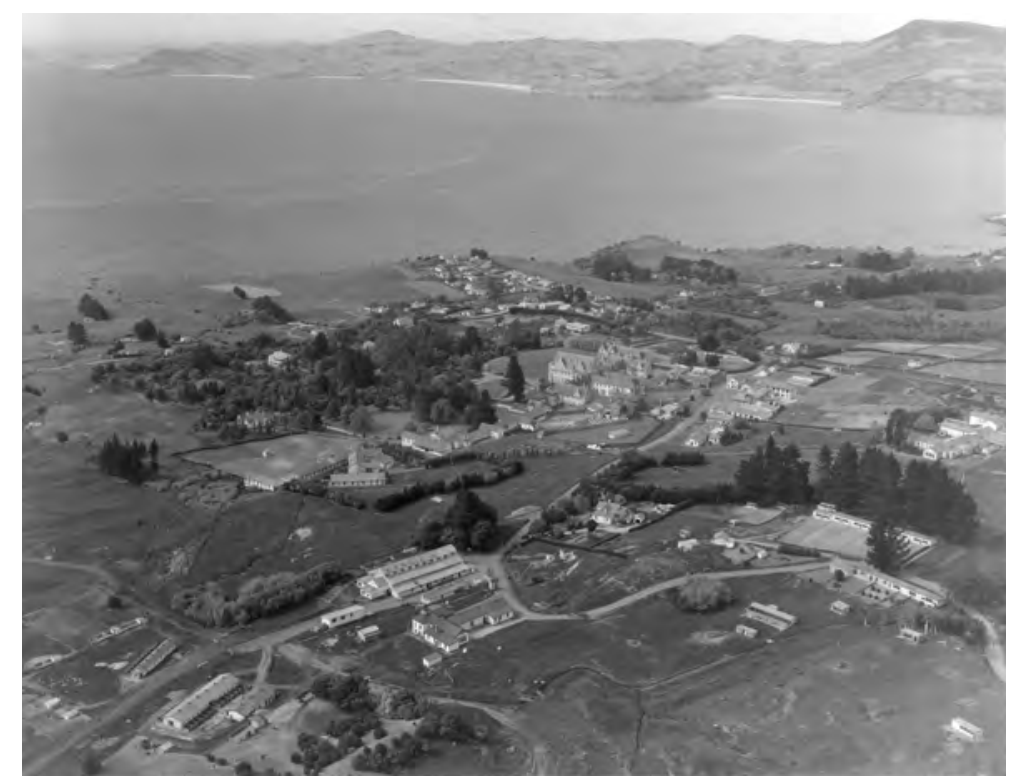

Figure 4.8: Aerial view of Seacliff Asylum and surrounds, 1947.

Photograph by Whites Aviation. Alexander Turnbull Library: WA-10628-F.

\section{Criteria one: Location}

The site at Brinns Point met the criteria set out by Tuke, Brown and Conolly: it was in close proximity to a railway line, offered extensive views and provided a suitable degree of privacy from public roads (figure 4.8). It also provided ample space for the construction of airing courts, although some flattening of the hillside would be required. ${ }^{58}$ Grabham considered this site "very good and healthy," although he acknowledged that its remote location was a drawback. ${ }^{59}$ While the Retreat at York was located only half a mile distant from the city, Skae estimated Seacliff's location as twenty-seven miles distant from Dunedin. ${ }^{60}$ Relatives, staff and visitors complained of the "difficulty and expense" of visiting the asylum, which Grabham described as "a grievous [financial] hardship." ${ }^{61}$ Despite being situated along the railway 
line, the train timetable was found quite unsuitable for the asylum's needs. ${ }^{62}$ In her honours thesis, Caroline Hubbard examined this issue in greater detail. She found evidence that some patients were taken on excursions to town, that the wider community was invited to monthly church services and that entertainers often visited the asylum. However, the superintendent, Dr Neil, felt that visits from family and friends were more important for a patient's recovery and lamented that the cost of transport was a disincentive for family members to visit. ${ }^{63}$ In 1893 a former attendant claimed that 70 per cent of patients at Seacliff received no visitors. ${ }^{64}$ At the Arthur Street asylum, by comparison, a weekly dance attracted many "visitors, friends of the patients and officers." ${ }^{65}$ This was something Tuke, Browne and Conolly would have likely considered a great advantage but Skae found to be a drawback. He felt the Dunedin public took part in asylum amusements with "excessive freedom" and feared the growing popularity of asylum amusements would result in the patients recreational needs coming second to those of their visitors. ${ }^{66}$

\section{Criteria two: Landscape}

In considering the curative ability of an asylum landscape, access to the exterior becomes important, as does the proportion and orientation of windows and the treatment of the landscape itself. The site chosen for Seacliff was covered by dense bush. Evocative accounts were given by early visitors to this site, of battles through "prickly scrub and tangled layers, over fallen trees... and through marshes." ${ }^{67}$ Any buildings constructed on this site, therefore, entailed considerable effort in clearing sufficient ground. An undated site plan suggests that clearing was undertaken only where necessary, for buildings and access ways (figure 4.9).

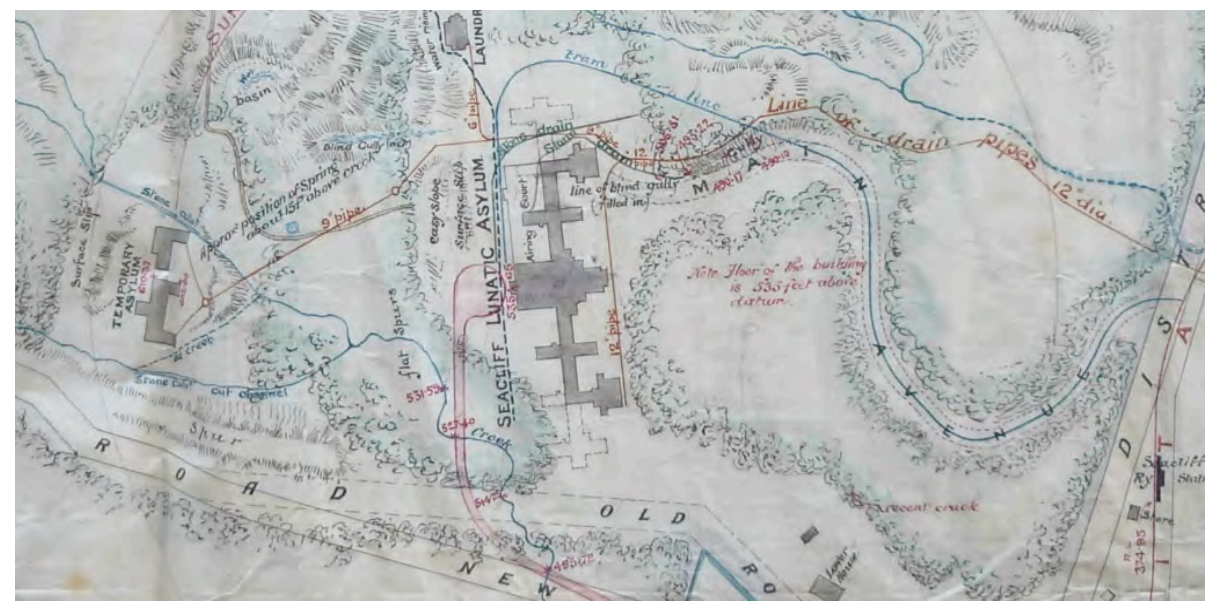

Figure 4.9: Seacliff Asylum Site Plan, date unknown. Archives New Zealand: W5 14114288 (drawing cropped). 


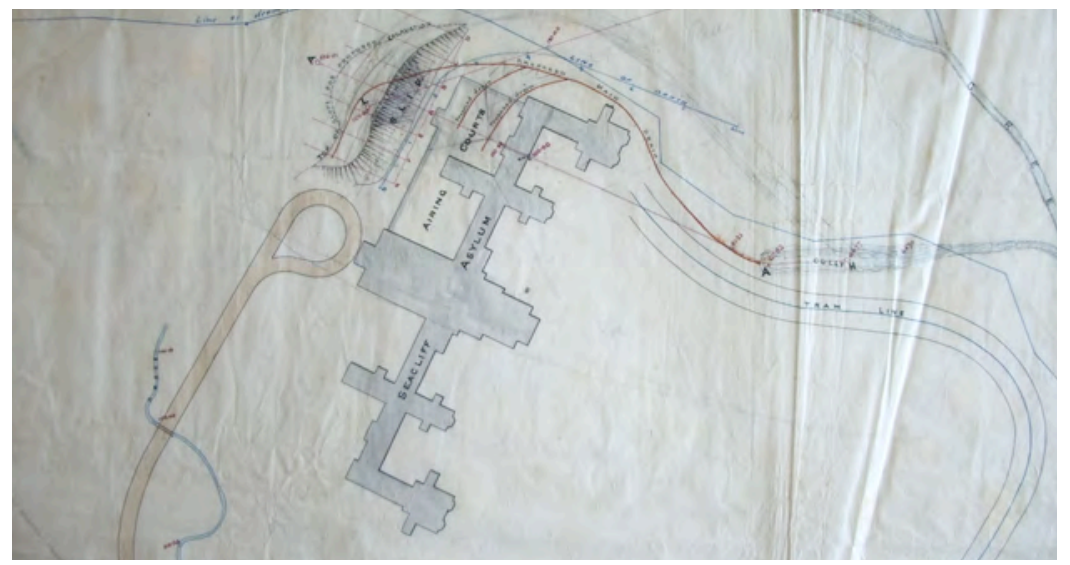

Figure 4.10: Seacliff Asylum Site Plan, 1885.

Archives New Zealand: W5 29312988 (drawing cropped).

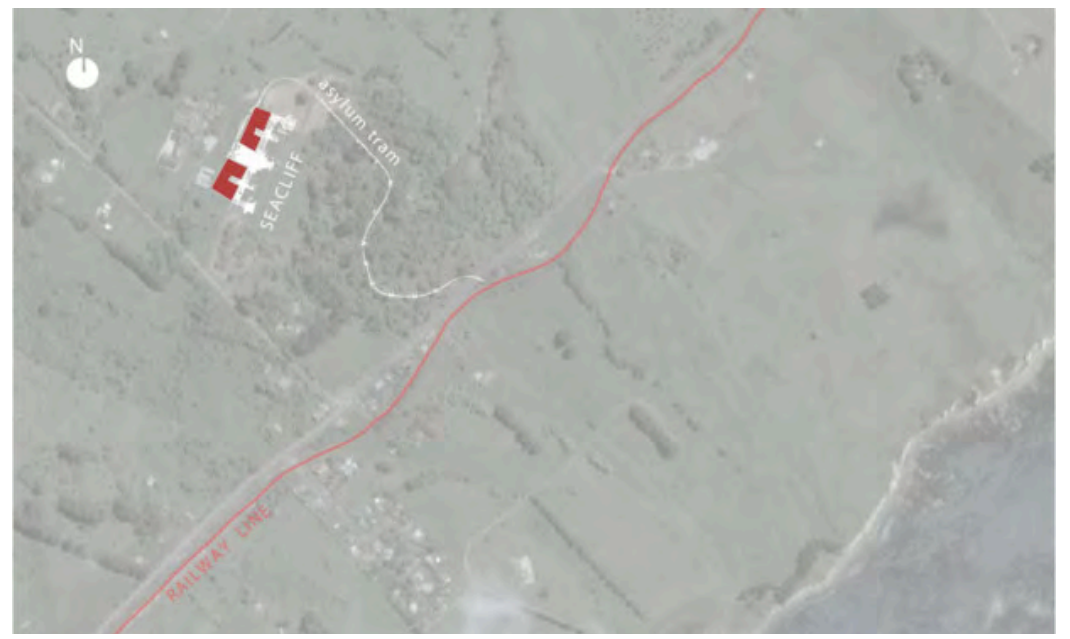

Figure 4.11: Placement of Airing Courts (red) on Seacliff site.

Archival plan superimposed over Google Earth image (26.12.2004) by author.

During the early years of occupation, the only engagement with the immediate landscape, as indicated in various drawings prepared by Lawson, were two closed airing courts constructed behind the asylum. The drawing above indicates the female airing court located directly behind the female wings (figure 4.10). A second court for male patients was later constructed to mirror this (figure 4.11). Located as they were, on the northwest side of the building, the airing courts received a degree of afternoon sun though no morning sun would have reached these spaces. Contradicting Conolly's advice, sunken walls were not employed and the placement of these courts behind the asylum did not afford patients "a view of the surrounding country." ${ }^{\text {" In }}$ fact, Grabham described them as

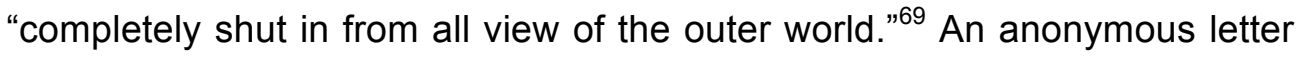
to the editor of the Otago Daily Times described these airing courts as "a barricade of corrugated iron 20 feet high... with no object for [the patient's] eye to rest on or mind to dwell on. It is almost enough to make a sane man mad." ${ }^{70}$ Since the hillside fell away in front of the asylum and ample land was available at either end of the building, this was a wasted opportunity. Similar to Tuke's criticism of the Retreat's airing courts; those at Seacliff 
must also have been "too small... of too little variety, to invite the patient to take exercise. The boundary of his excursion is always before his eye..." Grabham complained that the size of these temporary courts did "not even afford one half of the space now available for the patients at Dunedin.."72

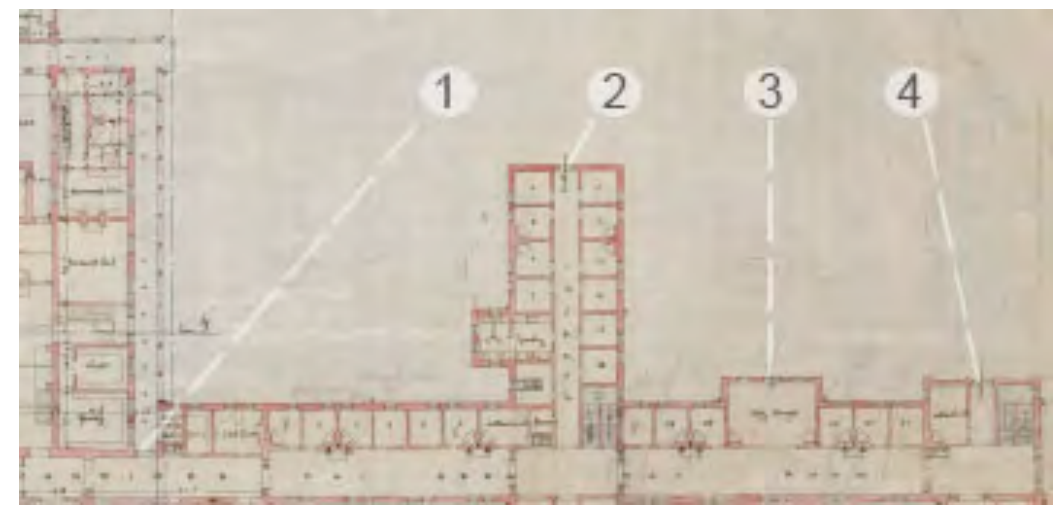

Figure 4.12: Access points to rear airing court (female side) indicated by nos 1-4. Alexander Turnbull Library: Plans-84-1186 (cropped, numbers superimposed).

Regarding the relationship of interior spaces to airing courts, Conolly recommended that:

each ward should communicate with an airing court containing no other patients... [and] tranquil wards should not overlook the patients of refractory wards. ${ }^{73}$

The temporary airing courts were accessed from the rear of the building, (figure 4.12). While these were not "overlooked" by the patient dayrooms, they allowed no means of classifying patients when outdoors. However, Lawson's original drawings allowed for six individual airing courts to be constructed (following to completion of two additional wings to be added to the extremities of the building). This would have allowed for adequate classification (figure 4.13).

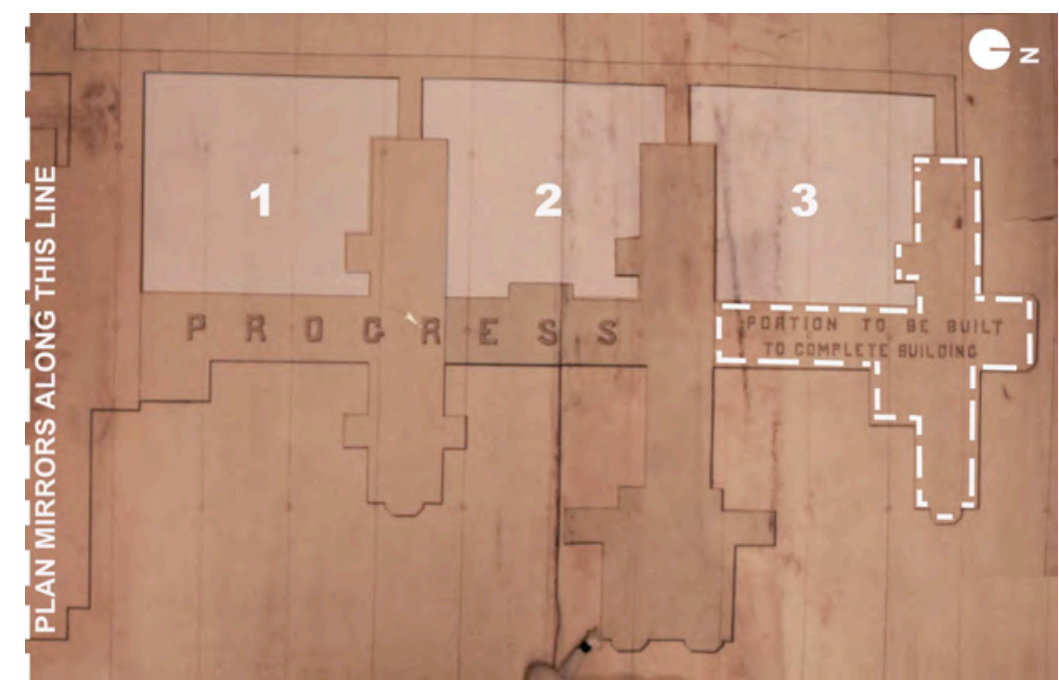

Figure 4.13: Section (half-plan) of Lawson's drawing titled "Block Plan."

The plan mirrored symmetrically along the dotted line at left, the additional wing is shown hatched and airing courts have been numbered by author for clarity. Hocken Collections: Salmon Collection - R4627 (cropped, overlays added). 
In 1880 James Hector, the government's Director of Geological Surveys, endorsed a recommendation by Skae to clear the ground surface "over a considerable area." ${ }^{74}$ In 1883 this work was yet to be put in hand. ${ }^{75}$ The lack of attention to landscape at Seacliff was not remedied until Truby King's appointment as superintendent in 1889. Within six years King had constructed expansive, landscaped airing grounds (figure 4.14). An official visitor to Seacliff described these, on subsequent visits, as "simply perfection... large and beautifully laid out," commanding "magnificent view[s]." 76

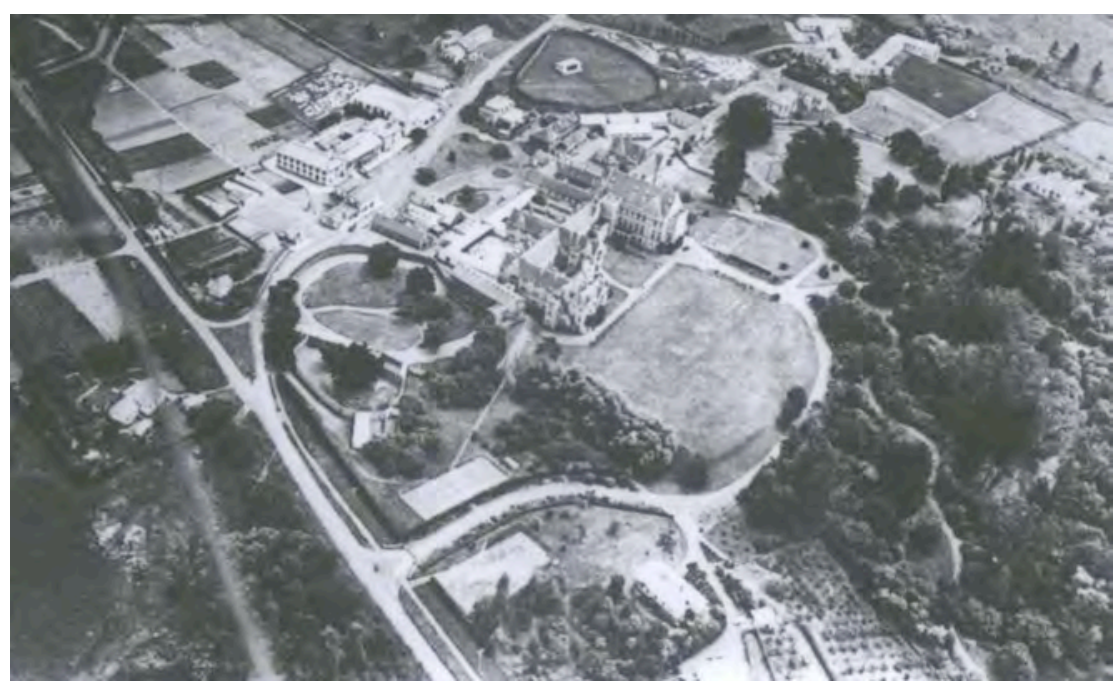

Figure 4.14: Seacliff from the air, date and photographer unknown. Men's airing ground shown at left, on the edge of the men's wards. Hocken Collections: 2465-01-003A (cropped).

The delay in the development of Seacliff's surrounds denotes a disquieting lack of commitment to the curative model of asylum care. At that time, six months was seen as the critical period within which a patient would be likely to recover. If no improvement was made during this time, the illness was regarded as incurable. ${ }^{77}$ Instead of developing the landscape and buildings concurrently, as would seem necessary for the successful on-going treatment of patients, the curative requirements of landscape were a low priority. While not acknowledged within official reports, the delay in completing this landscape may well have been attributable to the effects of the Long Depression. Lawson wrote, in a letter to the editor of the Otago Daily Times, that the temporary airing courts would be replaced with permanent ones facing the sea once "public funds are available."78 


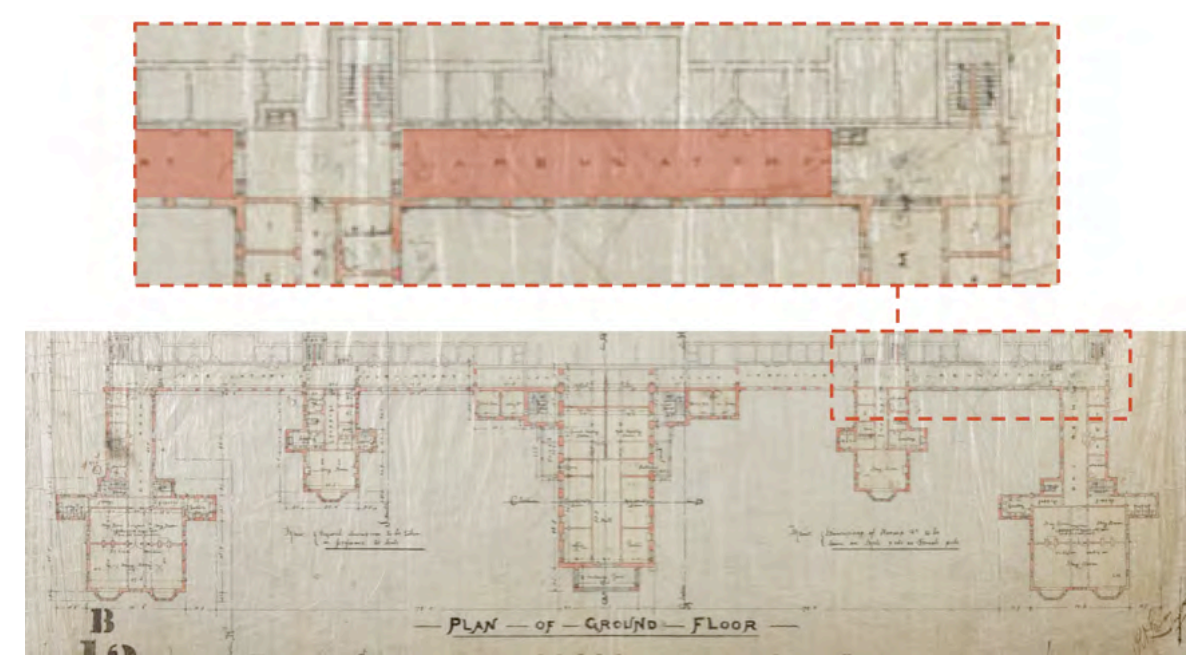

Figure 4.15: Section of ground floor plan; red shading indicates open ambulatory. Alexander Turnbull Library: PLANS-84-1185 (cropped, overlays added).

While landscaping would have fallen beyond the terms of the architect's appointment, there is reason to believe that Lawson gave thought to how some patients could be connected with the landscape without jeopardising the safety and security of others. His plan featured six stairways that directly linked each accommodation wing to their own ground floor day room without having to traverse through another ward (in addition to the two stairways that served the hall). At the base of each staircase was a secured corridor. From this point a patient may have been directed into the dayroom or out of doors, via an open colonnaded ambulatory that spanned between these secure hallways (figure 4.15). A photograph from 1926 may illustrate what Lawson had in mind when he included this open colonnade. It shows a cricket game in progress with a group of patients (identifiable by their identical, asylum-provided attire) watching on (figure 4.16). As photography within asylum grounds was tightly controlled, this photograph would have been staged, ${ }^{79}$ yet it suggests that patients were allowed some freedom of movement between the asylum interior and the surrounding gardens which Lawson's design would have supported. Archival photographs confirm that this colonnade was closed in sometime before $1946 .^{80}$

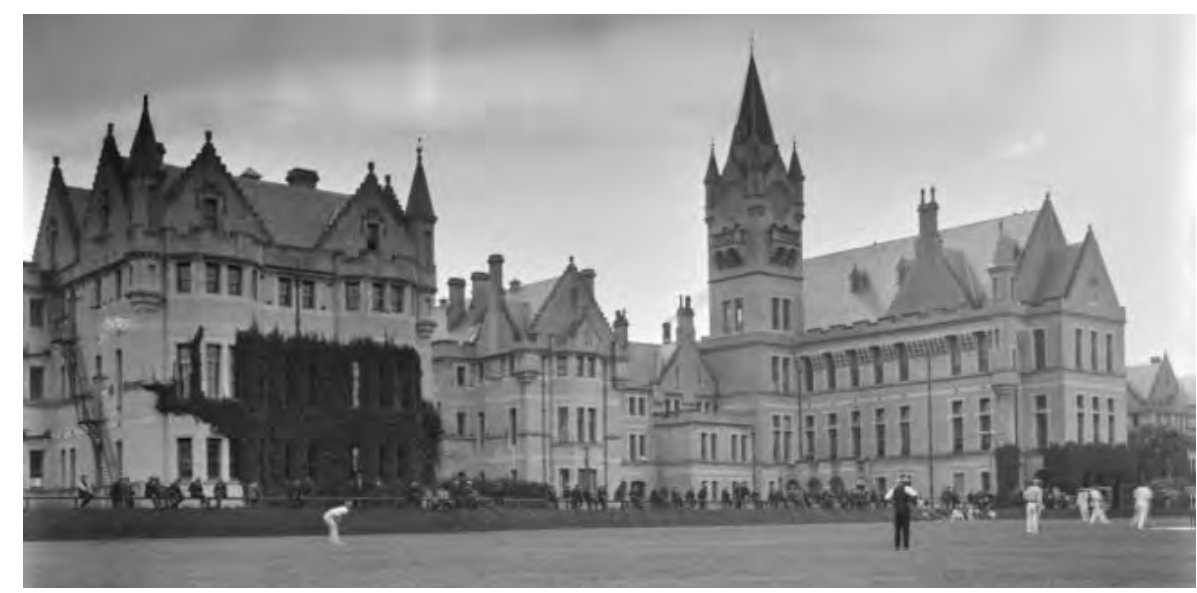

Figure 4.16: Seacliff, circa 1926. Photograph by Albert Percy Godber. Alexander Turnbull Library, Wellington, reference: APG-1319-1/2-G (cropped). 


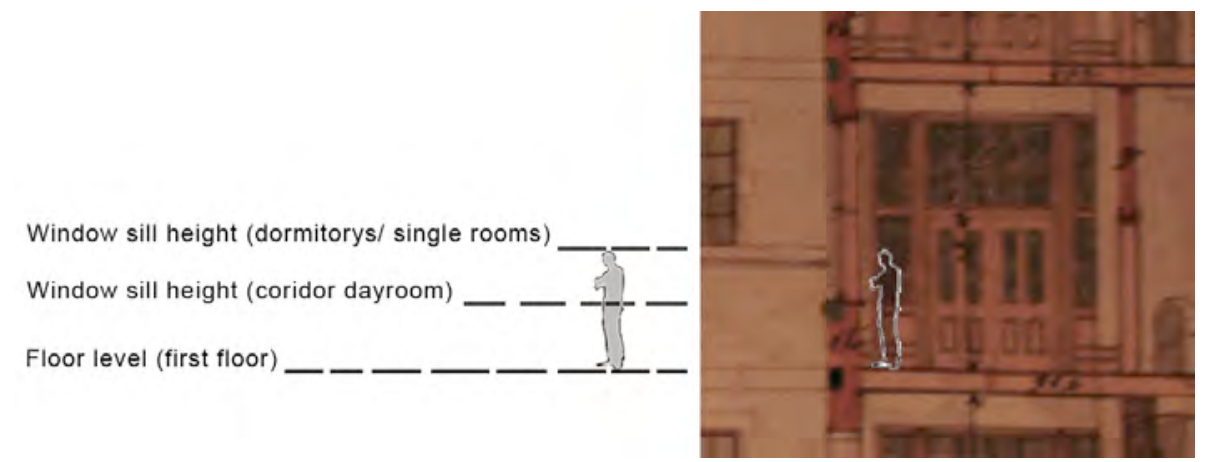

Figure 4.17: Section through Day Room Coridor showing window sill heights. Hocken Collections: Salmon Collection - R4627 (cropped, images superimposed).

The placement of windows was one of the most important considerations for those patients confined to indoor care. Grabham suggested that the windows through the corridor day rooms were "absolutely dangerous"; "large glass panes with nothing to protect them" ${ }^{11}$ while those within the dormitories were placed "so high that no view is possible." This rendered the dormitories "gloomy and cheerless." 82 In fact, the sill heights chosen by Lawson were not substantially different to those recommended by Conolly. The day room window sills were located somewhere between 700 and $870 \mathrm{~mm}$ above the floor level (figure 4.17). These were "low and large," as per Conolly's recommendation, and close to his preferred sill height of "2 feet, 6 inches" $(760 \mathrm{~mm}){ }^{83}$ The window sills to the single rooms and dormitories (shown in elevation, at the left of figure 4.17), occurred at around $1600 \mathrm{~mm}$ above adjacent floor level. These window sills were positioned, therefore, directly in the eye-line of an adult of average height whilst standing. ${ }^{84}$ This placement was considerably higher than Conolly's recommended "4 feet, 6 inches" $(1370 \mathrm{~mm})$ which would have allowed a view whist standing but not while seated. ${ }^{85}$ MacGregor considered that the height of these dormitory windows was one of the chief defects of Lawson's design (figure 4.18). Yet, even he conceded that patients were "seldom or never in these rooms, except for when they are in bed... the loss of the view, therefore, is no great matter." Nonetheless, he stated that "the architect blundered... he sacrificed the usefulness to the appearance of the building." ${ }^{\text {} 6}$ Through the day rooms, however, where curative landscape views were most necessary, Lawson ensured that views were available.

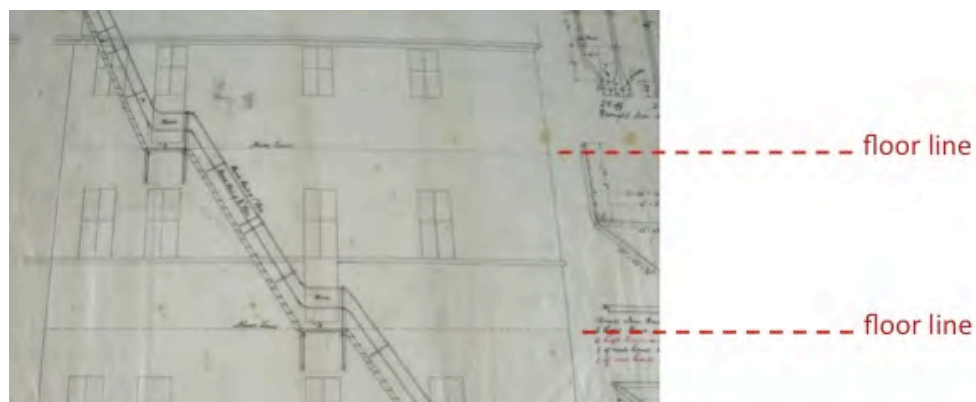

Figure 4.18: Drawing for New Fire Escapes, 1906. Indicates sill heights. Archives New Zealand, DAHI 9156 D342 2a (cropped). 


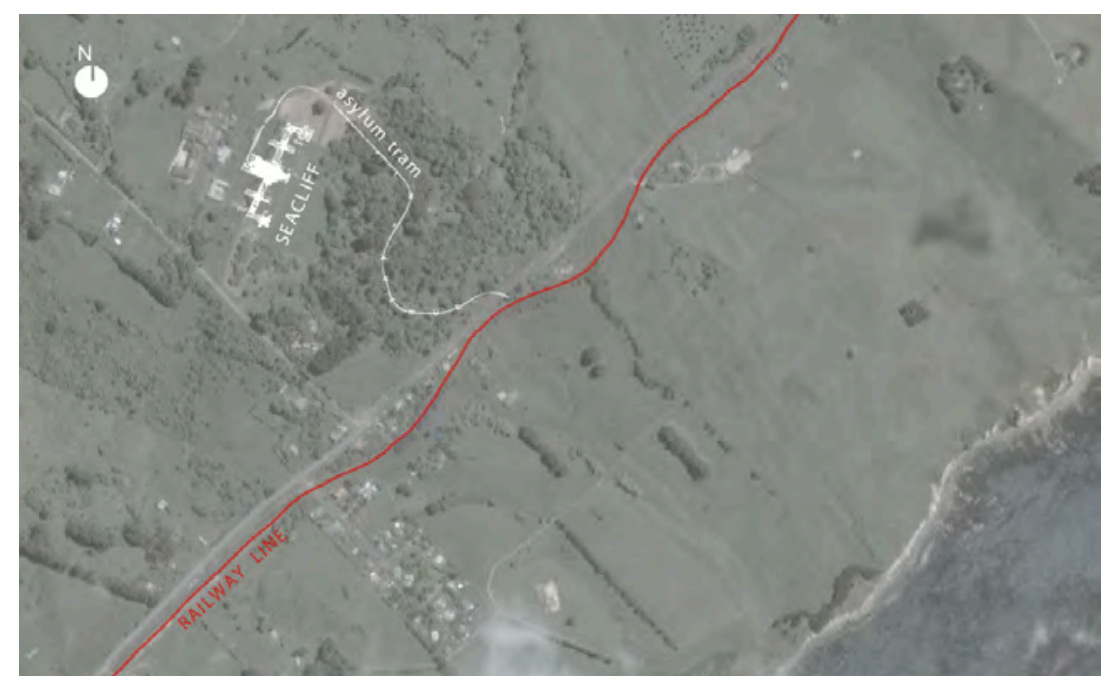

Figure 4.19: Aerial view of Seacliff relative to north, railway and coastline. Archival plan superimposed on Google Earth image (26.12.2004) by author.

Seacliff's orientation, however, was a much larger "blunder" than the height of the dormitory windows. In his unpublished manuscript on the history of Seacliff Asylum, Dr Charles Moore, former superintendent, wrote that the hazardously large windows to the corridor day rooms failed to provide adequate sunlight. ${ }^{87}$ Lawson positioned the asylum across the hill, parallel to the coast and the railway tracks that ran along the asylums lower boundary (figure 4.19). Given this orientation Seacliff's full majesty could be appreciated. It meant, however, that the building faced east and for maximum sun exposure in New Zealand buildings need to be orientated to the north.

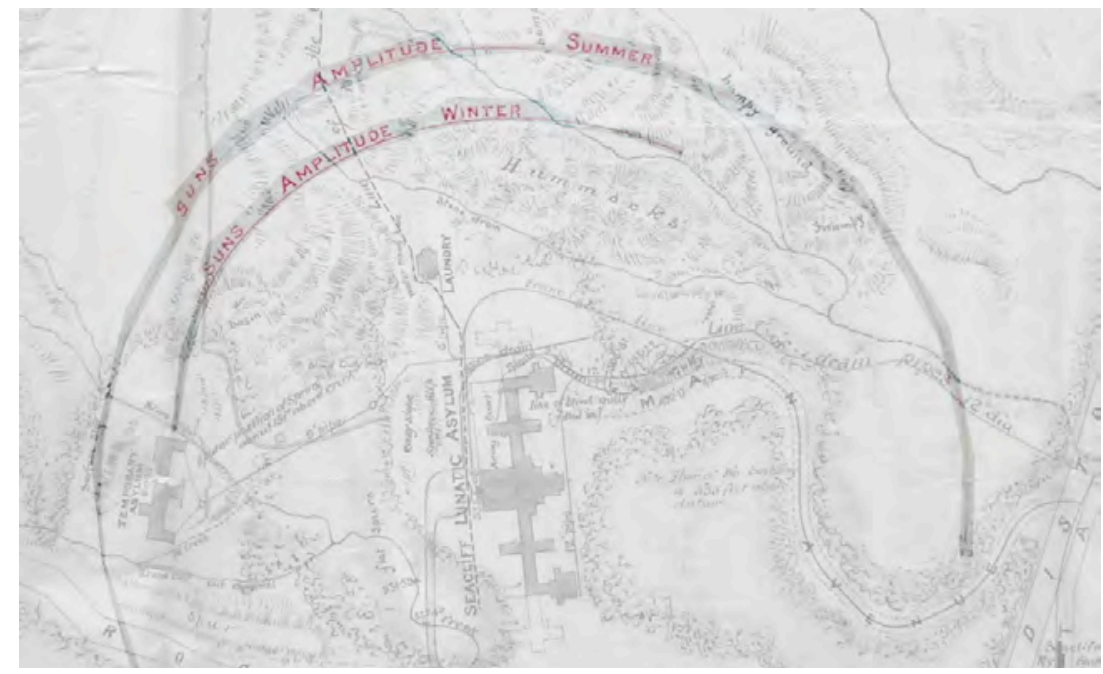

Figure 4.20: Seacliff Asylum Site Plan, date unknown.

Archives New Zealand, W5 14114288 (drawing cropped and desaturated).

While Lawson was trained in Scotland, where buildings are orientated to the South for maximum sunshine, he adequately understood sunshine in the Southern Hemisphere; a site plan created by Lawson clearly indicated the sun's amplitude for both summer and winter (figure 4.20). In summer the 
asylum's front elevation would have enjoyed morning sun but it would have been lost by mid-day. In winter, the asylum's front elevation would not have received any direct sunlight. The northern most cross wing was the only wing that received all day sunshine, year round (figure 4.21). Lawson's placement of the dayrooms on the southern side of this wing meant that single rooms, vacant during the day, stood between this day room and the much desired sun. This arrangement could easily have been reversed to allow this particular day room sunshine and views but it would have required Lawson to sacrifice the perfect symmetry of his floor plan.

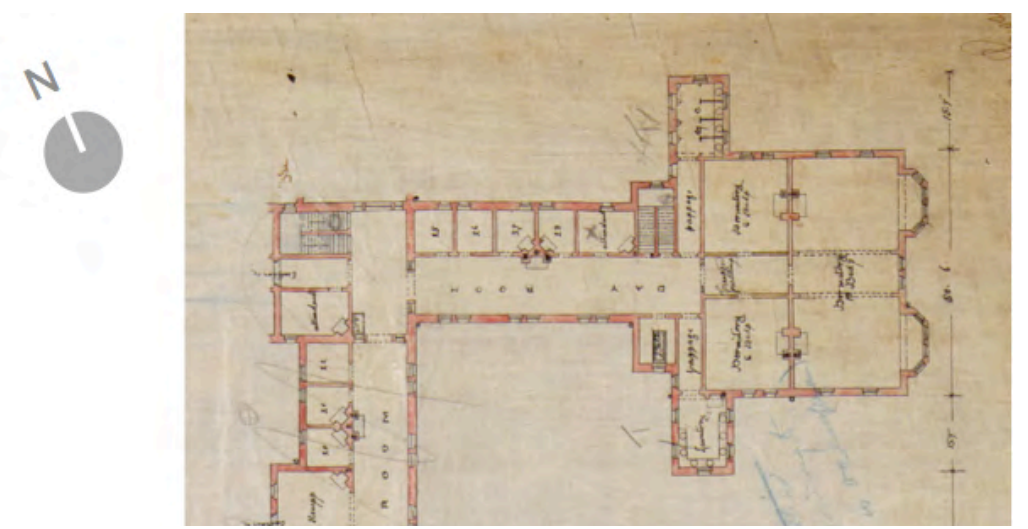

Figure 4.21: Partial plan (first floor) showing the asylums northern most wings. Alexander Turnbull Library: PLANS-84-1186 (cropped).

In 1880 problems with the stability of the asylum site became apparent and the government requested a geological report from James Hector. His report recommended that Lawson consider a revised plan that rotated the asylum ninety degrees, positioning the long axis down the slope instead of across it. Hector thought this would help to mitigate the site's unpredictable conditions by increasing the stability of the building's foundations but he also noted that shifting the building's axis would increase the sunshine available to the interior. ${ }^{88}$ Following this development, Skae hoped that the asylum's orientation could be altered to secure "a better aspect than the eastern one" chosen by Lawson. ${ }^{89}$ In January of 1880 Skae wrote that it was "an object of great importance that the principal dayrooms should face as nearly north as possible" and that, "it was distinctly settled," presumably between he and the architect, that these dayrooms "would at least have a north-eastern aspect." However, by July Skae reported that, while the asylum had been shifted "about five chains southward," its orientation could not be altered to even "the smallest extent." W.N. Blair, the Engineer in Charge of Middle Island (for the Public Works Department), informed Skae that he and Lawson had "carefully examined the plans" and that Lawson was satisfied that the building "would get as much sun on the main apartments as it was possible to give. ${ }^{90}$ The ease with which Skae's concerns regarding sunshine were dismissed suggests that medical advice was perhaps not as highly valued as it should have been within this design process. 
Lawson's positioning of Seacliff, across the hill and parallel to the railway tracks below seems, architecturally, to have been the most striking position available. It allowed a wide, symmetrical elevation, maximising the building's bulk and prominence on the hill. However, it also took into consideration operational concerns. Lawson's plan, like Phipson's plan for Norwich, followed Conolly's preferred arrangement with kitchen and service, medical and visiting spaces all located within the centre of the plan. ${ }^{91}$ While ease of staff circulation was not a therapeutic concern, it was important for the asylums successful operation. The length of the Norwich Asylum was 520 feet across, while Seacliff was 570 feet with cross wings measuring close to 230 feet in length. The central location of kitchen, medical and services spaces, both vertically and horizontally, was important in enabling the male and female wings to be accessed with equivalent efficiency. Lawson paid specific attention to ensuring that critical service spaces, such as the kitchen and dining room, occurred on one level. ${ }^{92}$ The prioritisation of some briefing requirements over others in the design of a building is part of the professional service that architects provide. However, given the high curative value placed upon sunshine, Lawson's ranking of this requirement below that of staff circulation is a questionable decision.

\section{Criteria three: Safety}

The dangerously low windows were not the only obstacle to maintaining safety at Seacliff. The term "insecure" was chosen to describe the fixing of doors, windows and fireguards, an issue that can be blamed in part on workmanship and in part on inadequate architectural specification. Lawson made two decisions with regards to safety that inferred a lack of understanding of the patients he was designing for. The first was his design of bathrooms; Lawson placed a single bath tub within its own enclosure. While this offered much more privacy than the bathrooms of traditional asylums, where a number of baths were arranged side by side with no divisions for privacy, it also required significantly more staff than Seacliff was able to employ. In 1889, King sent a request to head office to transform one of the dormitories into a bathroom containing three baths so that the staff may have some hope of bathing all the asylums patients within a single week. ${ }^{93}$ The second issue was Lawson's oversight regarding the provision of fire guards in wards for which there was none. ${ }^{94}$ Iron gratings were added as an afterthought, however, subsequent superintendents Neil and King found these to be inadequate. King felt they presented a risk "too great to permit our using fireplaces where they exist in bed-rooms" and for several months needed to assign "never less than two attendants... solely in fire watching." ${ }^{\text {"N }}$ Neil, on the other hand, had felt the risk was too great to allow fires even in the day rooms where there ought to have been a constant presence of attendants. ${ }^{96}$ The gravity of this situation was made evident in 1890, King reported that a patient "managed, by shaking the door, to slip the lock" on the fire grate resulting in the burning of her clothes "nearly to 
the skin." ${ }^{97}$ It must be acknowledged, however, that Conolly recommended the use of open fires in asylums:

It is impossible to witness a party of lunatics sitting round a cheerful fire in winter, without wishing to see a fireplace in every ward. There is no comfort more missed ... than that of an open fire. ${ }^{98}$

Window stops also suffered from inadequate fixing. Moore, citing comments recorded by an official visitor in 1884, wrote that these were "so insecure" that a patient managed to unscrew a window with "a button from his trousers" and "hurled himself 40 feet to the ground." ${ }^{99}$ While the patient's injuries extended only to a broken wrist, Browne's preference for single storied buildings would have mitigated this risk. ${ }^{100}$

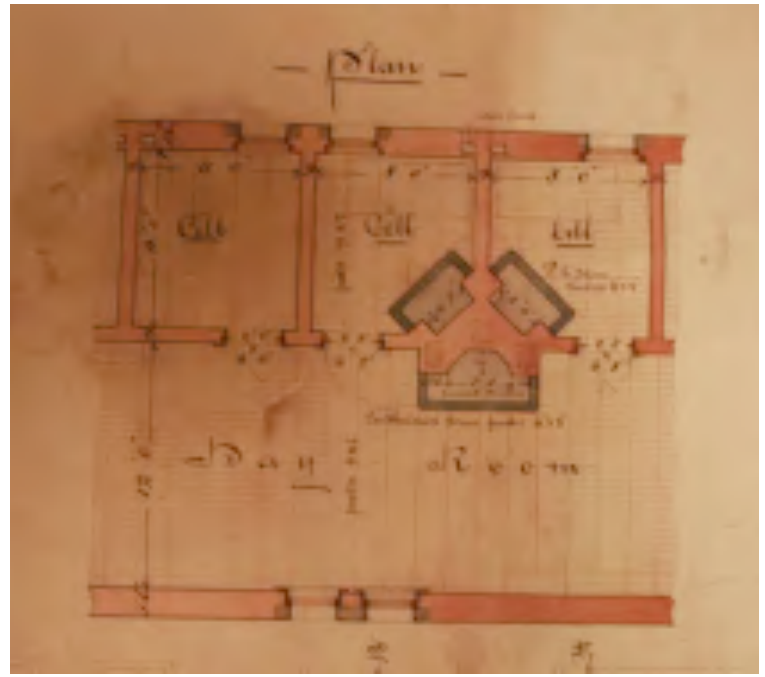

Figure 4.22: Plan of typical single room indicating door swings. Hocken Collections: Salmon Collection: R4627 (cropped).

A fourth issue of safety raised the question of the degree to which changes were made by the contractor, with or without Lawson's approval. Inward opening doors were installed to the single rooms at Seacliff, despite Lawson's drawings indicating outward opening doors (figure 4.22). This posed a significant safety issue and had to be reversed. As Conolly noted, this was important consideration for refractory wards, as patients were liable to block staff entry to their rooms by placing weight against the door. However, he did not recommend this for quiet patients who did not appreciate the reduction in privacy that resulted from this. ${ }^{101}$ While we do not know what proportion of doors were fitted this way, we do know that in the process of reversal the door frames were not well secured to the brickwork. Grabham wrote that "the whole framework has been shifted by a patient in more than one instance." This had to be remediated through the fitting of heavy iron bars across the door frames, a solution which "savour[ed] too much of the prison." ${ }^{102}$ These issues raise the question of whether Lawson was adequately briefed to undertake the design of such a complex institution and what degree of ongoing medical consultation he was afforded during the design process. This will be addressed in section 4.5. 


\section{Criteria four: Disguising Confinement}

The high walled, viewless airing courts (albeit temporary) and the barred bedroom doors were just two examples that little effort was made to disguise the patient's perception of their own confinement. Since few interior photographs of Seacliff exist, ${ }^{103}$ the changes made by King become increasingly important as a way of understanding the state of Seacliff's interior when he arrived in 1889. King described an interior of "cold, dimlylighted corridor[s]," where "sombre green and blue [paint] prevailed almost everywhere." The men's principal day room, for example, was a "bare, barnlike place." ${ }^{104}$ Despite King's criticism, interiors of blue and green were in keeping with hospital practices of the time as recommended by Henry Burdett, a leading expert on general hospital and asylum design in $1891 .{ }^{105}$ As Cheryl Caldwell has previously discussed, King repainted the interior in "light, pleasant colours," purchased comfortable furniture, blinds, hanging lamps and hearth rugs, polished floors, hung pictures and introduced flowers, ferns and singing-birds. ${ }^{106}$ These numerous changes saw King accused of "wasteful expenditure of public funds." 107 He defended his actions, determined that achieving a more comfortable and homely atmosphere for his patients was of the highest priority, an approach that resonated strongly with Conolly's.

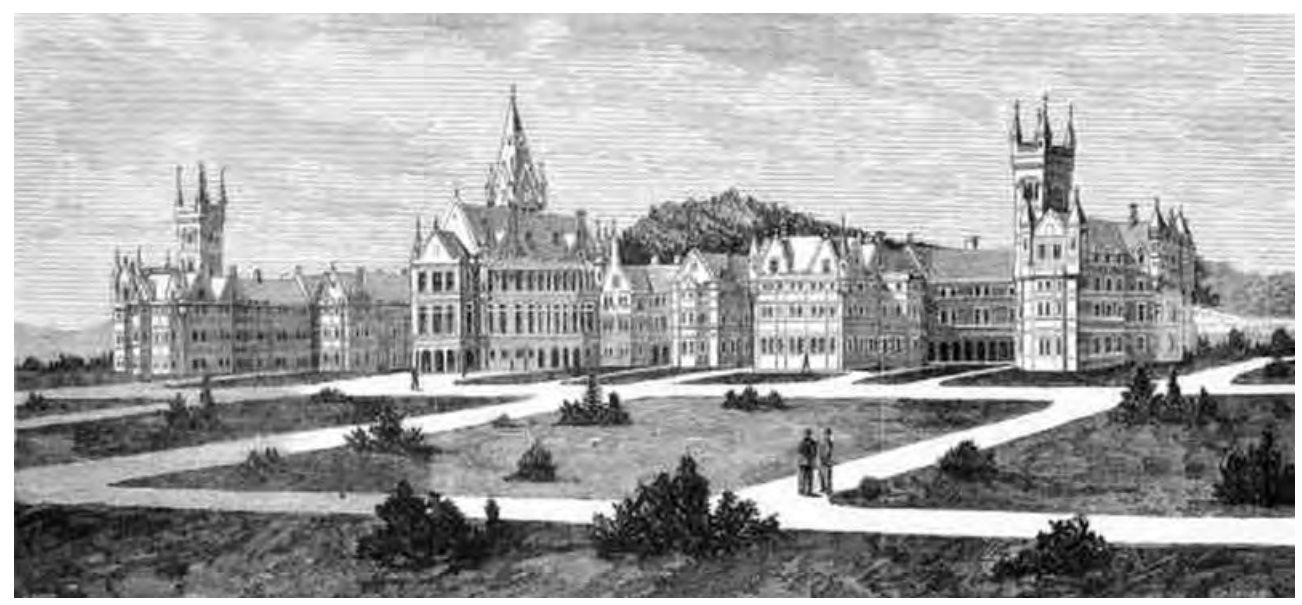

Figure 4.23: Seacliff Asylum etching, 1884, by Samuel Calvert (cropped).

The hall occurs at the centre, the end wings (with towers) were not completed.

Lawson's placement of tall windows through the great hall draws attention to the semi-public area of the asylum while the employment of smaller windows for the cross wings, containing the wards, gave a proportional domination of stone over glazing (figure 4.23). The resulting impression was one of permanence and security. These were elements that were very much desired in asylum design, not by the patients or the doctors, but by the general public. These glazing proportions in conjunction with the buildings orientation are in conflict with the curative requirements outlined by Tuke, Brown and Conolly, and suggest that Lawson's attention was drawn to satisfying an audience beyond the walls of the asylum. Disguising confinement may never have featured in Seacliff's brief. 


\section{Criteria five: Individual Treatment and Tranquillity}

A criticism of the temporary asylum in Arthur Street was the inadequacy of this facility for patient classification. There was insufficient space to "separate convalescent patients from grossly disturbed ones." ${ }^{108}$ Seacliff, with its dormitories positioned at the ends of the cross wings and its generous provision of single rooms, must have presented a significant advance on this early asylum. But it was not only the sleeping spaces where classification was made easier, the plans for Seacliff show twenty separate day rooms, connected but able to be shut off from adjacent day rooms (figure 4.24). The Porirua asylum, whose construction followed Seacliff in 1891, provided only twelve day rooms for 500 patients. ${ }^{109}$ Despite this generosity, MacGregor criticised Lawson's corridor day rooms as being "much too narrowed" (figure 4.25). ${ }^{110}$
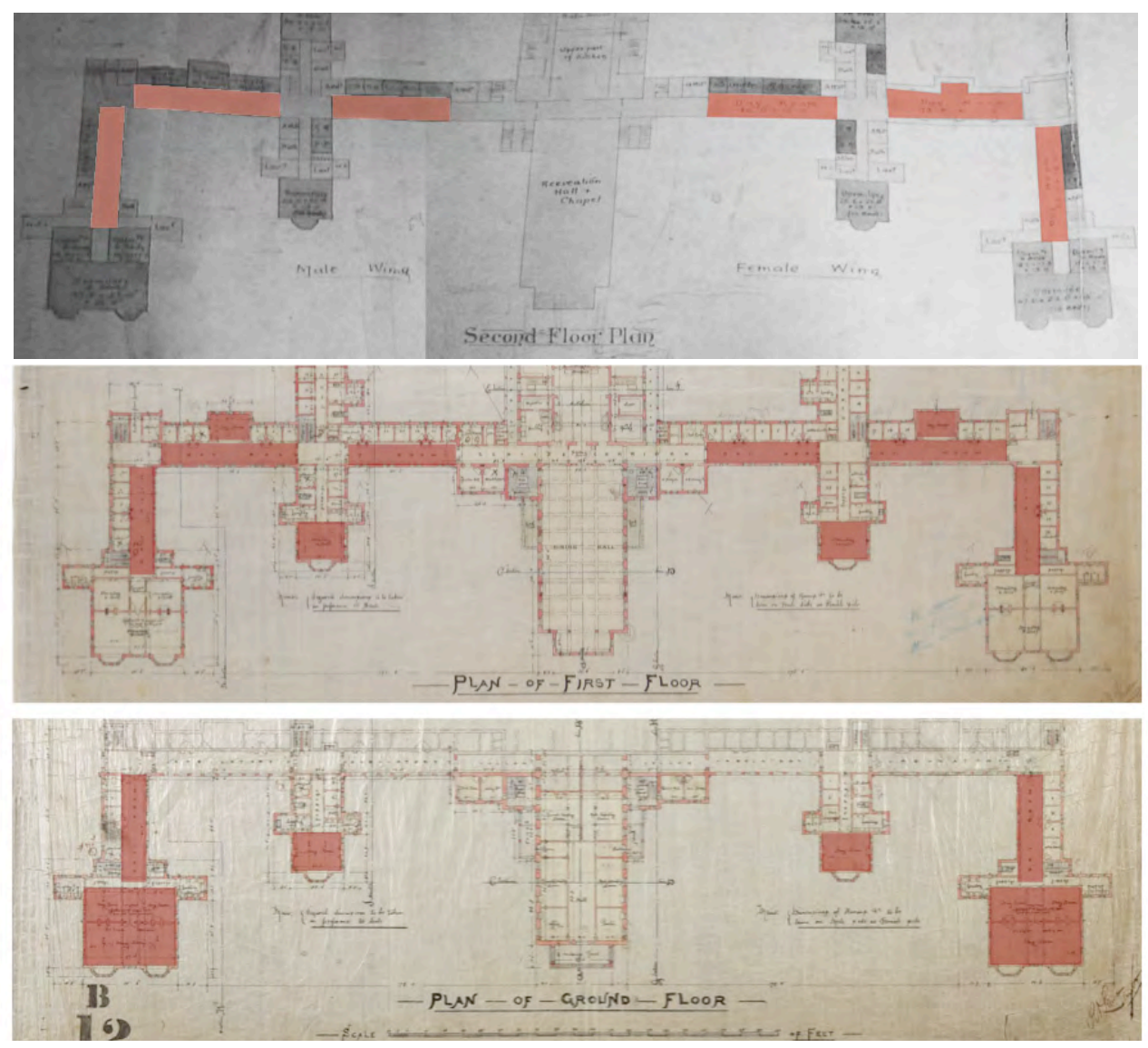

Figure 4.24: Partial floor plans with dayrooms highlighted in red.

Archives New Zealand: DADE D294 2a (top, cropped. Drawing by the Public Works Department, 1903, an original drawing by Lawson was not found).

Alexander Turnbull Library: PLANS-84-1186 (middle, cropped) Hocken Collections: Salmon Collection - R4627 (below, cropped). 


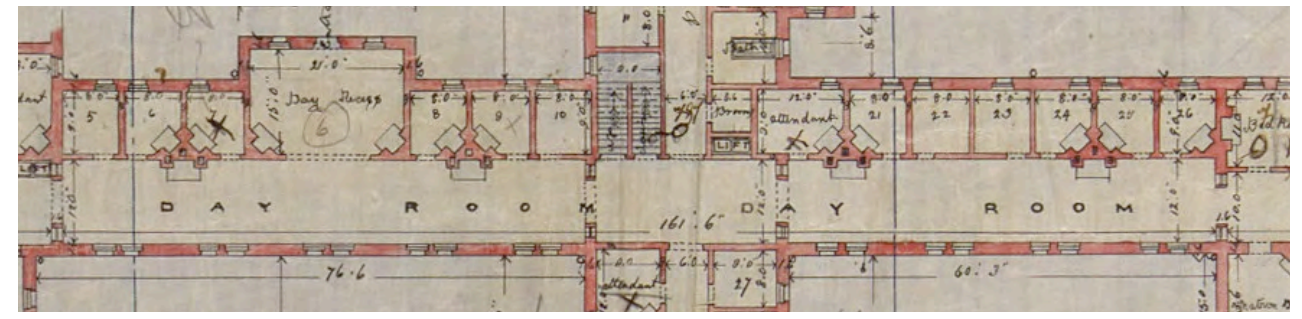

Figure 4.25: Seacliff Lunatic Asylum, Plan of first floor. Drawing No. 2. 1881.

Alexander Turnbull Library, Wellington, reference: Plans-84-1186 (cropped).

Despite MacGregor's criticism, corridor dayrooms were a common feature of British and American asylums during this period, such as the Bethlem Hospital (London, 1815) and the Buffalo State Hospital (New York, 1872). ${ }^{111}$ While no interior images have survived of the dayrooms at Seacliff, the dimensions of this space, at 3.6 metres wide and 3.9 metres high, matched those of the Buffalo State Hospital (figure 4.26). ${ }^{112}$ It is likely, given King's descriptions, that the furnishings were equally sparse and did not match the quality of hospitals such as Bethlem (figure 4.27).

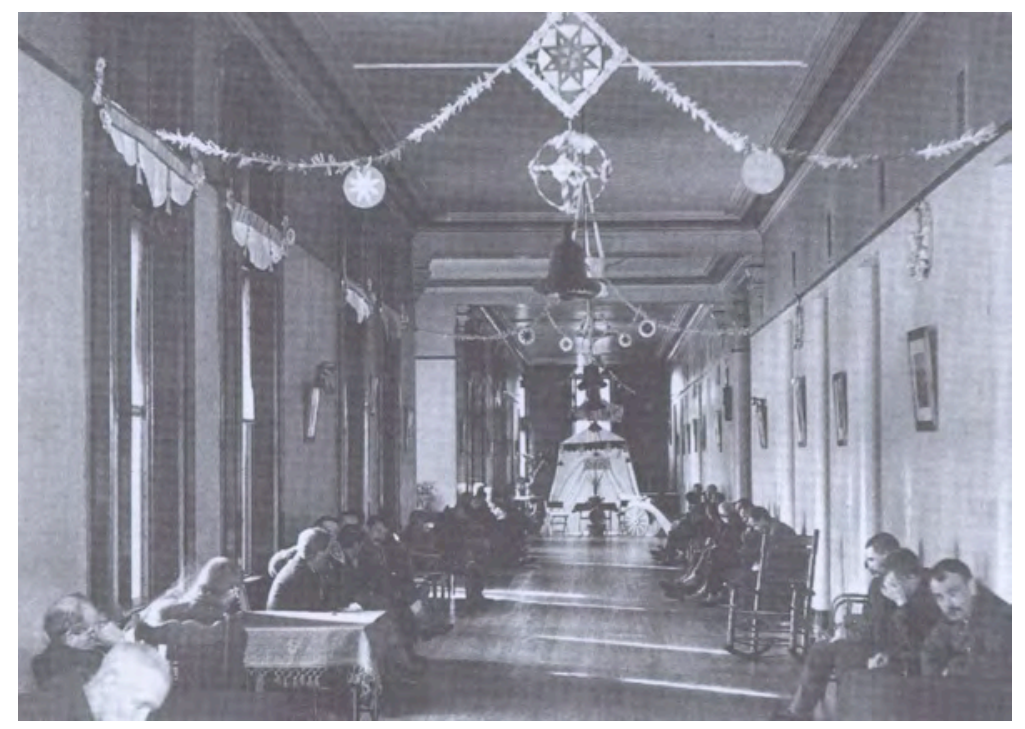

Figure 4.26: Dayroom, Buffalo State Hospital, ca. 1900.

As published in Kowsky 1992, 54 (original source not indicated by Kowsky).

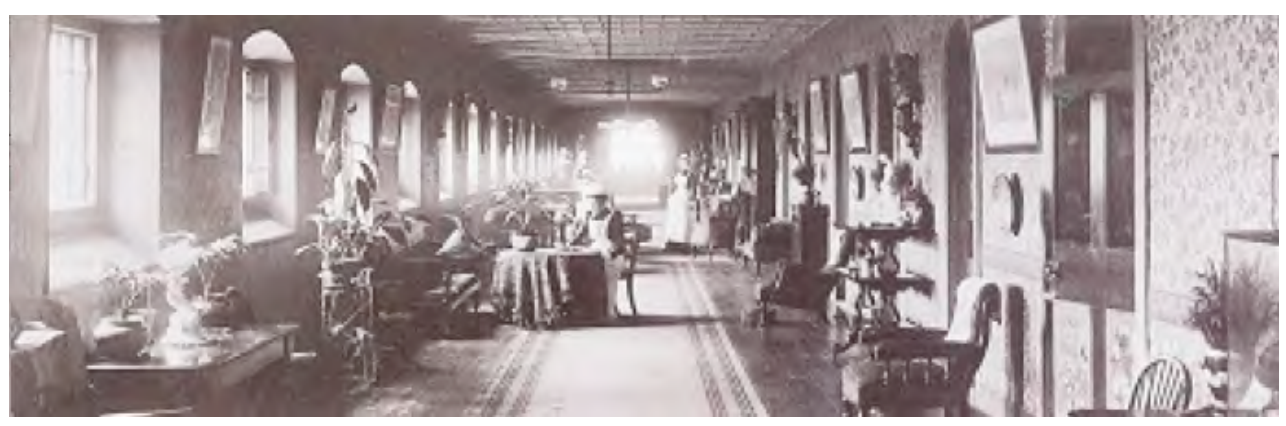

Figure 4.27: Dayroom, Bethlem Hospital, date unknown. Bethlem Royal Hospital Archive: neg.BED10 
Classification, or the separation of patients from those whose behaviour was considered harmful to their recovery, was a critical consideration in the provision of tranquillity for patients and the effective treatment of mental illness. At Seacliff patients were able to be classified to a far greater extent than was possible at Dunedin, Sunnyside or Auckland at that time (figures 4.28 and 4.29). Dayrooms and single rooms were both provided with a generosity that would never again occur within a New Zealand mental hospital. Seacliff provided 100 single rooms, accommodating one third of the patient population which failed to meet Conolly's preference for twothirds of patients to be accommodated within single rooms. However, Conolly himself acknowledged that his preference for two-thirds single rooms was at odds with Britain's Commissioners of Lunacy who did not find this necessary. ${ }^{113}$ MacGregor, however, credited not Lawson but the "well to do population" of the colony for this generous provision of single rooms. He felt there was a "dislike of associated dormitories" among this section of the community. ${ }^{114}$ The original design for the Auckland Asylum (1867) provided only a quarter of the patients with single rooms as did the Porirua Asylum constructed 13 years after Seacliff. ${ }^{115}$ Dormitories at Seacliff slept 6, 10 or 18 patients which also failed to meet Conolly's stipulated maximum dormitory size of 4 beds but presented an advance in comparison to its New Zealand counterparts. The largest dormitory at Porirua slept 56 patients, a far cry from the tranquil environments Conolly and Browne had pressed for.

\section{CHRISTCHURCH LUNATIC ASYLUM}

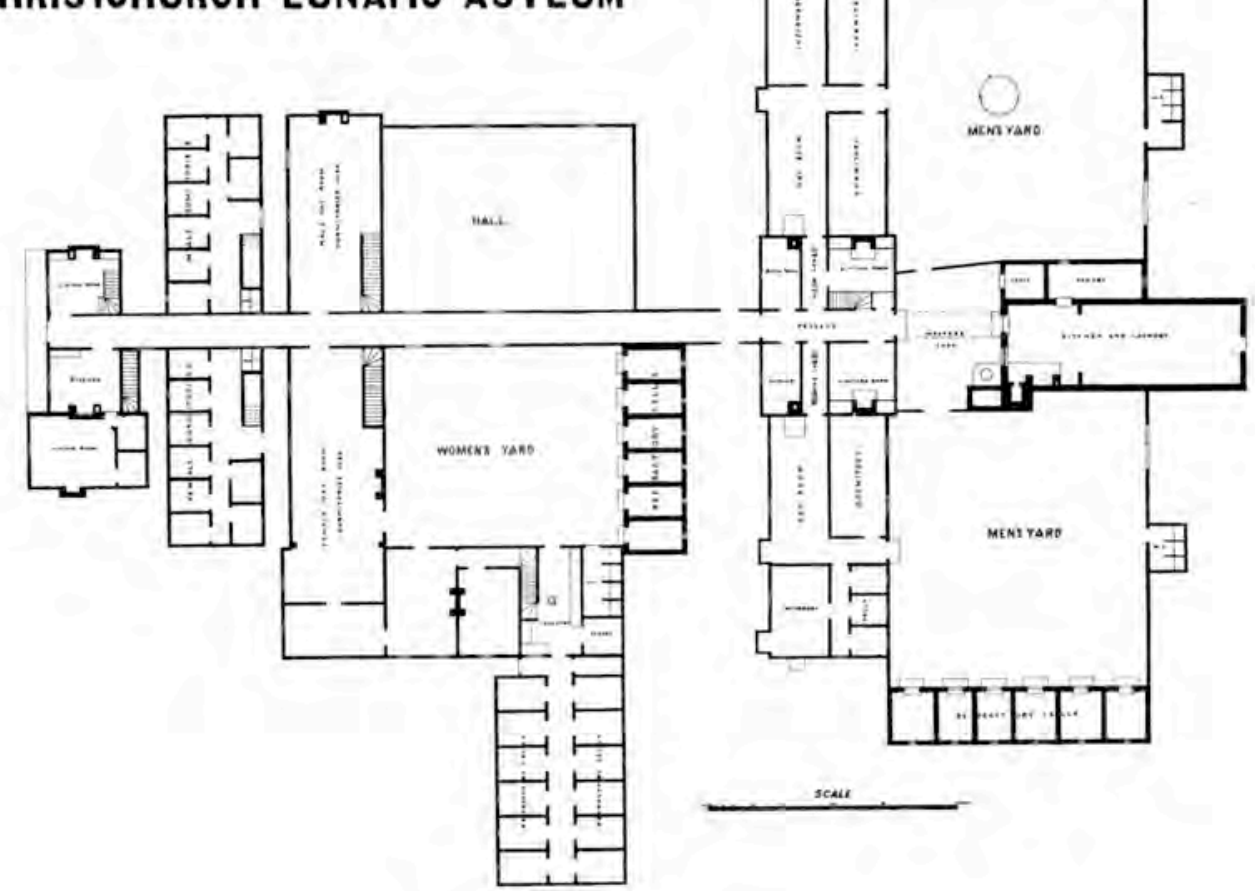

Figure 4.28. Plan of Sunnyside Hospital, Christchurch, 1877 As published in the AJHR 1877, H-08, 41. 


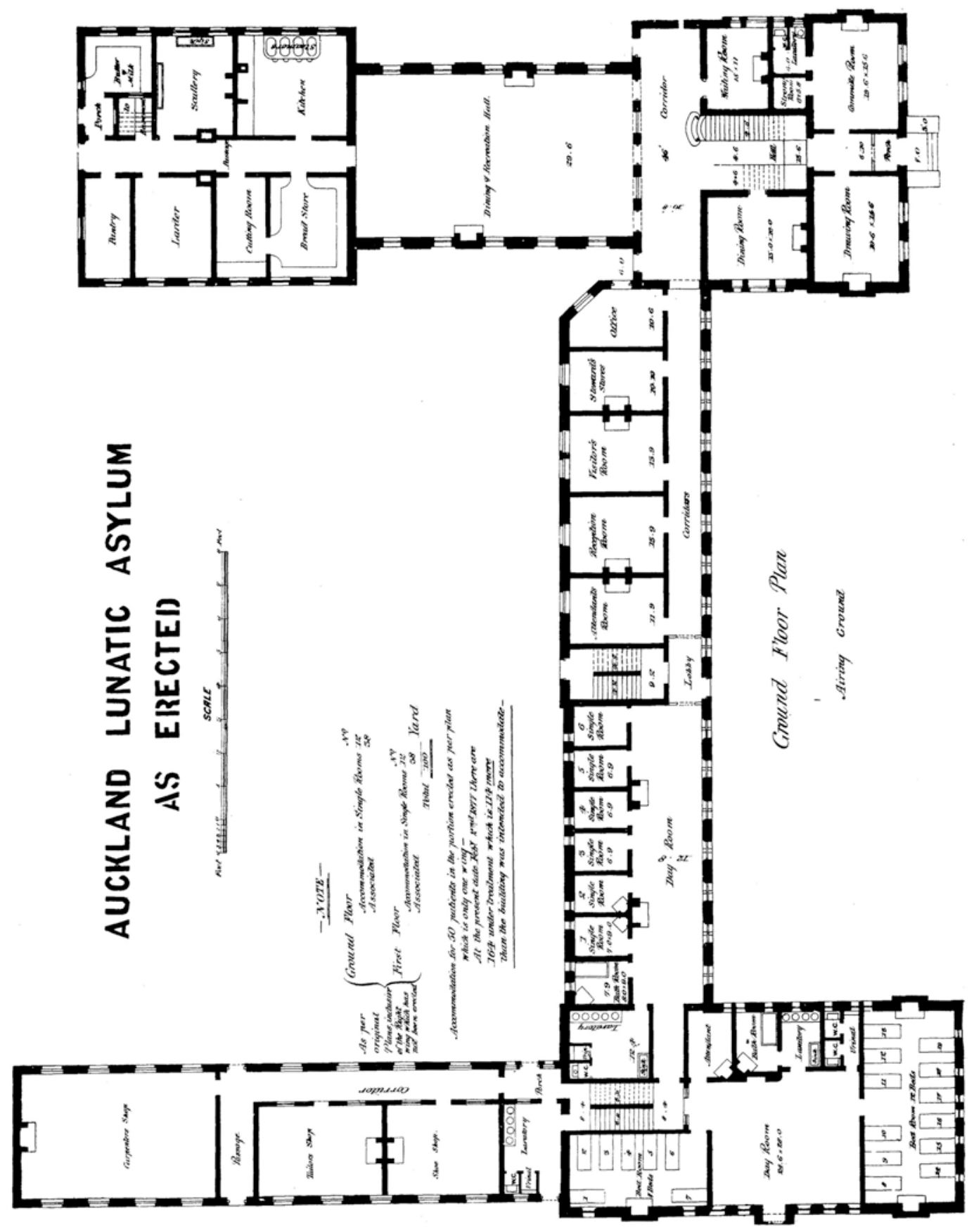

Figure 4.29: Plan of Whau Lunatic Asylum, Auckland, 1877 As published in the AJHR 1877, H-08, 29. 
A careful examination along medical lines makes clear that Grabham's criticism, that Seacliff was "badly designed," does not hold up. Lawson's design for Seacliff responded to much of the advice set out in Conolly's book and followed a relevant, contemporary precedent. Viewed against its New Zealand counterparts, Seacliff presented a clear advance in the provision it made for individual treatment and tranquillity. However, Seacliff Asylum did not provide an exemplar of the translation of ideal curative strategies into the built environment. Access to sunlight, the maintenance of safety, disguising the signs of confinement and employing a non-imposing architectural aesthetic were all important requirements in the design of an environment able to support the delivery of moral treatment. As the architect responsible, Lawson has been dealt harsh criticism but the question of whether Seacliff's failure to deliver on these five curative aspects can be placed entirely on his shoulders remains to be answered. The grandeur of Seacliff's aesthetic, in such stark contrast to Phipson's design and the preferences of Tuke and Browne, raises questions of political and colonial aspiration. While the inattention to landscape and interior furnishings suggests that the politicians who commissioned this asylum may have been more interested in constructing an institution that looked curative as opposed to one that could be considered to be curative. While the oversights regarding safety raise the question of how thoroughly Lawson was briefed and whether he was provided with an appropriate level of medical consultation throughout the design process. These questions will be addressed through the remainder of this case study. First, however, Grabham's assertion that Seacliff was "out of date" will be examined. 


\subsection{SEACLIFF IN AN INTERNATIONAL CONTEXT}

Henry Burdett's Hospitals and Asylums of the World was published in the last decade of the nineteenth century. Comprising four volumes and including a portfolio of hospital plans, Burdett created a document of some value for those involved in the design and construction of mental hospitals. ${ }^{116}$ Volume two, sub-titled Asylum Construction with Plans and Bibliography (1891), included recommendations on site, planning, ventilation, drainage, external ornamentation, interior furnishings and the appointment of architects. In preparing this work, Burdett requested plans and details on construction, administration, management and legislation from Europe, Britain and its colonies. This included New Zealand, Australia, India, Canada and Singapore and the United States. The arrival of Burdett's publication, thirteen years after Lawson prepared the plans for Seacliff, provides a convenient document for gauging the architectural achievement of Seacliff in an international context.

In 1877, The Builder described the Norwich Asylum as a "modification of the block plan."117 In 1891, Burdett, whose book classified asylums into four types, placed it within his "corridor-pavilion" category. ${ }^{118}$ The use of a pavilion arrangement for general hospitals rose to popularity in the midnineteenth century because it offered superior ventilation and thus aided in the prevention of disease transmission. The use of the pavilion plan for asylums was commended by the Journal of Mental Science, in 1862, for its ability to "diminish the main evil of asylum architecture": the "thick atmosphere of insanity" that resulted from a high concentration of patients in one place. ${ }^{119}$ In 1867, the British Medical Journal also commended this arrangement for its ease of patient classification according to "the nature of their disease, their bodily condition and the probability of recovery." ${ }^{120}$ The pavilion model also allowed for the easy and relatively affordable extension of these hospitals to respond to growing patient demand since additional pavilions could be tacked on to the existing complex. In some British instances this was done so exhaustively (figure 4.30). Lawson's design for Seacliff included two additional pavilions to be added at each end of the plan (figures 4.31 and 4.32). ${ }^{121}$

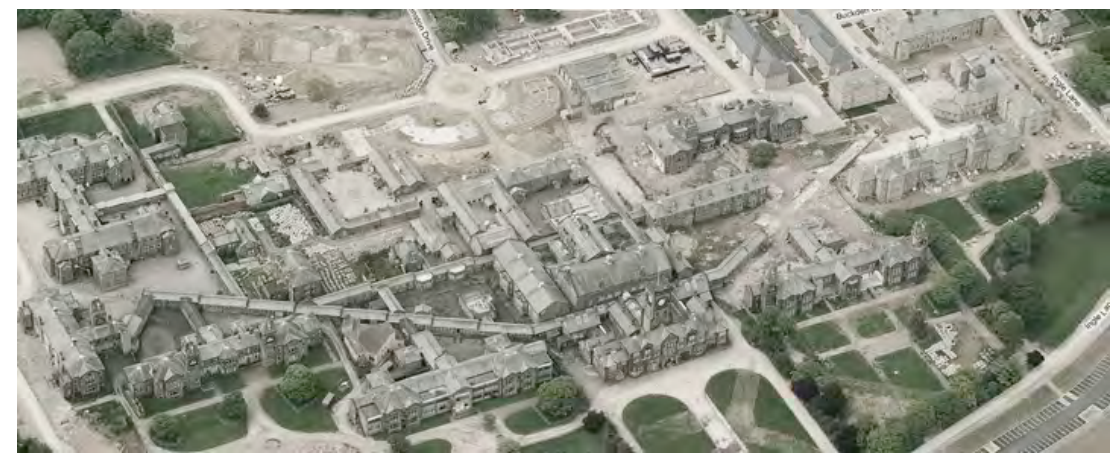

Figure 4.30: West Riding Pauper Asylum (now High Royds Hospital), opened 1888. Image source: www.thetimechamber.co.uk/beta/sites/asylums 

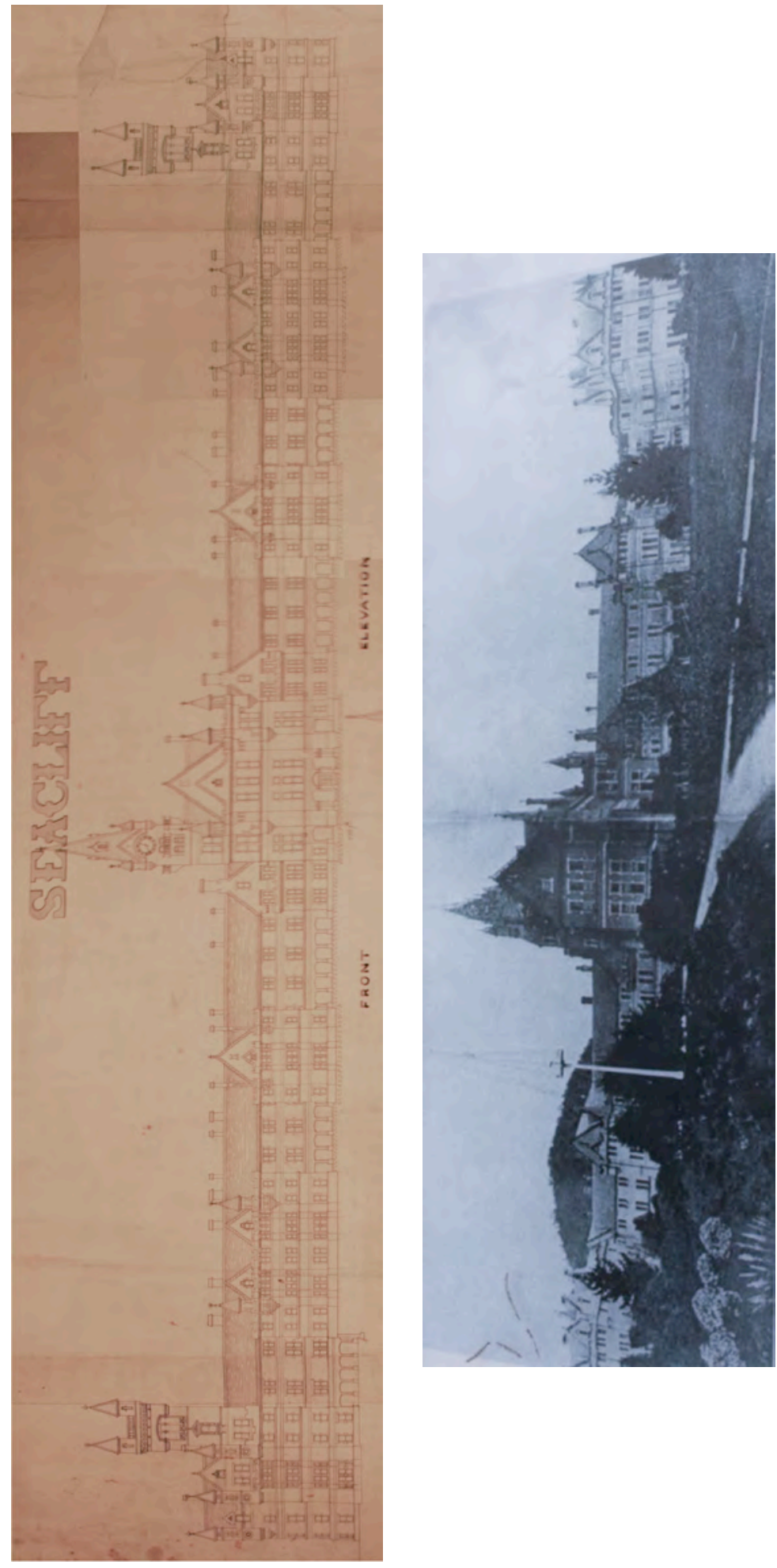

Figure 4.31 (left): Front elevation showing proposed future extensions (end wings). Hocken Collections: Salmon Collection - R4627.

Figure 4.32 (right): Seacliff as it was constructed. Date unknown. Hocken Collections: 2465-01-005A. 
The conclusion of Burdett's study was that the "corridor-pavilion" provided the best model for modern asylum construction. ${ }^{122}$ Although Burdett made no comment on Phipson's design for the Norwich Asylum, this was the only plan of a corridor-pavilion type reproduced within this publication. This suggests that he regarded Phipson's plan as a relevant exemplar for asylum architects despite it having been constructed 23 years earlier. ${ }^{123}$ Burdett outlined 14 broad principles of good asylum design of which 12 were relevant to the corridor-pavilion type and 11 can be tested with regard to the designs created for Norwich and Seacliff. ${ }^{124}$ Phipson's plan met 8 of the 11 points tested, Seacliff met only 5 . The most relevant considerations will be discussed below.

Burdett was insistent that corridors be used only for circulation and not as day rooms; one ward should never be traversed in order to reach another. ${ }^{125}$ This was a design flaw that Conolly also highlighted. ${ }^{126}$ In the plan for Norwich, corridors are labelled as "wards" and separate day rooms open off them. In the plans for Seacliff, the corridors are clearly labelled "day rooms." It is perhaps significant, however, to point out Lawson's placement of multiple stairwells across the plan, eight in total, made circulation possible without having to traverse these day rooms on route to another ward. Although it seems unlikely that staff would not have taken short cuts, patient access from the wards to the ground floor day rooms is clearly delineated via separate stairwells. The exception to this provision would have been patient access to the recreation hall. This was located on the second floor and it seems unlikely that patients would have been directed downstairs and then back up simply to avoid passing through the day room of another ward.

Unlike Conolly, Burdett felt that only one quarter of patients needed to be accommodated within single rooms, Seacliff exceeded this. At $8 \times 9$ feet, the single rooms at Seacliff were just shy of Burdett's recommendation for 80 square feet but, with their 13 foot high ceiling, they easily met his recommendation of 800 cubic feet. ${ }^{127}$ Lawson used a "modification of the block principle" but did not limit Seacliff to two stories as Burdett and Conolly favoured. ${ }^{128}$ Burdett recommended keeping the main floor including kitchen and service spaces on a single level which Lawson achieved. ${ }^{129}$ Another major criticism from Burdett was the use of double-loaded corridors; an arrangement which offered the greatest economy but reduced the availability of light, fresh air and outlook. Skae complained of this at Sunnyside in 1878, observing that patients accommodated on the southside of the corridor were unacceptably cold in winter. ${ }^{130}$ Lawson was prudent to avoid it at Seacliff. Additions to the Sunnyside and Whau asylums, in 1888 and 1895 respectively, both featured double loaded corridors (figures 4.33 and 4.34). 


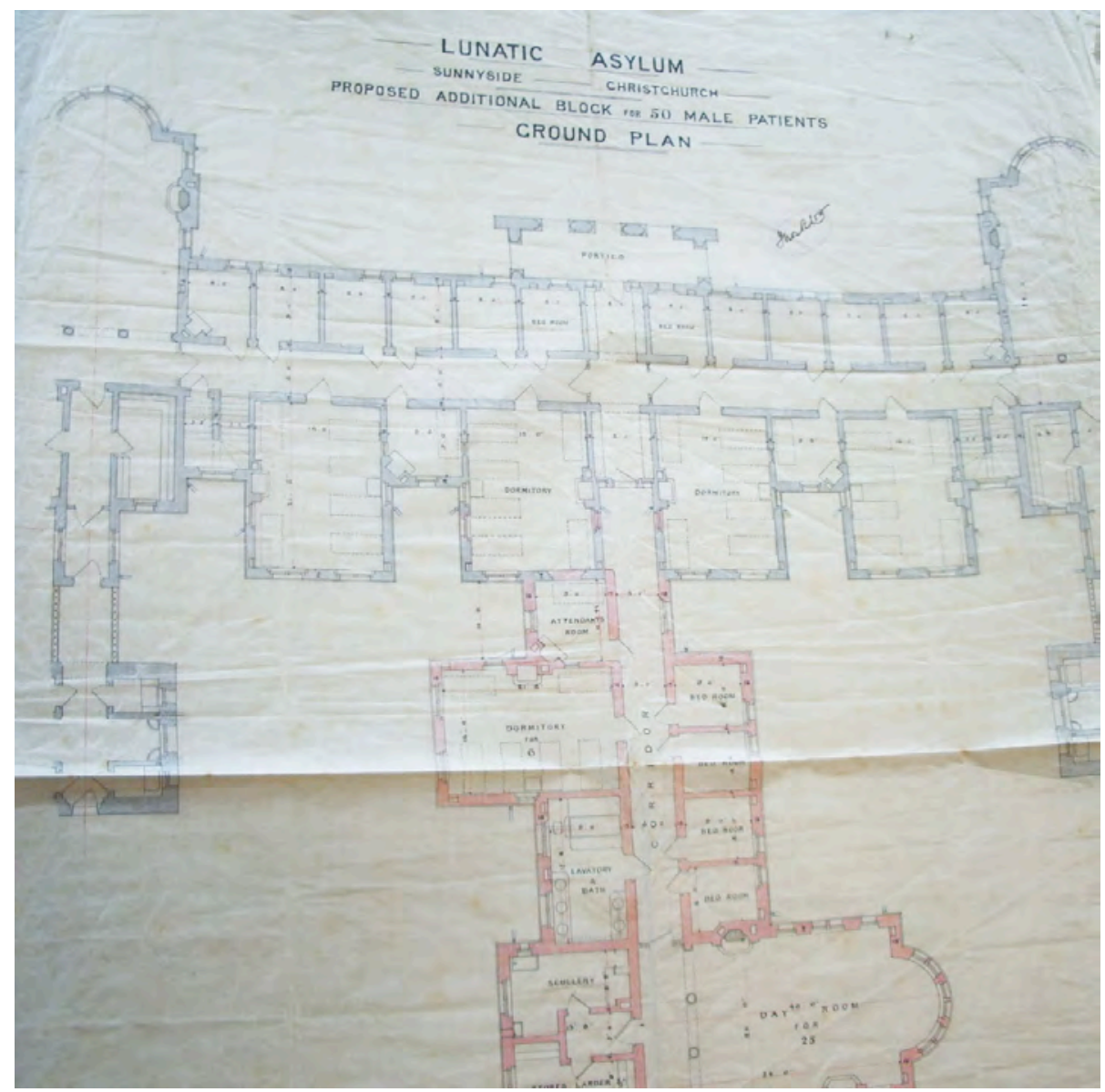

Figure 4.33: Sunnyside, Additional Accommodation for 50 Male Patients, 1888. Existing double-loaded corridors are shown in grey and new additions in red. Archives New Zealand: W5 26412609 (cropped).

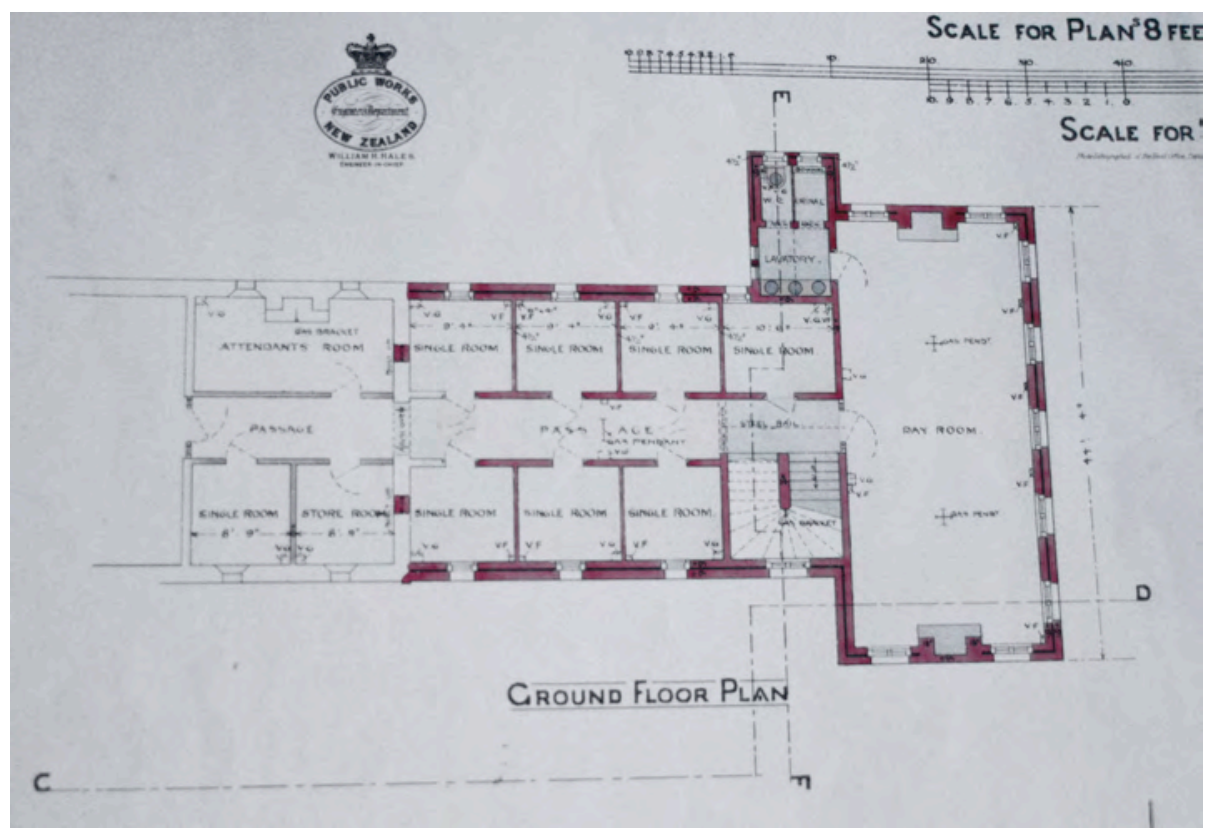

Figure 4.34: Whau Asylum, Additions to Male Wing, 1895.

Archives New Zealand reference: W5 119217554 (cropped). 
Burdett felt that "three walls of all day rooms and dormitories should be free [external]." At Norwich, Phipson achieved this by projecting the day rooms forward of the corridors. Lawson achieved this only in the ground floor day rooms (figure 4.35). Each ward was not provided its own dining room at Seacliff, as Burdett suggested, but this did not occur at Norwich either, except within acute wards. Instead, the recreational hall was likely used as a central dining space. The plans do not give us enough information to ascertain where the infirmary was located however single rooms most likely "opened directly onto day rooms" within these wards, as per Burdett's preference, since this situation prevailed throughout the plan.
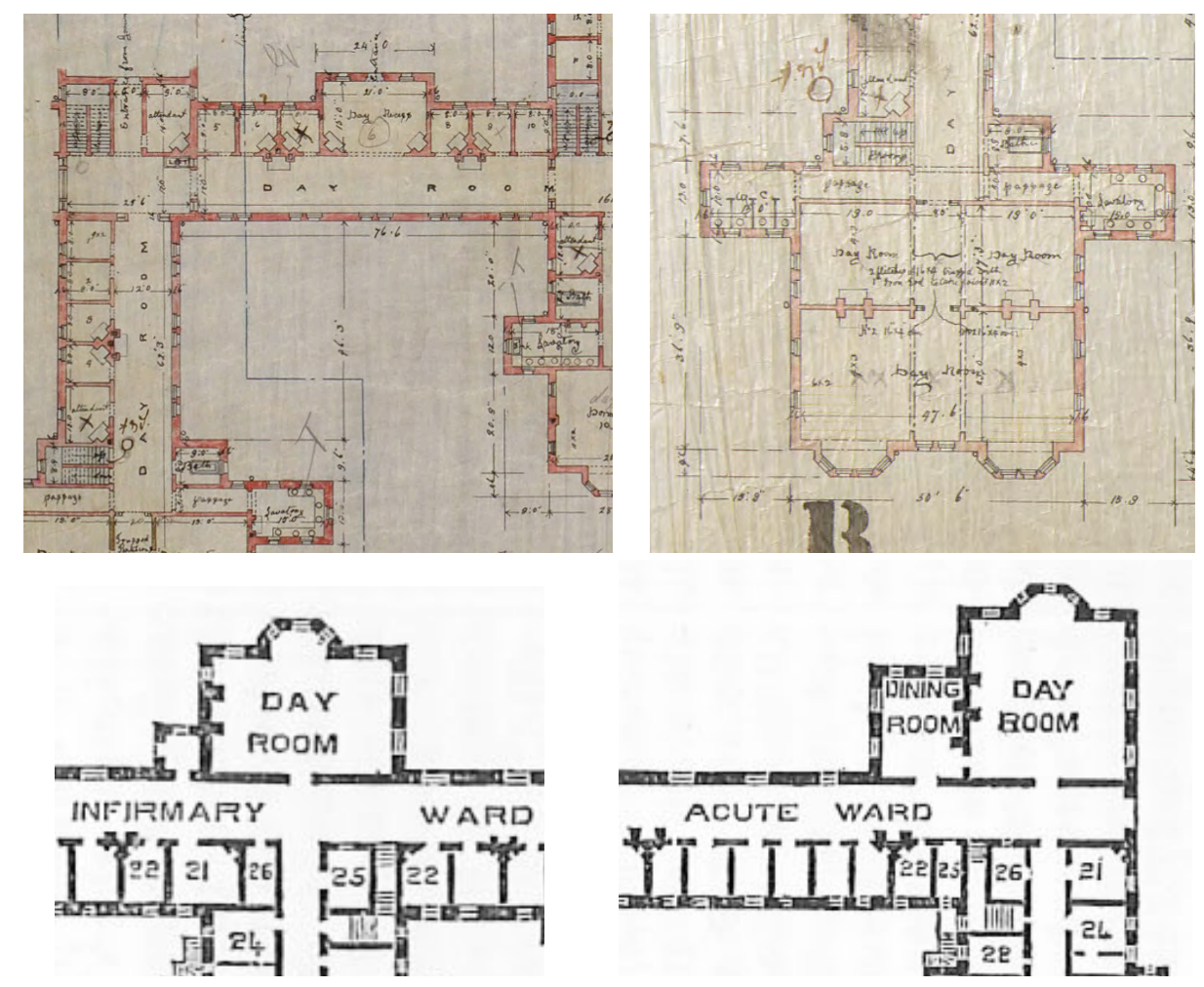

Figure 4.35: Day Room configurations for Seacliff and Norwich Asylums.

Clockwise from top left: First floor, Seacliff, Ground floor, Seacliff

Ground floor, Norwich, Ground floor, Norwich (third type).

Alexander Turnbull Library: Plans-84-1186 and Plans-84-1185 (cropped).

Norwich plans as published in The Builder, vol. 35, May 12 (1877): 481 (cropped).

Like Conolly, Burdett recommended the sparing use of ornamental detail. Conolly's recommendation would appear to have influenced Lawson's choice of the Scottish Baronial style, as it could be constructed with "few mouldings of any kind, and only a touch here and there of anything like ornament introduced." ${ }^{131}$ Burdett also advised that careful attention should be paid to glazing proportions in order to avoid that "prison-cell arrangement" that comes of windows placed "so high that the tallest man could not see out of them." While building orientation, he stipulated, should make available to patients "every gleam of sunshine." 132 
Viewing Seacliff through the lens of Burdett's research reinforces the findings of the previous section, that the design of Seacliff was deficient in some key areas, especially dormitory glazing and orientation. Regarding Burdett's design recommendations, those which Lawson did not comply with were the ones which would have incurred greater expense, such as Burdett's preferred dayroom arrangement which would have resulted in a greater proportion of external wall (this would have been more expensive to construct than internal walls owing to the stone required) and a doubling of circulation space to avoid traversing day rooms. Likewise, constructing two stories instead of three and providing a separate dining room to each ward would have resulted in a less centralised plan and may have required greater levels of staffing. Viewing Seacliff through the lens of Burdett's research also confirms, however, that Grabham did not have defensible grounds for accusing Lawson of creating a building that was "out of date."133 According to Burdett's criteria, Lawson selected a progressive model that remained relevant for at least fifteen years after Lawson's adoption of it. 


\subsection{OBSTACLES IN THE DESIGN OF SEACLIFF: RESOURCING ISSUES IN COLONIAL NEW ZEALAND}

Since architecture, within the nineteenth century, was considered an instrument of the curative process, compromise should no more have been accepted within asylum construction than one would consent to surgery with a blunt scalpel. Yet compromises did occur in the design of Seacliff. This section will examine the issues of resourcing in a young and isolated colony and the impact that this had on the design and construction of Seacliff, especially with regard to the quality of medical briefing and consultation received by Lawson and his own qualifications for a project of this complexity.

Burdett and Conolly both advised that the involvement of a medical physician throughout the design process, who was experienced in the condition of lunacy and the operational requirements of an asylum, would result in a superior outcome. ${ }^{134}$ Similarly, Lindsay advised that any Inspector of Asylums appointed to New Zealand ought to first embark on a study tour of the world's "most modern hospitals." He should compile a "colonial lunacy library of reference" that included copies of lunacy laws and asylum plans suitable for colonial requirements, an assortment of books, forms and reports, window, door and lock samples, designs for heating and ventilation systems, room and table furnishings, patient clothing and feeding apparatus. ${ }^{135}$ There is no evidence to suggest that Skae was granted the resources for such a trip or that he arrived in New Zealand with Lindsay's suggested array of samples. Lindsay made another observation worthy of consideration with regard to the quality of medical advice available to Lawson. He observed that professional appointments in colonial settlements seldom carried sufficient remuneration to attract properly qualified men; salaries rarely equalled what could be earned at home. Furthermore, they took no account of the incentives required to entice professionals to "exchange the comforts of home ... for the dangers of colonial travel, for the discomforts of exile from home and friends." ${ }^{136}$ From 1869 until 1877 Skae was the first Medical Superintendent appointed to the Stirling District Asylum, a position he held since the age of twenty-five. Brunton's early research paints Skae as well-meaning but with minimal experience for the role to which he was appointed. ${ }^{137}$ In 1872 , Lindsay observed that colonial inspectors were commonly "manufactured out of colonial asylum superintendents, who were originally in British Asylums." Skae may have skipped the step of personally superintending a colonial asylum but his appointment was otherwise no different. This is despite Lindsay's caution that:

the desirable experience should be so varied and so extensive that very few Physicians-in-chief of British asylums are qualified for so difficult an office. ${ }^{138}$ 
Prior claimed that Lawson was required to seek approvals from the Government's Public Works Department and medical authorities throughout all stages of the design process. ${ }^{139}$ However, the number of oversights regarding safety suggests that Prior's assumption is worth closer examination. The Seacliff Inquiry of 1888 recorded that there was "voluminous correspondence" held by the Public Works Department regarding the design and construction of Seacliff though little of this seems to have been retained. ${ }^{140}$ Likewise, little of Lawson's own correspondence appears to have survived so it is difficult to gauge just how much medical guidance he received. In a letter to the Otago Daily Times, however, Lawson stated that the plans for Seacliff were "prepared after the most modern and approved methods, and under the personal inspection of the late Dr Skae." ${ }^{141}$ With regard to the claim made by Prior, this may be based upon a single surviving memorandum from the head office of the Public Works Department (Wellington) to a local representative in Dunedin, regarding the design of a laundry for Seacliff. This was dated June 25, 1882, part way through construction and rejected a laundry design proposed by Lawson owing to expense. The memorandum instructed the architect to prepare a second design, based on sketches provided personally by Grabham. ${ }^{142}$ This document confirms that the Public Works Department acted as an intermediary between Lawson and his medical advisors. It also raises the question, did medical consultancy in the design of Seacliff occur to a very detailed level or was Grabham simply more forthright in exerting his influence than Skae. Differences in the tone of the reports written for the AJHR from each of these men suggest that Grabham possessed a more forceful manner. This fits with the explanation Lawson provided for the fact that Skae approved the same design that Grabham disapproved of. Lawson wrote to the Otago Daily Times in 1886:

we all know the common adage that "doctors differ," and it may fairly be presumed that in the lunacy department of the profession they differ especially. ${ }^{143}$

It is worth acknowledging, however, that Skae had far less manpower at his disposal as he was appointed no deputy inspectors or official visitors to lessen his workload. ${ }^{144}$ To put the workload of the Inspector-General's role into perspective, K.A. Simpson writes that, between November 1882 and April 1883, Grabham "travelled 4,158 miles by ship, coach and train, visiting all 38 hospitals and eight asylums in the colony." ${ }^{145}$

In 1886 Grabham suggested that the solution to the problem of New Zealand's "ill-designed asylums" was the employment of an English architect. ${ }^{146}$ However, the plans for the Whau Asylum (Auckland) had been sent to the Superintendents of the Colony Hatch Asylum, near London, for approval in $1863^{147}$ and this precaution failed to produce a better result. According to Grabham's own description, the Whau as an institution one could "speak of [only] with feelings akin to shame." ${ }^{148}$ This does raise the 
question, however, of Lawson's experience relative to the complexities of designing an asylum. While Lawson had completed several notable buildings in Otago, including the First Church of Dunedin (1873), the Bank of Otago (1871) and the Union Bank (1874), he had no prior experience in asylum or general hospital design. Seacliff was the largest architectural commission to have been awarded in New Zealand in $1878 .{ }^{149}$ Within his masters' dissertation, Prior suggests that Lawson would have gained "much valuable experience" relative to designing Seacliff from his appointment to design the Otago Benevolent Institution (1866) in Caversham (figure 4.36). ${ }^{150}$ This is an opinion that Ledgerwood has agreed with in his recent publication on Lawson. ${ }^{151}$ It is a dubious assumption, however, since the institution at Caversham (for fifty elderly people and children) would have required the architect to exhibit little more skill than in the design of a boarding house. Asylums posed a significantly more complex design problem, not only with regards to creating an environment capable of supporting moral treatment but also with regards to operational concerns such as circulation, security and safety requirements.

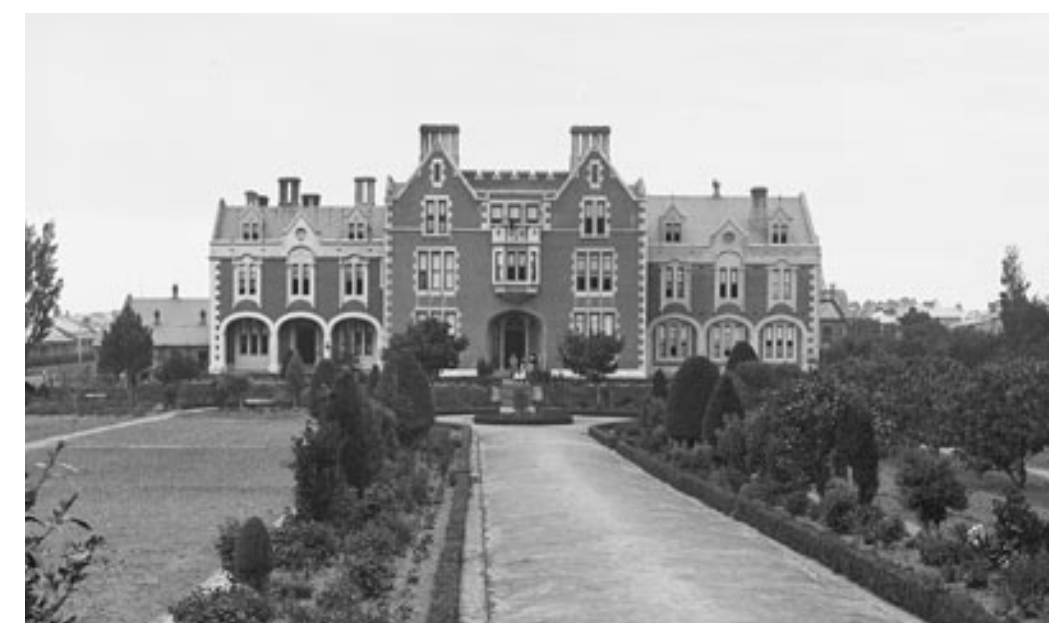

Figure 4.36: Otago Benevolent Institution. Photograph by William Williams. Alexander Turnbull Library: 1/1-025917-G (cropped).

While no judgements will be made within this thesis regarding the 1888 Commission of Inquiry into the construction of Seacliff, a brief overview of the Commission's proceedings offers some insight into Lawson's level of preparedness and commitment to the design process. ${ }^{152}$ There was much criticism by the contractor and representatives of the Public Works Department regarding the quality of Lawson's documentation, the timeliness of his correspondence and observation of site works. ${ }^{153}$ The Inspector of Works, Alfred Brindley, felt the plans were drawn to an inadequate scale for the contractors to build from and so created a number of larger scaled drawings himself. He suggested to the Commission that, as a result of Lawson's inadequate documentation, he made decisions normally reserved for the architect's domain. ${ }^{154}$ Brindley's complaints regarding scale may have had some merit. The plans and elevations for Seacliff were drawn to a 
scale of " $1 / 16^{\text {th }}$ of an inch to 1 foot." 155 This was a smaller scale than Lawson used for other public buildings drawn around the same time, the Union Bank and Oamaru Courthouse, for example, were both drawn at a scale of " $1 / 8^{\text {th }}$ of an inch to 1 foot." ${ }^{\text {"156 }}$ Drawings created for the Sunnyside Asylum between 1878 and 1881 (various architects) were also drawn at a larger scale of " $3 / 16^{\text {th }}$ of an inch to 1 foot." ${ }^{\text {"157 }}$ However, the Administration Block (1885) was drawn at the same scale as Seacliff suggesting that this scale was not unusual for public buildings. ${ }^{158}$ Furthermore, a set of drawings created for the Auckland Asylum in 1891 were drawn at an even smaller scale of " $1 / 20^{\text {th }}$ of an inch to 1 foot." 159 The nature of the decisions made by Brindley, owing to this issue of drawing scale, appeared to be restricted to the set out of the building works and construction detailing but we have no real way of ascertaining whether these decisions had any adverse effects on the curative ability of the architecture. The overly high window sills in Seacliff's dormitories, for example, could feasibly have resulted from the inadequate drawing scale Brindley accused Lawson of since floor to ceiling heights were noted on Lawson's drawings but no sill heights were given.

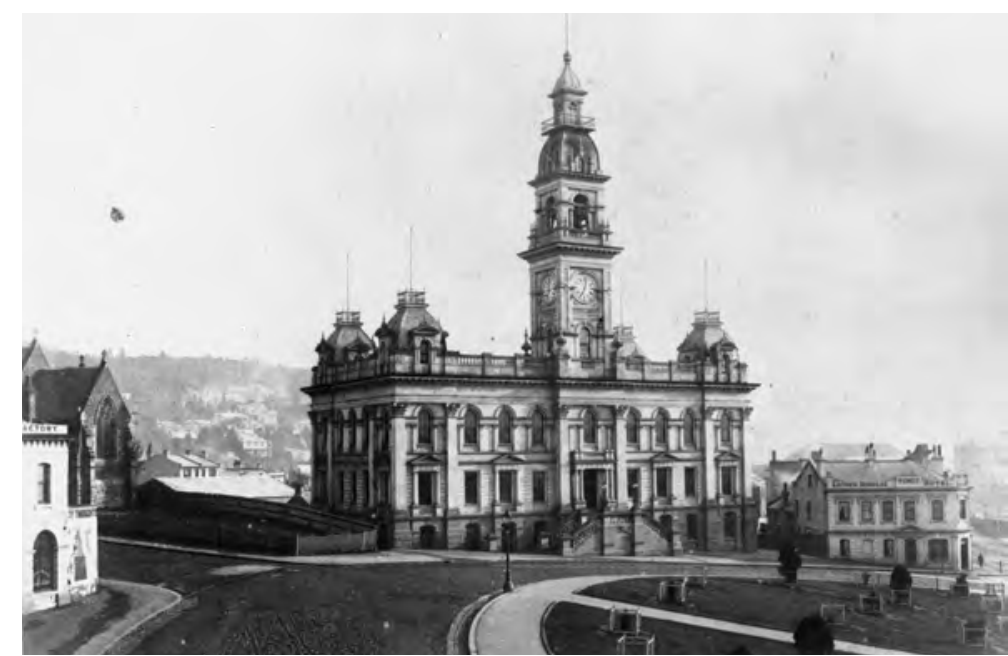

Figure 4.37: Dunedin Town Hall, ca 1885. Photograph by F.A. Coxhead. Alexander Turnbull Library: 1/2-041780-F

As Prior points out, Lawson would have been under immense pressure in the design and documentation of Seacliff since he was engaged with site observation on the Dunedin Town Hall project while he was preparing plans for the asylum (figure 4.37). ${ }^{160}$ Tenders for the Town Hall were accepted in February 1878 and construction began in May. ${ }^{161}$ Lawson received the commission for Seacliff in July of 1878 and was given twelve months to complete plans. Tenders were called for the asylum in July of $1879 .^{162}$ In January of 1880 the problems of site stability were discovered and the discussions around the provisions of a new plan and the possibility of an altered orientation (as discussed in previous sections) occurred. ${ }^{163}$ In response to the geological report provided by Hector, the Minister of Public Works suggested temporarily suspending building work at Seacliff. ${ }^{164}$ Lawson responded by stating that he had "no objection to prepar[ing] fresh 
plans" but was still of the opinion that "the arrangement of the building on the site available was the best." 165 It seems unlikely that Lawson would have been in any position to prepare fresh drawings in 1880. Ledgerwood has confirmed that Lawson's workload reached its peak between the mid-1870s and 1880, although no records have survived to confirm the size of his practice throughout this period; he also travelled frequently to Melbourne leaving his senior staff in charge. ${ }^{166}$

Around the time that these discussions were taking place, Lawson was engaged with a second prestigious project - he was awarded the commission for the Otago Boys' High School sometime between April 1879 and July 1882. The Arthur Street Asylum site was designated for high school use in April of 1879 and the construction contract was signed in July 1882, although the date Lawson was engaged remains unclear. ${ }^{167}$ This project not only contributed to Lawson's workload but also presented a significant conflict of interest which has not previously been recognised by historians (figure 4.38). The ground conditions at Seacliff created on-going problems for the asylum's construction and in 1881 only 130 of 305 patients had been shifted to the new asylum. The central portion of the building was required to be complete before the Arthur Street site could be vacated but this would not be ready for occupation until October $1883 .{ }^{168}$

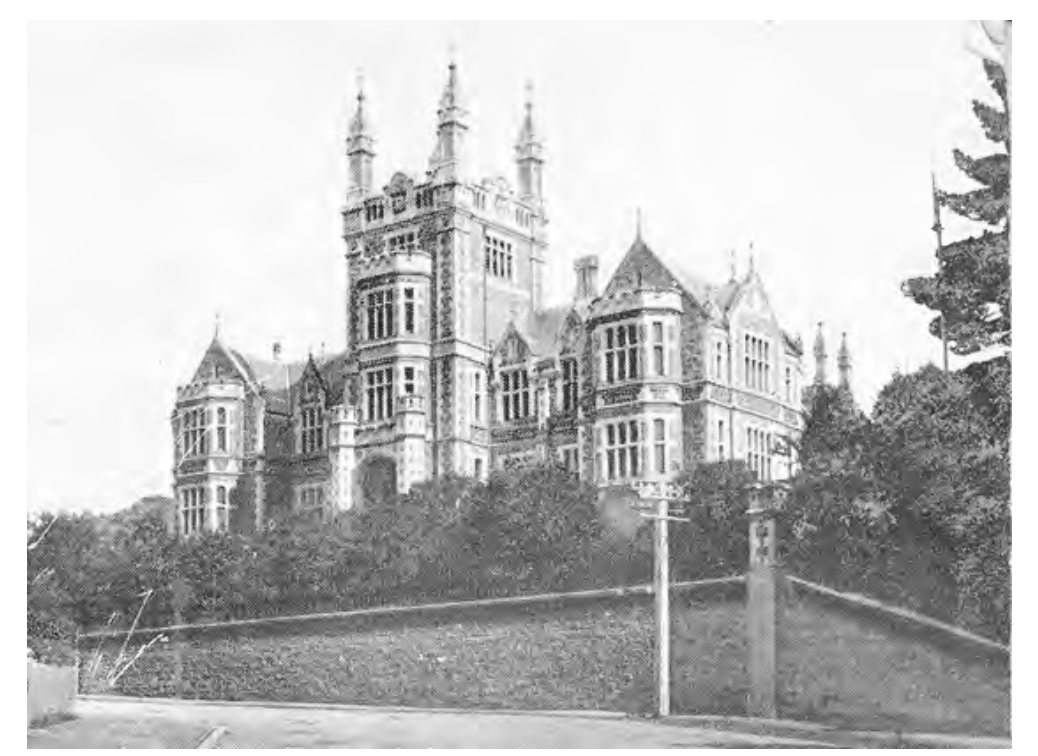

Figure 4.38: Otago Boys' High School. Date and photographer unknown.

Image source: rootsweb.ancestry.com, original source not confirmed by website.

The AJHR report on Education for 1882 detailed the effects of Seacliff's delayed completion on the high school project. Construction began in 1882 but could not be completed until 1885, three years later than desired. ${ }^{169}$ In order to secure access to the site to begin building in 1882, the School had to provide, at their cost, alternative accommodation for the remaining patients. $£ 1,809$ was spent on temporary buildings for this purpose. Only some of these temporary buildings were suitable for future reuse by the school. This put them out of pocket by $£ 1,000$, a fairly significant amount 
considering the total budget for the school building was $£ 14,800$. The time allowed for completion of works within the schools construction contract was sixteen months, expiring on December $1^{\text {st }} 1883$. By April of that year it was clear that this deadline was not going to be met. The Chairman of the Board warned:

Unless the Board is put in possession of the ground before the end of the year it, as well as the contractor, will be put to great loss and inconvenience. I would therefore take this opportunity of asking you to urge the Government to hasten the removal of the patients to Seacliff as soon as possible [emphasis added]. ${ }^{170}$

This situation must have created significant stress for Lawson and divided his loyalties. It also raises the question of whether this timing motivated Lawson to accept bad workmanship from the contractor, an accusation that was made during the 1888 Commission of Inquiry. This seems unlikely given the fact that bad workmanship was not isolated to the Seacliff project. The central block at Porirua, constructed in 1891, suffered equally from "defective workmanship and bad materials." Within two years of occupation the unseasoned timber used for the door lintels "was shrinking and had cracked the brickwork." 171

Lawson's was not the only commitment that ought to be interrogated in the construction of Seacliff. The question should be asked, what was the government's commitment to building a leading edge asylum for the treatment of lunacy? Cost, or "dollars spent," has come to be regarded as an accurate indicator of public support of various public health issues. ${ }^{172}$ If we apply this test in isolation to the construction of Seacliff, we would be forced to conclude that the commitment to providing a modern facility for the cure of mental illness was exemplary. Even during the initial planning stages, Skae's recommended budget for Seacliff was $£ 50$ above that recognised as necessary for the construction of "more modern English Asylums." 173 This was despite the fact that, at the time he set this budget, suitable timber buildings had been constructed at the Seaview Asylum (Hokitika) for only $£ 40$ per patient. Although, he felt a similar construction type at Seacliff would more likely cost $£ 100$ per patient - this still equated to half of the budget he recommended. ${ }^{174}$ It is difficult to know whether this was based on varying construction costs around the country or on a greater expectation regarding new architecture in Dunedin. This city was, as Belich has described it, "the jewel in progressive colonisation's urban crown." ${ }^{175}$ In 1878 when the budget was set, the difficulties with the ground conditions of this site were still unknown so this cannot have affected Skae's estimate. While no tender price has been located for Seacliff, the final construction cost was close to $£ 200,000$. ${ }^{176}$ This works out to a staggering $£ 650$ per patient or, in other terms, a budget overrun that could have housed an additional 700 patients based on the costs incurred for new patient accommodation at Sunnyside in 1879 and 1880. Built in permanent 
materials following the gothic style, the new accommodation constructed for the Christchurch asylum was consistent with Skae's estimates for Seacliff, at $£ 200$ per patient. ${ }^{177}$ Curiously, little is mentioned throughout the reports to the AJHR regarding the extravagant cost of Seacliff. We know only of its final build price because Lawson mentions it himself in the transcript of the 1888 Inquiry. ${ }^{178}$ Since this case study has already established that these funds were not directed toward vastly superior patient accommodation, the most likely explanation is that the additional costs were incurred owing to the late discovery of site instability. Changes had to be made during construction to the design of foundations, drainage and walls (which had to be underpinned). ${ }^{179}$

The translation of ideal curative strategies into Seacliff's architecture could only have been possible with a significant commitment of money, medical and architectural resource. Unlike many of its British and New Zealand counterparts, insufficient funding was not a dominant cause of compromise at Seacliff. A sizeable budget, in line with the costs of modern English asylums, was established at the outset, despite the presence of a suitable, low-budget precedent at Hokitika. The factors that compromised this design were a clear lack of collaboration throughout the design process and the appointment of men who were inexperienced and under-resourced for their respective roles. Neither Skae nor Lawson came to this project with sufficient practical experience furthermore, Skae was over-committed through the duration of this project and it is likely that Lawson was too. As Lindsay had forewarned, New Zealand's position as an isolated colony of modest income, created the environment within which this situation was able to occur. 


\subsection{COLONIAL ASPIRATION AND EXPECTATION IN THE DESIGN OF SEACLIFF ASYLUM}

Seacliff's majesty could be appreciated by passengers travelling the main trunk railway, between Christchurch and Dunedin, and those approaching the harbour by steam ship (figure 4.39). ${ }^{180}$ Author Janet Frame described the asylum, as it appeared from the train below, as "a castle of dark stone between the hills." ${ }^{181}$ Both the cost and grandeur of Seacliff raise the question of what role colonial aspiration, public, political and personal, played in the design of this asylum. While no written brief for Seacliff has survived, this section argues that Lawson was not only asked to provide a design in accordance with best medical practice, which is the basis upon which it has been criticised in existing sources, but that he was also asked to address three colonial concerns: the fear of instability, the fear of lunacy and the desire to make Britain proud. The need to respond to these colonial concerns could provide an explanation for Seacliff's failure to offer a nonimposing curative environment that disguised obvious signs of confinement. This section will begin by examining what drove Lawson and to what degree his personal ambition may have compromised this design.

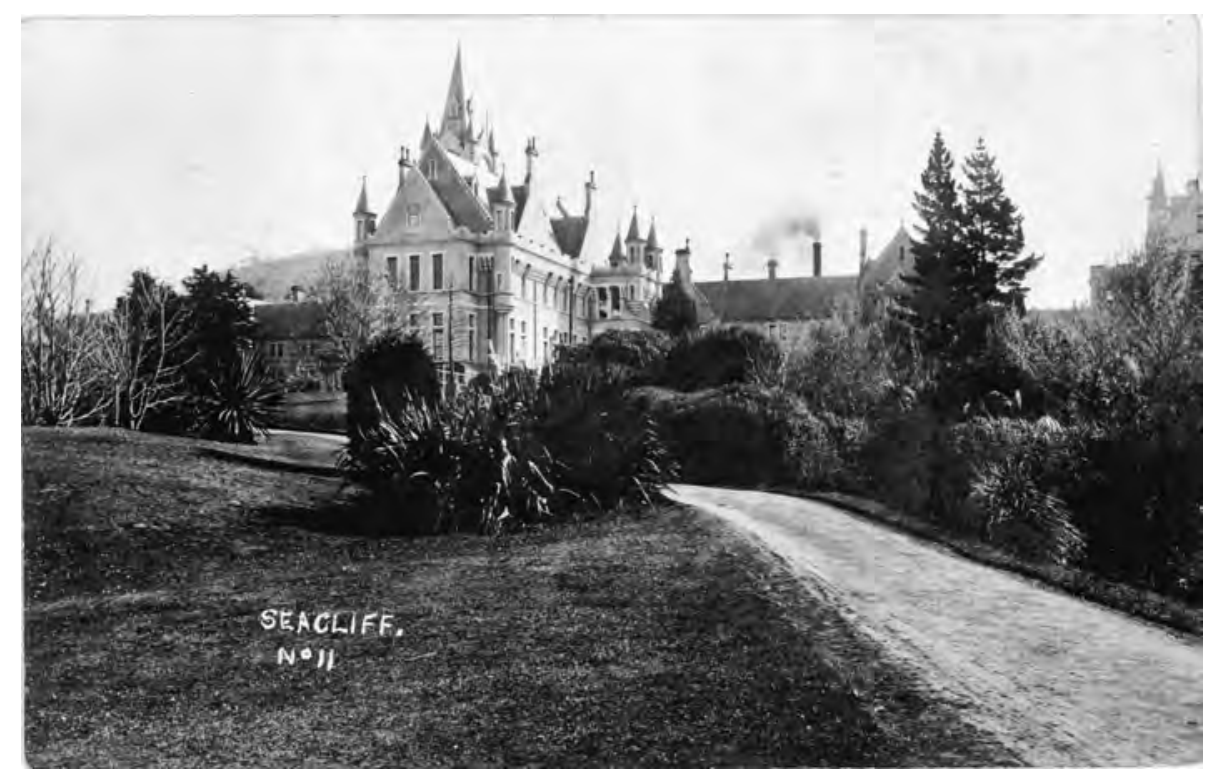

Figure 4.39: Seacliff Asylum, ca 1912. Photographer unknown.

Alexander Turnbull Library: PAColl-8769-04

Amid Lindsay's discussion on the difficulties of obtaining suitably qualified professionals he conceded that "there may be... men to whom it would be a great inducement to have the opportunity of moulding or forming the lunacy system of a new country." ${ }^{182}$ In the case of the architectural profession, the opportunity to shape new cities must have seemed an exciting prospect. Architectural historian lan Lochhead suggests that Canterbury architect Benjamin Mountfort was drawn to colonial New Zealand because it offered "the possibility of building a complete Victorian Gothic city" and because the absence of an architectural tradition allowed a certain freedom. ${ }^{183}$ 
Along the voyage from Scotland to Australia in 1854, at age twenty-one, Lawson kept a journal. This informs us that he prepared designs for a Gothic church and a municipal building in the Italian Renaissance style. He hoped these would one day make worthy future memorials. ${ }^{184}$ In 1933 , the Otago Daily Times described Lawson as "the man who enriched the city with its finest buildings." The article focused on these entries to Lawson's journal and, while acknowledging that little was known of Lawson's character, stated that "even at an early age Lawson was turning over in his mind plans for a building that in the years to come would perpetuate his name." ${ }^{185}$ The article infers, but does not provide sufficient evidence to confirm, that Lawson sailed for New Zealand with the purpose and ambition of making his mark on this new land. It is an opinion shared by Tyler and Barsby who have suggested that it was Lawson's ambition to shape Dunedin's "entire cityscape." ${ }^{186}$ The journal entries themselves, however, render the drawings prepared by Lawson as one of many strategies to defy boredom. In addition to preparing these two designs, Lawson led the Sunday Sabbath service for his fellow passengers, started a newspaper for the ship, wrote poetry and completed small watercolour paintings. ${ }^{187}$ Lawson did, however, write in his journal that:

My motives for this step I had scarcely even hinted to myself ... the means of satisfying a nameless craving which no doubt analysed would prove itself to be an ambition, that which unbridled, has become a source of ruin and devastation to many millions of the human race. ${ }^{188}$

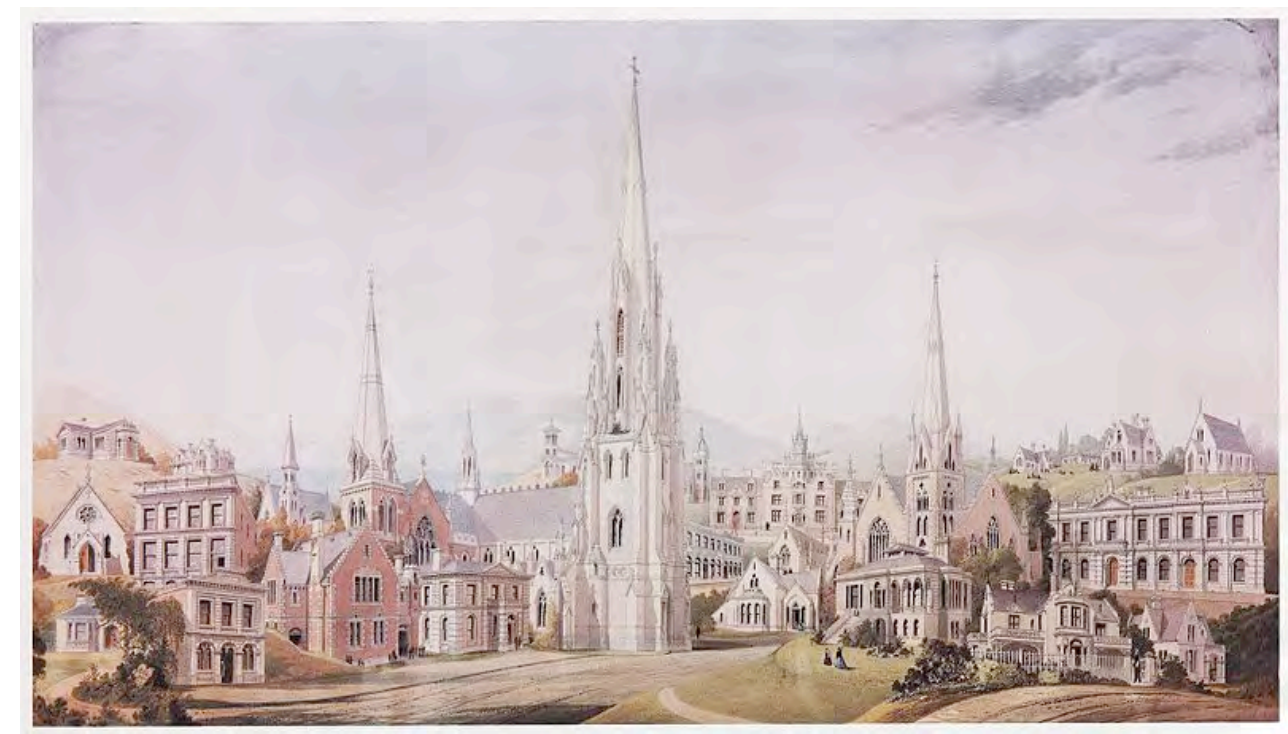

Figure 4.40: “Designs of R.A. Lawson” by George O’Brien (1821-88) Otago Settlers Museum. Photograph of original painting by Peter Entwisle. 
Ledgerwood suggests that Lawson had "friends and patrons in the right places" and that his list of clientele read like a "who's who' of the Dunedin business community." ${ }^{189}$ It is likely that Lawson worked hard to achieve this, early in his career he entered competitions for prestigious buildings such as the First Church of Otago and the Dunedin Town Hall, and also entered his work into Industrial Exhibitions in Dunedin and Wellington. ${ }^{190}$ In his later career, Lawson involved himself in the public life of Dunedin. He chaired lectures for the Young Men's Christian Association, served as a juror for the Dunedin Industrial Exhibition of 1881 and for the Benevolent Institution Carnival Committee in 1882, attended meetings of the Patients' and Prisoners' Society, and was active in the work of the congregation of the First Church of Otago. ${ }^{191}$ Painter George O'Brien painted a composition in the late 1860s titled "Designs of R.A. Lawson," where he positioned the architects built and unbuilt work in an imaginary landscape that resembled Dunedin (figure 4.40). O'Brien's painting visually sums up Tyler and Barsby's observations on Lawson and perhaps reflected the architect's own desire to make his mark on the Edinburgh of the South.

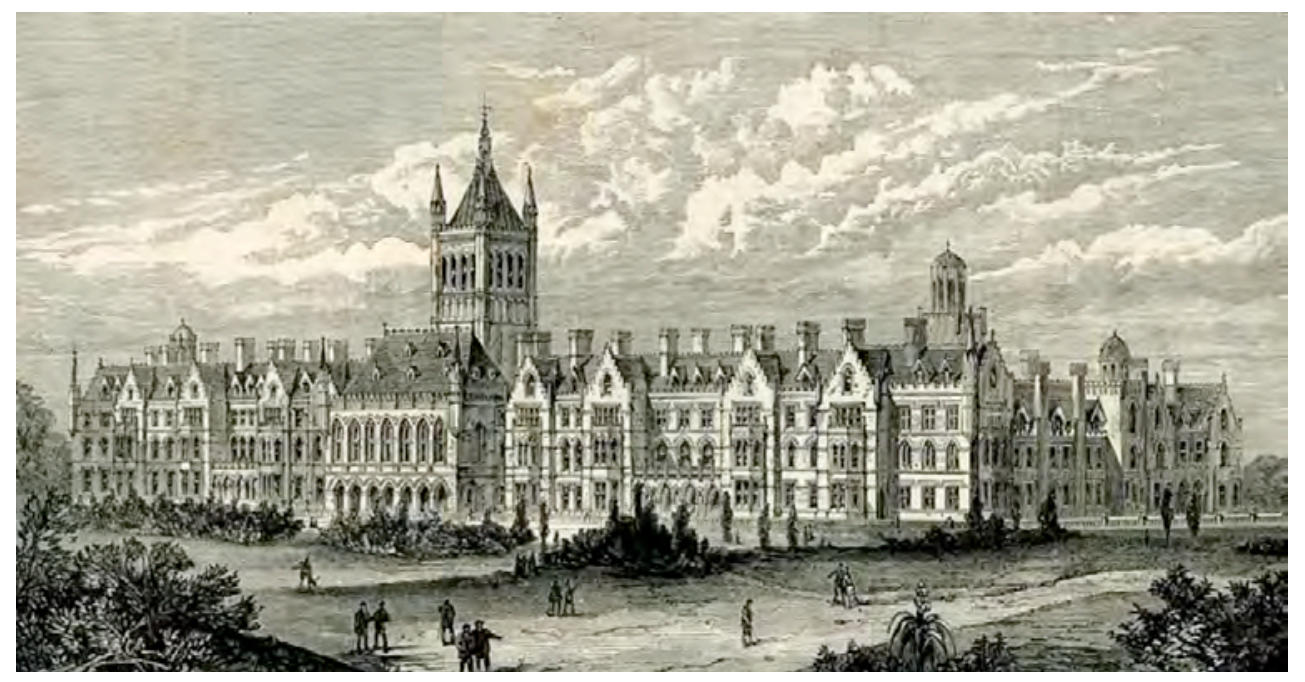

Figure 4.41: Halloway Sanatorium, 1884, etching, artist unknown.

As published in The Illustrated London News, January 5, 1884

Seacliff was the largest commission Lawson was awarded within the course of his architectural career and he accepted it at a time when he was engaged in the design of some of Otago's most significant buildings. The expectations on Lawson to deliver a building of substantial quality and stature must have been high. Seacliff's plan may have been based on the Norwich Asylum but it in no way imitated the modest architectural style of this institution. Phipson's design was praised by The Builder as being an unpretentious solution that nonetheless delivered the essential elements of a curative environment. ${ }^{192}$ Seacliff's appearance had more in common with the Halloway Sanatorium, by W.H. Crossland, than Phipson's humble design. Halloway was a private asylum of "lavish expenditure," completed in Virginia Water (Surrey) the same year that Seacliff was completed in 
Dunedin (figure 4.41). ${ }^{193}$ It is unlikely that Lawson had knowledge of the Halloway design at the time he completed plans for Seacliff. A building that Lawson would likely have been familiar with, however, was the Royal Edinburgh Infirmary also designed in the Scottish Baronial style by David Bryce. Although this was constructed between 1870 and 1879, after Lawson's departure from Scotland, a perspective drawing was published in The Builder in 1870 (figure 4.42). Various Dunedin newspapers also reported on construction progress at the infirmary between 1870 and $1877 .^{194}$

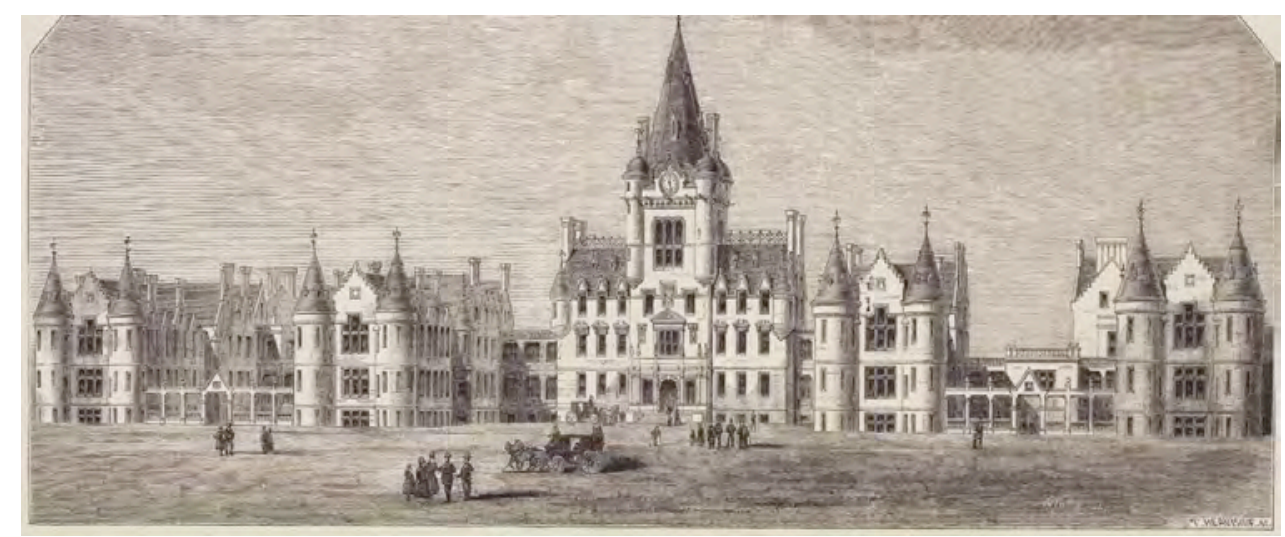

Figure 4.42: Royal Edinburgh Infirmary.

As published in The Builder, vol. 28, December 17, 1870: 1007.

Jeremy Taylor wrote that Halloway was given "the architectural disguise of a large, rambling country house," in order to push aside "institutional connotations." 195 This was not a unique approach in the design of asylums, nor was it a unique approach for Lawson. According to Prior, Lawson was experienced in the design of grand country houses, having begun his architectural training at the Scottish firm, Heiton and Heiton who specialised in this type of work. ${ }^{196}$ Ledgerwood described the design that Lawson created for the Otago Boy's High School as "castle-like" with a "commanding presence over... the city." 197 While the original scheme for the Otago Benevolent Institution featured an ornate central tower which was never constructed (figure 4.43, compare against figure 4.36). 


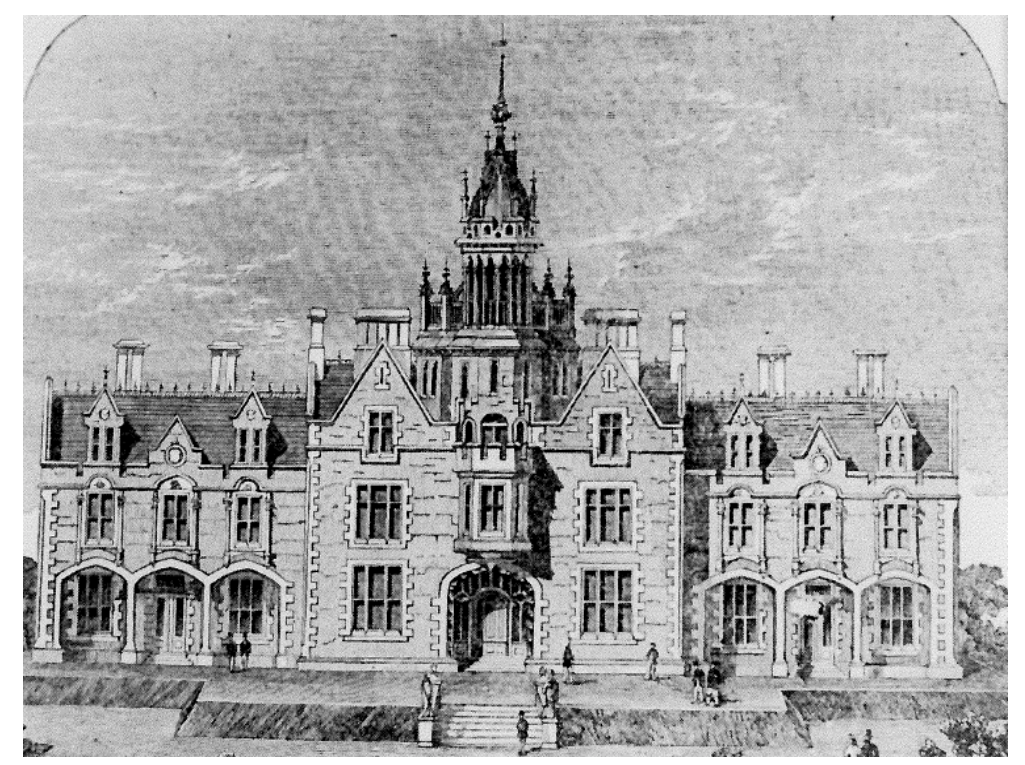

Figure 4.43: Design for the Otago Benevolent Institution 1863.

As published in Otago Cavalcade 1931-1935. Knight 1985, 134

(original source not indicated by this publication).

Similar to the decorative, unbuilt elements, Lawson envisioned for the Otago Benevolent Institution, his design for Seacliff included a number of elements that were questionable relative to their curative value. In the design of the laundry, for example, Grabham questioned Lawson's priorities, he wrote that "the money expended... on architectural details would have been better employed elsewhere." ${ }^{198}$ It was a criticism that could have been extended to the wider asylum. The soaring clock tower, which Lawson envisioned would be only one of three, and the angled turrets both came under question with regards to their necessity in an asylum building. ${ }^{199}$ Likewise, Lawson had a magnificent hammer beam ceiling installed to the recreation hall but funds ran short for the installation of lighting to this space and for years it remained unused (figures 4.44 and 4.45). ${ }^{200} \mathrm{He}$ also exaggerated the height of the already three-story building by including tall gabled roofs that created, in Grabham's estimation, "useless space in the attics." 201 The Scottish Baronial style is said to have kept many of the features of high walled medieval castles and was employed for a number of prestigous building in Scotland including the reconstruction of Balmoral Castle in $1856 .{ }^{202}$ While Lawson informed members of the 1888 Commission of Inquiry that this aesthetic was chosen because it could be achieved with little ornamentation, the fact that this style was associated with buildings of prestige likely also influenced this choice. $^{203}$ 


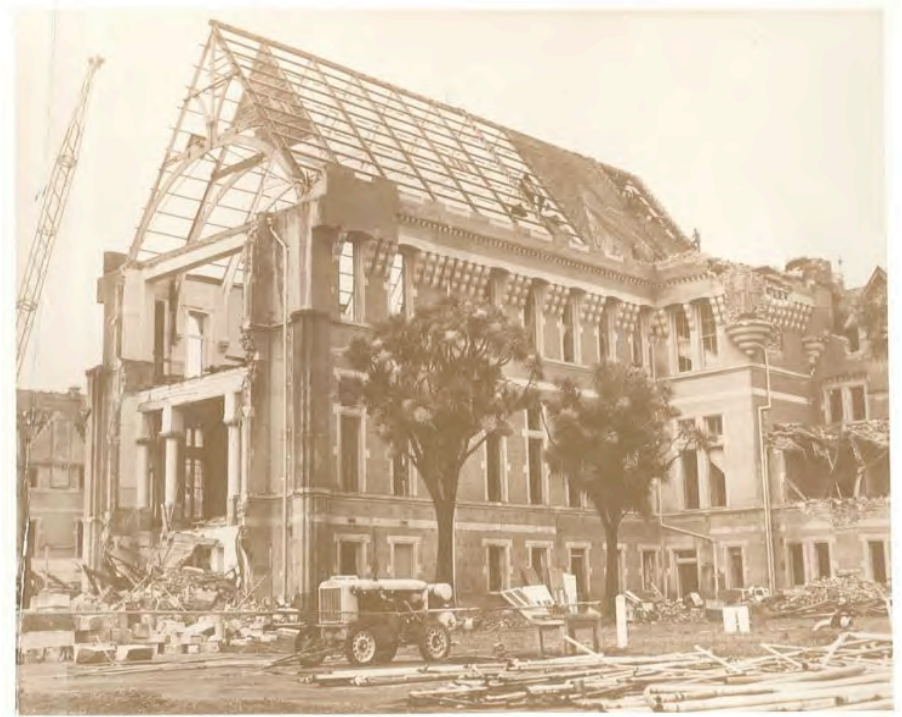

Figure 4.44: Seacliff, Recreation hall under demolition, 1959. Archives New Zealand: DAHI 20271 D266 520c

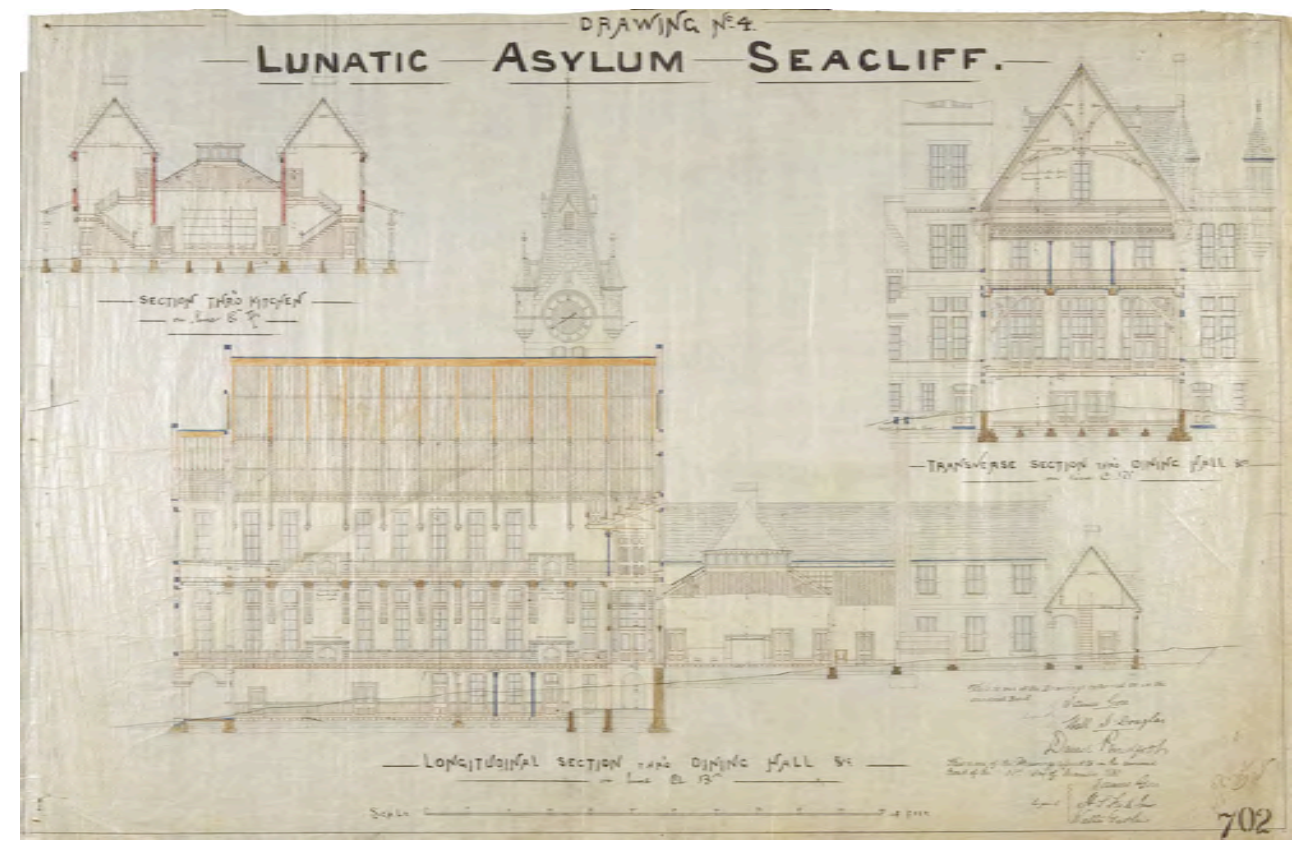

Figure 4.45: Lunatic Asylum, Seacliff. Section drawings through the Recreation Hall. Drawing No. 4. 1881. Alexander Turnbull Library: Plans-84-1187

There is no doubt that Lawson had a vested interest in protecting his professional reputation in the design of Seacliff and a humble style such as Phipson employed would not have fitted within his wider body of work. Furthermore, the very appointment of Lawson, an architect who was then engaged with some of the city's most prestigious projects, infers that a building of some stature was desired. The asylums constructed at Auckland and Christchurch must have provided valuable precedents for those who appointed Lawson to design Seacliff. Grabham described the appearance of Auckland as "poverty-stricken... reminding one forcibly of a bad English workhouse," while Christchurch, he claimed, looked "much more like the leasehold of a bankrupt farmer than the grounds of a well-managed public 
institution." 204 Seacliff was visible from the railway line that linked Canterbury with Otago and from the decks of steamships as they approached the harbour - Lawson could not have delivered a more fitting gateway building to the country's most prosperous province. Lawson's design for Seacliff answered to an important political desire: to express maturity and benevolence to those at home in Britain. According to Reeves, the "great dream" that drove Edward Gibbon Wakefield in his settlement of New Zealand was that colonization could be lifted "out of disrepute" by colonies that were "worthy of their great mother." 205 In 1905 the Cyclopaedia of New Zealand described Seacliff as "one of the most noteworthy institutions in the Colony." ${ }^{206}$ It certainly had more in common aesthetically with the Royal Edinburgh Infirmary than Phipson's modest arrangement of pavilions for Norwich.

In her study of early Australian prison design, Joan Kerr observed that building facades in colonial settlements "belonged to the beholder." ${ }^{207}$ The beholders in this case suffered, according Belich, from a "dread of disrepute" and a "universal fear of the poorhouse." 208 As a symbol of disrepute and social disharmony lunacy was feared, but so too were lunatics themselves. Escaped lunatics often made headlines in colonial newspapers. In 1875 the Daily Southern Cross reported that "a dangerous maniac" who "once nearly killed a man" had escaped from the Whau Asylum and posed "a far greater danger to the community" than an escaped criminal. The paper called for an inquiry and for warders to "pay more attention to the safe keeping of the demented creatures placed under their charge." ${ }^{209}$ Seacliff with its wide, towering wall of stone upon the hillside gave the impression of an impenetrable fortress. It conveyed the strength of authorities to contain madness and played into the image that colonists had been sold of a country that was tranquil, and free from crime and chaos. ${ }^{210}$

Lawson was not asked to respond to a simple medical brief, his task was heavily weighted with colonial expectation. Seacliff conveyed permanence and prosperity. It eased colonial fear and consolidated myths of settlement. It reassured colonists that their collective struggle in the creation of a "Better Britain" was paying off. Lawson was required to address these concerns whether or not this was made explicit at the time of his appointment. However, Lawson's absolute success in answering to colonial concerns provided the greatest obstacles to Seacliff's curative ability. The greatest criticism that can be made of Lawson's design was his willingness to sacrifice sunlight and his failure to provide an environment that would not intimidate patients or heighten the awareness of confinement in favour of a building worthy of the great colonial dream. Lawson's skill in balancing these two conflicting briefs while not straying too far from best practice in asylum design was a substantial achievement for which Lawson has not been recognised. 


\subsection{AGAINST ASYLUM CARE: EARLY WARNINGS \& ALTERNATIVE DESIGN RESPONSES}

As discussed in chapter three, Browne and Conolly were honest regarding the shortcomings of asylum care and the difficulites of maintaining a curative environment even where an insitution had been constructed upon ideal lines. Conolly's warnings that isolating the mentally ill from regular society could exacerbate their illness, and that many patients would simply not respond to asylum care, ${ }^{211}$ must certainly have raised questions regarding the judiciousness of constructing a one size fits all solution. When he visited in 1862, Lindsay believed that the New Zealand Government had signalled a "readiness to do something in the direction of progress or reform in local lunacy matters." ${ }^{212}$ This section will examine the recognised alternatives to care within a large asylum and the opportunities presented by this new colony.

At the time when the decision to build at Seacliff was made, the Scottish were using a "boarding out" system based on the model developed in Belgium, at Gheel. The Scottish model of boarding out was formalised with the Lunacy Act of 1857. Citizens were paid an allowance by the government to provide patients with food, shelter and supervision and the guidelines provided for guardians advised them to treat patients "as members of their own families." ${ }^{213}$ Lindsay felt that the boarding out system was well suited to New Zealand because settlers were "liberal and tolerant in their views, eminently adaptive and progressive in their social economy" and the country had a "peasant-proprietor class" well positioned to act as guardians. ${ }^{214}$ Some evidence suggests that colonists may have been open to a boarding out system. In 1870, the Dunedin Asylum experimented with entrusting sixteen patients to the care of their friends which resulted in the recovery of fourteen patients. ${ }^{215}$ Furthermore, in 1875, the West Coast Times expressed concern with the overcrowded state of the Seaview Asylum and encouraged legislators to consider the approach taken in Belgium where lunatics were boarded out with "the most successful results." ${ }^{216}$ Colonists were not as willing to take on the care of lunatics as Lindsay had assumed. In 1874 MacGregor lamented that even the families of patients seemed unwilling to take charge of their care and later observed that New Zealanders exhibited "an unreasonable aversion to have anything to do with persons of unsound mind." Those of "moderate independence," had little interest in the responsibility that caring for a harmless, chronic patient entailed. ${ }^{217}$ Skae had shared in this observation, noting that the situation was not helped by the lack of government assistance in caring for patients beyond the asylum. ${ }^{218}$ Boarding out could have provided a more cost-efficient solution to New Zealand's lunacy problem whilst mitigating the risks of neglect and dependency that Conolly and Browne warned against. 
The first Lunatics Ordinance was passed in New Zealand in 1846. This was ten years prior to the formalisation of the Scottish boarding out system in Britain and also a decade prior to the construction of provincial asylums in New Zealand which occurred from 1854-67. Lindsay acknowledged in 1872, that owing to the delay between his visit and the publication of his report, the time when "the greatest amount of good might have been affected" had likely passed:

for laws have been enacted and amended, and asylums built, after the orthodox English fashion; and after money has been sunk and laws have taken hold, it is not easy to undo ... however desirable progress or reform may be. ${ }^{219}$

Brunton's view, that settlers adopted British models without reservation reflects a comment made by Lindsay that:

colonial legislators, with an overwhelming confidence in everything that is of home growth, and with an inordinate penchant for home precedents ... frame their lunacy laws and construct their asylums after the fashions of the faulty ones of England [emphasis original]. ${ }^{220}$

Boarding out aside, New Zealand was presented with another opportunity for advancing the space in which lunacy care was delivered. Brunton has pointed out that in 1878, the same year that plans for Seacliff were being drawn up, detached, domestically scaled cottages were being erected at Seaview Asylum on the remote West Coast of the South Island. ${ }^{221}$ These developed from a pragmatic approach to overcrowding. Dormitory additions were first constructed using patient labour and timber available on site; the following year a detached cottage for twelve male patients followed (figure 4.46). ${ }^{222}$ This response was not dissimilar to a private asylum, near Paris, discussed by Browne in his publication of 1837 where four separate, single storied buildings were located at a distance from each other within a "well laid out park."223 

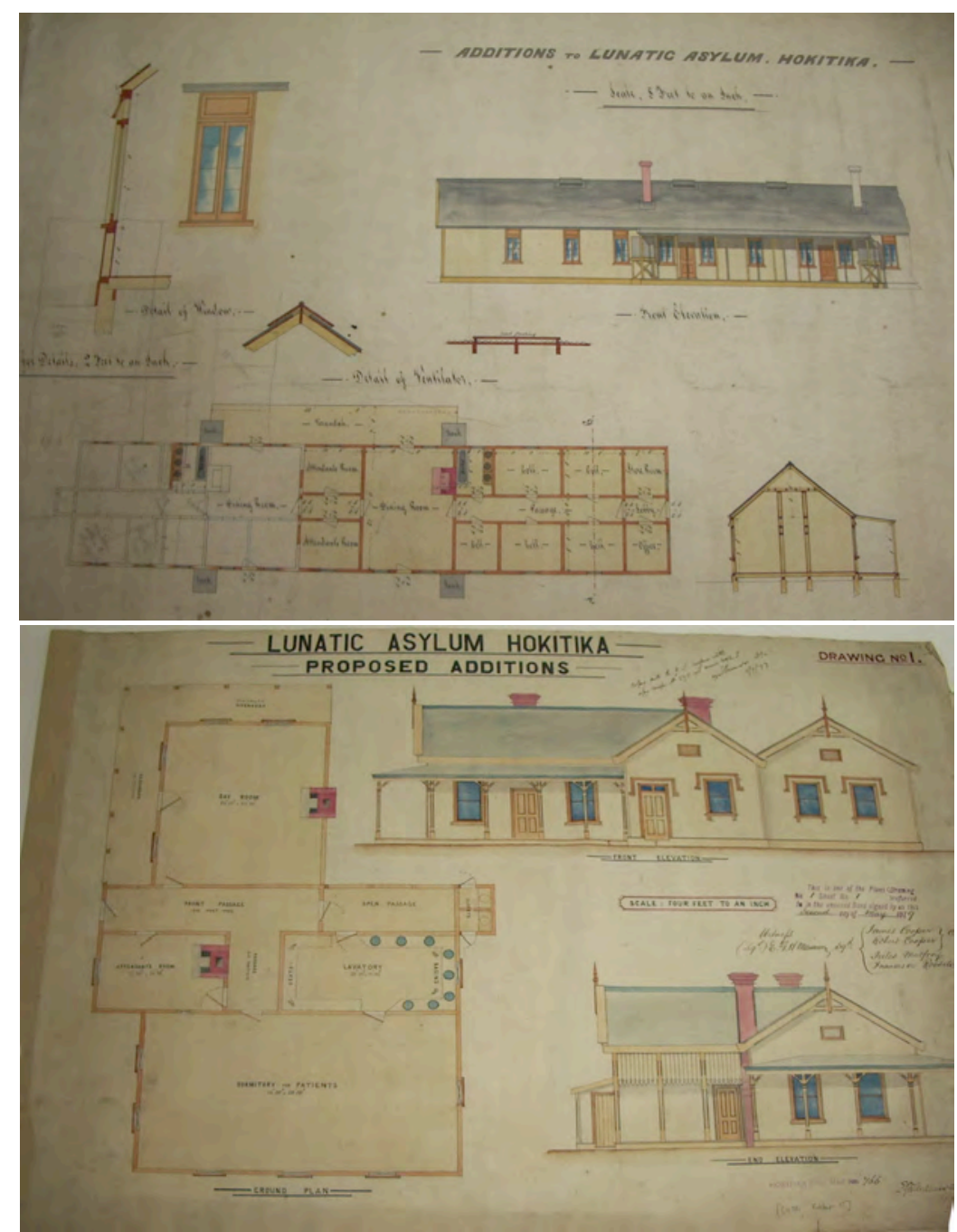

Figure 4.46: Seaview Asylum, Hokitika, undated (top) and 1879 (bottom). Archives New Zealand: CABA 86 GR 766 MC3.

In 1879, Skae observed that "harmless and industrious" patients appeared to be much happier in Seaview's small, simple dwellings than in "a vast asylum." 224 He began recommending this humble accommodation type for chronic patients at hospitals around the country, including for the extension of Seacliff less than a year after construction had begun, however, he was aware of this response when he set the budget for Seacliff in $1878 .{ }^{225}$ In light of this development, Skae recommended that only acute cases required "the costly arrangements of a modern asylum"; the "simple, homely and inexpensive" cottages created at Seaview were more suitable for chronic patients. ${ }^{26}$ The question that Brunton's research only partially addresses is why, if Skae was cognisant of and so impressed by this costeffective solution to patient accommodation in 1878, did he recommend such a high budget for Seacliff's construction. Brunton suggests that this was a consequence of ministerial preference. ${ }^{227}$ In a presentation to parliament in 1879, Colonial Whitmore stated his preference for asylum buildings of a "permanent character" instead of temporary timber buildings, hurriedly constructed in a "slip slop manner." ${ }^{228}$ In 1862, prior to the 
construction of the temporary Dunedin Asylum, a competition was held for the design of a permanent asylum. While six designs were received and winners announced, Provincial Councillors decided they could not wait for the construction of a "handsome and costly building" and called tenders for the construction of the temporary asylum instead. ${ }^{229}$ The resulting inadequacies of this institution may explain Whitmore's view that it was "absurd to run up buildings that would not be of a permanent character." However, he acknowledged that the small villas constructed at Hokitika "entirely met the needs" of that asylum. ${ }^{230}$ As the debate progressed, however, the insincerity of Whitmore's humanitarian call to look after "these poor people who cannot look after themselves" is revealed as he proceeds to blame Skae for the current, inadequate state of the country's asylums. ${ }^{231}$ This further supports the observation that colonial aspiration and propaganda influenced the design of these institutions; Brunton's hypothesis of ministerial preference does not address the full story.

In 1878, the same year that construction began on Seacliff, construction began on the villa hospitals at Alt-Sherbitz and Kankakee but not until 1897 would these developments come to the attention of New Zealand's asylum administrators. ${ }^{232}$ For Skae to have recognised the value of the Seaview villas for the treatment of acute patients in 1878 and 1879 would have been a remarkable departure from accepted practice. Even the villa hospitals constructed at Alt Scherbitz and Kankakee continued to provide traditional asylum buildings for the reception and treatment of acute patients, only chronic patients were housed in villas. ${ }^{233}$ The more interesting question is why this solution was overlooked for the development of the Porirua Asylum in 1891 given that this facility was constructed primarily for chronic patients.

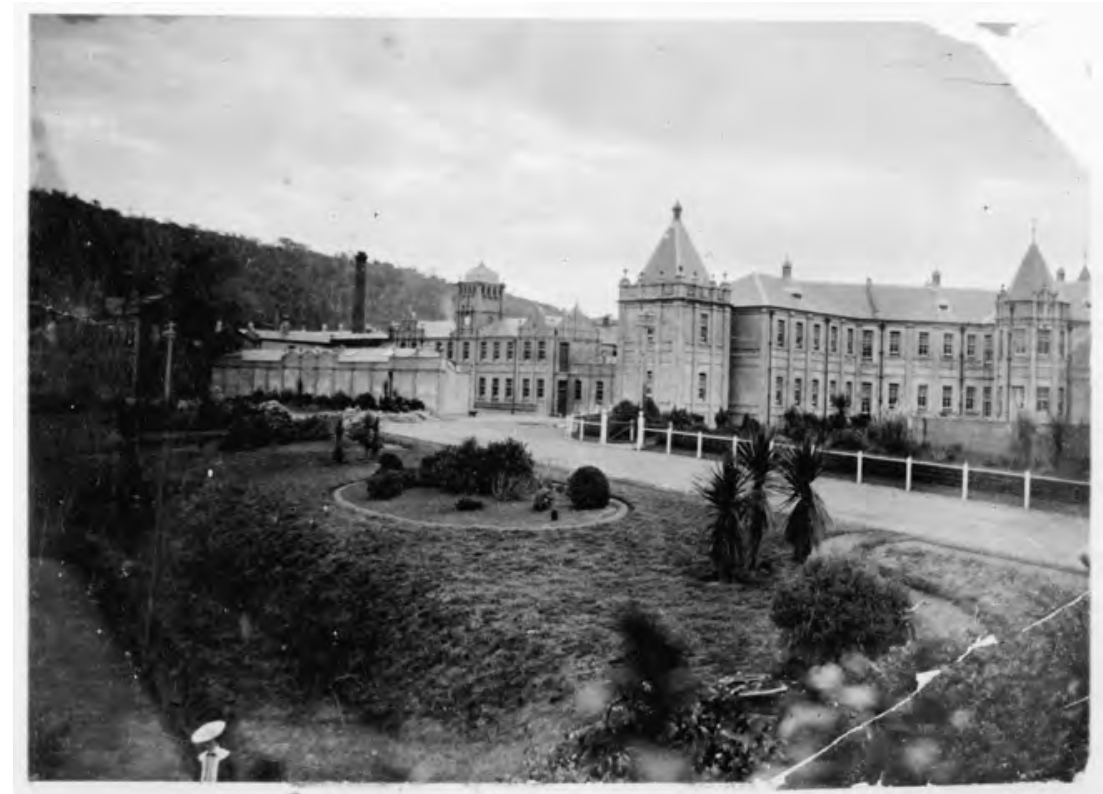

Figure 4.47: Porirua Asylum, ca 1910. Photograph by D. Squires. Alexander Turnbull Library, Wellington, reference: 1/ 2-057695. 
The design for Porirua, by the Government Architect, John Campbell, followed a traditional, heavy masonry construction for 500 patients (figures 4.47 and 4.48). ${ }^{234}$ Porirua's construction began in the closing years of the Long Depression and the architecture itself tells this story. Its planning is crude and economical. Dormitories held up to 56 beds and scarce day room space was provided. Ironically, MacGregor would later claim that, in the design of this hospital, the colony system was carried out "as far as could be done without departing further than experience then warranted from the accepted English and American practice."235 There is little architectural evidence to suggest that this was the case (figures 4.48 and 4.49 ).

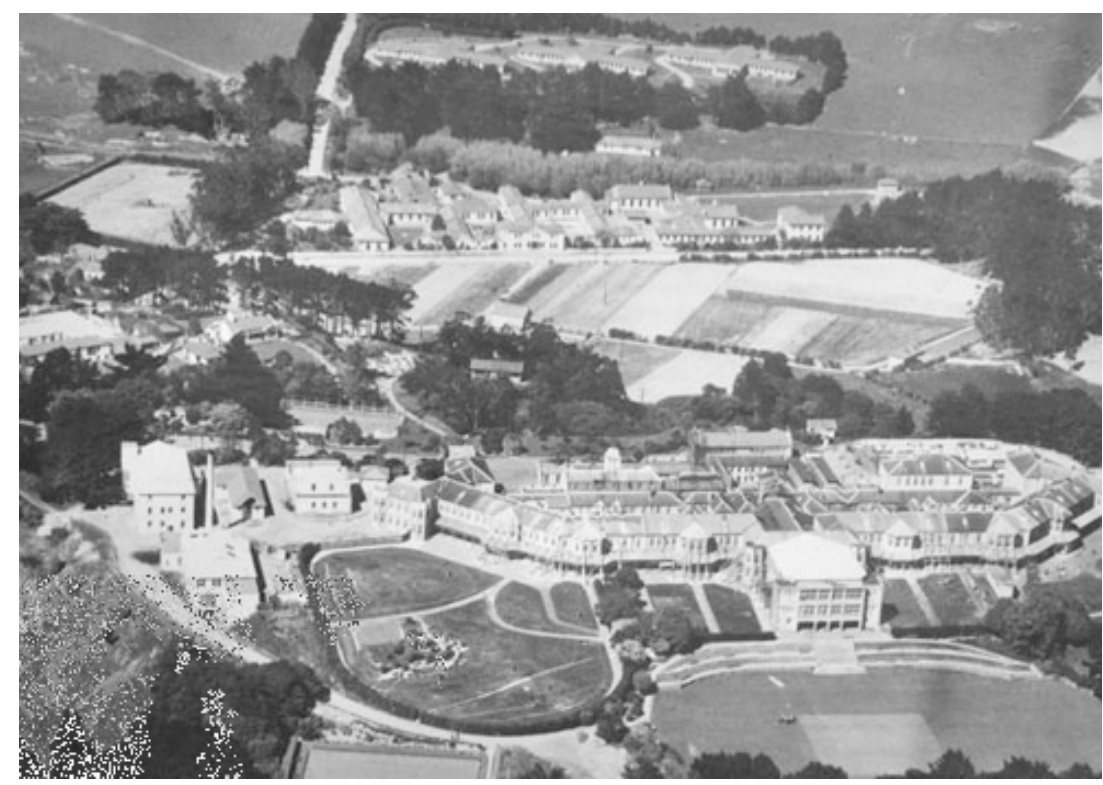

Figure 4.48: Porirua Asylum, early 1900s. Image source:

Porirua City Council, "History of health care in Porirua," http://www.pcc.govt.nz

Brunton believes that King came across a book review of Albrecht Paetz's Die Kolonisirung de Geisteskranken (English translation: The Colonization of the Insane in Connection with the Open-door System) in a medical journal in 1897 and wrote to Paetz for further details. He also requested a copy of Paetz's book be obtained and translated (from German) by the Lunatic Asylums Department around 1899. ${ }^{236}$ Eight years after Porirua was designed, King began constructing detached cottages at Seacliff in 1898, the "Simla" ward for males, and in 1899, "The Cottage" for convalescent female patients. Concurrently MacGregor obtained information regarding the colony hospital at Kankakee and later sent Dr A.H. Crosby, the medical superintendent of the Mt View Asylum, to visit the Kingseat Asylum in Aberdeen, the first villa hospital to have been constructed in the United Kingdom (1901-04). ${ }^{237}$ It seems unlikely that MacGregor had sufficient knowledge of the subsequent architectural developments that were based upon Gheel's colony system to have considered this in the design of Porirua Hospital in 1891. 


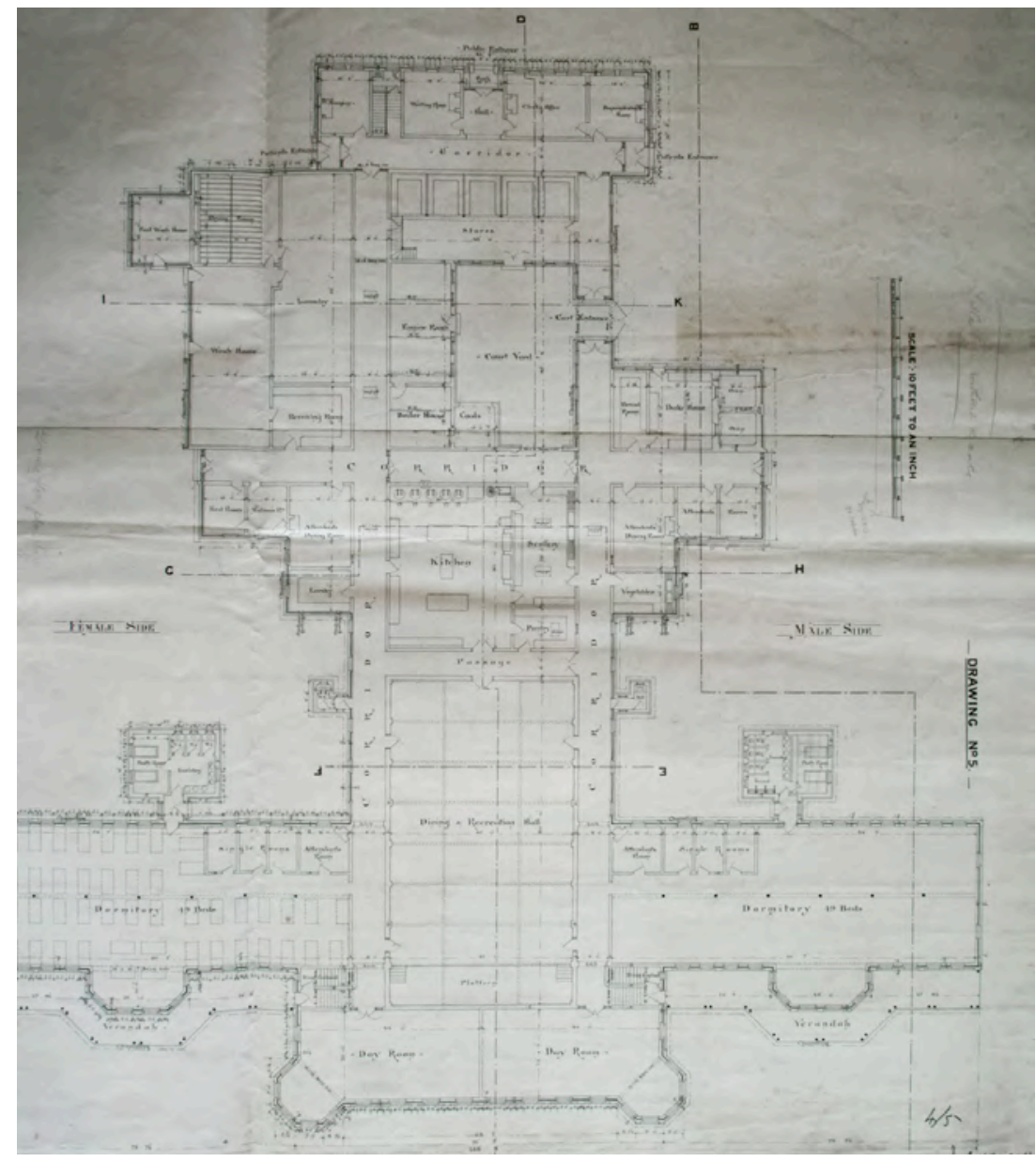

Figure 4.49: Ground Floor Plan, Porirua Asylum, 1891. Archives New Zealand: R18671884.

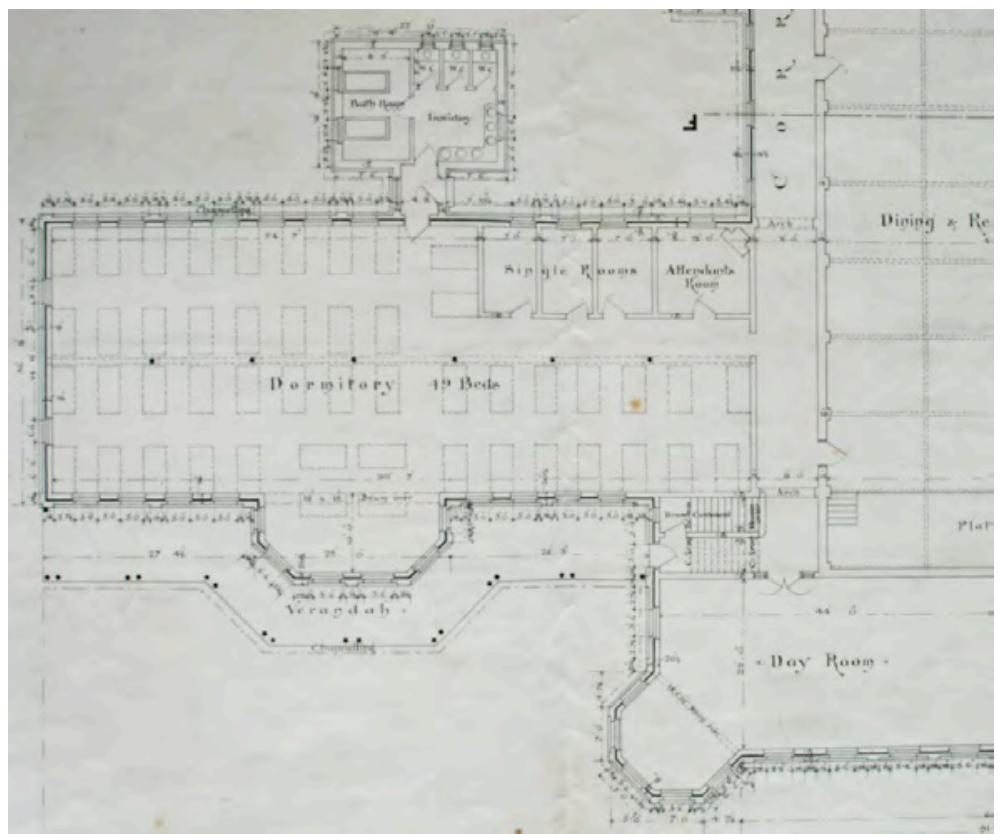

Figure 4.50: Close up of dormitory layout, ground floor, Porirua Asylum, 1891. The first floor dormitories accommodated 56 beds (fewer single rooms provided). Archives New Zealand: R18671884. 
Not until the development of Tokanui Hospital, announced in 1899 but not constructed until 1912, was the full potential of the villa solution recognised in New Zealand. ${ }^{238}$ The unwillingness to replicate the Seaview villas more widely can be explained by Britain's late adoption of the villa system. The earliest American experiments in decentralised hospital accommodation occurred at Worcester Asylum (Massachusetts) in $1870 .{ }^{239}$ The first villa hospitals to be constructed in the United Kingdom occurred in Scotland where land was purchased for this purpose in 1898. The Bangour Village Hospital (West Lothian) and the Kingseat Asylum (near Aberdeen) both opened in $1904 .^{240}$ The first villa hospital to be constructed in England itself was not announced until $1906 .{ }^{241}$ It is worth acknowledging, that despite the warnings from Browne, Conolly and others, Britain did not question the judiciousness of their own model of asylum care. Even Browne and Conolly appeared willing to accept that this was a necessary evil. In his publication of 1891, Burdett concluded that Britain could learn little from other countries. $^{242}$

When MacGregor announced the construction of Tokanui Hospital, in 1899, he wrote that what was intended was to go "a step further" than the accepted English and American practice since he considered it:

impossible for this young country to continue the building of expensive blocks connected by long corridors ... [and] to provide expensive accommodation for incurable patients, who can be made much more comfortable in cheaper structures. ${ }^{243}$

MacGregor worded this statement as though he was proposing a significant advance on New Zealand's current practice. He proposed nothing, however, that had not already been identified by Skae two decades earlier. In fact, the plan for the first 50-bed villa at Tokanui did not provide an advance on the small villas created at Seaview in 1877 and 1879. While surviving plans for the Seaview villas do not indicate the number of beds provided by each villa, the physical size of the only dormitory provided suggests it held only 12 patients. Single rooms were the preference. At Tokanui this scale was doubled as two dormitories of twenty beds were provided (figure 4.51). 


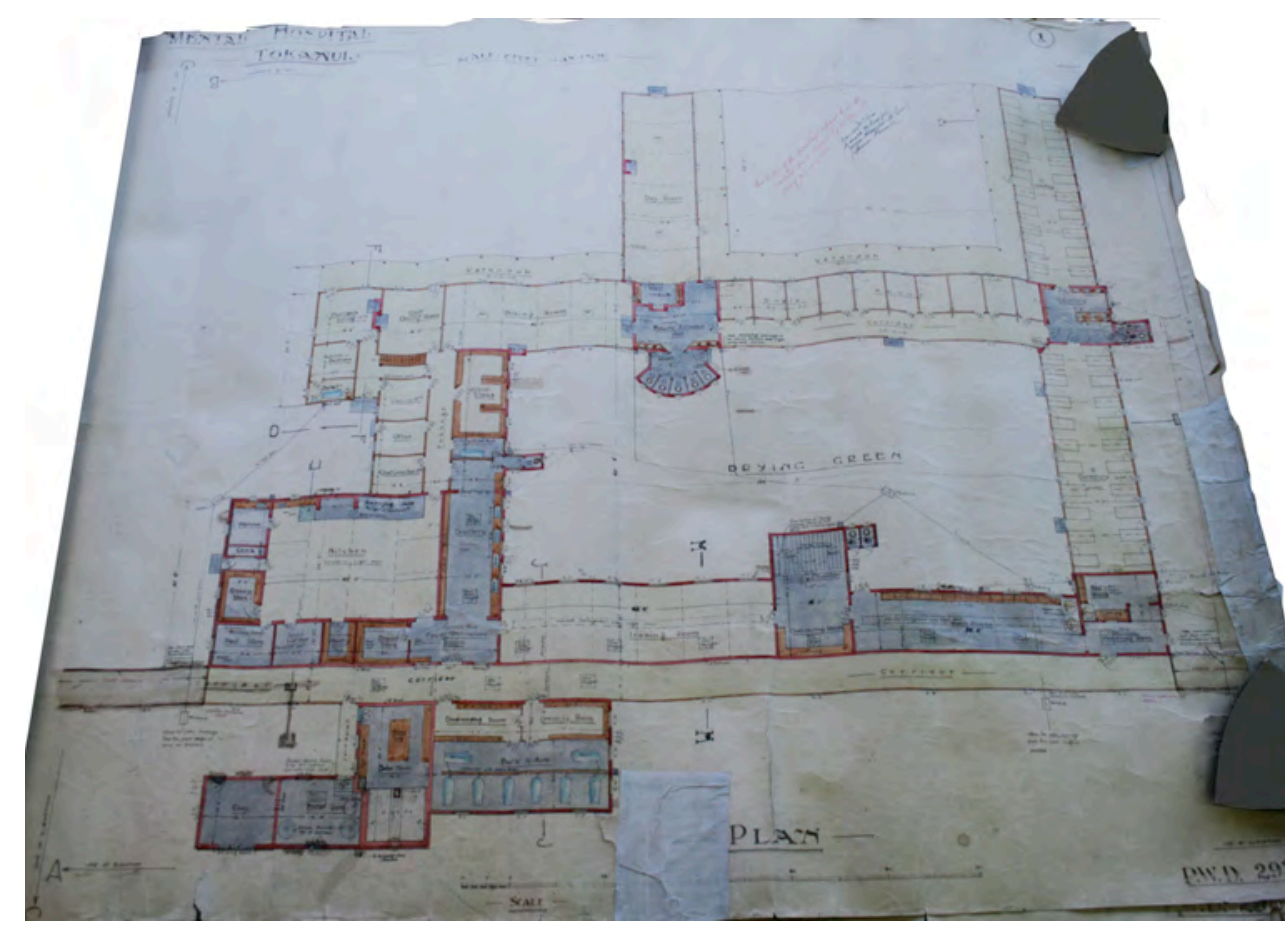

Figure 4.51: Tokanui Hospital 50-bed villa, 1912 (dormitories located far right). Archives New Zealand: R16564855 (drawing weights visible at right).

The adoption of an existing model of boarding out could not be considered innovative, it would, however, have qualified as a more progressive approach to mental health care than the continued construction of large scale asylums. New Zealand's real opportunity for advancement was the development of the Seaview villas which, if replicated early and nationally for chronic patients, would have placed New Zealand amongst the leaders in this field. However, while Lindsay may have seen a unique opportunity in the founding of New Zealand's lunacy policy and the construction of its institutions, the men who were employed to design this system of care and the institutions that housed it were not innovators. They did not seem to share Lindsay's enthusiasm to "do something in the direction of progress." ${ }^{244}$ Skae did recognise the value of the Seaview villas and recommended the wider use of this model, however, Grabham and MacGregor shared a conservative outlook that was compounded by the fear of moving too far beyond the accepted practices of Mother England. 


\section{CONCLUSION}

When W.L. Lindsay visited from Scotland in 1861 he was able to see a unique opportunity in the founding of New Zealand's lunacy policy and the construction of its institutions. The men who were employed to undertake this work were far more conservative. With the exception of Skae, they did not have the confidence to question accepted British practice. The decision not to replicate the Seaview villas earlier and more widely was not a simple case of one minister's preference but the result of a conservative, British outlook and the same desire for colonial propaganda that impacted on the design of Seacliff. In defence of these medical administrators, however, it must be recognised that they were over-committed and under-resourced for the job they were appointed to carry out. The fact that so much time elapsed before the appointment of a national inspector for these institutions and that little administrative support was made available to Skae suggest, that in colonial New Zealand where money was scarce and much capital development was required, the care of the mentally ill was a low priority for expenditure.

As the first study to closely examine Lawson's design for Seacliff relative to the medical theories to which it was expected to respond, this dissertation revises a number of existing assumptions about Lawson's contribution to the deficiencies of this building. The country's geographical isolation, sparse population and struggling economy gave rise to a situation where the architect and the chief medical advisor were inexperienced and, to varying degrees, over-committed. and furthermore, in Lawson's case, subject to a significant conflict of interest. Lawson and Skae both possessed a depth of theoretical knowledge regarding modern, humane approaches to the treatment of mental illness in their relative fields, however, neither could be considered an expert. The many oversights regarding safety suggest it was unlikely that Lawson was given adequate medical support in preparing the plans for Seacliff. The limitations of insufficient consultation were exacerbated by a design process that prevented direct communication between the architect and his medical advisor. Furthermore, as the discussions regarding building orientation suggest, medical advice was relegated to political aspiration. A majestic elevation and the mitigation of construction delays was considered more important by the Public Works Department than attaining the curative offerings of sunshine. To an extent, Lawson may have been guilty of relegating the needs of these patients to personal aspiration and conflicting professional commitments, however, he delivered an architectural solution of reasonable curative quality and currency. Seacliff Asylum was constructed to a high quality, relative to other New Zealand asylums. It was able to support many aspects of the delivery of mental health care such as physical and visual access to landscape and the provision of individual treatment and tranquility. The criticism metered out by Grabham, that Seacliff was badly designed and out of date, does not stand up to interrogation. 
The main deficiencies of Seacliff Asylum - the sacrifice of sunshine, the failure to disguise signs of confinement and the employment of an imposing aesthetic - cannot be attributed to the decisions made by Lawson alone but are a detrimental result of political aspiration in the briefing of Seacliff Asylum. The most limiting factor in the curative potential achieved at Seacliff was that the architect was asked to create a building that was able to contribute to the cure of mental illness and respond adequately to colonial fear and expectation - objectives which stood in direct conflict with each other. While Lawson provided a building that was a visual match for the great colonial dream this came at the heavy cost of important curative criteria. Within nineteenth century New Zealand, the needs of the mentally ill were a secondary consideration relative to satisfying the aspirations of the nation's colonial population.

${ }^{1}$ Edginton 1994, 379.

2 Scull 1979, 189-90, and 1993, 243. Caplan 1969, 49, 89-90.

${ }^{3}$ Brunton, 2001, 60.

${ }^{4}$ Prior 1990, 62-4. Tod 1970, 25, 32.

5 "First Church. ... Tablet to Architect," 1933. Barsby and Tyler 2006.

${ }^{6}$ AJHR 1888, $\mathrm{H}-07$.

${ }^{7}$ Prior 1990, 70. Ledgerwood 2013, 203.

${ }^{8}$ Ledgerwood 2013, 210, 220.

${ }^{9}$ Dunedin City Council, "Peopling of Dunedin," 25-6, 49-50.

${ }^{10}$ King 2003, 209.

${ }^{11}$ Dunedin City Council, "Peopling of Dunedin," 49-50.

${ }^{12}$ Belich 1996, 373.

${ }^{13}$ Belich 1996, 292, 377, 437.

${ }^{14}$ Belich 2001, 21.

${ }^{15}$ Reeves 1998, 323.

${ }^{16}$ Fairburn 1989, 62-4.

${ }^{17}$ AJHR 1878, H-10, 1-2.

${ }^{18}$ Lindsay $1872,807-8$.

${ }^{19}$ Brunton, 2001, 50.

${ }^{20}$ AJHR 1871, $\mathrm{H}-10,11$.

${ }^{21}$ AJHR 1874, H-02, 9. 1874 Report by James Hume, Asylum Keeper, Dunedin Asylum as quoted in Tod 1971, 13. Original source not sighted as could not be found.

${ }^{22}$ AJHR 1878, H-10, 1-2.

${ }^{23}$ Fairburn 1989, 164. 
${ }^{24}$ Brunton, 1997, 12.

${ }^{25}$ New Zealand Lunatics Ordinance 1846.

${ }^{26} \mathrm{lbid}$.

${ }^{27}$ Brunton 2001, 106-7.

${ }^{28}$ AJHR $1872 \mathrm{H}-10,1$.

${ }^{29}$ Lindsay 1872, 808.

${ }^{30}$ Brunton 1972, 46-51. Also refer Brunton 2001, 177-8. Simpson, "Grabham, George Wallington."

${ }^{31}$ Tennant, "MacGregor, Duncan."

32 King 2003, 229. There are varying opinions regarding the duration of the Long Depression. Reeves $(1998,243)$ states that the Long Depression ran from 18701895. King $(2003,234-6)$ dates it 1877-1894. While The Reserve Bank of New Zealand $(2007,7)$ suggests that the effects of recession were felt from 1879 until 1890.

${ }^{33}$ AJHR 1878, H-10, 10.

${ }^{34}$ Prior 1990, 38.

${ }^{35}$ McLintock, "The Colonial Era."

${ }^{36}$ Ibid.

${ }^{37}$ Lindsay 1873 , 499-500. Lindsay cites a letter received from Buchannan.

${ }^{38}$ AJHR 1886, H-09, 1-2, 6.

${ }^{39}$ AJHR 1878, H-10, 10.

${ }^{40}$ AJHR 1880, $\mathrm{H}-06,7$.

${ }^{41}$ AJHR 1888, H-07, 108.

${ }^{42}$ AJHR 1882, H-9, 17.

${ }^{43}$ Brunton 2003, 84.

${ }^{44}$ Tod 1971, 12.

${ }^{45}$ Tod 1971, 12.

${ }^{46}$ AJHR 1877, $\mathrm{H}-08,3$.

${ }^{47}$ Griffiths, Eccles and McCoy 1983, 27, 43.

${ }^{48}$ AJHR 1877, $\mathrm{H}-08,3$.

49 Ibid.

${ }^{50}$ AJHR 1880, H-06, 4. AJHR 1888, H-07, 17.

51 "Norwich Lunatic Asylum," 1877, 479-82. Also refer: AJHR 1887, H-09, 6. Note: this was constructed as an annex to the Norfolk County Asylum, located approximately $9 \mathrm{~km}$ away (see Burdett 1891, 79). The Norwich Lunatic Asylum was renamed the Norfolk Hospital in 1889; existing studies are not consistent in the way they refer to this hospital, some historians use Norwich, others Norfolk. In later years it was renamed the Hellensdon Hospital.

52 "Norwich Lunatic Asylum," 482.

${ }^{53}$ AJHR 1888, H-07, 167.

${ }^{54}$ Blake-Palmer et al. 1972, 5,8, 11,14. 
${ }^{55}$ AJHR 1878, $\mathrm{H}-10,10$.

${ }^{56}$ AJHR 1886, $\mathrm{H}-06,8$.

${ }^{57}$ G.W. Grabham, entry to Inspector's Book for Seacliff Asylum, October 6, 1883. ANZ: R6670281.

${ }^{58}$ This is evident from Grabham's discussion of the site intended for the Porirua Asylum. AJHR 1886, H-09, 2.

${ }^{59}$ G.W. Grabham, entry to Inspector's Book for Seacliff Asylum, January 30, 1883. ANZ: R6670281.

${ }^{60}$ AJHR 1879, $\mathrm{H}-04,10$.

${ }^{61}$ G.W. Grabham, entry to Inspector's Book for Seacliff Asylum, January 11, 1883. ANZ: R6670281.

${ }^{62}$ D. MacGregor, entry to Inspector's Book for Seacliff Asylum, May 29, 1886. ANZ: R6670282.

${ }^{63}$ Seacliff Outwards Correspondence Book, Vol. 1, September 19, 1885, as quoted in Hubbard 1977, 61-4. Original source not cited as could not be located.

${ }^{64}$ Globe, April 18, 1893 as quoted in Hubbard 1977, 61-4. Original source not cited.

${ }^{65}$ AJHR 1878, $\mathrm{H}-10,5$.

${ }^{66}$ Ibid.

${ }^{67}$ Tod 1971, 18.

${ }^{68}$ Conolly $1847,53$.

${ }^{69}$ AJHR 1885, H-06, 10.

70 "Seacliff Asylum," 1886.

${ }^{71}$ Tuke 1813, 95.

${ }^{72}$ G.W. Grabham, entry to Inspector's Book for Seacliff Asylum, October 6, 1883. ANZ: R6670281.

${ }^{73}$ Conolly $1847,53$.

${ }^{74}$ Report by Dr. Hector, dated April $3^{\text {rd }}, 1880$, transcribed within the 1888 Commission of Inquiry regarding instability at Seacliff. Refer AJHR 1888, $\mathrm{H}-07$, 145.

${ }^{75}$ G.W. Grabham, entry to Inspector's Book for Seacliff Asylum, October 6, 1883. ANZ: R6670281.

${ }^{76}$ N.R. Morrison, entries to Inspector's Book for Seacliff Asylum, dated September 21, 1895 and November 4, 1896. ANZ: R6670282

77 Truby King in transcript of evidence, R. v. W.F. Kitchen, 1893. Mental Health Division File: $M H 1891 / 2511$ as quoted in Brunton 1997, 21. Original source not cited.

78 "Seacliff; To the Editor," 1886.

${ }^{79}$ Brunton 1997, 53.

${ }^{80}$ A photograph held by the Hocken Collections, dated 1946-60 confirms that the open colonade was closed in at some point. Hocken Collections: 2465-01-017A.

${ }^{81}$ G.W. Grabham, entry to Inspector's Book for Seacliff Asylum, October 6, 1883. ANZ: R6670281. Also refer: AJHR 1884, H-07, 8-9. 
${ }^{82}$ G.W. Grabham, entry to Inspector's Book for Seacliff Asylum, April 15, 1884. ANZ: R6670281. AJHR 1884, H-07, 8-9. D. MacGregor, entry to Inspector's Book for Seacliff Asylum, May 29, 1886. ANZ: R6670282

${ }^{83}$ Conolly $1847,15,21,35$.

${ }^{84}$ These heights have been calculated based on the fact that the ceiling height through this day room corridor was 13 feet (just under 4 metres) as can be read clearly from the original drawing (Hocken Collections: Salmon Collection - R4627). This suggests a door height of around 2 metres; the sills have been located relative to this height. The average adult height has been assumed at $1700 \mathrm{~mm}$ and has been ascertained from Disabled World, "Height Chart of Men and Women in Different Countries," which gives the average height of a New Zealand male at $1770 \mathrm{~mm}$ and a woman at $1650 \mathrm{~mm}$.

${ }^{85}$ Conolly $1847,15,21,35$.

${ }^{86}$ D. MacGregor, entry to Inspector's Book for Seacliff Asylum, May 29, 1886. ANZ: R6670282

87 Charles Moore, unpublished manuscript, page 3 of chapter 2. Hocken Collections: MS-3182/001.

${ }^{88}$ Report on Seacliff site by James Hector, 1880, reprinted in Tod 1971, 19-22. Also refer: AJHR 1888, H-07.

${ }^{89}$ AJHR 1880, $\mathrm{H}-06,8$.

${ }^{90}$ AJHR 1880, $\mathrm{H}-06,8$.

${ }^{91}$ Conolly $1847,12$.

${ }^{92}$ AHJR 1888, H-7, 98.

93 Superintendent, Seacliff Asylum, to the Inspector-General of Asylums, September 10, 1889. Reprinted in AJHR $1891 \mathrm{H}-20$ (appendix N), 14-5.

${ }^{94}$ Report by G.W. Grabham, October 10, 1883, as quoted in Charles Moore, unpublished manuscript, page 4 of chapter 2. Hocken Collections: MS-3182/001.

${ }^{95}$ Truby King to the Hon. Minister of Native Affairs, August 29, 1891, reprinted in AJHR 1891, H-29, 5. Also refer: Truby King to the Inspector-General of Asylums, July 13, 1890, reprinted in AJHR 1891, H-29, 14.

${ }^{96}$ Truby King to Inspector-General of Asylums, July 7, 1890. Superintendents Outwards Letter Books [Seacliff]. ANZ: R6670288.

${ }^{97}$ Ibid.

${ }^{98}$ Conolly $1847,33$.

${ }^{99}$ Report by an official visitor, April 1884, as quoted in Charles Moore, unpublished manuscript, page 5 of chapter 2. Hocken Collections: MS-3182/001.

${ }^{100}$ Browne 1837, 149, 183-4, 187-9.

${ }^{101}$ Conolly 1847, 23.

${ }^{102}$ AJHR 1884, H-07, 9.

103 Photographs that are available of Seacliff's interiors tend to focus on construction faults or the demolition process, taken decades after the period in question.

${ }^{104}$ Truby King to the Hon. Minister of Native Affairs, August 29, 1891, reprinted in AJHR 1891, H-29, 6-7. 
105 Burdett 1891, 40-53. Burdett devoted a chapter of this publication to "Asylum Furniture and Decoration."

${ }^{106}$ Truby King to the Hon. Minister of Native Affairs, August 29, 1891, reprinted in AJHR 1891, H-29, 6-7. Caldwell 2001, 40.

${ }^{107}$ AJHR 1891, $\mathrm{H}-29,1$.

${ }^{108}$ Report by James Hume, Keeper, Dunedin Asylum, September, 1864, as quoted by Charles Moore, unpublished manuscript, page 3 of chapter 1 . Hocken Collections: MS-3182/001.

${ }^{109}$ Refer 1903 Accommodation Study (drawings) prepared by the Public Works Department. ANZ: DADE D294 2a.

110 D. MacGregor, entry to Inspector's Book for Seacliff Asylum, May 29, 1886. ANZ: R6670282.

${ }^{111}$ A plan of the Buffalo State Hospital is reprinted in Yanni 2007, 136 (figure 4.29). For plans of the Bethlem Asylum at Southwark (1815) refer: http://www.bethlemheritage.org.uk/explorebethlem/map.asp

${ }^{112}$ The dimensions for Buffalo State have been judged from published photographs (refer Kowsky 1992, 54 and Payne 2009, 61). The dimensions of the Seacliff dayrooms are noted on drawings (Hocken Collections: Salmon Collection - R4627)

${ }^{113}$ Conolly $1847,24-5$.

114 D. MacGregor, entry to Inspector's Book for Seacliff Asylum, May 29, 1886. ANZ: R6670282.

115 AJHR 1877, H-08, 29 (see enclosed floor plan). Also refer 1903 Accommodation Study (drawings) prepared by the Public Works Department. ANZ: DADE D294 2a.

${ }^{116}$ Burdett 1891, vol. 2, vi. Available online:

https://archive.org/details/hospitalsasylums02unse

117 "Norwich Lunatic Asylum," 1877, 482.

${ }^{118}$ Burdett 1891, vol. 2, 108-9.

119 "Description of a Proposed New Lunatic Asylum for 650 Patients on the Separate-Block System, for the County of Surrey," 1862, 600.

120 "Pavilion Asylums," 1867, 116.

${ }^{121}$ Lawson's drawings showing the additional pavilions are held by the Hocken Collections: Salmon Collection, R4627.

${ }^{122}$ Burdett 1891, vol. 2, 109.

${ }^{123}$ Note: the Norwich Lunatic Asylum in Hellensdon (for which Burdett shows the plan on page 109), is referred to by Burdett as an annex to the Norfolk County Asylum, located around $9 \mathrm{~km}$ away in Thorpe, Norwich. Burdett 1891, 79.

124 Ibid, 7-8.

${ }^{125}$ Ibid, 67, 109.

${ }^{126}$ Conolly $1847,18-9$.

${ }^{127}$ Burdett 1891, vol. 2, 7-8.

${ }^{128}$ Conolly $1847,10,15$.

${ }^{129}$ Burdett 1891, vol. 2, 8.

${ }^{130}$ AJHR 1878, $\mathrm{H}-10,2$. 
131 AJHR 1888, H-07, 167.

132 Burdett 1891, vol. 2, 1-3, 8-9.

133 AJHR 1886, H-06, 8.

134 Conolly 1847, 7. Burdett 1891, vol. 2, vi.

135 Lindsay 1872, 813-14, 827.

${ }^{136}$ Ibid, 811.

${ }^{137}$ Brunton 1972, 46-51. Also refer Brunton 2001, 177-8.

${ }^{138}$ Lindsay 1872, 811-2.

139 Prior 1990, 57.

${ }^{140}$ AJHR 1888, $\mathrm{H}-07,17$.

141 "Letter to the Editor," 1886.

${ }^{142}$ Public Works Department to Mr O'Conner, June 25, 1882, Re. Seacliff Asylum. Hocken Collections: MS-3821/093.

143 "Letter to the Editor," 1886.

144 Brunton 2003, 177-8.

145 Simpson, "Grabham, George Wallington."

${ }^{146}$ AJHR 1886, H-09, 8.

147 James Wrigley, "Letter to the Editor ... Auckland Lunatic Asylum," 1863.

${ }^{148}$ AJHR 1886, H-09, 6, 8-9.

${ }^{149}$ Frank Tod states that Seacliff held the position of New Zealand's largest public building for fifty years. Tod 1971, 24.

150 Prior 1990, 25.

151 Ledgerwood 2013, 30.

152 For a conclusion regarding Lawson's role in the eventual structural failure of Seacliff see Ledgerwood 2013, 200-4.

${ }^{153}$ AJHR 1888, H-07, 6-8, 18.

154 Ibid, 124.

155 Refer drawings held by the Hocken Collections (Salmon Collection - R4627) and the Alexander Turnbull Library (Plans-84-1186).

${ }^{156}$ Refer drawings held by the Hocken Collections: MS-3511/092.

${ }^{157}$ Refer drawings held by ANZ: W5/ 251/ 12998; W5/ 4222/ 12610.

${ }^{158}$ Refer drawing held by ANZ: W5/ 301/ 13192.

${ }^{159}$ Refer drawing held by ANZ: W5/ 1148/ 16822.

160 Prior 1990, 57.

161 lbid, 45.

162 Skae's report to the AJHR for 1879 , dated July $6^{\text {th }}$, states that plans are "now ready" and tenders are about to be called. AJHR 1879, H-04, 10.

${ }^{163}$ Report on Seacliff site by James Hector, 1880, reprinted in Tod 1971, 22.

164 Ledgerwood 2013, 191. 
${ }^{165}$ AJHR 1888, H-7, 98. Lawson cites his own letter of January 1880 within the proceedings.

${ }^{166}$ Legerwood 2013, 109, 145.

${ }^{167}$ Despite considerable effort the date that Lawson was awarded this commission has not been discovered. Legerwood and Prior appear to have had the same problem as neither cites a date for this.

${ }^{168}$ Charles Moore, unpublished manuscript. Refer page 16 of chapter 1 and page 3 of chapter 2. Hocken Collections: MS-3182/001.

${ }^{169}$ Prior 1990, 51.

${ }^{170}$ AJHR 1883, E-08, 12.

${ }^{171}$ AJHR 1897, H-7, 8. AJHR 1899, H-7 11.

172 United States National Institute of Health, Joint Commission on Mental Illness and Health 1961, 5.

${ }^{173}$ AJHR 1878, $\mathrm{H}-10,10$.

174 Ibid.

${ }^{175}$ Belich 1996, 369.

${ }^{176}$ AJHR 1888, H-07, 108.

177 AJHR 1880, H-06, 7.

${ }^{178}$ AJHR 1888, H-7, 108.

${ }^{179}$ AJHR 1888, H-7, 97, 117.

${ }^{180}$ Cyclopaedia Company Limited 1905, 147.

181 Janet Frame 2000, 11.

${ }^{182}$ Lindsay $1872,814$.

${ }^{183}$ Lochhead 1991,120.

${ }^{184}$ R.A. Lawson, Journal, July - November 1854. Hocken Collections: MS-0807.

185 "First Church ... Tablet to Architect," 1933.

${ }^{186}$ Barsby and Tyler 2006.

${ }^{187}$ R.A. Lawson, Journal, July - November 1854. Hocken Collections: MS-0807. ${ }^{188}$ Ibid.

${ }^{189}$ Ledgerwood 2013, 80, 167.

190 "Report to the Committee of the Industrial Exhibition," 1863. "Industrial Exhibition," 1885.

191 "Lecture," 1884. "The Exhibition Jurors," 1881. "Presentation to Mr Lawson," 1887. "Patients' and Prisoners' Society," 1881. "Benevolent Institution Carnival," 1882.

192 "Norwich Lunatic Asylum," 482.

193 Taylor 1991, 157-8. The budget for Halloway was $£ 300,000$.

194 Refer, for example: "News by the Mail," 1871. "News by the Mail," 1875. "Our Correspondant; Scotland," 1877. "Scotch Notes," 1870a. "Scotch Notes," 1870b.

195 Ibid, 44. 
${ }^{196}$ Prior 1990, 7-8.

${ }^{197}$ Ledgerwood 2013, 171.

${ }^{198}$ AJHR 1885, H-06, 11.

${ }^{199}$ AJHR 1888, H-07, 98, 167. Report on Seacliff site by James Hector, 1880, reprinted in Tod 1971, 22.

${ }^{200}$ D. MacGregor, entry to Inspector's Book for Seacliff Asylum, May 29, 1886. ANZ: R6670282.

${ }^{201}$ AJHR 1886, H-09, 8.

${ }^{202}$ Wikipedia contributors 2014, "Scottish Baronial Style."

${ }^{203}$ AJHR 1888, H-07, 167.

${ }^{204}$ AJHR 1886, H-09, 6, 8-9.

${ }^{205}$ Pember Reeves 1998, 139.

${ }^{206}$ Cyclopaedia Company Limited 1905, 147.

${ }^{207}$ Kerr 1988, 3.

${ }^{208}$ Belich 1996, 308.

209 "Escape of a Dangerous Lunatic ...," 1875. Also refer: "Editorial [escape from Nelson Asylum]," 1882.

${ }^{210}$ Fairburn 1989, 62-4.

${ }^{211}$ Conolly 1830, 31. Also see Browne 1837, 144.

${ }^{212}$ Lindsay $1872,808-10$.

${ }^{213}$ Hutchison, "Institutionalization."

${ }^{214}$ Ibid, 808-10, 914-5.

${ }^{215}$ AJHR 1870, D-29, 13.

216 "Editorial [citing the Physiological Journal of Medicine]," 1875. The paper cites the Physiological Journal of Medicine via an article that appeared in the Tribune (no dates are given for these references).

${ }^{217}$ AJHR 1874, H-02, 9. AJHR 1892, H-04, 2.

${ }^{218}$ AJHR 1881, $\mathrm{H}-13,2$.

${ }^{219}$ Lindsay $1872,811$.

${ }^{220}$ Lindsay 1872, 810-1. Brunton, 2001, 60.

${ }^{221}$ Brunton 1997, 23.

${ }^{222}$ AJHR 1877, $\mathrm{H}-08,4,6$. AJHR 1878, $\mathrm{H}-10,4$.

${ }^{223}$ Browne 1837, 220-1.

${ }^{224}$ AJHR 1879, H-04, 10.

${ }^{225}$ AJHR 1878, H-10, 10. Refer also: AJHR 1880, H-06, 4.

${ }^{226}$ AJHR 1880, H-06, 4.

${ }^{227}$ Brunton 2003, 88.

${ }^{228}$ New Zealand Parliamentary Debate, November 4 1879, vol. 33. 61-2.

${ }^{229}$ Griffiths, Eccles and McCoy 1983, 27. 
${ }^{230}$ New Zealand Parliamentary Debate, November 4 1879, vol. 33. 61-2.

231 Ibid, 61-5.

${ }^{232}$ Brunton 2003, 81-9.

${ }^{233}$ Yanni 2007, 91.

${ }^{234}$ Richardson, "Campbell, John."

${ }^{235}$ AJHR 1899, H-07, 3.

${ }^{236}$ Brunton 2003, 81-9.

${ }^{237}$ Brunton 2001, 253, 256.

${ }^{238}$ AJHR 1899, H-07, 3.

${ }^{239}$ Yanni 2007, 89-90.

240 "Special Correspondence" 1906, 1498.

241 "The First British Village Asylum," 1906, 1498.

${ }^{242}$ Burdett 1891, vol. 1, 137.

${ }^{243}$ AJHR 1899, H-07, 3.

${ }^{244}$ Lindsay $1872,808-10$. 


\section{CHAPTER FIVE \\ Kingseat: a Vision in Gray}

In 1925, the decision was made to vacate the existing Auckland Asylum, constructed in 1867, and shift patients to a new hospital, constructed along modern lines. ${ }^{1}$ Of all the facilities constructed for the New Zealand Mental Hospitals Department, Kingseat Hospital (near Papakura) ought to have been the most up to date. It was planned in 1927, shortly after Dr. Theodore Gray, who was head of the Mental Hospitals Department from 1927 to 1947, returned from an international study tour where he visited the "most modern" institutions for mental health care within Great Britain, the United States, Canada and the Continent. When the Papakura Hospital was opened (1931) staff recalled that villa hospitals were considered "very modern thinking!"2 This case study will begin by establishing the quality and currency of Kingseat Hospital as a response to current thought on patient care and best architectural practice of the time.

In the five years prior to Kingseat's construction, New Zealand's Mental Hospitals Department had been severely criticised by the public. Shayleen Thompson has suggested that public regard for these institutions became increasingly negative following World War I. Many soldiers returned from war suffering from mental illness and the mere possibility that these men might be committed to a public mental hospital was considered unacceptable. ${ }^{3}$ This case study will establish the extent to which the need to reshape the image of the country's mental hospitals, and improve the public standing of this department, influenced the design decisions made at Kingseat.

Warwick Brunton believes that Gray deliberately sought a "showpiece" mental hospital with the construction of Kingseat. ${ }^{4}$ As the focus of Brunton's research has, thus far, been related to matters of policy, this hypothesis has not been tested in architectural terms. Gray did leave a number of written records that suggested a desire to establish himself as a critical figure in the development of the villa hospital model in New Zealand. ${ }^{5}$ These efforts extended to an attempt to usurp credit for the advances made by his predecessors. The idea to replace New Zealand's Victorian-era mental asylums with villa hospitals came from Truby King and the land for Kingseat was purchased during his time as Inspector-General. ${ }^{6}$ It is likely, however, that King handed over the planning of this hospital to Gray as he was 
nearing the end of his career at this time and also had heavy commitments to the Plunket Society. This chapter will look at how Gray's professional desire, to be credited with substantially advancing the delivery of mental health care in New Zealand through the construction of villa hospitals, influenced the design approach taken at Kingseat. It will also look at wider issues of professional marginalization in the design of this hospital.

Brunton and Kate Prebble are in agreement that Gray's leadership was institutionalized and conservative. ${ }^{7}$ Brunton recounts that Gray was sceptical of all new forms of treatment, including electroconvulsive therapy, psychotherapy and advances in psychopharmacology, while capital expenditure during his term was almost always along villa lines. ${ }^{8}$ Gray's steadfast belief in the therapeutic value of an appropriately designed hospital environment has yet to be examined. It is tempting, therefore, to dismiss his commitment to villa hospital construction as indicative of the same retrograde approach that saw him resist a raft of new therapeutic offerings. This chapter will address the question that historians have yet to investigate; did Gray's dedication to the villa hospital model result in an improvement to the environment in which mental health care was delivered?

This case study aims to understand the curative potential of the architecture created for Kingseat Hospital and the extent to which this may have been compromised by agendas that were peripheral to the delivery of mental health care, including, but not limited to, concerns of public relations and professional ambition. An understanding of these issues will add a further dimension to our existing knowledge of official attitudes to mental illness in New Zealand in the 1930s.

Kingseat Hospital was planned during a period of rising public discontent with New Zealand's mental hospitals, the first section of this chapter will provide an overview of public sentiment toward the Mental Hospitals Department in the late 1920s. The main body of the chapter will evaluate Kingseat Hospital against the design criteria established, to ascertain how closely ideal curative strategies were adhered to, before considering this design in the context of international trends. Next, the political and professional agendas which influenced this architectural response will be examined, especially with regard to Kingseat's role as a vehicle for improving public relations. Finally, the differences between the architectural responses created for New Zealand's Queen Mary (neuropathic) Hospital and the resources directed toward Returned Service Men will be discussed in order to contextualise the Government's response to the needs of mental hospital patients. 


\subsection{OUT WITH THE MENTAL HOSPITAL: PUBLIC DISSASTISFACTION IN THE 1920s}

In 1923 The [Christchurch] Press labelled mental hospital care "cruel, dangerous and costly." The paper accused the department of "entrenched conservatism" and of "do[ing] little or nothing in the way of seeking... fresh thought upon the problems of mental illness. ${ }^{9}$ While public criticism of these institutions wasn't new, simultaneous, nation-wide media criticism was. Thompson has put this down to the presence of returned service men in New Zealand's mental hospitals which resulted in an increased public interest in these institutions and, ultimately, increased dissatisfaction. ${ }^{10}$ However, the influence of a book written by British doctor Montagu Lomax (1921) strongly influenced the opinion of the New Zealand media in the early 1920s. Lomax was a retired general physician who took a temporary position at the Prestwich Asylum (Manchester) in order to assist with war time staffing shortages. According to the New Zealand Herald, Lomax's The Experiences of an Asylum Doctor made a "deep public impression."11 This section will offer an overview of the context within which Kingseat Hospital was planned in order to better understand the peripheral pressures that affected the development of this hospital.

Only a very small proportion of returned service men, those whose conditions were considered incurable, were committed to public mental hospitals. Every effort was made to segregate these men from the wider mental hospital population. The Wolfe Home, constructed in 1910, was the only facility connected with a mental hospital that was used for returned service men. Following World War I the Auckland Mental Hospital offered the use of this new unit, located just across the road from the main institution, to the Defence Department. ${ }^{12}$ It was a generous offer since the hospital was then struggling with overcrowding. The Defence Department accepted the offer but underutilised the Wolfe Home; it remained largely empty over the course of their occupation. Simply being in sight of a mental hospital proved too close for comfort. There were two issues at play here. Firstly, the public believed that solider patients who were suffering from shellshock (as well as civilian patients who were suffering from nervous breakdowns) were a class above the usual occupants of mental hospitals; they should not be confined with the genuinely insane. Secondly, there was a fear of contagion regarding mental illness. The Auckland Star acknowledged the presence of the fear that admission to a mental hospital might condemn a patient, however mild the illness they arrived with, to a lifetime of insanity. ${ }^{13}$ While the New Zealand Herald informed readers that incipient cases:

are inadequately segregated from incurables. Differential treatment is denied them. They are treated as incurable - and so are made incurable....we get what Sir Henry Maudsley called, with illuminating frankness, "asylum-made lunatics." 14 
The New Plymouth Daily News claimed that "humanity calls for these people being tended in their affliction, cured if possible, but not herded with the worst cases of insanity." 15 The public clearly and consistently stated their preference for the provision of "borderline institutions" for the treatment of patients experiencing the incipient stages of mental illness. Between 1922 and 1924 the Mental Hospitals Department received thirteen written requests for the provision of "halfway houses" from various branches of the Returned Soldiers Association, the Soldiers Mothers League, the Woman's Christian Temperance Association and even from the Boards of four general hospitals (Wanganui, Thames, Waikato and Patea). ${ }^{16}$ In 1923 articles in support of the construction of half-way houses appeared in the The Press, the Auckland Star, the New Zealand Herald and the New Plymouth Daily Times, and were restated by the Justices of the Peace Association in $1930 .^{17}$

A regular contributor to The Press, Dr. E.G. Levigne, asserted that New Zealand's mental hospitals were falling short, making little effort to promote a "scientific atmosphere and spirit of research."18 The Minister of Health responded that Levigne had not been employed, in a full time capacity, by a New Zealand mental hospital in twenty years. He was not, therefore abreast of the current condition of these institutions. ${ }^{19}$ In fact, the New Zealand public knew very little about the actual conditions of its own mental hospitals since the department carefully controlled the flow of information from within hospital confines to the public. Staff were forbidden to discuss hospital business off site, the movement of visitors within hospital grounds was precisely managed and photographs were not permitted. ${ }^{20}$ In lieu of genuine knowledge the wartime problems of Britain's mental hospitals, as asserted by Lomax, were projected onto New Zealand's mental hospitals. Much of the sentiment expressed throughout the nations newspapers during this period echoed opinion from Lomax's book, in some cases citing it closely without acknowledging the source. ${ }^{21}$ In 1923 the New Plymouth Daily News asserted that ill-treatment was taking place in mental hospitals, even though this could not be proven, since "the nature of the very institutions safeguard the officials from blame."22 Compare this with the following passage from Lomax's The Experiences of an Asylum Doctor:

the administrative system under which our public asylums were conducted... permitted the occurrence of grave defects and abuses, which appeared to be involved in the system itself... ${ }^{23}$

A half-way house, as the New Zealand public understood and requested, was an institution divorced from public mental hospitals, one that would protect acute patients from coming into contact with chronic patients and spare them the stigma of committal simply by being separate. They did not ask for increased research efforts or closer ties to be formed with universities and general hospitals. Nor did they request outpatient clinics as were then being offered by the Maudsley Hospital. They asked simply that 
these institutions be located far away from existing mental hospitals. Ironically, in 1923, separate facilities for the reception and treatment of acute patients were already being provided. Reception villas were in use at all of New Zealand's mental hospitals. While these were located on hospital grounds they were situated some distance from the existing asylum buildings and approached via their own separate driveways. Proximity remained a sticking point. Levigne questioned the suitability of reception houses on mental hospital grounds since these were part of the main asylum "with its objectionable surroundings and associations." Furthermore, Levigne claimed, reception houses were liable to be filled with chronic (incurable) patients, a consequence of overcrowding. ${ }^{24}$ Frank Hay, then Inspector-General of Mental Hospitals, argued that situating these facilities further away from existing mental hospitals would require their own establishment of staff, a considerable cost which would benefit only a very small number of patients. ${ }^{25}$

Curiously, however, given Hay's position on half-way houses, he was responsible for the establishment of a ten bed unit, named Hornby Lodge, in 1920 (figure 5.1). It was overseen by Sunnyside but located, according to official reports, in a "separate district" and intended for patients who were "able and willing to pay more than the usual maintenance." ${ }^{26}$ King was also against the idea of half-way houses yet he too planned four cottages for the accommodation of twelve "more sensitive and recoverable" patients along the lines of the Hornby Lodge. ${ }^{27} \mathrm{He}$ would later refer to these as "special neuropathic hospitals." 28 The Press suggested that if facilities such as Hornby Lodge were made available to all patients, not simply those who could pay, then such facilities would "meet the public demand admirably." ${ }^{29}$

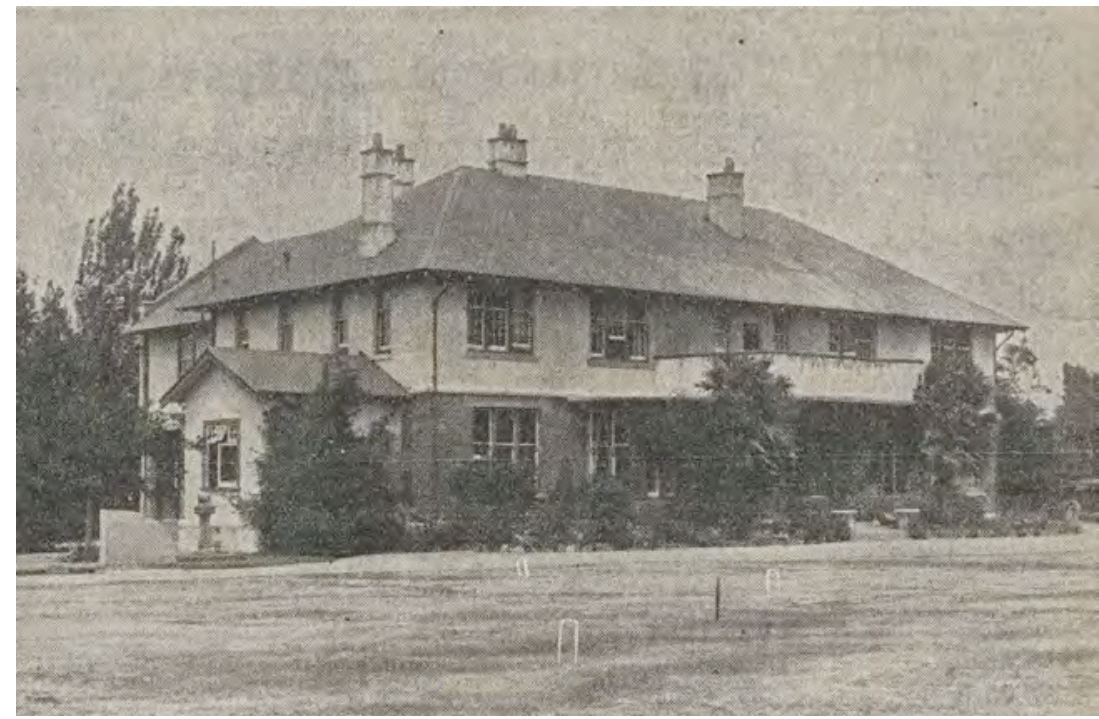

Figure 5.1: Hornby Lodge, Christchurch.

The lodge was housed within an existing dwelling.

As published in The Press, January 10, 1931. 
When Gray assumed the position of Director-General of the Mental Hospitals Department the land for Kingseat was already purchased and design work was underway. However, the money for new buildings had not yet been spent. It was Gray's job to advise the Prime Minister on the future direction and shape of New Zealand's mental hospital network. Despite visits to the Maudsley Hospital and the Phipps Clinic during his study tour of 1927, Gray's faith in the villa system as the ideal environment for treatment remained steadfast. He was convinced that the best course of therapy for recoverable patients was based in the old tenets of moral treatment:

fresh air, sunshine... suitable diet, exercise, recreation, rest and sleep, everything indeed conducive to the establishment of active, regular, daily habits. ${ }^{30}$

Gray was fundamentally opposed to the idea of providing half-way houses or psychopathic hospitals. He felt the cost of their establishment would be "so enormous as to place any such scheme outside practical politics." While they catered only to those patients whose conditions were deemed valuable from an educational perspective. ${ }^{31}$ Furthermore, he felt it was unlikely these institutions would achieve the results the public desired. Gray reported that the psychopathic hospitals he had visited on his study tour still contended with stigma despite their disassociation from mental hospitals. ${ }^{32}$ The villa hospital, on the other hand, provided for the full spectrum of New Zealand's mental hospital population in a cost effective way. Gray had no doubt that this model provided New Zealand with "the means of meeting all reasonable demands" in the provision of treatment and that it would go "beyond the demand" for half-way houses, providing accommodation for "all degrees of mental trouble."33

In 1927, when planning for Kingseat Hospital commenced, the public had little faith in the curative abilities of New Zealand's mental hospitals or even the integrity of these institutions. Gray had no intention of pursuing alternative hospital models despite what may be viewed as conciliatory efforts on the part of Hay and King, to provide some semblance of the halfway houses the public called for. Kingseat Hospital would need to succeed in convincing the public that the villa hospital would go beyond what they had asked for. 


\subsection{KINGSEAT: THE "SHOWPIECE” MENTAL HOSPITAL}

Kingseat was located near the southern limit of the Auckland region, 30 kilometres out of the city. It was to be comprised of a number of fifty bed villas complimented by a hospital block, administration building, nurses home and recreation hall (figure 5.2). Facilities for occupational therapy were added to the building programme in $1937 .{ }^{34}$ Recreation halls and dedicated spaces for occupational therapy were necessary tools for recovery and mitigated the detrimental effects of institutionalisation by ensuring patients were kept occupied and their minds active. ${ }^{35}$ While the intended bed limit for this hospital was not stated, Gray believed in a maximum hospital size of 1000 patients. ${ }^{36}$ Gray himself felt that Kingseat was the "best example" of a villa system "in New Zealand, and indeed in Australasia." ${ }^{37}$ This section will examine the relationship of Kingseat's architecture to contemporary treatment, using the criteria set up within chapter three (table 3.2). It will also examine this hospital with regard to how public perception may have affected this design response.

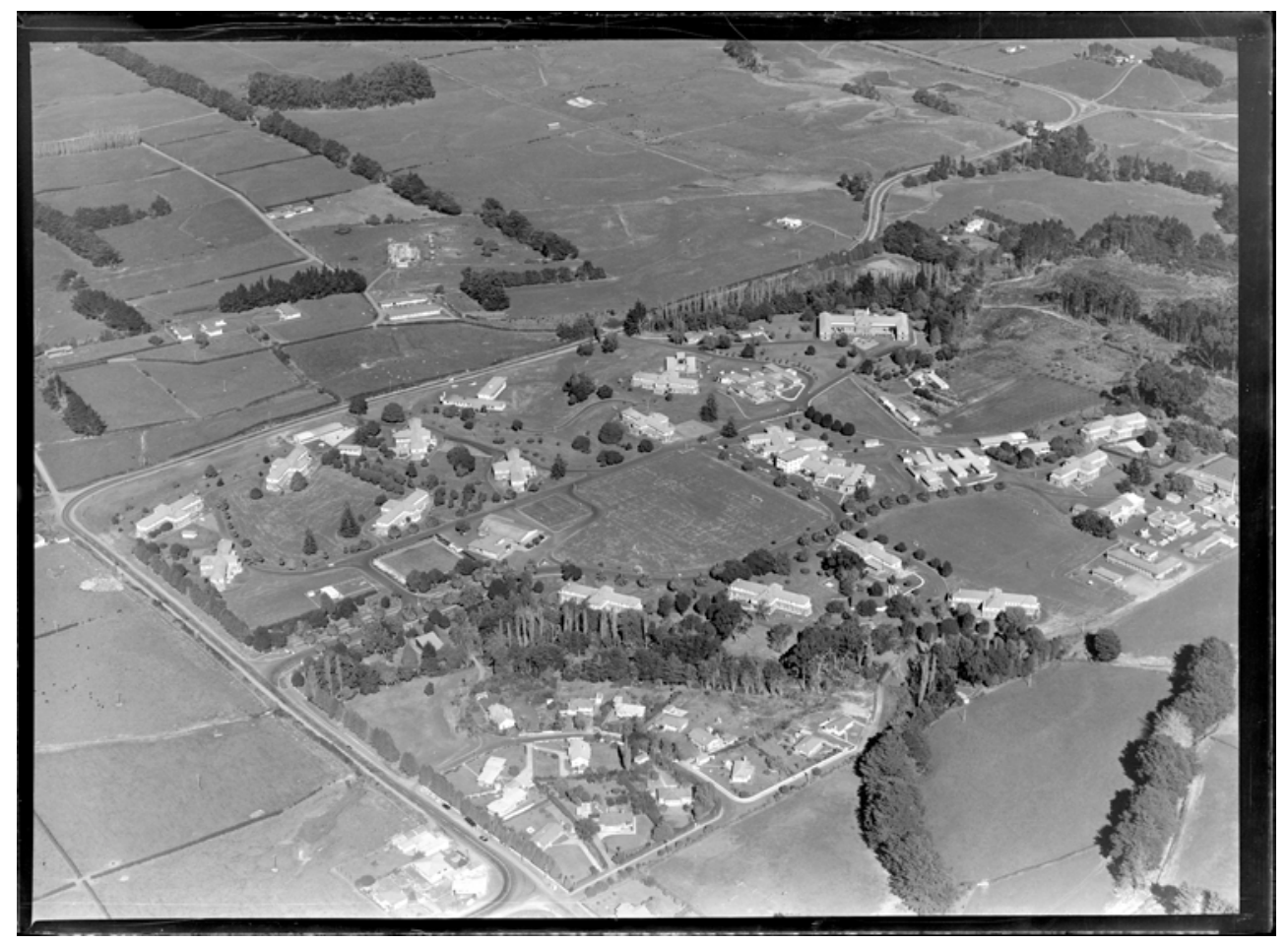

Figure 5.2: Aerial photograph of Kingseat Hospital, 1972.

Photograph by Whites Aviation. Alexander Turnbull Library: WA-71752-G

The external appearance of these villas will be discussed first, followed by their internal planning and the relationship of this design to the surrounding landscape. Aesthetically, the Kingseat villas followed the preferences of men such as John Conolly and Henry Maudsley of the previous century. Instead of resembling humble rural cottages, the villas adopted a statelier neo-Georgian architectural style (figure 5.3). This style was already firmly established for general hospital use in New Zealand with early hospitals at Auckland, Wellington and Palmerston North all constructed in the Georgian tradition. ${ }^{38}$ 


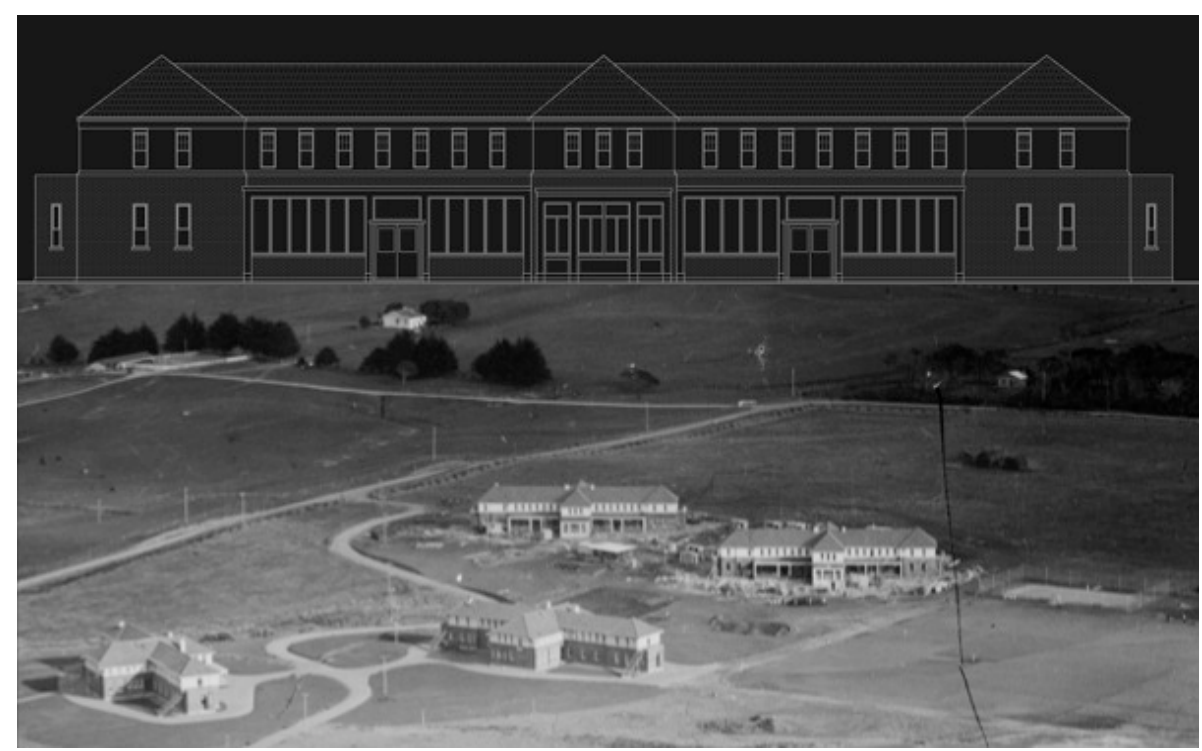

Figure 5.3: Kingseat Hospital, 1937. Photograph by Whites Aviation (cropped) with a drawing of the front elevation shown above (reconstructed).

Alexander Turnbull Library: WA-55912-G. Reconstruction by author.

The 50-bed villas constructed at Kingseat, with their weighty red brick base, clean white banded plaster first floor and Marseille tiled roofs, conveyed a sense of elegance and order that villas designed for other hospitals during this period did not. The new villas added to Sunnyside and Seaview Hospitals in 1929 were single story and constructed of weatherboard over timber framing with corrugated iron roofing (figure 5.4). This clear difference in material selection was reflected in the construction cost. The new villas at Sunnyside and Seaview were constructed at a cost of $£ 10,000$ each while those at Kingseat cost $£ 12,500 .^{39}$ The Kingseat villas were some of the most expensive built by the Department between 1925 and 1949. The hospital itself was still regarded by the department two decades later as an "expensive" hospital. ${ }^{40}$ Only three villas of this type were constructed at Ngawhatu. The remaining nine villas at that hospital followed the more affordable Sunnyside design (or a later iteration of this design). At Kingseat fourteen of the fifteen original villas were constructed using this design, at the higher cost of $£ 12,500$. The only exception was the villa constructed for farm workers.

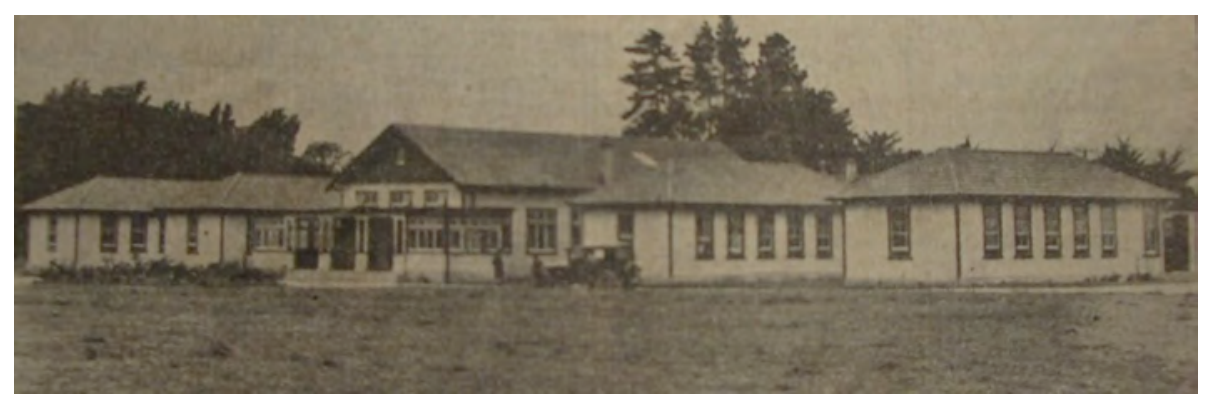

Figure 5.4: Sunnyside villa type as constructed at Templeton Farm School. As published in The Press January 10, 1931. 


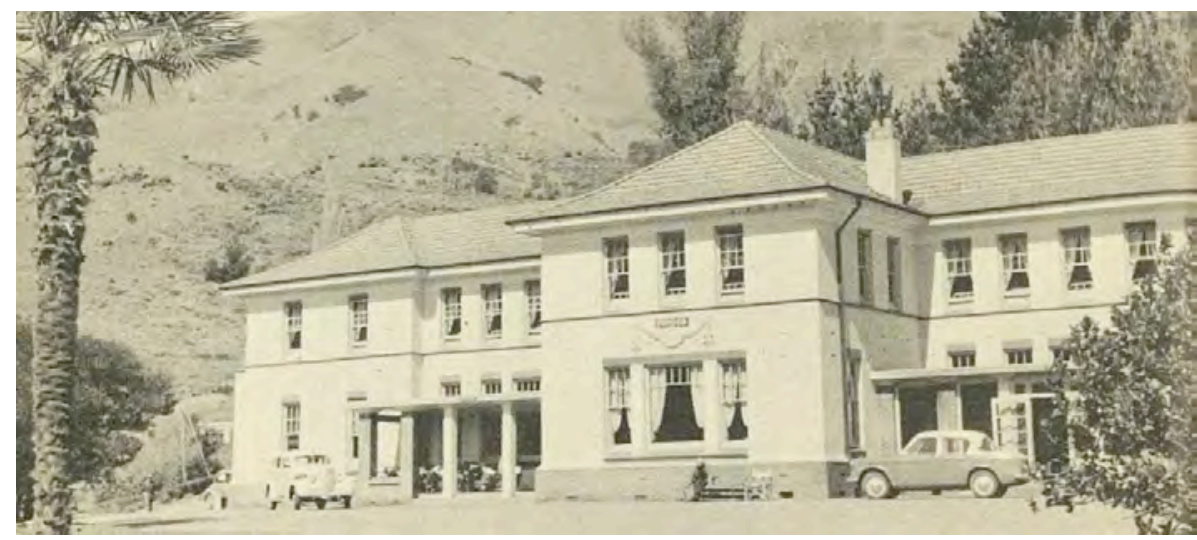

Figure 5.5: Dunoon Villa, Ngawhatu (opened 1929). Photographer unknown. Image source: Friends of the Nelson Library (nelson.photonews.org.nz).

The Kingseat villa was a slight variation of the villa created for the Ngawhatu Hospital, in Nelson (figures 5.5 and 5.6). Ngawhatu was a new villa hospital built to replace the aging Nelson Asylum. Construction began while Gray was superintendent there and Brunton suggests he was influential in the design. ${ }^{41}$ The first of three villas of this design was opened at Ngawhatu in 1925 and the following two in 1929. ${ }^{42}$ While the villas created for Seaview and Sunnyside followed a traditional, pavilion plan, where dormitories extended outwards in parallel wings as was popular for general hospital construction in the late nineteenth century, the Kingseat villas were far less institutional in their arrangement. The fact that the Ngawhatu villas, upon which the Kingseat design was based, were under construction in 1924 rules out the possibility that the design may have replicated something seen by Gray on his overseas study trip (August 1926 - June 1927).

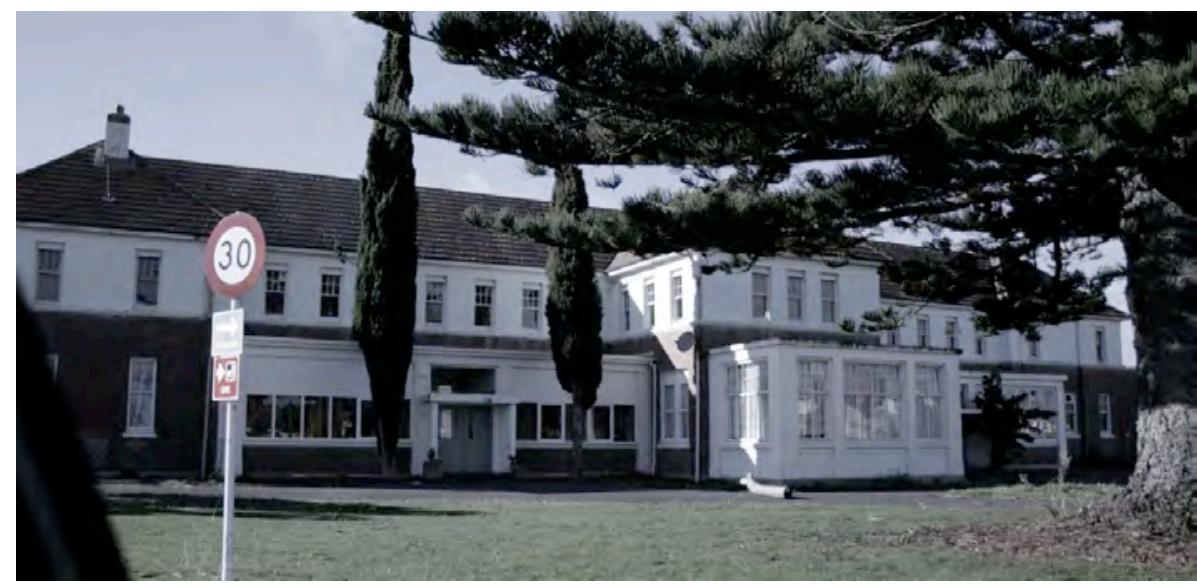

Figure 5.6: Kingseat Hospital Villa, October 10, 2010.

The verandas were sequentially enclosed in the 1950 s.

Glazing was originally installed to ceiling height but was reduced for ease of maintenance (replacing broken panes). Photograph by author. 
It was not just in appearance, however, that the Kingseat villas surpassed their counterparts (figure 5.7). The provision of two separate dayrooms, eight single rooms and intimately scaled bathrooms all presented clear advances on the villa designs created for Tokanui in 1912 and Sunnyside Hospital in 1929 (figure 5.8). The Kingseat villas also retained a position of superiority over subsequent villa designs created for Porirua (1945) and Cherry Farm Hospitals (1949), despite the fact that the Porirua design was a clear derivative of the Kingseat plan (each villa type was named for the hospital it was first created for). The provision of two separate day rooms offered patients a choice of spaces to occupy during the day. According to Mercier, the provision of "plenty of room... where there need be no struggle to get to the fire; where [a patient] can move about freely without jostling other patients" the risk of aggression and violence was mitigated. ${ }^{43}$
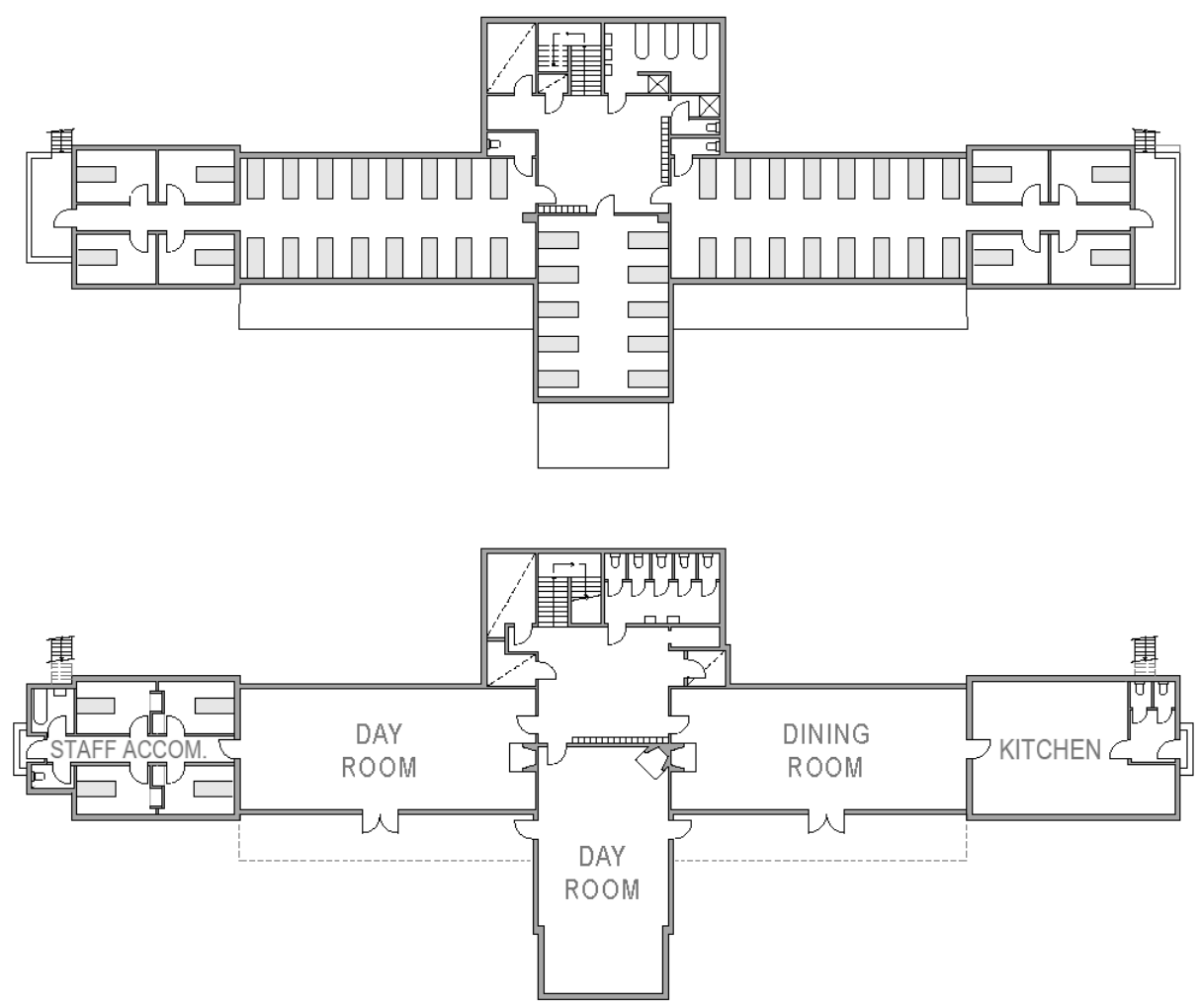

Figure 5.7: Kingseat Hospital villa plans; ground and first floor (top). The veranda is shown dotted, these were enclosed in the 1950s.

Plan reconstructed from site visits and Kingseat Heating [plan]

Stage 3 (1974), Archives New Zealand reference W-33-6-26452.

Reconstruction by author. 


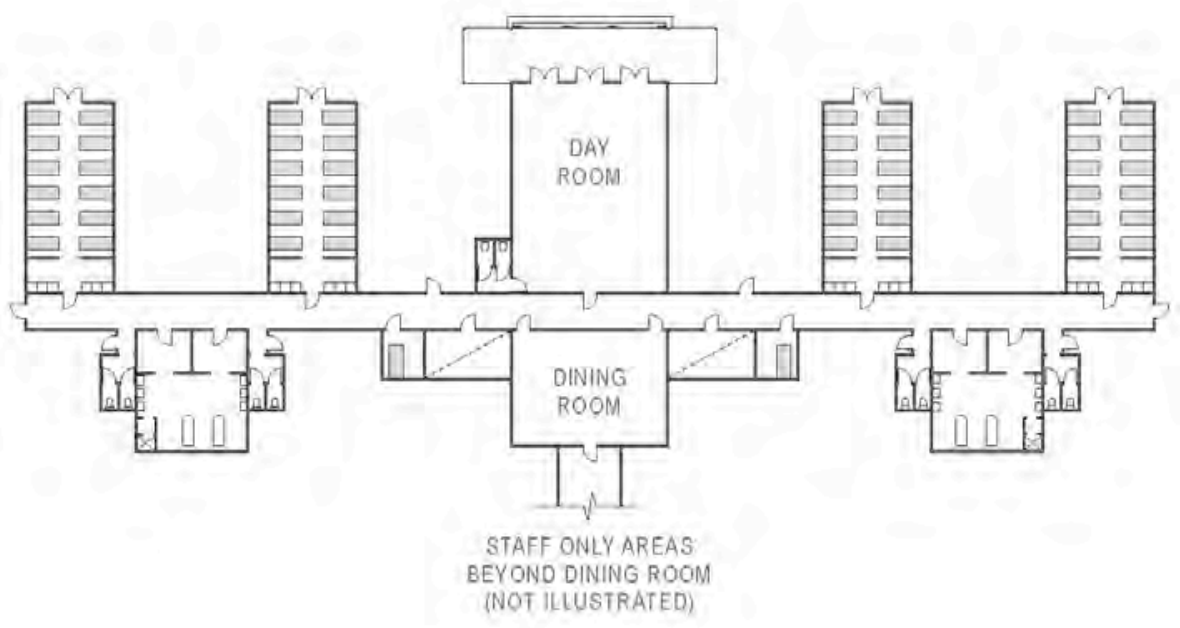

Figure 5.8: Sunnyside 50-bed villa type, 1929.

Plan reconstructed by author from site visits and fire services plan.

Hokitika Museum: Seaview Fire Services Plan, 1980.

The Kingseat villas were well placed to support the delivery of individual treatment and the provision of tranquillity. Restricting the size of villas and dormitories was considered an important factor in mitigating the dehumanising effects of large asylums because they reduced the risk of "herding" patients together - of losing sight of each as an individual. Mercier had expressed the importance of small dormitories and recommended the installation of privacy screens in both dormitories and bathrooms. ${ }^{44}$ The dormitories at Kingseat slept between ten and sixteen beds. This did not present a significant advance on Seacliff whose largest dormitory was designed to sleep eighteen. Nor did it more closely approach Conolly's preference for a limitation of five beds. ${ }^{45}$ However, it was an improvement on the fifty person villa designed for Tokanui Hospital in 1912 whose dormitories housed twenty beds. While no privacy screens were installed at Kingseat, the spatial quality of these dormitories was superior to those constructed elsewhere; at Sunnyside and Seaview, in 1929, and at Porirua and Lake Alice, in 1945. The Kingseat dormitories were almost a metre wider, the ceilings were higher and the windows taller. These were more spacious, lighter and airier than their counterparts (figure 5.9). Likewise the eight single bed rooms are worthy of mention. Within the history of New Zealand's mental hospitals only the high security villas (for dangerous and criminal patients) boasted more single rooms than the eight provided at Kingseat.

Dormitory design was not the only point on which Kingseat presented an advance on Tokanui's design. The first 50 -bed villa constructed at Tokanui provided a single bathroom fitted with six baths. The bathrooms in the Kingseat villas were more intimately scaled and provided only three bath tubs. Despite Mercier's recommendation, no privacy screens or curtains were installed. Though Mercier's text offers an explanation for this; baths 
were "the only source of water that could be used [by patients] for suicidal purposes." ${ }^{46}$ Grouping baths together, therefore, provided a secondary line of defence for times when staffing levels were low.
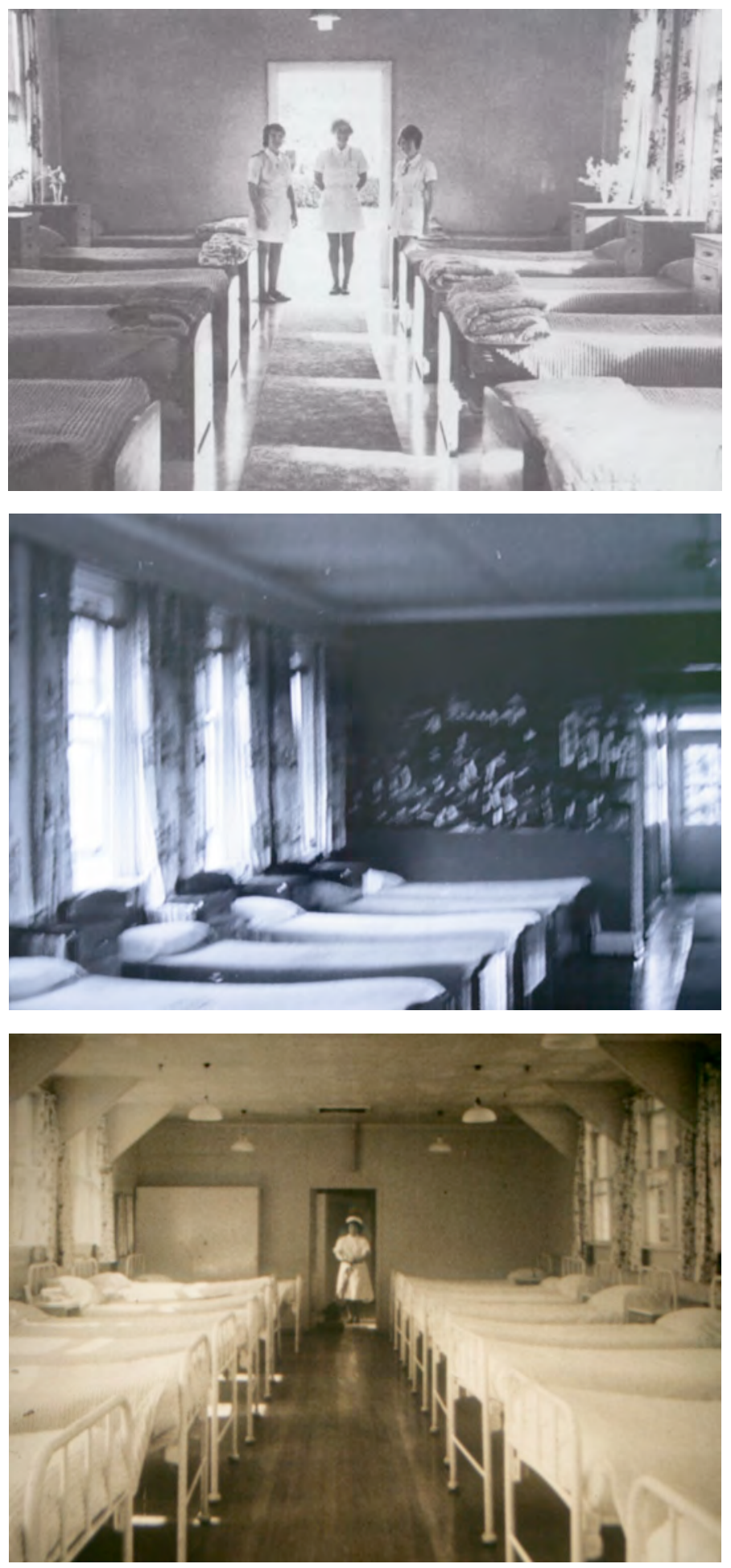

Figure 5.9: Photographs of dormitories in various villa types (from top) Seaview (1972), Kingseat (1968) and Porirua (ca. 1964).

Seaview image from the Hokitika Museum \#0935,

Kingseat and Porirua images from the Television

New Zealand Archive: "The Distorted Image" and P48594. 


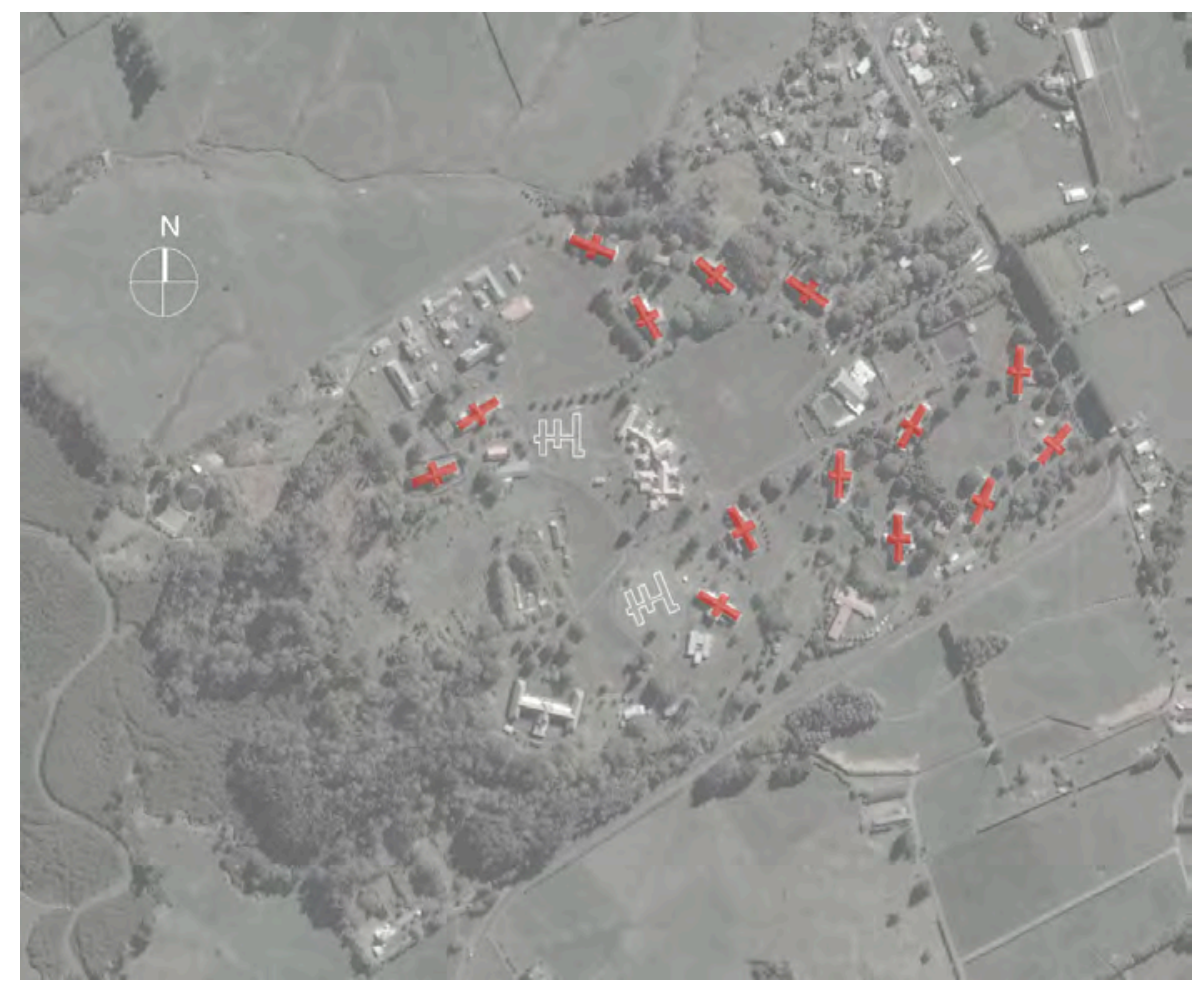

Figure 5.10: Aerial view highlighting villas in red.

The Cherry Farm villas, added in 1957, are denoted by a white outline. Google Earth image (05.05.2012) with colour overlays by author.

The 50-bed villas constructed for New Zealand's mental hospitals were created by the Public Works Department as standard designs. Planned largely independent of their site and context, and replicated around one (or several) mental hospital sites (figure 5.10). While villa designs were created with an understanding of the general locality within which they would be constructed they did not respond to the idiosyncrasies of any given site. If the standard villa plan created for Kingseat is analysed in isolation it appears to have been designed with maximum sun exposure in mind. This is assuming that the veranda faced north which, in New Zealand, would limit overheating from direct summer sun while allowing winter sun (which travels lower through the sky) to enter freely. Positioned in this way the Kingseat villas would have received morning sun to the dining room and all day sun to the day rooms. Service spaces such as bathrooms, toilets and storage, positioned behind the day rooms, would be on the cold side of the building. 


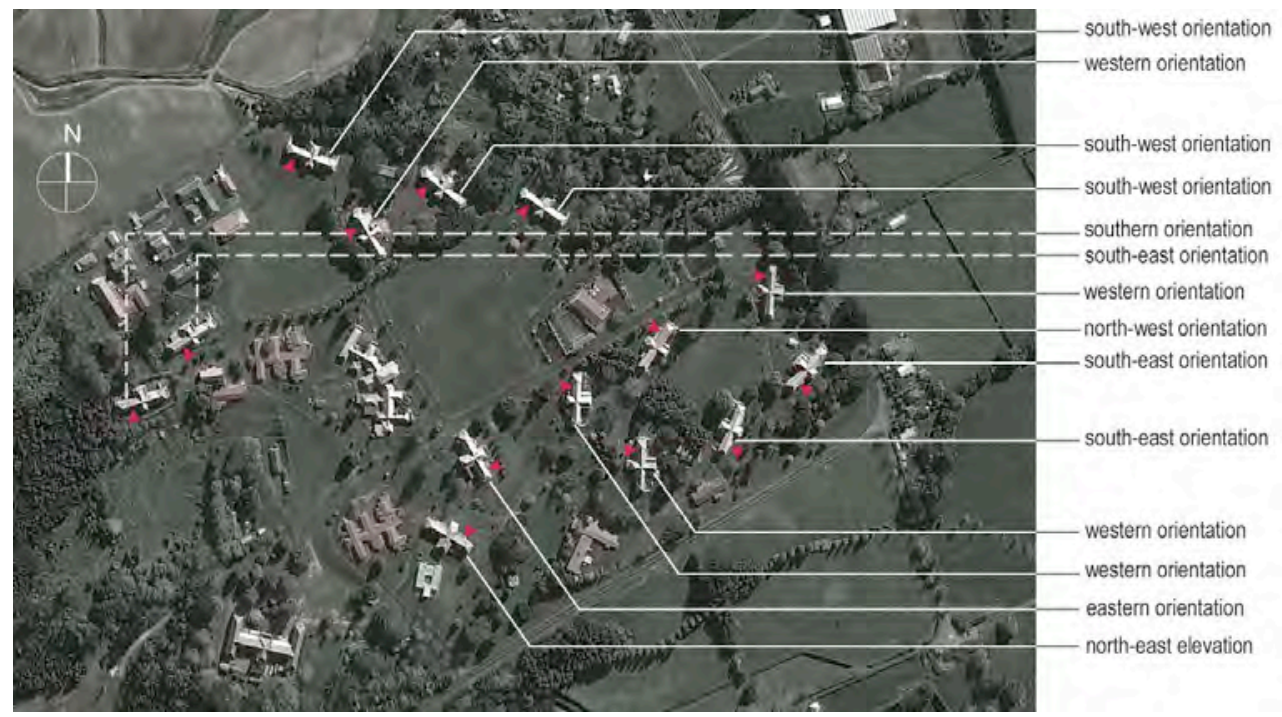

Figure 5.11: Kingseat villa orientation analysis, arrows indicate day room position. Authors analysis overlaid on Google Earth image (05.05.2012) by author.

Yet, a thorough analysis of the site, undertaken for this dissertation, reveals that not a single Kingseat villa was positioned to face north (figure 5.11). While one villa was oriented to the north-west, making the most of available afternoon sun, the remaining villas were faced toward the south and west. The majority of available sunshine to these villas would have fallen upon the service spaces with little sun reaching the day rooms or verandas (figure $5.12)$.

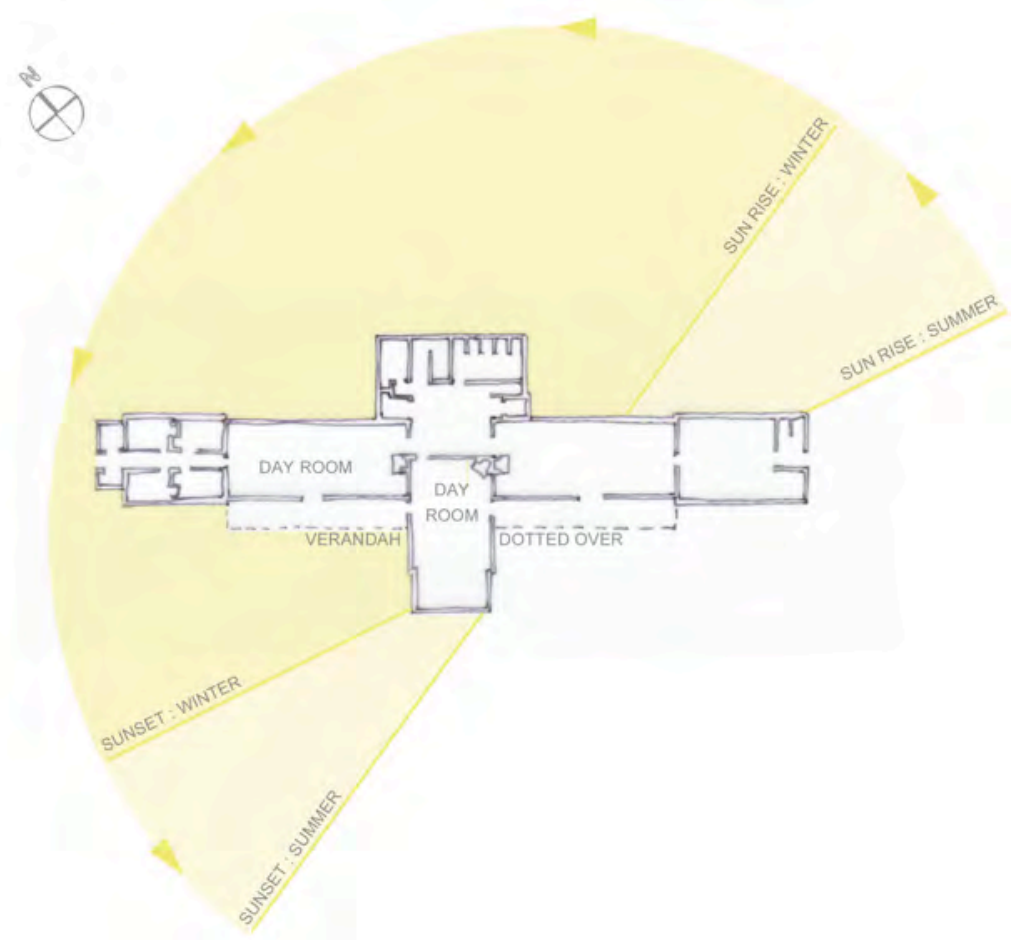

Figure 5.12: Sun diagram for Kingseat villas oriented South-West. Diagram by author. 
Sunshine in mental hospital design had not lost its importance. At Kingseat in Aberdeen, for example, every building in the complex is orientated towards the south-west, extending toward the sun in a fan-shape (south being the optimal direction for access to sunshine in the Northern Hemisphere). At Ngawhatu Hospital, in Nelson, eight of nine villas faced north, with the ninth orientated to the north-east (making the most of morning sun). Ngawhatu Hospital, which weaves its way up through a valley and thus would have been a far more demanding site, was adequately laid out for maximum sunshine. Likewise the design for Lake Alice Hospital (1943), which was never completed, included villas of three different designs yet all were orientated for maximum sun exposure relative to the position of the day rooms within each plan type (figure 5.13). ${ }^{47}$ The orientation of the Kingseat villas, therefore, provides an anomaly within New Zealand's history of villa hospital construction.

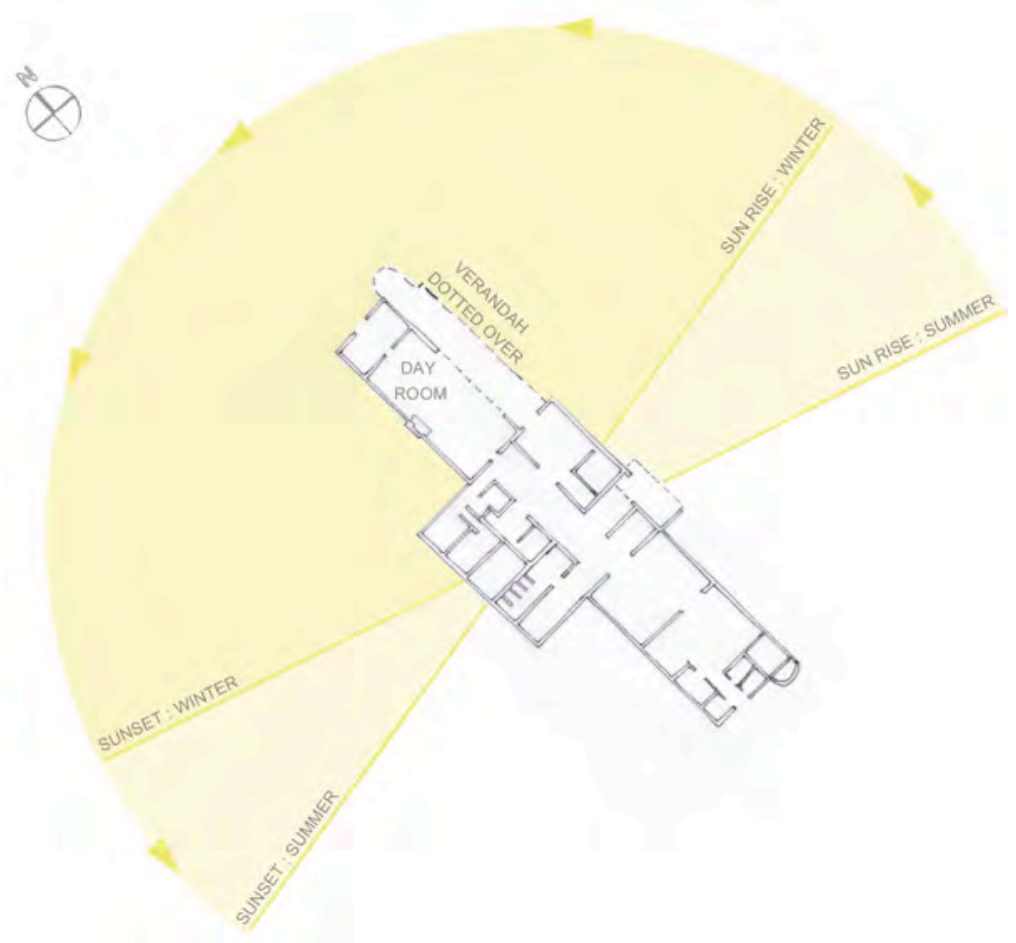

Figure 5.13: Sun diagram for the Porirua villa type as positioned at Lake Alice Hospital with day room oriented to the north. Diagram by author.

The intriguing question is why the Kingseat villas were positioned to undermine the very logic upon which this plan seems to have been created? A possible explanation might be that a number of British architects were employed by the Public Works Department during the period in which Kingseat was designed. They, like Gray, would have been familiar with south-facing building orientations (the direction for achieving maximum sun exposure in Britain). It should also be acknowledged that a north facing orientation was not routinely a priority in New Zealand architecture until the 
mid-1930s. The preference for residential housing in nineteenth century New Zealand (in particular, the suburban villa typology) was to face the street irrespective of sun direction. It was between 1936 and 1949 that New Zealand architects came to appreciate the value of correct sun orientation, including the location of living rooms to the north and the employment of verandas to prevent overheating in summer. ${ }^{48}$ Hospital staff believed that these villas had been orientated relative to view rather than sunshine. When asked to comment in 1947 on how the design of new standard villa plans for the department could be improved they replied: "sun should not be sacrificed for view in facing a villa on its site." orientation of these villas relative to each other, however, suggests another plausible explanation; that they were positioned to impart a strong impression to visitors.

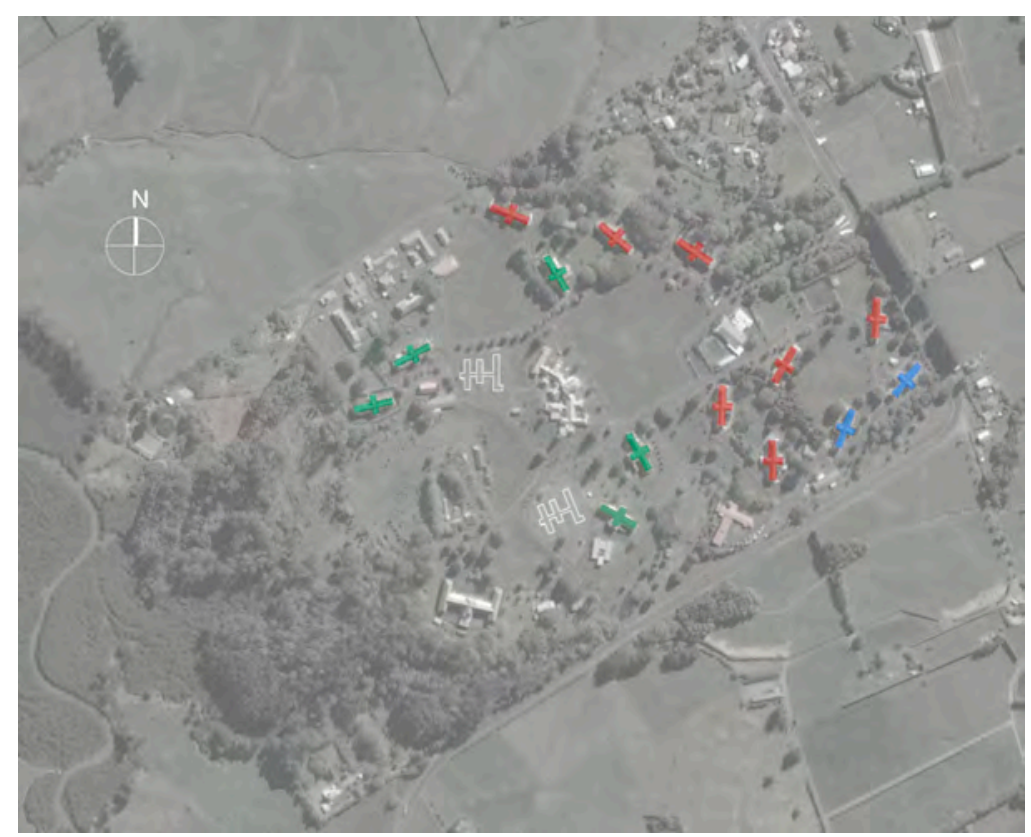

Figure 5.14: Aerial view highlighting villa orientation.

Google Earth image (05.05.2012) with colour overlays by author.

If the orientations of the Kingseat villas are grouped, as in the diagram above, the logic underlying the orientation of each villa emerges (figure 5.14). The seven villas shown in red are orientated toward the reception building, otherwise termed "admission and treatment" (the fan-shaped building positioned in the centre of the site). The villas shown in blue are oriented outward to Kingseat Road, which borders the southern and eastern boundaries of the hospital. The villas shown in green share no common orientation but appear to be positioned relative to the nearest open green space. 


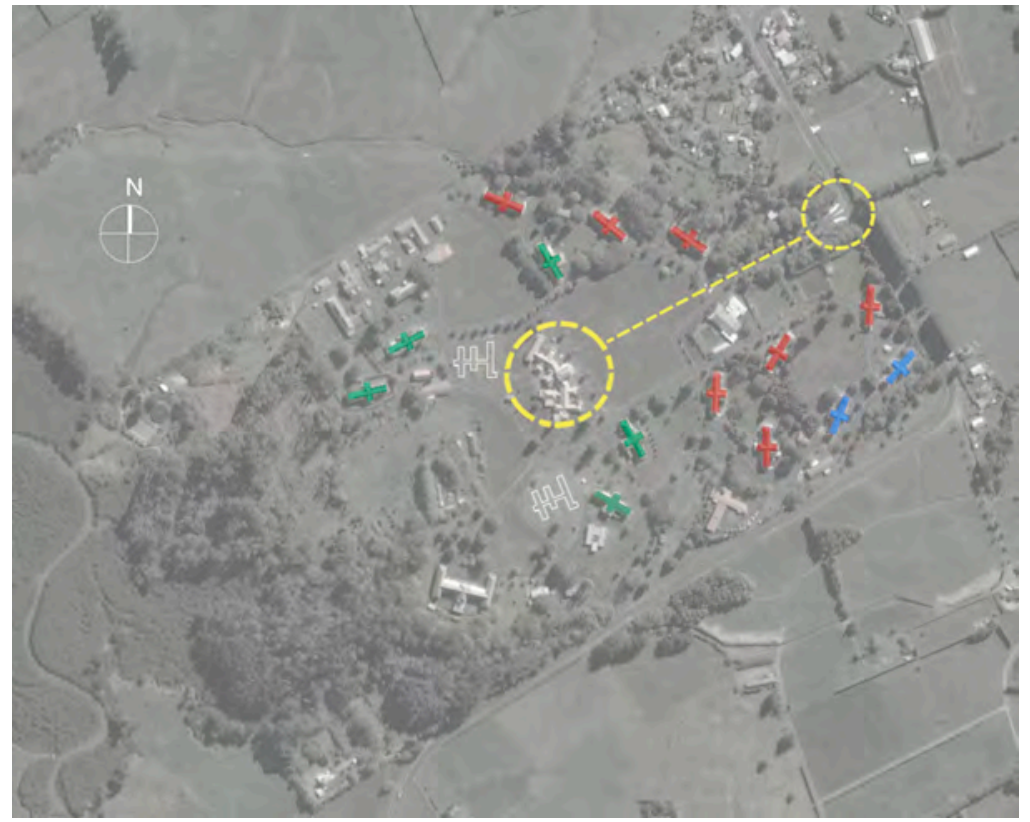

Figure 5.15: Orientation diagram highlighting axis between entry and treatment unit. Google Earth image (05.05.2012) with colour overlays by author.

A tree-lined promenade leads visitors into Kingseat, drawing the eye across the hospital's most significant open green space toward the admission and treatment building where acute patients would be received (figures 5.15 and 5.16). The fact that this pivotal building was also orientated to the east lends weight to the hypothesis that the logic underlying this arrangement was to create a strong axis between the entrance and the reception building. The surrounding villas were positioned to reinforce this axis whist making the central public spaces (the driveway and sports field) appear more open. The villas did not face these public spaces as occurs in a city square where containment is the desired result. Instead, the ends of the villas faced the public space, mitigating the scale of these buildings and reducing the sense of enclosure to these central, semi-public spaces. Gray was well aware of the need to improve the public standing of New Zealand's mental hospitals. Ensuring that the reception building was the most prominent within the site while ensuring a feeling of openness supported two clear messages that the department wanted to send: treatment was the paramount aspiration at Kingseat and relative freedom was extended to all patients. The end result, however, was that the exact same compromise was allowed to occur at Kingseat Hospital as was allowed to occur at Seacliff Asylum; the curative offerings of sunshine were sacrificed in order to make a public statement. 


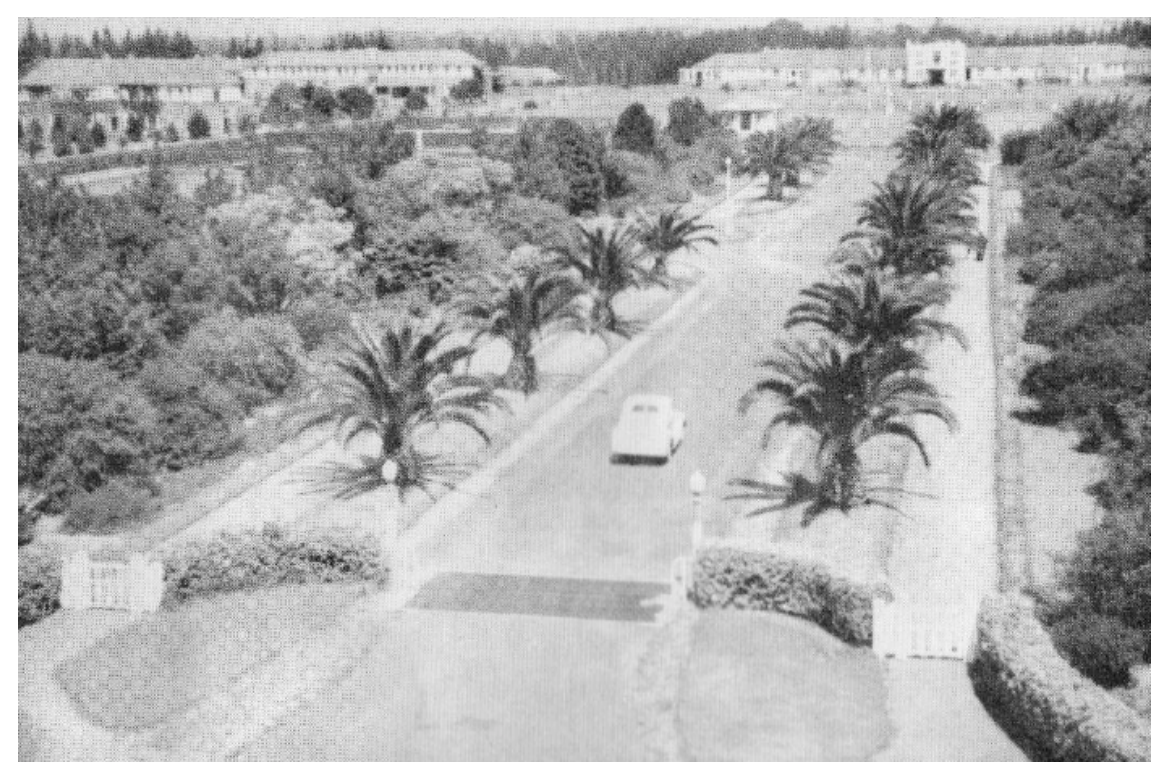

Figure 5.16: Entrance to Kingseat Hospital in the 1940s.

Published in Kingseat Hospital, 50 Years, 1932 - 1982.

With a mix of intimate versus open landscape spaces, and formal versus relaxed, the provision of a quality landscape a Kingseat was taken seriously from day one. Staff also believed in the importance of this aspect of the hospital environment. According to one account, no one returned from leave without "their [car] boot full of native trees, shrubs and plants... [from] around the country." 50 The placement of external doors within the Kingseat villas suggests that these were designed with the genuine intent of allowing patients ready access to this landscape. Two doors were located on each side of the central day room, opening onto the veranda (figure 5.17). While double doors opened up from the second day room and dining room (on opposite sides of the plan). These four doorways were for patient use. Two further doors were positioned at each end of the building for staff use. These doors were unsuitable for providing patient access into the villa as either the kitchen or staff quarters would need to be traversed to reach the centrally positioned patient spaces. The direct access to landscape that the Kingseat villas provided was not standard for mental hospital construction. In later designs, created for Porirua and Cherry Farm, external doors from the day room lead into an entrance vestibule or glazed space where a second door is located. This allowed the careful control of these points of exit. This was replicated at Kingseat following 1954 when the verandas were closed in to form additional rooms. Staff and patient toilets were located at the extremities of this villa, adjacent to external doors suggesting that patients were expected to access these from outside the villa during the day, and staff from both directions. The placement and provision of these external doors suggests that the Kingseat villas did aspire to a support an open-door system of hospital administration. With regard to creating a physical connection to the landscape, the Kingseat villa design was the high point in New Zealand's history of mental hospital architecture. 


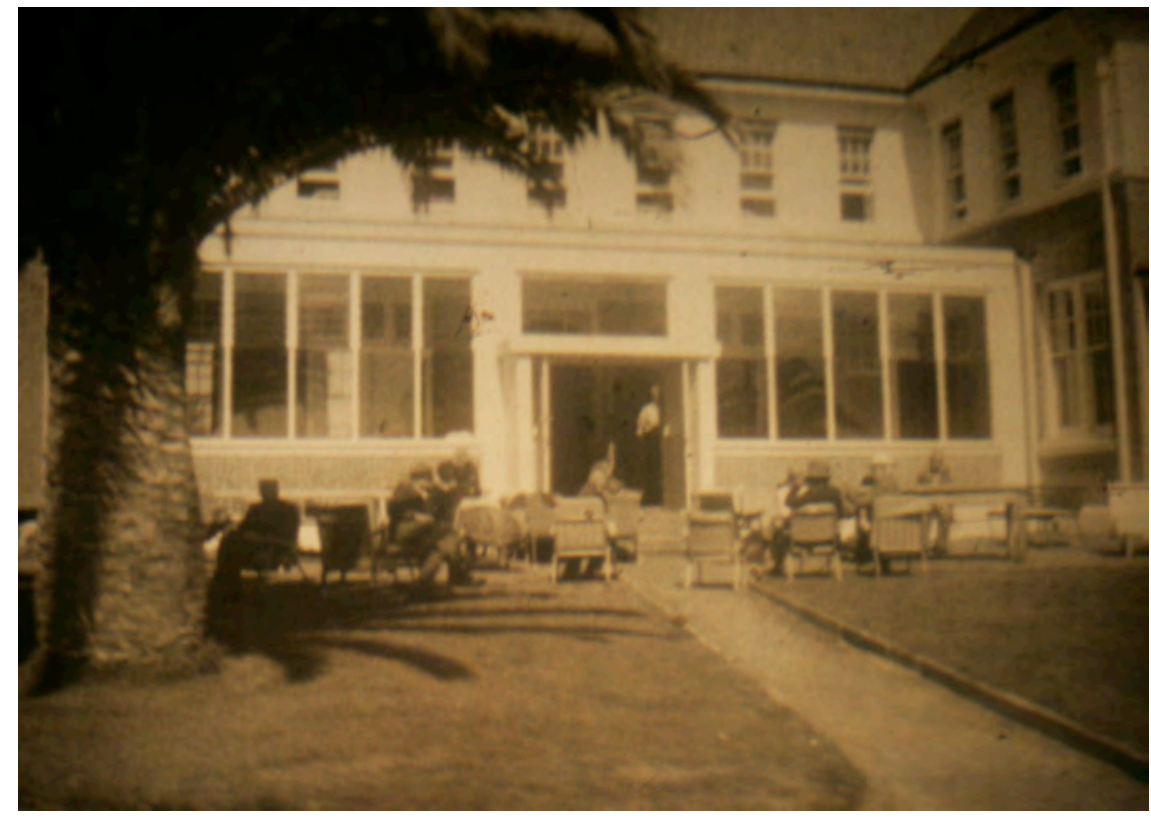

Figure 5.17: Patients sitting outside a closed-in veranda. Still from 1967 stock footage of mental hospitals. Television New Zealand Archive: P48594.

The evidence provided by the architecture at Kingseat is supported by various records left by Gray regarding the appointment of staff for this new hospital. Gray's experience at Ngawhatu, as discussed in his autobiography, alerted him to the need to carefully select staff for Kingseat:

Trained as [staff] had been in the old system, wherein the majority of patients [were]... never allowed out of sight, and obsessed by the fear of suicides, escapes, and violent outbursts, it is scarcely to be wondered at that at first the staff regarded [open door practices] as little removed from sheer lunacy, the complete reversal of all that they had been taught. ${ }^{51}$

When Gray recommended which staff should be transferred to Kingseat in 1936, the reasons given for his selection resembled the passage above: men who were trained in the "old system" would find it "impossible" to accommodate themselves with the approach necessary for the running of an open door hospital. ${ }^{52}$

As the previous section highlighted, at the time of Kingseat's construction little progress had been made regarding the attitude of the public toward mental hospitals or the mentally ill themselves. The preference of a rural location for villa hospitals was based on many of the same considerations that Seacliff's location had been based on: ample space for the occupation of patients with farm and garden work and protection from the prying eyes of the public. While the latter consideration was nowhere formally acknowledged, the relative isolation of Kingseat's site enabled the opendoor system to be practiced. A tolerant community grew up around Kingseat, as was the case with the hospitals at Seacliff, Seaview and 
Tokanui. The properties neighbouring the hospital were often occupied by employees or their families who were unlikely to be alarmed by the sometimes unusual behaviour of patients. As Dr. J.J. Crawshaw told the Auckland Star in 1957:

Occasionally, someone wanders too far off. But people living in the district have a sixth sense for spotting Kingseat patients. They'll ring the hospital - and the wanderer is soon back.... ${ }^{53}$

Crawshaw's comments contrast starkly with those made in Gray's autobiography regarding the open-door practices at Ngawhatu around the same time. Allowing Ngawhatu patients "town-parole" attracted criticism from some residents who believed that Gray had gone "too far with his ideas on freedom for patients. ${ }^{54}$

Kingseat's location, however, was not without its drawbacks. At 30 kilometres from Auckland, this was similar to the distance of Seacliff Asylum from Dunedin. It was twice the distance of the Aberdeen hospital from the city, which was only 16 kilometres away. Like Seacliff, Kingseat suffered from its isolation with direct regard to staff recruitment and retention. In 1946 Gray requested the construction of eight staff residences in anticipation of staffing difficulties becoming "more and more acute" owing to the hospital's distance from "any urban area. ${ }^{55}$ Despite the differences in distance between the Auckland and Aberdeen hospitals, it cannot be said that Kingseat veered too far from best practice with regard to location. The villa hospital constructed at Kankakee in 1886 was close to 100 kilometres from Chicago. Applying a more contemporary standard, when the Bethlem Hospital was relocated from Southwalk to Kent in 1930 the hospital's new site was 60 kilometres distant from their previous position in central London. Kingseat's location therefore, at only 30 kilometres from Auckland, cannot be criticized too harshly.

It took seventeen years to produce 700 bed spaces at Kingseat. Construction began in 1929. Two villas were completed in the first two years and ten villas between 1931 and 1937 . Two further villas of the Kingseat design were added between 1940 and 1946. Construction was slow, even by the standard set at Seacliff. This led Gray's successor, Dr. J. Russell, to complain, in 1950, that even after twenty years Kingseat had "only bare necessities." It lacked administrative buildings, a hospital ward, recreation hall and an occupational therapy building. ${ }^{56}$ The shortages of manpower and materials, associated with the depression (1930s) and with the outbreak of World War II (1939), go some way to explain these delays. A hospital and administration block (elsewhere referred to as the "admission and treatment" or "reception" building) had been constructed in 1939 but it was not of the quality the department had hoped for. Administration space was added to this building in the form of subsequent floors in 1953 and wards for the isolation of patients suffering from tuberculosis (within the mental hospital) added in 1959. It was 1953 before an occupational therapy 
block was constructed and the recreation hall, complete with café, library and canteen, was not finished until $1959 .{ }^{57}$ Kingseat, in common with other New Zealand mental hospitals, struggled increasingly with overcrowding as the years progressed. Consequently, between 1954 and 1959, the verandas on the 50-bed villas were sequentially "glassed in." Twelve of fourteen villas had their verandas closed in to provide additional bed space, or extra day room space where the original day rooms had been reappropriated for dormitory use. ${ }^{58}$ In the end Kingseat did not provide the replacement facility for the Auckland Mental Hospital that was first envisioned. Owing to an ever-increasing patient population the 1867 asylum was instead upgraded and kept in operation. It continued to be occupied by patients until the hospital was finally closed, following deinstitutionalisation, in 1992.

Against the criteria set up for evaluating the translation of ideal curative strategies into built form Kingseat was a remarkable hospital. It could not escape the rural isolation that made staff retention difficult. Nor the funding restrictions, common to all mental hospitals, that ultimately limited Gray's vision for an "ideal" villa hospital. Public opinion clearly influenced the design approach taken to Kingseat Hospital yet the presence of an external audience seemed to result in a higher quality hospital environment. The synthesis of architecture and landscape created at Kingseat remained unmatched within New Zealand's network of mental hospitals. Unlike the lower budget villas created for Sunnyside and Seaview hospitals in 1929, the Kingseat villas were constructed from high-quality, permanent materials, they were more generously glazed and offered more voluminous interiors. The spatial generosities within these villas - the additional dayrooms, the quality of the dormitories, the number of single rooms and the more intimately scaled bathrooms - all provided architectural support for the treatment of patients as individuals and the provision of tranquilly. While the liberal provision of external doorways provides clear evidence that, whatever may have later transpired, this hospital was constructed with a serious commitment to pursuing an open-door system of management. In contrast to the result at Seacliff, designing for an external audience at Kingseat had its advantages, although, it can be held responsible for the one serious architectural criticism that is able to be made. The curative requirement of sunshine was minimised in order to impress those beyond the walls of the hospital; this diminishes an otherwise significant architectural achievement. 


\subsection{ARCHITECTURAL CURRENCY VERSUS GEOGRAPHICAL ISOLATION: KINGSEAT IN AN INTERNATIONAL CONTEXT.}

Kingseat may have been remarkable within the New Zealand context but how did this hospital compare with what was considered best international practice in the design of mental hospitals in the 1930s? This section will critically evaluate Kingseat in relation to leading British hospitals built during the same era: the Barrow Mental Hospital, the Shenley Park Mental Hospital and the rebuild of the Bethlem Royal Hospital between 1923 and 1930. ${ }^{59}$ The Architect and Building News credited Bethlem's new facilities as being "well in advance of current practice and should provide many new ideas in mental hospital planning." ${ }^{60}$ If, as Brunton suggests, Gray was aiming for a modern, "showpiece" mental hospital then, according to media accounts, the Bethlem rebuild could have provided a valuable precedent (figure 5.18).

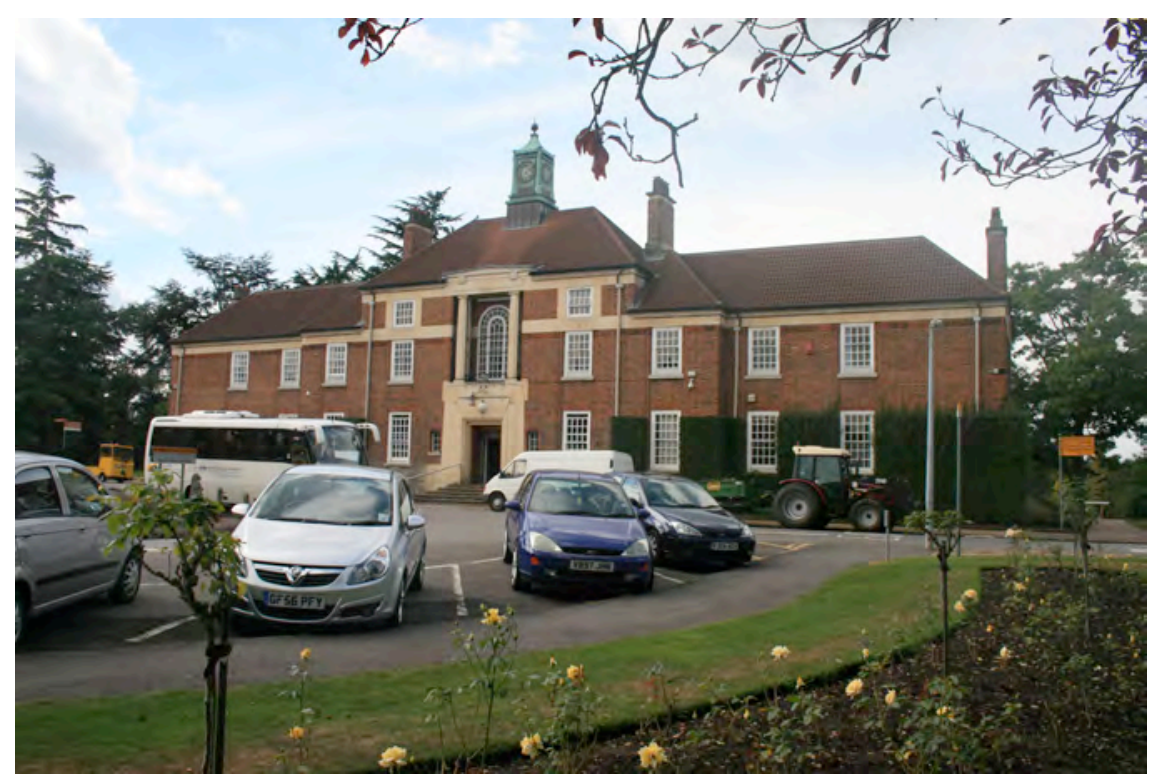

Figure 5.18: The Entrance Building at Bethlem Hospital, September 10, 2013. Photograph by author.

In 1923 the Bethlem Hospital (founded in 1247) made the decision to vacate its third residence, a centrally located nineteenth century building, for a new, purpose built villa hospital on the city's outskirts. Plans were initially prepared for 300 patients but funding shortfalls resulted in the construction of only 250 beds. ${ }^{61}$ The hospitals own statements regarding their new facilities, along with the media reviews it was given, suggested that Bethlem was the hospital to emulate. ${ }^{62}$ The superintendent's report from 1926 expresses the desire for this hospital to go beyond what was considered the ideal approach to hospital design at the time:

The new Hospital should not be "up-to-date" only, but even "beyond date" and give a definite lead in the development of an ultra-modern type of building for the treatment of the mentally afflicted. ${ }^{63}$ 
Bethlem's new hospital included separate blocks for "administration, occupational therapy, refractory patients, convalescent patients, treatment and research, along with a... chapel [and] reception hospital." A recreation hall, lecture theatre and isolation block for the treatment of infectious diseases were later added to the brief. Owing to budgetary constraints, however, the isolation block and lecture theatre were not completed. ${ }^{64}$ That this hospital hoped to establish a more modern, and scientific, approach to mental health care is evident in the language used in the 1926 report which stated that a "science block" was to be established for "bacteriological, pathological and chemical laboratories," alongside "x-ray and dental departments, [an] operating theatre, anesthetic and sterilizing rooms, electrical treatment room, consulting room[s]... [and] a properly equipped lecture theatre to seat 100 [students]." Hydrotherapy equipment was also to be installed. ${ }^{65}$

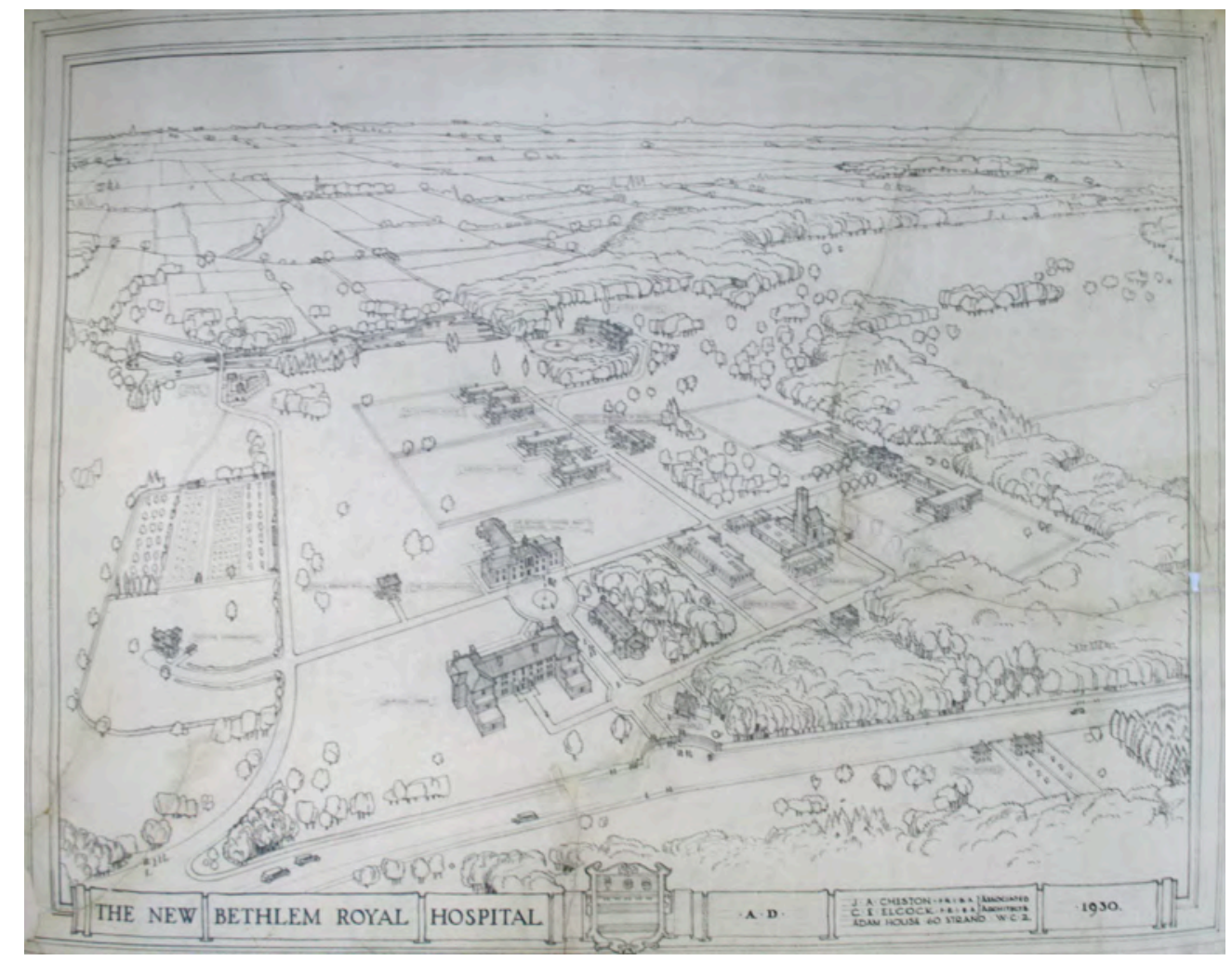

Figure 5.19: Perspective drawing of Bethlem Hospital, 1930. Bethlem Hospital Archive: YCP-57 M1/12.

While media accounts seemed to accept the hospitals own statements without question, a careful examination of the architectural drawings suggest that Bethlem was not the cutting edge villa hospital development it was stated to be. At Kingseat (Papakura) close attention seems to have been paid to the spacing of villas, giving the impression that a patient could wander out from the day room of his own villa and socialise with patents from a neighbouring villa within the green spaces that occurred between these buildings. At Bethlem, only four villas were constructed, each accommodating 62 patients, mostly in single rooms but supplemented by 
dormitories of four to five beds. ${ }^{66}$ Each villa was spaced at a significant distance from its neighbour and had a more institutional appearance than those at Kingseat. The most interesting aspect of Bethlem's design, however, was that the perspective drawing created for this hospital in 1930 showed all villas, except the convalescent villa, surrounded by walls (figure 5.19). The "Architect's Notes," published in an information booklet in 1926, clearly stated that "to the South [sunny] side of each [accommodation] building are shown the gardens, an area of 5 acres being made available for each sex." ${ }^{67}$ Various site plans held by the Bethlem Hospital Archive indicate that some debate occurred regarding how much garden space should be allocated to each villa. The boundaries of these gardens varied between several plans drawn over a fifteen-month period (figure 5.20). The question of whether these gardens were to be demarcated by low garden walls, a traditional English landscape feature that would fail to contain patients, or an actual fence is confirmed by drawing dated March 27, 1928, which notes: "6ft chain link fencing." ${ }^{68}$ Greater freedom was accorded to the Convalescent Unit. The "Architect's Notes" state that 20 acres would be "set aside for gardens and recreation grounds." 69 The fact that this is the only patient villa that has no associated fencing is indicated within various plans.

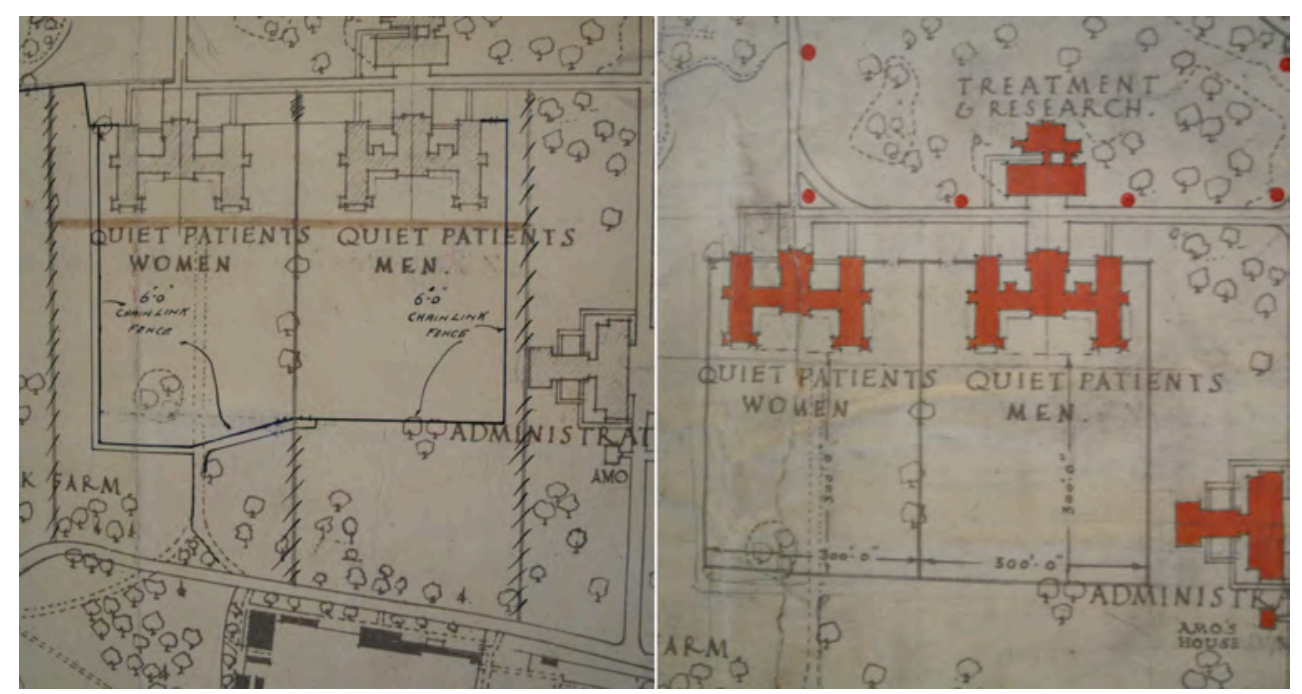

Figure 5.20: Partial site plans, Bethlem Hospital, March 27, 1928 (left) and August 15,1929 (right). The plan on the left contains the notation " 6 '-0" chain link fence." Bethlem Hospital Archive: YCP-46 C08/5. Note: the archival holding description states "Site plans and maps... including ward boundary revision maps."

While Bethlem's commitment to open door practices did not seem to match Kingseat's there are other areas in which this British hospital presented an advance. The generous provision of single rooms and the smaller ward sizes were one example of this. The most significant advance that Bethlem provided over Kingseat was the provision of research and teaching facilities. The Builder remarked that these would make "the study of psychological medicine available to a large body of students." ${ }^{70}$ While an Admission and Treatment Building was envisioned within the original master plan for Kingseat it was not constructed until 1939 and so could have taken inspiration from the new facilities at Bethlem. While planning this unit in 
1936, Gray's report to the AJHR confirmed that "ample provision" was to be made for "all the most modern forms of treatment, including massage, continuous baths, light, electricity and X-rays, and ... also includes a laboratory, dispensary and operating theatre.."11 No mention was made, however, of a lecture theatre for Kingseat Hospital. It was 1945, before Gray recognised the value of "lecture and demonstration" facilities and included these in the brief he compiled for the Lake Alice Hospital. ${ }^{72}$ It was not until 1959, however, during the construction of the Cherry Farm Hospital, was any mention made of integrating research facilities within the grounds of New Zealand's mental hospitals. ${ }^{73}$ The construction of a new, modern mental hospital in the greater Auckland area provided the opportunity for greater collaboration with the Auckland University School of Medicine. However, as the Bethlem Hospital discovered with the move from central London (Southwark) to their new site in Kent, the isolation inherent in the villa hospital model made accessibility for students difficult and teaching ceased to be delivered at the hospital itself. ${ }^{74}$ Traditionally students from the University of Otago Medical School visited the Seacliff Asylum as part of their training. However this was irregular and by no means provided the close collaboration that was desired by Bethlem and achieved more successfully by the Maudsley and Johns Hopkins Hospitals. In choosing the Papakura site for the development of Kingseat, King and Gray ruled out any possibility of pursuing a hospital type with aspirations closer to that of the psychopathic hospital.

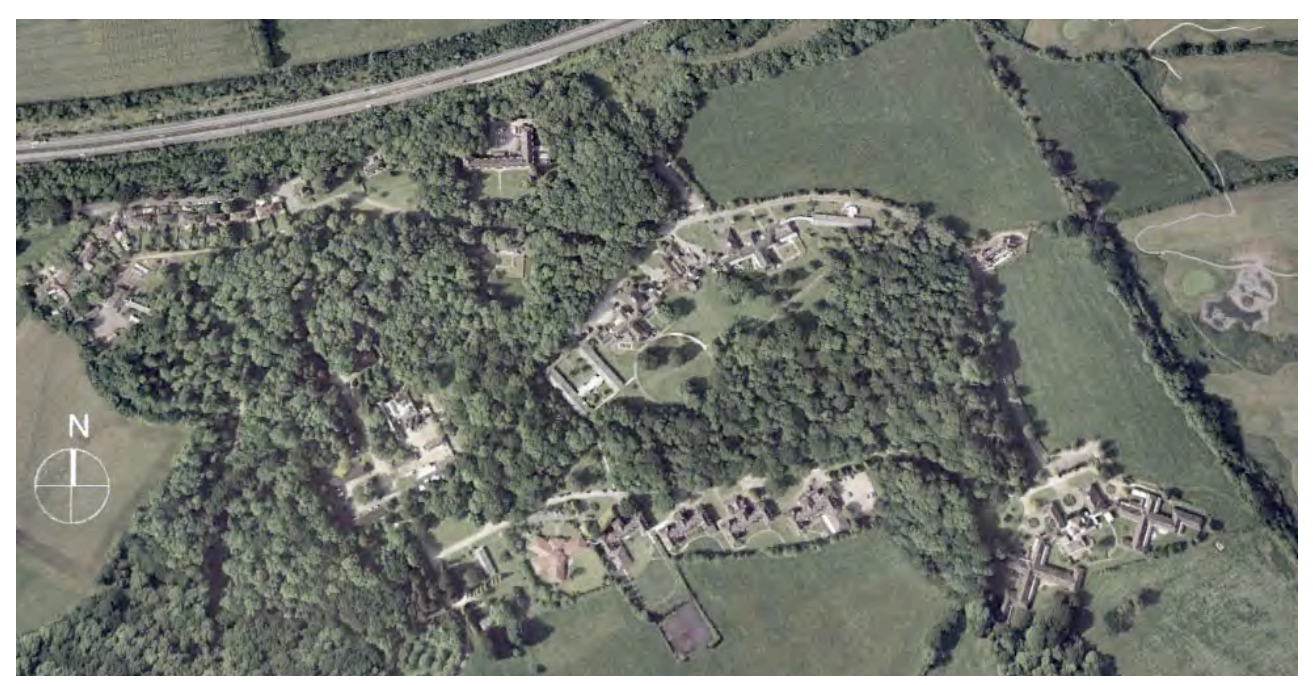

Figure 5.21: Aerial photograph of Barrow Mental Hospital, Somerset. Google Earth image: July 06, 2005.

Two other villa hospitals constructed in Britain around the same period evidence an approach to villa hospital construction that resided much closer to that of Kingseat. The Shenley Park Mental Hospital (Middlesex County) and the Barrow Mental Hospital (Somerset) were both constructed in the early 1930s (figure 5.21). Photographs of Barrow along with written accounts of Shenley Park suggest that both hospitals exhibited a 
commitment to the premise of an open door hospital with its provision of relative freedom for patients. Both hospitals constructed small villas clustered within the landscape. The Barrow Mental Hospital was intended to house 1,200 patients over 25 villas, an average of 48 patients per villa (figure 5.22). The Shenley Park Hospital was constructed between 1932 and 1939 for 1,000 patients. ${ }^{75}$

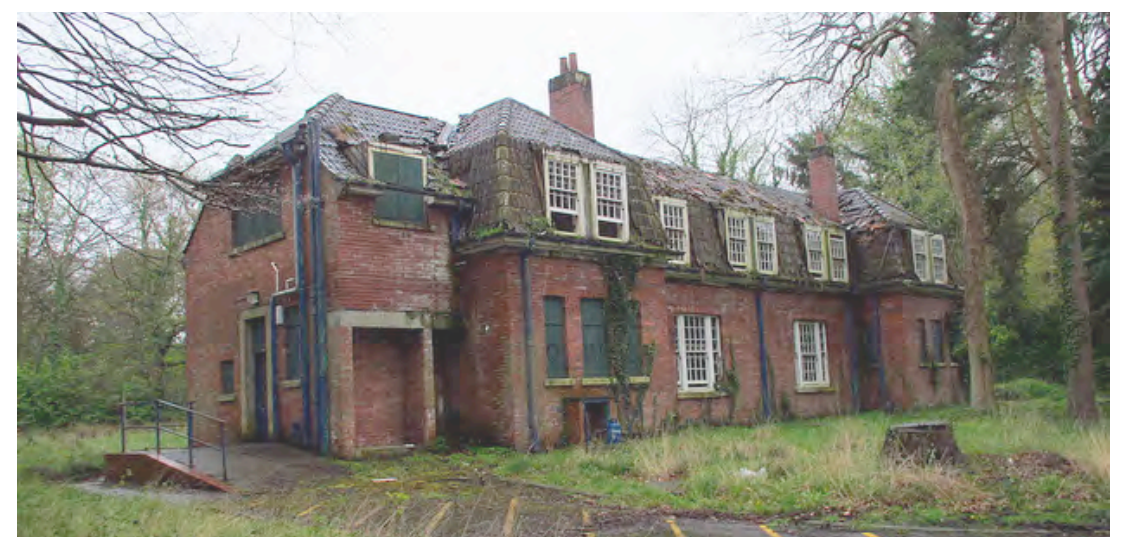

Figure 5.22: A villa at Barrow Mental Hospital, May 07, 2012. Image source: http://www.flickr.com/photos/ricksphotos101

By 1959, Shenley Park had been extended to accommodate 2,000 patients, approximately half of whom were resident in open villas. ${ }^{76}$ Unlike at Kingseat, the architectural responses at Shenley Park varied between patient types. The most prevalent cottage design was a two-storied brick cottage for 33 patients and was comprised of two day-rooms, nine single rooms and four dormitories of six beds. ${ }^{77}$ Reception villas accommodated a similar number of patients but in dormitories of eight or 12 beds. While the villas constructed for difficult patients accommodated 53 patients, in dormitories of varying sizes, the largest of which held 36 beds (figure 5.23). ${ }^{78}$

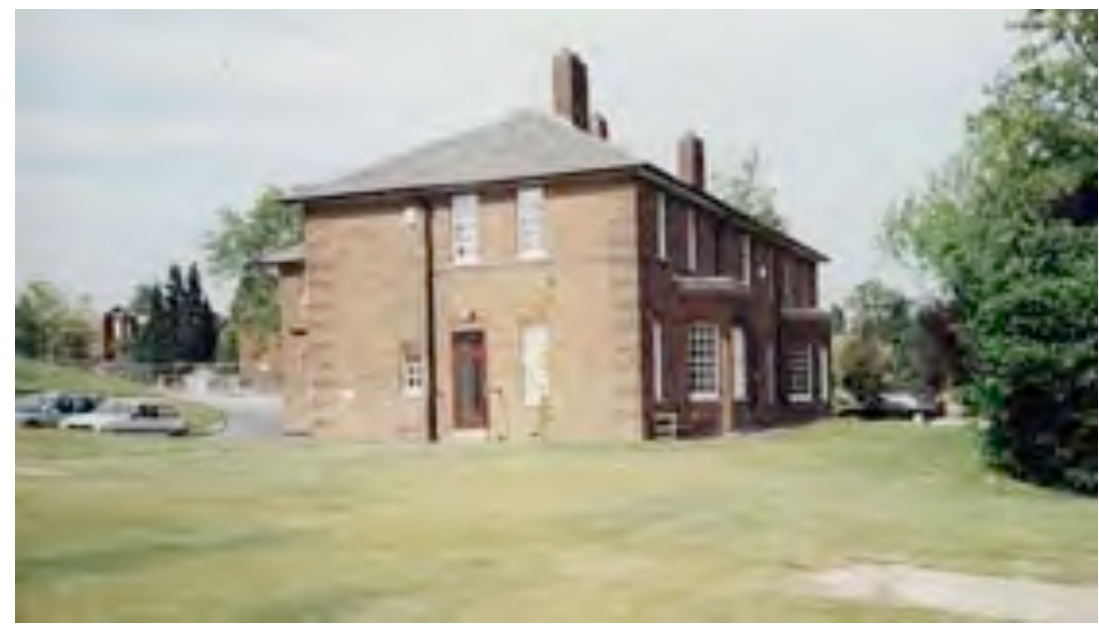

Figure 5.23: A villa at Shenley Park Mental Hospital.

Image source: http://www.shenleypark.co.uk/historyofshenleypark 
The fact that Gray selected the Aberdeen hospital, a precedent that was almost two decades old for the design of the Papakura hospital, does raise the question of the currency of this selection. The fact that British decision makers also opted to follow this model in the 1930's, however, confirms its ongoing relevance. Kingseat was clearly compliant with current ideals of best architectural practice in the field of mental hospital design. Its commitment to maintaining open door practices should not be understated. This practice was not universally accepted in 1930 as the approach taken to Bethlem illustrated. Bethlem was the most celebrated and expensive hospital constructed within Britain during the same era as Kingseat. ${ }^{79} \mathrm{~A}$ comparison between these two hospitals highlights what an achievement Kingseat Hospital was given that far fewer financial resources were at the disposal of the Mental Hospitals Department. What remains a disappointing oversight, however, was the lack of consideration toward research and teaching. While not overtly stated, it can be inferred from Brunton's research that Gray's faith in the villa system blinkered him to the necessity of research. The following section will look more specifically at the influence Gray's outlook had on the development of both Kingseat Hospital and the wider development of the villa hospital model in New Zealand. 


\subsection{KINGSEAT AS A PUBLIC RELATIONS EXERCISE AND THE INFLUENCE OF THEODORE GRAY}

As the Seacliff case study illustrated, in projects where the client is not the end user, there is a danger that peripheral agendas, including professional ones, can influence the design outcome in counterproductive ways. Brunton has suggested that the quality achieved at Kingseat came at a direct cost to other hospitals because Gray instructed head office staff that any spare funds were to be directed towards the construction of Kingseat. ${ }^{80}$ The proportion of mental hospital patients relative to the overall population peaked in $1944 .^{81}$ That year New Zealand's total mental hospital population numbered 7,097, of which 780 resided at Kingseat. ${ }^{82}$ This calls into question Gray's prioritisation of expenditure on a hospital that accommodated only eleven per cent of New Zealand's total mental hospital population. Furthermore, had villas of the more affordable Seaview design been constructed at Kingseat, accommodation for an additional 150 patients would have been achieved for the same financial outlay. This section will examine the desire for public and professional legitimization in the design of Kingseat Hospital, as well as Gray's personal outlook.

Thompson has suggested that, prior to 1923, public prejudice was closely tied to the physical presence of mental hospitals:

psychiatrists believed that the future of their specialty was dependent on public acceptance of the mental hospital as a place of treatment and cure rather than a place of incarceration. ${ }^{83}$

A comment made by Gray, in his report to the AJHR for 1937, suggests that this belief persisted far beyond 1923 :

The experience of each successive year adds to my conviction that in the villa system we have the means... of obviating all the objectionable features which loom so large in the public mind." ${ }^{\text {"4 }}$

King gave some background to this issue in his report to the AJHR for 1925. He wrote that the public attitude toward institutional psychiatrists resembled the type of distrust a child might show toward his dentist. Public requests for half-way houses often included the stipulation that these would be "free from any association... with the present mental hospitals... run by medical and lay staffs not connected with them in any way [emphasis added]." Attitudes from within the medical profession were no better. With regard to the outpatient clinics King had initiated, he wrote:

It has been suggested professionally that it would be wiser not to have a mental hospital doctor attending the weekly clinic, and that it would be better for the patients to be seen and advised only by members of the staff of the general hospitals - on account of the dread people have of facing an "asylum doctor." ${ }^{86}$ 
Dread notwithstanding, the idea that doctors trained in general medicine could adequately perform the same job as psychiatrists, despite their years of specialist experience, expressed a clear lack of professional regard. A comment made in Gray's autobiography puts the relationship between psychiatrists and the remaining medical profession in context. He recounts that the decision to take up psychiatry was regarded by one's peers as "evidence of eccentricity... the recently qualified man who joined the staff of a mental hospital was regarded as having committed professional harikari." ${ }^{87}$

Kingseat, with its graceful buildings and rich landscape, not only provided a pleasant curative environment but it aimed to combat the prejudice with which the public regarded these institutions. Its reception building was not hidden, not approached by a separate driveway in order to negate its connection to the wider hospital; it was placed right at the heart of this complex. The access ways, the landscape, the surrounding villas all acknowledged the central position of this building. Similarly, the 50-bed villas were not hidden from the road but turned to face it. Aesthetically Kingseat sent a clear message that the mentally ill were not to be locked away and forgotten; they were to be cured, where possible, and otherwise given a life that resembled normality in a modern, villa hospital. In an article written for the New Zealand Herald in 1937, a desire to establish links between contemporary architecture and modern treatment is confirmed. The very title of the article links these themes: "Kingseat Hospital. Atmosphere of Freedom. New Methods of Treatment. Extensions to Buildings [emphasis added]." The article stated that "locks, bars and bolts are unknown... and patients are granted a maximum of liberty... liv[ing] under almost normal conditions." Special mention was made of the Hospital Block, then under construction. It was to be "the centre of clinical work" and include "an operating theatre, a dispensary and a massage department." ${ }^{\text {" }}$

It was not simply general issues of professional marginalisation that influenced Gray, however, he had the unenviable task of following in the shadow of Truby King. History, thus far, has regarded him harshly because of it. In his doctoral thesis, Brunton claimed that Gray was "innately conservative," had an "institutionalized attitude" and "lacked King's intellectual brilliance." ${ }^{~}{ }^{9}$ While Prebble claims wartime restrictions such as clothing, bed linen and food, which impacted the comfort and dignity of patients, were "accentuated by Gray's conservative approach to spending and reform." 90 The circumstances under which Gray's resignation was tendered in 1946 further contributes to the idea of Gray as a poor second to King. Brunton suggests that this was tendered in light of public criticism and industrial unrest regarding "deteriorating living conditions in mental hospitals." 91 
King took an innovative approach to mental illness. He advised adolescents against undue academic pressure, experimented with nutrition and made recommendations for the appropriate care of infants as a means of securing good mental health in adulthood. This work led to his formation of the Plunket Society in $1907 .^{92}$ King was acting head of the Mental Hospitals Department for only three years but during this time he initiated outpatient clinics for "nervous afflictions." He made changes to the transit care of new patients so that they were not held overnight in prisons (a practice he argued caused "indignity, distress and humiliation"), he also encouraged hospitals to ensure the point of arrival for patients was made "as attractive as possible." ${ }^{\text {93 }}$ All this was in addition to building four neuropathic hospitals, purchasing the site for Kingseat and overseeing the early development of new villa hospitals at Christchurch (Templeton) and Nelson. While King was attuned to the benefits of classification and a carefully considered environment, he appreciated these as part of a much larger treatment milieu. Gray, by contrast, believed that "in spite... of all that can be done outside a mental hospital, admission offers the best hope of recovery." ${ }^{94}$

According to Brunton, Gray improved the accessibility of New Zealand's mental hospitals, through the provision of voluntary admission, but was unwilling to explore alternatives to institutional care. Gray was initially suspicious of new treatments such as electroconvulsive therapy, psychotherapy and advances in psychopharmacology ${ }^{95}$ Gray's faith in the mental hospital environment was steadfast; he believed that a modern hospital such as Kingseat should require less resort to sedation than any other institution in the country. ${ }^{96}$ As Director-General of the Mental Hospitals Department, Gray took over the development of new villa hospitals at Nelson, Papakura and Christchurch, that had been initiated by King. In addition, he spearheaded the redevelopment of Porirua Hospital in 1942, after its nineteenth century building was damaged by an earthquake, and oversaw the purchase of land for new hospitals near Marton (Lake Alice) and Dunedin (the Cherry Farm hospital, eventually constructed as a replacement for Seacliff). Gray also appealed, although unsuccessfully, for a new hospital for mentally deficient children near Auckland. Had the finances been available to match Gray's vision, this would have amounted to the most significant building programme undertaken in the history of New Zealand's Mental Hospitals Department.

While very few archival records relating to the design of Kingseat seem to have survived, records relating to the design of the Lake Alice Hospital (1937 - 1945) attest that Gray paid significant attention to all aspects of hospital design. In the case of Lake Alice he provided the Government Architect with the plan of a domestic dwelling that he wanted developed for patient accommodation. This plan was accompanied by specific instructions as to cost, which rooms could be eliminated from the design and how many showers and baths were to be installed. ${ }^{97}$ Throughout the design process, Gray consulted regularly with the superintendent of the Auckland Mental 
Hospital (under whose charge Kingseat was to be placed) and with the Public Works Department. He passed comment on aesthetics, siting, window proportions, internal planning, lighting and equipment specification. He even requested that the Lake Alice villas be "pegged out" so that he could "get a better idea of [the] spacing" between them. ${ }^{98}$

The scale of Gray's ambition, coupled with the written record he has left, suggests he may have seen these villa hospitals as an opportunity to leave a physical legacy of his personal contribution to mental health care in this country. Gray arrived in New Zealand in October of 1911 to take up an Assistant Medical Officer's position at Porirua Hospital. Plans for the development of Tokanui Hospital, along villa lines, were already then underway following A.H. Crosby's visit to the Aberdeen Hospital in 1910.99 Yet, staff members at Kingseat were led to believe that the villa hospital was "new to New Zealand."100 Gray himself announced that Kingseat was the first mental hospital "to be built on the villa system and to have been conducted on the villa plan from its foundation." 101 There is likely some truth in this last statement relative to Tokanui Hospital, however, it entirely disregards the development of Ngawhatu Hospital, five years prior to Kingseat. Other documents suggest a more overt attempt to rewrite history. In 1937 and, again, in 1941 Gray claimed that New Zealand had three villa hospitals, Ngawhatu, Seaview and Kingseat "all constructed within the last ten years." 102 These claims inferred that it was 1927 before any villa hospitals were constructed in New Zealand. The construction of villa hospitals would thus have coincided with Gray's appointment as DirectorGeneral of New Zealand's Mental Hospitals Department. While a press release from Gray's department to local newspapers in 1937 went so far as to state that: "In New Zealand the villa system was inaugurated by Dr Gray 14 years ago, and was further developed at Kingseat, South Auckland."103 Nevertheless, as Brunton has already pointed out, the Seaview Hospital (Hokitika) had been extended via small, freestanding villas since 1877. While Tokanui, which Gray acknowledged within his report of 1929, had been constructed "mainly in accord with modern ideas," received no mention in his correspondence of 1937 or $1941 .^{104}$ While both of these hospitals were modest examples, low-cost and slow to evolve, they nonetheless confirm that New Zealand was committed to constructing villa hospitals prior to Gray's arrival. 
These attempts to reframe history through media releases are consistent with comments made by Gray within his autobiography. He wrote that upon arrival to New Zealand he found that:

My enthusiasm for the villa system failed entirely to evoke any response, suggestions as to parole for patients were regarded as fantastic, whilst proposals to abolish airing courts were held to be flights from reality which almost qualified me to be one of my own patients. There seemed to be no desire for change, no realisation that improvements were possible, and indeed, were taking shape on the other side of the world [emphasis added]. ${ }^{105}$

While it is fair to assert that Skae and MacGregor overlooked the relevance of villa accommodation for all but chronic patients (as outlined in the previous chapter), the same criticism cannot be made of Frank Hay or Truby King. Hay's enthusiasm for reception houses ensured separate villas for this purpose were in common use before Gray assumed directorship of this department. While the development of Tokanui Hospital, as suggested by Brunton, was largely a consequence of King's recognition of the benefits of villa accommodation and his subsequent experiments at Seacliff. These experiments began in 1897, four years before the foundation stone for the Aberdeen hospital was laid and nine years before Gray graduated from medical school. All the evidence points to a strong desire on Gray's part to leave a personal legacy. In relation to Brunton's observation, that additional funds were directed to Kingseat at the expense of other hospitals, it certainly casts suspicion over the sincerity of Gray's efforts to replace New Zealand's nineteenth century asylums with villa hospitals.

The structure of the Mental Hospitals Department insulated Gray from challenges to his own decision making as, unlike with General Hospitals, Boards of Public Management were not in place for psychiatric institutions. Brunton states that Gray began his administration by appointing old colleagues to key positions. ${ }^{106}$ There were no hurdles to the easy translation of Gray's enthusiasm for constructing villa hospitals into official policy. According to Brunton, under Gray's leadership, capital expenditure was almost always along villa lines. ${ }^{107}$ This raises the question at what cost was this policy followed? The most obvious casualty was Gray's outright dismissal of the psychopathic hospital model. Within the report Gray submitted to the Prime Minister in 1929, advising on the future shape of New Zealand's mental hospitals, he listed several hospitals under the subheading "Half-way Houses," including the Maudsley Hospital, the Chicago Psychopathic Hospital, the Boston Psychopathic Hospital and the Henry Phipps Psychiatric Clinic (Johns Hopkins University Hospital). While he clarified that the Boston Hospital and the Henry Phipps Clinic were not half-way houses of the type asked for by the New Zealand public, this categorization suggests he did not recognise the full potential of this new hospital model. Gray labelled the Boston Hospital a "clearing station" where 
only the interesting cases were kept and treated. While patients whose illness were curable but commonplace were discharged to the care of traditional mental hospitals. He intimated a similar sentiment regarding the Phipps Clinic, noting that it was devoted to "the intensive study of a relatively few cases." In general, Gray felt that psychopathic hospitals "subordinate[d patient care] to the teaching of students and to research."108 By contrast, Dr. Alexander Falconer, Superintendent of Ashburn Hall (New Zealand's only private mental hospital, near Dunedin) drew a very different conclusion regarding these institutions during his own study tour of 1929. Falconer was most impressed with the Henry Phipps Clinic. While the Maudsley Hospital so inspired him that he established a "psychiatric institute" in connection with the University of Otago. According to Judith Medlicott, "Ashburn Hall became integrally involved with the advancement of psychiatric research" at the university. ${ }^{109}$ Falconer also recommended the establishment of a school of social service associated with Otago University, believing that this presented one of the "most serious obstacle[s]" to the rehabilitation of mentally ill patients. ${ }^{110}$ Gray argued that the high running costs of a hospital such as the Phipps Clinic was "well beyond" New Zealand's resources. ${ }^{111}$ While he had a point, Falconer, nonetheless, found a way to make improvements to the system through collaboration with the University of Otago. Ultimately Gray failed to recognise the true potential of a hospital model that aspired to advance the scientific understanding of mental illness, through research collaborations with general hospitals and universities.

Issues of professional marginalization, however, likely also played a role in obstructing the adoption of the psychopathic hospital model and the greater collaboration with general hospitals and medical schools that this model entailed. This psychopathic hospital model presented a serious threat to traditional mental hospitals. As observed by Gray, there was a tendency for a high percentage of resources to be concentrated in these city-based units while their rural counterparts missed out. ${ }^{112}$ Traditional mental hospitals were then at risk of becoming catchments for incurable cases where little actual medicine was able to be practiced by institutional psychiatrists because there were no curable patient's resident to treat. The resulting consequence for institutional psychiatrists was further marginalisation within a profession that already failed to appreciate their contribution to the medical field. While this concern was seldom acknowledged within medical literature, it was present and began to be discussed more openly in the late 1940s and throughout the 1950s. Dr J.J. O'Reilly commented, for example, in the Journal of Mental Science in 1948 that:

Unless there is the freest possible interchange of staff between the clinic and the neighbouring mental hospital ... there is a great danger that the mental hospitals will be isolated from the main stream of psychiatry, and become overloaded with long-term and chronic patients. ${ }^{113}$ 
According to Brunton, Gray was weary of collaboration with general hospitals and opposed the establishment of a university chair based upon the "high falutin' theories" it might subject the Department to. ${ }^{114}$ Brunton's observations support the possibility that fears of exacerbating professional marginalisation contributed to Gray's resistance to the psychopathic hospital model.

While Gray's faith in the curative effects of architecture has, to date, been dismissed as conservative and retrograde, historians have yet to address whether Gray advanced mental hospital care through his dedication to the villa hospital. Notwithstanding his efforts to usurp credit from his predecessors, the quality of both landscape and accommodation provided for patients at Kingseat was exemplary. Ngawhatu had been constructed to the same exacting standards. However it is the Lake Alice Hospital (planned between 1937 and $1943^{115}$ ) where Gray's contribution to improving mental hospital care can best be appreciated. Gray conceived of Lake Alice as an advance on traditional villa hospitals since the majority of patient accommodation would be provided by 11-bed villas. These were designed to give "more privacy" to a very specific patient group: "the long-stay, middle-aged chronic who did not get visitors... [and was] capable of working and caring for himself..."116

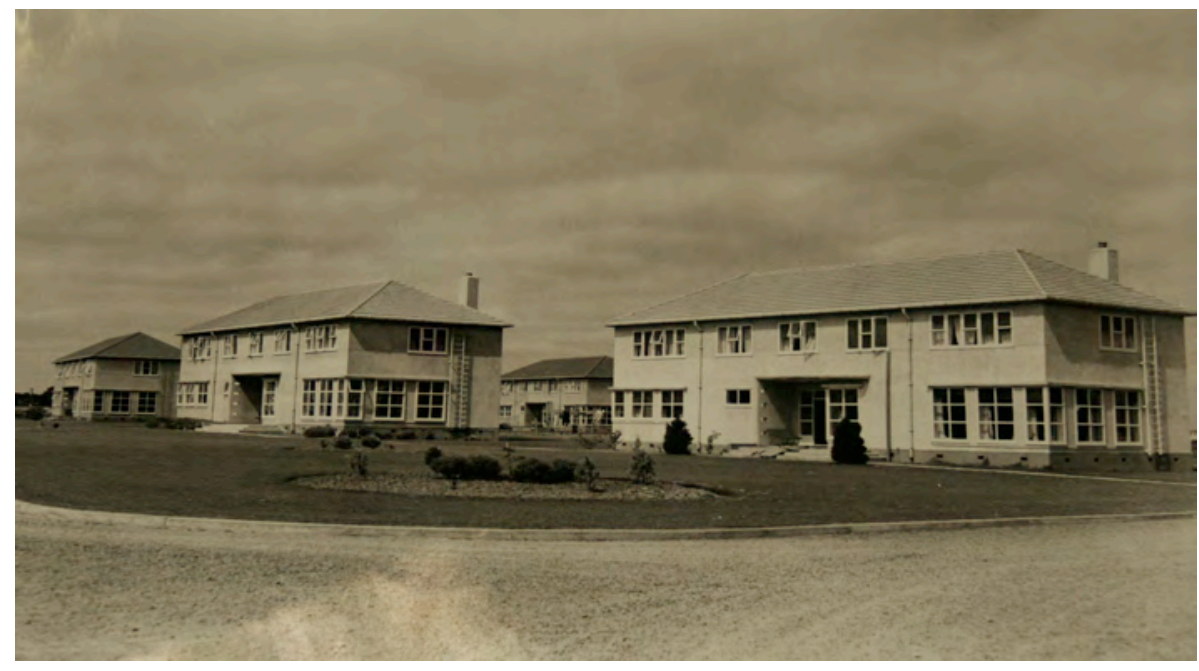

Figure 5.24: Lake Alice 11-bed villas, Lake Alice Hospital, ca. 1948. Archives New Zealand: C399174 H10 1227296

Just under half of Lake Alice's intended 1,000 patients were to be housed in these intimately scaled villas, clustered together amid trees and gardens, and loosely arranged into pedestrian streets (figures 5.24). Each villa contained a kitchen and dining room, living room, writing room, bathroom and laundry. Patients slept in either single rooms or groups of four. Villas for male and female patients would face each other across a communal recreation field (figure 5.25). This villa design illustrates that Gray had a real understanding of the drawbacks of hospital life for chronic patients. The 11- 
bed villas evidence a sincere desire to advance the villa system typology, to more closely approximate normal life. In 1940, Gray wrote to the Minister of Health regarding his proposed plan for Lake Alice that, although the villa system was a great advance, he felt that:

in a new institution... we should not be bound even to the villa system as we know it... I believe that aggregations of fifty [patients] even have tended to produce a feeling of being herded together and I think that if diminution in size of the units to about that of a family could be achieved within the limits of reasonable economic possibility, we should try to devise such a scheme [emphasis added]. ${ }^{117}$

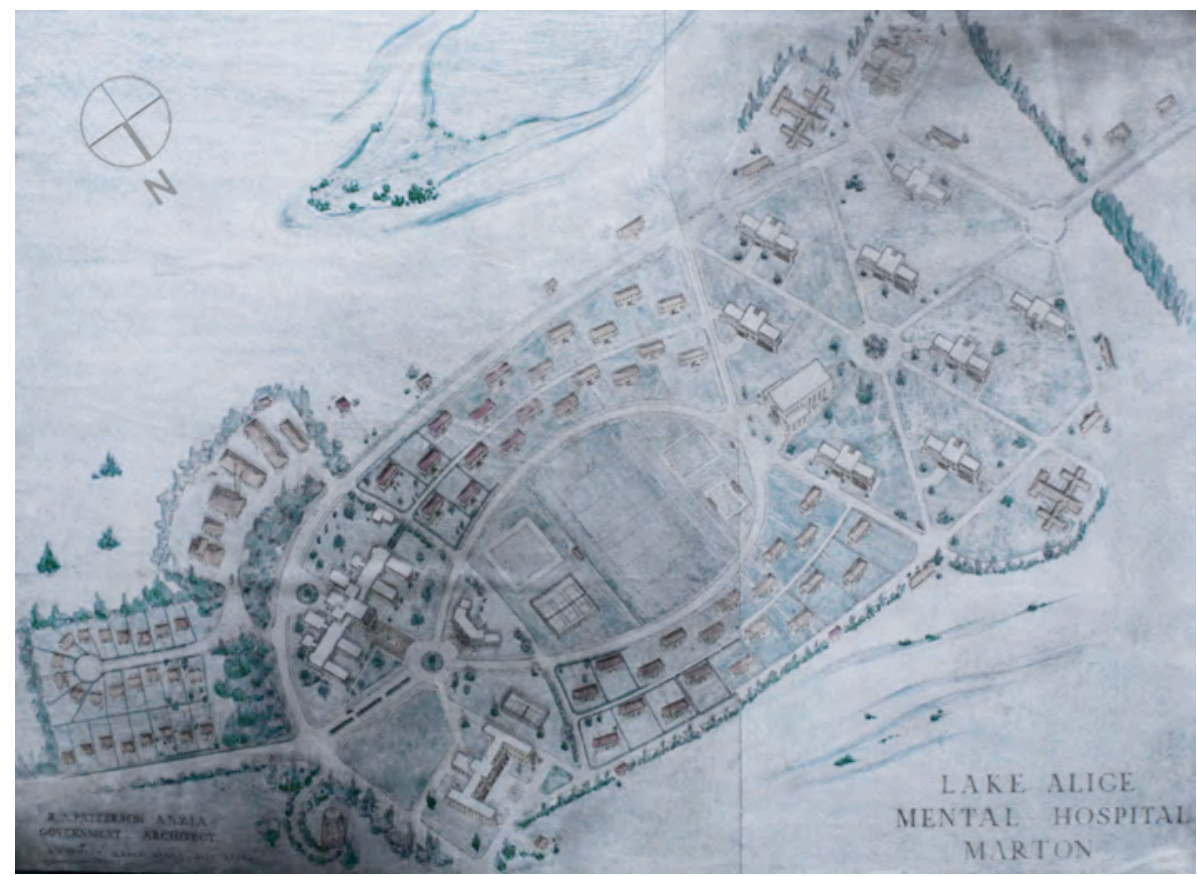

Figure 5.25: Lake Alice Hospital, aerial perspective of grounds, ca 1943. The 11-bed villas are the small buildings that occur through the centre of the drawing. Archives New Zealand: AADU 576 1-12

Gray not only acknowledged, as others had before him, that the mental hospital environment dehumanized patients because it "herded [them] together," he actively sought a solution for mitigating this. The 11-bed villas present the most progressive architectural solution created for mental hospital patients within the history of New Zealand's Mental Hospitals Department. Despite the criticisms historians have made of Theodore Gray, within the realm of mental hospital planning he was a clear innovator. There was no international precedent for the 11-bed villas. When Gray first proposed this new approach to hospital construction in 1940, he told the Minister in Charge of Mental Hospitals that it was "a new one so far as mental institutions are concerned." He had devised the scheme based on what he had seen at Gheel in Belgium (discussed in the previous chapter) and at Lier, near Oslo, which had a similar system to Gheel, and in Scotland 
with the boarding out system. Gray had "no doubt that the system I propose would be a great advance on what we have now." 118

With the design of Kingseat, New Zealand was provided with a hospital that aimed to follow the best international precedents in villa hospital construction of its time. With Lake Alice, however, the country was promised a truly innovative architectural response to the care of the mentally ill. Construction delays and funding shortages meant that this hospital was never finished. This may explain why Gray neglected to mention this innovative response in his own autobiography. The Lake Alice 11-bed villas, designed with the express objective of safeguarding the self-esteem of patients, were so far ahead of their time that they exceeded a set of curative criteria written sixteen years after they were first designed. The fittingness of this design to the treatment aspirations of the 1953 World Health Organisation report will be expanded upon within the following chapter.

The design of Kingseat Hospital cannot be divorced from the context of public criticism within which it was constructed. This hospital was motivated by a number of peripheral concerns: personal and professional legitimization and the desire to improve the public standing of New Zealand's Mental Hospitals. In contrast to what occurred at Seacliff Asylum, however, these peripheral concerns did not lead to significant compromises in the curative quality of Kingseat Hospital (the limitations on sunshine aside). There is little doubt that Gray was driven to create an architectural legacy, however, he managed to channel this ambition into a better architectural response for New Zealand's mental hospital patients. Kingseat Hospital remains one of the best examples of the translation of ideal curative strategies into built form within New Zealand's network of mental hospitals. While Lake Alice Hospital was a truly innovative response. Gray may have resisted therapeutic advances in his general approach to mental health care but his development of the villa hospital typology evidences a sincere desire to improve the lives of chronic mental patients. 


\subsection{DELAYS, FUNDING SHORTAGES AND COMMUNICATION ISSUES: OBSTACLES IN THE CONSTRUCTION OF KINGSEAT}

The Mental Hospitals Department could not operate in isolation, it was reliant on funding from central government and on architectural services from the Public Works Department. The first step in procuring new mental hospital accommodation was for this department to undertake their own investigative work and then seek approval, in principle, from the Minister in Charge of Mental Hospitals. Following this the Public Works Department would be engaged to provide plans and estimates for the work in question. Once the Minister had concurred on the proposed expenditure, tenders could be called. Finally, cabinet approval for the expenditure had to be obtained before construction could proceed. ${ }^{119}$ Despite the quality and reach of Gray's vision for the construction of Kingseat Hospital and the wider development of New Zealand's network of mental hospitals, funding issues and construction delays limited what Gray was ultimately able to achieve. It is important that we acknowledge the external factors that limited Gray's contribution to New Zealand's mental hospitals.

Over the period 1931 to 1935, seventeen new villas were erected at mental hospitals around New Zealand, including the eight constructed at Kingseat. This provided new accommodation for 850 patients. ${ }^{120}$ It wasn't enough. In 1936 Gray reported on the present condition of New Zealand's mental hospitals. He stated that severe overcrowding had extended over many years and no "long-range programme" had ever evolved to fix it. Three brand new hospitals were required in addition to a separate institution for "difficult and dangerous cases" and "several" new villas at existing hospitals. ${ }^{121}$ The Mental Hospitals Department required a serious funding commitment from the New Zealand Government. They would not get it. In 1945 Gray appraised the accommodation situation as "extremely serious...dangerous and unhealthy." ${ }^{122}$ Earthquake damage at Porirua (1942) had resulted in the evacuation of half of the hospital's 1200 patients. Within four years, while the 600 evacuated patients awaited their chance to return, 500 new admissions had arrived to replace them. Over the same period, only three of the intended fifteen replacement villas had been constructed. 150 new beds were provided at Porirua when 1050 were required. The following year, Gray threatened that if the pace of construction did not pick up Porirua would have to turn patients away. Conditions were little better elsewhere. At Nelson, 250 children were accommodated in the original asylum, an unsuitable timber building that presented a serious fire risk. ${ }^{123}$ Only a few years prior a fire in the women's ward at Seacliff, a building of similar construction and vintage, had caused the deaths of 39 patients. Meanwhile the main asylum building at Seacliff was becoming increasingly unsafe owing to ground instability that, although discovered in 1880, had been allowed to destabilize this structure over many years. To call this situation serious, dangerous and unhealthy was no overstatement on Gray's part. 
In 1931 New Zealand was still suffering from the effects of the Great Depression and government spending had been restricted in response. In 1935 , however, the country found itself within a period of prosperity and economic growth that would continue until 1966. ${ }^{124}$ Construction resources became stretched nation-wide. The correspondence between the Public Works Department, the Minister for Mental Hospitals and the Mental Hospitals Department itself provides valuable insight into the challenges involved with building new hospitals. Between 1937 and 1949 the Public Works Department (which became the Ministry of Works in 1945) issued various memorandums that carried a similar message. Owing to heavy demand for labour and materials, all departments must order their works programmes by urgency, only the most necessary works could be completed. ${ }^{125}$ In 1945 it was decided that public works would be ordered on the basis of "national importance." Between 1947 and 1949 government policy favoured "housing and hydro-electric development" and all other work was deferrable at the discretion of the Building Controller. ${ }^{126}$ Gray's response to one of these memorandums read simply: "a great deal of ink is being spilt, but the spilling of ink does not house patients." 127

Between 1936 and 1946 Gray reiterated concerns that the Public Works Department could not meet the needs of the Mental Hospitals Department. Funding appropriations were awarded on an annual basis and were required to be spent within the year specified. According to Russell, who worked in head office from 1928-1950 (succeeding Gray as department head in 1947), in "no single year" between 1928 and 1950 was the full allocation of funds awarded to the Mental Hospitals Department able to be spent. ${ }^{128}$ In 1945, Gray observed that the process of drawing plans and tendering work took months with the result that the building programme never managed to "keep pace with the steady influx of patients." ${ }^{129} \mathrm{He}$ even requested his department be given "an architect of its own - one who will specialise in mental hospital design... and push through projects." ${ }^{130}$ It was wishful thinking. In 1949 Russell asked the Minister of Health to "implore" the Minister of Works to give a higher priority to mental hospital work: "if we are to make any reasonable progress, we must have... some impetus given to the Works Department, which will enable the work to be done." ${ }^{131} \mathrm{He}$ explained that while no difficulty was experienced in obtaining monetary authorizations for new works this was nonetheless delayed by "the apparent reluctance of contractors to tender for our work." This problem was exacerbated, Russell said, by the works department submitting insufficient estimates for work so that prices obtained in tender "are so much in excess of estimates, that they cannot be accepted." ${ }^{132}$ 
Communication issues seemed to plague the relationship between the Mental Hospitals Department and the Public Works Department. Gray's request that the Mental Hospitals Department to be appointed their own architect may have been a direct response to a comment made to him by the superintendents of Auckland and Kingseat hospitals a year earlier:

It is hoped that you will be able to have a competent Architect "au fait" with Mental Hospital conditions to check over points in the specification and supervise the building whilst erected. This will avoid so many of the vexations that usually arise when buildings are taken over. $^{133}$

In 1946 Gray wrote to the Public Works Department to express his frustration at being unable to access information regarding various projects underway at New Zealand's Mental Hospitals. He felt that the works department had failed to keep him abreast of progress, or even to respond to the successive requests for information he had made. ${ }^{134}$ In 1948, Russell claimed that "great difficulty" was still being "experienced in obtaining replies to correspondence."135 Russell believed that "[in]sufficient continuity of consultation" over a number of years had prevented the department's works programme from being "handled to the best advantage." In 1947 Russell appointed a Developments Officer to head office to act as a full time liaison position between head office, mental hospital superintendents and the Public Works Department. ${ }^{136}$ Russell resigned from this department in 1950. According to Brunton this was in protest of the recent amalgamation of the Mental Hospitals Department with the Department of Health. ${ }^{137}$ In a departing memorandum, he wrote to the Minister of Health that:

This Division is one, which unfortunately, has no political bias nor voting strength.... and when curtailment of expenditure is necessary, it has been the policy of all Governments' over the period I know to restrict expenditure on this Division [emphasis added]. ${ }^{138}$

Russell reiterated Gray's sentiments, in 1950, that to delay necessary works at various hospitals any longer would result in "major calamity and scandal." ${ }^{139}$ However, little heed was paid to these progressively desperate pleas for adequate funding to improve the living conditions of these patients.

While Gray's prioritisation of expenditure on Kingseat over other hospitals suggests he may have performed a disservice to those patients resident elsewhere, there is an alternative argument. Gray envisioned that Kingseat would be the first of many new, modern mental hospitals that were required for a nation-wide overhaul of an outdated network of facilities. Gray's refusal to compromise on quality had two advantages. Even temporary buildings were known to remain in use for decades within New Zealand's network of mental hospitals. Accepting a less expensive villa would, therefore, have saddled this department with a sub-standard facility for years afterward. In the second instance, a modern hospital built to the highest affordable standard should have been an asset in lobbying parliament for the funds 
necessary to continue the building programme envisaged by Gray. If the funds required to carry out Gray's ideas had been made available, New Zealand's mental hospital accommodation would have set an example for the world to follow.

Meeting the necessary and basic accommodation requirements of $\mathrm{New}$ Zealand's mental hospitals were a low priority for government spending. The procurement of these facilities was equally challenging. The apathy displayed by the government towards New Zealand's mental hospitals appears to have given license to the Public Works Department, as their agents, to regard the Mental Hospitals Department similarly. A lack of professional respect can be seen within the written correspondence between these two departments, while their inability to ensure the works programme for the Mental Hospitals Department was carried out in full for the years spanning 1929 to 1950 suggests a lack of commitment to meeting the needs of this department. In response, Gray worked in a focused and specific way to improve hospital environments despite the tight financial and political constraints his department was bound by. Despite the quality of Gray's vision, however, he could not overcome the challenges to the procurement of new accommodation and the marginality of these institutions. 


\subsection{SPENDING PRIORITIES AND THE QUESTION OF QUEEN MARY HOSPITAL}

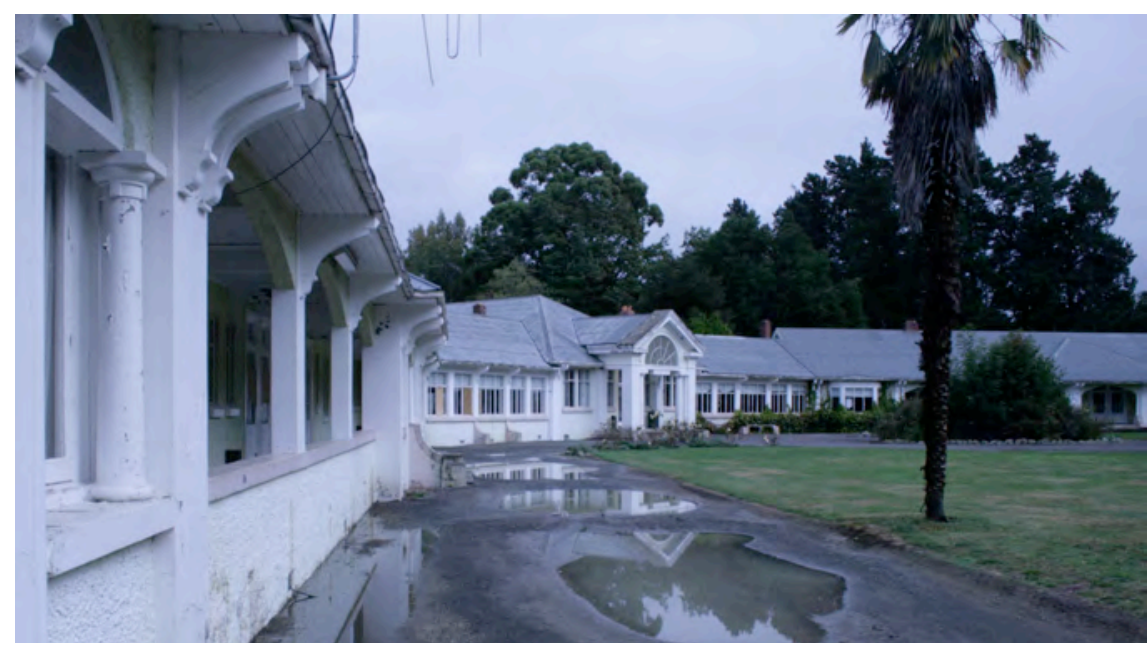

Figure 5.26: The Women's Ward, Queen Mary Hospital. March 28, 2010. Photograph by author.

Leonard Smith has observed that choices related to architecture, whether they are related to style or expense, can reveal truths too controversial to have been openly acknowledged within their own time. ${ }^{140}$ This section will examine two variant approaches to hospital construction in New Zealand in order to better understand the government's approach to mental hospitals. The first is the architectural approach taken at Queen Mary, a neuropathic hospital constructed in Hanmer Springs, in 1926. The second is the administrative approach taken to planning the construction of accommodation for returned soldiers in 1943. The differences in these approaches offer valuable insights regarding the Government's commitment to the provision of appropriate facilities for New Zealand's mental hospital patients.

The 55-bed ward constructed for female patients at the Queen Mary Hospital provides an exceptional example of what can be achieved, architecturally, with regard to supporting the delivery of individual treatment and tranquillity (figure 5.26). This building was on the drawing board of the Public Works Department just two years earlier than Kingseat Hospital and was likely to have been developed about the same time as the villas for Ngawhatu. The Women's Ward (renamed the Chisholm Ward in 1943) was designed for the treatment of female patients suffering from "functional nervous diseases," this included anxiety disorders, puerperal psychoses (now known as postpartum depression), addictions, depression, hypertension and arthritis. ${ }^{141}$ Queen Mary was a facility for the treatment of acute, recoverable, mental disorders but the architectural approach taken to this hospital was starkly different to that taken at Kingseat. 


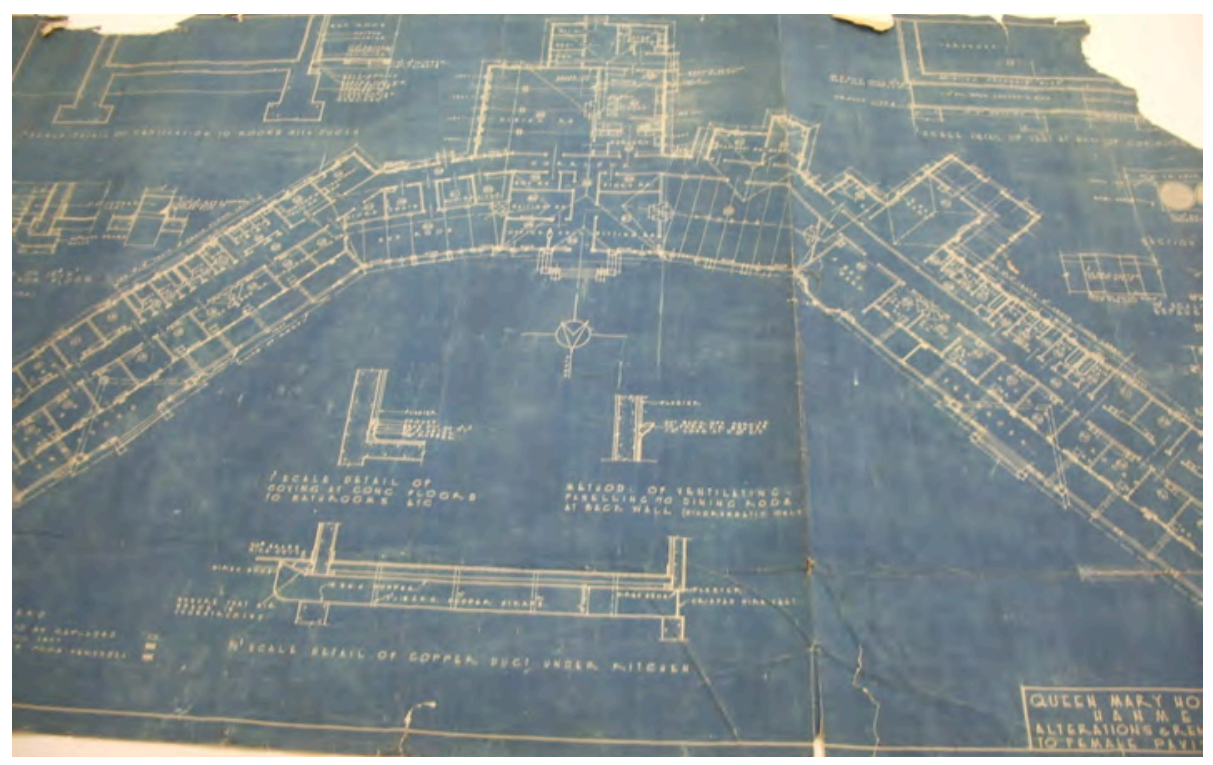

Figure 5.27: Plan of Chisholm Ward, Queen Mary Hospital.

Plan is dated 1950 and shows "alterations and renovations"; drawing notation suggests that no spatial alterations were made to the existing accommodation and common day spaces.

Archives New Zealand: CAWU 556 41AE MC 16.

In plan, this villa was configured in a v-shape (figure 5.27). Kitchen, dining and three separate day rooms were located in the centre, while single rooms extended along the wings either side of these common areas. Two wards were provided, one accommodating six beds and the other four. The building was orientated toward the north for maximum sunshine. Almost two-thirds of the single rooms faced this direction and opened onto a deep veranda via a glazed door (figure 5.28). Each single room contained a wardrobe and dresser with mirror and basin. Six baths were provided, all in their own separate rooms.
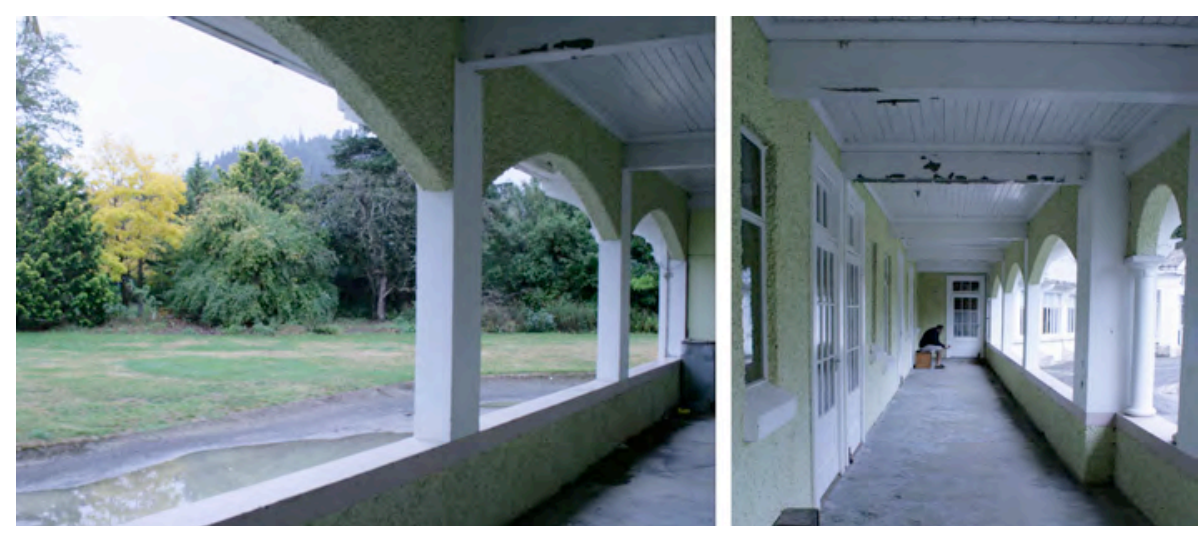

Figure 5.28: Images of the Chisholm Ward veranda and its views, March 28, 2010. Photograph by author. 


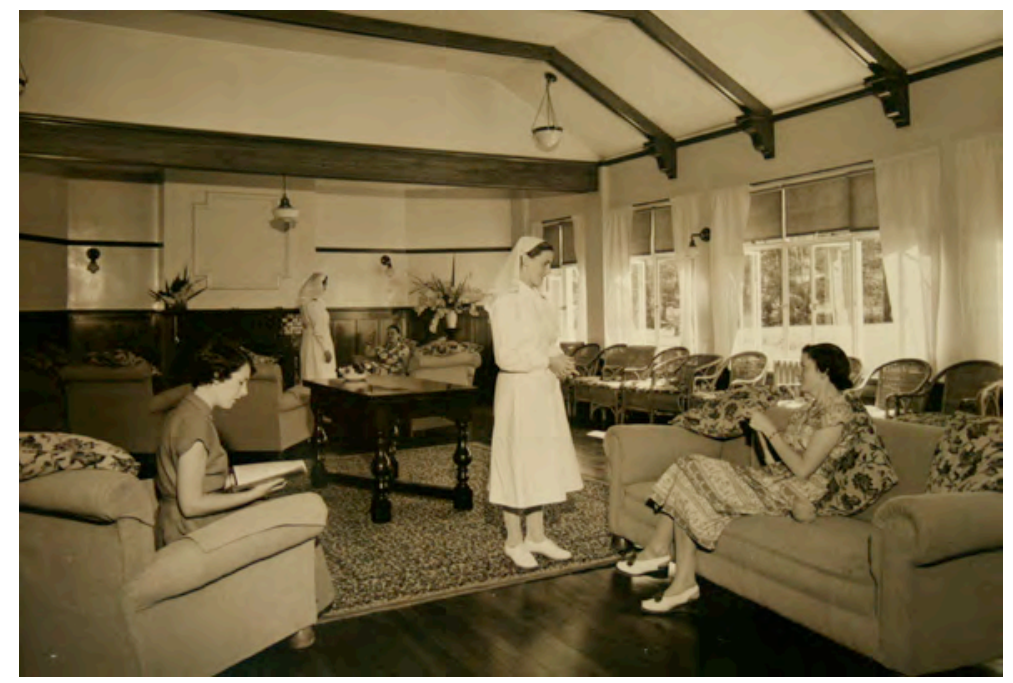

Figure 5.29: The Women's Lounge Room at Queen Mary Hospital, c. 1950. Archives New Zealand: C399074 H10 1199214.

According to Dr. Crawford, superintendent from 1976 to 1991, the design of the women's ward "went to some lengths to retain a domestic, homely feel." ${ }^{142}$ Exposed beams, doors, joinery and wall panelling were constructed of oak and furniture was custom made to match (figure 5.29). While the number of dayrooms within the women's ward was unusual, the desire to replicate the lounge room of a carefully attended home was not. Within the reception wards of New Zealand's mental hospitals (and some newer wards), day rooms were not dissimilar to those at Queen Mary, although more sparsely furnished (figure 5.30). What was significantly different, however, was the quality to which the single rooms were appointed (figure 5.31). These had more in common with a private hotel than a mental hospital. The single rooms at Wellington's Waterloo Hotel, for example, constructed a decade later in 1937, offered built in wardrobes, hand basins and mirrors. The accommodation offered for nurses within mental hospital grounds were not even as generous as the patient accommodation at Queen Mary. Built-in wardrobes and mirrors were provided for nurses but no hand basins.

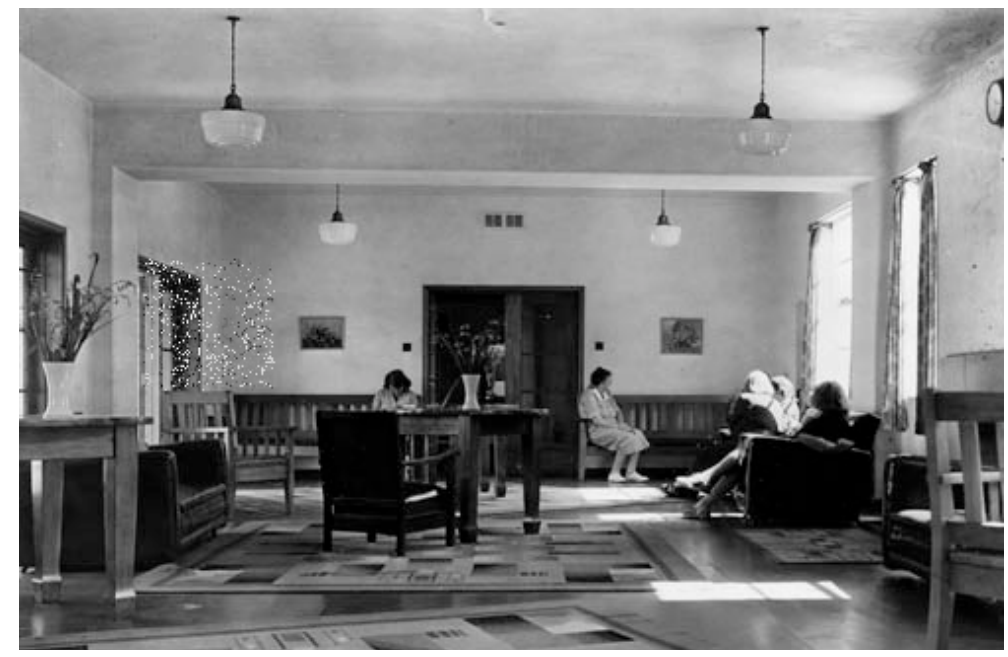

Figure 5.30: A Day Room at Porirua Hospital, c. 1950. Alexander Turnbull Library: PAColl-7327 (cropped). 


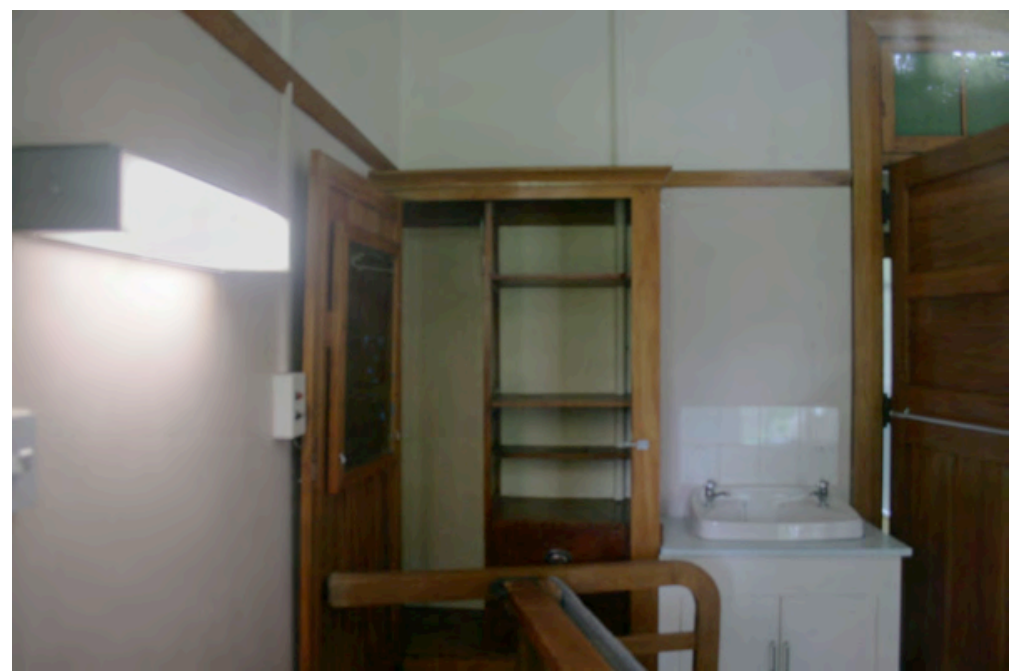

Figure 5.31: Interior of a single room in the Chisholm Ward, March 28, 2010. Photograph by author.

The Queen Mary Hospital in Hanmer began life as a Government Sanatorium, in 1897, owing to the presence of natural hot pools. It became a retreat for returned soldiers following World War I but was returned to the Department of Public Heath in 1922. While it treated civilian and war neuroses, otherwise termed "functional nervous diseases," the Queen Mary Hospital was never under the control of the Mental Hospitals Department. Patients could not be "committed" to Queen Mary, admissions were voluntary only. The public viewed this as an entirely different institution, so much so that the waiting list for admission was often three-months long. ${ }^{143}$

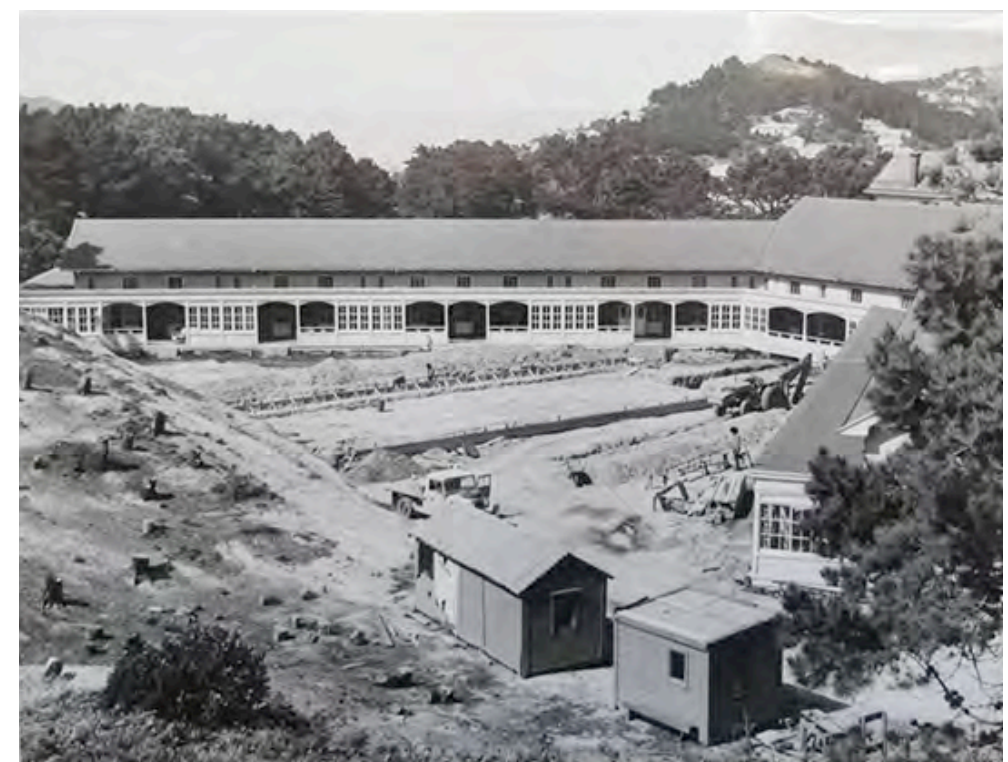

Figure 5.32: Wellington Fever Hospital (showing central wing under construction), 1972. Wellington City Council Archives.

Sunlight, fresh air and landscape views were key principles in the design of the women's ward; architectural principles that were favoured in general hospital design in order to prevent the airborne spread of infection. ${ }^{144}$ The Wellington Fever Hospital, with its v-shaped plan and deep verandas, 
designed by Crichton and McKay in 1917, is the obvious comparison to make with Queen Mary (figure 5.32). The Maudsley and Bethlem Hospitals took similar approaches in the buildings they constructed around the same time. In 1931 the Maudsley opened a ward whose written description suggests similarities with the Women's Ward at Queen Mary; it was comprised of "a row of bedrooms, with verandas facing the sun." ${ }^{145}$ While the single rooms at the new Bethlem Hospital (1930) were deliberately appointed to a hotel standard and opened onto spacious verandas (figure 5.33). ${ }^{146}$

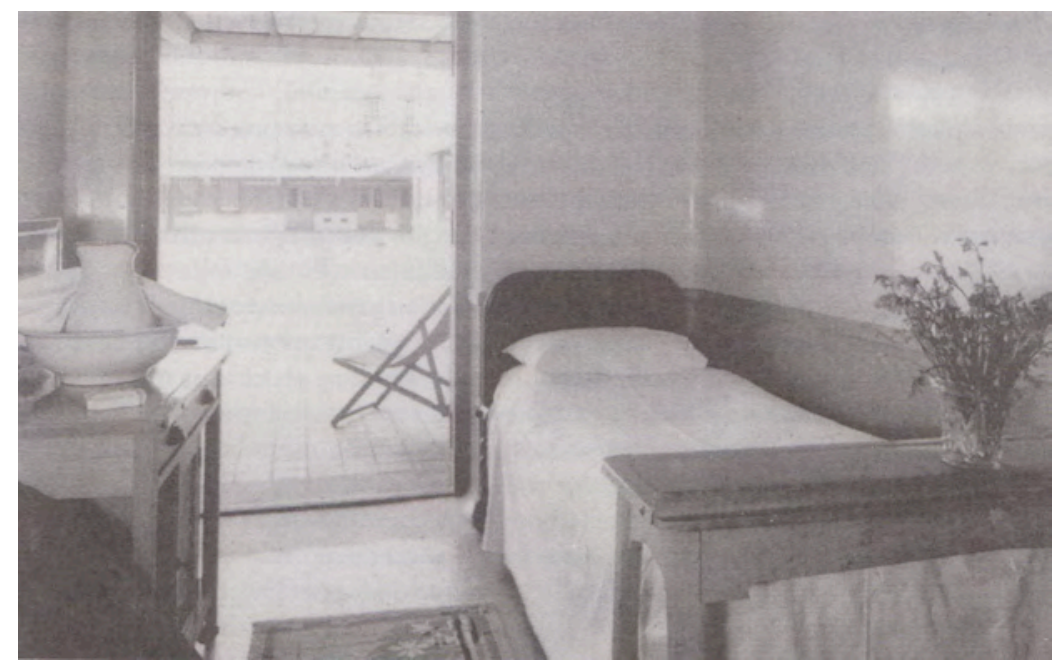

Figure 5.33: Interior of a single room at Bethlem Hospital. Bethlem Royal Hospital Archive.

In comparison to the architectural response created for Sunnyside and Seaview Hospitals and, to a lesser extent, Kingseat itself, the women's ward at Queen Mary was an enlightened approach to the accommodation of mentally ill patients. The cost and quality of the buildings constructed at Queen Mary, the 1926 women's ward followed by a new ward for men in 1940 , suggest that the public were not the only ones to view this institution as a class above regular mental hospitals. The construction cost of the Women's Ward was $£ 24,000^{147}$ to Kingseat's $£ 12,500,{ }^{148}$ this was close to double the cost for the same number of patients. Economies of space, materials and staffing go some way to explain why the design approach taken at Queen Mary was not replicated for New Zealand's other mental hospitals. The Kingseat villa type was able to house the same number of patients in a more compact plan that required less land, less money and would have made staff supervision easier. Nonetheless, the fact that the wards designed for Queen Mary so closely mimicked the quality and architectural approach of general hospital design, while those created for the Mental Hospitals Department did not, reflects that a better class of patient was anticipated here. At Queen Mary, as at the Bethlem and Maudsley Hospitals, only voluntary admissions were accepted. The implication here is that those patients who required committal to a mental 
hospital, as opposed to admitting themselves, must, in turn, have required an appropriately severe architectural response.

Even the architectural drawings suggested that these patient groups were regarded differently. Common spaces on the floor plan of the Women's Ward at Queen Mary were designated "lounge," "sunroom" and "sitting room." While various plans created for the Mental Hospitals Department labelled similar spaces as "day room[s]," even where two day rooms were provided within the same villa, as was the case with Kingseat. As Thomas Markus has pointed out, the language employed in labelling spaces indicates social intention. ${ }^{149}$ While the terms lounge, sunroom and sitting room echo the rational, ordered domesticity of polite society, the term "dayroom" suggests little more than a space to inhabit because it is day. The Random House Dictionary defines the term as follows:

1. A room at an institution, as on a military base, providing facilities for leisure activities.

2. (in a hospital) a recreation room for ambulatory patients. ${ }^{150}$

The Queen Mary Hospital was an "institution," a "hospital," yet the architects elected to borrow spatial labels from the home. To return to Smith's assertion, that architecture reveals truths too controversial to be acknowledged, ${ }^{151}$ this comparison suggests that mental hospital patients were to be treated differently than their physically ill or voluntarily admitted counterparts.

A second occurrence that supports the observation that mentally ill patients were a low priority for government spending was the decisions made in relation to wartime construction. In May of 1943 a committee was assembled to prepare a "comprehensive scheme of hospital building" to meet the demands of the Army, Air Force and United States Services. Representatives from the Tourist Department and the Health Department were in attendance, as was Gray. The committee decided that 1,250 new bed spaces would need to be created for returned service men and eventually turned over for civilian use. These beds would be provided through the construction of convalescent homes and new hospitals in addition to the extension of selected general hospitals. The new facilities would be charged to the War Expenses Account with a small proportion of funding contributed by the United States Services. This would bypass the usual funding procedures and allow for more rapid construction. ${ }^{152}$ At this meeting, in 1943, Gray advised the committee that a third mental hospital would soon be required for the Auckland region. The Auckland Mental Hospital was full and Kingseat was approaching maximum capacity. The United States Services had already stated their need for a hospital within the Auckland region, for short term use, and were willing to fund it. It was decided by the committee that a new hospital unit would be constructed near Auckland but there was no mention of this being earmarked for future use by the Mental Hospitals Department. Conversely, the minutes recorded, 
that this new unit would be constructed "despite the fact that there is no immediate use for a building of this nature."153 That New Zealand's mental hospitals were seriously short of beds in 1943 did not seem to factor into this consideration. ${ }^{154}$ The only concern exhibited toward the overcrowded state these patients were then subject to was peripheral. Patients who were accommodated at the Chateau Tongariro and the Hostel at Wairakei would need to be relocated; these facilities were wanted for returned services use. The Committee expressed their desire for the new accommodation already proposed for Porirua and Lake Alice (to replace accommodation lost in the 1942 earthquake) to be sped up. ${ }^{155}$

In time the Mental Hospitals Department was able to make do with the remnants of wartime construction. A Convalescent Home, constructed at Ravensthorp, and an Air Force Base, constructed at Weraroa (near Levin), were both eventually turned over for mental hospital use. Though neither facility was especially well suited to the needs of mentally ill patients. The Tourism Department fared much better. They were promised the future use of two Convalescent Homes, in Rotorua and Marlborough. Each would provide accommodation for 300 and be fitted out with swimming baths, tennis courts and croquet lawns. The minutes do not record whether there was to be any exchange of payment in handing these facilities over to the Tourist Department. ${ }^{156}$ Nonetheless, meeting the needs of the Mental Hospitals Department did not feature highly on the government's agenda.

The variances in architectural approach between the Queen Mary Hospital and Kingseat, and the decisions made regarding wartime construction reveal underlying prejudices toward mental hospital patients. Funds were more readily contributed to the care of those suffering from physical illness and those whose mental illnesses were considered curable. While it is unlikely government officials would have openly agreed with Russell's 1950 statement, that mental hospital patients had "no voting strength," 157 the decisions made regarding the accommodation of returned service men lends support to this observation. The money spent on Queen Mary and the gifting of new facilities to the Tourism Department, while the Mental Hospitals Department were forced to fight for adequate funding and limp along with insufficient accommodation, indicates a hierarchy of government expenditure that did not prioritise the care of the mentally ill. 


\section{CONCLUSION}

The architectural approach taken to Kingseat Hospital was in line with leading approaches to mental health care in the 1930s. While this response was heavily influenced by public perception, this did not lead to compromises in the curative potential of this hospital environment. The design of Kingseat responded in an exemplary way to contemporary thought regarding the treatment of mental illness through a solution that supported the treatment of patients as individuals, the provision of tranquillity and the maintenance of open door practices.

At Kingseat, Gray managed to mitigate the compromises that usually arose from inadequate government funding and the low prioritisation of the Mental Hospitals Department's public works programme. Patients at Kingseat had to wait 30 years, however, before the full complement of facilities that were envisioned for this hospital were finally completed. In response to insufficient funding, recreation halls and facilities for occupational therapy became dispensable features at a time when both were considered necessary for securing recoveries and mitigating the effects of institutionalisation by keeping the minds of patients active. Despite these deficiencies, the quality of the architecture and landscape, the focus on outdoor occupation and the freedom this architectural response aspired to provide, ensured Kingseat's position as an exemplary mental hospital of its time. Gray could not, however, mitigate the effects of insufficient funding elsewhere. New Zealand's wider mental hospital network suffered considerably from a failure to respond adequately to the needs of this department on the part of the New Zealand Government and their Public Works Department. Both the spatial quality and the attention directed to the proportioning of the facades of the Kingseat villas suggest that the architects involved were committed to producing a building of high architectural quality. However, the failure of the works department to complete the full works programme for these hospitals for the years spanning 1929 to 1950 , and the tone of the correspondence between these two departments, suggests that the Mental Hospitals Department were a low priority in relation to the division's other public projects. The funding directed to the Queen Mary Hospital, and to constructing facilities for Returned Service Men suggests that there was an underlying prejudice towards mental hospital patients and a reluctance to spend money on those who were not considered curable.

In light of these obstacles, the quality of the hospitals constructed under Gray's directorship was a remarkable achievement. Gray worked in a focused and specific way to improve hospital environments despite the tight financial and political constraints his department was bound by. With the Lake Alice villas Gray made a conscious effort to mitigate the dehumanizing effects of mental hospital care. The accommodation of patients in groups of eleven, in villas that closely resembled domestic dwellings advanced this hospital typology and offered tangible benefits, such as privacy and 
tranquillity, for the patients they housed. Gray's ability for innovation, however, occurred only within his existing frame of reference; his experience as a junior doctor at Aberdeen did, as Brunton hypothesized, have a profound effect on Gray's approach to mental health care. The absolute faith that Gray placed in the villa hospital also presented limitations. To an extent, this blinded him to new therapeutic developments and alternative hospital models, specifically, the psychopathic hospital. Gray's resistance to this model, and to the greater collaboration with general hospitals and medical schools that it encouraged, was partially motivated from a fear of exacerbating the existing professional marginalisation of institutional psychiatrists.

Regarding official attitudes to mental illness in New Zealand between 1930 and 1945, the approach taken to Kingseat Hospital indicates that meeting the needs of these patients was not a priority for the government or the Public Works Department. The isolation in which the New Zealand Government allowed this department to operate during this period confirms the apathy with which New Zealand's mental hospital patients were regarded. However, viewing Gray's contribution to mental health care in New Zealand through the lens of architecture allows an appreciation of his personal commitment toward improving the lives of those who suffered from mental illness.

${ }^{1}$ Director-General, MHD, to the Minister in Charge of Mental Hospitals, January 17, 1936. ANZ: R16195938.

${ }^{2}$ Thompson 1981, 4.

${ }^{3}$ Thompson 1992, 69.

${ }^{4}$ Warwick Brunton, personal correspondence, November 19, 2010. Also refer: Brunton 2001, 256.

${ }^{5}$ This is most evident within Gray, 1958, 64, 88-92., however various additional documents support this as is set out under Section 4.7

${ }^{6}$ AJHR 1927 H-07, 3. AJHR 1925, H-07, 8. AJHR 1926, H-07, 5. Gray, 1929, 28.

${ }^{7}$ Brunton 2001, 181-3, 347-8. Prebble 2007, 100-1.

${ }^{8}$ Brunton, "Gray, Theodore Grant - Biography."

9 "Editorial [on mental hospitals]," 1923. "Mental Hospitals Report," 1923.

10 Thompson 1992, 69.

11 "Mental Maladies," 1923.

12 Inspector-General, MHD, to the Minister in Charge of Mental Hospitals, October 9, 1918. ANZ: R16195770.

13 "Halfway!... Need for a Great Reform," 1923.

14 "Mental Maladies," 1923.

15 "Mental Patients," 1923. 
${ }^{16}$ Refer letters held within the ANZ file: R16195638.

17 Refer: "Editorial [on Mental Hospitals]," 1923. "Halfway! ... Need for a Great Reform," 1923. Levigne, "Mental Hospitals. Weaknesses and Necessary Reforms," 1923. "Mental Cases. Hospital Villa System ... Minister Explains," 1930. "Mental Hospitals Report," 1923. "Mental Maladies," 1923. "Mental Patients," 1923. "Ministers Statement Criticised," 1923.

${ }^{18}$ Levigne, "Mental Hospitals. Weaknesses and Necessary Reforms," 1923.

19 'Borderland Cases...C.J. Parr,' 1923.

${ }^{20}$ Williams 1987, 87, 233. Brunton 1997, 53.

${ }^{21}$ For example see: "Mental Maladies," 1923.

22 "Mental Patients," 1923.

${ }^{23}$ Lomax 1921, 13.

24 "Ministers Statement Criticised," 1923.

${ }^{25}$ Inspector General, MHD, to the Minister in Charge of Mental Hospitals, April 19, 1923. ANZ: R16195638.

${ }^{26}$ AJHR 1927, H-07, 5. Draft Public Works Statement for 1920. ANZ: R16195794.

${ }^{27}$ AJHR 1925, H-07, 3, 7. Note that King lists "receiving cottages" and "units for the more sensitive and recoverable cases" as separate new building types to be erected.

${ }^{28}$ AJHR 1927, H-07, 5.

29 "Ministers Statement Criticised," 1923.

${ }^{30}$ Gray 1929, 15, 20-5, 37.

${ }^{31}$ Gray 1929, 15, 20-5, 37.

32 Gray 1929, 20-1.

${ }^{33}$ Draft notes for a newspaper article for the Auckland Star, October 28, 1935. While no author details are given the handwriting on the document resembles that of Theodore Gray. ANZ reference: R16195637

${ }^{34}$ Director-General, MHD, to the Minister in Charge of Mental Hospitals, January 17, 1936. ANZ: R16195938.

${ }^{35}$ Thompson 1992, 120. "Dutch Mental Hospitals," 1929, 936.

${ }^{36}$ Director-General, MHD, to the Medical Superintendent, Brisbane Mental Hospital, November 25, 1941. ANZ: R20960887.

${ }^{37}$ Director-General, MHD, to the Minister in Charge of Mental Hospitals, September 7, 1935. ANZ: R16195938.

${ }^{38}$ Bowman 2010, 13.

${ }^{39}$ Director-General, MHD, to the Assistant Secretary to the Treasury and Chairman, Building Coordination Committee, September 20, 1937. ANZ: R16195938.

40 Director-General, MHD, to the Commissioner of Works, March 8, 1950. ANZ: R16195940.

${ }^{41}$ Brunton 2001, see caption under Ngawhatu villa photograph, unnumbered and unpaginated but follows page 250 .

${ }^{42}$ Webby 1991, 35-9.

${ }^{43}$ Mercier 1894, 135.

${ }^{44}$ Mercier 1894, 23, 34. 
${ }^{45}$ Conolly $1847,10-5,24-5$.

${ }^{46}$ Mercier 1894, 133.

${ }^{47}$ Lake Alice aerial perspective of grounds, ca 1943. ANZ: AADU 576 1-12.

${ }^{48}$ Peter Shaw suggests that under the leadership of Gordon Wilson, following 1936, the government's Department of Housing Construction (later the Housing Division, Ministry of Works) recognised the importance of orientating living spaces toward the sun. This was influenced by modernist design approaches from Europe. Shaw 1997, 141. Cedric Firth's 1949 publication State Housing in New Zealand talked at length about the importance of correct sun orientation and shading in the design of state houses. Firth 1949, 31, 71-2.

${ }^{49}$ Medical Superintendent, Kingseat Hospital, to the Director-General, MHD, August 8, 1947. ANZ: R20960887.

${ }^{50}$ Thompson 1981, 7-8.

${ }^{51}$ Gray 1958, 130.

52 Director-General, MHD, to the Secretary, Public Service Commissar, August 11, 1936. ANZ: R16195531.

53 "New Drugs Beating Psychiatric Troubles," 1957.

${ }^{54}$ Gray 1958, 127-8.

55 Basic report: Kingseat mental hospital - additions. March 19, 1946. ANZ: R16195940.

${ }^{56}$ Director, DMH, to the Commissioner of Works, March 8, 1950. ANZ: R16195940.

${ }^{57}$ Phear, Farley, Burnett and Clough 2010, 16.

${ }^{58} \mathrm{DMH}$, Circular Memorandum 152, February 11, 1955. Director, DMH, to the Medical Superintendent, Kingseat Hospital, June 08, 1959. Kingseat Hospital Progress Report[s] on Ministry of Works Authorities: Quarter Ended December 31, 1956 and Quarter Ended June 30, 1956. Division of Mental Hygiene Circular Memorandum 1954/ 152, February 11, 1955. All documents held in ANZ file: R18553317.

${ }^{59}$ Standard American approaches to mental hospital design during this era were also investigated (specifically the Camarillo State Hospital in California and the Manteno State Hospital in Illinois) however these were not as progressive as the British examples and owing to thesis size limitations these have been omitted.

${ }^{60}$ Architect and Building News, 2 (1930), 71, as cited in Andrews et al. 1997, 553.

${ }^{61}$ Andrews et al. 1997, 549-50, 553.

62 "Bethlem Royal Hospital... Removal," 1930. The Builder 1930 (October 03), 563.

${ }^{63}$ Superintendent's report 1926, 2. Bethlem Hospital Archive: BMO-10 B10/1.

${ }^{64}$ Andrews et al. 1997, 550, 553.

${ }^{65}$ Superintendent's report 1926, 8. Bethlem Hospital Archive: BMO-10 B10/1.

${ }^{66}$ Andrews et al. 1997, 551, 558.

${ }^{67}$ Architect's report, 1926. Bethlem Hospital Archive: BMO-11 B10/1.

${ }^{68}$ Various site plans dated 1928 -1929. Bethlem Hospital Archive: YCP-46 C08/5.

${ }^{69}$ Architect's report, 1926. Bethlem Hospital Archive: BMO-11 B10/1.

${ }^{70}$ Builder 1930 (October 03), 563, as cited in Andrews et al. 1997, 559.

${ }^{71}$ AJHR 1937, H-7, 2. 
${ }^{72}$ Medical Superintendents, Auckland Mental Hospital and Kingseat Mental Hospital, to the Director-General, MHD, February 2, 1945. ANZ: R22502230.

${ }^{73}$ Medical Superintendent, Cherry Farm Hospital, to the Director, DMH, May 18, 1959. ANZ: R18458498.

${ }^{74}$ Andrews et al. $1997,571-3$.

${ }^{75}$ Wikipedia contributors 2013, "Barrow Hospital." Shenley Park Trust 2012, "History of Shenley Park."

${ }^{76}$ Guttersen 1959, 112.

${ }^{77}$ Ibid, 112.

${ }^{78}$ Ibid, 112-3.

79 Bethlem cost $£ 1,700$ per bed, which included the purchase of land and the construction of all necessary support and research facilities; the standard expenditure for British hospitals at that time as $£ 1,500$ per bed. Andrews et al. 1997, 551.

${ }^{80}$ Personal correspondence with Warwick Brunton, November 19, 2010. Also refer: Brunton 2001, 256, and Brunton "Gray, Theodore Grant - Biography."

81 Brunton 2001, 188. Brunton suggests that the "downward pattern" following this date "showed the impact of [new] treatment[s]."

${ }^{82}$ AJHR 1945, H-7, 2.

${ }^{83}$ Thompson 1992, ii, 65-66.

${ }^{84}$ AJHR 1937, H-07, 2.

${ }^{85}$ AJHR 1925, $\mathrm{H}-07,4$.

${ }^{86}$ AJHR 1925, H-07, 4.

${ }^{87}$ Gray 1958, 76.

88 "Mental Patients... Extensions to Buildings," 1937.

${ }^{89}$ Brunton 2001, 181-3, 347-8.

${ }^{90}$ Prebble 2007, 100-1.

${ }^{91}$ Brunton, "Gray, Theodore Grant."

${ }^{92}$ King 1948, 87-8, 93.

${ }^{93}$ AJHR 1925, H-07, 2.

${ }^{94}$ Gray $1958,77$.

95 In his presidential address of 1947, Gray stated that psychopharmacology heralded "the dawn of a new era in psychology...in which the last vestiges of superstition, prejudice and ignorance will pass away," however, Gray's internal correspondence to Medical Superintendents contradicts this. Refer: Gray, "Presidential Address." New Zealand Medical Journal 46 (1947), 85. Various Memorandums to Superintendents, 1932-35, ANZ: R16195637. Brunton, "Gray, Theodore Grant - Biography."

${ }^{96}$ Refer various circular memorandums: Gray to All Hospital Superintendents, 1935. ANZ: R16195637.

${ }^{97}$ Gray to the Government Architect, January 15, 1940. ANZ: R22502230.

${ }^{98}$ Gray to the Government Architect, various dates: June 29, 1943, October 29, 1943, June 19, 1944, February 13, 1945. Medical Superintendent, Auckland Mental Hospital, to Gray, various dates: June 24, 1943, February 2, 1945. ANZ: R22502230.

${ }^{99}$ AJHR 1899, $\mathrm{H}-07,3$. 
100 Thompson 1981, 4.

101 Director-General, MHD, to the Secretary, Public Service Commission, August 11, 1936. ANZ: R16195531.

102 Director-General, MHD, to the Medical Superintendent, Brisbane Mental Hospital, November 25, 1941. ANZ: R20960887. Also refer: AJHR 1937, H-07, 2.

103 "A Humanitarian Task," 1937. That this article originated from a departmental press release is suggested by the fact that several articles printed around the same day repeated the material contained within it. Refer also: "Mental Hospital...State Purchase," 1937. "Helping the Insane," 1937. "Mental Health [Lake Alice]," 1937. Furthermore, Brunton states that Gray approved all departmental communications with the media. Brunton 2001, 151.

104 Gray 1929, 28.

${ }^{105}$ Gray 1958, 89-91.

${ }^{106}$ Brunton, "Gray, Theodore Grant - Biography."

${ }^{107}$ Brunton, "Gray, Theodore Grant - Biography."

108 Gray 1929, 21, 24-6, 34.

${ }^{109}$ Medlicott 2001, 121-2. Refer also: “Mental Disorder... New Zealand's Part," 1929.

110 "Mental Hygiene...Lecture by Dr A.R. Falconer," 1932.

${ }^{111}$ Gray 1929, 24-6.

112 Ibid, $19,75$.

${ }^{113}$ O'Reilly 1948, 113. Also refer Blain 1959, 48.

${ }^{114}$ Brunton, "Gray, Theodore Grant - Biography." Brunton 2001, 285.

115 Land for Lake Alice was purchased in 1937: refer various correspondence, dated 1937, ANZ: R18769106. The design was finalized in 1943: Director-General, MHD, to the Government Architect, June 29, 1943. ANZ: R22502230.

116 Lake Alice Hospital, Marton: $25^{\text {th }}$ Anniversary Souvenir Booklet, 1975, 5. Director-General, MHD, to the Medical Superintendent, Brisbane Mental Hospital, November 25, 1941. ANZ: R20960887.

117 Director-General, MHD, to the Minister of Health, April 22, 1940. ANZ: R22502230.

118 Ibid.

${ }^{119}$ Director, DMH, to the Commissioner of Works, March 8, 1950. ANZ: R16195940.

${ }^{120}$ Director-General, MHD, to the Minister in Charge of Mental Hospitals, September 7, 1935. ANZ: R16195938.

${ }^{121}$ Director-General, MHD, to the Minister in Charge of Mental Hospitals, January 17, 1936. ANZ: R16195938.

122 Director-General, MHD, to the Organisation for National Development, April 11, 1945. ANZ: R16195940.

${ }^{123}$ Ibid.

${ }^{124}$ Easton 2012.

${ }^{125}$ Acting Secretary to the Treasury to All Permanent Department Heads, July 15, 1937. Director, Organization for National Development, to the Director-General, MHD, April 6, 1945. Commissioner of Works to All Permanent Department Heads, February 12, 1948, September 1, 1952 and December, 6, 1955. ANZ: R16195940. 
${ }^{126}$ Director, Organization for National Development, to the Director-General, MHD, April 6, 1945. Commissioner of Works to All Permanent Department Heads, February 12, 1948. ANZ: R16195940.

${ }^{127}$ Commissioner of Works to All Permanent Department Heads, February, 5, 1946. ANZ: R16195940.

${ }^{128}$ Director, DMH, to the Minister of Health, March 22, 1950. ANZ: R16195940.

${ }^{129}$ Director, Organization for National Development, to the Director-General, MHD, April 11, 1945. ANZ: R16195940.

${ }^{130}$ Director-General, MHD, to the Organisation for National Development, March 22, 1946. ANZ: R16195940.

${ }^{131}$ Director, DMH, to the Minister in Charge of Mental Hospitals, May 9, 1949. ANZ: R16195940.

132 Ibid.

${ }^{133}$ Superintendents, Auckland and Kingseat hospital, to the Director-General, MHD, February 2, 1945. ANZ: R22502230.

134 Director-General, MHD, to the Under-Secretary of Public Works, July 11, 1946. ANZ: R16195940.

${ }^{135}$ Development Officer, DMH, to the Government Architect, June 24, 1948. ANZ: R16195940.

${ }^{136}$ Acting Director-General, MHD, to the Government Architect, June 18, 1947. ANZ: R16195940.

${ }^{137}$ Brunton 2001, 145.

${ }^{138}$ Director, DMH, to the Minister of Health, March 22, 1950. ANZ: R16195940.

${ }^{139}$ Director, DMH, to the Commissioner of Works, March 8, 1950. ANZ: R16195940.

${ }^{140}$ Smith 1999, 38.

${ }^{141}$ Crawford 2005, "Return to Civilian Administration."

142 Crawford 2005, "Women's Hospital (1926)."

${ }^{143}$ Crawford 2005, "Return to Civilian Administration."

${ }^{144}$ Bowman 2010, 22.

${ }^{145}$ Medlicott 2001, 121. Jones, Rahman and Woolven 2007, 357-378.

${ }^{146}$ Andrews et al. 1997, 552, 559.

${ }^{147}$ Bowman 2010, 13.

${ }^{148}$ Director-General, MHD, to the Assistant Secretary to the Treasury and Chairman, Building Coordination Committee, September 20, 1937. ANZ: R16195938.

${ }^{149}$ Markus 1982, 4.

${ }^{150}$ Random House Incorporated 2013. Date accessed: August 122013.

151 Smith 1999, 38.

${ }^{152}$ Commissioner of Defence Construction to the Secretary to the, May 6, 1943. ANZ: R16195940.

153 Ibid. 
${ }^{154}$ Statistics regarding overcrowding were left out of Gray's reports to the AJHR for 1943 and 1944 owing to wartime exigencies. However, by April of 1945 (accounting for the Porirua accommodation losses) Gray described this situation as "extremely dangerous." Director-General, MHD, to the Organisation for National Development, April 11, 1945. ANZ: R16195940.

${ }^{155}$ Commissioner of Defence Construction to the Secretary to the, May 6, 1943. ANZ: R16195940.

${ }^{156}$ Ibid.

${ }^{157}$ Director, DMH, to the Minister of Health, March 22, 1950. ANZ: R16195940. 


\section{CHAPTER SIX \\ Cherry Farm: the Changing Face of Mental Health Care}

The planning and construction of the Cherry Farm Hospital spanned from 1943 to $1971 .{ }^{1}$ While patients at Cherry Farm Hospital were initially to be accommodated within Porirua style villas, shortages of building materials, specifically steel and cement, meant that this two-storied, concrete design had to be discarded. ${ }^{2}$ In 1947, a new single-storied, timber framed villa was designed for this hospital. ${ }^{3}$ In 1952 it was decided that the Cherry Farm villa design would become the standard design for all new mental hospital construction in New Zealand. ${ }^{4}$ Across six sites, between 1952 and 1957, twenty-four villas of this design were constructed (including thirteen at Cherry Farm). Sunnyside, Porirua, Kingseat, Tokanui and Lake Alice all received new villas of the Cherry Farm design.

The period in which this hospital was designed and constructed coincided with a period of rapid change regarding the way that mental health care was understood and delivered, as chapter three has already outlined. The curative criteria established within chapter three (table 3.3) takes into account the information that was available at the time when the hospital was initially planned and the additional information that was available when the decision was made to replicate the Cherry Farm villas nationally. The timing of this hospital's development presented an opportunity for the Division of Mental Hygiene's new architecture to respond to emerging values regarding the delivery of mental health care. This case study will examine whether this opportunity was grasped in the design of the Cherry Farm Hospital and villas, did these designs respond to contemporary thought regarding the treatment of mental illness.

Constructed just two decades after Kingseat, Cherry Farm was subject to similar concerns of public relations and professional marginalisation that were present in the design of this earlier hospital. Official press releases during the era in which Cherry Farm was constructed stated that New Zealand's mental hospitals were "on a level with the best in the world" 5 and that Cherry Farm itself would be "an outstanding hospital of its kind." 6 This case study will examine whether the design of the Cherry Farm villa fulfilled publically stated claims and to what extent concerns of public relations and professional marginalisation affected this design response. 
The Cherry Farm case study also provides a useful foil to the earlier two case studies allowing for comparisons to be drawn within the following (discussion) chapter. Distinct from the examples of Seacliff Asylum and Kingseat Mental Hospital, no single dominant figure emerges within the design documentation for Cherry Farm Hospital. The Cherry Farm case study will thus allow comparisons to be drawn regarding the level of compromise that was able to occur within this architectural typology owing to personal ambition and professional agendas. This case study will also indicate whether, in light of new approaches to treatment, decision makers continued to place faith in the curative effects of an appropriately designed hospital environment.

An understanding of the effort that was undertaken to ensure this architecture responded to new approaches to treatment and the peripheral concerns that were allowed to influence this design response will aid our understanding of official attitudes towards mental illness between 1945 and 1960.

Within the first section of this chapter, the Cherry Farm Hospital will be tested relative to the architectural criteria set up under chapter three. The villa design will be discussed separately within the following section owing to its relevance to New Zealand's wider mental hospital network. Section three will explore the obstacles to the adoption of emergent research relative to design approaches taken in America. It will also evaluate the response created for Lake Alice relative to the concerns of the WHO report. Section four will look at issues of funding and staffing in the design of this hospital. Finally, section five will address questions of public expectation and professional limitations in the design of Cherry Farm Hospital and its villas. 


\subsection{CHERRY FARM: "AN OUTSTANDING HOSPITAL OF ITS KIND"}

The design of the Cherry Farm Hospital took place between 1943 and $1949 .^{7}$ Construction began in 1951 with the first patients occupying this hospital in 1952. In 1957, when the decision was made to build more accommodation at this hospital than was originally intended, the Minister of Health informed the Otago Daily Times that Cherry Farm would be "an outstanding hospital of its kind." ${ }^{8}$ In 1992 this hospital was closed down. The short duration of Cherry Farm's operation confirms the advice given within the 1953 WHO report, that new hospitals should be designed with their own obsolescence in mind. ${ }^{9}$ The WHO's expert committee felt that the therapeutic community model would only remain relevant for twenty to thirty years. The mass closure of mental hospitals that occurred across the western world, and included the closure of Cherry Farm, took place forty years after the WHO report was released. This raises a number of questions regarding the degree of forward thinking that decision makers engaged with in the design of this hospital. This section will examine the planning of the Cherry Farm Hospital in relation to the architectural considerations raised by the WHO report and the associated emergent research. The design of the Cherry Farm villas will be reviewed in the following section, however, issues of location, building scale, common facilities, the diversification of facilities and collaboration with general hospitals and universities are all considerations that can be examined at the scale of the hospital.

Cabinet approval was initially granted for a 900 bed hospital at Cherry Farm in 1946. It was to be comprised of sixteen 50-bed villas and two 10-patient villas, a hospital block, administration block and all necessary associated service buildings. ${ }^{10}$ However, the government's commitment was not as steadfast as the 1946 cabinet approval suggested. In 1952 the Evening Star confirmed that only 750 beds were to be constructed. The article went on to say that:

Until the Government's intentions are made known... and the department is allotted further finance for the work, it is not known what alterations will be made in the [Cherry Farm] plans; nor is it known just when the whole project can be completed, as this, too, is bound up with the availability of finance. ${ }^{11}$

While the intent in 1943 was to replace Seacliff Asylum, at some point the idea of running Seacliff alongside Cherry Farm became a more attractive option as Seacliff could be retained to accommodate the "most disturbed and dangerous patients." ${ }^{12}$ By 1957 it had become apparent, however, that the increasingly hazardous condition of this building would force its closure. In June of that year, Cabinet approved a further $£ 250,000$ to be spent on additional buildings at Cherry Farm. ${ }^{13}$ In August this was raised to $£ 1,000,000$. The Ashburton Guardian reported that Cherry Farm would be expanded to "a full-size 1060-bed hospital." ${ }^{14}$ Despite this expenditure, 
Cherry Farm Hospital would not reach full operation until 1964 (figure 6.1). Jeff Kavanagh has pointed out the irony in the fact that by the time Cherry Farm was fully completed "thought concerning [the treatment of] mental health had moved beyond institutionalism." 15

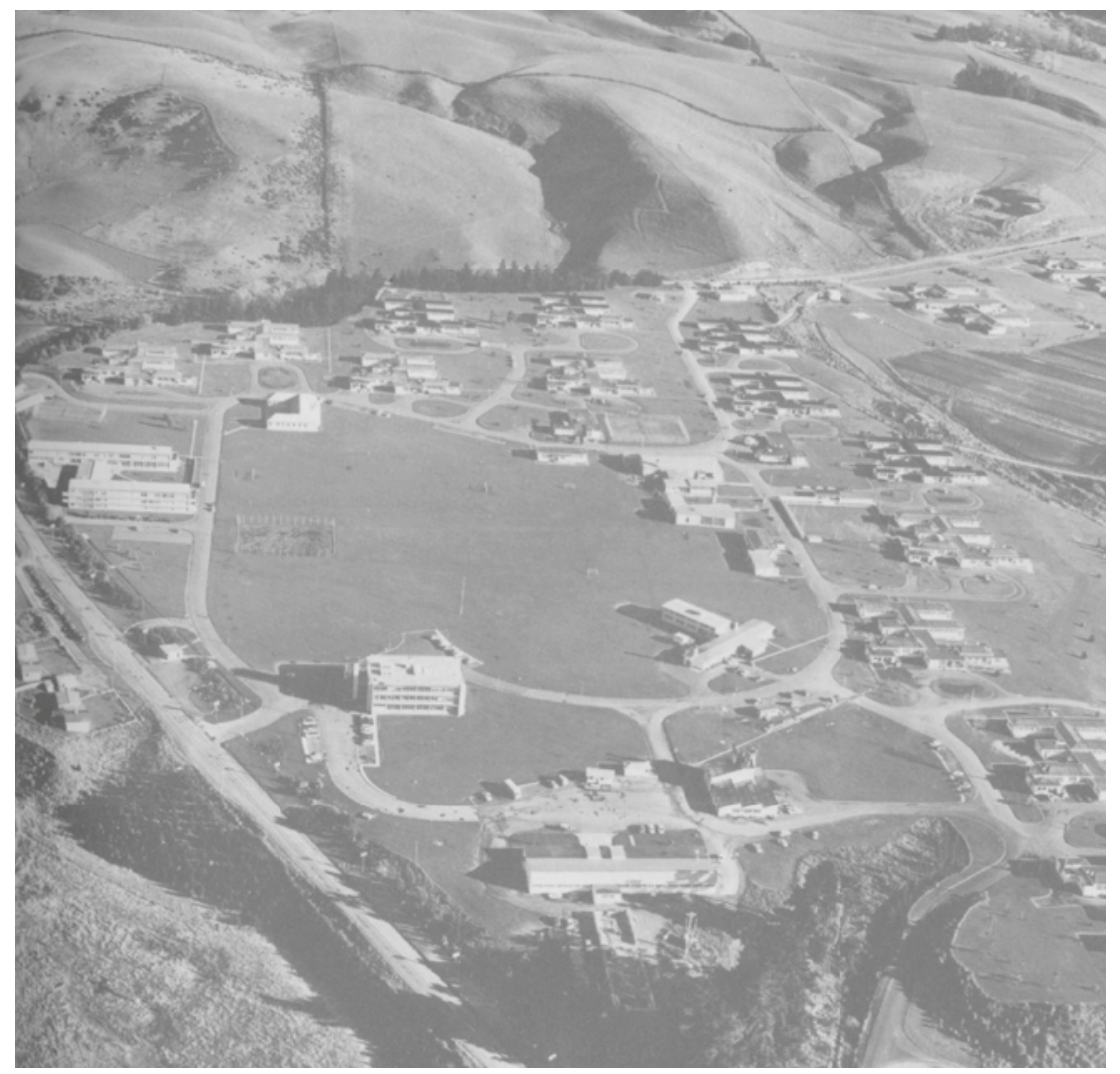

Figure 6.1. The Cherry Farm Hospital, ca. 1970

As printed in the Otago Daily Times under "Historic Seacliff Hospital," date unknown - clipping from Joan Morrow Scrapbook, Hocken Archive: MS-3109/010.

The WHO report suggested that two varying approaches to the provision of mental hospital services were required: a new response for those patients who were now regarded as able to live beyond the hospital, with appropriate outpatient support, and a traditional response for those who would continue to require institutional care. ${ }^{16}$ The Cherry Farm Hospital was a traditional, conservative approach to mental hospital design, however, with regard to the response recommended for chronic, long-stay patients, this hospital satisfied a number of the specifications contained within the WHO report. As recommended by the report, Cherry Farm Hospital took the village as its model. ${ }^{17}$ It was set amid a rural landscape with single storied buildings that were unlikely to "dwarf" patients. ${ }^{18}$ The recommendation that more space be devoted to common activities was also adhered to. ${ }^{19}$ Temporary "shell buildings" were constructed for occupational therapy and recreational activities in 1957, while a permanent community centre, which housed a hall, cafeteria, canteen and library, was constructed in $1961 .{ }^{20}$ It is likely that many of these facilities were intended when the hospital was planned in 1946. While no brief has been located for Cherry Farm, it was initially 
planned under Gray's directorship so facilities at this hospital likely matched what was specified for Lake Alice six years earlier. A number of occupational therapy centres, a recreation hall and central playing fields, complete with tennis courts, bowling greens and a rugby field were included in the master plan for Lake Alice. ${ }^{21}$ Gray understood the value of common, recreational activities long before the emergence of the WHO report in 1953.

Decisions around hospital location had implications for both the traditional response, recommended for long-stay patients, and the new ideas around treatment that encouraged a more diverse and dispersed network of facilities. Cherry Farm was located on State Highway One, 36 kilometres north of downtown Dunedin. The hospital was situated just a kilometre from the same railway line that served Seacliff but, instead of being a halfkilometre walk to the nearest station, Cherry Farm was five kilometres distant. At the time it was planned, Cherry Farm was not serviced by a regular bus route though one would later be added. ${ }^{22}$ The distance of this hospital from Dunedin caused similar problems for visitation as were experienced at Seacliff. This situation was foreseeable given the close proximity of these hospitals. In 1958, the superintendent of Seacliff (under whose superintendence Cherry Farm was placed) confirmed that there was "a need for accommodation in Waikouaiti for visitors to our patients at Cherry Farm Hospital." The superintendent confirmed that many visitors travelled from distant, rural districts and faced difficulties of both accommodation and transport, "sometimes requiring a taxi service at least one way [from Dunedin]."23 Because Cherry Farm was located so far from the main population base it served (Dunedin city) it was not optimally positioned to provide opportunities for wider community engagement with this hospital. Nor did it aid patient access to extramural organisations and activities. In constructing a traditional, rurally located villa hospital model, Cherry Farm was limited with regard to these two key ideas contained within the WHO report.

Another central idea contained within the WHO report was that mental hospitals refocus themselves as coordinators of a variety of mental health services and as educators actively involved in research. ${ }^{24}$ There was little talk of research during the time that Cherry Farm was planned. The provision of research facilities did not appear within departmental correspondence until $1959 .{ }^{25}$ Collaboration with external research bodies was not publically discussed until a year later. The Otago Daily Times reported that the new reception unit intended for Cherry Farm would include research facilities and that research would be undertaken in "close association" with the University of Otago and the Medical Research Council. $^{26}$ Seacliff had traditionally undertaken the teaching of a small number of medical students from the University of Otago. However, maintaining the continuity of this service throughout the transition from Seacliff to Cherry Farm was not high on the hospital's list of priorities. 
Student accommodation was slow to be constructed and, when it was available, it was partially re-appropriated for dental facilities. In 1957 the hospital superintendent informed the director of the Division of Mental Hygiene that continuing of the "full sixth year clinical service" would be difficult owing to the lack the lack of student accommodation at the new hospital. ${ }^{27}$ Not until 1966 when the decision was made to construct Cherry Farm's Acute Admission Unit within the city, on the grounds of the Wakari General Hospital were the reccommendations of the WHO report fulfilled. ${ }^{28}$ Owing to construction delays, this was not opened until 1971 (March), nearly two decades after the report was released. However it fulfilled many of the WHO report recommendations as the superintendent of Cherry Farm outlined within a press release in 1969. This stated that this new unit would increase the existing scope of outpatient treatment while facilitating Cherry Farm's access to the "laboratory and diagnostic facilities" of the general hospital. The proximity of this new unit to the facilities run by the University's Department of Psychological Medicine would allow both the division's medical officers and the university staff a wider array of experience while strengthening the existing teaching resource for under-graduate medical students. ${ }^{29}$

Two years after the publication of the WHO report, accommodation for only 120 patients had been completed at Cherry Farm while four further 50-bed villas were under construction. This equated to only one third of the accommodation "approved in principle" by cabinet in 1946. The majority of the funds allocated to the Cherry Farm Hospital had not been expended, nor committed to building contracts. In September of 1955, £650,000 had been spent at Cherry Farm and an estimated $£ 1,935,207$ would be required to finish the hospital. ${ }^{30}$ Significant sums of taxpayer funds were being expended over a delayed period in a field where ideas around treatment were rapidly evolving. Yet, with the exception of the relocation of the Admission Unit to Wakari, little re-evaluation of the design decisions made in the procurement of this hospital occurred.

In terms of the response recommended by the WHO report for long-stay patients, the Cherry Farm Hospital responded adequately. However, the report did not ask for a different architectural solution to that which had already been followed at villa hospitals constructed in New Zealand between 1924 and 1943. The less conservative approaches recommended by the report were slow to be taken up, despite the fact the ideas relating to city based psychiatric units and greater collaboration with universities and general hospitals were not new. International precedents for this approach, such as the Maudsley and Johns Hopkins Hospitals, had been in existence for four decades. The conservative approach taken to Cherry Farm's location perpetuated the traditional drawbacks of patient, community and professional isolation that had long been associated with these institutions. The fact that so little forward thinking was engaged with in the design of Cherry Farm Hospital raises a number of questions. Were decision makers 
unaware of the available emergent research? Alternately, was this research too new to be embraced in the design of Cherry Farm Hospital or were New Zealand decision makers simply too conservative? Furthermore, what additional factors impacted the decisions made around the construction of this hospital? The following sections will address these issues. But first, the 50-bed villas created for Cherry Farm will be examined regarding their relationship to the new ideas around patient treatment that were contained within the WHO report. 


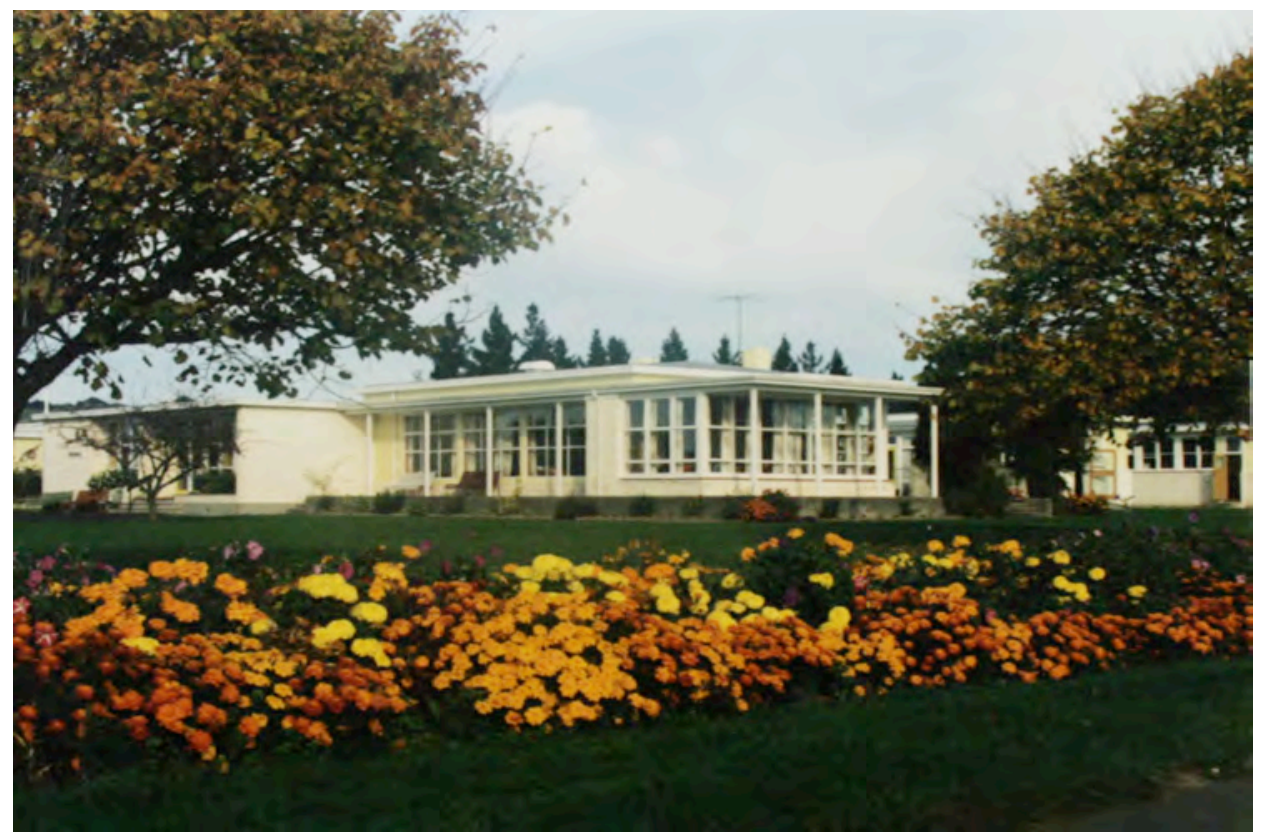

Figure 6.2: Cherry Farm Hospital Villa ca 1980.

Archives New Zealand: DAHI D266 20271 521s

In 1955 six villas were in varying stages of completion at Cherry Farm and seven additional villas were intended for this site (figure 6.2). That year the decision was made to build 15 further villas of this design at hospital sites around the country. ${ }^{31}$ In total 28 villas of this design were intended for construction, this included four villas of a "modified" Cherry Farm design for the Levin Farm Colony (figure 6.3). ${ }^{32}$ These remaining 22 (of 28 intended) villas represented new accommodation for 1400 mental hospital patients, or 14 per cent of New Zealand's total mental hospital population in $1955 .{ }^{33}$ This design, therefore, would affect a greater proportion of the patient population than any other design created for New Zealand's Mental Hospitals. A collection of press releases created by the Division of Mental Hygiene, between 1954 and 1957, employed terminology that suggested the design of these new villas responded to a number of ideas contained within the WHO report. Furthermore, the division claimed that the Cherry Farm villas were "breaking new ground in construction and design [emphasis added]," that they demonstrated a "new approach" to mental health care and boasted "new architectural features in design and layout." This section will evaluate the Cherry Farm villa in relation to the values espoused within the WHO report and in relation to the media statements made about this architecture by the Division of Mental Hygiene. 


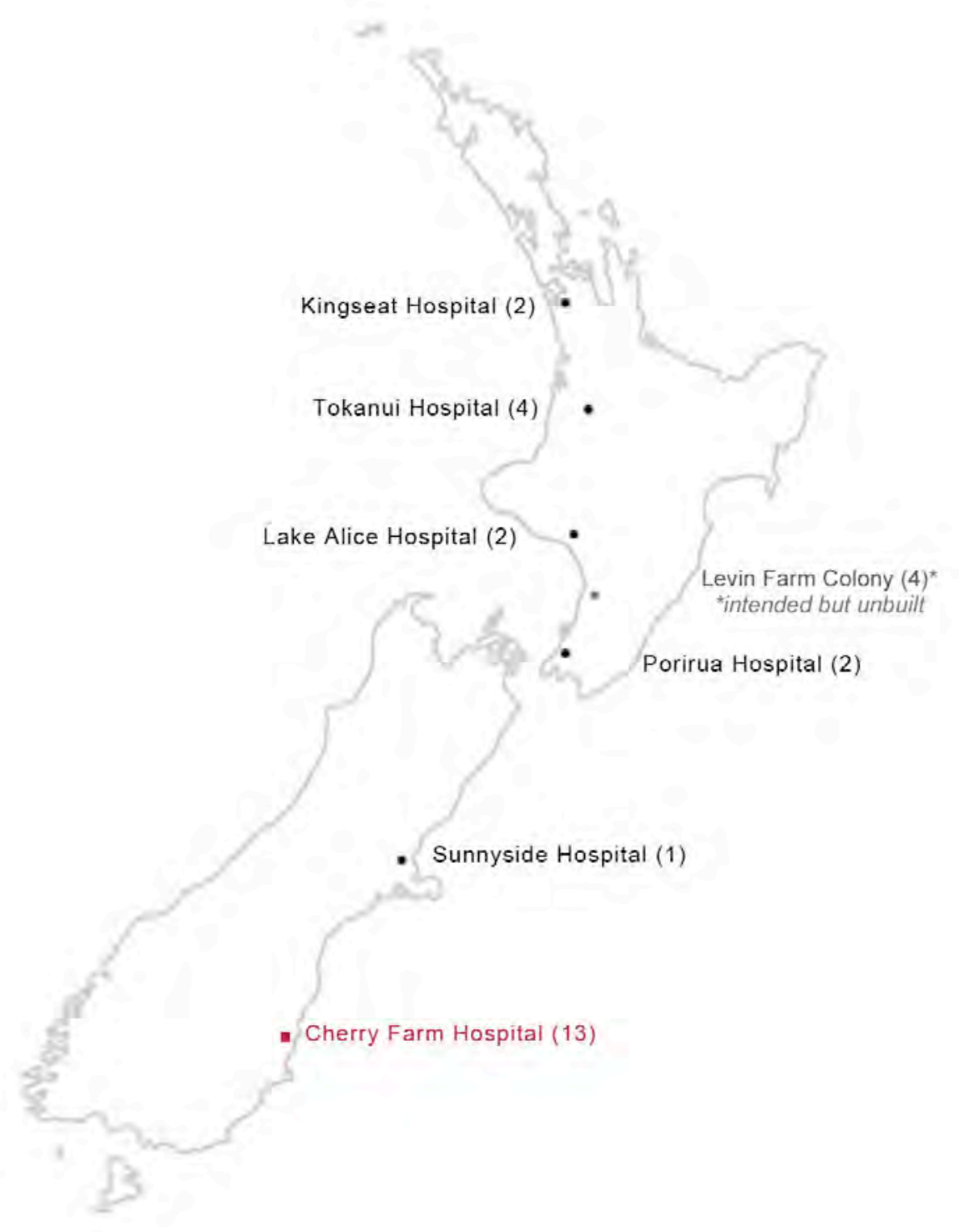

Figure 6.3: Cherry Farm villas: location and distribution map.

The number of villas received by each hospital is noted in brackets.

Drawing by author.

For the hospital to function as a therapeutic community, supportive networks needed to be created throughout the hospital. A departmental press release dated around 1953, outlined that the "modern approach" to mental hospital design was to "place as many buildings throughout the extensive grounds so that the hospital becomes a therapeutic community rather than an institutional unit [emphasis added]. ${ }^{35}$ Another stated: "the smaller, self-contained, homely, well-furnished villa encourages a group life among the patients [emphasis added]. ${ }^{36}$ These documents suggested that a group-based therapeutic community was being pursued through architecture. It not only confirms a cognisance of the ideas contained within the WHO report but also intimates that this design was a deliberate response to them. In terms of supporting the treatment of mental illness, 
however, the Cherry Farm villa offered little advance on the designs of Kingseat or Ngawhatu. The aesthetic may have changed but the internal arrangement of this villa itself was not significantly different from those constructed five and 19 years earlier (figure 6.4). How did such a traditional response address the treatment aspirations outlined within the WHO report?

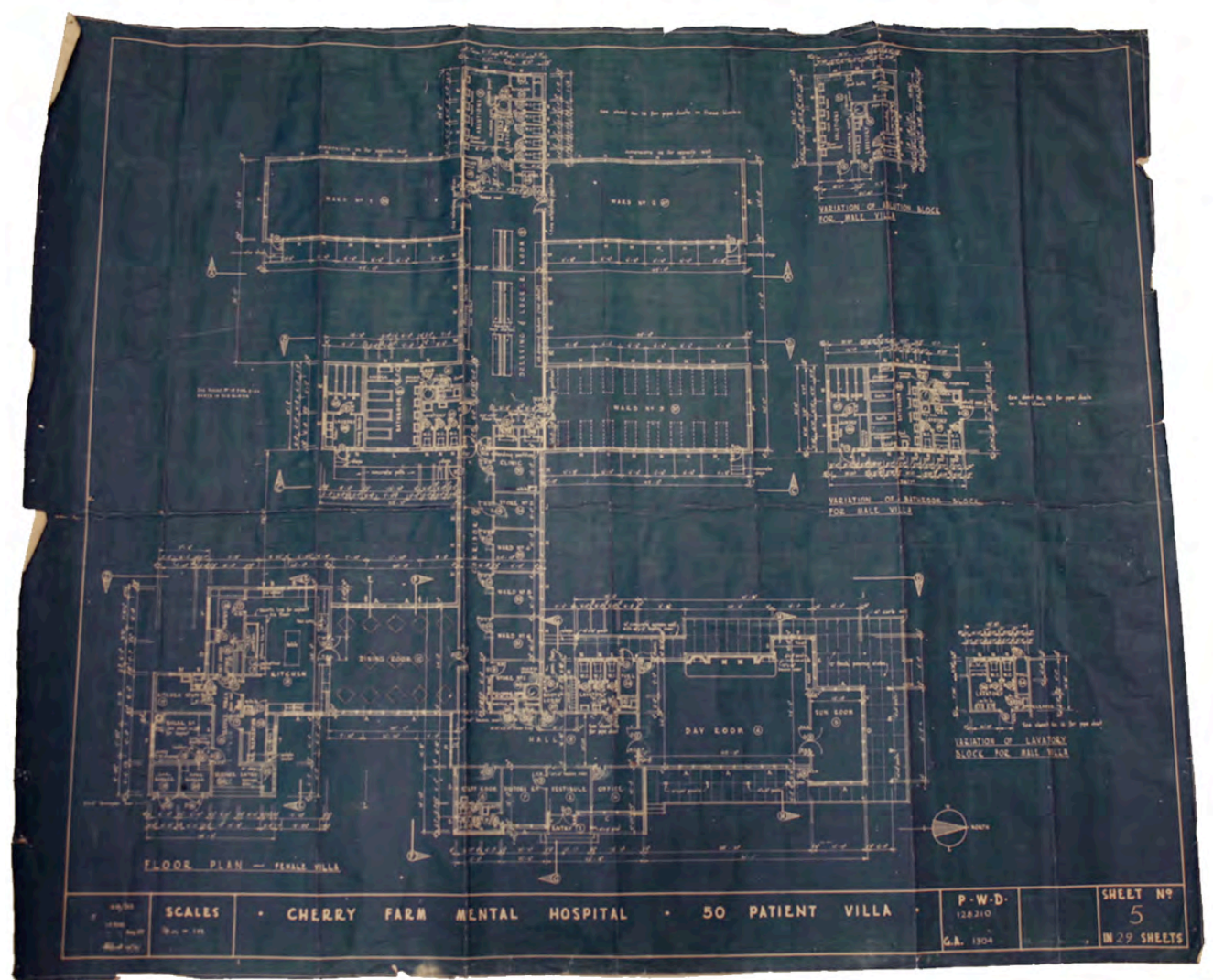

Figure 6.4: Cherry Farm Mental Hospital, 50-Bed Villa, 1949. Archives New Zealand: DAHI-D494-5b.

While permeability is generally discussed at the wider scale of the hospital, in terms of boundaries and proximity to the extramural community, it begins at the scale of the villa. The Cherry Farm design visually embodied the idea of an open-door hospital. Aesthetically, the extensive glazing and low level terraces that stretched out into the landscape, intimated a freedom of movement previously unseen in New Zealand mental hospital design. It was an image that the official photographs of this these villas supported. The 1953 publicity image for these villas shows a person relaxing with a newspaper on an open terrace (figure 6.5). Likewise, in the 1980 publicity image, every doorway visible in the photograph is left open (refer figure 6.2). 


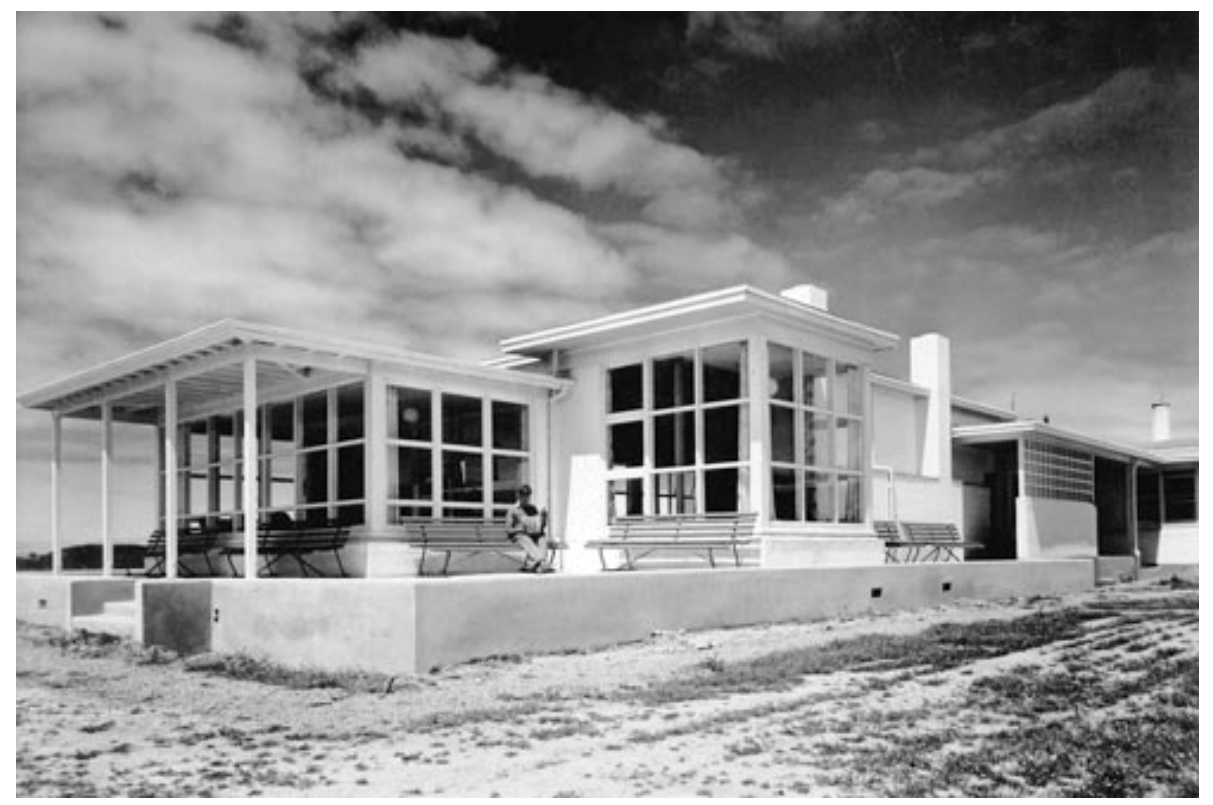

Figure 6.5: Cherry Farm Mental Hospital, 1953. Photographer: K V Bigwood. Archives New Zealand: AAQT 6539, A29455.

Once inside the day room of this villa, however, the difficulty of finding a door to access the exterior becomes apparent. These are solid and tucked around corners (figure 6.6). The day room space does not flow freely onto the terrace as the architectural aesthetic primes one to expect. These seemingly inaccessible terraces and the low number of external doors per square metre of façade, especially when compared with the Kingseat villas, suggests an incongruity. The ideals of the open door system were not as deeply embedded within this villa as the architecture, the press releases and the media rhetoric led the public to believe. With regard to a key criteria of the WHO report, that trust be accorded to patients, little more than lip service was paid to this idea in the division's new architectural approach. 


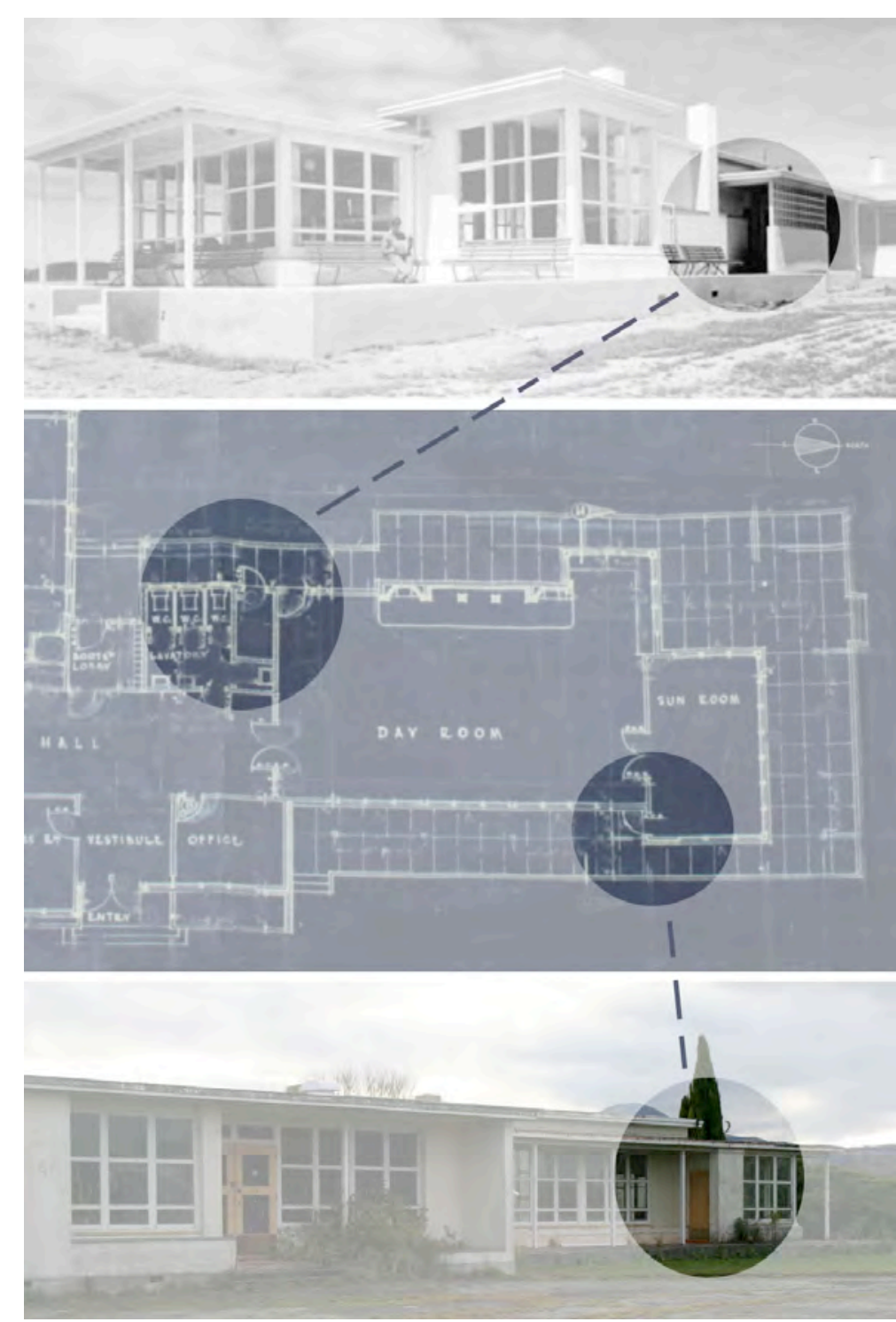

Figure 6.6: Location and treatment of external doors (top to bottom) Archives New Zealand: AAQT 6539, A29455.

Archives New Zealand: DAHI-D494-5b.

Photograph by author, July 6, 2012 (all images altered by author).

The matter of permeability, as Main pointed out, had to go both ways in order to successfully remove the barriers to community engagement. Entrances and visitor spaces prove equally informative regarding the division's attitude toward the role of family within the hospital and, by extension, the treatment process. The wide entrances at Cherry Farm suggested that visitors were welcome, that these villas were wide open for public inspection. By comparison, the Porirua villas offered only a small concrete overhang at the front entrance while the symmetry of the Kingseat villas made the identification of an appropriate point of entry confusing. At Cherry Farm, visitors were met with raised planter boxes and walls of chalky-soft Oamaru (lime) stone, three wide stairs led into a generous, timber veneered entrance vestibule. This openness, however, ceased abruptly. The visitors' room was located just three steps inside the front 
door. It allowed family members to catch a glimpse of the well-appointed day room but little beyond that (figure 6.7). This was not in keeping with the WHO's instruction that the traditional restriction of visitors to "specially prepared and segregated visiting rooms" was to cease. ${ }^{37}$
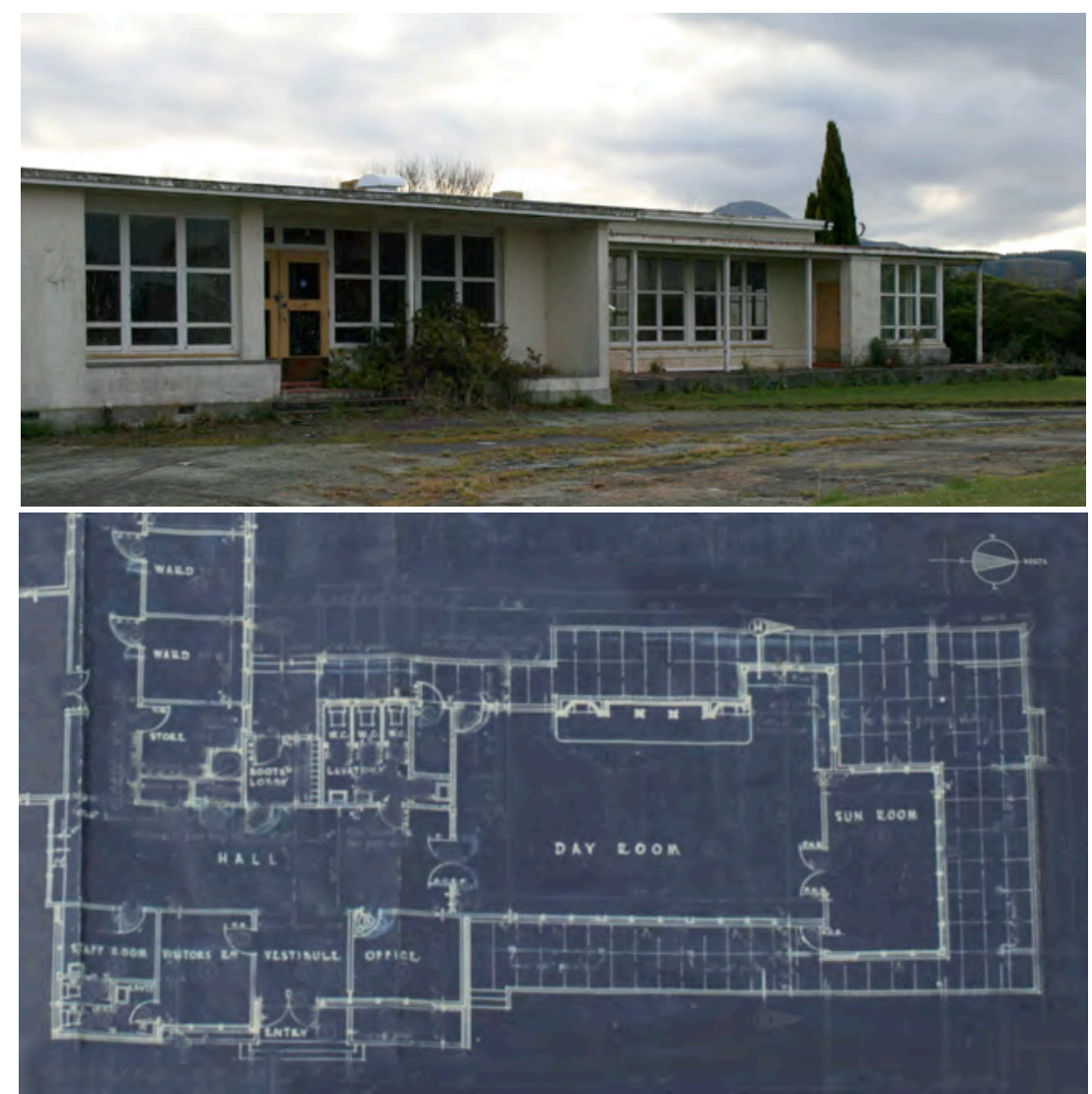

Figure 6.7: Villa entrance, Cherry Farm Hospital, July 6, 2012 (above) and the plan this area (below). Archives New Zealand: DAHI-D494-5b. The plan has been cropped by the author and dimensions obscured for clarity. Photograph by author.

The practice of protecting certain spaces from the prying, and potentially critical, eyes of visitors was standard, both within New Zealand and internationally. Erving Goffman observed, at St. Elizabeth's Hospital (Washington D.C.) that visitors' spaces had a tendency to occur within the newest or most presentable parts of a hospital. ${ }^{38}$ Janet Frame wrote of receiving visitors, at the Seacliff and Auckland asylums, within the dining room of an adjacent ward or outside in the gardens. ${ }^{39}$ Former nurses confirmed that these strategies were deliberately employed at Porirua. Visitors entered from a side door and "all these screens would be placed so they couldn't see into the dayroom." 40 The inclusion of a dedicated visiting space suggests families weren't anticipated within the dining or day rooms of these villas. The visitors' room, measuring $3 \times 4$ metres, was the only space provided within the villa itself for family to gather. It is worth noting, however, that the American Psychiatric Association disagreed with this aspect of the WHO report, believing that a space "where patients can meet with visitors in relative privacy" helped to maintain a patient's social ties. ${ }^{41}$ 
While constructing hospitals with a home-like appearance was not directly prescribed by the WHO report, this was implied by the recommendation that, in new mental hospital construction, the village should be taken as a model and collaborations with domestic architects may be beneficial. ${ }^{42}$ Themes of domesticity featured heavily amid the late 1950s media coverage of these hospitals. The Nelson Evening Mail (1958), Northland Times (1957) and Rotorua Post (1957) all emphasised parallels between the mental hospital villas and the domestic abode. A close variation on the following description appeared in each of these papers: "patients are housed in... self-contained units with dormitories, dining rooms and kitchens and well-furnished day rooms... [set] amid beautiful lawns and gardens." ${ }^{33}$ These accounts evidence continuity with earlier press release drafts which conveyed that the "modern approach" to patient accommodation was to construct residences with "all the functions of a large house." ${ }^{44}$ Newspaper articles implied an attention to detail within these new villas that was akin to that devoted to one's own home. The Northland Times reported that Matron Elliot had helped to select the colour schemes and furnishings at Tokanui Hospital, while a full page of Dunedin's Evening Star was devoted to the hospital superintendent's personal selection of artworks for these villas. ${ }^{45}$

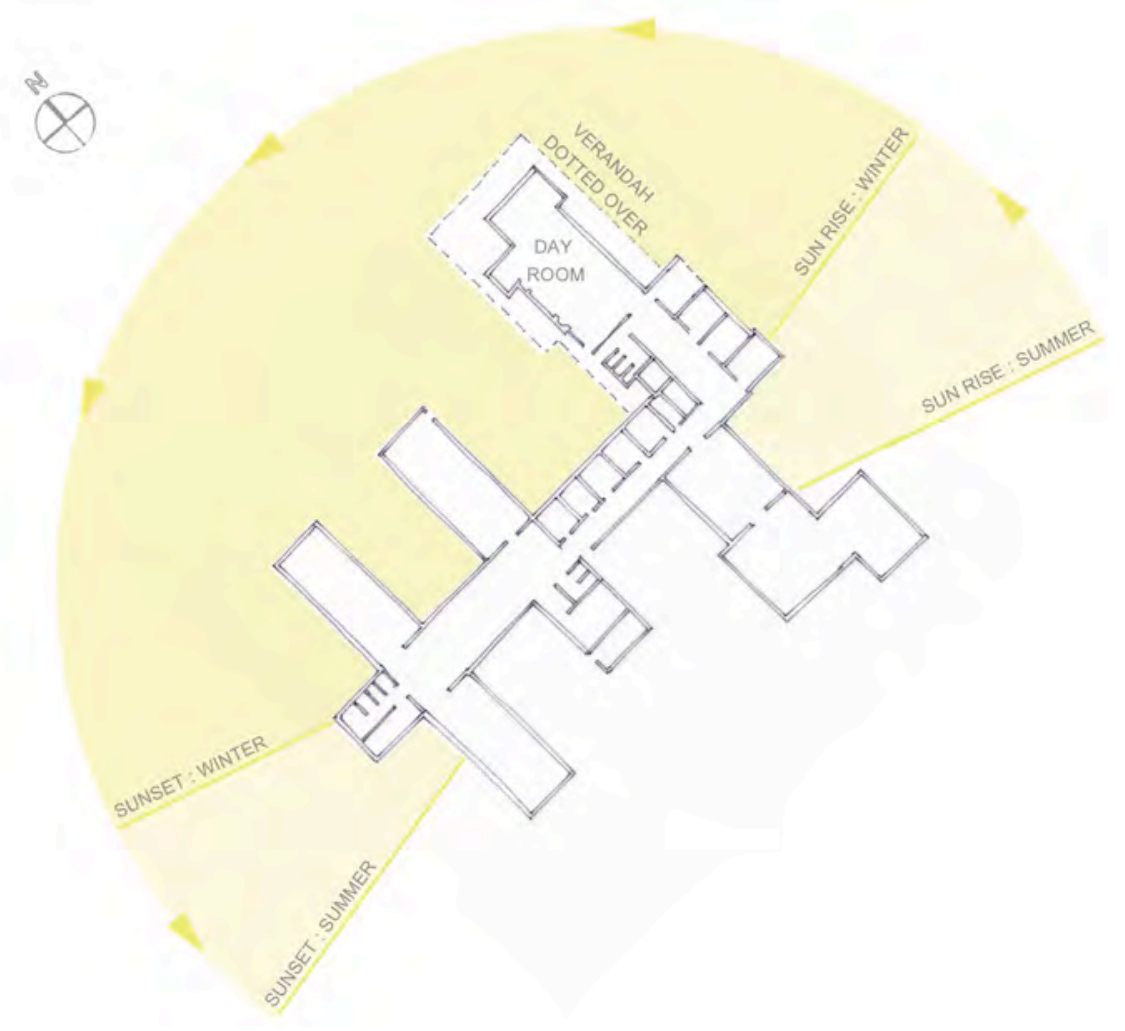

Figure 6.8: Sun diagram for Cherry Farm villas (villa orientations were consistent around the site). Diagram by author.

The Cherry Farm villa evoked homeliness most overtly along its entrance façade and in the interior treatment of its day room which offered a generosity of space and architectural attention which earlier villas lacked. 
Spaces of intimacy were crafted while a window seat and fully glazed veranda were orientated to catch the afternoon sun (figure 6.8). Extending across the rear of the day room were two open fireplaces situated together within a stone surround. These elements offered an interior richness diametrically opposed to the more utilitarian interiors of prior designs, suggesting instead, a well-appointed home. In appearance and interior appointments these villas were closely aligned with contemporary domestic trends (figures $6.9-6.12$ ).
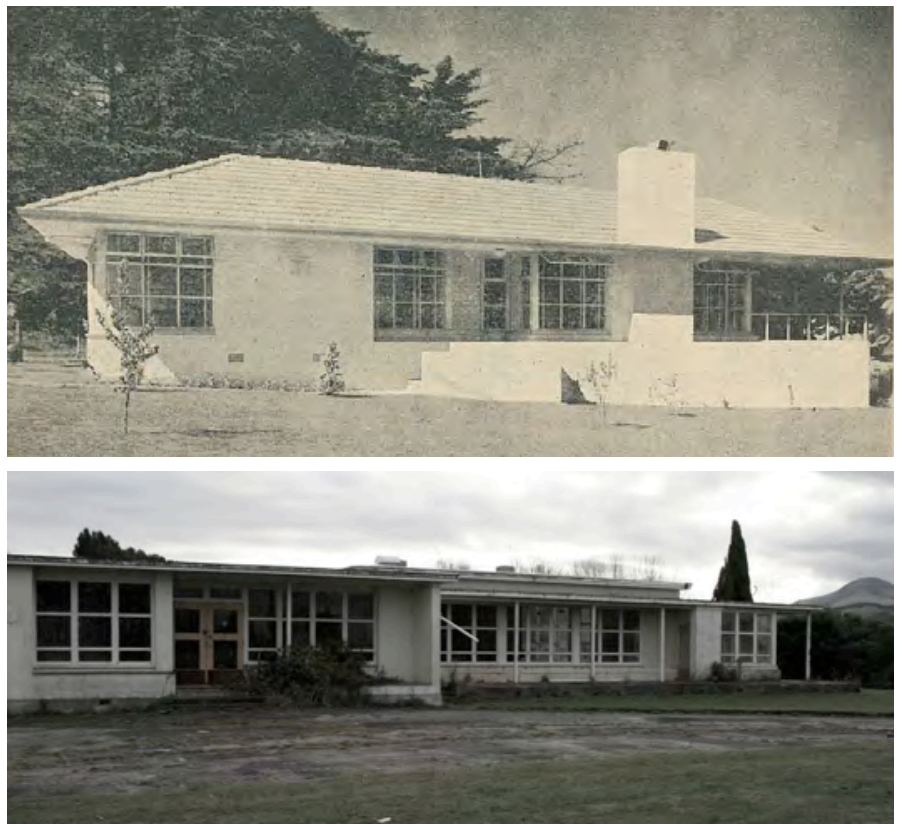

Figure 6.9: New house by Watkin \& Stemson Architects, Home and Building Dec. 1949 (above) and Cherry Farm villa (below), July 6, 2012.

Top image courtesy of ACP Media, New Zealand, photograph below by author.
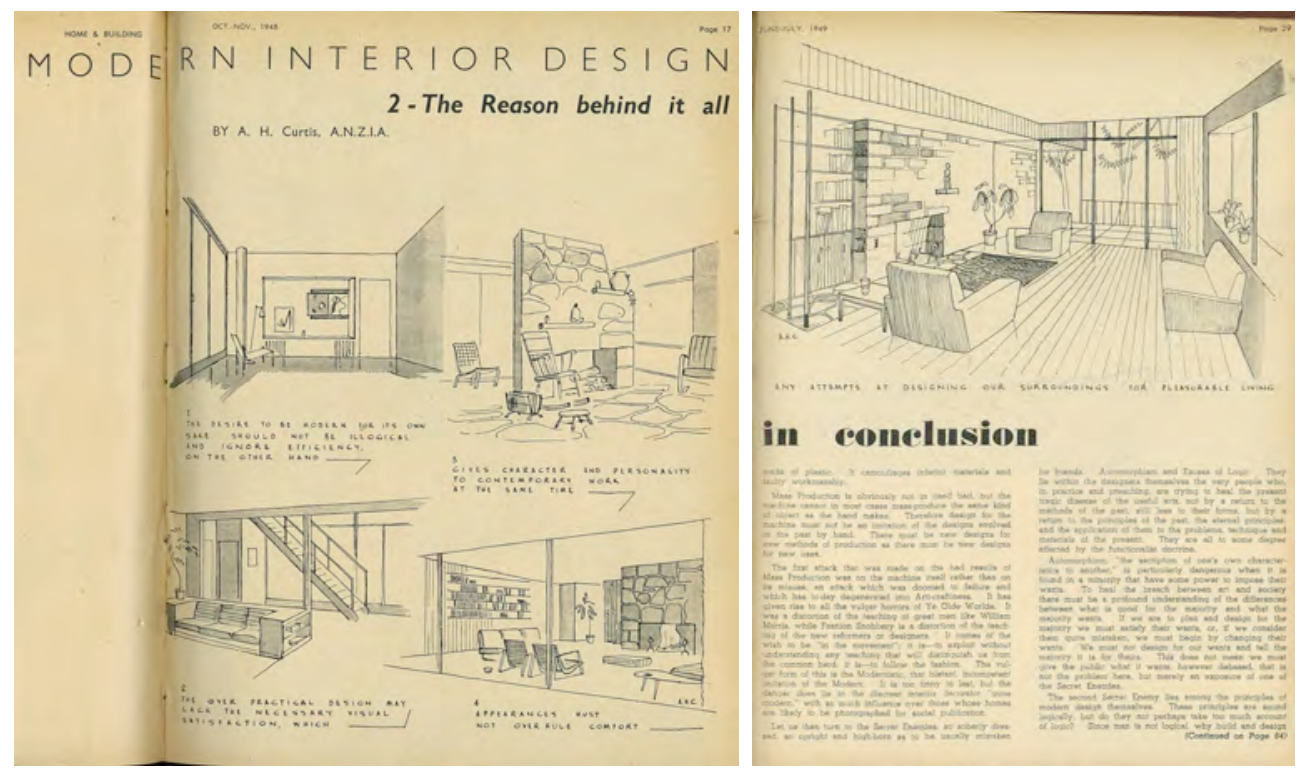

Figure 6.10: Selected pages from Home and Building Oct/Nov Issue 1948 (left) and June/July Issue 1949 (right). Images courtesy of ACP Media, New Zealand. 

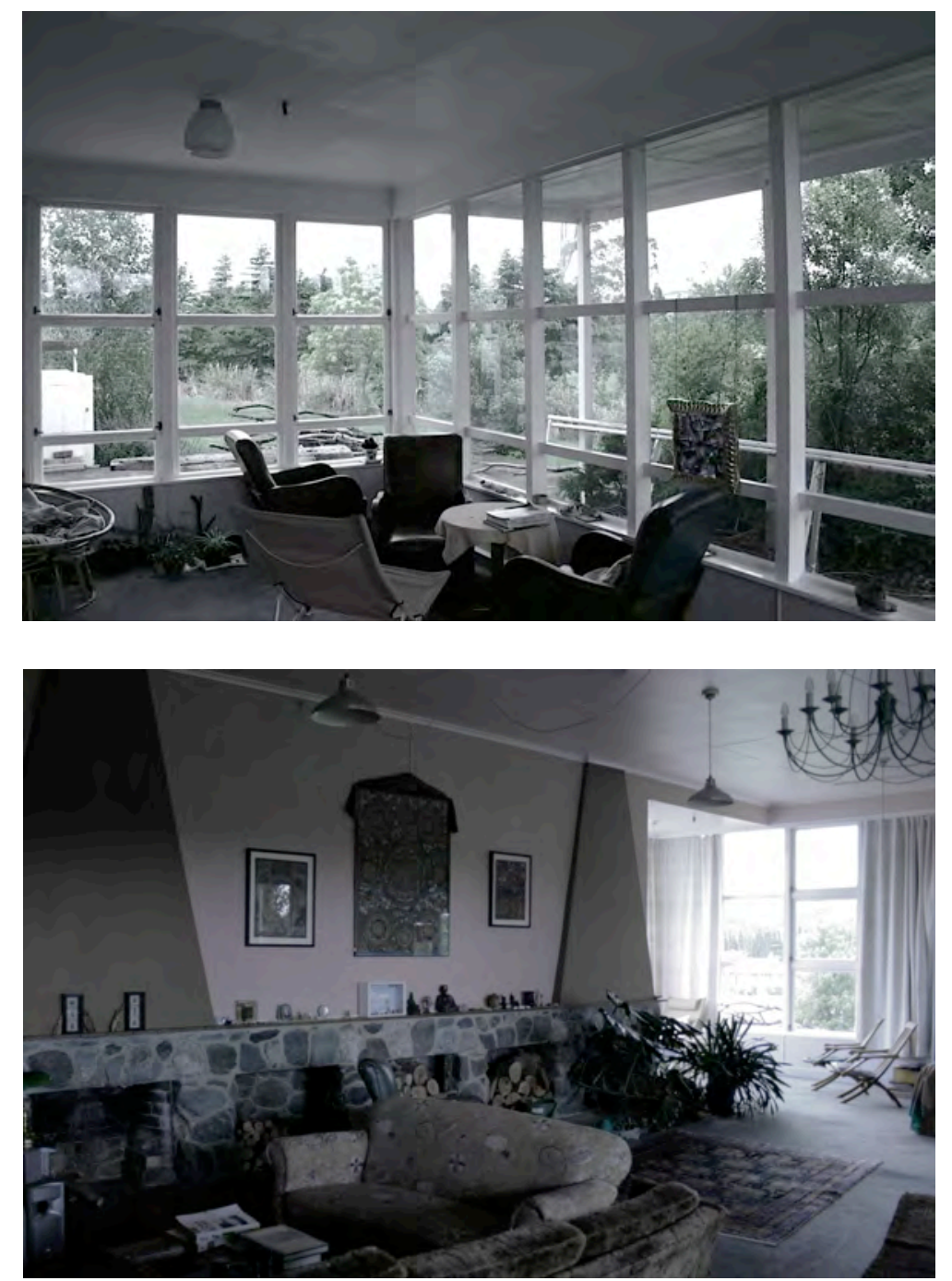

Figure 6.11: Interior of the day room within a Cherry Farm villa (privately owned and occupied), Cherry Farm Hospital, November 17, 2010.

Photograph by author. Note: the owner's furnishings do not reflect this interior as it would have appeared during mental hospital occupation.

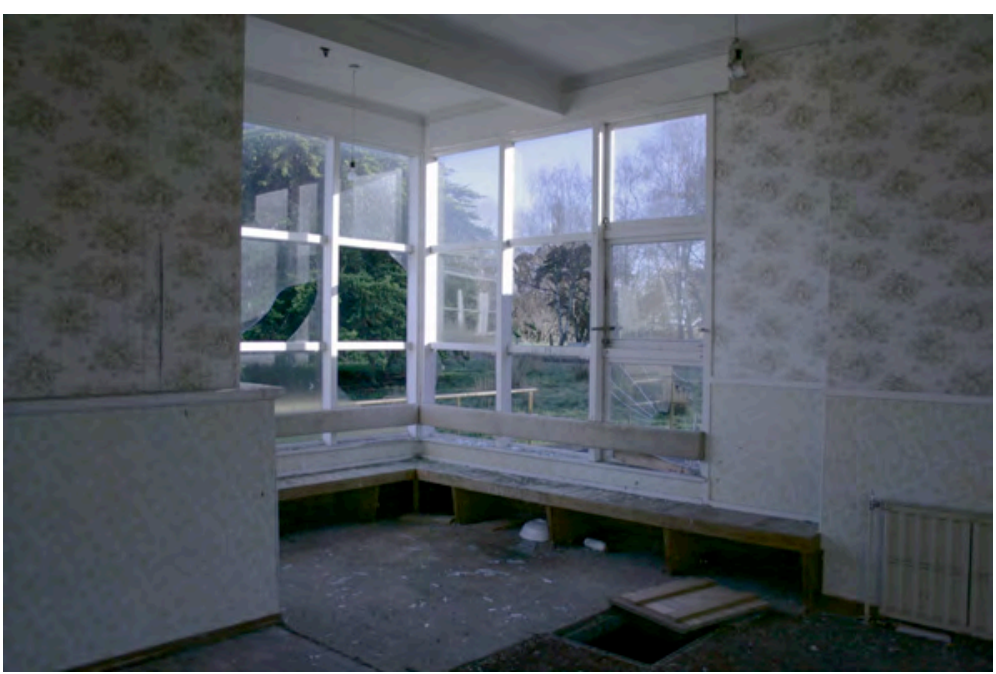

Figure 6.12. Interior of a Cherry Farm villa (vacant), Lake Alice Hospital, June 6, 2010. Photograph by author. 
Unfortunately, the division's commitment to domesticity did not extend to bathrooms, dressing rooms or sleeping spaces. While sleeping spaces were given specific attention within the WHO report, ideals around spaces for bathing and dressing were inferred. These spaces had direct implications for the delivery of care given the reports emphasis on trust, respect and preserving the dignity of the patient "even at the cost of considerable inconvenience." ${ }^{\text {"6 }}$ Dormitories at Cherry Farm slept 16, as did the Porirua and Kingseat villa types designed five and 19 years earlier. In lieu of private rooms, each Cherry Farm villa provided two two-bed wards, a step backwards from Porirua, which provided four private rooms, and Kingseat, which provided eight. This was in keeping with the limitations set within the WHO report and also those given by the Journal of Mental Science (1948). The journal advised a maximum dormitory size of ten to 15 beds and the provision of two to three single rooms associated with each ward. ${ }^{47}$ However, it did not meet the optimum recommendations set out within the WHO report, that dormitories should be limited to eight beds and that single rooms were preferred. ${ }^{48}$ The discussion of privacy in relation to sleeping arrangements was not a new one. Within the nineteenth century, Tuke and Conolly both preferred private rooms over dormitory sleeping. ${ }^{49}$ Mercier had gone as far as to assert that dormitory sleeping was the one great obstacle in the provision of individual care (1894). ${ }^{50}$ The design of bathrooms at Cherry Farm also followed prior models. Similarities between Porirua, Kingseat and Seaview villa types suggested a standardised approach had been in place since the late 1920s: an open room containing two or three bathtubs (as seen at Kingseat). The exception to this rule is the single bathroom provided within the Cherry Farm plan. While this single, private bathroom presented an advance for patients able to attain bathing privileges, it offered no real improvement for the majority. Not until the 1980s were privacy screens erected in the bathrooms and dormitories of New Zealand's mental hospitals.

The dressing space within the Cherry Farm villas, while taking its cue from prior models, advances this design principle in a disconcerting direction. At Kingseat and Porirua dormitories were accessed off a central circulation space that joined them to the main stair. The function of this space was twofold, providing both circulation and dressing space. Between Kingseat and Cherry Farm the physical dimensions of this circulation-cum-dressing space more than doubled in size. Kingseat's dressing room measured roughly $6 \mathrm{x}$ 6.5 metres, while rooms at Porirua were increased to $6 \times 15$ metres with Cherry Farm following suit at $6 \times 16$ metres. At Porirua two banks of 1.7 metre high lockers loosely sub-divided this space into three, a minor attempt at privacy. At Cherry Farm the dressing room was separated only by a series of high backed chairs, providing a partition just 900 millimetres high. Patients referred to this space as "the bus station," 51 fitting for a scale more public than private. The size of Kingseat's dressing space relative to the 50 patients the villa accommodated suggests that patients were likely dressed 
in their dormitory groups of around sixteen. The sheer scale of this space at Cherry Farm suggests that all 50 patients could have been dressed at once (figure 6.13). This was hardly an architectural response that aspired to the preservation of patient dignity and self-esteem.

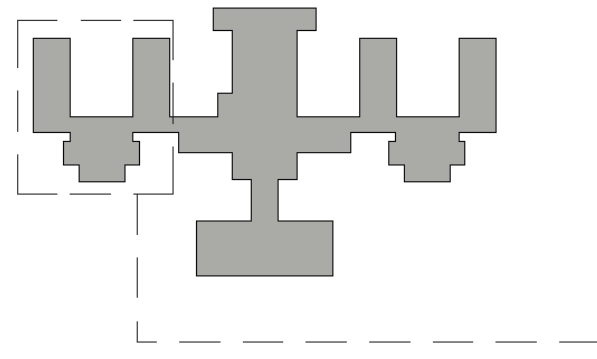

SUNNYSIDE VILLA, 1929

BATHROOM \& DRESSING FACILITIES MIRROR ACROSS VILLA.

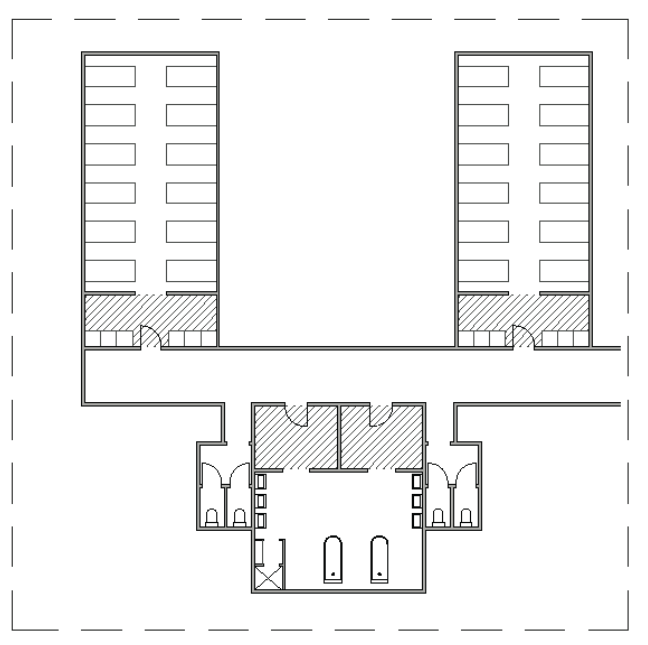

KINGSEAT VILLA, 1924-29

GROUND FLOOR BATHROOOM FACILITIES

INCLUDED 5 W.C.'S AND 2 HAND BASINS.
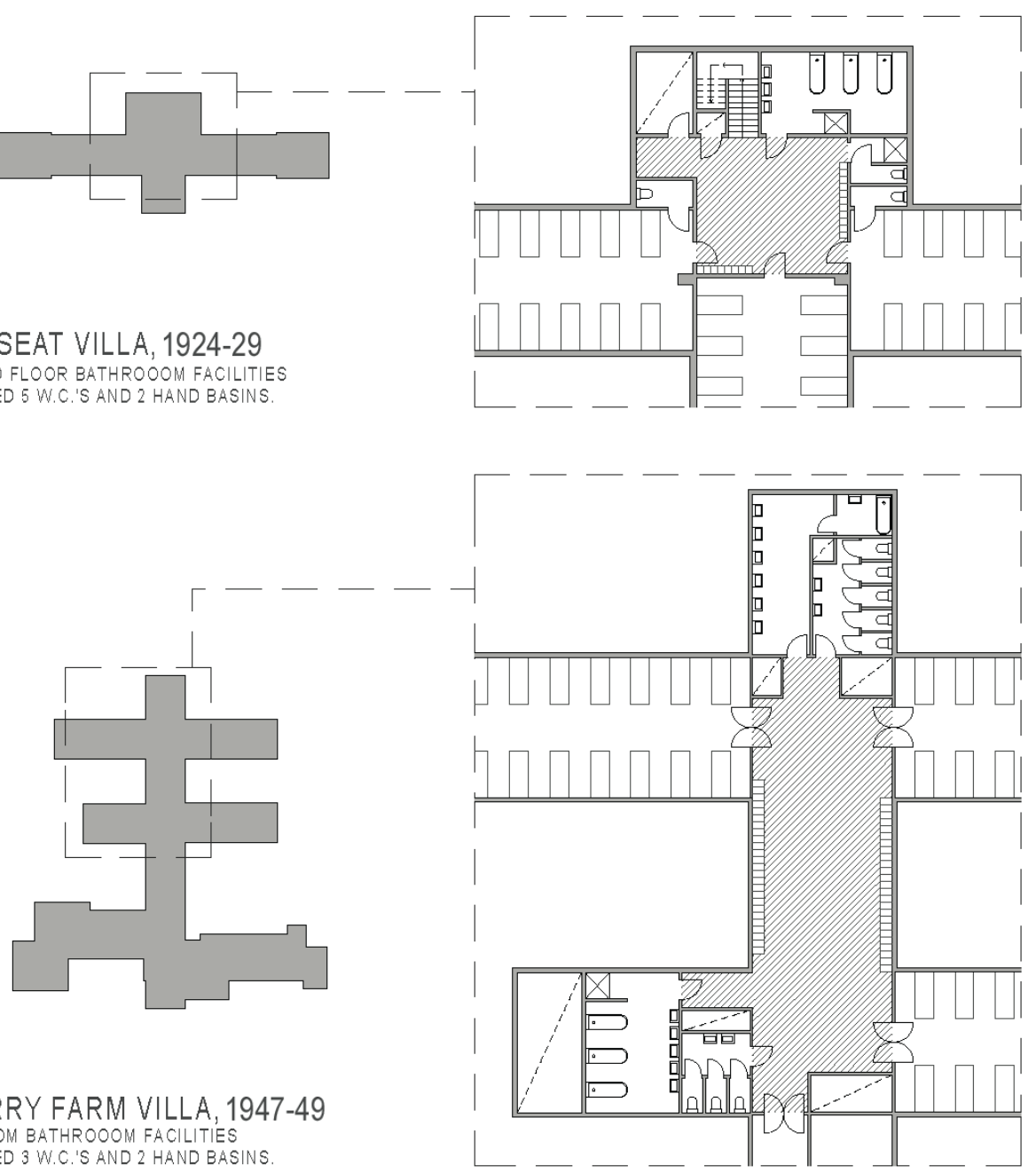

Figure 6.13: Development of bathing and dressing spaces, hatching indicates dressing space. Reconstruction by author. 
The timing of the construction of the greater majority of these villas, following 1955) would have allowed for a review of this design relative to the ideas contained within the WHO report published two years earlier. The media statements made about the Cherry Farm villas relative to the new ideas around treatment begin around 1953, after the release of the WHO report, but are discussed with greater frequency between 1955 and $1957 .{ }^{52}$ While the division inferred, in media statements made about this villa, that this design responded to the ideas contained within this report, these statements were misleading. No improvements were made to the 1947 Cherry Farm villa design. The argument that this design may have incorporated the emergent research that was available prior to the release of this report is refuted by a close examination of this architectural response. Despite claims that these villas provided "a different type of accommodation" and contained "new architectural features in design and layout," 53 these villas offered no real advance over what was already provided by the Kingseat villas, designed two decades earlier. The Cherry Farm villa design made little attempt to respond to new ideas regarding the treatment of mental illness. The design of dressing and sleeping spaces was a key area where architecture could have supported new approaches to treatment, namely, the preservation of self-esteem. Yet, in the provision of these spaces, the Cherry Farm villas appear retrograde against earlier designs. The commitment to constructing more domestic environments did not extend beyond the facades or the spaces that were available for public inspection (entrances and day rooms). The media discussion of the Cherry Farm villas seemed to post-rationalise design intent along the lines espoused in the WHO report which was written four years after the design of these villas was finalised. The WHO report was available, however, when the decision to replicate these villas nationally was made between 1953 and 1955. The following section will discuss whether this research was simply too new at that point in time to have motivated a review of this villa design. 


\subsection{RESPONSES TO EMERGENT RESEARCH}

David Clark may have claimed that the arrival of the WHO report was "an important point in the spread of the general therapeutic community approach," ${ }^{54}$ however, a full decade after its release, he lamented that there was still no "clear prescription" for the successful establishment of a therapeutic community. ${ }^{55} \mathrm{~A}$ direct comparison between the Cherry Farm villas and leading international precedents for this era cannot be made because precedents did not exist. The Cherry Farm Hospital provides a rare example, internationally, of a whole new hospital designed during this era of rapid change. While new wards were added to existing hospitals in Britain following the release of the WHO report, no new hospitals were constructed. In 1959 the Shenley Park Mental Hospital (1932-39), discussed in chapter four as a contemporary of the Kingseat Hospital, was still considered one the most recently constructed mental hospitals in England. ${ }^{56}$ The situation was similar in America where a number of "Treatment Units" were constructed at general hospitals but no new mental hospitals were built. Acknowledging that a hospital cannot be designed in accordance with a report released after construction began, this section will look specifically at the design response of the Cherry Farm 50-bed villa. This section will examine the difficulties around the integration of such new research in the design approach taken to these villas. It will also examine this villa in relation to the design approach taken in America following 1953 and in relation to the existing Lake Alice 11-bed villa design (1940-43).

T.F. Main's call for the mental hospital to be recast as a therapeutic institution, ${ }^{57}$ five years before the WHO report called for this approach, seems remarkable in retrospect but this was not the reception it received at the time. Although the publication Modern Trends in Psychological Medicine 1948 was given a glowing review in the Journal of Mental Science, Main's article was not among the nine that received special mention. The essays that merited further discussion covered such topics as psychosomatic, constitutional and causative factors of mental illness, diagnostics, electrophysiology, psychotherapy and child guidance. ${ }^{58} \mathrm{~A}$ similar reaction followed the release of the WHO report in 1953. Clark recalled that it was generally seen as:

impracticable, idealistic and a distraction from "real doctoring" insulin coma therapy, electroconvulsion therapy, leucotomy and other medical treatments fashionable at that time. ${ }^{59}$

This reaction was paralleled in the New Zealand context. Thompson observed that articles published within the New Zealand Medical Journal evidenced a bias towards scientific approaches. ${ }^{60}$ Although group and psychotherapy were considered integral to the creation of a therapeutic community, these methods remained problematic because they were illdefined. In 1948 J.C. Whitehorn, a professor of psychiatry at Johns Hopkins Hospital, wrote that the literature on psychotherapy had yet to be formulated 
in a scientific way and that there lacked a school of common thought regarding the various techniques: "psychotherapy is an abstract concept; like the skill of a draftsman or surgeon, it is knowable by its results but not in its essence." ${ }^{61}$

What is interesting about the creation of the Lake Alice 11-bed villas is that Gray acknowledged the same drawbacks to institutional care that were acknowledged within the WHO report, released over a decade later. This suggests that while the issues identified in the WHO report, and the research leading up to it, had only been recently acknowledged in the literature, these had been known to hospital staff for decades. An anonymous reviewer for the Journal of Mental Science, for example, wrote in 1895 :

Let us be under no delusion... to many patients the monotony of institution life serves to cripple the intelligence and depress the spirits, so that reaction in either sphere becomes ever weaker and finally fades away all together. ${ }^{62}$

While the villa hospital model was welcomed for its promise of alleviating the negative effects of institutionalization on patients, Gray had recognised that accommodating patients in groups of 50 did not go far enough. ${ }^{63}$ Gray's predecessor, Russell, was also aware of the deterioration of a patient's selfesteem that occurred within the hospital environment. In 1948 a number of non-architectural improvements were made to the hospital environment, under Russell's directorship, and were aimed at encouraging "selfconfidence and esteem" among patients. ${ }^{64}$ This suggests an engagement with emergent research. The non-architectural improvements included the supply of underwear to any patient who desired it (this was not previously done), the appointment of hairdressers to mental hospitals and the provision of a small weekly allowance for all patients. ${ }^{65}$ The application of these new ideas to architecture, however, occurred only in a piecemeal fashion. In 1949 , for example, Russell issued instructions that all hospital dining rooms were to be refurnished with "small tables for four, six or eight [patients]," fulllength mirrors were to be installed to patient dressing rooms and wards were refurnished to include comfortable chairs, rugs, "bright" curtains and coloured bedspreads. Small laundries were added to some wards in order to "encourage patients to wash and care for their personal clothing." Spaces within "every ward of every hospital" were to be made available for the purpose of clinical examination and patient interviews. ${ }^{66}$

In June of 1947, Russell sent a memorandum to all mental hospital superintendents asking for their suggestions regarding the design of the new villa type that was being developed for Cherry Farm. While Russell's own thoughts regarding "various improvements" which, he informed hospital superintendents had been "in his mind for some time" are missing from archival files, the responses to this memorandum are available. ${ }^{67}$ The recommendations received related largely to matters of material durability 
and the specification of various fittings. Sunnyside Hospital, for example, advised that "windows with sash chains [were] unsuitable," while Kingseat requested that closer attention be paid to the adequacy of pantry fittings and door latches. Seaview advised that a villa built on similar lines to their existing "Irangatau" villa "would be the most suitable for patients and staff." Sunnyside and Tokanui agreed that fireplaces were troublesome and central heating was preferred. Seaview, Tokanui and Ngawhatu all requested "more space," either in general or specifically related to dormitories, dining, dressing and bath rooms. This request was a reflection of operational concerns - staff requested more space to circulate patients and equipment within these spaces. ${ }^{68}$

Very few recommendations that would directly benefit the patient experience of these villas were included in the feedback received from superintendents. Separate visiting rooms were requested by the Levin Farm Colony, Kingseat, Tokanui and Ngawhatu Hospitals, however, the correspondence indicates that this was as much a concern of patient privacy as one of alleviating pressure on staff. Tokanui noted that the provision of separate visitor spaces would be especially useful for wet days. ${ }^{69}$ In comparison to the recommendations received from other hospitals, those sent in from Ngawhatu evidenced a level of insight missing elsewhere. While replies from the other hospitals were headed up "New Villas," the subject line of Ngawhatu's reply was "Ideal Villa." Their response began: "Below is a brief summary of suggestions collected from various members of staff as a basis for an ideal villa [emphasis added]." Staff felt that a villa of 44-beds was the "most feasible" size if the present, nationwide staffing shortages were taken into account. They recommended that dormitories be limited to 12 beds and that eight single rooms be provided within each villa. ${ }^{70}$ The staff at Ngawhatu had experience with two variant villa types, an earlier version of the Kingseat villa and the Seaview villa design (refer chapter four for plans). The latter featured dormitories of only 12 beds, four less than the Kingseat dormitories, and the Kingseat villas provided eight single rooms where Seaview provided none. In villas for better behaved patients, staff suggested that single rooms should have wardrobes fitted, similar to what was already being provided for nurses. Additional storerooms should be located close to dormitories where patients' clothing could be hung up, instead of stored in bundles. In villas where physically sick patients were to be accommodated, the addition of glazed verandas to the ends of dormitories was suggested. Staff felt that dining rooms should be furnished with small tables and that skylights should be installed to dining rooms, kitchens and day rooms in order to make them brighter. ${ }^{71}$ These two suggestions were adopted in the design of the Cherry Farm villas, along with the provision of storage space to hang patients' clothes but no further suggestions made by the Ngawhatu staff were incorporated. 
The suggestions provided by the Ngawhatu staff resided much closer to the ideals that would later be outlined within the WHO report than the suggestions made by other hospitals. As the previous chapter outlined, Ngawhatu was the first villa hospital constructed by Gray. While Brunton suggests that Gray was instrumental in the planning of Ngawhatu, archival records suggest he remained closely involved with the running of this hospital even following his shift to head office in Wellington. ${ }^{72}$ The fact that staff, of their own accord, gave thought to an "Ideal Villa," and considered so many factors from the perspective of patient comfort, may be indicative of Gray's residual influence at this hospital. This seems a more likely explanation than that they were somehow simply more cognisant of the emergent research than staff situated at other hospitals, or even within head office. Another point in support of this hypothesis is that Ngawhatu's feedback was the only set of suggestions that made any reference to the Lake Alice 11-bed villas, Gray's personal attempt to advance the villa hospital model. While the response from Ngawhatu admitted unfamiliarity with the layout of these new villas, the superintendent felt that they were worthy of consideration (figure 6.14). He did add, however, that Ngawhatu Hospital did not have a "very great" number of patients who would be "suitable for caring for themselves in such groups."73

The response that had already been created for Lake Alice met many of the therapeutic aspirations set out within the WHO report. They offered increased privacy, not only for dressing and bathing but also for day to day living. In fact, Gray stated that "more privacy" was a key design intent in the creation of these villas. ${ }^{74}$ Patients slept either in single rooms or in a maximum dormitory size of four. Baths and showers were located within separate enclosures. While a locker room was provided downstairs, no central dressing space was required as patients could dress in their own bedrooms where each was provided with a wardrobe and dresser. The scale of these buildings was deliberately related to the scale of a family home and their clustering in the landscape gave the clear impression that the "village had been taken as its model" far in advance of the WHO report recommending so. ${ }^{75}$ An architectural response that allowed patients to live in small groups, cook their own meals, launder their own clothes and bathe in private created a situation where the accordance of trust to patients was non-negotiable. Furthermore, it provided opportunities for patient autonomy and supported the process of reacquainting patients with the everyday responsibilities of life beyond the hospital. The Lake Alice 11-bed villas went a step further than the prescriptions of the WHO report's recommendation that patients be housed in groups of 25 to $30 .^{76}$ 

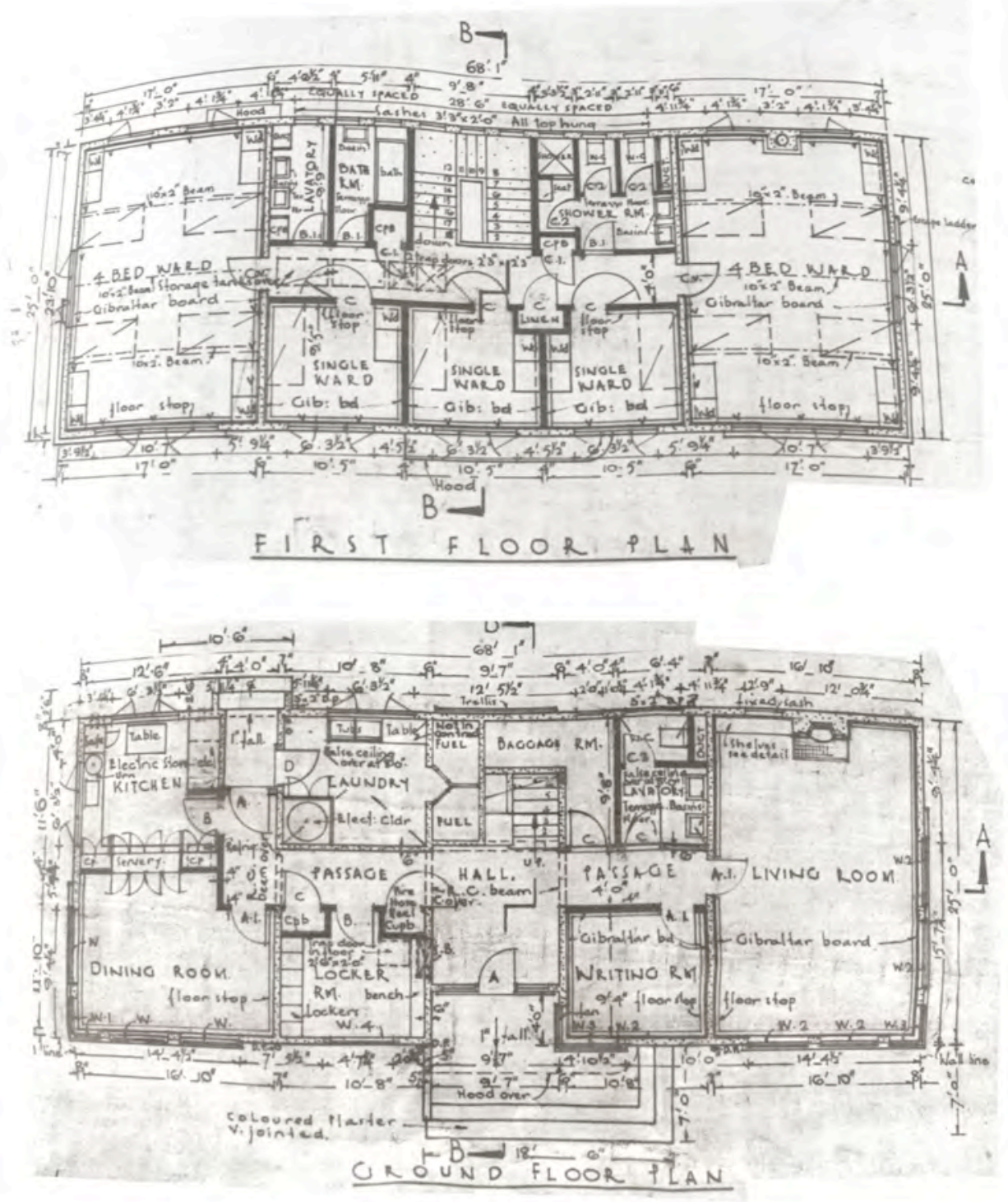

Figure 6.14: Lake Alice eleven-bed villa, 1947 (plan cropped and colour adjusted by author for clarity). Archives New Zealand: W33 4716889.

The fact that the Ngawhatu staff made a number of suggestions that resided closer to the ideals of the WHO report discounts the argument that this research was simply too new to be incorporated. In the design of the Cherry Farm villas there was a distinct lack of vision. While Gray was motivated by concerns of how architecture could best support the treatment of mental illness, Russell's attention was drawn to operational issues. Expressing concern for hospital laundries, for the durability of hospital interiors and for maintaining the appearance of cleanliness, Russell issued the following instructions: checked "gingham" was preferred over plain white tablecloths. Coloured bedspreads should be used for all but admission wards where "crisp white" bedding should be retained. Plain brown linoleum should be kept in admission and hospital wards but elsewhere, "patterned" flooring was to be installed. ${ }^{77}$ 
Following the publication of the WHO report in 1953, American professionals embarked on an active search for an architecture that could respond to changing approaches to patient care. This provides a valuable example of how emergent research can be integrated into the architectural design process for new hospitals, even before such research is consolidated. After attending the meeting of the WHO's expert committee in Geneva, Dr Daniel Blain, Director of the American Psychiatric Association (hereafter APA), organised a conference of this association in April of 1952. At that conference it was decided that an Architectural Study Project was required to consider how the professions of architecture and psychiatry might "collaborate more effectively in relating [the] design of psychiatric facilities to the actual needs of the patients who inhabit them." ${ }^{\text {"78 }}$ A number of hospitals, who were engaged in the construction of new facilities between 1952 and 1956, became involved with this programme.

The design of an Intensive Treatment Unit for the Central State Hospital in Indiana (1951-56) offers a particularly relevant example because it closely matches what might be considered an ideal design approach. Dr C.L. Williams acknowledged that the problem of changing therapeutic programs relative to the longevity of these facilities made it necessary to plan for what the hospital may need in five or ten years time.$^{79}$ According to Williams, the medical team "studied all the materials we could lay our hands on," including the most recent journal literature on design, day centres and outpatient clinics, and turned this information over to their appointed architect. In addition to familiarising himself with this research, the architect spent time with key hospital staff including the superintendent, outpatient clinic director and director of nursing. He also paid visits to a number of similar units located within the United States. More importantly, however, the architect "saw patients admitted, worked with the intake staff, conferred with the nursing department, the social service workers, the psychologists and the recreational therapists." The final design for the Indiana Hospital Unit represented nearly "one and a half years of close collaboration with the hospital personnel." 80

This was very different to the design approach taken in New Zealand. Firstly, the division had no say over the appointment of architects as mental hospital work was carried out by the Government's Ministry of Works (formerly the Public Works Department). This arrangement had been in place since the design of Porirua Asylum in 1890. Regardless of the hospitals location, designs were prepared by head office in Wellington, in consultation with the Director of the Division of Mental Hygiene. If hospital staff wanted to provide feedback on any design issues this had to be sent to the Government Architect via the director of the division. A local, or district, architect, would be responsible for supervising the works on site and attending to any issues that cropped up during the procurement process (figure 6.15). 


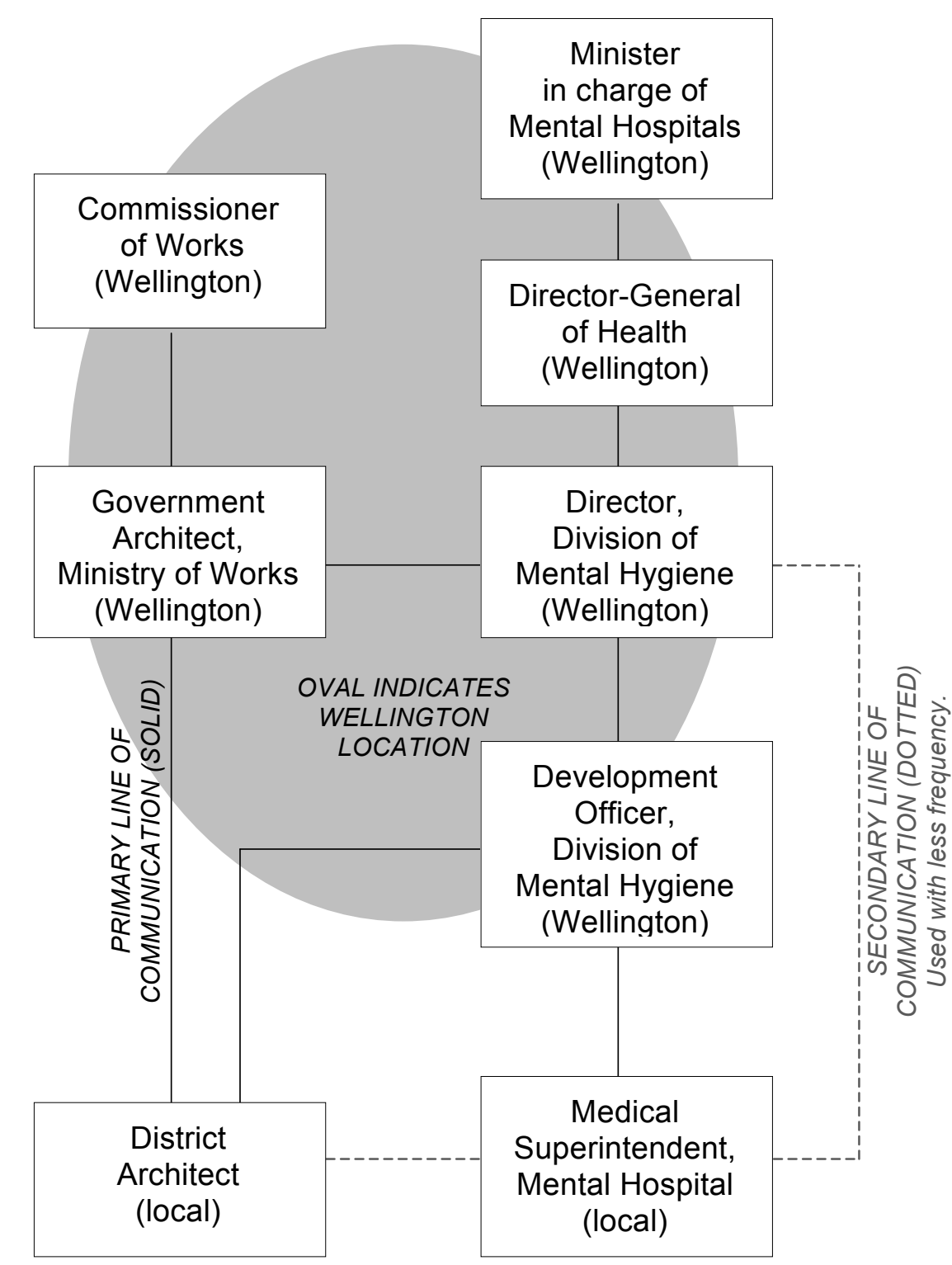

Figure 6.15: Relationship Diagram showing lines of communication for Design and Procurement Process of New Zealand Mental Hospitals.

Diagram by author.

Similar to the design process taken for the Indiana Facility, it had been suggested, in 1944, by the superintendent of Tokanui Hospital that "it would be advisable for the architect to see the hospital under actual working conditions." ${ }^{11}$ It was an excellent idea but not one that was evidently taken up. While few archival records pertain to the design of the Cherry Farm villas or the hospital itself, much correspondence survives with regard to the design of the Admission Hospital for this site in 1958. These documents suggest that the head office architects responsible for these designs seldom visited the site. Nor did they seem particularly interested in responding to the preferences of hospital staff. ${ }^{82}$ This led to misunderstandings around site constraints, operational procedures and the factors staff considered necessary to achieve an optimal environment for treatment. ${ }^{83}$ This is evident 
within the correspondence between the hospital superintendent and the director of the division, regarding the design of the Admission Hospital in 1958:

As orientated in the latest Head Office suggestions, the building will suffer considerable loss of sun and will not be well sited in relation to prevailing cold winds. It is also within a chain and a half [30 metres] of the laundry and the site will appear far more cramped in practice than it does in plan as the considerable volume of traffic, both vehicular and pedestrian, to the services block will further restrict space. $^{84}$

In the case of the Admission Hospital, the District Architect consulted with staff on site and prepared a more suitable scheme that responded to the site's constraints, staff preferences and operational concerns. It was then up to the Government Architect to approve this design for construction. ${ }^{85}$ While this unit was never constructed at Cherry Farm, the correspondence highlights the value of not designing these facilities from a distance. Nonetheless, this was an approach that continued to be followed. A decade later this same, standard design was constructed instead on the site of the Wakari General Hospital grounds and little design development appeared to have taken place. ${ }^{86}$

The Ministry of Works suffered from significant shortages of experienced professional staff during the period when the Cherry Farm villas were designed and replicated nationally. In 1954, Lewis complained that the priorities of the Division of Mental Hygiene had been repeatedly forced to change owing to issues beyond their control. During World War II "capital was available and labour and materials were not" and once these became available the Ministry of Works suffered a shortage of draftsmen to carry out the work. ${ }^{87}$ For the period 1950-1952, despite being in a position of severe overcrowding, only 75 per cent of the funding allocated to the division for new works was able to be spent. ${ }^{88}$ While the ministry's Annual Report for 1956 stated that, owing to a "lack of suitable trained staff" only 77 per cent of the ministry's workload was able to be completed during that year. The report acknowledged that the ministry had been operating with severe staff shortages for many years. ${ }^{89}$ These shortages had a direct impact on the effort the ministry was willing and able to spend on the design development of mental hospital facilities as the examples of the Cherry Farm admission unit and the villas created for the Levin Farm Colony illustrate.

The model created for the Admission Unit on the Cherry Farm site was published in the Otago Daily Times in 1964 but, owing to the decision to locate this unit at Wakari instead, tender documents were not ready until June of 1968. That year a new Admission Unit was under construction at the Palmerston North (general) Hospital. While a plan of this unit could not be located, correspondence suggests that this design was an advance on the one created for Cherry Farm. ${ }^{90}$ The Dunedin Office of the Ministry of 
Works was asked to amend the Wakari documentation to reflect the more recent design. Their response offers some indication of the wider impact of stretched staffing resources within the works department relative to the procurement of new mental hospital facilities. Having first documented this unit for the Cherry Farm site and re-documented it for the Wakari site, the District Architect stated his unwillingness to entertain further amendments to this project in no uncertain terms. Following a lengthy memorandum to the Government Architect outlining his position, the District Architect concluded that: "we offer the greatest protest possible to the suggestion of using the Palmerston North [design]."

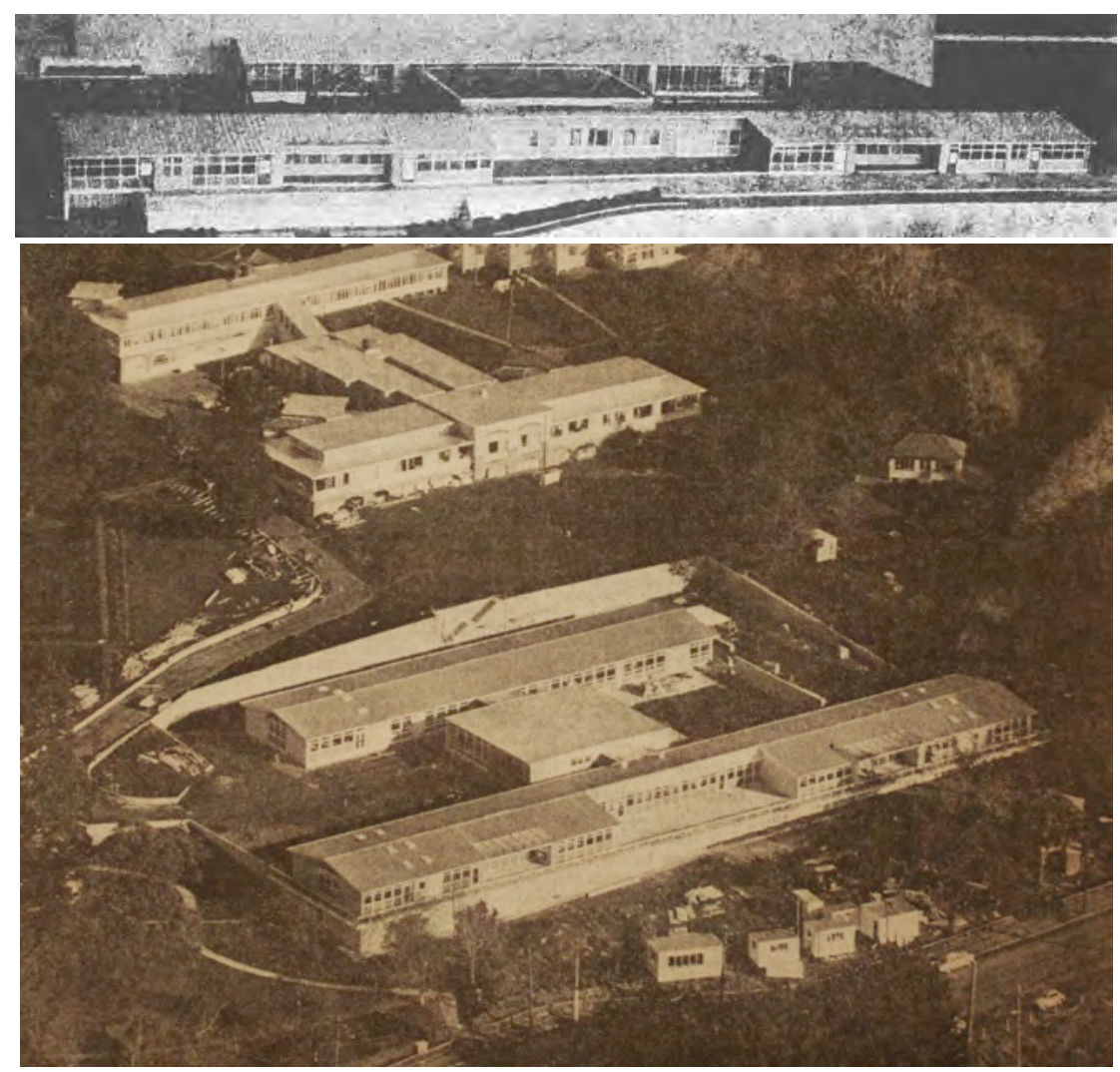

Figure 6.16: Development of the Cherry Farm Reception Unit.

A model of the design prepared for the Cherry Farm site (top), as published in the

Otago Daily Times, August 11, 1964, and the unit under construction at Wakari (bottom), from a newspaper clipping dated July 08, 1970, publication not disclosed. Archives New Zealand: AAQB W3950 305.

Anne Hunt's description of the design and consultation process surrounding new villas for the Levin Farm Colony in 1953 provides a further example of the toll that these shortages took. A senior staff member of the Levin Farm Colony recounted to Hunt that despite having provided a number of planning suggestions to the Ministry of Works, staff were told to accept their designs or have nothing at all. ${ }^{92}$ Once the buildings were completed, he recalled, "we would then have to set our own workman to get the place serviceable." 93 This observation was consistent with an account given by the former maintenance manager of this hospital. He stated that new 
buildings provided by the Ministry of Works were often unsuitable for the hospitals needs, especially since this facility accommodated a large number of physically and intellectually handicapped children. Changes made by the maintenance team included raising the height of bathtubs, so that nursing staff could bathe children more easily, altering shower cubicles for wheelchair access and filling in the open air walkways (that linked the dormitories to the dining rooms) so that these were suitable for all weather use. $^{94}$ These were fundamental operational oversights on the architect's part.

The architect appointed to design the Indiana Unit had no previous design experience with mental hospitals which may explain his enthusiasm for learning all that he could through first hand observation. ${ }^{95}$ By comparison, the prior experience of the Ministry of Works in designing facilities for New Zealand's mental hospitals may have provided a hindrance. To approach the design of these villas from first principles would have been regarded as an unnecessary expense. Even if the division had requested a review of the Cherry Farm villas relative to the WHO report, between 1953 and 1955, it is unlikely that the Ministry of Works would have had the staffing capacity to meet this request.

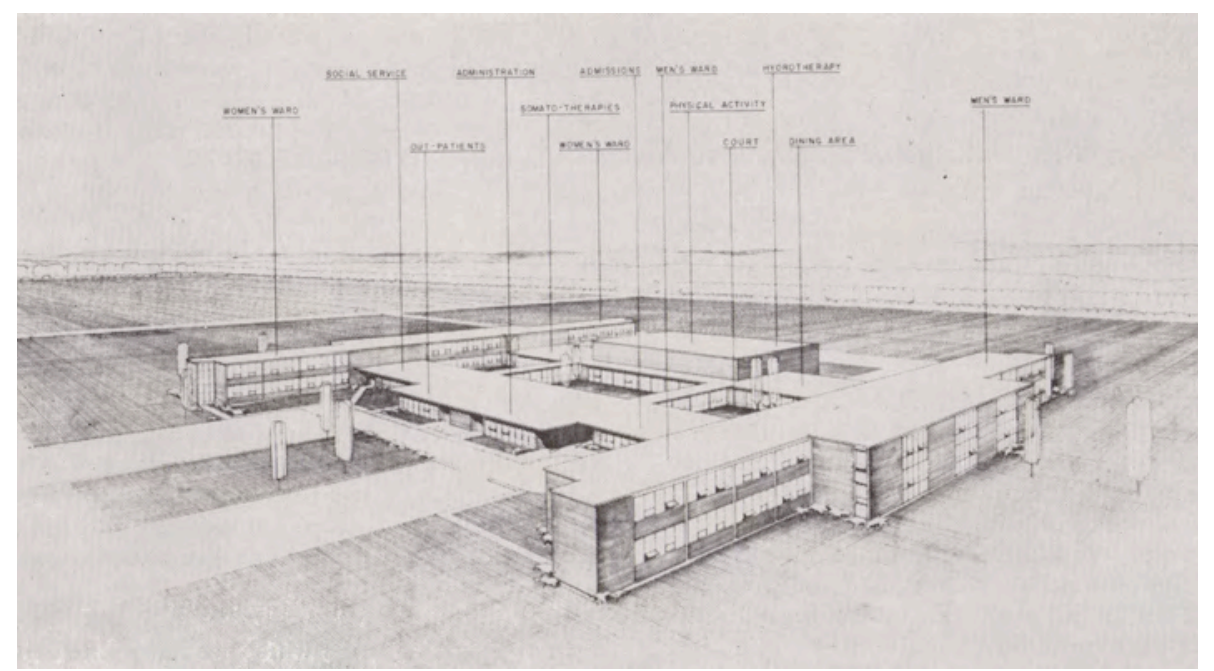

Figure 6.17: Proposed Acute Care Unit at Central State Hospital, Indiana. As published in Psychiatric Architecture (APA: Washington, 1959).

Design process aside, the Intensive Treatment Unit at the Central State Hospital in Indiana could not be considered a leading precedent (figure 6.17). The constraints of budget, site and inadequate staffing were all acknowledged as having an effect on this architectural outcome. The architect even stated that a villa hospital (or "a cottage-type plan" in American terminology) was the option deemed "to best serve the needs of patients" but the space available and the close proximity of the site to a residential area prevented this response. ${ }^{96}$ The Indiana Unit did not offer any new ideas regarding mental hospital architecture, however, the ambition behind the design merits acknowledgement. While some design 
solutions were more successful than others, the architect confirmed a desire to support treatment values through architecture and to employ spatial design to safeguard the delivery of individual care. ${ }^{97}$

While the WHO report suggested an ideal dormitory size of six to eight beds, decision makers in the design of the Indiana Unit acknowledged that an eight-bed dormitory could easily be occupied by 12 to 16 beds. A dormitory containing only two beds, on the other hand, would not have the available space to accommodate more beds than it was designed for. The decision was made to restrict the physical size of patient rooms to the "minimum comfortable dimensions" for two beds with the explicit intention of avoiding a "future threat of overcrowding." ${ }^{\text {" }}$ Furthermore, architectural solutions were sought that could "encourage the formation of stable human relationships." The architect explained that they hoped to achieve this through the placement of glazed corridors and the careful positioning of living rooms relative to these corridors. Providing areas for large and small groups as well as individual retreats was hoped to "encourage [the development of] small interpersonal relationships" which would help get patients "back into society as soon as possible." "While this was probably wishful thinking, it was, nonetheless, an attempt to address wider issues regarding the relationship between architecture and the treatment of mental illness.

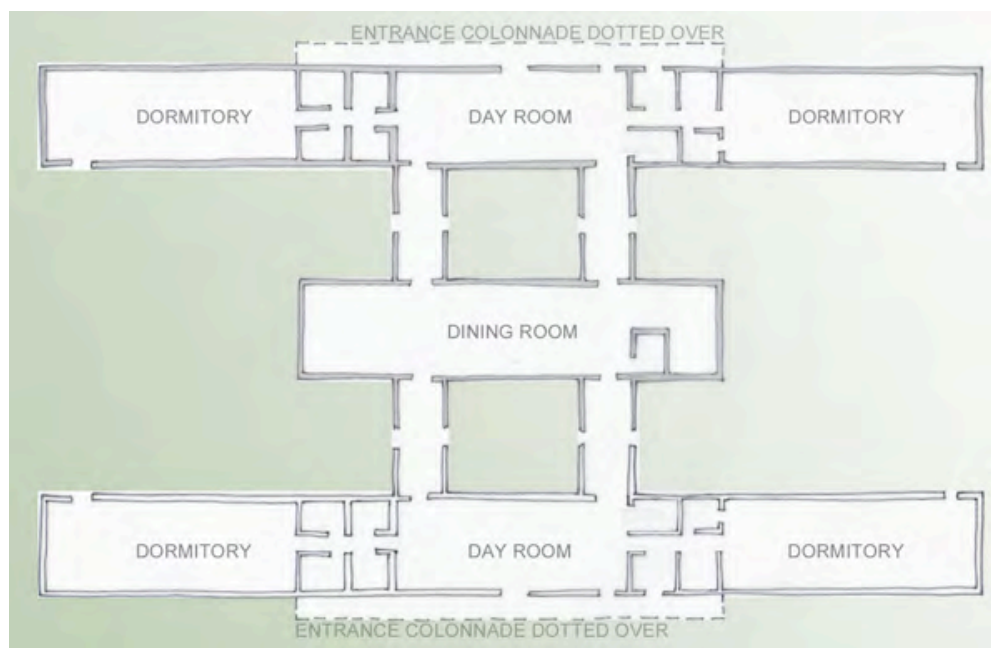

Figure 6.18: Plan of a 160-bed villa, Manteno State Hospital, Illinios.

Redrawn for clarity by author from a site analysis drawing by Megan Read

for the Manteno Project - http://www.mantenostatehospital.com

It should be acknowledged that, in 1952 when Blain organised the conference of the APA to specifically address hospital architecture relative to the WHO's new recommendations on treatment, American mental hospitals were entirely unsuitable to foster and house therapeutic communities. Facilities in America consisted of either nineteenth century facilities (often of the Kirkbride design) or inter-war constructions that $\mathrm{Dr}$ Charles Goshen, speaking on behalf of the APA, called "human warehouses ... [where] the most prevalent design theme... [was] their 
similarity to prisons." ${ }^{100}$ The Manteno State Hospital, a 10,000-bed hospital constructed in Illinois between 1928 and 1935, fits with Goshen's observation (figures 6.18 and 6.19). ${ }^{101}$ It was this situation that led to the APA to identify that "a serious contradiction existed between the treatment programme [encouraged by the WHO report] and the existing hospital designs." ${ }^{102}$ New Zealand did not face such a crisis of contradiction because, in 1953, a significant percentage of accommodation was already being provided in 50-bed villas. Porirua had been demolished (following earthquake damage) and the end was in sight for Seacliff, leaving only the nineteenth century facilities at Sunnyside and Auckland in use. The late, and therefore limited, construction of nineteenth century asylums combined with a relatively early adoption of the villa hospital put New Zealand in a comparatively enviable position in 1953. This does not change the fact, however, that American professionals took seriously the WHO's recommendation that there was "room for much experimentation" in the planning mental healthcare facilities while New Zealand professionals did not. ${ }^{103}$ Furthermore, in 1953 New Zealand already had an experimental architectural response that was able to satisfy a number of concerns contained within the WHO report. Gray had already undertaken the work of experimentation with his development of the 11-bed villa. While two 10-bed villas were constructed at the Cherry Farm Hospital (of a varying design to those at Lake Alice) these were intended to house only two per cent of the hospital population, not the 40 per cent intended at Lake Alice.

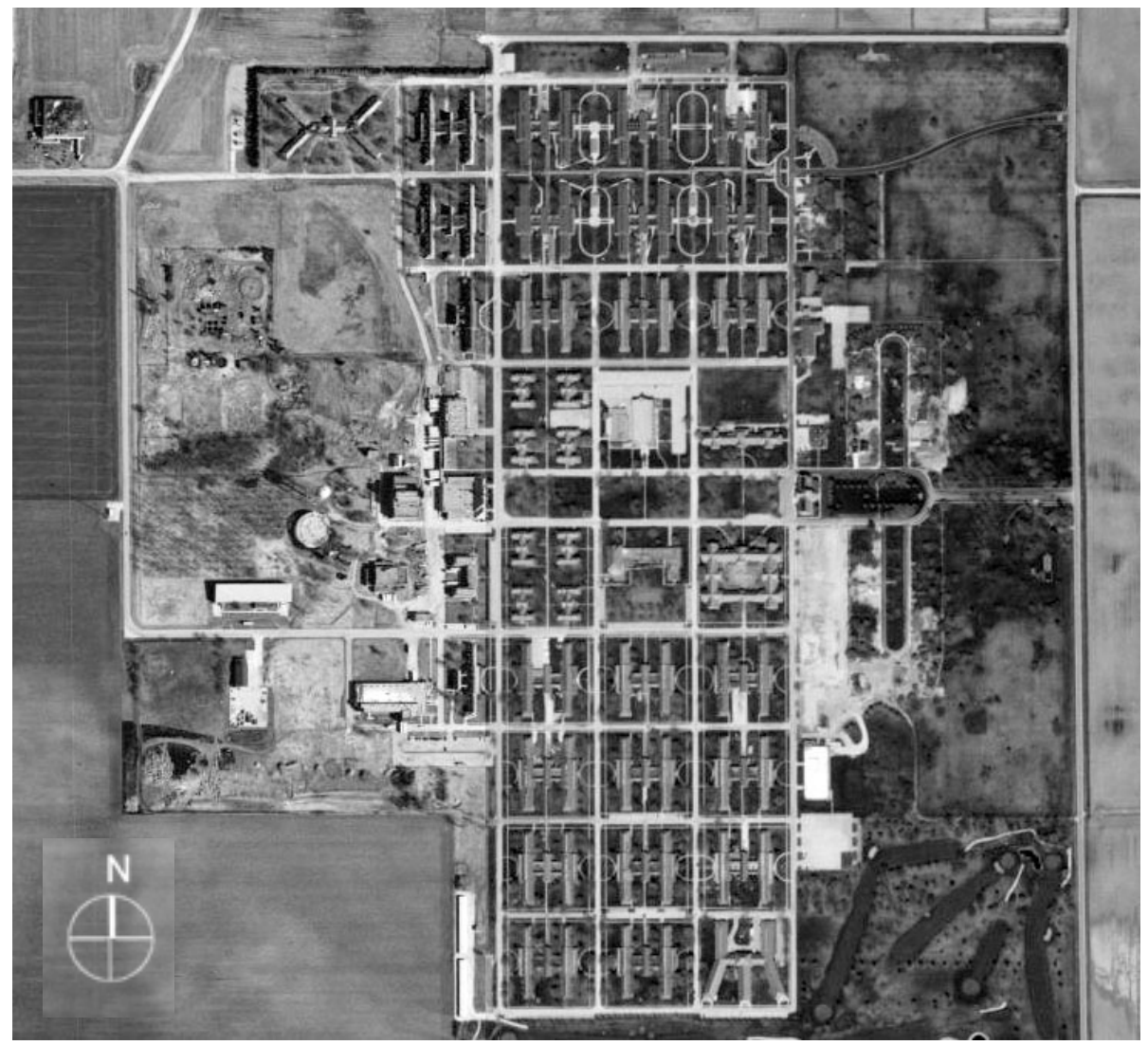

Figure 6.19: Satellite photograph of Manteno State Hospital, 1998. Google earth image (April 12 1998): U.S. Geological Survey, NASA. 
The response created for Cherry Farm villas was not limited by the timing of the emergent research around patient care but by a lack of vision on the part of those who consulted on their design. American professionals documented active experimentation, following 1953, in order to address the wider issues regarding the relationship between architecture and treatment, and to find an appropriately fitting response. The Division of Mental Hygiene lacked the control over their design and procurement processes that would have enabled closer collaboration between doctors and architects. They were limited in this regard. A review of the Cherry Farm villas following 1953 would have been impossible given the staffing shortages experienced by the Ministry of Works. However, existing already within the portfolio of New Zealand's mental hospitals was a solution that met the aspirations of the WHO report. Gray had already undertaken this work. All the division needed to do was recognise the potential of the Lake Alice 11-bed villas. The following section will examine issues that were peripheral to the delivery of treatment but nonetheless impacted negatively on the design approach taken to these villas, to the wider hospital and, furthermore, prevented the replication of the Lake Alice 11-bed villas. 


\subsection{OBSTACLES TO INNOVATION IN THE DESIGN OF CHERRY FARM}

Earlier sections have hinted at the precarious funding environment in which the Cherry Farm Hospital was procured; this section will look at the wider implications of funding for New Zealand's network of mental hospitals. Likewise, where earlier sections have detailed the international context within which these villas were designed, this section will focus on issues of national concern. Finally, it will provide an explanation for why the Lake Alice 11-bed villas were never replicated.

While Brunton suggests that Russell's resignation in 1950 was in protest of the recent amalgamation of the Mental Hospitals Department with the Department of Health, ${ }^{104}$ frustration regarding the procurement of adequate hospital accommodation likely contributed to his decision. Before leaving, Russell confirmed that the situation that Gray had previously warned the government was likely to occur (1936) was now upon them:

Mental hospitals are overcrowded to an extent of over 1,000 patients ... a complete new mental hospital its urgently necessary, "on a short term programme" ... Cherry Farm is of no assistance whatever in overcoming the overcrowding situation. All buildings there will only meet the local situation, which requires ... the destruction of the most dangerous parts of Seacliff Hospital. ${ }^{105}$

Fourteen days later, in the same memorandum where he stated that it had been "the policy of all Government's" between 1928 and 1950 "to restrict expenditure" on his department (discussed in the previous chapter), Russell wrote:

such a policy cannot continue indefinitely. I have done what is in my powers to improve internal conditions. Neither I nor my successor can improve housing conditions and accommodation without considerable expenditure. ${ }^{106}$

Three months later, the division's Development Officer calculated that the funding allocated to mental hospitals, for the years 1951-1954, would not be enough to meet the financial commitments of projects already under construction, let alone to begin new ones. He also calculated that the number of new admissions each year added 200 patients to New Zealand's national mental hospital population. The result was that, despite the new accommodation already under construction, within four years, bed shortages would climb to $1,256 .{ }^{107}$ Russell's successor, R.G.T. Lewis, made his own calculations. Since Seacliff, the original Nelson Asylum building (then occupied by children) and the "Tin Wing" at Sunnyside all still required replacement, in actual fact, 1,670 new beds would be required by $1954 .^{108}$ Despite making this point to the New Zealand Government in 1951, less than a year later Lewis received a memorandum that read:

Cabinet has decided that the annual expenditure on works development [across all sectors] has reached a figure which cannot 
be sustained if we are to continue financing the cost of development works on sound lines... there will be little finance available for new works. ${ }^{109}$

At this time, the patients of New Zealand's mental hospitals were sleeping in day rooms, corridors, storerooms or verandas - anywhere that additional beds would fit. But bed space was not the only problem caused by overcrowding. Lewis complained, in 1954, that finding room for new medical equipment, staff training or patient recreation was impossible. This impacted negatively on several aspects of the hospital environment. Lewis explained that voluntary patients tended to leave earlier than was suited to their recovery because a suitable therapeutic atmosphere could not be achieved in admission wards. As there was nowhere else to put them, "unsuitable patients" were being housed in these wards where they retarded the recovery of newly admitted patients. This also affected the recruitment and retention of staff because, Lewis wrote:

the overcrowding of patients makes working conditions less attractive... it is impossible for staff to give proper care to patients under such conditions and they become discouraged. ${ }^{110}$

In 1954 the funding required to overcome present bed shortages within New Zealand's mental hospitals was calculated at $£ 2,848,000$. To put this in context, it was over double the total amount voted for all public buildings to be constructed across New Zealand that year. In accordance with typical annual allocations of expenditure, the Division of Mental Hygiene could expect around $£ 350,000$ to service its building programme. Lewis asked whether it would be possible for the Government to address the needs of this department under a separate funding vote owing to its very different nature and urgent need. ${ }^{111}$ It didn't happen.

As a result of the obstacles to building procurement, the Division of Mental Hygiene made a number of compromises. The construction of tuberculosis units, for which documentation had already been completed and tenders called, was deferred in favour of providing accommodation for the children resident in the Nelson Asylum and at various hospitals around the country. At Kingseat, for example, 50 children were resident in 1953, accommodated within adult wards. ${ }^{112}$ The waiting list for admission to the Levin Farm Colony that year contained the names of 400 children. ${ }^{113}$ The division made further sacrifices in lowering their standards regarding new accommodation at this facility. While four villas of a modified Cherry Farm design were intended to be constructed at Levin Farm, the division offered to construct the same number of beds at half the cost. A more affordable "H-type" villa was suggested at a cost of $£ 31,000$ against Cherry Farm's $£ 69,000$ (figure 6.20 and 6.21). ${ }^{114}$ In terms of the quality and provision of internal spaces these villas were significantly inferior. Landscape views, sunshine and play space, all elements that could have improved the experience of these villas for children, were absent. The division's motivation in making this 
compromise, however, was beyond reproach. There is no doubt that this presented a lesser evil than caring for children within mental hospitals "with adult psychotics who can do harm to the child's development."

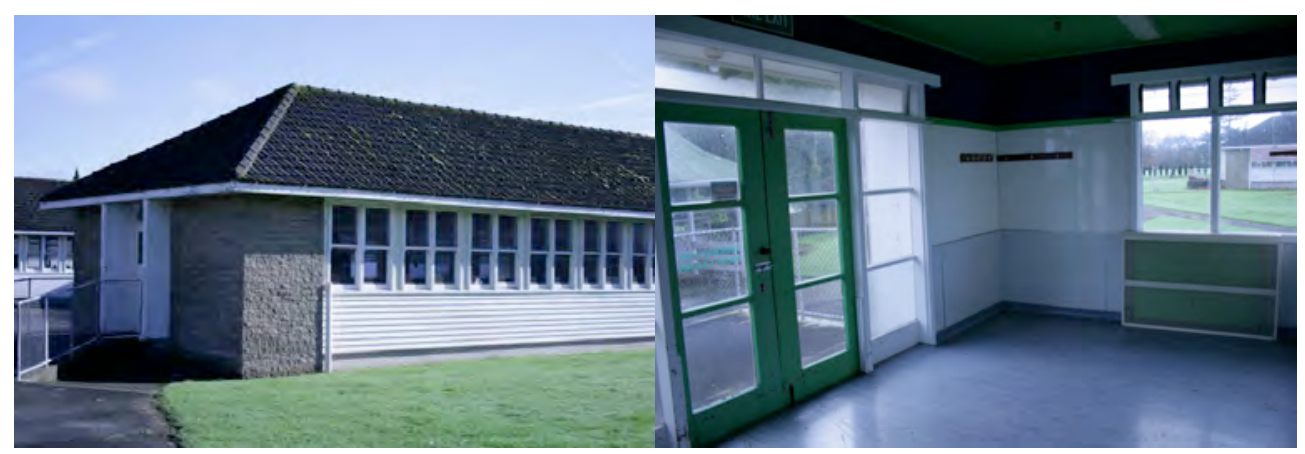

Figure 6.20: The exterior treatment and sun room interior of the $\mathrm{H}$-shape villas at Levin Farm Colony. June 3, 2010. Photograph by author.
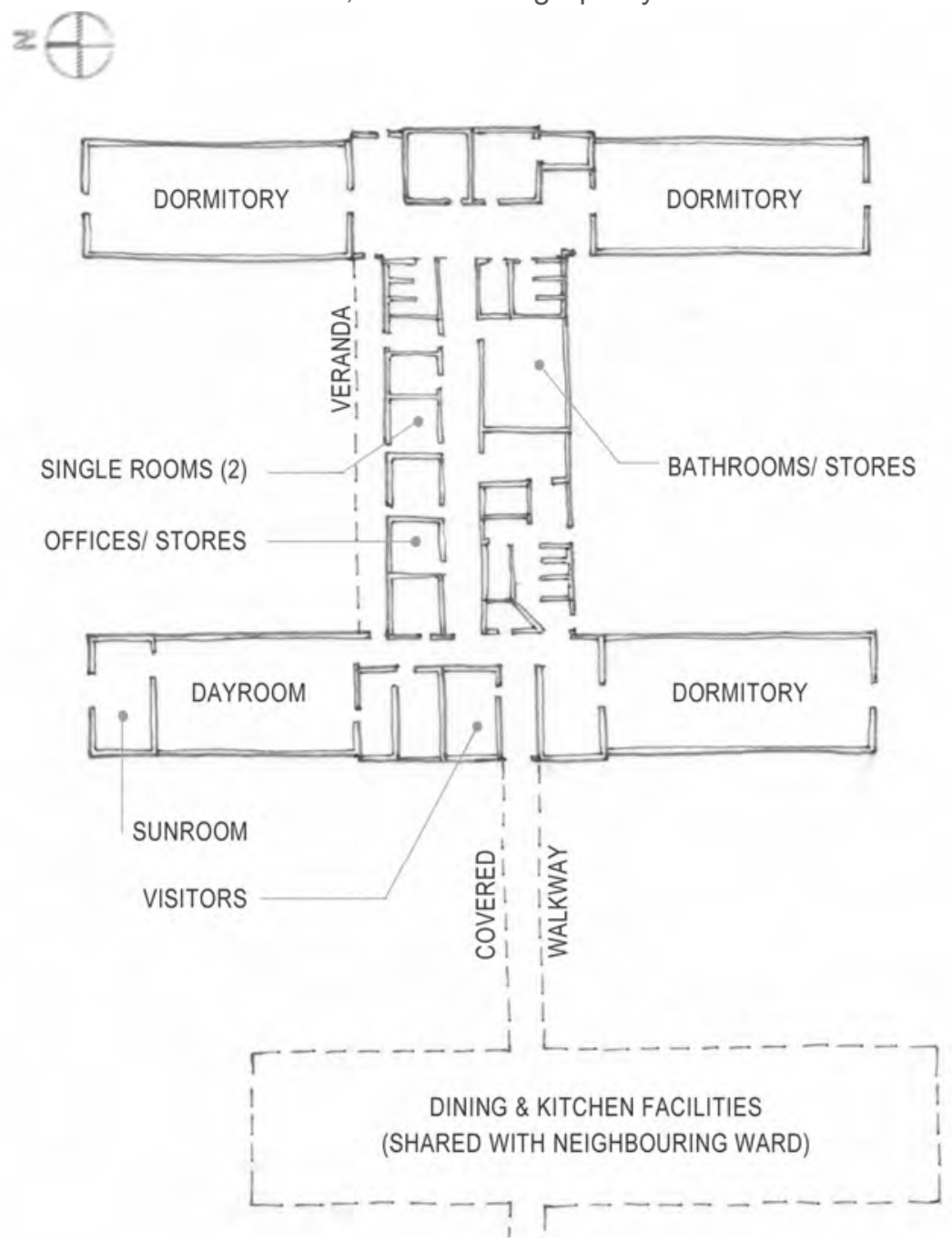

Figure 6.21: Levin Farm Colony, H-shape villa.

Redrawn by author from maintance floor plans held on site (June, 2000).

Note: although designated "dayroom" on the plan the interior treatment of this space was no different to that of a dormitory. 
At Cherry Farm, the government's piecemeal approach to funding this hospital contributed to the curative limitations of this environment. ${ }^{116}$ This would have obstructed the department's ability to explore alternative options, such as the diversification of facilities, and siting for this new facility. Since the department owned this land already no further capital expenditure would be required; this must have provided one of the strongest arguments for constructing a new facility in this isolated rural location. A decade passed before permanent facilities for recreational and occupational therapy were provided at Cherry Farm and delays to the construction of student accommodation hindered the continuity of medical training throughout the transition from Seacliff to this new site. ${ }^{117}$

Funding shortages also go a long way to explaining why the Lake Alice 11bed villas were never replicated elsewhere. In 1951, two years ahead of the release of the WHO report, the decision was made not to construct any further villas of this type. While the shortages of cement and steel that had provoked the redesign of the Cherry Farm villa affected this decision, the Minister of Health informed Cabinet that these were also thought to be "uneconomical" to construct. ${ }^{118}$ In briefing the architects for Lake Alice, Gray had stipulated that the cost of these villas, per bed, must be kept as close as possible to the construction cost of a 50-bed villa. The construction estimates for 1940 placed these at just $£ 10$ per bed more expensive than the 50-bed villas most recently constructed at Kingseat. This would equate to an additional $£ 4000$ expenditure across a 1000 bed hospital, since they would be constructed for only 40 per cent of the hospitals population. ${ }^{119}$ The document to confirm the final cost of these villas has not surfaced, though records indicate that, when they were completed late in 1947, they cost around 20 per cent more to construct than Gray's original estimate. ${ }^{120}$ Construction costs had risen across the board between 1940 and 1947. Three 50-bed villas constructed at Porirua Hospital in 1948 cost 30 per cent more than the figure given by Gray in $1940^{121}$ and the Ministy of Works stated that the cost of housing construction in 1949 was two and a half times pre-war construction costs. ${ }^{122}$ It seems unlikely, therefore, that the cost of constructing 11-bed villas was significantly more expensive than 50bed villas.

While cost may have been the official explanation offered, it seems likely that staffing issues played a role in this decision. By 1951 it was clear that these villas were more difficult to staff than 50 -bed villas. It was originally thought that a group of five villas, accommodating 55 patients, could be staffed in the same way that a 50-bed villa was staffed. One attendant would be stationed within a 50-bed villa at all times, while additional assistance would be provided, by two further attendants, in the mornings between $7 \mathrm{am}$ and 9am, during mealtimes and in the evenings. Even at peak times, therefore, only three attendants would be present to supervise 50 patients (exceptions occurred for reception or high dependency wards). ${ }^{123}$ In 1951 the Chief Clerk of Lake Alice Hospital pointed out that, despite 
supervising the same number of patients, the job of a Charge Attendant assigned to five 11-bed villas was substantially more difficult than that of a Charge Attendant assigned to a traditional 50-bed villa. He calculated that an attendant responsible for a group of five villas had to maintain supervision over an additional 5,400 square feet of floor area and had to move between villas which were, from door to door, $1 \frac{1}{2}$ chains apart (30 metres). They had to supervise not one day room, kitchen and dining room but five individual dayrooms, kitchens and dining rooms which included: 25 additional hand basins, four additional toilets, three additional showers and three additional baths. Glazing was also included in this comparison, while the Charge Attendant of a 50-bed villa had 2,600 square feet of glazing to worry about, the attendant assigned to five eleven-bed villas had twice that amount. ${ }^{124}$ Baths and windows provided two of the most dangerous architectural elements for patients intent on suicide. In 1930, when the first patients were moved from Nelson Asylum to the new Ngawhatu Hospital, the superintendent wrote to Gray that one of the patients was "a famous window smasher" and would have to be carefully watched in the new villas. ${ }^{125}$ Ethics and Rules of Conduct for Staff, a guide published after 1947, stated that while many patients were able and willing to bath themselves, staff must "always remember... that bathrooms are dangerous places." 126

The design created for Cherry Farm suggests that significant architectural attention was directed toward reducing the burden of patient supervision. When this design was confirmed in 1948, New Zealand's mental hospitals were 37 per cent short of nurses and 14 per cent short of male attendants for a resident patient population of over 8,000. A slight improvement had occurred by 1953; nursing shortages were reduced by seven per cent. In real terms: a full, national nursing establishment required 844 nurses, it was 250 short in $1953 .{ }^{127}$ Staff worked overtime to compensate for these shortages yet this was not enough to provide ideal, or sometimes even safe, staffing numbers. ${ }^{128}$ Prebble used the term "conveyor belt care" to provide an evocative description of how large numbers of patients were cared for, in spite of these shortages, "with the least risk of harm."129 The Cherry Farm plan enabled fewer staff to maintain safety through scale and clear sightlines. The design of dressing rooms for example, allowed a maximum staff presence for the duration of this task - if all 50 patients could occupy a single space then supervision was not required elsewhere. Likewise, the lack of external doors in these villas allowed a minimum number of staff to regulate patient movement. Open-door practices may have been the aim but they could not be maintained without adequate nursing levels. In 1957, Dr Crawshaw told the Auckland Star that "persistent escapees" were still locked up at Kingseat but only because they lacked sufficient staff to extend open door practices to these patients. ${ }^{130}$ It was 1961 before the last villas at Kingseat were unlocked. ${ }^{131}$ When it was announced, in 1953, that the Cherry Farm villa was to be the new standard for mental hospital construction in New Zealand, the AJHR recorded that this design was 
convenient from the perspective of the organization of work and the management of the villa. ${ }^{132}$ In the design of this new accommodation type the architect's attention seems to have been squarely directed at mitigating the strain on hospital staff.

Shortages of staff and beds were two of the most pressing concerns in the design of the Cherry Farm villa. In 1947, when Russell superseded Gray as department head, he informed the superintendent at Seacliff Hospital that:

[shortages of] bed-space will be quite enough for me to overcome in my time, and I will see to that before I ever recommend expenditure on a Church or Recreation Hall. ${ }^{133}$

In isolation this appears to be a highly conservative approach. However, viewed in light of the impending crisis of accommodation that was apparent in 1947 , and the precarious funding environment the division was forced to operate within, Russell's approach is defensible. Nonetheless, the Cherry Farm villa design responded by accepting and addressing traditional limitations in conventional ways. This resulted in an architectural response that perpetuated custodial modes of care in direct opposition to the treatment values outlined within the WHO report. The question that remains to be addressed is how did public opinion influence the approach taken to the provision of new mental hospital facilities in the late 1940s and 1950s. 


\subsection{PUBLIC EXPECTATION IN THE DESIGN OF CHERRY FARM}

At an open day at Cherry Farm, in 1961, invited guests were advised by the chairman of the Otago Association for Mental Health that "community fears and lack of interest" dictated the location of this hospital. He commented, to the four hundred guests present, that the size of the visitor turn out demonstrated a changing public attitude which if present ten years earlier would have resulted in a hospital much closer to the city. ${ }^{134}$ This section will examine the extent to which public perception was considered by the Division of Mental Hygiene in their response toward the provision of facilities for mental health care and to the design of patient accommodation. It will also discuss the role of public perception with regard to fears of professional marginalisation and how this affected the division's response. Finally, this section will discuss why the Division of Mental Hygiene led the public to believe, through a series of press releases, that the Cherry Farm villa had been purposely designed to meet the aspirations of the WHO report when this was not the case.

Brunton suggests that when the construction of Cherry Farm was announced, in 1943, the Otago Daily Times "challenged the decision on the grounds that further retreat from the city would exacerbate the shortage of staff." ${ }^{135}$ Yet the editorial cited by Brunton doesn't make the link between staff shortages and the distance of this hospital from town. It did, however, question how adequate staff would be secured for this hospital in light of nationwide deficiencies. ${ }^{136}$ In direct contrast to Brunton's reading of this article, the editor expressed "regret" at Cherry Farm's location, owing not to its distance from town but, because:

a locality so closely bound with the genesis of Otago settlement should become the home of an afflicted section of the community that is distressingly numerous. ${ }^{137}$

This article, thereby, supports the assertion that the public played a role in Cherry Farm's geographical isolation. While sections of the community had lobbied for half-way houses for certain types of cases it is unlikely that any solution other than a public mental hospital for the terminally mad would have found acceptance with the wider population. In 1958 Dr Robert Hunt, of the Hudson River State Hospital (New York), observed that:

the custodial culture within the mental hospital is... an inevitable consequence of the expectations of the population we serve. Our society hopes for successful treatment, but it demands safe custody of those whom it rejects. The pressure for security is constant [and] unremitting... [emphasis original]. ${ }^{138}$

In 1961, the same year that Cherry Farm's open day was held, research by Dr Shirley Star, of the University of Chicago, found that:

a kind of lip service [was] being paid mental health information to the effect that psychotics are sick and are treatable, but behind this, a 
rejecting attitude toward patients and toward treatment... The prevalent attitude of rejection became more complete in that "relatively few people thought of psychiatry as something which had any relevance for themselves or for the kind of people they knew"...139

Star's findings were echoed within two short dissertations completed by fifth year medical students from the University of Otago in 1967 and 1970. Read together the dissertations of A.J. Wilson and R.J.A. Tregonning canvas opinion from 32 Dunedin residents. While this does not allow for generalization, their studies provide an interesting snapshot of public opinion at the time when the inpatient unit was being constructed at Wakari Hospital, two decades after Cherry Farm was planned. Wilson's interview subjects were in general agreement that societal stigma toward mental illness had diminished in recent years, yet, 10 of his 12 respondents said "they would be reluctant to form any permanent relationship with a mentally ill person." ${ }^{140}$ Similarly, Tregonning observed that questions seemed to be answered in a way that respondents felt "was expected of them" and that derogatory responses to questions were often followed by a verbal expression of guilt. ${ }^{141}$ In 1962, according to Kavanagh, the residents of Waikouatiti "expressed concern about the dangerous nature of their new neighbours at Cherry Farm."142

Public attitudes notwithstanding, the siting of Cherry Farm Hospital closer to the city was unlikely. Brunton's discussions with former staff suggested that "forward thinking staff at Seacliff... favoured a move to Wakari Hospital [and] opposed the decision" to rebuild Seacliff's facilities at Cherry Farm. Staff blamed this decision "on Gray's stubbornness." ${ }^{143}$ This observation is consistent with the commitment Gray showed toward the villa hospital, and his resistance to psychopathic hospitals. It was not until 1959, under Lewis' directorship, that city based facilities for day hospitals and outpatient units were planned for Auckland and Christchurch. However, these were constructed on existing mental hospital sites. It was another seven years before the Division of Mental Hygiene took steps to diversify its facilities by constructing Admission Units on the grounds of general hospitals in Dunedin, Invercargill and Palmerston North. The intent was to run these as satellite facilities of the Cherry Farm and Porirua hospitals. This decision was a response to the recommendations of a government inquiry into Psychiatric Services in Public Hospitals (1957-60). ${ }^{144}$ Kavanagh points out that, among the provisions included in the Mental Health Amendment Bill of 1961 was the establishment of day wards in general hospitals. ${ }^{145} \mathrm{He}$ also suggests that general hospital psychiatrists played a role in pushing for the greater utilisation of general hospitals in the treatment of mental illness in the 1960 s. ${ }^{146}$ The decision to shift the admission unit to Wakari was not made until 1966 after full documentation had been completed for this unit on the Cherry Farm site. ${ }^{147}$ Furthermore, Cherry Farm staff believed they required their own on-site Admission Unit, in addition to the one that would 
be provided at Wakari, suggesting that staff support for this new facility may not have been particularly high. ${ }^{148}$

A contributing factor in the resistance to greater collaboration with general hospitals and universities was the fear of professional subjugation. As discussed within the previous chapter, institutional psychiatrists had suffered from a history of professional marginalisation and greater collaboration risked exacerbating this further. Handing over acute cases to general hospitals, as occurred in the psychopathic hospital model, risked giving up all claim to medical practice. Blain, who consulted on the 1953 WHO report, outlined the danger of treating a high proportion of recoverable patients in general or psychopathic hospitals:

There is no more certain way of turning the community mental hospital into a "madhouse" and depriving it of its role of a therapeutic community. ${ }^{149}$

Blain claimed this concern was shared by the WHO's expert committee, despite their concession that there was a place for the treatment of some mental illnesses within general hospitals. But only, if "a complimentary course of development [emphasis original]" could be sought whereby the two facilities "may be run in close association so that neither functions to the detriment of the other." Blain's personal recommendation, however, that mental hospital staff should be given the responsibility for administering the psychiatric wards of general hospitals, suggests a degree of professional territory guarding. ${ }^{150}$ The superintendent of Cherry Farm Hospital expressed a similar sentiment, in 1969, following the handing over of a new Admission Unit to the Palmerston North Hospital Board by the Porirua Mental Hospital (Wellington). While this occurred owing to administrative difficulties of oversight given the distance between these two hospitals, the superintendent of Cherry Farm wrote in response, that he foresaw:

considerable dangers in the Division giving away its more attractive units piecemeal to Hospital Boards, while retaining the less attractive units often caring for larger numbers of long term patients... [as] the long term hospital... [could become] divorced from acute facilities. ${ }^{151}$

He also expressed the view that the medical staff of Cherry Farm Hospital should not be "banished to the country asylum." ${ }^{152}$ With regard to siting of the Cherry Farm Hospital, it is unclear to what extent the fear of professional subjugation played a role, however, it is clear that this existed. For example, correspondence suggests that it was the University who reached out to the Division of Mental Hygiene and not vice versa. In 1959, when the Admission Unit was still intended for the Cherry Farm site, Dr Horace Smirk, Professor of Pharmacological Research at the University of Otago, suggested the interchange of research personnel between Cherry Farm and the Department of Medicine. ${ }^{153} \mathrm{~A}$ decade later, when this unit was under construction in Dunedin, a number of issues were raised regarding 
co-operation between Cherry Farm's unit and the nearby independent professorial unit, run by Dr Ironsides, Professor of Psychological Medicine (University of Otago). In three instances the Otago Health Board approached the superintendent of Cherry Farm with suggestions for closer collaboration between these units. It was questioned whether local psychiatrists would be permitted to admit their own patients to the Cherry Farm Admission unit and, secondly, whether patients of the professorial unit could access occupational therapy services offered by Cherry Farm. Thirdly, it was questioned whether Psychiatric Registrars could be exchanged, for training purposes, between the Dunedin General Hospital and the Cherry Farm site. The superintendent of Cherry Farm responded with reluctance to all three requests. ${ }^{154}$ It was clear that, while these requests would be diplomatically considered, cooperation would only occur on the division's terms.

The approach taken to greater collaboration with the Otago Health Board and the local medical school was consistent with the approach taken to greater collaboration with the Queen Mary (neuropathic) Hospital. Between 1948 and 1956, subsequent directors of the Division of Mental Hygiene advised against the further development of the Queen Mary Hospital, despite their proposals offering substantial benefits to the division's own institutions. As discussed in the previous chapter, Queen Mary was run under the Department of Health and administered separately from New Zealand's mental hospitals. The primary job of this hospital was the treatment of psycho-neuroses which, staff believed, "represent[ed] the most frequent types [of cases] met in general practice and in out-patient psychiatry work." 155 In 1948, the medical superintendent of Queen Mary put together a proposal that included: the extension of outpatient services offered by Queen Mary, the construction of a second unit in the North Island and the training of recent medical graduates. ${ }^{156}$ The proposal acknowledged that, inquiries received from various medical graduates indicated a hesitancy to take up psychiatric training in New Zealand's mental hospitals as they "fear[ed] that as juniors they will have largely custodial duties," whereas, they desired experience in the treatment of neuroses. These students suggested that they would take up training in psychiatry if it was offered at Queen Mary. The proposal cited the division's own annual report for 1946 which pointed out that when New Zealand's mental hospitals needed to recruit 14 additional psychiatrists they could only find six. It also cited "increasing demand" for out-patient work which the mental hospitals were struggling to keep up with. ${ }^{157}$ The advantage to the Division of Mental Hygiene was clear, if Queen Mary could be used to draw graduates into psychiatric practice then, over the long term, this would help to solve the division's severe lack of trained medical staff. The construction of a second unit in the North Island would likely be oversubscribed by voluntary patients, as the Hanmer Springs hospital was, because it did not carry the associated stigma that the larger mental hospitals did. ${ }^{158}$ Queen Mary was offering to 
help the division with two of its most pressing concerns: staff recruitment and increasing voluntary admissions. Yet, when asked by the Department of Health to offer advice, Lewis wrote that his view "is that the training for a psychiatrist is best started in a Mental Hospital." 159 While, Russell earlier expressed "extreme doubt" that an extension of Queen Mary's current services were necessary, he also confirmed that:

In our hospitals we deal with psycho-neuroses and I have no doubt that experience in this sphere is just as extensive in our department as at Queen Mary Hospital. ${ }^{160}$

Given that the departments most pressing concerns between 1948 and 1956 were staff recruitment and increasing voluntary admission to mental hospitals, the fear of exacerbating the existing professional marginalisation of institutional psychiatrists was allowed to limit this department.

Returning to the issue of enduring public prejudice, this did more than affect issues of hospital location. It obstructed the recruitment of staff and dissuaded those suffering from mental illness from seeking early voluntary treatment. This was still regarded as the best chance for a patient's successful recovery. The difficulties of nursing recruitment in the 1950 s are indicative of the wider public regard for these institutions as was the formation of voluntary groups such as the Auckland Mental Hospital Reform Association (1946). The declaration of mental hospitals as an "essential industry" during wartime (1943) failed to improve nursing numbers. Even the Manpower Industrial Committees' responsible for directing young women into mental hospital work did not seem committed to the task. The Wellington committee cited a "deep-rooted" prejudice "in the minds of the public generally" and, on the part of young girls directed to work in these institutions, "horror [and] dread." 161 In 1946 Arthur Sainsbury self-published a book on behalf of the Auckland Mental Hospital Reform Association titled Misery Mansion: Grim Tales of New Zealand Asylums. Within it he painted a picture of wrongful admission and frequent abuse, presided over by asylum officials prepared to turn a blind eye. Sainsbury claimed that patients were treated like slaves, that mental hospitals created insanity, and that patient suicides were motivated, not by the illness itself, but by the unbearable nature of the hospital environment. ${ }^{162}$ While the tone of Sainsbury's book was sensational - Gray maintained that it was "fantastic and untrue nonsense"163 - Sainsbury was correct in his observation that many people suffering from mental illness were reluctant to admit themselves voluntarily to a mental hospital. ${ }^{164}$

The staff shortages experienced by New Zealand's mental hospitals provide an explanation for the media campaign that promoted Cherry Farm's retrograde architectural approach as modern and homely. According to Prebble, mental hospital work was perceived as "dangerous, dirty... and isolating," and potentially "detrimental" to any future pursuit of marriage or motherhood. ${ }^{165}$ Wellington's Manpower Industrial Committee expressed 
concern, in 1943, that pressuring young women to work in public mental hospitals "might well amount to mental cruelty and... be attended by tragic consequences." 166 Prebble believes that the Division of Mental Hygiene realised that these institutions needed to be "repackaged" if they were to be successful in recruiting "respectable, educated young women" to mental hospital nursing. ${ }^{167}$ The media campaign constructed around the new Cherry Farm villas established a parallel discourse of modernity and domesticity. It was a compelling media strategy to combat the public fear of these institutions. Architecture was employed to advance this discourse because, from a public relations perspective, it offered an accessible, nonthreatening view of care in a benign environment.

A discourse of domesticity helped to establish parallels between the mental hospital and the family home, thus recasting this environment and by extension the patients within it as relatively normal and, therefore, harmless. In a 1955 press release, intended for the New Zealand Truth, the division's journalist observed the following homely features within the new villas constructed at Porirua Hospital: "leather-upholstered chairs... a good Manet print on the wall... attractive rugs... tasteful curtains... and flowers on the mantel piece." Special mention was made of the kitchens within these villas, which the division's journalist felt "would have delighted the most fastidious housewife." 168 Similarly, the Otago Daily Times, when invited to view the new villas at Cherry Farm, commented on the shining stainless steel, the plentiful cupboard space and the size of the refrigerators and cake mixers. Readers were assured that "the first batch of scones to be made in the brand new coal range tasted fine." 169 That independent journalists had been versed in this media strategy, via their hospital tour guides, is supported by the fact that the sentiments expressed by these journalists closely paralleled the division's own press releases. ${ }^{170}$ In highlighting similarities between the mental hospital and the family home an environment with which everyone was familiar, the public's fear of the unknown was addressed.

In the 1930s the relationship between Kingseat's new facilities and a modern approach to medical care was subtly inferred in press releases but in the 1950s campaign this relationship was overtly stated. A press release prepared in 1954 suggested that modern architecture went hand in hand with advances in mental health care:

Modernization of hospitals is an essential part of the new approach. A different type of accommodation, a new atmosphere, and a new character distinguishes mental treatment. ${ }^{171}$

In 1957 the Waikato Times printed a photograph of a Cherry Farm villa and quoted Matron Elliot who stated that: "the new villa type hospitals are a much greater aid towards recovery than the old time buildings..." (refer figure 6.5). ${ }^{172}$ Similarly, the hospital's Chief Clerk commented that the hospital had come a long way since the days when "it was one degree better than Dickens' workhouse." ${ }^{\text {173 }}$ The tone, format and content of the 
Tokanui article are consistent with those comprising a press release package created by the division in 1955 . Each article within this package discussed the experience of a member of the nursing staff and each commented specifically on the improvements they had witnessed within the hospital environment. These changes were discussed in relation to medical advancement and the more enlightened approach now taken to treatment. A nurse from Porirua was asked, by the division's journalist, to "debunk" impressions of padded cells and straitjackets. She replied that a fundamental change had occurred in mental health care following World War II:

in spirit and practice we are more than fifty years ahead of the old "asylums"... A visit to a mental hospital is a most convincing illustration of enlightened progress. ${ }^{174}$

According to Cameron Logan, Australian architects had discovered the value of a modernist aesthetic in the 1930s, and redeployed this again in the 1950s, to recast the image of General Hospitals as "progressive" and "scientific," putting distance between themselves and a history of charitable service. ${ }^{175}$ A discourse of modernity helped to reframe New Zealand's mental hospitals as progressive, professionally staffed places of science and this architecture was ideally positioned to achieve this. The promise of greater freedom intimated by the wide entranceways, heavily glazed facades and low terraces of the Cherry Farm design suggested an advance on traditional mental hospitals. These villas provided a foil to the ageing Seacliff Asylum, which was synonymous with mental health care in Otago, and also to the Sunnyside Asylum where a new villa was constructed behind this nineteenth century building. In 1953 the Division boasted "right through the Dominion massive stone institutions are giving way to the cheerful, attractive, modern villa hospital." ${ }^{176}$ A clear distinction between the asylum stereotype of darkness and enclosure and a new architecture of transparency and light was set up throughout this media campaign. This strategy was passed on to independent journalists who visited these hospitals. In 1957 the Otago Daily Times reported that the new Cherry Farm villas illustrated "great advances in the care of the mentally ill" and were "far different from the misery and the ugliness surrounding those in mental hospitals not so many years ago [emphasis added]." ${ }^{177}$ The act of contrasting old with new was in keeping with Joan Kerr's observation that, commonly with asylums and prisons, guilt for a defective system of institutionalization is transferred "onto the fabric of the building which houses it." 178 This approach was consistent with a 1977 television documentary that blamed Sunnyside's gothic architecture for the enduring stigmatization of mental hospitals. The voice over lamented public prejudice toward mental illness before stating: "getting rid of this relic of the past will help to remove that stigma." 179 Prebble has remarked that the division's media campaign of the 1950s "raise[d] public awareness of psychiatric hospitals" but did not likely result in improved recruitment. She believes this 
was a result of other factors such as changing demographics. ${ }^{180}$ In light of the media discussion of the Cherry Farm villas, the question remains, was the evocation of domesticity and portrayal of modernity made explicit within the design agenda for this new architecture?

An examination of the lineage of villa designs created between 1924 and 1948 confirms that the employment of modern architectural styling in the construction of new mental hospital facilities was deliberate (figure 6.22). The Cherry Farm design followed a post-war modernist style and the Porirua villas were created in a modernist international style. Even Kingseat, while seeming more conservative with its neo-Georgian aesthetic, was as modern as New Zealand could handle in 1927. Peter Shaw explained that although "new European directions in architecture" were reaching the country throughout the 1920s, New Zealand remained conservative in its architectural approach. Owing to their simplicity, Georgian styles were able to "pass as Modern." ${ }^{181}$ Nowhere in departmental records was modernism acknowledged as a design strategy. However, Yanni, Topp and Logan have made evident that the employment of modern design in general and mental hospital construction was an ingrained practice. ${ }^{182}$ That the division were aware of this strategy in 1955, as opposed to simply following it out of habit, is suggested by a press release written that year which quoted a nurse from Porirua Hospital as saying:

It was the sight of that rather wonderful new hospital at Cherry Farm that made me interested in psychiatric nursing. When I saw a modern mental hospital for myself, my prejudices vanished. ${ }^{183}$ 


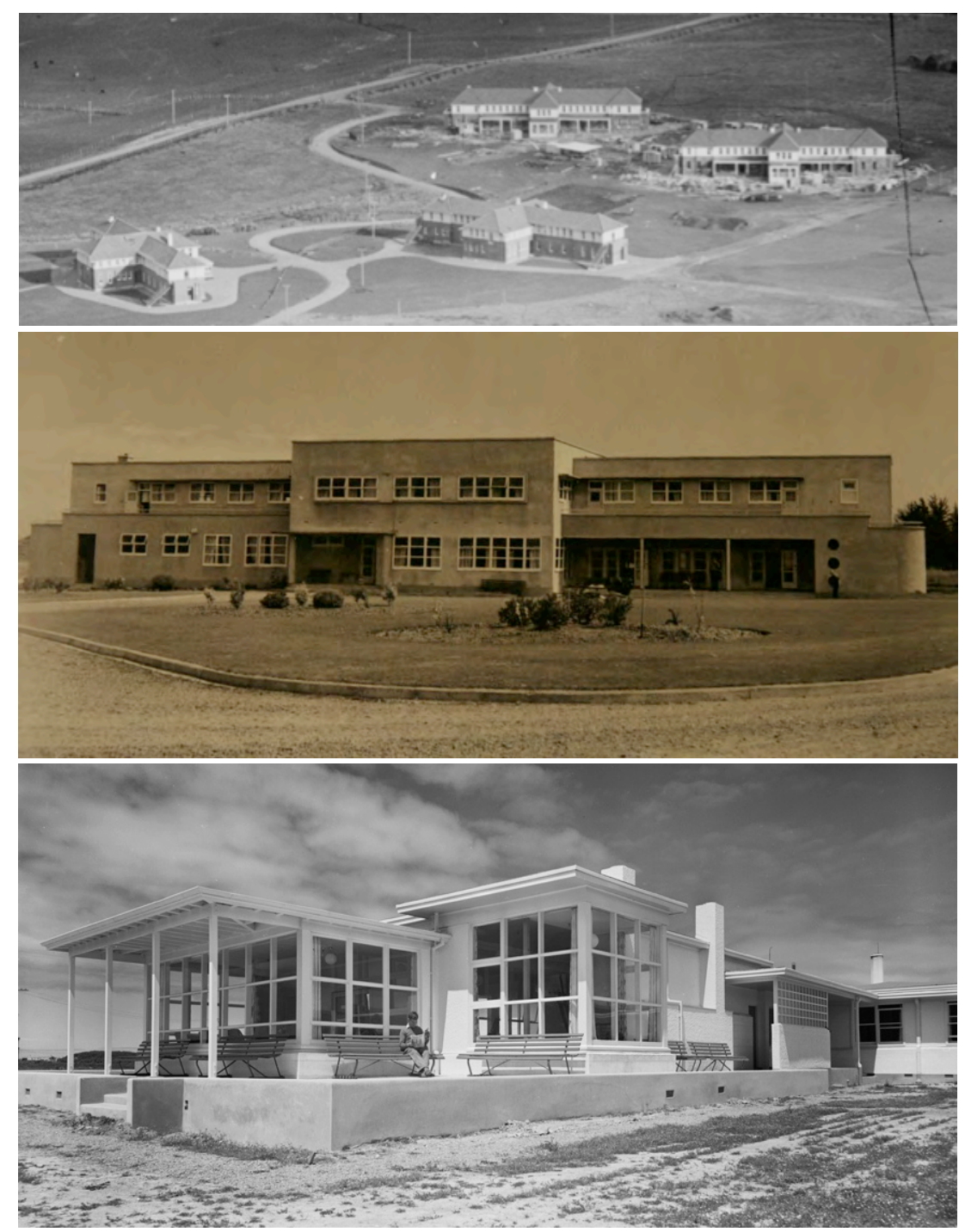

Figure 6.22 : Lineage of modernist styles employed (top to bottom) Kingseat 1937. Alexander Turnbull Library: WA-55912-G.

A Porirua villa type (at Lake Alice), 1948.

Archives New Zealand: C399174 H10 1227296.

Cherry Farm, 1953. Archives New Zealand: AAQT 6401, A29455.

Domesticity, on the other hand, was conclusively documented as a design intention. During the design of the Porirua villa type (1943) Gray wrote to the Government Architect that, although the Kingseat villas were "excellent... we might strive for something of a more homely appearance [emphasis added]." ${ }^{184}$ The Freelance, reporting on the new Cherry Farm villas in 1952, relayed that homeliness, lightness and brightness were deliberate design intents. The villas looked:

for all the world like an attractive country home and anything less like an institution would be hard to imagine. The greater part of the outside walls is glass, for light and fresh air have been aimed at in every way [emphasis added]. ${ }^{185}$ 


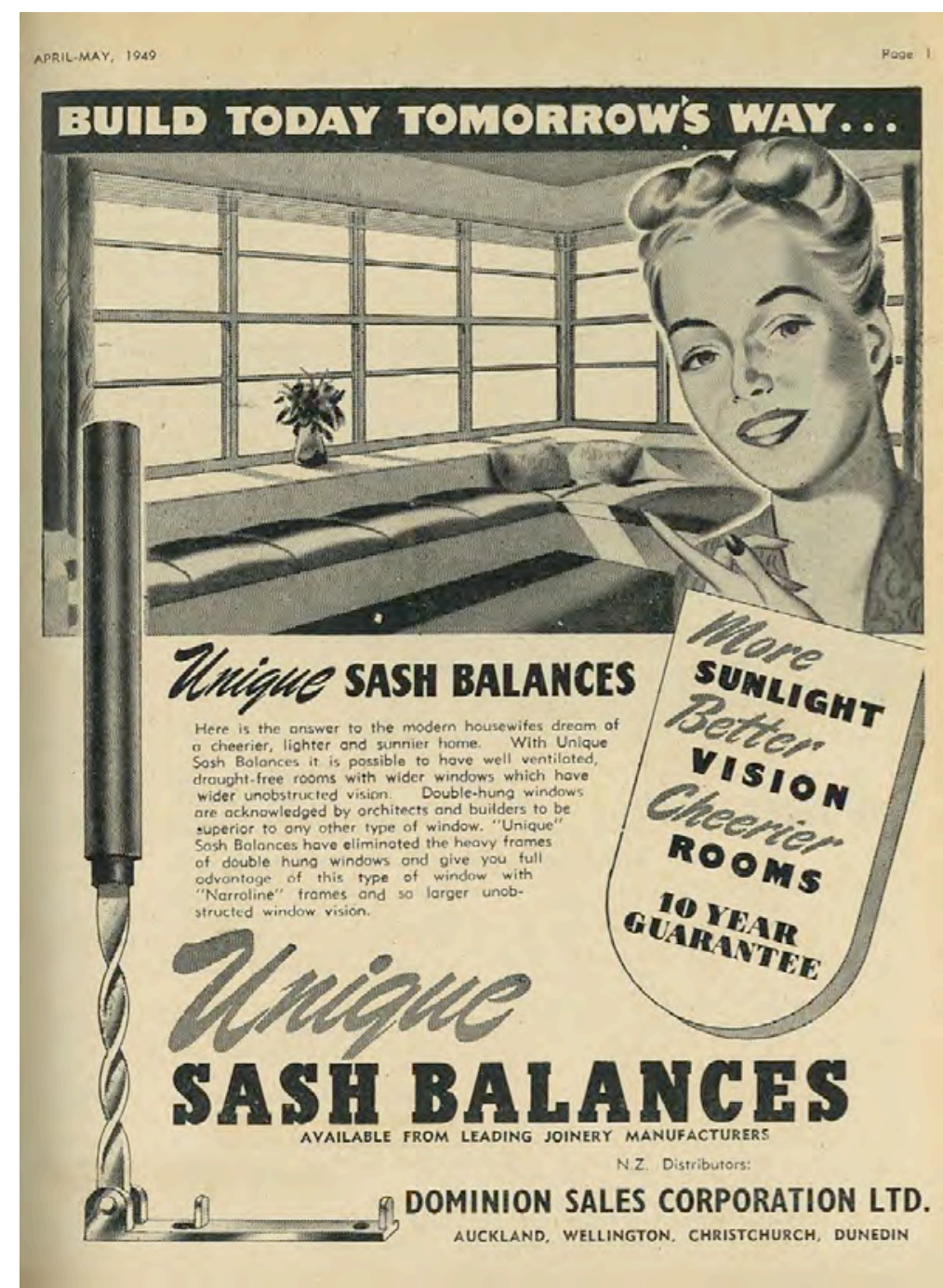

Figure 6.23: Glazing advertisement, Home and Building, April/May 1949. Image courtesy of ACP Media, New Zealand.

In proportion and placement, the glazing of the Cherry Farm villa followed homes that appeared in architectural magazines of the era (figure 6.24). ${ }^{186}$ Similarly, the media description of these villas mimicked contemporary glazing advertisements that claimed "the modern housewives dream" was a "cheerier, lighter and sunnier home" (figure 6.23). ${ }^{187}$ The Mirror (1953), the New Zealand Women's Weekly (1954) and the Northland Times (1957), in addition to various unpublished press release drafts, all celebrated the "modern approach" in the construction of new facilities with an emphasis on "fresh air and sunshine," "brightness and cheerfulness." 188 This approach to glazing may have arisen as the result of a suggestion from Ngawhatu staff, in 1947, that more natural light would be preferable in day rooms, dining rooms and kitchens. As well as their request for a glazed sun verandas. ${ }^{189}$ While sunshine had always been considered important in mental hospital design, this renewed celebration of light and sun was in keeping with the design approach taken to state housing by the government's Division of Housing (Ministry of Works) at that time. ${ }^{190}$ 


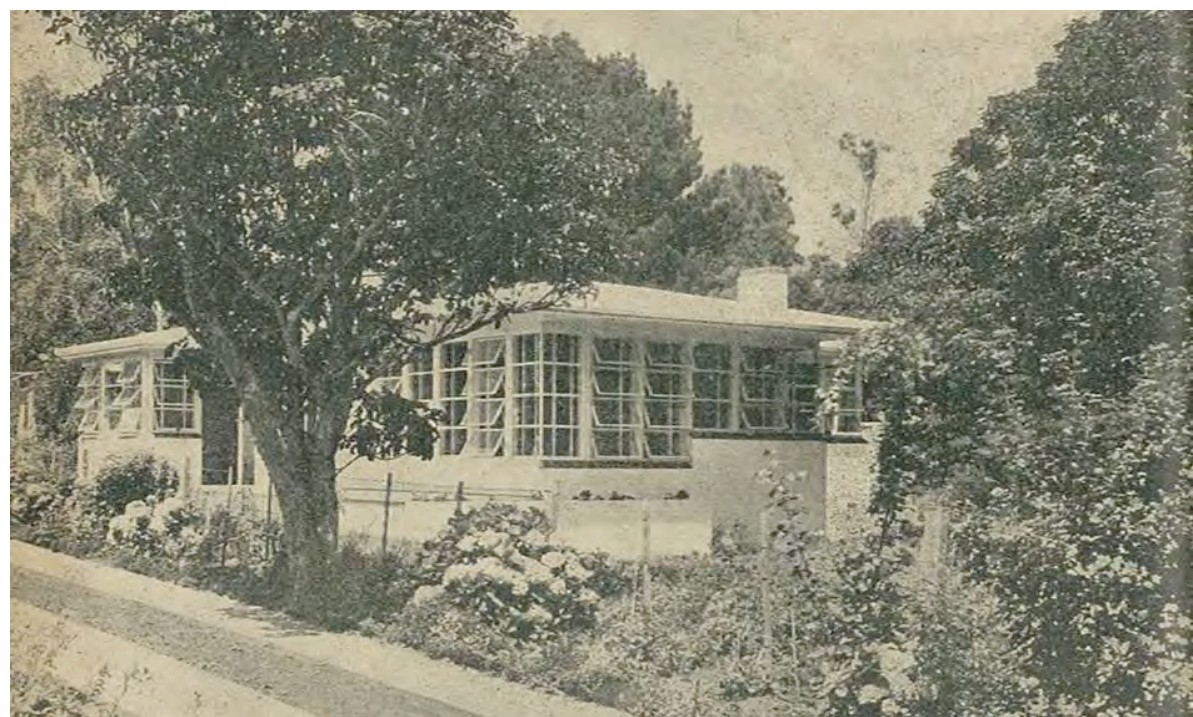

Figure 6.24: Cover image, Home and Building Magazine, Dec. 1946.

House by Massey, Beatson, Rix-Trott and Carter. Image courtesy of ACP Media.

What is interesting, however, is that the Freelance article also reported that "the external colouring is white and with their flat roofs the villas resemble American-type summer homes." ${ }^{191}$ It seems very unlikely that the division would have expressed a preference for "American" design. While Gray was closely involved with architectural decisions, Russell was simply not as enthused with architectural detail. It is unlikely that his correspondence with the Ministry of Works resembled anything like Gray's who, with regards to Lake Alice, advised the Government Architect to create some "variety" in the "outward appearance" of the 11-bed villas, perhaps "low windows or an alternative design of entrance" in order to avoid monotony. ${ }^{192}$ The more likely explanation is that the relationship to American architecture was a product of the architect's preference and the wider interest of the architectural community in the late 1940s. The similarities between this villa and the domestic houses that were starting to appear in New Zealand's Home and Building magazine support this hypothesis (refer again, figures 6.9 and 6.24). Harry Burt was the architect of the Cherry Farm villas. ${ }^{193}$ Burt must have worked for the Ministry of Works because his name is recorded on the drawings and mental hospital work was not contracted out at that time, however, his name did not appear elsewhere within the surviving archival records for this hospital. While little further information could be found regarding Burt, other designs he created, during his time in private practice with Arthur Salmond (in the years following his work on the Cherry Farm design) confirms his interest and engagement with international modernism. Examples are an office and store for Messr's Stronarch and Morris in Cromwell (1952) and the State Fire Insurance Building in Dunedin (1954) (figure 6.25). ${ }^{194}$ 


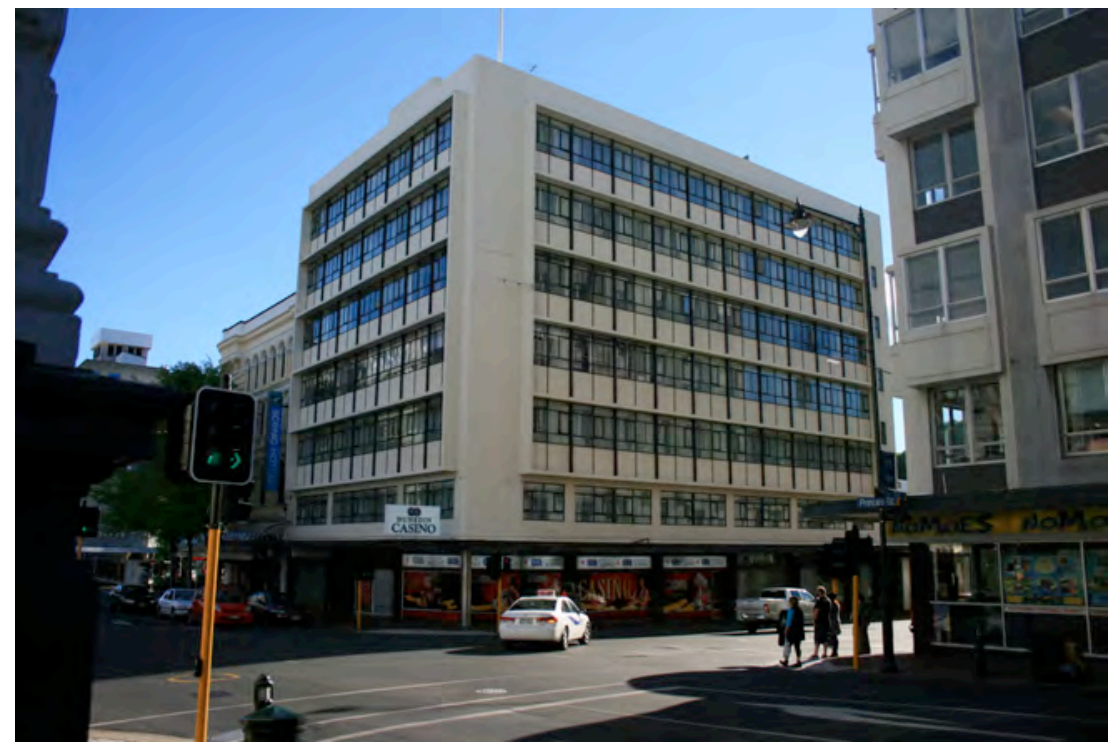

Figure 6.25: State Fire Insurance Building, October 24, 2013.

Salmond and Burt Architects, 1954. Photograph by author.

With regard to the Cherry Farm Hospital and its villas, the expectations and the perceptions of the public influenced this design response. While the public, on record, lobbied for facilities that followed the psychopathic hospital model, they viewed these as being provided for a small, and elite percentage of New Zealand's mentally ill population. The community served by Cherry Farm Hospital were not ready to accept a community based model of care in 1953, even if circumstances had allowed the subsequent diversification of the facilities provided by this hospital to inner city locations. Likewise, in the design of these villas, the needs of the public audience were placed before the needs of the patients themselves. The Cherry Farm villas responded to a public who regarded them as out-dated and untrustworthy with an architectural response that was transparent and modern. Modernism and domesticity were considered in the design of these villas but that these factors were considered for the benefit of patients was misleading. It was more important for the Cherry Farm villas to look modern and homely than to reflect these values spatially. This was primarily an exercise in public relations. It must be acknowledged, however, that public attitudes limited these institutions. This is directly traceable with regard to the difficulties of nursing recruitment and encouraging those suffering from mental health issues to seek voluntary treatment. However, one of the strongest limitations in the evolution of New Zealand's response to mental health care was not the public's fear, it was the fear of professional marginalisation. The need of institutional psychiatrists to protect their professional territory motivated the decision makers in the design of Cherry Farm Hospital to respond to new ideas in ways that were not conducive to progress. 


\section{CONCLUSION}

The timing of the WHO report and emergent research relative to the construction of Cherry Farm offered the division a unique opportunity to advance existing models of institutional care relative to changing approaches to mental health care. While this research was new and lacked workable precedents for the direct transfer of these ideas into built form, it offered possible solutions to the harmful effects of institutionalisation that were understood by the Division of Mental Hygiene. Gray's attempts to mitigate these within the design of the Lake Alice Hospital (1943) and the non-architectural improvements made to mental hospital environments by Russell (1948) evidence that this knowledge existed within the head office of this department prior to the release of the WHO report (1953).

The seeking of traditional values, such as homeliness and contemporary architectural styling, in the case of the Cherry Farm villas highlights a lack of vision, on the part of the medical professionals who advised on their design, as does the response of a self-contained, rural mental hospital. To an extent, this approach was defensible given the unstable funding environment and the unlikelihood that the Dunedin public were ready to accept facilities located closer to town. The prioritisation of operational concerns, such as nursing shortages and overcrowding, left little scope for improving the patient experience of these buildings; the bulk of architectural attention was directed toward the design of the day rooms. While the attitude of the architects involved is difficult to gauge given the lack of design related correspondence available, as with Kingseat villas, the spatial quality and treatment of the day rooms and entrance facades at Cherry Farm suggests a commitment to providing buildings of reasonable architectural quality. However, the basic characteristics of the Cherry Farm plan were not substantially different to that created for the Ngawhatu villas in 1924. The design of these facilities from a distance (Wellington), the over reliance on existing villa typologies and the lack of time available for architects to engage with the relationship between treatment theory and inhabitation were limiting factors. Given the staffing restrictions of the Ministry of Works during the period in which this hospital was designed and the higher visibility of the department's other public projects (that included post offices, social housing, hydroelectric dams, halls of residence for various universities and a new maternity hospital for Christchurch ${ }^{195}$ ) the needs of New Zealand's mental hospitals were a relatively low priority.

The division lacked the architectural resources to engage in an active search for new spatial responses to care that American professionals engaged with following 1953. However, Gray had already provided a response capable of meeting the new treatment ideals outlined in the WHO report with the Lake Alice 11-bed villas. All the division needed to do was recognise the potential of this new accommodation model and to spend the necessary energy to iron out the issues of supervision these posed. That there was no (documented) attempt to do this is the greatest oversight 
within New Zealand's architectural history of mental health care. The sincere desire shown by Gray to improve the lives of chronic patients was not evident in the design of the Cherry Farm villas. Although it was publically stated that architecture continued to play a role in the treatment of mental illness, the design of Cherry Farm hospital relative to the media descriptions of it evidenced that the faith previously shown by medical professionals in the healing power of curative environments was waning.

Similar to Seacliff, the Cherry Farm villas were designed for a public audience. Where money could have been spent on improving patient comfort it was instead directed toward the use of expensive materials, the construction of flat roofs and the installation of large expanses of glass. While the glazed facades of the day rooms provided a more pleasant interior environment for patients, Oamaru stone claddings and flat roofs could not have provided any tangible, curative benefits to the patients themselves. In this case it was not the government but the division's psychiatrists who had the most to gain from architectural propaganda. However, the prioritisation of public relations was not the only compromise due to professional agendas to have occurred in the design of this hospital. The need felt by the medical administrators of New Zealand's mental hospitals to protect their professional territory limited the division's ability to explore alternatives to traditional, rural hospital models. The fact that nearly two decades passed before the Admission Unit was opened at Wakari and collaborations began to occur with the medical school and general hospital was, in hindsight, regrettable. These ideas were not new they simply followed the lead of institutions such as the Maudsley and Johns Hopkins Hospitals. By the time the WHO report was published in 1953 it should have been clear to the Division of Mental Hygiene that the psychopathic hospital model was a necessary adjunct to any public mental hospital network. The largest obstacle in the adoption of new ideas around collaboration and the diversification of mental health facilities was not public fear but professional fear from within the division itself.

As was the case with Kingseat Hospital, meeting the needs of New Zealand's mentally ill between 1945 and 1971 was a low priority for the government and its architectural division, the Ministry of Works. What sets Cherry Farm apart from earlier hospitals created for this department is that this hospital suffered to the greatest extent from the professional agendas of institutional psychiatrists. Satisfying these agendas caused direct conflicts with the curative potential of this architecture.

1 While the land was purchased in 1926, while King was department head, planning didn't until 1943 under Gray's direction. The villas were redesigned in 1947 under the direction of Russell.

2 AJHR 1948, H-7, 3. Director-General, DMH, to the Minister in Charge of Mental Hospitals, May 9, 1949. ANZ: R16195940. 
${ }^{3}$ While the earliest dated drawing of the Cherry Farm villa held by ANZ was dated November 23, 1948 (R4256620), Russell's report to the AJHR for 1948 confirms that the redesign of villa plans occurred during 1947.

${ }^{4}$ AJHR 1953, H-31, 23.

${ }^{5}$ Division of Mental Hygiene, "The Doctor in Annam," Draft Press Releases, April August 1954. ANZ: R16195751.

6 "Extensions Planned at Cherry Farm," 1957.

7 "The Seacliff Mental Hospital," 1943. Architectural plans viewed in relation to these villas confirm that no changes were made after 1949.

8 "Extensions Planned at Cherry Farm," 1957.

${ }^{9}$ WHO 1953, 31-2.

${ }^{10}$ Commissioner of Works to the Secretary, Cabinet Works Committee. September 15, 1955. ANZ: R18458498.

11 "First Patients to move into Cherry Farm Soon," 1952.

12 Kavanagh 2001, 168.

13 "Extensions Planned at Cherry Farm," 1957.

14 "Expenditure of 1M pounds For New Mental Hospital Approved," 1957.

${ }^{15}$ Kavanagh 1996, 2.

${ }^{16}$ WHO 1953, 9-12, 31.

17 Ibid, 31.

${ }^{18}$ Ibid, $29,31$.

${ }^{19}$ Ibid, 19, 20, 22, 31.

${ }^{20}$ Medical Superintendent, Cherry Farm Hospital, to the Director, DMH, July 22, 1957. ANZ: R18458498. "Cherry Farm Centre Valuable Amenity," 1961.

${ }^{21}$ Lake Alice Hospital was planned 1940-1943. Director-General, MHD, to the Government Architect, June 29, 1943. ANZ: R22502230. Drawing: Aerial perspective of Lake Alice Hospital by R. Patterson, undated but indicates layout for full 1,000 bed scheme and relates to correspondence dated 1943. ANZ: R21009821.

${ }^{22}$ Efforts have been made to confirm when this bus service began, however, enquiries to the Dunedin City Council and archival sources have failed to confirm a date.

23 Medical Superintendent, Cherry Farm Hospital, to the Secretary of the Palmerston-Waikouaiti Licensing Restoration Committee, August 15, 1958. ANZ: R18458498.

${ }^{24}$ WHO $1953,10-12$.

${ }^{25}$ Medical Superintendent, Cherry Farm Hospital, to the Director, DMH, May 18, 1959. ANZ: R18458498.

26 "Need for Patience in Mental Therapy," 1960.

${ }^{27}$ Medical Superintendent, Cherry Farm Hospital, to the Director, DMH, September 27, 1957. ANZ: R1845498.

${ }^{28}$ Superintendent, Cherry Farm to the Chairman, Otago Hospital Board. June 13, 1968. ANZ: R18830390. Note: this document confirms when the decision was made however details regarding what prompted this decision, and whether it came from the $\mathrm{DMH}$ or the Hospital Board is unclear. 
${ }^{29}$ Medical Superintendent, Cherry Farm, to the Director General of Health, June 17, 1969. ANZ: R18458498.

${ }^{30}$ It is unclear whether this estimate included the $£ 1,000,000$ that was voted in 1957. Commissioner of Works to the Secretary of the Cabinet Works Committee, September 15, 1955. ANZ: R18458498.

${ }^{31}$ Some changes to material were made between the Cherry Farm villas and their replication elsewhere. At Sunnyside, Porirua, Lake Alice, and Kingseat these villas were clad in brick instead of Oamaru stone and low pitched, corrugate roofing was used instead of a "flat roof" $\left(1.5^{\circ}\right.$ pitch, constructed of water-proof membrane over ply wood). The schist fireplaces were not replicated elsewhere either, fireplaces of a brick or plaster finish were constructed at other hospitals. These decisions appeared to be cost-related. The author was not able to establish whether the Tokanui villas also incorporated these changes however, given that these villas were constructed at the same time as those at Sunnyside, Porirua, Lake Alice, and Kingseat, it seems most likely that this would have been the case.

${ }^{32}$ Hunt 2000, 47.

${ }^{33}$ The New Zealand Official Yearbook for 1955 states that 9,742 patients were resident in Mental Hospitals at the end of the year.

${ }^{34}$ Division of Mental Hygiene, see "The Doctor in Annam," "Witch Doctors and Hoodoos" and "Nursing Career Grows in Popularity," Draft Press Releases, 1954. ANZ: R16195751.

${ }^{35}$ Division of Mental Hygiene, "A Community within the Community."Draft Press Release dated between 1952 and 1954. ANZ: R16195751.

${ }^{36}$ Division of Mental Hygiene, "Interest and Pleasure Help Towards Recovery of Mental Sickness," Draft Press Release, 1955, ANZ: R16195752.

${ }^{37}$ WHO 1953, 18-19.

${ }^{38}$ Goffman 1961, 102.

${ }^{39}$ Frame 2005, 111, 129-30.

${ }^{40}$ Williams 1987, 87, 212.

${ }^{41}$ Goshen 1959, 4.

${ }^{42}$ WHO 1953, 31.

43 "More Psychiatric Nurses Are Needed in Nelson," 1958. Similar wording appears within the following two articles: "Psychiatric Nursing Is a Rewarding and Interesting Career," 1957 and "Northland Has Considerable Interest in Kingseat Hospital,"1957.

44 Division of Mental Hygiene, "A Community within the Community," Draft Press Release dated between 1952 and 1954. ANZ: R16195751.

45 "Psychiatric Nursing a Satisfying Career: 'Bad Old Days' Gone," 1957. "Pictures to Please Everyone on the Walls of Cherry Farm," 1960.

${ }^{46}$ WHO 1953, 18.

${ }^{47}$ O'Reilly $1948,110$.

${ }^{48}$ WHO 195331.

${ }^{49}$ Tuke 1813, 144. Edginton 1997, 94. Conolly 1847, 25.

${ }^{50}$ Mercier 1894, 2-3, 23.

${ }^{51}$ Personal communication with a Cherry Farm villa owner previously acquainted with a number of patients (name withheld), November 20, 2010. 
${ }^{52}$ McLaughlan 2012, 238.

53 Division of Mental Hygiene, see "The Doctor in Annam," "Witch Doctors and Hoodoos" and "Nursing Career Grows in Popularity," Draft Press Releases, 1954. ANZ: R16195751.

${ }^{54}$ Clark 1965, 948.

${ }^{55}$ Clark 1964, 31.

${ }^{56}$ Guttersen 1959, 112.

${ }^{57}$ Main 1946, 66.

${ }^{58}$ Henderson 1949, 205-6.

${ }^{59}$ Clark 1988, 34.

${ }^{60}$ Thompson 1992, 103-12.

${ }^{61}$ Whitehorn 1948, 219-20.

62 "Review: The Colonization of the Insane ... By Dr Albrecht Paetz..." 1895, 699.

63 Director-General, MHD, to the Minister of Health, April 22, 1940. ANZ: R22502230.

${ }^{64}$ Director, DMH, to the Minister in Charge of Mental Hospitals, November 1, 1949. ANZ: R16195938.

${ }^{65}$ Ibid.

${ }^{66}$ Ibid. Also refer: Director, DMH, to All Medical Superintendents, February 10, 1949. ANZ: R16195938.

${ }^{67}$ Acting Director-General, MHD, to All Medical Superintendents, June 20, 1947. ANZ: R20960887.

${ }^{68}$ Medical Superintendent, Seaview Hospital, to the Director-General, MHD, June 30, 1947. Medical Superintendent, Kingseat Hospital, to the Director-General, MHD, August 8, 1947. Medical Superintendent, Sunnyside Hospital, to the Director-General, MHD, August 12, 1947. Medical Superintendent, Levin Farm, to the Director-General, MHD, August 18, 1947. Medical Superintendent, Tokanui Hospital, to the Director-General, MHD, August 20, 1947. Medical Superintendent, Ngawhatu Hospital, to the Director-General, MHD, September 12, 1947. ANZ: R20960887.

69 Medical Superintendent, Kingseat Hospital, to the Director-General, MHD, August 8, 1947. Medical Superintendent, Levin Farm, to the Director-General, MHD, August 18, 1947. Medical Superintendent, Tokanui Hospital, to the DirectorGeneral, MHD, August 20, 1947. Medical Superintendent, Ngawhatu Hospital, to the Director-General, MHD, September 12, 1947. ANZ: R20960887.

70 Medical Superintendent, Ngawhatu Hospital, to the Director-General, MHD, September 12, 1947. ANZ: R20960887.

${ }^{71}$ lbid.

72 Brunton 2001, see caption under Ngawhatu villa photograph, unnumbered and unpaginated but follows page 250. Refer correspondence between Gray and the Medical Superintendent, Ngawhatu Hospital, dated between January 7, 1930 to December 31, 1930. ANZ: R16195699.

${ }^{73}$ Medical Superintendent, Ngawhatu Hospital, to the Director-General, MHD, September 12, 1947. ANZ: R20960887.

74 Director-General, MHD, to the Medical Superintendent, Brisbane Mental Hospital, November 25, 1941. ANZ: R20960887. 
75 Director-General, MHD, to the Minister of Health, April 22, 1940. ANZ: R22502230. WHO 1953, 31.

${ }^{76}$ WHO 1953, 31.

77 Director, DMH, to All Medical Superintendents, February 10, 1949. ANZ: R16195938.

78 American Psychiatric Association 1959, "Foreward."

${ }^{79}$ Williams 1959, 23-4.

80 Ibid, 24.

${ }^{81}$ Medical Superintendent, Tokanui Hospital, to the Director-General, MHD, June 13, 1944. ANZ: R22502230.

${ }^{82}$ Refer for example correspondence held in ANZ file: R16195940.

${ }^{83}$ Refer for example correspondence held in ANZ file: R18458498.

${ }^{84}$ Medical Superintendent, Cherry Farm Hospital, to the Director, DMH, November 29, 1958. ANZ: R18458498.

85 Ibid. The authors overall understanding of MOW staffing organisation was enhanced through discussions with her supervisors who both previously held positions with this department. Also refer: Ministry of Works, 1963-65. Ministry of Works, 1960.

86 Refer drawings and correspondence held within the following ANZ files: R18458498 and R16989665.

87 Director, $\mathrm{DMH}$, to the Commissioner of Works [stamped: file copy], undated but filed between March 17, 1954 and Feb 01, 1954. ANZ: R16195940.

${ }^{88}$ File note: Division of Mental Hygiene "Works Programme," undated but filed between March 17, 1954 and Feb 01, 1954. ANZ: R16195940.

${ }^{89}$ Ministry of Works 1956.

${ }^{90}$ Refer correspondence within ANZ: R20122994.

${ }^{91}$ District Architect to Government Architect, June 06, 1968. ANZ: R20122994.

92 Hunt 2000, 48.

93 Ibid.

94 Verbal correspondence with the former Maintenance Manager, Levin Farm Colony, during a tour of the hospital facilities (closed) on June 03, 2010.

${ }^{95}$ Fleck 1959, 25.

96 Ibid.

97 Ibid.

98 Ibid.

99 lbid, 26.

100 Goshen 1959, 1-2.

${ }^{101}$ Many American hospitals constructed during the inter-war period took a similar architectural approach to Manteno. Examples investigated by the author include: Camarillo State Hospital (California, 1929-36), Metropolitan State Hospital (Massachusetts, 1928-30), Pilgrim State Hospital (New York, 1932-41), Ypsilanti State Hospital (Michigan, 1930-31).

102 Goshen 1959, 1-2. 
${ }^{103}$ WHO 1953, 31.

${ }^{104}$ Brunton 2001, 145.

105 Director, DMH, to the Commissioner of Works, March 8, 1950. ANZ: R16195940.

${ }^{106}$ Director, DMH, to the Minister of Health, March 22, 1950. ANZ: R16195940.

107 Development Officer, DMH, to the Director, DMH, June 16 1950. ANZ: R16195940.

108 Director, DMH, to the Minister in Charge of Mental Hospitals, November 20, 1951.ANZ: R16195940.

109 Commissioner of Works to the Director, MHD, September 1, 1952. ANZ: R16195940.

${ }^{110}$ Director, DMH, to the Commissioner of Works (stamped: file copy), undated but filed between March 17, 1954 and Feb 01, 1954. ANZ: R16195940.

111 File note: Division of Mental Hygiene "Works Programme," undated but filed between March 17, 1954 and Feb 01, 1954. ANZ: R16195940.

${ }^{112}$ Thompson 1981, 22-3.

${ }^{113}$ Hunt 2000a.

${ }^{114}$ Director, $\mathrm{DMH}$, to the Commissioner of Works [stamped: file copy], undated but filed between March 17, 1954 and Feb 01, 1954. ANZ: R16195940.

115 Ibid.

116 "First Patients to move into Cherry Farm Soon," 1952. "Extensions Planned at Cherry Farm," 1957. "Expenditure of $1 \mathrm{M}$ pounds For New Mental Hospital Approved," 1957.

117 Medical Superintendent, Cherry Farm Hospital, to the Director, DMH, September 27, 1957. ANZ: R18458498.

118 Minister of Health to All Members of Cabinet, December 14, 1951. ANZ: R22502230.

119 Director-General, MHD, to the Minister of Health, April 22, 1940. ANZ: R22502230.

${ }^{120}$ The estimated cost was $£ 3,300$ per villa, in 1947 the cost of construction had reached $£ 3,900$ and these were nearing completion. Final fittings were being installed at the time this figure was stated so while this would not have been the final cost but fairly close to it. Resident Engineer, MOW, to Fletcher Construction, September 2, 1947. ANZ: R15964069.

${ }^{121}$ AJHR 1949, H-7, 4. The report states that the completion of three 50-bed villas cost $£ 61,671$. This total also included minor works to hospital laundries suggesting that the cost of each villa would have been approximately $£ 20,000$ relative to the $£ 14,500$ estimated by Gray in 1940 .

${ }^{122}$ AJHR 1949, D1, 13.

${ }^{123}$ Chief Clerk, Lake Alice Hospital, to the Director, DMH. October 25, 1951. ANZ: R20961995. Head Attendant, Kingseat Hospital, to the Medical Superintendent, Kingseat, September 20, 1959. ANZ: R16195531.

${ }^{124}$ Chief Clerk, Lake Alice Hospital, to the Director, DMH. October 25, 1951. ANZ: R20961995.

${ }^{125}$ Medical Superintendent, Nelson Mental Hospital, to Gray. December 31, 1930. ANZ: R16195699. 
${ }^{126}$ Division of Mental Hygiene, undated [post-1947].

${ }^{127}$ Brunton 1997, 51. AJHR 1948, H-07, 1. AJHR 1953, H-31, 23.

${ }^{128}$ Williams 1986, 177, 206.

${ }^{129}$ Prebble 2007, 112.

130 “New Drugs Beating Psychiatric Troubles," 1957.

131 This excludes the two wards for disturbed patients which safety dictated remained locked. Thompson 1981, 16.

${ }^{132}$ AJHR 1953, H-31, 23.

133 Director-General, MHD, to the Medical Superintendent, Seacliff Hospital, October 22, 1947. Cited in Brunton 2001, 238. Original archival source not personally sighted.

134 "Tour of Cherry Farm Draws 400 Visitors," 1961.

${ }^{135}$ Brunton 2001, 245. Brunton cites "The Seacliff Mental Hospital," 1943.

136 "The Seacliff Mental Hospital," 1943.

${ }^{137}$ Ibid.

${ }^{138}$ United States National Institute of Health 1961, 46.

139 Ibid, 74-7. The report cites an unpublished monograph by Star titled "The Dilemmas of Mental Illness."

${ }^{140}$ Wilson 1970.

${ }^{141}$ Tregonning 1967.

${ }^{142}$ Kavanagh 2001, 169.

${ }^{143}$ Brunton 2001, 245. Brunton cites personal correspondence with former staff in footnote 135.

${ }^{144}$ Board of Health, 1960. Also refer Brunton 2005 (table 1).

${ }^{145}$ Kavanagh 2001, 170.

${ }^{146}$ Ibid, 173-4.

${ }^{147}$ Superintendent, Cherry Farm to the Chairman, Otago Hospital Board. June 13, 1968. ANZ: R18830390.

${ }^{148}$ Medical Superintendent, Cherry Farm Hospital (on behalf of), to the Director, DMH, January 4, 1967. ANZ: R18458555.

${ }^{149}$ Blain 1959, 48.

150 Ibid.

151 Superintendent, Cherry Farm Hospital, to the Deputy Director-General of Health, April 12, 1969. ANZ: R18830390.

152 Ibid.

153 Superintendent, Cherry Farm Hospital, to the Director, DMH, January 27, 1959 (includes citation of Smirk's correspondence). ANZ: R18458498.

${ }^{154}$ Meeting minutes: Acute Psychiatric Unit at Wakari, May 16, 1968. Meeting minutes: Acute Psychiatric Unit at Wakari, not dated by filed near June 7, 1968. Director, DMH to the Secretary, Otago Hospital Board, Dunedin, March 3, 1967. ANZ: R18458498. 
${ }^{155}$ Medical Superintendent, Queen Mary Hospital, "Survey: Queen Mary Hospital ... The Advancement of its Contribution to New Zealand Psychiatry." March 12, 1948. ANZ: R16195957.

${ }^{156}$ Ibid.

${ }^{157}$ Ibid.

${ }^{158}$ Crawford 2005, "Return to Civilian Administration."

159 Director, DMH, to the Director-General of Health, June 01, 1950. ANZ: R16195957.

${ }^{160}$ Director, DMH, to the Director-General of Health, June 24, 1948. Director, DMH, to the Medical Superintendent, Queen Mary Hospital, July 14, 1948. ANZ: R16195957.

161 Newspaper clipping, "Manpower Policy In Respect Of Mental Hospitals. Committees Statement," paper title not recorded, undated but filed near June 2, 1943. ANZ: R16195547.

162 Sainsbury 1946, 7, 14, 38.

${ }^{163}$ Gray to the Health Committee, House of Representatives. July 30, 1946. ANZ: R16195644.

${ }^{164}$ Sainsbury 1946, 38.

${ }^{165}$ Prebble 2007, 66.

166 Newspaper clipping, "Manpower Policy In Respect Of Mental Hospitals. Committees Statement," paper title not recorded, undated but filed near June 2, 1943. ANZ: R16195547.

${ }^{167}$ Prebble 2007, 79-80.

168 Division of Mental Hygiene, "Male Attendants See Many Changes in N.Z. Mental Hospitals", Draft Press Release, 1955. ANZ: R16195752.

169 "Attractive New Otago Hospital Villa," 1957.

${ }^{170}$ Refer, for example: Joyce Halstead, "Are they the Forgotten People?," 1954. "Our Mental Hospitals, 2," 1954.

171 Division of Mental Hygiene, "Witch Doctors and Hoodoos," Draft Press Release, 1954. ANZ: R16195751.

172 "Psychiatric Nursing a Satisfying Career" 1957.

173 Ibid.

174 Division of Mental Hygiene, "New Methods Mean More Cures for Mental Illness." Draft Press Release, 1955. ANZ file: R16195752.

${ }^{175}$ Logan 2009, 70-1.

${ }^{176}$ Division of Mental Hygiene, "Interest and Pleasure Help Towards Recovery on Mental Sickness," Draft Press Release, 1955, ANZ: R16195752.

177 "Attractive New Otago Hospital Villa," 1957.

178 Joan Kerr 1988, 6.

179 Television New Zealand, Dateline Monday: Mental Health, June 13, 1977. TVNZ Archive reference: P1173

${ }^{180}$ Prebble 2007, 89.

181 Shaw 1997, 102, 119.

${ }^{182}$ Logan 2009, 70-1. Yanni 2007, 15. Topp 2007, 242-6. 
183 Division of Mental Hygiene, "New Methods Mean More Cures for Mental Illness," Draft Press Release, 1955. ANZ: R16195752.

${ }^{184}$ Gray to the Government Architect, June 29, 1943. ANZ: R22502230.

185 "Cherry Farm. New Zealand's Most Modern Hospital," 1952.

${ }^{186}$ Note: the aesthetic trends shown in architectural magazines were distinct from popular residential building practices within New Zealand at the time which were far more restrained

${ }^{187}$ House and Building, Auckland, April-May (1949), 1.

188 "Northland Has Considerable Interest in Kingseat Hospital, 1957." Hackett (for the Division of Mental Hygiene), "Mental Illness in New Zealand its Treatment and Cure," 1953. Halstead, "'Are they the Forgotten People?," 1954.

189 Medical Superintendent, Ngawhatu Hospital, to the Director-General, MHD, September 12, 1947. ANZ: R20960887.

${ }^{190}$ Firth 1949.

191 “Cherry Farm. New Zealand's Most Modern Hospital," 1952.

${ }^{192}$ Gray to the Government Architect, June 29, 1943. ANZ: R22502230.

${ }^{193}$ H.C. (Harry) Burt's signature appears on drawings dated 1948, 1949 and 1951 [ANZ files: DAHI D494 648 35; DAHI D494 5b PWD1282105; W331933]. The Sheppard Files (held at the Auckland University), however, state that J.O. (Jack) Aimers designed this hospital. Aimers had received no proper architectural training at that time that these villas were designed (he attended the Auckland Architecture School shortly afterwards). According to family members, Aimers decision to attend university was because he was engaged in design work for the MOW for which he received little credit [personal correspondence with Jacqui Aimers, October 24, 2013]. Burt, however, seems the more likely designer of this building as the plan suggests a refined architectural skill that tends only to be developed through years of professional practice. Burt became a Registered Architect in 1941. Furthermore, similarities can be seen between the Cherry Farm plans and the State Fire Insurance Building, Dunedin [Hocken Collections: MS-0688/083].

${ }^{194}$ Arthur Salmond was also known for his design ability and interest in modernism and it is unknown to what degree these two projects were influenced by one or other architect. Refer drawings held by the Hocken Collections: MS-0688/247 (Office and Store, Cromwell); MS-0688/083 (State Fire Insurance Building, Dunedin).

${ }^{195}$ AJHR 1947, D1, 8. AJHR 1948, D1, 8. AJHR 1949, D1, 8. 


\section{CHAPTER SEVEN Discussion}

Following Leach's definition of interdisciplinary research, this thesis sought to employ the tools available to architectural historians in order to contribute "new perspectives on issues beyond architecture." It aimed to expand our existing understanding of official attitudes to mental illness in New Zealand through an examination of the architecture created for its treatment and containment, specifically, through a close examination of the compromises that were allowed to occur in the commissioning and construction of these facilities. This chapter will discuss the patterns of compromise that have emerged from the examination of Seacliff, Kingseat and Cherry Farm hospitals and the relative contribution, toward this compromise, of the politicians, architects and medical professionals who were involved. No conclusions will be made within this chapter as these will be reserved for the chapter that follows. 


\subsection{FAITH AND COMPROMISE IN THE CONSTRUCTION OF SEACLIFF ASYLUM, KINGSEAT AND CHERRY FARM HOSPITALS}

Architecture was believed to be capable of performing a curative role in the treatment of mental illness; the administrators of New Zealand's mental hospitals stated this belief publically, in various press releases and reports to the $A J H R$, between 1878 and 1957. The first question to be addressed within this dissertation was whether, in light of this belief, these facilities were constructed taking full account of current medical knowledge and leading architectural developments in the field. Seacliff Asylum followed an appropriate and current architectural precedent and responded to much of the advice set out by John Conolly in his publication of 1847. Relative to the asylums constructed for Auckland, Christchurch and Wellington, Seacliff was a superior solution with regard to the provision of individual treatment and tranquility regarding the treatment of the mentally ill. However, the design for Seacliff was deficient with regards to the provision of sunlight, the maintenance of safety, disguising visible signs of confinement and providing an environment that was unimposing. The delays faced in the establishment of a curative landscape around this asylum further compromised its curative potential. Kingseat Hospital, by contrast, was a remarkable hospital in its provision of architectural support for the delivery of individual treatment, tranquility and relative freedom for patients. The criticisms that can be made of Kingseat are relatively minor in comparison to other hospitals. Access to sunshine was not maximised, delays occurred in the completion of occupational and recreational facilities and the rural isolation of this hospital obstructed the development of research and teaching partnerships with general hospitals and medical schools which were relatively new at that time. By contrast, the architectural response created for the Cherry Farm Hospital was outdated relative to changing approaches to mental health care and in relation to the villas created for the Lake Alice Hospital five years earlier. The replication of a traditional, rurally located villa hospital also overlooked the value of the psychopathic hospital model, with its research focus, greater community accessibility and collaborative relationships with general hospitals and medical schools, despite this model having been widely used throughout Britain and America for four decades prior to the construction of Cherry Farm. Although imperfect, Kingseat was an exemplary mental hospital of its time. While Seacliff was current and a presented clear advance on other New Zealand mental hospitals of the period spanning $1867-1891$ it contained some significant flaws. With the design of the Cherry Farm Hospital, and the nationwide replication of this villa type, between 1945 and 1954, a very real opportunity was missed to improve the architectural response to mental health care in New Zealand.

The curative role of mental hospital architecture was publically stated by New Zealand officials, between 1878 and 1957, however, existing research in this field highlights the danger of accepting this at face value. Scull and Caplan have suggested medical professionals in Britain lost their faith in moral 
treatment prior to 1878 , the year in which Seacliff was designed. ${ }^{2}$ This observation calls into question the ongoing relevancy of a curative environment purposely designed to support the delivery of moral treatment. Similarly, Topp's examination of the development of the villa hospital typology infers that these late nineteenth hospitals were not created for their curative potential but as vehicles for a public relations campaign. ${ }^{3}$ In the United States, the rapid and widespread adoption of the psychopathic hospital model, alongside architectural responses such as the Manteno State Hospital (discussed in chapter five), suggests that a belief in the curative effects of architecture had lapsed by 1928, the year before Kingseat Hospital was planned. $\mathrm{Dr}$ Goshen's retrospective observation that the state mental hospitals constructed in America during the interwar period were "human warehouses" further supports this observation. ${ }^{4}$ Belich has suggested that certain ideas that were carried from Britain by colonists, such as the fear of poverty, persisted much longer in New Zealand than in Britain. ${ }^{5}$ The examples of Seacliff and Kingseat suggest that this was also the case regarding the faith vested in the curative potential of an appropriately designed environment for mental illness; this belief persisted much longer in New Zealand than elsewhere. At Seacliff, the engagement with best international practice in asylum design, the conversations had, criticism metered out and the money expended all suggest that the decision makers involved in the design of this institution retained a sincere belief in the curative ability of architecture. Likewise, Gray's personal faith in the villa model resulted in the construction of high quality hospital environments that responded to current thought regarding the treatment of mental illness and, in the case of Lake Alice, improved markedly on current practice. When the first colonists departed from Britain the inadequacies of the asylum as a curative environment were largely unknown, the Lunatics Act had only recently been passed (1845) and the new spatial typology of the asylum carried all the promise of a more humane and more successful solution. By the time that Skae departed Britain in 1875, however the limitations of asylum care were fairly widely recognized. ${ }^{6}$ It is likely that Skae considered that a return to smaller asylums (300 patients maximum) would mitigate the negative effects of asylum care that had been observed in British asylums. As Scull has observed, increasing the size of asylums "inevitably made the doctors more remote, and broke the ties which were supposed to unite superintendent and patient" and were, thus, central to securing cures. ${ }^{7}$ Similarly, Gray departed from Scotland when the villa hospital was in its infancy. This was long before it came to be understood that accommodating patients in smaller groups could not eliminate the risks of patient dependency and the damage to self esteem that occurred in large asylums, as identified by Conolly in $1830 .{ }^{8}$ At Cherry Farm, however, the discrepancy between the architecture created and the media discussion of this architecture suggests that the Division of Mental Hygiene no longer believed in the relevance of an appropriately constructed environment as an adjunct to curing mental illness. 


\subsection{POLITICAL AGENDAS : PUBLIC EXPECTATION AND FUNDING}

The role that public expectation played in the design of facilities for mental health care in the nineteenth and twentieth centuries has been commented upon by both Smith and Hunt. Both have suggested that the public placed a higher value on the containment of madness than on its treatment. ${ }^{9}$ With regards to funding, both Scull and Smith have both commented on the compromise that occurred in nineteenth century asylum construction owing to a progressive lack of public concern for the needs of the mentally ill that resulted in a reduction of expenditure on asylum construction. ${ }^{10}$ In the construction of Seacliff, Kingseat and Cherry Farm hospitals, compromise occurred from public expectation and a lack of funding; both issues can be identified as arising from the political agendas of the successive governments who commissioned and paid for these facilities.

While the designs of Seacliff, Kingseat and Cherry Farm responded to public expectation, the resultant compromise from this political concern varied widely across these three hospitals. Seacliff suffered to the greatest extent from political agendas because it was subjected to the political desires of a young British colony: to proclaim the colony's maturity, prosperity and benevolence (colonial propaganda), and to reassure colonists that lunacy was safely contained. Important curative strategies - access to sunshine and the provision of an environment that was unimposing where obvious signs of confinement were disguised in order to protect the sensibilities of patients were sacrificed in order for these political agendas to be manifested aesthetically. At Cherry Farm the distance of this hospital from the city contravened current thought regarding the optimum treatment of mental illness but appeased the Dunedin public who were not ready to accept an institution closer to town. The transparency of this new architecture intimated a new, more modern and humane approach to the treatment of mental illness where patient abuse was mitigated because staff conduct was placed on public display. This benefited both political agendas and professional concerns of public relations. Of the three hospitals examined, Kingseat suffered least from public expectation because of Gray's single-mindedness in the design of this hospital. Instead of pandering to public expectation by locking patients up, the architectural response created for Kingseat sought to educate the wider public regarding a more enlightened response to patient care. This hospital, along with the corresponding press releases written by Gray, conveyed the message that patients were to be treated in buildings of a high standard and given the relative freedom to move between these buildings and the expansive landscape that surrounded them. ${ }^{11}$ Kingseat's distance from the city, however, was a response to the public's reluctance to associate with the mentally ill. Gray favoured rural hospital settings because patients could be given relative freedom "without offending the eyes" of those members of the public who were not accustomed to visiting mental hospitals. $^{12}$ 
While Seacliff, Kingseat and Cherry Farm were not subject to the same level of financial constraint as many of their counterparts, these case studies nonetheless illustrate that no New Zealand mental hospital constructed between 1878 and 1971 received the funding that was necessary to provide an ideal curative environment for mental illness. Six years passed before landscaping work and the appropriate furnishing of interiors was put in hand at Seacliff Asylum. Yet, these aspects were considered crucial for the support of a treatment regime that relied upon patients forming an attachment to nature and recovering their ability to behave sensibly in social settings. At Kingseat it took 30 years to complete the full complement of facilities that were envisioned for this hospital within the first seven years of its development. In the 1930s, recreation halls and dedicated spaces for occupational therapy were deemed necessary to keep the minds of patients active and for calming those patients who, if left unoccupied, were likely to become restless and destructive. ${ }^{13}$ Similarly, at Cherry Farm, a decade passed before permanent facilities for recreational and occupational therapy were provided. Restrictions on funding at Cherry Farm also hindered the ongoing training of medical students throughout the transition from Seacliff to Cherry Farm and likely influenced the decision to persevere with construction at this remote site instead of moving the facility closer to the city. Since the department owned this land already no further capital expenditure would be required. This may have provided a strong argument for constructing a new facility on the Cherry Farm site but the result was a hospital that was unable to respond fully to modern ideas regarding the treatment of mental illness. The Levin Farm Colony provides one of the most compelling examples of the government's unwillingness to provide the funding required for the provision of adequate facilities. With regard to operational requirements, environmental quality and educational potential (in lieu of curative potential as these villas accommodated children with intellectual handicaps), the villas constructed for this hospital in 1953 failed to respond appropriately to the children they housed. In both the nineteenth and twentieth centuries when competition for government funds occurred, developments such as roading, hydroelectricity and state housing were prioritised above the needs of the mentally ill. This finding is consistent with Brunton's research. ${ }^{14}$ The most extreme example of the government overlooking the needs of this department was the funding directed to the construction of rehabilitation facilities for returned servicemen and the quality and expense of the new accommodation constructed for the Queen Mary (neuropathic) Hospital. These examples, similar to the villas created for the Levin Farm Colony, suggest an underlying reluctance towards spending money on patients who were not considered curable. The isolation in which the Mental Hospitals Department was left to operate, ${ }^{15}$ relative to the interest shown in the governance of general hospitals over the same period, confirms the apathy with which New Zealand's mental hospital patients were regarded. 


\subsection{PROFESSIONAL AGENDAS : ARCHITECTURAL}

In the case of Seacliff, Kingseat and Cherry Farm, it is clear that a flawed design and procurement process limited the curative potential achieved at each of these hospitals. A limitation of this research, however, is the difficulty of gauging the contribution of individual architects to the compromise of these facilities. The structure of the Public Works Department (later the Ministry of Works) in combination with the sparse archival evidence that has survived renders the architect somewhat anonymous within this process. Even in the case of Seacliff Asylum, where Robert Lawson is clearly identifiable as the architect in charge, the lack of surviving documentation obscures the depth of understanding that can be achieved. Nonetheless, this dissertation will use the information that is available to offer some conclusions regarding the likely attitudes of these architects.

The role of the architect in the design of New Zealand's mental health facilities shifted over time. Lawson was considered a visionary whose opinion was deemed to have more authority in the design of this architectural typology than that of Fredrick Skae, the country's medically qualified Inspector of Asylums. This was evident in the decision of the Public Works Department to accept that Lawson had ensured ample sunshine to the asylums interiors despite Skae expressing his dissatisfaction with this design. ${ }^{16}$ In the hospitals constructed following 1927, however, the architect became a technician who was given clear directions from the medical administrators and was able to rely on an existing villa typology, beyond this they required little understanding of the curative philosophies underpinning this typology. The progressively retrograde responses created for the Cherry Farm Hospital (1949) and the Levin Farm Colony (1954), relative to the designs for Kingseat (1929) and Lake Alice (1943), suggests that the architects appointed to design these facilities were not accorded the time necessary to gain a deeper understanding of these institutions as short-term curative, or long-term residential, environments. Between the 1924 design for Ngawhatu Hospital and the 1949 design for Cherry Farm, the typology of the 50-patient villa was not developed to any significant degree. These villas continued to provide three dormitories with a centrally positioned, communal dressing room and bathrooms that contained three baths.

What emerges from a review of these three hospitals is that the architects involved in these projects were routinely under-resourced and limited by a design and procurement process that obstructed direct communication between the architect (or architectural team) and their departmental client, the medical experts who best understood the needs of these patients. At Seacliff the role taken by the Public Works Department, as a conduit for the transmission of information between Lawson and Skae, isolated the architect from his most valuable source of medical advice. The oversights related to patient safety in Lawson's design suggest that he was not provided with a necessary level of medical consultation throughout the design process. In further support of this observation is the fact that no evidence has surfaced to 
suggest that Skae was allocated the resources to accumulate the "colonial lunacy library of reference" that the Scottish physician W.L. Lindsay recommended was necessary for anyone appointed to the role of asylum inspector in colonial New Zealand. ${ }^{17}$ While this isolation was not as pronounced at Kingseat and Cherry Farm, the situation remained less than ideal. These institutions were designed remotely, from the Wellington office, and the only opportunity for the architects responsible for the design of these buildings to correspond directly with hospital staff was through the national director of mental hospitals. The local District Architects who were in a position to meet with hospital staff, to gain a thorough understanding of the site and to observe the hospital carrying out its daily routines, were given only limited responsibility in the design of these institutions. Briefing and feedback processes regarding the design of these facilities predominantly occurred at high levels, from department head to department head.

During the period in which the Kingseat and Cherry Farm hospitals were designed the government's works department were severely under-resourced to carry out the number of national building projects they were charged with delivering. The correspondence between the Public Works Department and the administrators of New Zealand's mental hospitals between 1937 and 1971 made clear that the needs of New Zealand's mental hospitals were a low priority in relation to the division's other public projects. The government's own apathy toward the needs of New Zealand's mental hospitals exacerbated this situation as it gave license to the Public Works Department to regard them similarly. The inability of the Public Works Department and their successor, the Ministry of Works, to ensure the works programme for the Mental Hospitals Department was carried out in full for the years spanning 1929 to 1950, and their lack of attention to detail in the design of the Levin Farm Colony villas (1954), supports the observation that there was a lack of architectural commitment to meeting the needs of this department.

Since mental health facilities in New Zealand were publically funded, tension existed regarding who the predominant stakeholder was in the construction of these institutions. Was it the end users of these buildings (the patients) who, as Russell so bluntly described in 1950 , had "no voting strength," 18 the medical professionals who administered them or the taxpayers who funded these expensive projects? The effects of this conflict were clearly visible in the design of Seacliff, where the appearance of the asylum was elevated above its curative potential, and at the Levin Farm Colony, where costs were cut to a minimum with little thought toward environmental quality or fitness for purpose. The most likely explanation for this seeming lack of architectural commitment was that it was a consequence of the terms under which these architects were engaged. In the examples of Seacliff, Kingseat and Cherry Farm, the architects were expected to respond firstly to the desires of the politicians who had commissioned them and secondly to the operational needs of these institutions. These operational needs were defined by the political and social context of the time, they responded to issues such as low 
staffing numbers, overcrowding and tight budgets. The needs of the patients could be addressed only after the first two priorities (political and operational) had been met. As was evident with the design of the Cherry Farm villas, this left little scope for improving the patient experience of these buildings. At Cherry Farm the treatment of interior finishes and glazing within the day rooms provided the only real improvement, for patients, to these hospital environments. Despite Lawson's desire to leave a significant architectural legacy, any compromise arising from his personal ambition could have had only a marginal effect in relation to the damage that resulted from having to balance the needs of patients against public and political desire. 


\subsection{PROFESSIONAL AGENDAS : MEDICAL}

Much of the existing research regarding the construction of asylums has focused on the motivations of medical professionals. Scull and Topp, for example, have suggested that the asylum typology was susceptible to compromise due to professional agendas of legitimisation and public relations. ${ }^{19}$ Issues that have emerged from the study of Seacliff, Kingseat and Cherry Farm hospitals include the fear of professional marginalisation, concerns of public relations and the personal ambitions of Theodore Gray. Existing research in the colonial context has also highlighted the limitations of a conservative British outlook and isolation from professional networks. These issues will be discussed here along with Brunton's hypothesis of deinstitutionalisation. ${ }^{20}$

Concerns of public relations influenced the architectural approaches taken to Seacliff, Kingseat and Cherry Farm Hospitals. Institutional psychiatrists were marginalised and architecture was a vehicle through which the reputation of these men could be updated and the work carried out by this department legitimised. At Seacliff architectural grandeur was employed to signify modern, humane treatment, whereas, at Kingseat and Cherry Farm contemporary architectural styles were utilised to infer modern medical care. In both cases this was paired with a media discourse, of varying scope and overtness, which reinforced the idea that the modern treatment of mental illness was dependent on modern architectural surroundings. This study has found, however, that while an awareness of public relations was present in all three hospitals this did not routinely jeopardise the curative potential of these environments. In the case of Seacliff Asylum concerns of public relations were outweighed by political agendas, at Cherry Farm the opposite occurred. While the sparse archival evidence regarding the design of these institutions makes it difficult to categorically state whether political desire to meet the expectations of the public or professional desire to raise the public standing of institutional psychiatry weighed more heavily in the design of each hospital, contextual factors provide valuable clues. Belich and Fairburn have offered evidence of the wider context of colonial aspiration that existed during the period in which Seacliff was designed suggesting that political agendas were likely to have exerted more pressure. In the case of Cherry Farm Hospital, the increasing public criticism directed towards New Zealand's mental hospitals, and their administrators, and the difficulties of nursing recruitment suggest that the department's own motivation to look modern and humane would have outweighed any pressure exerted by the government in this direction. Cherry Farm was the only case study hospital that suffered from significant compromise owing to professional concerns of public relations. Where money could have been spent on improving patient comfort it was instead directed toward the use of expensive materials, the construction of flat roofs and the installation of large expanses of glass. While the glazed facades of the day rooms provided a more pleasant interior environment for patients, Oamaru 
stone claddings and flat roofs could not have provided any tangible, curative benefits to the patients themselves.

Topp's observation, that the priority of the villa hospital typology was to present an image of humane asylum care without necessarily delivering an improved patient experience, suggests that addressing matters of public relations and constructing a curative environment may have existed in conflict with each other. ${ }^{21}$ The example of Kingseat Hospital challenges this because these concerns were clearly present, and adequately addressed, in the construction of this hospital, however, the compromise to the curative potential of this architecture was minimal. Patient access to sunshine was sacrificed in order to make a strong impression on visitors to this hospital; villas were oriented not for sunshine but to set up a central axis that drew attention to Kingseat's large recreation ground and acute treatment facilities. No further compromise occurred at Kingseat Hospital. Furthermore, the juxtaposition of the villas created for the Cherry Farm Hospital and those created for the Levin Farm Colony provides a convincing illustration of how the awareness of an external audience can result in the production of higher quality of patient accommodation. Although the curative quality of Cherry Farm's architecture was not exemplary, it provided day spaces that were spatially varied and generous, that provided unprecedented access to sunshine and landscape views and were more richly decorated than those provided for the Levin Farm Colony. Cherry Farm was located along a main highway and the relatively close proximity of the Otago University Medical School heightened the public profile of this institution. The Levin Farm Colony was not located on a main road and was more than twice the distance of Cherry Farm from a major city.

Brunton suggests that hospital and departmental administrators recognised that asylums dehumanised patients and attempted to mitigate this through a series of improvements aimed at creating less institutional hospital environments. ${ }^{22}$ The contribution made by Truby King in this regard has only briefly been touched upon within this thesis. However, this has been discussed at length by other historians, such as Cheryl Caldwell in Unfortunate Folk, Theodore Gray in his autobiography and in Mary King's biography of her father. ${ }^{23}$ The development of Ngawhatu and Kingseat hospitals confirms that Gray and King were both driven by the desire to make these environments less institutional. Gray's efforts at Lake Alice, to create an architectural solution that could replicate what he considered to be leading non-institutional responses to care - the Scottish Boarding Out System and the Colony at Gheel - was the most compelling architectural example in support of Brunton's hypothesis. However, the response created for the Cherry Farm villas does not fit with this view. The design of dressing spaces within the Cherry Farm villas, and the repetition of traditional responses to bathing and sleeping, suggest that hospital administrators were not focused on developing less institutional environments for care in the design of this hospital. 
This dissertation also reveals that the commitment of hospital and departmental administrators was not as consistently focused on the wellbeing of patients as Brunton's hypothesis suggests. Professional agendas were allowed to impact on the curative potential of the architecture created for New Zealand's mental hospitals between 1927 and 1971. At Kingseat and Cherry Farm the fear of exacerbating the already marginalised position held by institutional psychiatrists limited the development of mental health care in this country. The need felt by the administrators of New Zealand's mental hospitals to protect their professional territory motivated various administrators of this department to make decisions that were counterproductive to progress. Collaborations with medical schools and general hospitals that could have potentially advanced the treatment of mental illness continued to be resisted by this department until 1971. Almost two decades after the 1953 WHO report was published, the Division of Mental Hygiene was still reluctant to adopt the collaborative models of care that were encouraged by the WHO.

One of the conclusions of Piddock's research was that Australia's geographical isolation from the lunacy "knowledge pool," based in Britain, contributed to compromise in the construction of ideal curative environments for mental illness within the nineteenth century. ${ }^{24}$ In the instances of Seacliff, Kingseat and Cherry Farm, geographical isolation played a role but it did not feature as prominently as a cause of compromise relative to Piddock's findings in Australia. The compromise suffered at Seacliff can only partially be attributed to issues of professional isolation since, unlike Piddock's Australian case studies it was based on a current, highly relevant precedent. Gray's rejection of the psychopathic hospital model may be partially attributable to professional isolation, since this was a new model that Gray had no direct experience with, however, fears of professional marginalisation, provide a more likely explanation for this (especially given that Gray's reaction to this new model reflected a wider resistance from within this profession). At Cherry Farm, the question could be asked, if a New Zealand representative had been invited to consult with the WHOs expert committee on mental health care in 1952, would there have been more impetus, from within the department, to implement these new approaches to care. In comparing the architectural approaches of New Zealand and America, a key difference is that the Director of the American Psychiatric Association was present at the drafting of the 1953 WHO report. This allowed a situation whereby the information contained within this report could be fed back in a timely fashion, and with a full understanding of the issues that informed it, to American professionals. The value of this connection should not be underestimated since Blain himself lamented, six years after this report had been released, that the report had not been widely read in the United States despite the fact that it was widely discussed. ${ }^{25}$ However, this also reflects the ease with which existing British architectural models were rejected within the American culture. As identified 
by Yanni and Turner, new design approaches were developed for both the university and the asylum (the Kirkbride plan) within the nineteenth century. ${ }^{26}$

While the medical professionals involved in the construction of Seacliff, Kingseat and Cherry Farm contributed to compromise in the construction of these institutions, this did not arise from insincerity but because, without exception, these men were overcommitted and under-resourced within the roles they were appointed to perform. Furthermore, they were encumbered with a conservative outlook that privileged British practice and obstructed their ability to innovate. Belich and Brunton have both highlighted that the presence of conservativism within the New Zealand culture limited opportunities for innovation. ${ }^{27}$ From Seacliff through to Cherry Farm, adversity to new ideas remained a constant source of compromise. While this can be partially attributed to fears of professional marginalization, the men appointed with shaping New Zealand's system of mental health care lacked the vision or confidence to innovate. The examples of Seacliff, Porirua and Tokanui suggest that Skae, Grabham and MacGregor were largely incapable of the vision expressed by Lindsay in his 1872 report on the state of lunacy in New Zealand. Where Lindsay saw opportunities for the advancement of existing models of care these three men responded by replicating traditional, British approaches. Likewise, at Cherry Farm, traditional architectural values of homeliness and modernism were sought with no consideration to the ongoing relevance of these values for a rapidly changing therapeutic milieu. Even with regard to Gray's creation of the 11-bed villas for Lake Alice, the most innovative architectural response within the history of New Zealand's mental hospitals, his ability to innovate was restricted to an existing frame of reference - the villa hospital in which he received his training. The 11-bed villas were, nonetheless, a brave and exciting departure from existing precedent that highlighted the timidity of his successors to persevere with such a challenging model. This timidity echoed the response to Skae's enthusiasm for the Seaview villas in 1879.

While the existing research in the field of asylum architecture primes researchers to be suspicious of the motivations of institutional psychiatrists, ${ }^{28}$ Brunton and Prebble's research has raised questions regarding the motivations of Theodore Gray. ${ }^{29}$ Gray was highly driven and expressed the desire to leave an architectural legacy. While he may have been responsible for limiting the development of various aspects of mental health care in this country, he significantly improved the environments in which this care was delivered. His willingness to devote significant time to direct, regular and detailed correspondence with the Government Architect, in the examples of Kingseat and Lake Alice hospitals, mitigated the drawbacks of an inept design and procurement process. The energy expended by Gray in providing the Public Works Department with floor plans, attending to the specification of items such as wash basins and lighting and visiting sites to ensure that buildings were set out at optimal distances was evident in the quality of the resulting architecture.$^{30}$ However, Russell's appointment of a Developments 
Officer in 1947, and the observations made by Brunton, all go some way to suggest that the time devoted by Gray to matters of architecture must have reduced the attention he was able to give to development in other spheres. ${ }^{31}$

${ }^{1}$ Leach 2010, 71.

${ }^{2}$ Scull 1979, 189-90. Caplan 1969, 49, 89-90.

${ }^{3}$ Topp 2007, 242-6.

${ }^{4}$ Goshen 1959, 1-2.

${ }^{5}$ Belich 1996, 292.

${ }^{6}$ Scull 1979, 189-90. Caplan 1969, 49, 89-90.

${ }^{7}$ Scull 1993, 172.

${ }^{8}$ Conolly $1830,11,17,21,31$.

${ }^{9}$ Smith 1999, 38. United States National Institute of Health 1961, 46 (Robert Hunt of the Hudson River State Hospital is cited within this report).

${ }^{10}$ Scull 1979, 117. Smith 1999, 81-2.

11 "Mental Patients. Kingseat Hospital... Extensions to Buildings," 1937.

12 Director-General, MHD, to the Minister of Mental Hospitals, April 18, 1935, as cited in Brunton 2001, 244.

${ }^{13}$ Thompson 1992, 120. “Dutch Mental Hospitals,” 1929, 936.

${ }^{14}$ Brunton 2001, 158.

${ }^{15}$ From 1878 until their merger with the Health Department in 1947.

${ }^{16}$ AJHR 1880, $\mathrm{H}-06,8$.

${ }^{17}$ Lindsay 1872, 813-14, 827.

${ }^{18}$ Director, DMH, to the Minister of Health, March 22, 1950. ANZ: R16195940.

${ }^{19}$ Scull 1979, 44, 93-4, 165. Topp 2007, 242-6.

${ }^{20}$ Brunton 2003.

${ }^{21}$ Topp 2007, 242-6.

${ }^{22}$ Personal correspondence with Warwick Brunton, November 19, 2010. Also refer: Brunton 2003.

${ }^{23}$ Cauldwell 2001. King 1948. Gray 1958.

${ }^{24}$ Piddock 2007, 191.

${ }^{25}$ Blain 1959, 47.

${ }^{26}$ Turner 1894, 37, quoted in Yanni 2007, 95-6.

${ }^{27}$ Belich 2001, 122-3, 307. Brunton, 2001, 60.

${ }^{28}$ Foucault 1964, 258. Topp 2007, 242-6. Scull 1979, 44, 93-4, 165.

${ }^{29}$ Brunton 2001, 181-3, 256, 347-8. Prebble 2007, 100-1.

${ }^{30}$ Gray to the Government Architect, various dates: June 29, 1943, October 29, 1943, June 19, 1944, February 13, 1945. Medical Superintendent, Auckland Mental Hospital, to Gray, various dates: June 24, 1943, February 2, 1945. ANZ: R22502230.

${ }^{31}$ Brunton, "Gray, Theodore Grant - Biography." 


\section{CHAPTER EIGHT Conclusion}

This dissertation sought to address three lines of inquiry: was the architecture created for mental health care in New Zealand up to date, to what extent did public expectation influence these design responses, and what were the factors that contributed to compromise in the construction of ideal curative environments? This dissertation revises three existing assumptions within this field: the idea that the asylum was susceptible to exploitation by individuals, that Robert Lawson was primarily responsible for deficiencies in the therapeutic potential of Seacliff Asylum and that Theodore Gray's leadership in mental health care was retrograde and lacked innovation. In addition, this dissertation establishes new understandings around the level of faith that existed in New Zealand regarding the curative effects of a therapeutic environment and the role of the architect in mental hospital design. This chapter will first answer the three lines of inquiry listed above before outlining the additional findings. It will finish by answering the overarching question of this research: what does the architectural approach taken to Seacliff, Kingseat and Cherry Farm mental hospitals indicate about official attitudes to mental illness in New Zealand between 1878 and 1971?

Three case study hospitals were selected from three different eras, while each was not the only hospital constructed at the time, each was more expensive than contemporary developments. Despite the relative expense of the three case study hospitals, only Kingseat could be considered an exemplary hospital of its time. While Seacliff had it faults, it was generally constructed in accordance with best practice in asylum design. Cherry Farm is the hospital that represents the real missed opportunity. It failed to respond to a changing therapeutic milieu and overlooked the value of the psychopathic hospital model, with specific regard to its emphasis on research, teaching, greater collaboration with general hospitals and greater accessibility to the city it served. This was despite the fact that this model had been constructed in America and Britain for four decades.

Kingseat suffered least from the pressures of public expectation, this was owing to Theodore Gray's unwillingness to submit to public pressure. Despite public requests, Gray refused to direct any funds available for new hospital 
construction toward the "half-way houses" (as distinct from psychopathic hospitals) that were called for in the media and by members of the public, or to scale back on open-door practices at Kingseat and Ngawhatu based on expressions of public concern. At Seacliff, the two most detrimental factors in achieving an optimum curative environment arose from public pressure; the need to reassure colonists that lunacy was safely contained and to reinforce the manifestation of the great colonial dream. Likewise, Cherry Farm's distance from the city contravened current thought regarding the modern treatment of mental illness and was a direct result of public expectation. At the time this hospital was designed the people of Dunedin were largely unwilling to accept an institution closer to town. Prior to 1947, the media claims made regarding the therapeutic benefits of the mental hospital reflected a sincere faith on the part of this department that was led by Gray. However, the media discussion of the Cherry Farm's villas was an exercise in propaganda; the design intent in the creation this villa type was postrationalised along the lines espoused in the WHO report which was written four years after these villas were designed.

A number of peripheral factors contributed to compromise in the construction of ideal curative environments. From an architectural perspective, a flawed design and procurement process limited the curative potential achieved at each of these hospitals. This was exacerbated by the fact that the needs of New Zealand's mental hospitals were a low priority in relation to the Public Works Department's other public projects. While the attitudes of the architects involved with the design of New Zealand's mental hospitals is difficult to accurately gauge, the careful articulation of the facades and floor plans produced for all three case study hospitals suggests that the architects involved were committed to providing solutions of some quality. They were limited, however, by a design process that promoted political and operational concerns over patient needs and failed to allocate the resources or processes necessary to allow them to attain a thorough understanding of the curative philosophies that underpinned this typology. The evident priority within the design approaches taken to all three institutions was efficiency of both cost and time; this was a product of the government's failure to devote sufficient architectural resource toward the development of these institutions.

The medical administrators of New Zealands mental hospitals limited the development of these facilities owing to their conservative outlook and a fear of professional marginalisation. While the needs of the mentally ill were a high priority for these men, their commitment was not as consistently focused on the well being of patients as Brunton's hypothesis of deinstitutionalisation suggests. An examination of the architectural approach taken to Kingseat and Cherry Farm hospitals indicate that, however inadvertently, the department's psychiatrists allowed these hospitals to be limited by their own fear of professional marginalisation. This restricted the development of the mental hospital typology in ways that could have resulted in significant benefits to patients. The conservative outlook of decision makers, attributable to New 
Zealand's cultural conservatism and its position as a young British colony, exacerbated this situation. With the exception of King and Gray, medical professionals were uncomfortable with innovative approaches that moved too far beyond trusted British practice.

The most obstructive factor in the creation these environments, however, was the failure of successive governments to grant sufficient financial and architectural resource to meet the needs of these hospitals. The needs of the mentally ill were a diminishing priority for successive New Zealand governments between 1878 and 1972. Seacliff, Kingseat and Cherry Farm were jewels in the crown of New Zealand's mental hospital network, however, sufficient funds were not provided to complete these hospitals to the standard that was originally envisioned. No hospital constructed between 1878 and 1972 was granted the funds necessary to provide adequate accommodation for the growing numbers of patients who became resident within these institutions over time. Furthermore, at Seacliff and Cherry Farm public expectation was prioritised over the needs of these patients. The design of the Women's Ward at Queen Mary Hospital (1926), the approach taken to the construction of facilities for Returned Service Men (1943) and the villas created for the Levin Farm Colony (1953) all suggest that successive governments were reluctant to spend money on patients who were not considered curable.

This dissertation examined the role of individuals in design of New Zealand's mental hospitals and thus revised three existing assumptions within this field. Firstly, the assumption that this architectural typology could easily have been exploited for the advancement of personal agendas. Since the asylum typology served a disenfranchised and vulnerable patient group that was widely demonised by the public this assumption is logical. Especially so given that public scrutiny of asylums was sporadic and sensationalist but shortlived. The examination of Seacliff Asylum revealed, however, that the design and procurement process in place for these institutions was too complex for any single individual, such as an architect or medical administrator, to successfully exploit in order to advance their own professional standing. The personal contribution of Theodore Gray further refutes this assumption; it illustrates that the involvement of a committed, single-minded individual in the procurement of this building typology can mitigate the effects of compromise that can arise from political agendas and an ill-adapted design and procurement process. The Cherry Farm case study lends further support to these findings. Unlike Seacliff and Kingseat, no dominant character emerged from the architectural development of this hospital; yet, the architectural solution was inferior, in terms of its ability to support the delivery of mental health care, to the solutions created for Seacliff, Kingseat and Lake Alice.

While it has long been assumed, based on criticisms from medical administrators of the era, that Robert Lawson was primarly responsible for deficencies in the therapeutic potential of Seacliff Asylum, this dissertation 
establishes otherwise. When examined in relation to the medical theories to which this architecture was expected to respond, and in relation to contemporary developments in New Zealand and abroad, it becomes clear that Lawson designed the highest quality asylum constructed within nineteenth century New Zealand. Likewise, Theodore Gray's leadership in mental health care has traditionally been considered retrograde and lacking in innovation. A close examination of the architecture created under his leadership illustrates that Gray made significant improvements to the environments in which mental health care was delivered. His concept for the 11-bed villas at Lake Alice was the most innovative architectural development within New Zealand's history of mental hospital architecture. Lawson and Gray deserve greater recognition for their relative contributions to the architecture created for the treatment of mental illness in this country.

In addition, this dissertation establishes that the role of the architect changed throughout this architectural history, from that of a visionary to that of a technician. Furthermore, an analysis of this architecture indicates that faith in the curative effects of an appropriately designed environment persisted much longer in New Zealand than elsewhere. Until 1947 a sincere belief existed that architecture was able to contribute to the treatment of curable mental illnesses, this ended with the resignation of Theodore Gray from the Mental Hospitals Department. Although it was publicly stated that architecture continued to play a role in the treatment of mental illness, the design of Cherry Farm evidenced that the faith previously shown by medical professionals in the healing power of curative environments was waning. With the design of the Cherry Farm villas in 1949 mental hospital architecture was no longer considered able to strategically facilitate the delivery of mental health care and was reduced to a vehicle for professional and political propaganda regarding the humane and modern treatment of the mentally ill.

A close examination of the architecture created for mental health care in New Zealand tells us that meeting the needs of the mentally ill was only one of a number of agendas that were addressed by the officials involved in the design of these institutions. Many of these agendas were peripheral to the delivery of mental health care and conflicted with the attainment of ideal environments for the treatment of mental illness. Relative success in the construction of these environments was very much dependent on the individuals involved and the political conditions under which each hospital was procured. The most obstructive factor in the creation of ideal curative environments for mental illness was the failure of successive governments to grant sufficient financial and architectural resource to meet the needs of New Zealand's mental hospitals. 


\section{BIBLIOGRAPHY}

This bibliography is ordered as follows (page numbers given at right);

\section{PRIMARY SOURCES:}

Archival Sources, text based: $\quad$ Archives New Zealand 297

Bethlem Royal Hospital 299

Hocken Collections 299

Archival Sources, drawing based: $\quad$ Archives New Zealand 300

Bethlem Royal Hospital 302

Alexander Turnbull 302

Canmore Archive 302

Hocken Collections 302

Wellington City Council 302

West Coast Historic Society 302

Official Publications: $\quad$ New Zealand 303

International 304

Medical Sources (by case study): Seacliff: 1860-1900 305

Kingseat: 1906- $1958 \quad 306$

Cherry Farm: 1939-1975 308

Hospital Histories (mainly staff accounts) 313

Patient Histories (published) 314

Newspaper and Magazine Articles 314

$\begin{array}{ll}\text { Audiovisual } & 317\end{array}$

Miscellaneous - Literature 317

SECONDARY SOURCES:

Books and Articles 318

Theses and Dissertations 326

Web-based Material 327

\section{Important notes:}

Owing to the categorization of sources some authors appear in multiple categories; works by Brunton, for example, occur under "Hospital Histories," "Books and Articles," "Theses and Dissertations," and "Web-based Material."

While the Appendicies to the Journals to the House of Representatives [abbreviated AJHR] have been cited within this work they are not listed seperately.

The Journal of Mental Science was renamed the British Journal of Psychiatry in 1964. Between 1853 and 1858 this was known as the Asylum Journal. 
PRIMARY: $\quad$ ARCHIVAL SOURCES - TEXT BASED

\section{Archives New Zealand}

(ordered by Archives "item ID" with full reference given in brackets):

R15964069 - Villas, 12 Patient [Lake Alice], 1946 - 1949 (AATC 5114 W3457/204).

R16195531 - Kingseat Hospital - Establishment - nursing and domestic, 1927-1959 (ADCB 16173 H-MHD1 2/ 8/2/1 1).

R16195637 - Treatment of recoverable patients, 1927-1942. (ADCB 16173 H-MHD1 29/4/4/1).

R16195638 - Treatment of Incipient Mental Disorders, 1921. (ADCB $16173 \mathrm{H}-\mathrm{MHD} 1$ 30/ 4/4/2 1).

R16195641 - International Conference on Mental Hygiene at Washington, USA, and various correspondence, 1929-1936 (ADCB 16173 H-MHD1 30/ 4/4/6).

R16195644- Mental Hospital Reform Association, 1944-56 (ADCB 16173 H-MHD1 31/ 4/4/9).

R16195699 - Establishment, Reorganisation - Nelson and Ngawhatu, 1930 - 1935 (ADCB 16173 H-MHD1/41).

R16195702 - Re. cooperation between Public Works Department and Mental Hospital Department in preparing plans (ADCB 16173 H-MHD1/42 8/18).

R16195751 - Publicity, recruitment of nurses, 1951-60 (ADCB 16173 H-MHD1/51 8/116/12/1 1).

R16195752 - Publicity, recruitment of nurses, 1955 (ADCB 16173 H-MHD1/51 8/116/12/1).

R16195770 - Accommodating Returned Soldiers at the Wolfe Home, Auckland Mental Hospital (ADCB 16173 H-MHD1/53).

R16195784 - Re. Soldier Patients at Wolfe Home and other institutions (ADCB 16173 H-MHD1/53 8/430).

R16195794 - Mental Hospitals Department Public Works statement, 19161921 (ADCB 16173 H-MHD1 54/ 8/606).

R16195841 - Report on trip to Continent by Dr Theo Gray 1927 [and 1929]. *File includes Part 1 dated October 01, 1927, and Part 2 dated October 17, 1929 (ADCB 16173 H-HMD1 58/ 8/1041).

R16195871 - Recoverable patients, 1936 (ADCB 16173 H-MHD1 60/ 8/1416).

R16195879 - Ministry of Works Authorities - Building programmes, 1955-58 (ADCB 16173 H-MHD1/61 10/44/1 4).

R16195938 - Improvements at Mental Hospitals, 1928- 1949 (ADCB 16173 H-MHD1 70/ 26/8).

R16195940 - Building Co-ordination, 1929-1956 (ADCB 16173 H-MHD1 71 26/9). 
R16195944 - Applications to visit Mental Hospitals, 1925-58 (ADCB 16173 H-MHD1 71/ 26/31).

R16195547 - Shortage of Staff, Appeals, 1943 - 1949 (ADCB 16173 H-MHD1/5).

R16195951 - Annual report - Correspondence, 1938 - 1949 (ADCB 16173 H-MHD1 74/ 26/40/1).

R16195957 - Report of Hanmer Springs Hospital, 1943-57 (ADCB 16173 H-MHD1 76/ 26/46).

R16195958 - General Review of Mental Hospitals, 1943-1960 (ADCB 16173 H-MHD1 76/ 26/46).

R16195967 - Mental Health Services overseas, 1956-1961 (ADCB 16173 H-MHD1/77 26/77).

R18458498 - Seacliff Hospital, Cherry Farm Buildings, 1950 -1975 (AAFB 632 W2883/94).

R18458555 - Seacliff Hospital, Buildings, MOW Programme, 1955- 1975 (AAFB 632 W2883/98).

R18553317 - Kingseast Hospital Buildings, MOW Programme, 1956-1972 (ADBZ 16163 H1W2191/8 38/1/17 41816).

R18769106 - Lake Alice Hospital - General 1936 - 1968 (ABQU 632 W4415/111).

R18830383 - Buildings, general, Cherry Farm, 1950-1957. (DAHI 19849 D266 466/g 8/3/2).

R18830384 - Buildings, general, Cherry Farm, 1957-1963 (DAHI 19849 D266 467/g 8/3/2).

R18830385 - Buildings, general, Cherry Farm, 1963-66 [mislabeled in archway as1964-65]. (DAHI 19849D266 467/b 8/3/2).

R18830386 - Buildings, general, Cherry Farm, 1966- 1968 (DAHI 19849 D266 467/c 8/3/2).

R18830387 - Buildings, general, Cherry Farm, 1969-1980 (DAHI 19849 D266 467/d 8/3/2).

R18830390 - Buildings at Wakari, 1966- 1969 (DAHI 19849 D266/468/a).

R20960887 - Mental Health, Buildings, General 1941 - 1967 (ADBZ $16163 \mathrm{H} 1 / 617$ ).

R20961995 - Lake Alice, Staff, Establishment - Nursing and domestic, 1950 - 1965 (ADBZ $16163 \mathrm{H} 1 / 279$ ).

R22502230 - Lake Alice, Buildings, General, 1940 - 1975 (AAFB 632 W4914/87).

R6670281 - Dunedin Lunatic Asylum/ Seacliff Lunatic Asylum Inspectors Book, 1870-1886 (DAHI D264 19826 1e).

R6670282 - Seacliff Lunatic Asylum Inspectors Book, 1886-1949 (DAHI D264 19826 1).

R6670288 - Superintendents Outwards Letter Books [Seacliff], 1890-1891 (DAHI D264 19828 4/ 2a). 
R20122994 - Government Buildings, Otago Hospital Board, Wakari:

Reception and Early Treatment Unit (AAQB W3950 305).

\section{Bethlem Royal Hospital Archive:}

BMO-10 B10/1 - Draft report by Physician Superintendent on the proposed new hospital. February 2, 1926.

BMO-11 B10/1 - Architect's report on the lay-out of the proposed new hospital. 1926.

Hocken Collections, University of Otago:

Misc-MS-0931- Wilson R.M.: Mental Hospital Staff Manuals

MS-0807 - L L Lawson, Robert Arthur: papers.

MS-1202 - C Collin James: papers.

MS-2432/095 - Preston Family: papers.

MS-3109/010 - J Joan Morrow: scrapbooks.

MS-3182/001 - Moore, Charles S.: papers.

MS-3290/056 - Frank Tod: papers.

MS-3539/003 - $\quad$ Otago Association for Mental Health Records

MS-3821/093 - Seacliff Specification (Salmon Collection).

MS-93-065 - Kershaw: papers. 
Archives New Zealand:

(owing to the timing of changes to Archives New Zealand's referencing system, and the presence of MOW drawings which are referenced differently, the files below are variously listed by their full reference or their "item ID."):

AAQT 6539, A29455 - $\quad$ Photograph: Cherry Farm, 1953. K V Bigwood.

CABA 86 GR 766 MC3 - Drawings: Seaview, Cottages, 1879.

CAWU 556 41AE MC 16 - Drawing: Queen Mary, Women's Ward, Ground Floor Plan (rennovations), 1950.

C399074 H10 1199214 - Photograph: Queen Mary, Lounge Room, Women's Ward, ca. 1950.

C399174 H10 1227296 - Photographs: 11 and 50-Bed Villas Lake Alice, ca. 1948

C930 898 w33 3316264 - Drawings: Lake Alice 50-Bed Villas (Porirua type) 1945.

DADE D294 2a.

Drawings: Accomodation Study, various New Zealand asylums, 1903.

DAHI 20271 D266 520c Photograph: Seacliff, Dining Hall under demolition, 1959.

DAHI 20271 D266 522b Photographs: Seacliff, demolition, 1959.

DAHI D266 $20271521 s$ Photograph: Cherry Farm 50-Bed Villa ca 1980.

DAHI D494 5a -

Drawing: Cherry Farm, Site Plan, 1960.

DAHI D494 5b -

Drawing: Cherry Farm, 50-Bed Villa, 1949.

DAHI D494 6 48-35 -

Drawing: Cherry Farm, 50-Bed Villa, 1948.

DAHI 9156 D342 2a -

Drawing: Seacliff, new Fire Escapes, 1906.

DAHI 9156 D342 2b -

Drawing: Clifton Cottage, additions, undated.

DAHI 9156 D342 5c -

R16564855 -

Drawing: Seacliff, Convalescent Cottage, additons, undated.

Drawing: Tokanui, 50-Bed Villa, 1912 (ACHL 19315 WW510/25).

R16989665 -

Drawing: Wakari Hospital, Reception Centre, 1968 (ACHL 19315 W33/688).

R16989175 -

Drawing: Sunnsyide, Recepition Centre, 1962 (W 33385 24789).

R18671883 -

Drawing: Porirua, Elevations, 1891

(ACHL 22541 W5/1141 3).

R18671884 -

Drawing: Porirua, Ground Floor Plan, 1891

(ACHL 22541 W5/1141 4).

R18671885 -

Drawing: Porirua, First Floor Plan, 1891

(ACHL 22541 W5/1141 5). 


\begin{tabular}{|c|c|}
\hline R18732735 - & $\begin{array}{l}\text { Photographs: Lake Alice Villas } \\
\text { (ADBZ } 16168 \text { H10 1/ 227-276). }\end{array}$ \\
\hline R21009821 - & $\begin{array}{l}\text { Drawing: Lake Alice, Perspective, ca. } 1943 \\
\text { (AADU } 576 \text { 1-12). }\end{array}$ \\
\hline R4256620 - & $\begin{array}{l}\text { Drawing: Cherry Farm, 50-Bed Villa, } 1948 \text { [mislabeled } \\
1918 \text { in Archives description] (DAHI D494/6/c). }\end{array}$ \\
\hline W 338 26896W- & Drawings: Ngawhatu Hospital, Heating Upgrade, 1972. \\
\hline W 33626452 - & Drawing: Kingseat, Heating Upgrade, 1974. \\
\hline W 334416714 - & Drawings: Porirua Hospital, 50-Bed Villa, 1945. \\
\hline W 334716889 - & Drawings: Lake Alice 11-Bed Villa, 1947. \\
\hline W 339419133 - & Drawings: Cherry Farm 50-Bed Villas, 1951. \\
\hline W 514114288 - & Drawing: Seacliff Site Plan, undated. \\
\hline W 5114816822 - & Drawings: Avondale Lunatic Asylum, 1891. \\
\hline W 5119217554 - & Drawing: Whau Asylum, additions, 1895. \\
\hline W 525112261 - & Drawings: Nelson Lunatic Asylum, 1893. \\
\hline W 525112998 - & Drawings: Sunnyside Lunatic Asylum, 1878. \\
\hline W 526412609 - & Drawing: Sunnyside, additions (male), 1888. \\
\hline W 529312988 - & Drawing: Seacliff Site Plan, 1885. \\
\hline W $530113192-$ & Drawing: Sunnyside Administration Block, 1885. \\
\hline W 5422212610 - & Drawing: Sunnyside, additions (female), undated. \\
\hline W 568729618 - & Drawing: Whau Asylum, 1903. \\
\hline WW 510511524 - & $\begin{array}{l}\text { Drawings: Wolfe Bequest Home, Auckland Asylum, } \\
1909 .\end{array}$ \\
\hline
\end{tabular}

\section{Alexander Turnbull Library Collections, Wellington:}

1/1-025917-G - Photograph: Otago Benevolent Institution. William Williams.

1/2-041780-F - $\quad$ Photograph: Dunedin Town Hall, ca 1885. F.A. Coxhead.

1/ 2-057695 - $\quad$ Photograph: Porirua Asylum, ca 1910. D. Squires.

APG-1319-1/2-G Photograph: Seacliff, ca 1926. Albert Percy Godber.

PA2-0005 - $\quad$ Photograph: Dunedin Lunatic Asylum, 1874. J.W. Allen.

PAColl-7327 - $\quad$ Photograph: Porirua, Womens Day Room, ca. 1950.

PAColl-8769-04 - Photograph: Seacliff, ca. 1912.

Plans-84-1185 - Drawing: Seacliff, Ground Floor Plan,1881.

Plans-84-1186 - D D Drawing: Seacliff, First Floor Plan, 1881. 
WA-10628-FPhotograph: Aerial view of Seacliff, 1947. Whites Aviation.

WA-55912-G - $\quad$ Photograph: Kingseat, 1937. Whites Aviation.

WA-71752-G - Photograph: Kingseat, 1972. Whites Aviation.

\section{Bethlem Royal Hospital Archive:}

neg.BED10 - Photograph: Dayroom, Bethlem Hospital, undated.

YCP-46 C08/5 - Drawings: Bethlem, various, 1928-1933.

YCP-57 M1/12 - Drawing: Bethlem, Perspective of Site, 1930.

YDP-01 M1/14 - Drawings: Maudsley Hospital, various, 1912-13.

\section{Canmore Archive, Royal Commission on the Ancient and Historical Monuments of Scotland:}

SC755772 -

Photograph: Kingseat Hospital, Aberdeen, undated.

Hocken Collections, University of Otago:

2465-01-003A - Photograph: Seacliff from the air, undated.

2465-01-005A- Photograph: Seacliff, undated.

2465-01-017A - $\quad$ Photograph: Seacliff dated between 1946 and 1960.

MS-0688/247- Drawings: Office and Store for Messer's Stronarch and Morris, Cromwell, by Salmon and Burt, 1952.

MS-0688/083 - D Drawings: State Fire Insurance Building, Dunedin, by Salmon and Burt, 1954.

R4627 - Drawings: various by R.A. Lawson (Salmon Collection).

S09-038D - $\quad$ Photograph: Seacliff pre 1917. E. A. Phillips.

\section{Wellington City Council Archives:}

Photograph: Wellington Fever Hospital, 1972.

\section{Hokitika Museum:}

A number of drawings and photographs were sighted from the Seaview Hospital Collection and the following were utilized (these were not differentiated by individual reference numbers):

Drawing: Sunnyside, 50-bed villa, 1929

Drawing: Seaview, fire services plan, 1980.

Photographs: various, Seaview Historical Collection. 
Board of Health (under Health Act 1956), 1960. "Psychiatric Services in Public Hospitals 1957-60 Psychiatric Services in Public Hospitals." Wellington: Government Printer.

Commission of Inquiry into Psychiatric Services at Oakley Hospital. 1971. "Psychiatric Services at Oakley Hospital Report to the Commission of Inquiry." Wellington: Government Printer.

Department of Health. 1961. "Mental Breakdown: A Guide for the Family." Wellington: Government Printer.

Department of Health. 1975. "Survey of Patients in Psychiatric Hospitals, Department of Health." Wellington: Government Printer.

Department of Internal Affairs. 2007. "Te Aiotanga: Report of the Confidential Forum for Former In-Patients of Psychiatric Hospitals." Wellington: Government Printer.

Department of Statistics. 1949. New Zealand Official Yearbook 1950. Wellington: Government Printer.

Division of Mental Hygiene, undated [post-1947]. "Ethics and Rules of Conduct for Staff." Wellington: Government Printer. Held by Hocken Collections: Misc-MS-0931.

Lunatic Asylums Department (authored by Truby King). 1900. "Seacliff Rules and Instructions for the Guidance of Attendants and Nurses." Wellington: Government Printer.

Mental Hospitals Department (authored by Theodore Gray). 1940. "Mental Hospitals: Rules for Staff." Wellington: Government Printer. Held by Hocken Collections: Misc-MS-0931.

Mental Hospitals Department (authored by J.F. Hay). 1910. "Mental Hospitals, New Zealand, General Rules and Instructions for the Guidance of the Nursing Staff and Other Workers." Wellington: Government Printer. Held by Hocken Collections: Misc-MS-0931.

Ministry of Works, 1956, Annual Report on Buildings By the Government Architect. Wellington: Government Printer.

., 1960, "A Brief History and Descrption of the Ministry of Works: A Handbook for the Information of New Appointees." Wellinton: Minstry of Works. Held by the National Library.

., 1963-65, "Manual of organisation and management/ New Zealand Ministry of Works." Wellington: Ministry of Works.

Parlimentary Debate, November 4 1879, vol. 33. 61-2.

Public Works Department. 1971. "100 Years, Ministry of Works" from New Zealand Official Yearbook. Wellington: Government Printer. 
PRIMARY: OFFICIAL PUBLICATIONS, INTERNATIONAL

First International Congress on Mental Hygiene. Organisation Committee. 1929. "Preliminary Announcement: First International Congress on Mental Hygiene." Held by Archives New Zealand: R16195641.

United States National Committee for Mental Hygiene. 1942. A Brief Review of Current Work." Reprinted in Beers, 1944.

United States National Institute of Health. Joint Commission on Mental IIIness and Health. 1961. Action for Mental Health: Final Report of the Joint Commission on Mental Illness and Health. New York: Basic Books.

World Health Organization. 1953. The Community Mental Hospital: Third Report of the Expert Committee on Mental Health. Geneva: W.H.O. 
PRIMARY: MEDICAL SOURCES (ordered by case study)

\section{Seacliff Asylum: $1860-1900$}

Browne, W.A.F. 1837. "What Asylums Were, Are and Ought to Be." Reprinted in The Asylum as Utopia: W.A.F. Browne and the Mid-Nineteenth Century Consolidation of Psychiatry, Andrew Scull, ed. London \& New York: Tavistock, 1991.

Burdett, Henry. Hospitals and Asylums of the World: Volumes I-3, London: $\mathrm{J} \&$ A Churchill, 1891.

Conolly, John. 1830. An Inquiry Concerning the Indications of Insanity. London: John Taylor.

., 1847. "The Construction and Government of Lunatic Asylums and Hospitals for the Insane." Reprinted in The Construction and Government of Lunatic Asylums and Hospitals for the Insane with an introduction by Richard Hunter and Ida MacAlpine. 1968. London: Dawsons of Paul Mall.

"Description of a Proposed New Lunatic Asylum for 650 Patients on the Separate-Block System, for the County of Surrey," 1862. British Journal of Psychiatry 7, no. 40: 600 - 608.

Galt, John M. 1854-55. "The Farm of St. Anne," American Journal of Insanity II: 352.

Lindsay, W.L. 1872. "Colonial Lunacy Boards; with special reference to New Zealand," Edinburgh Medical Journal 17: 807- 829.

, 1873. "Luancy Legislation in New Zealand," Journal of Mental Science, 18: 498- 521.

Norman, Conolly. 1894. "Presidential Address, delivered at the Royal College of Physicians, Dublin, June $12^{\text {th }}, 1894 . "$ Journal of Mental Science 40, no. 171: 487-499.

"Norwich Lunatic Asylum," 1877. The Builder (May 12): 479-82.

"Pavilion Asylums," 1867. British Medical Journal (February 2): 116.

"Review: On the Plans of Modern Asylums for the Insane Poor By John Sibbald, M.D., Commissioner in Lunacy for Scotland (Edinburgh: J. Turner and Co., 1897), 1897. British Medical Journal (May 8): 1164.

"Review: The Colonization of the Insane in connection with the Open-Door System: Its Historical Development and the Mode in which it is carried out at Alt Scherbitz Manor. By Dr. Albrecht Paetz, Director of the Provincial Institution for the Insane, "Alt Scherbitz Manor," and of the Asylum for Imbeciles, "Imperial Foundation of William and Augusta" (Berlin: Springer, 1983)," 1895. Journal of Mental Science, 41 (October): 697-703.

Steen, R.H. 1900. "The Evolution of Asylum Architecture, and the Principles Which Ought to Control Modern Construction." British Journal of Psychiatry 46 (January): 87-109.

"The First British Village Asylum," 1906. British Medical Journal, November 24: 1498-1502. 
Tuke, D. Hack, 1891. "German Retrospect," Journal of Mental Science, 37 (July): 465 - 473.

Tuke, Samuel. 1813. "Description of the Retreat." Reprinted in Description of the Retreat with an introduction by Richard Hunter and Ida Macalpine. 1964. London: Dawsons of Paul Mall.

Kingseat Hospital, 1906 - 1958:

Barham, G.F. 1926. "Mental Hospitals and their Relation to General and to other Special Hospitals." The Lancet 208, no. 5384: 986-987.

Beers, Clifford Whittingham. 1944. 5th ed. (first published 1908). A Mind that Found Itself. New York: Doubleday, Doran \& Company Inc.

"Bethlem Royal Hospital. Its Approaching Removal," 1927. British Medical Journal 1, no. 3465: 1017-8.

"Bethlem Royal Hospital. Its Approaching Removal," 1930. British Medical Journal 2, no. 3627: 74.

"Dutch Mental Hospitals," 1929. The Lancet 214, no. 5540: 936.

“French Mental Hospitals," 1930. The Lancet 216, no. 5582: 412.

Gray, Theodore G. 1927. "Report [to the Prime Minister] of Visits of Inspection to Various Institutions in Great Britain, America and the Continent (part 2)." Held by Archives New Zealand: R16195841.

1929. "Report [to the Prime Minister] of Visits of Inspection to Various Institutions in Great Britain, America and the Continent (part 2)." Held by Archives New Zealand: R16195841.

1947. "Presidential Address," New Zealand Medical Journal 46: 85.

1958. The Very Error of the Moon. Ilfracombe, Devon: Arthur H. Stockwell Ltd.

Groves, Ernest R. and Phyllis Blanchard. 1930. Introduction to Mental Hygiene. London: Gerald Howe Limited.

Hart, Bernard. 1927. Psychopathology: Its Development and its Place in Medicine. London: Cambridge University Press.

Henderson, D.K. and R.D. Gillespie. 1940. $5^{\text {th }}$ ed. (first published 1927). A Text-Book of Pyschiatry for Students and Practitioners. London: Oxford University Press.

Hollander, Bernard. 1931. Brain, Mind, and the External Signs of Intelligence. London: George Allen \& Unwin Ltd.

Hubert Bond, C. 1921. "The Position of Psychological Medicine in Medical and Allied Services: The Presidential Address at the Annual Meeting of the Medico-Psychological Association of Great Britain and Ireland, held in London on July $11^{\text {th }}-15^{\text {th }}, 1921$, " British Journal of Psychiatry 67: 404-449. 
Knowles Stansfield, T.E. 1914. "The Villa or Colony System for the Care and Treatment of Cases of Mental Disease." Journal of Mental Science 60, no. 248: 31.

Lindlahr, Henry. 1931. $27^{\text {th }}$ ed. (first published 1901). The Practice of Nature Cure. The Nature Cure Library: New York.

Lomax, Montagu. 1921. The Experiences of an Asylum Doctor. London: George Allen \& Unwin.

"Mental Hospital Administration," 1925. The Lancet 205, no. 5304: 883

"Mental Hospitals in America," 1931. The Lancet 217, no. 5617: 929.

Mercier, Charles. 1894. Lunatic Asylums: their Organisation and Management. London: Charles Griffin and Company.

"New Mental Hospital Accommodation," 1924. The Lancet 203, no. 5260: 1280.

"Notes and News [Minutes from the Medical-Psychological Association of Great Britain and Ireland $81^{\text {st }}$ Annual Meeting, July 1921, 1922]," 1922. British Journal of Psychiatry 68: 433.

"Notes and News [Minutes from the Medical-Psychological Association of Great Britain and Ireland $83^{\text {rd }}$ Annual Meeting, July 2-5, 1924]," 1924. British Journal of Psychiatry 70: 694.

"Proposed New Hospital for Mental Diseases," 1908. The Lancet 171, no. 4410: 728-729.

"Public Mental Hospitals," 1922. The Lancet 200, no. 5162: 289-290.

"Report of the Board of Control," 1931. The Lancet 218, no. 5628: 90-2.

Stanford Read, C. 1921. "Familial Care of the Insane." British Journal of Psychiatry 67: 186-195.

"The Case for the Small Hospital for Mental Disorders," 1913. The Lancet 181, no. 4683: 1543.

"Wards for the Observation and Treatment of Temporary Mental Disorder in General Hospitals." The Lancet 168, no. 4344 (1906): 1525-1526.

Winslow, C-E.A. 1933. "The Mental Hygiene Movement and its Founder." Reprinted in Beers, 1944. 
Cherry Farm: 1939 - 1975

“A New Mental Hospital," 1937. The Lancet 229, no. 5938: 1478.

Aaron, K. W., and S. Smith. 1953. "The Bristol Psychiatric Day Hospital." Journal of Mental Science 99: 564-571.

Anderson, Myrl. 1941. "The Role of Prescribed Social Gatherings in the Treatment of the Mentally III." Bulletin of the Menninger Clinic 5, no. 2: 56-60.

Atkin, I. 1962. "Letter to the editior: The Open Door," The Lancet 280, no. 7251: 350-351.

Barnard, Ruth, I., Lewis L. Robbins and Fred M. Tetzlaff. 1952. "The Day Hospital as an Extension of Psychiatric Treatment." Bulletin of the Menninger Clinic 16, no. 2: 50-56.

Barnes, Elizabeth, ed. 1968. Psychosocial Nursing. New York: Tavistock Publications.

Bell, G.M. 1955. "A Mental Hospital with Open Doors." International Journal of Psychiatry 1: 42-48.

Bierer, J. 1948. "Modern Social and Group Therapy" in Modern Trends in Pscyhological Medicine 1948. Ed. Haris, Noel G. London: Buttefwork \& Co. Ltd.

. and F.P. Haldane. 1941. "A Self-Governed Patients' Social Club in a Public Mental Hospital." Journal of Mental Science 87: 419-426.

Blake-Palmer, G. 1962. "Honest Prejudices and Unnecessary Deviations." Thomas Cawthron Memorial Lecture No. 37. Nelson: Cawthron Institute.

Blain, Daniel. 1959. "The Function of the General Hospital Psychiatric Unit: Some Observations by the WHO Expert Committee on Mental Health," in Psychiatric Architecture. Washington: American Psychiatric Association.

Bridger, H. 1946. "The Northfield Experiment." Bulletin of the Menninger Clinic 10, no. 3: 71-76.

1990. "The discovery of the therapeutic community" in A New Social Psychiatry. Ed. Trist e H Murray. Canada: Moderntimesworkplace.com

Brock, Laurence G. 1946. "The Twentieth Maudsley Lecture: Psychiatry and the Public Health Service," Journal of Mental Science 92: 287-304.

Boudreau, Frank G. and Ernest M. Gruenbergs, eds. 1956. The Elements of a Community Mental Health Program: 1955 Annual Conference of the Millbank Memorial Fund. New York: Millbank Memorial Fund.

Clark, David H. 1964. Administrative Therapy: The Role of the Doctor in the Therapeutic Community. London: Tavistock Publications.

. 1965. "The Therapeutic Community Concept, Practice and Future." Journal of Mental Science 111: 947-954.

. 1988. "Social Psychiatry: The Therapeutic Community Approach" in Therapeutic Communities: Past, Present and Future, eds. Penelope Campling and Rex Haigh. London: Jessica Kingsley Publishers Ltd. 
Clark, Dorothy E. 1953. "The Little Things Do Count." American Journal of Nursing 53, no.7: 813-815.

Crawford, J.P. 1962. "Letter to the editior: The Open Door," The Lancet 280, no. $7251: 351$.

Cook, L.C. 1962. "Letter to the editor: The Open Door." The Lancet 280, no. 7250: 299.

Cowen, Emory L., Elmer A. Gardener and Melvin Zax. 1967. Emergent Approaches to Mental Health Problems. New York: Appleton-CenturyCrofts.

Flind, James. 1939. "Some Practical Considerations in Relation to In-Patient and Out-Patient Treatment in the Psychoneruoses." Journal of Mental Science 85: 886-891.

Fleck, John. 1959. "Translating the Psychiatric Needs into Architectural Solutions," in Psychiatric Architecture. Washington: American Psychiatric Association.

Foulkes, S.H. 1946. "Principles of Group Therapy." Bulletin of the Menninger Clinic 10, no. 3: 85-89.

"Freedom in Mental Hospitals," 1954. The Lancet 264, no. 6845: 964 - 966.

Gilbreth, Lillian. 1950. "The Family as a Basic Unit in Community Strength." Bulletin of the Menninger Clinic 14, no. 2: 61-65.

Gralnick, Alexander. 1975. Humanizing the Psychiatric Hospital. New York: Jason Aronson.

Goldschmidt, H. 1946 "Social Aspects of Ageing and Senility." Journal of Mental Science 92: 182-194.

Goshen Charles E. 1959. "A Review of Psychiatric Architecture and the Principles of Design," in Psychiatric Architecture. Washington: American Psychiatric Association.

Guttersen Alston, G. 1959. "Mental Health Programs and Facilities in Europe and Asia," in in Psychiatric Architecture. Washington: American Psychiatric Association.

Haris, Noel G., Ed. 1948. Modern Trends in Pscyhological Medicine 1948. London: Buttefwork \& Co. Ltd.

. 1939. "Treatment and Accommodation for the Psycho-Neuroses." Journal of Mental Science 85: 892-901.

Henderson, D.K. 1949. "Book review for 'Modern Trends in Psychological Treatment 1948" Journal of Mental Science 95: 205-6.

Hemphill, Robert E. 1946. "The Aims and Practice of Recreational Therapy." Bulletin of the Menninger Clinic 1, no. 4: 177-122.

Hooper, D.F. 1962. "Changing the Milieu in a Psychiatric Ward," Human Relations 15: 111-122.

"Hospital Quarters for Mental Patients," 1941. The Lancet 237, no. 6141: 608.

"Hospital Buildings of Tomorrow," 1947. The Lancet 250, no. 6482: 767-768. 
James, Martin.1948. "Diagnostic Measures" in Modern Trends in Pscyhological Medicine 1948. Ed. Haris, Noel G. London: Buttefwork \& Co. Ltd.

Jones, M., A. Barker and T. Freeman. 1952. Social Psychiatry: A Study of Therapeutic Communities. London: Tavistock Publications Limited.

Kimber, W.J.T. 1939a "Social Values in Mental Hospital Practice", Journal of Mental Science, no. 85 (1939a): 29-44.

. 1939b. "The Value of Mental Hospital Participation in Early Treatment." Journal of Mental Science 85: 871-876.

Klemes, Marvin A. 1951. "The Therapeutic Effect of Group Morale on a Psychiatric Hospital Ward." Bulletin of the Menninger Clinic 15, no. 2: 58-63.

Knight, Robert P. 1937a. "Application of Psychoanalytical Concepts in Psychotherapy." Bulletin of the Menninger Clinic 1, no. 4: 99-109.

. 1937b. "Psychoanalysis of Hospitalized Patients." Bulletin of the Menninger Clinic 1, no. 5: 158-167.

Leader, Marcia. 1951. "Psychiatric Social Service in a Small Private Hospital." Bulletin of the Menninger Clinic 15, no. 3: 85-90.

MacKeith, S.A. 1946. "Lasting Lessons of Overseas Military Psychiatry." Journal of Mental Science 92: 542-550.

Main, T. F. 1946. "The Hospital as a Therapeutic Institution", Bulletin of the Menninger Clinic 10, no. 3: 66-71.

1948. "Rehabilitation and the Individual," in Modern Trends in Pscyhological Medicine 1948. Ed. Haris, Noel G. London: Buttefwork \& Co. Ltd.

McGlashan, Alan. 1954. "Letter to the editior: The Unlocked Door," The Lancet 264, no. 6849: 1175-1176.

McRae, Douglas. 1937. "Some Observations on the Care of the Insane: The Presidential Address Delivered at the Ninety-Sixth Annual Meeting of the Royal Medico-Psychological Association, held at Ayr, July 7, 1937." Journal of Mental Science 83: 489-504.

Menninger, William C. 1936. "Psychoanalytic Principles Applied to the Treatment of Hospitalized Patients." Bulletin of the Menninger Clinic 1, no. 2: 35-43.

1938. "Psychiatric Nursing: the Viewpoint of the Psychiatrist." Bulletin of the Menninger Clinic 2, no. 2: 33-39.

. 1942. "The Functions of the Psychiatric Hospital." Bulletin of the Menninger Clinic 6, no. 4: 109- 116.

. 1950. "The Relationship of Clinical Psychology and Psychiatry." Bulletin of the Menninger Clinic 14, no. 1: 1-21.

1951. "Prescribing a Therapeutic Program." Bulletin of the Menninger Clinic 15, no. 5: 167-174.

, and Jeanetta Lyle Menninger. 1946. "Recreation for Morale." Bulletin of the Menninger Clinic 6, no. 3: 96-102. 
"Mental Disease in a General Hospital," 1941. The Lancet 237, no. 6138: 513-514.

"Mental Hospital as a Teaching Centre," 1934. The Lancet 225, no. 5800: 935-936.

“Mental Hospitals from Within," 1947. The Lancet 250, no. 6485: 880.

"Mental Hospitals in the New Service," 1946. The Lancet 248, no. 6412: 94.

Myers, K., and David H. Clark. 1972. "Results in a Therapeutic Community." British Journal of Psychiatry 120: 51-58.

"On Leaving the Mental Hospital," 1940. The Lancet 235, no. 6084: 654.

O'Reilly, J.J. 1948. "The Planning of Modern Psychiatric Units." Journal of Mental Science 94: 107-133.

Palmer, Harold. 1948. "Recent Technique of Physical Treatment and Its Results" in Modern Trends in Pscyhological Medicine 1948. Ed. Haris, Noel G. London: Buttefwork \& Co. Ltd.

Pentreath, E.U.H., and E. Cunningham Dax. 1937. "Mental Observation Wards: A Discussion of their Work and its Objects." Journal of Mental Science 83: 347-365.

Petrie, A.A. 1944. "Mental Health Services-Present and Future." Journal of Mental Science 90: 3-14.

1945. "Psychiatric Developments: The Presidential Address Delivered at the One Hundred and Third Annual Meeting of the Association on Wednesday, November 29, 1944." Journal of Mental Science 91: 267280.

Racliff, R.A.W. 1962. "The Open Door: Ten Years' Experience at Dingleton Hospital," The Lancet 280, no. 7248: 188-90.

Ralston, Peggy. 1940. "Educational Therapy in a Psychiatric Hospital." Bulletin of the Menninger Clinic 4, no. 2: 41-50.

Rees, T.P. 1957. "Back to Moral Treatment and Community Care: The Presidential Address Delivered at the One Hundred and Fifteenth Annual Meeting Held at Warlingham Park Hospital, 18 July, 1956," Journal of Mental Science 103: 303-313.

Rees-Thomas, W. 1949. "What the Patient Thinks: The Presidential Address Delivered at the One Hundred and Seventh Annual Meeting of the Association on Wednesday, July 7th, 1948," Journal of Mental Science 398: 1-9.

Reider, Norman. 1937. "Hospital Care of Patients Undergoing Psychoanalysis." Bulletin of the Menninger Clinic 1, no. 5: 168-175. 1939. "Amateur Dramatics as a Therapeutic Agent in the Psychiatric Hospital." Bulletin of the Menninger Clinic 3, no. 1: 20-26. 
Robb, Douglas. 1940. Medicine and Health in New Zealand: A Retrospect and a Prospect. Auckland: Whitcombe and Tombs.

1947. Health Reform in New Zealand. Auckland: Whitcombe and Tombs.

Russell, J Ivison. 1949. "The Role of the Mental Hospital in the National Health Service: The Presidential Address Delivered at the One Hundred and Eighth Annual Meeting of the Association on Wednesday, 20 July, 1949," Journal of Mental Science 95: 785-794.

Simmel, Ernst. 1937. "The Psychoanalytic Sanatorium and the Psychoanalytic Movement." Bulletin of the Menninger Clinic 1, no. 5: 133-143.

Stone, J.A.W. and A. Edward Evans. 1938. 'The Boarding-Out of Mental Patients in the Scottish Highlands,' Journal of Mental Science, no. 84: 381-399.

Taylor Fox, J. 1939. "Epileptics in the Community." Journal of Mental Science 85: $940-952$.

"The Situation of Mental Hospitals," 1952. The Lancet 260, no. 6730: 387.

“The Unlocked Door," 1954. The Lancet 264, no.6845: 953-954.

Tidd, Charles W. 1936. "An Examination of the Recovery Process in Three Cases of Schizophrenia." Bulletin of the Menninger Clinic 1, no. 2: 5360.

Todd, J., and J.R.M. Mackie. 1963. "Letter to the editor: Open Doors in Psychiatric Hospitals." The Lancet 281, no. 7287: 952.

Williams, C.L. 1959. "An Intensive Treatment Unit, Central State Hospital, Indiana: Psychiatric Considerations in Planning," in Psychiatric Architecture. Washington: American Psychiatric Association.

Whitehorn, J.C. 1948. "Psychotherapy" in Modern Trends in Pscyhological Medicine 1948. Ed. Haris, Noel G. London: Buttefwork \& Co. Ltd.

Webster, F.C. 1948. "Modern Trends in the Planning of Mental Hospitals and other Psychiatric Units in England." Journal of Mental Science 94: 99106.

Wilde, J.F. 1952. "The Situation of the Mental Hosptials." The Lancet 260, no. 6730: 387. 
Baird, Bob, ed. 1990. Lake Alice 40 Years. Wanganui: Community Health Services, Manawatu-Wanganui Area Health Board.

Blake-Palmer, G., et al. 1972. "The End of an Era: Seacliff Hospital Final Farewell." Dunedin: Otago Hospital Board.

Brunton, Warwick. 1997. Sitivation 125: A History of Seaview Hospital, Hokitika and West Coast Mental Health Services, 1872 -1997. Hokitika: Seaview Hospital 125th Jubilee Committee.

Crawford, Robert. 2005. The Queen Mary Hospital Hanmer Springs, 1916 2003. Hanmer Springs. Hanmer: Queen Mary Reserve Trust.

Hunt, Anne. 2000. The Lost Years: From Levin Farm Mental Deficiency Colony to Kimberley Centre. Christchurch: A. Hunt.

Lake Alice Hospital, Marton: 25 ${ }^{\text {th }}$ Anniversary Souvenir Booklet, 1950 - 1975. 1975. Wanganui: Lake Alice Hospital.

McLaren, Rodger., ed. 1997. "A History of Tokanui Hospital, Te Awamutu 1912-1997." Te Awamutu: Tokanui Hospital.

Seager, Madeleine. 1987. Edward William Seager: Pioneer of Mental Health. Waikanae: The Heritage Press..

Thompson, L.B., ed. 1981. Kingseat Hospital, 50 Years, 1932 - 1982. Papakura: Kingseat Jubilee Editorial Committee.

Webby, Marjorie M. 1991. From Prison to Paradise: the Genealogy of Ngawhatu Hospital. Nelson: Marjorie M Webby.

Williams, Wendy Hunter. 1987. Out of Mind out of Sight: The Storey of Porirua Hospital. Wellington: Porirua Hospital.

PRIMARY: STAFF ACCOUNTS [FICTIONAL BASED ON EXPERIENCE]

Kennedy, Marion. 1963. The Wrong Side of the Door. London: George G. Harrap \& Co.

Kersey, Ken 1962. One Flew Over the Cuckoo's Nest. New York: Viking Press.

PRIMARY: HOSPITAL ACCOUNTS, NON-STAFF BASED

Sainsbury, Aurthur. 1946. Misery Mansion: Grim Tales of New Zealand Asylums. Auckland: A. Sainsbury. 
Finlay, Peter. 2010. Blue Messiah. Auckland: Toi Ora Live Art Trust.

Frame, Janet. 2000 (first published 1984). An Angel at My Table. Auckland: Vintage.

, Faces in the Water. 2005 (first published 1961). Auckland: Random House.

Ogdon, J.A. Howard. 1947. The Kingdom of the Lost. London: Bodley Head.

Packard, Elizabeth. 1973. $12^{\text {th }}$ ed. (first published 1875). Modern Persecution or Insane Asylums Unveiled. New York: Arno Press, 1973.

Ward, Mary Jane. 1946. The Snake Pit. New York: Random House.

White, Antonia. 1954. Beyond the Glass. London: Eyre \& Spottiswoode.

Woodley, H.G. (pseud.). 1947. Certified. London: Victor Gollancz.

PRIMARY: NEWSPAPER \& MAGAZINE ARTICLES

"A Humanitarian Task," 1937, December 24. The Dominion.

"An Escaped Lunatic," 1874, January 14. Daily Southern Cross.

"Another Lunatic Escapes," 1888, October 1, Bay of Plenty Times.

"Attractive New Otago Hospital Villa, Cherry Farm's Approach to Mentally III 'Advanced'," 1957, January 12. Otago Daily Times.

"Benevolent Institution Carnival," 1882, October 24. Otago Daily Times.

"Borderland Cases. Statement by the Hon. C.J. Parr," 1923, May 14. The Press.

"Cherry Farm Centre Valuable Amenity," 1961, August 26. Otago Daily Times.

"Cherry Farm. New Zealand's Most Modern Hospital," 1952, May 21. New Zealand Free Lance.

"Correspondence. The Escape from the Asylum," 1875, June 19. Daily Southern Cross.

"Editorial [citing the Physiological Journal of Medicine]," 1875, August 07, West Coast Times.

"Editorial [escape from Nelson Asylum]," 1882, May 11. Nelson Evening Mail.

"Editorial [on Mental Hospitals]," 1923, September 18. The Press.

“Escapes," 1868, December 5. Otago Witness.

"Escape of a Dangerous Lunatic from the Asylum," 1875, June 18. Daily Southern Cross.

"Expenditure of $1 \mathrm{M}$ pounds For New Mental Hospital Approved. Seacliff Accom. to be Replaced," 1957, August 27. Ashburton Guardian. 
"Extensions Planned at Cherry Farm. State to Spend $£ 250,000$ on Additional Buildings." 1957, June 27. Otago Daily Times.

"First Church. Sixtieth Anniversary. Unveiling of Tablet to Architect," 1933, November 25. Otago Daily Times.

"First Patients to move into Cherry Farm Soon," 1952, March 18. Evening Star.

"Industrial Exhibition," 1885, May 2. Otago Daily Times.

"Halfway! The Borderland. 'Twixt Madness and Sanity. Need for a Great Reform," 1923, January 10. Auckland Star.

Hackett, Marjorie (for the Division of Mental Hygiene). "Mental Illness in New Zealand its Treatment and Cure," 1953, March. The Mirror.

Halstead, Joyce. "Are they the Forgotten People?," 1954, June 24. New Zealand Women's Weekly.

"Helping the Insane," 1937, December 28. Auckland Star.

"Lecture," 1884, June 12. Otago Daily Times.

Levigne, E.G., "Mental Hospitals. Weaknesses and Necessary Reforms," 1923, September 14. The Press.

"Letter to the Editor," 1886, May 27. Otago Daily Times.

"Letter to the Editor [escapes from Nelson Asylum]," 1885, January 24. Marlborough Express.

"Lunatic at Large," 1871, July 10. Wellington Independent.

"Need for Patience in Mental Therapy," 1960, June 18. Otago Daily Times.

"New Drugs Beating Psychiatric Troubles," 1957, February 18. Auckland Star.

"News by the Mail," 1871, October 28. Otago Witness.

"News by the Mail," 1875, May 28. Bruce Herald.

"Northland Has Considerable Interest in Kingseat Hospital," 1957, February 22, Northland Times.

"Mental Cases. Hospital Villa System. Better than half-way houses. Minister Explains," 1930, June 14. The Auckland Star.

“Mental Disorder, Man's Last Spectre, International Action, New Zealand's Part," 1929, Decmeber 27. The Evening Post.

"Mental Health [Lake Alice]," 1937, December 28. New Plymouth Daily News.

Mental Hospitals Department, "Mental Disorders. General Paralysis. Malarial Treatment," 1931, March 6. Evening Post.

"Mental Illness: Physical Causes. Conflicts and Consequences," 1931, February 27. Evening Post. (also published in the Auckland Star, 1931, March 14.)

., "Sleepy Sickness: Strange Affliction. Onset and Symptoms," 1931, March 13. Evening Post.

., "Sleepy Sickness: Illustrative Cases. Character Change," 1931, March 24. Evening Post. 
"Mental Hospital. Another Building. Site near Marton. State Purchase," 1937, December 22. Evening Post.

"Mental Hospitals Report," 1923, August 1. The Press.

"Mental Hygiene, Some Progressive Movements, Lecture by Dr A.R. Falconer," 1932, November 8. Otago Daily Times.

"Mental Maladies," 1923, March 10. New Zealand Herald.

"Mental Patients," 1923, August 02. The New Plymouth Daily News.

"Mental Patients. Kingseat Hospital. Atmosphere of Freedom. New Methods of Treatment. Extensions to Buildings," 1937, October 26. New Zealand Herald.

"Ministers Statement Criticised," 1923, April 19, The Press.

"More Psychiatric Nurses Are Needed in Nelson," 1958, February 19, Nelson Evening Mail.

"Our Correspondent: Scotland," 1871, September 29. Otago Witness.

"Our Mental Hospitals, 2 - The 'New Freedom' Comes To Avondale, City's Oldest Mental Hospital Is Living Down the Past," 1954, September 7. New Zealand Herald.

"Patients' and Prisoners' Society," 1881, August 12. Otago Daily Times.

"Pictures to Please Everyone on the Walls of Cherry Farm," 1960, February 13. The Evening Star.

"Presentation to Mr Lawson," 1887, June 15. Otago Daily Times.

"Psychiatric Nursing a Satisfying Career: 'Bad Old Days' Gone," 1957, February 23. Waikato Times,

"Psychiatric Nursing Is a Rewarding and Interesting Career," 1957, February 23. Rotorua Post.

"Report to the Committee of the Industrial Exhibition," 1885, May 2. Otago Witness.

"Scotch Notes," 1870a, February 19. Otago Witness.

"Scotch Notes," 1870b, August 05. Otago Daily Times.

"Seacliff Asylum," 1886, June 3. Otago Daily Times.

"Seacliff; to the Editor," 1886, June 7. Otago Daily Times.

"The Exhibition Jurors," 1881, July 1. Otago Daily Times.

"The Seacliff Mental Hospital," 1943, November 17. Otago Daily Times.

“Tour of Cherry Farm Draws 400 Visitors," 1961, October 16. Otago Daily Times.

Wrigley, James., "Letter to the Editor: The Plans for the Proposed Auckland Lunatic Asylum," 1863, October 15. Daily Southern Cross. 
Remembrance: Songs and Stories from Orokonui, Seacliff and Cherry Farm. Dunedin: 2005. Held by the Hocken Collections: 12905 (Music Collection).

New Zealand Broadcasting Commission, Compass: Mental Health, filmed 1967 (no date given for airing of this footage). TVNZ Archive: P48593. ., Gallery: Psychiatric Nurses, July 1, 1971. TVNZ Archive: P49682.

., The Distorted Image: Mental Health, 1968 (documentary never completed). TVNZ Archive: The Distorted Image.

Television New Zealand, Dateline Monday: Mental Health, June 13, 1977. TVNZ Archive: P1173.

\section{PRIMARY: MISCELLANEOUS - LITERATURE}

Collins, Wilkie. 1952 (first published 1869). The Woman in White. London \& Glasgow: Collins.

Sheridan Le Fanu, J. 1982 (first published 1895). The Rose and the Key. New York: Dover Publications, 


\section{SECONDARY: BOOKS \& ARTICLES}

Addison, J. 1712. "On the Pleasures of the Imagination," reprinted in The Spectator with Sketches of the Lives of the Authors (1824), James Grissy: Philadelphia. Quoted in Hickman, 2009.

Andrews, Jonathan., Asa Briggs, Roy Porter, Penny Tucker and Keir Waddington. 1997. The History of Bethlem. London: Routledge.

Beaglehole, Ernest. 1950. Mental Health in New Zealand. Wellington: New Zealand University Press.

Belich, James. 1996. Making Peoples: A History of New Zealanders from Polynesian Polynesian Settlement to the End of the Nineteenth Century. Auckland: Penguin Books.

2001. Paradise Reforged: A History of the New Zealanders from the 1880s to the Year 2000. Auckland: Penguin Books.

Belknap, Ivan. 1956. Human Problems of a State Mental Hospital. New York: Blakiston Division McGraw-Hill.

Borden, lain, and Katerina Ruedi. 2005. The Dissertation: An Architecture Student's Handbook. Oxford: Architectural Press.

Brantley, Richard. 1975. Wordsworth's Natural Methodism. New York: Yale University Press. Quoted in Hickman, 2009.

Brookes, Barbara, and Jane Thompson, eds. 2001. Unfortunate Folk: Essays on Mental Health Treatment,1863 - 1992. Dunedin: University of Otago Press.

Brunton, Warwick. 1972. "If Cows Could Fly," Australia/ New Zealand Journal of Psychiatry 6, no. 46: 46-51.

., 2003. "The Origins of Deinstitutionalisation in New Zealand." Health \& History 5, no. 2: 47-75.

., 2005. "The Place of Public Inquiries in Shaping New Zealand's National Mental Health Policy 1858-1996." Australia and New Zealand Health Policy 2, no. 24: unpaginated (available online: http://www.anzhealthpolicy.com/content/2/1/24).

Campling, Penelope, and Rex Haigh, eds. 1999. Therapeutic Communities: Past, Present and Future. London: Jessica Kingsley Publishers.

Caplan, Ruth B. 1969. Psychiatry and the Community in Nineteenth-Century America: The Recurring Concern with the Environment in the Prevention and Treatment of Mental IIIness. New York \& London: Basic Books.

Caldwell, Cheryl. 2001. "Truby King and Seacliff Asylum, 1889 -1907," in Unfortunate Folk: Essays on Mental Health Treatment 1863 - 1992, eds. Barbara Brookes \& Jane Thompson. Dunedin: University of Otago Press.

Chapman, Lloyd. 2003. In a Strange Garden: The Life and Times of Truby King. Auckland: Penguin Books. 
Coolidge, John. 1992. "The Architectural Importance of H.H. Richardson's Buffalo State Hospital" in Changing Places: Remaking Institutional Buildings. eds. Marchis Feuerstein, Barbara Campagna and Lynda Schneekloth. New York: White Pine Press.

Crammer, John. 1990. Asylum History Buckinghamshire County Pauper Lunatic Asylum - St Johns. London: Gaskell.

Crossley, Nick. 1998. "R.D. Laing and the British Anti-Psychiatry Movement: A Socio-Historical Analysis." Social Science and Medicine 47, no. 7: 877-889.

Cyclopaedia Company Limited. 1905. "Seacliff Asylum" in The Cyclopaedia of New Zealand: Otago and Southland Provincial Districts. Christchurch: The Cyclopaedia Company Limited.

Dain, Norman. 1989. "Critics and Dissenters: Reflections on 'Anti-Psychiatry' in the United States." Journal of the History of the Behavioural Sciences 25: 3-25.

Dalley, Bronwyn and Margaret Tennant. 2004. Past Judgement: Social Policy in New Zealand History. Dunedin: University of Otago Press.

Danaher, Geoff., Tony Schirato and Jen Webb. 2000. Understanding Foucault. Sydney: Allen \& Unwin.

Deaux, Kay., and Lawrence S. Wrightsman. 1998. Social Psychology. California: Brooks/Cole Publishing Company.

Digby, Anne. 1985. Madness, Morality and Medicine: A Study of the York Retreat 1796 - 1914. New York: Cambridge University Press.

Dixon, Roger., and Stefan Muthesius. 1985. Victorian Architecture. London: Thames and Hudson.

Dwyer, Ellen. 1987. Homes for the Mad: Life inside Two Nineteenth Century Asylums. New Brunswick \& London: Rutgers University Press.

Edginton, Barry. 1994. "The Well-Ordered Body: The Quest for Sanity through Nineteenth Century Asylum Architecture." Canadian Bulletin of Medical History, 11, no. 2: 375-86.

1997. "Moral Architecture: The Influence of the York Retreat on Asylum Design." Health \& Place 3, no. 2: 91-99.

2007. "A Space for Moral Management: The York Retreat's Influence on Asylum Design" in Madness, Architecture and the Built Environment: Psychiatric Spaces in Historical Context, eds. Leslie Topp, James E. Moran and Jonathan Andrews. New York, London: Routledge.

Entwisle, Peter. 1986. "Et in Arcadia Ego? The Origins, Development and Nature of George O'Brien's Vision of the New Zealand Landscape" in Pavilioned in Splendour: George O'Brien's Vision of Colonial New Zealand, eds. Roger Collins and Peter Entwisle. Dunedin: Dunedin Public Art Gallery.

Ernst, Waltraud., and Thomas Mueller. 2010. Transnational Psychiatries: Social and Cultural Histories of Psychiatry in Comparative Perspective, c. 1800-2000. Newcastle: Cambridge Scholars Publishing. 
Evans, Robin. 1997. Translations from Drawing to Building and Other Essays, London: Architectural Association.

1982. The Fabrication of Virtue: English Prison Architecture, 1750 - 1840. Cambridge: Cambridge University Press.

Fairburn, Miles. 1989. The Ideal Society and its Enemies: The Foundations of Modern New Zealand Society 1850 - 1900. Auckland: Auckland University Press.

Firth, Cedric. 1949. State Housing in New Zealand, Wellington: Ministry of Works.

Foucault, Michel. 1964. Madness and Civilization. Trans. d'Editions, Union Generale. $2^{\text {nd }}$ ed., (first published 1961). London \& New York: Routledge Classics.

., 1972. The Archaeology of Knowledge and the Discourse on Language. Trans. Sheridan, Allan. 3rd ed. New York: Pantheon.

., 1977. Discipline \& Punish: The Birth of the Prison. Trans. Sheridan, Allan. UK: AllenLane.

., 2006. The History of Madness. Trans. Jonathan Murphy and Jean Khalfa. New York and London: Routledge.

Goffman, Erving. 1961. Asylums: Essays on the Social Situation of Mental Patients and Other Inmates. New York: Doubleday.

Goodwin, Claire. 2004. Shadows \& Silence. Wellington: Steel Roberts.

Griffiths, G.J., Alfred Eccles and E.J. McCoy. 1983. Otago Boys' High and its Historic Neighbourhood. Dunedin: Otago Heritage Books.

Groat, Linda, and David Wang. 2001. Architectural Research Methods. New York: John Wiley and Sons.

Hickman, Clare. 2009. "Cheerful prospects and tranquil restoration: the visual experience of landscape as part of the therapeutic regime of the British asylum,1800-60," History of Psychiatry, 20, no. 4: 425-441.

Harold, Denis and Pamela Gordon, eds. 2011. Janet Frame: In Her Own Words. Auckland: Penguin Books.

Hirst, Paul. 2005. Space and Power: Politics, War and Architecture. Cambridge, Mass.: Polity Press.

., and Penny Woolly. 1982. Social Relations and Human Attributes. London, New York: Tavistock Publications.

Horrocks, Chris., and Zoran Jevtic. 2004. Introducing Foucault. Cambridge: Icon Books.

Jones, Edgar., Shahina Rahman and Robin Woolven. 2007. "The Maudsley Hospital: Design and Strategic Direction, 1923-1939." Medical History 51, no. 3: 357-378.

Jones, Julia. 2000. "Mental health care reforms in Britain and Italy since 1950: a cross-national comparative study." Health and Place 6: 171-187.

Joseph, AE., RA. Kearns, and G. Moon. 2009. "Recycling Former Psychiatric Hospitals in New Zealand: Echoes of Deinstitutionalisation and Restructuring." Health \& Place 15, no. 1: 79-87. 
Kavanagh, Jeff. 2001."Cherry Farm 1952 - 1992; Social and Economic Forces in the Evolution of Mental Health Care in Otago," in Unfortunate Folk: Essays on Mental Health Treatment 1863 - 1992, eds. Barbara Brookes \& Jane Thompson. Dunedin: University of Otago Press.

Kerr, Joan. 1988. "Forward" in Out of Place, out of Mind: Australia's Places of Confinement 1788-1988, James Semple-Kerr and Joan Kerr. Sydney: Shervin Gallery.

King, A. 1966. "Hospital Planning: Revised Thoughts on the Origin of the Pavilion Principle in England." Medical History 10, no. 4: 360-373.

King, Mary. 1948. Truby King the Man. London: George Allen \& Unwin Ltd.

King, Michael. 2000. Wrestling with the Angel: A Life of Janet Frame. Auckland: Penguin Books.

., 2003. The Penguin History of New Zealand. Auckland: Penguin Books.

Klob, G. ed., 1907. Sammel-Atlas fur den Bau von Irrenanstalten: Ein Handbuch fur Behorden, Psychiater und Baubeamte, 2 vols. Haller: Carl Marhold. Quoted in Topp, Leslie 2007 (with translation by Leslie Topp).

Knight, Hardwicke. 1985. Otago Cavalcade 1931-1935. Dunedin: Allied Press.

Kowsky, Francis R. 1992. "Architecture, Nature, and Humanitarian Reform: The Buffalo State Hospital for the Insane," Changing Places: Remaking Institutional Buildings, eds. Lynda H. Schneekloth, Marchis F. Feuerstein and Barbara A. Campagna. New York: White Pine Press.

Leach, Andrew. 2010. What Is Architectural History? Cambridge Mass.: Polity Press.

Ledgerwood, Norman. 2013. R.A. Lawson: Victorian Architect of Dunedin. Dunedin: Historic Cemeteries Conservation Trust of New Zealand.

Lochhead, lan. 1991. A Dream of Spires: Benjamin Mountfort and the Gothic Revival. Christchurch: Canterbury University Press.

Logan, Cameron. 2009. "The Modern Hospital as Dream and Machine: Modernism, Publicity and the Transformation of Hospitals." Fabrications: The Journal of the Society of Architectural Historians of Australia and New Zealand 19, no. 1: 68-95.

Suibhne, Seamus Mac. 2011. "Erving Goffman's Asylums 50 years on." British Journal of Psychiatry, 198: 1-2.

Malcolm, Elizabeth. 2009. "Asylum Architecture through German Eyes: Kew, Melbourne, 1867. Health and History 11, no.1: 46-64.

Markus, Thomas A. 1982. Order in Space and Society: Architectural Form and Its Context in the Scottish Enlightenment. Edinburgh: Mainstream Publishing Company.

Martin, Lewis E. 2004. Built for us: the work of government and colonial architects, 1860 s to 1960 s. Dunedin: University of Otago Press. 
McLaughlan, Rebecca. 2014. "Editing for Public Consumption: the Use of Documentary Film in the Promotion of New Zealand's Mental Hospitals." Forum: University of Edinburgh Postgraduate Journal of Culture and the Arts, 18: page no.s to be confirmed.

., 2012 "Farewell to the Bad Old Days: Architectures' Curtain Call on the Myths of Mental Health Care." Traditional Dwellings and Settlements Working Paper Series: Myth in Design Theory and Practice 248: $37-$ 61.

., 2012. "Post-rationalization and Misunderstanding: Mental Hospital Architecture in the New Zealand Media." Fabrications: The Journal of the Society of Architectural Historians of Australia and New Zealand 22, no.2: 232-256.

Medlicott, Judith Clare. 2001. "Ashburn Hall 1905-1947," in Unfortunate Folk: Essays on Mental Health Treatment 1863 - 1992, eds. Barbara Brookes \& Jane Thompson. Dunedin: University of Otago Press.

Miller, Sara Cedar. 2003. Central Park, an American Masterpiece: A Comprehensive History of the Nation's First Urban Park. New York: Harry N. Abrams Inc.

Moran, James. 2009. "Book Review of Susan Piddock, A Space of their Own: the Archaeology of Nineteenth Century Lunatic Asylums in Britain, South Australia, and Tasmania (New York: Springer, 2007)," History of Psychiatry 20, no. 4: 501-2.

Noonan, Rosslyn, J. 1975. By Design: A Brief History of the Public Works Department, Ministry of Works 1870 - 1970. Wellington: A.R. Shearer, Government Printer.

Payne, Christopher. 2009. Asylum: The Closed World of State Mental Hospitals. Cambridge: MIT Press.

Piddock, Susan. 2007. A Space of Their Own: The Archaeology of Nineteenth Century Lunatic Asylums in Britain, South Australia and Tasmania. New York: Springer.

"Proceedings of the Association of Medical Superintendents of American Institutions for the Insane," 1890. The American Journal of Insanity 47: 166-239. Quoted in Caplan 1969, 264.

Ralley, Oliver Josef Dumolo. 2012. "The Rise of Anti-psychiatry: A Historical Review." History of Medicine Online: unpaginated (available online: http://www.priory.com/history_of_medicine/Anti-Psychiatry.htm)

Reeves, William Pember. 1998 (first published 1898). The Long White Cloud: Ao Tea Roa. Middlesex: Senate.

Rosenhan, David L. 1973. "On Being Sane in Insane Places." Science 179: 250-58. 
Scull, Andrew T. 1979. Museums of Madness: The Social Organization of Insanity in 19th Century England. London: Allen Lane.

1993. The Asylum as Utopia: W.A.F. Browne and the Mid-Nineteenth Century Consolidation of Psychiatry, Andrew Scull, ed. London \& New York: Tavistock.

1993. The Most Solitary of Afflictions: Madness and Society in Britain 1700 - 1900. New Haven \& London: Yale University Press.

2006. The Insanity of Place/ the Place of Insanity: Essays on the History of Psychiatry. Oxon \& New York: Routledge.

2007. "The Fictions of Foucault's Scholarship: a review of

'History of Madness' "The Times Literary Suppliment, March 21.

Sennett, Richard. 1990. The Conscience of the Eye: The Design and Social Life of Cities. New York: Alfred A. Knopf.

Shaw, Peter. 1997. A History of New Zealand Architecture. Auckland: Hodder Moa Beckett.

Smith, Leonard. 1999. 'Cure, Comfort and Safe Custody: Public Lunatic Asylums in Early Nineteenth-Century England. London: Leicester University Press.

2007. "The Architecture of Confinement: Urban Public Asylums in England, 1750 - 1820," Madness, Architecture and the Built Environment: Pyschiatric Spaces in Historical Context, eds. Leslie Topp, James E. Moran and Jonathan Andrews. London and New York: Routledge.

Stevenson, Christine. 2000. Medicine and Magnificence: British Hospital and Asylum Architecture, 1660 - 1815. New Haven: Yale University Press.

Strub, Harry. 1989. "The Theory of Panoptical Control: Bentham's Panopticon and Orwell's Nineteen Eighty-Four," Journal of the History of the Behavioral Sciences, 25: 40-59.

Taylor, Jeremy. 1991. Hospital and Asylum Architecture in England 1849 1914: Building for Health Care. London: Mansell Publishing Limited.

Treadwell, Jeremy. 1998. "Therapeutic Landscapes," Firmness, Commodity, Delight? Questioning the Canons: Proceedings of the $15^{\text {th }}$ Annual Conference of the Society of Architectural Historians of Australia and New Zealand, eds. Julie Willis, Philip Goad and Andrew Hudson. Melbourne: SAHANZ: 389-395.

2003. "A Home for Inebriates." Fabrications: The Journal of the Society of Architectural Historians of Australia and New Zealand 13, no. 1: $79-93$.

Tod, Frank. 1971. Seacliff: A History of the District to 1970. Dunedin: Otago Daily Times Print. 
Topp, Leslie. 2005. "Otto Wagner and the Steinhof Psychiatric Hospital: Architecture as Misunderstanding." The Art Bulletin 87 no. 1: 130-65. 2007. "The Modern Mental Hospital in Late Nineteenth-Century Germany and Austria: Psychiatric Space and Images of Freedom and Control," Madness, Architecture and the Built Environment: Psychiatric Spaces in Historical Context, eds.Leslie Topp, James E. Moran and Jonathan Andrews. London and New York: Routledge.

Turner, Paul. 1984. Campus: An American Planning Tradition. Cambridge, Mass.; MIT Press. Quoted in Yanni, Carla. 2007.

Weiner, Deborah E.B. 2004. "The Erasure of History: From Victorian Asylum to "Princess Park Manor," in Architecture as Experience: Radical Change in Spatial Practice ed. Dana Arnold and Andrew Ballantyne. London: Routledge.

Yanni, Carla. 2007. The Architecture of Madness; Insane Asylums in the United States. Minneapolis, London: University of Minnesota Press. 
Brunton, Warwick. 2001. "A Choice of Difficulties: National Mental Health Policy in New Zealand, 1840 - 1947." PhD Diss. University of Otago.

Campion, Michelle. 2009. "Narratives from the Mind's Eye: The Significance of Mental Health Pathography in New Zealand, 1980-2008." Masters Diss. University of Waikato.

Hamilton, Judith. 1985. "Sunnyside Hospital: the Development of its Buildings from ca. 1863 to 1900," Undergraduate diss. University of Canterbury. Held in the Sunnyside File, Historic Places Trust, Christchurch Office.

Hubbard, Caroline. 1997. "Lunatic Asylums in Otago, 1882-1911," Honours diss. University of Otago.

Hyde de Krester, Amanda. 2003. "Towards and Ethics of Site in Architectural Education: Foucault's Archaeological Method." PhD Diss. University of Auckland.

Kavanagh, Jeff. 1996. "Cherry Farm 1952-1992 : The Social and Economic Forces Behind the Evolution of Mental Health Care in Otago " PostGradDip Diss. University of Otago.

Prebble, Catherine Mary (Kate). 2007. "Ordinary Men and Uncommon Women: A History of Psychiatric Nursing in New Zealand Public Mental Hospitals, 1939-1972." PhD diss. University of Auckland.

Richardson, Peter. 1997. "Building the Dominion: Government Architecture in New Zealand 1840 - 1922." PhD Diss. University of Canterbury.

Prior, William. 1990. "Robert Arthur Lawson, Architect, 1833-1902." Masters Diss. University of Otago.

Shaw, N. W. G. 1971. "Expatients View of a Mental Hospital (Cherry Farm) Compared to an Ideal Mental Hospital." Undergraduate (medicine) Diss. University of Otago.

Thompson, Shayleen Ann. 1992. "Keepers of Happiness": European Psychiatry and the Insane in New Zealand, 1911 to 1950." Masters Diss. University of Auckland.

Tregonning, R.J.A. 1967. "The General Public and Its Conception of Mental Illness." Undergraduate (medicine) Diss. University of Otago.

Wilson, A.J. 1970. "Mental Health and the Public." Undergraduate (medicine) Diss. University of Otago. 
Barsby, Ann, and Linda Tyler. 2006. "Inspired: The Dunedin Architecture of R.A. Lawson." Dunedin: Hocken Collections, University of Otago. http://www.southernheritage.org.nz/otagotrails/trails/pdf/lawson.html Date accessed: November 14, 2010.

Bauchop, Heather. 2012. "Registration Report for a Historic Place: Seacliff Lunatic Asylum Site." New Zealand Historic Places Trust. http://www.historic.org.nz/TheRegister/RegisterSearch/RegisterResult s.aspx?RID=9050 Date accessed: January 282011.

Royal Bethlem Archives and Museum "Floor Plan (from the online exhibition)" http://www.bethlemheritage.org.uk/explorebethlem/map.asp Date accessed December 01. 2013.

Brookes, Barbara. 2012. "King, Frederic Truby." Dictionary of New Zealand Biography, updated October 30, 2012. Accessed April 20, 2013. http://www.TeAra.govt.nz/en/biographies/2k8/king-frederic-truby

Brunton, Warwick. "Gray, Theodore Grant." Dictionary of New Zealand Biography. http://www.teara.govt.nz/en/biographies/4g19/graytheodore-grant. Accessed January 21, 2012.

Bowman, lan. 2010. "Conservation Plan: Chisholm Ward, Queen Mary Hospital, Hanmer." http://hurunui.govt.nz/assets/Documents/ Technical-Reports/QMHHR\%20Conservation\%20Plan\%20Chisholm\% 20Ward.pdf Accessed April 22, 2013.

California State University. 1997. "The Camarillo State Hospital Collection 1936-1997." http://209.129.118.23/history/documents/history.html Accessed February 04, 2013.

Camarillo State Hospital Historical Society. 2009. "Camarillo State Mental Hospital 1936-1997."

http://users.resist.ca/ kirstena/pagecamarillo.html Accessed February 04, 2013.

Disabled World, "Height Chart of Men and Women in Different Countries" http://www.disabled-world.com/artman/publish/height-chart.shtml Accessed November 19, 2012.

Dunedin City Council, "Peopling of Dunedin," http://dcc.squiz.net.nz/ data/assets/pdf_file/009/97083/thematicvol1-theme2-peopl ingofdunedin.pdf Accessed December 18, 2011.

Easton, Brian. 2012. "Economic history," Te Ara - the Encyclopedia of New Zealand. http://www.TeAra.govt.nz/en/economic-history Accessed August 092013.

Gordon, Colin. "Extreme Prejudice: notes on Andrew's Scull's TLS review of Foucault's History of Madness." http://foucaultblog.wordpress.com/2007/05/20/extreme-prejudice/ Accessed August 19, 2010.

Hutchison I, "Institutionalization," International Encyclopedia of Rehabilitation, eds. Stone, J.H. and M Blouin. http://cirrie.buffalo.edu/encyclopedia/en/article/40/ Accessed August 15, 2012. 
Knott, Richard (for AECOM New Zealand Limited). 2010. "Kingseat Structure Plan, Area Assessment of Former Kingseat Hospital."

http://www.franklin.govt.nz/LinkClick.aspx?fileticket=3SoChtsxqiQ\%3D \&tabid=1302 Accessed May 07, 2011.

McLintock, A. H. ed., "The Colonial Era," in An Encyclopedia of New Zealand, http://www.TeAra.govt.nz/en/1966/finance-public/1 Accessed September 20, 2011.

Phear, Sarah., Glen Farley, Zarah Burnett, and Rod Clough (for Clough and Associates). 2010. "Kingseat Structure Plan, Franklin District: Heritage Assessment." http://www.aucklandcouncil.govt.nz/SiteCollectionDocuments/building propertyconsents/districtplan/franklindp/planchange28/pc28kingseath eritage.pdf Date accessed: April 29, 2013.

Porirua Hospital Museum and Resource Centre Trust, "The Porirua Hospital Museum" (webpage), http://www.poriruahospitalmuseum.org.nz/ Accessed March 17, 2013.

Read, Megan (for the Manteno Project), "Manteno State Hospital News, The Official Blog of the Manteno Project," http://www.mantenostatehospital.com Accessed February 04, 2013.

Reserve Bank of New Zealand. 2007. "The Reserve Bank and New Zealand's Economic History." www.rbnz.govt.nz/publications/3072801.pdf Accessed November 27, 2012.

Richardson, Peter. "Campbell, John," Dictionary of New Zealand Biography. http://www.TeAra.govt.nz/en/biographies/2c3/1 Accessed September 15, 2012.

Shenley Park Trust. "History of Shenley Park Hospital - 1934 - 1998." http://www.shenleypark.co.uk/historyofshenleyhospital jb.html Accessed December 19, 2012.

Simpson, K.A., "Grabham, George Wallington," Dictionary of New Zealand Biography. http://www.TeAra.govt.nz/en/biographies/2g14/1 Accessed December 4, 2012.

Tennant, Margaret. "MacGregor, Duncan," Dictionary of New Zealand Biography. http://www.TeAra.govt.nz/en/biographies/2m7/1 Accessed December 04, 2012.

Thomas, Catherine. "Ngawhatu Hospital...Home or Nightmare?" http://www.theprow.org.nz/ngawhatu-hospital/ Accessed February 08, 2012.

Wikipedia Contributors. 2013. "Barrow Hospital," Wikipedia, The Free Encyclopaedia. http://en.wikipedia.org/w/index.php?title=Barrow Hos pital\&oldid=549195143 Date accessed April 23, 2013.

., 2013. "Henry Cotton (doctor)," Wikipedia, The Free Encyclopaedia. http://en.wikipedia.org/wiki/Henry_Cotton_(doctor).

Date accessed: March 14, 2013.

., 2014. "Scottish Baronial Architecture," Wikipedia, The Free

Encyclopaedia.

http://en.wikipedia.org/wiki/Scottish_Baronial_architecture

Date accessed: May 19, 2014. 